Det här verket har digitaliserats vid Göteborgs universitetsbibliotek.

Alla tryckta texter är OCR-tolkade till maskinläsbar text. Det betyder att du kan söka och kopiera texten från dokumentet. Vissa äldre dokument med dåligt tryck kan vara svåra att OCR-tolka korrekt vilket medför att den OCR-tolkade texten kan innehålla fel och därför bör man visuellt jämföra med verkets bilder för att avgöra vad som är riktigt.

This work has been digitised at Gothenburg University Library.

All printed texts have been OCR-processed and converted to machine readable text. This means that you can search and copy text from the document. Some early printed books are hard to OCR-process correctly and the text may contain errors, so one should always visually compare it with the images to determine what is correct. 


\section{GÖTEBORGS UMIVERSITETSBIBHOTEK}

|ก

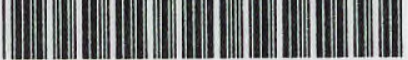

1001767008

\section{STUDIEN DER BIBLIOTHEK WARBURG}

ERNST CASSIRER INDIVIDUUM UND KOSMOS IN DER PHILOSOPHIE DER RENAISSANCE

B. G. TEUBNER / LEIPZIG 1927 


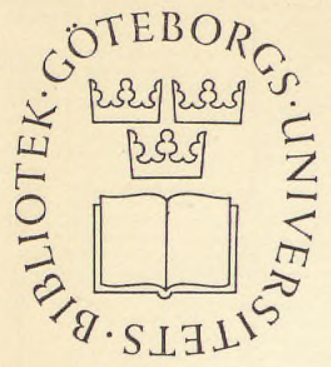

Allmänna Sektionen

Polygr.

Utl.

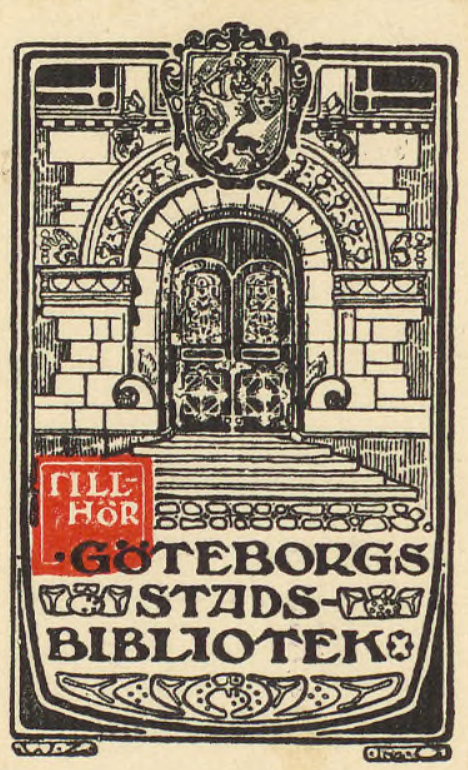









\section{STUDIEN DER BIBLIOTHEK WARBURG HERAUSGEGEBEN VON FRITZ SAXL}

X. ERNST CASSIRER, INDIVID U UM UND KOSMOS

B. G. TEUBNER/LEIPZIG / B ERLIN 1927 


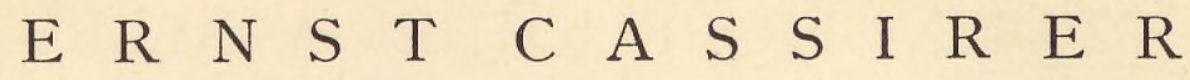
INDIVIDUUM UND KOSMOS IN DER PHILOSOPHIE DER RENAISSANCE

B. G. TEUBNER, LEIPZIG / B ER L I N 1927 


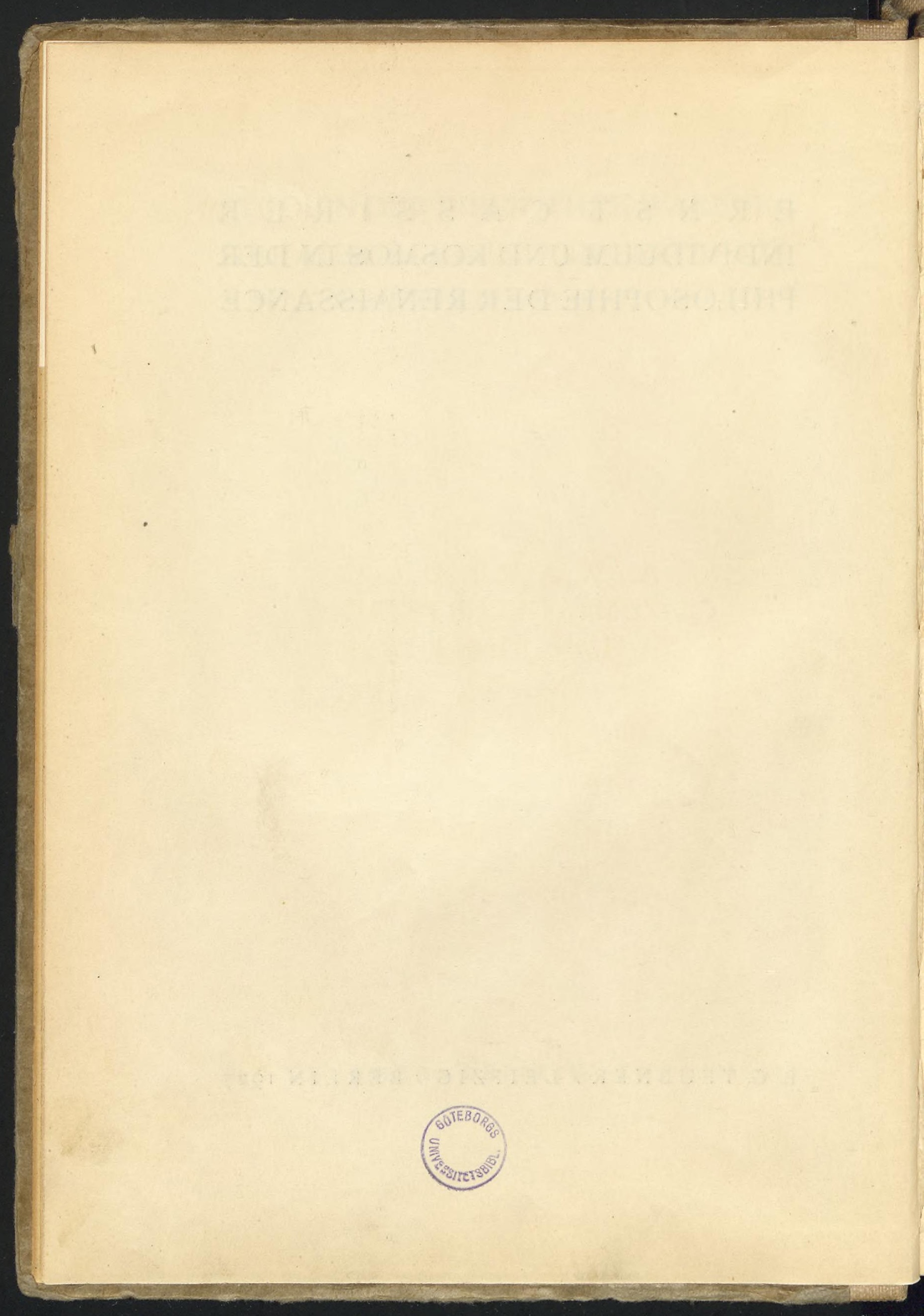


A. W A R B U R G
ZUM 60.GEBURTSTAG
A M 13. J U N I 1926 


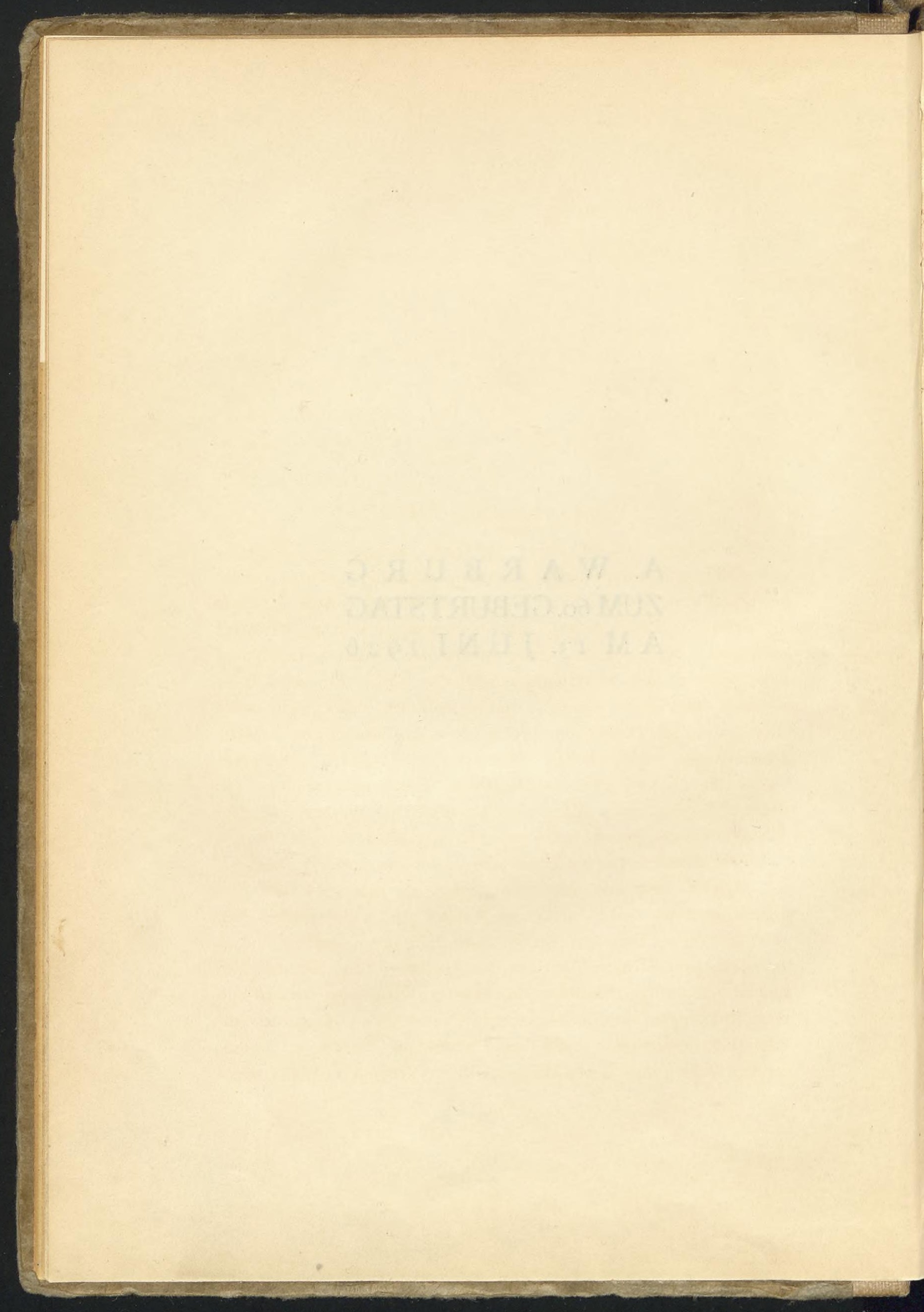


Lieber und verehrter Freund!

Die Schrift, die ich Ihnen zu Ihrem sechzigsten Geburtstag überreiche, sollte ursprünglich ein rein persönlicher Ausdruck meiner herzlichen Freundschaft und Verehrung für Sie sein. Aber ich hätte die Arbeit an dieser Schrift nicht durchführen können, hätte ich mich nicht beständig der Anregung und der Förderung durch jene Arbeitsgemeinschaft zu erfreuen gehabt, die in Ihrer Bibliothek ihren geistigen Mittelpunkt besitzt. Heute darf ich daher nicht mehr allein im eigenen Namen sprechen, sondern im Namen dieser Arbeitsgemeinschaft - im Namen all derer, die in Ihnen seit langem einen Führer der geistesgeschichtlichen Forschung verehren. In stiller und beharrlicher Arbeit hat die Bibliothek Warburg seit drei Jahrzehnten das Material für die geistesgeschichtliche und für die kulturwissenschaftliche Forschung bereitzustellen gesucht. Aber sie hat zugleich mehr als dies getan, indem sie uns mit einer Eindringlichkeit, wie selten zuvor, die Maxime vor Augen gestellt hat, unter der diese Forschung stehen muß. In ihrem Aufbau und in ihrer geistigen Struktur hat sie den Gedanken der methodischen Einheit und des methodischen Zusammenschlusses aller Gebiete und aller Richtungen der Geistesgeschichte verkörpert. Heute, wo die Bibliothek in eine neue Phase ihrer Entwicklung eintritt, wo sie mit der Begründung ihres neuen Hauses auch die Kreise ihrer Wirksamkeit 
weiter zieht, dürfen auch wir, ihre Mitarbeiter, es einmal öffentlich aussprechen, wieviel sie uns bedeutet, und was wir ihr verdanken. Wir hoffen und wissen, daß über den neuen sachlichen Aufgaben, die die Bibliothek fortan zu erfüllen hat, die alte Tradition unserer gemeinsamen freundschaftlichen Zusammenarbeit nicht vergessen werden, sondern daß sich das geistig-persönliche Band, das uns bisher verknüpft hat, künftig nur um so fester schlingen wird. Möge das Organon geistesgeschichtlicher Forschung, das Sie mit Ihrer Bibliothek geschaffen haben, uns noch auf lange Zeit hinaus immer wieder neue Fragen stellen, und mögen Sie selbst uns, wie bisher, neue Wege $\mathrm{zu}$ ihrer Beantwortung weisen.

Hamburg, den I3. Juni I926.

ERNST CASSIRER. 
IN HALT.

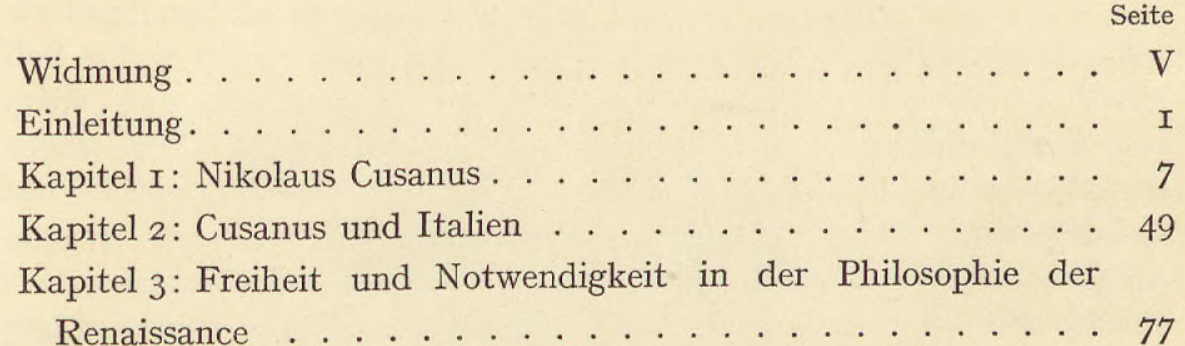

Kapitel 4: Das Subjekt-Objekt-Problem in der Philosophie der

Renaissance . . . . . . . . . . . . . I30

Anhang:

Nicolai Cusani liber de mente, hrsg. von Joachim Ritter, übers.

von Heinrich Cassirer . . . . . . . . . . . . . 203

Caroli Bovilli liber de sapiente, hrsg. von Raymond Klibansky . . 299

Indices zum Text . . . . . . . . . . . . . . . . . 4II3

Indices zu Cusanus . . . . . . . . . . . . . . . . . . . . . 4434

Indices zu Bovillus . . . . . . . . . . . . . 453 


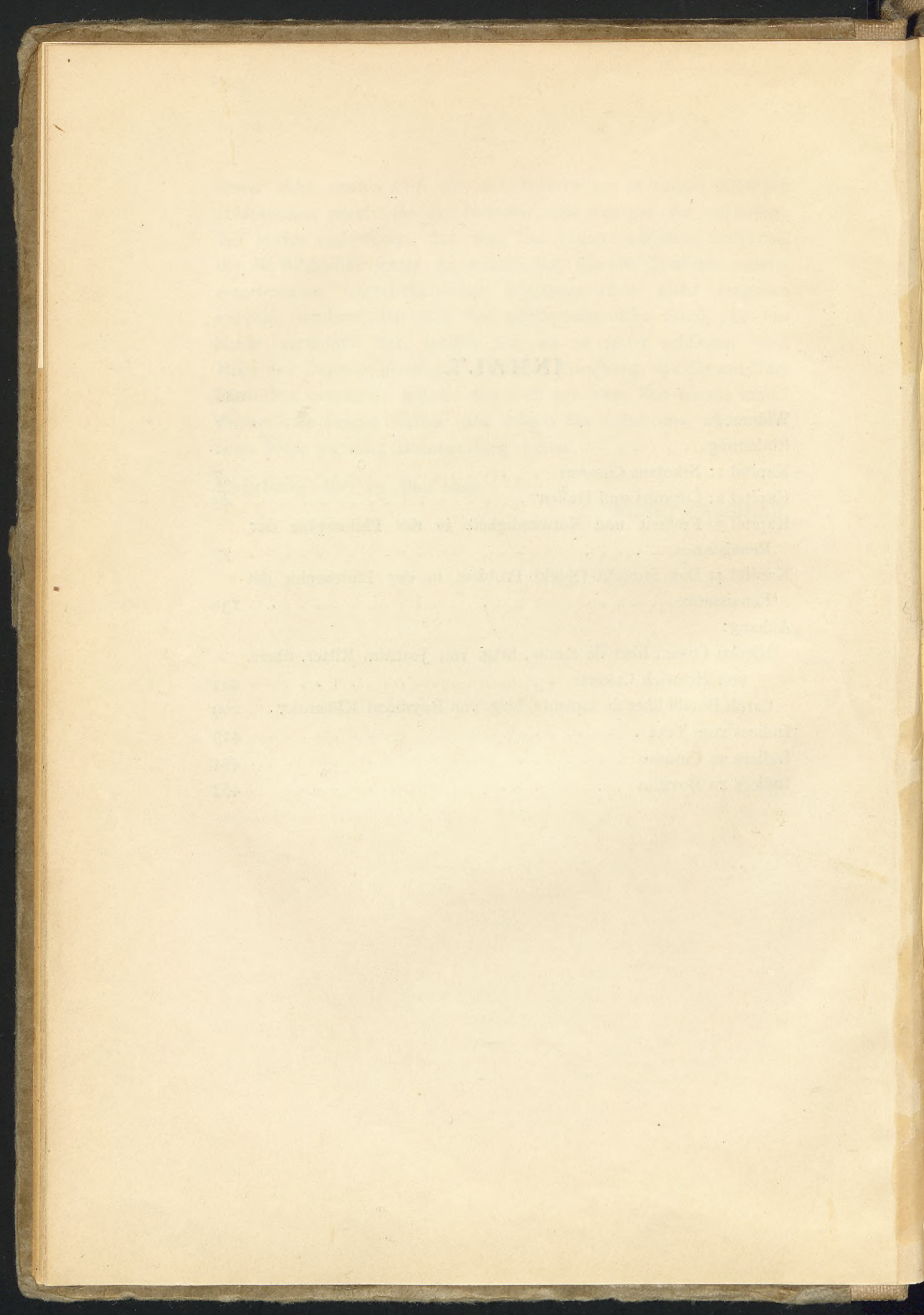


Hegels Voraussetzung, da $\beta$ die Philosophie einer Epoche das Bewußtsein und das geistige Wesen ihres ganzen Zustandes in sich schließe, da $ß$ sich in ihr als dem einfachen Brennpunkte, dem sich wissenden Begriffe, dies vielgestaltete Ganze abspiegele, scheint sich für die Philosophie der Frührenaissance nicht zu bewähren. Das neue Leben, das um die Wende des I3. und I4. Jahrhunderts in allen Gebieten des Geistes einsetzt, das in der Dichtung und in der bildenden Kunst, im staatlichen und geschichtlichen Dasein immer mächtiger emporwächst und sich zugleich immer bewußter als geistige Erneuerung weiß und fühlt, scheint im Denken der Zeit zunächst keinen Ausdruck und Widerhall zu finden. Denn ganz und gar ist dieses Denken, auch dort, wo es sich im einzelnen von den Resultaten der scholastischen Philosophie zu befreien beginnt, in den allgemeinen Formen dieser Philosophie gebunden. Der Angriff, den Petrarca in der Schrift "De sui ipsius et multorum ignorantia“" gegen die Schulphilosophie wagt, ist nur ein Zeugnis dafür, mit welcher noch ungebrochenen Macht eben diese Philosophie die Zeit beherrscht. Denn das Prinzip, das Petrarca der Scholastik und der Aristotelischen Lehre entgegenstellt, hat selbst weder philosophischen Ursprung noch Gehalt. Es ist keine neue Methodik des Denkens, sondern es ist das neue Bildungsideal der „Eloquenz“, das hier der Schulphilosophie gegenübertritt. Fortan soll und darf Aristoteles nicht mehr als der Meister des Wissens, als der Repräsentant der „Bildung“" schlechthin gelten - enthalten doch seine Schriften, so weit sie auf uns gekommen, ,keine Spur von Wohlredenheit." Nicht der Inhalt der Aristotelischen Schriften, sondern ihr Stil ist es somit, wogegen die humanistische Kritik sich wendet. Und diese Kritik hebt allmählich ihre eigene Voraussetzung auf. Denn je mehr der Umkreis des humanistischen Wissens sich weitet, und je feiner und schärfer seine wissenschaftlichen Instrumente werden, um so mehr muß das Bild des scholastischen Aristoteles vor dem Bilde des wahren Aristoteles weichen, das nunmehr aus den Quellen selbst erarbeitet wird. Aristoteles selbst - so urteilt jetzt Leonardo Bruni, der erste Übersetzer der Aristotelischen Politik und der Nikomachischen Ethik würde seine eigenen Bücher in der Umgestaltung, die sie durch die 
Scholastik erfahren haben, nicht wiedererkennen - so wenig wie Aktaeon nach seiner Verwandlung in einen Hirsch von seinen Hunden erkannt wurde. $\left.{ }^{1}\right)$ In diesem Urteil hat die neue geistige Bewegung des Humanismus ihren Frieden mit Aristoteles geschlossen. An Stelle des Kampfes gegen ihn tritt die Forderung seiner sprachlich-geistigen Aneignung. Die Probleme, die hieraus erwuchsen, aber waren selbst eher philologischer als philosophischer Art. Eifrig wird jetzt erörtert, ob der Begriff des Aristotelischen $\tau^{\prime} \alpha \hat{\gamma} \alpha \alpha^{\prime} \dot{\circ} \nu$ - wie es in der Übersetzung Leonardo Brunis geschehen war - durch die Bezeichnung summum bonum oder durch die Bezeichnung des bonum ipsum wiederzugeben sei. An dem Streit um die Schreibung des Aristotelischen Begriffs der Entelechie (als entelechia oder endelechia) und um die verschiedenen Deutungsmöglichkeiten, die sich aus ihr ergeben, nehmen die bekanntesten Humanisten wie Filelfo, Angelo Poliziano u. and. teil. ${ }^{2}$ ) Aber auch außerhalb des engeren Kreises des Humanismus, - auch dort, wo in dem neuen Bündnis, das Philosophie und Philologie jetzt eingehen, der Primat der ersteren anerkannt wird, kommt es in der Philosophie selbst zu keiner wahrhaft methodischen Erneuerung. Der Kampf um den Vorrang der Platonischen oder Aristotelischen Lehre, wie er in der zweiten Hälfte des 15. Jahrhunderts geführt wird, führt nirgends in die Tiefe letzter prinzipieller Voraussetzungen zurück. Der Maßstab, in dessen Anwendung die beiden gegnerischen Parteien einig sind, liegt auch hier jenseits des systematischphilosophischen Bereichs in religiösen Voraussetzungen und in dogmatischen Entscheidungen. So bleibt denn auch dieser Kampf zuletzt ohne eigentlichen geistesgeschichtlichen Ertrag: an Stelle der scharfen Scheidung zwischen dem sachlichen Grundgehalt und Grundprinzip der Platonischen und Aristotelischen Lehre tritt alsbald wieder die Forderung und der Versuch ihrer synkretistischen Verschmelzung. Gerade die Florentinische Akademie, die sich als Hüterin des echten Platonischen Erbguts fühlt, geht in diesem Versuch am weitesten. Neben Ficin steht hier Pico von Mirandula, der "Princeps Concordiae“, wie er von den Freunden genannt wurde. Die Vereinigung und Versöhnung der Scholastik mit dem Platonismus erscheint ihm als Hauptziel des Denkens. Nicht als Überläufer, sondern als Kundschafter - so spricht er selbst es in einem Briefe an Ermolao Barbaro aus - sei er an die Akademie in Florenz gekommen. Und als Ergebnis dieser Erkundung zeigt sich,

I) Leonardi Aretini Libellus de disputationum usu (I40I), p. 25; vgl. Georg Voigt, Die Wiederbelebung des klass. Altertums ${ }^{2}$ II, I69 und Fiorentino, Il risorgimento filosofico nel Quattrocento, Napoli 1885 , S. $183 \mathrm{f}$.

2) Näheres hierüber in dem Kapitel L'umanismo nella filosofia bei Fiorentino, a. a. O., S. $184 \mathrm{ff}$. 
da $\beta$ Aristoteles und Platon, so sehr sie in Worten miteinander zu streiten scheinen, in der Sache überall einig sind. ${ }^{1}$ ) In solchem Vereinigungsstreben verlieren die großen philosophischen Systeme zuletzt ihr eigenes Gesicht; gehen sie in den Nebel einer einzigen christlich-philosophischen Uroffenbarung auf, als deren Zeugen bei Ficin Moses und Platon, Zoroaster und Hermes Trismegistos, Orpheus und Pythagoras, Vergil und Plotin angeführt werden ${ }^{2}$ ) So scheint gerade in der Philosophie die geistige Grundkraft der Epoche: der Drang zur scharfen Begrenzung und Formung, zur Sonderung und Individualisierung noch nicht wirksam geworden zu sein oder doch im ersten Ansatz zu erlahmen.

Von hier aus läßt es sich vielleicht verstehen, daß der Kulturhistoriker, der für seine Zusammenschau von fest ausgeprägten, scharf umrissenen Einzelgestalten ausgehen muß, dazu gedrängt werden kann, die philosophischen Dokumente der Zeit, die diese Bedingung nirgends zu erfüllen scheinen, bei Seite zu stellen. Jacob Burckhardt zum mindesten hat in dem grandiosen Gesamtbild, das er von der Kultur der Renaissance entworfen hat, der Philosophie der Renaissance keine Stelle vergönnt. Sie ist hier nicht einmal als ein einzelnes Moment der geistigen Gesamtbewegung gewürdigt, geschweige daß sie im Sinne Hegels als ihr ,einfacher Brennpunkt", als der ,,substantielle Geist der Zeit" angesehen würde. Man könnte versuchen, über diesen Gegensatz mit der Bemerkung hinwegzugehen, daß in dem Konflikt zwischen dem Geschichtsforscher und dem Geschichtsphilosophen die Entscheidung notwendig zu Gunsten des ersteren fallen müsse, daß jeder spekulativ-konstruktive Aufbau sich den einfachen Fakten gegenüber zu bescheiden und in ihnen seine Schranke anzuerkennen habe. Aber mit einem derartigen methodischen Gemeinspruch wäre der Gegensatz, der sich hier auftut, nicht begriffen, geschweige abgetan. Verfolgt man ihn in seine Tiefe zurück, so zeigt sich, daß Burckhardt, indem er die Philosophie der Renaissance aus seiner Betrachtung ausschied, damit implizit zugleich eine weitere Einschränkung vorgenommen hat, die mit dieser ersten notwendig verbunden war. Gerade der scholastische Charakter, den diese Philosophie noch überall zu tragen scheint, bringt es mit sich, da $\beta$ sich hier noch nirgends eine klare und scharfe Grenz-

I) ,Diverti nuper ab Aristotele in Academiam, sed non transfuga . . verum explorator. Videor tamen (dicam tibi Hermolae quod sentio) duo in Platone agnoscere et Homericam illam eloquendi facultatem supra prosam orationem sese attolentem et sensuum si quis eos altius introspiciat, cum Aristotele omnino communionem, ita ut si verba spectes, nihil pugnantius, si res nihil concordius." Ioann. Pici Mirandulae Opera (Basel o. J.) I, 368f. $\mathrm{Zu}$ Picos scholast. Studien s. ibid. I, 35 If.

2) S. Ficins Briefe, Opera, Basileae o. J. S. 866,871 ; vgl. bes. Ficinus, De christiana religione, Cap. XXII (Opera, p. 25). 
scheide zwischen der philosophischen und der religiösen Gedankenbewegung ziehen läßt. Die Philosophie des Quattrocento ist und bleibt, gerade in ihren bedeutendsten und folgereichsten Leistungen, wesentlich Theologie. Ihr gesamter Gehalt drängt sich in die drei großen Probleme: Gott, Freiheit, Unsterblichkeit zusammen. Sie sind es, um die sich in der Schule von Padua der Streit der Meinungen, der Streit zwischen „Alexandristen“" und „Averroisten" bewegt; sie bilden zugleich den Kernpunkt aller Spekulationen des Florentiner Platonischen Kreises. Burckhardt hat, offenbar völlig bewußt, in der großen zusammenfassenden Darstellung, die er von Sitte und Religion der Renaissance gegeben hat, auf diese Zeugnisse Verzicht geleistet. Sie mochten ihm als eine bloße Weiterführung einer im Grunde schon erstorbenen Tradition erscheinen, als ein theoretisches Außen- und Nebenwerk, das mit den eigentlich bewegenden religiösen Kräften der Zeit nicht mehr in lebendigem Zusammenhang steht. Diese Kräfte mußte er, seiner Gesamtanschauung nach, nicht in theoretischen Aussagen, nicht in philosophischen Sätzen über die Religion, sondern im unmittelbaren Tun des Menschen, in seiner praktischen Stellung zur Welt und zur geistig-sittlichen Wirklichkeit $\mathrm{zu}$ erfassen suchen. Aber - so wird man fragen dürfen entspricht dieser scharfe Schnitt zwischen "Theorie" und "Praxis" des Religiösen dem Gegenstand selbst oder ist er nicht vielmehr ein Werk des - Philosophen Burckhardt? Gehört es nicht eben zum "Geist der Renaissance", wie Burckhardt ihn gezeichnet hat, daß für sie diese Trennung nicht bestand, - daß die beiden Momente, die hier im Bilde des Kulturhistorikers auseinandergehalten werden, im wirklichen Leben der Epoche noch ständig ineinander schillern und ineinander übergehen? Ist nicht hier alle Naivität des Glaubens zugleich dogmatisch, wie andererseits auch der theoretische Dogmatismus noch durchaus naiv ist, sofern er die verschiedenartigsten Bestandteile des ,Glaubens" und „Aberglaubens" unbefangen in sich aufnimmt? So hat denn auch die Kritik, die von der fortschreitenden empirischen Forschung an Burckhardts Grundwerk geübt worden ist, vornehmlich an diesem Punkte eingesetzt. Die Kunstgeschichte, die politische Geschichte, die allgemeine Geistesgeschichte schienen hier denselben Weg zu weisen. Die zeitlichen wie die inhaltlichen Grenzen zwischen Renaissance und Mittelalter begannen sich, gegenüber Burckhardts Auffassung und Darstellung, mehr und mehr zu verschieben. ${ }^{1}$ ) Von dem

I) Für diesen Prozeß, der hier nicht in seinen einzelnen Stadien verfolgt werden kann, verweise ich insbesondere auf die grundlegenden Schriften Kon radBurd a chs: Vom Mittelalter zur Reformation. Forschungen zur Geschichte der deutschen Bildung, Berlin I9raff, s. auch Burdach, Deutsche Renaissance ${ }^{2}$, Berlin 1918 und Reformation, Renaissance, Humanismus, Berlin r9r8. 
Versuch Henry Thodes, den Anfang der künstlerischen Renaissance in Italien bis zum Beginn des I3. Jahrhunderts zurückzuverlegen, und in Franz von Assisi, dem Erwecker eines neuen Frömmigkeitsideals, zugleich den Bahnbrecher der künstlerischen Bewegung zu sehen, die in der Malerei und in der Dichtung des 5 . Jahrhunderts zu ihrer Vollendung gelangt, kann hier abgesehen werden - die These Thodes findet in der Form, die er ihr gegeben hat, heute wohl kaum noch eine wissenschaftliche Vertretung und Verteidigung. $\left.{ }^{1}\right)$ Das eine jedoch scheint unverkennbar, daß der Gegensatz zwischen dem ,,mittelalterlichen Menschen " und dem ,,Menschen der Renaissance " um so flüssiger und flüchtiger zu werden drohte, je mehr man ihn in concreto durchzuführen versuchte, je mehr die biographische Einzelforschung der Künstler, der Denker, der Gelehrten und Staatsmänner der Renaissance fortschritt. „Versucht man" - so urteilt neuerdings ein auf diesem Gebiet bewährter Forscher - ,das Leben und Denken der führenden Persönlichkeiten des Quattrocento, eines Coluccio Salutati, Poggio Bracciolini, Leonardo Bruni, Lorenzo Valla, Lorenzo Magnifico oder Luigi Pulci rein induktiv zu betrachten, so ergibt sich regelmäßig, daß gerade für die studierte Person die aufgestellten Merkmale (die Merkmale des "Individualismus" und „Paganismus", des ",Sensualismus" und der "Skepsis") sonderbarerweise absolut nicht passen. Versucht man diese . . . Merkmale in ihrem engen Zusammenhange mit dem Lebenslaufe des geschilderten Mannes und vor allem aus dem breiten Strome des ganzen Zeitalters zu begreifen, dann erhalten sie regelmäßig ein ganz anderes Aussehen. Und hält man die Resultate induktiver Forschung zusammen, so steigt allmählich ein neues Bild der Renaissance empor, nicht weniger gemischt aus Fromm und Unfromm, Gut und Böse, Himmelssehnsucht und Erdenlust, aber unendlich viel komplizierter. "2) Auch die Geschichte der Philosophie wird sich diese Sätze und die Mahnung, die in ihnen liegt, zu eigen machen dürfen. So wenig sie jemals auf das Streben zum Allgemeinen und Allgemeinsten verzichten kann, so sehr muß sie sich andererseits mit dem Gedanken durchdringen, daß nur die Vertiefung in die konkrete Besonderung, in die letzte Feinheit des historischen Details die echte Allgemeinheit zustande bringen und verbürgen kann. Was zu fordern ist, ist die Allgemeinheit eines systematischen Gesichtspunktes und einer systematischen Orientierung, die jedoch mit jener Allgemeinheit bloß empirischer Gattungsbegriffe, wie sie zur Periodisierung der

I) Vgl.Thode, Franz von Assisi u. die Anfänge der Kunst der Renaissance in Italien, Berlin $\mathrm{r} 885$.

\footnotetext{
S. 5 f.

2) Ernst Walser, Studien zur Weltanschauung der Renaissance, Basel 1920 ,
} 
Geschichte und zur bequemen Abgrenzung ihrer einzelnen Epochen gebraucht werden, in keiner Weise zusammenfällt. Auf dieses Ziel sind die folgenden Betrachtungen gerichtet. Sie wollen nicht in den Streit um den Inhalt und um das Recht der ",historischen Beziehungsbegriffe" Renaissance und Mittelalter eingreifen, wie er gegenwärtig in der politischen Geschichtsschreibung, in der Literatur- und Kunstgeschichte geführt wird. ${ }^{1}$ ) Sie bleiben vielmehr innerhalb der philosophischen Problemgeschichte stehen und suchen von hier aus eine Antwort auf die Frage zu gewinnen, ob und inwiefern die Gedankenbewegung des 15. und I6. Jahrhunderts bei aller Mannigfaltigkeit der Problemansätze und bei aller Divergenz der Lösungen eine in sich geschlosseneEinheit bildet. Gelingt es, diese Einheit aufzuweisen, gelingt es, das Wirrsal von Fragen, das uns die Renaissancephilosophie darbietet, auf bestimmte systematische Mittelpunkte zu beziehen, dann wird sich damit von selbst die Frage nach dem Zusammenhang beantworten, in dem die theoretische Gedankenarbeit der Renaissance zu den anderen Lebensmächten steht, durch die ihre geistige Gestalt bestimmt wird. Es wird sich ergeben, da $B$ auch hier die Arbeit des Gedankens der geistigen Gesamtbewegung und ihren treibenden Kräften nicht als ein Abgesondertes und Absonderliches gegenübersteht, noch daß sie ihr als ein schlechthin Abstraktes, als ein bloßer Schatten folgt, sondern daß sie produktiv und bestimmend in sie eingreift. Sie ist nicht nur ein Teil, der sich mit anderen Teilen verbindet, sondern sie stellt das Ganze selbst dar und bringt es zum begrifflich-symbolischen Ausdruck. Wie das neue universelle Leben, zu dem die Renaissance sich durchringt, zu der Forderung eines neuen Universum des Gedankens führt, und wie in ihm dieses Leben sich reflektiert und sich erst ganz findet, soll im folgenden dargelegt werden.

I) Für die Entstehungsgeschichte dieses Streites und seinen gegenwärtigen Stand sei außer auf die früher genannten Schriften Konrad Burdachs besonders auf Walter Goetz, Renaissance und Antike, Histor. Zeitschr., Bd. II3, S. 237 ff.; Renaissance und Mittelalter, Histor. Zeitschr. Bd. 98 , S. 30 ff., sowie auf das reichhaltige Material bei Karl Borinski, Die Weltwiedergeburtsidee in den neueren Zeiten I. Der Streit um die Renaissance und die Entstehungsgeschichte der historischen Beziehungsbegriffe Renaissance u. Mittelalter, (Sitzungsberichte der Bayer. Akad. d. Wissensch., Philos-philol. Klasse 1919) verwiesen. 


\title{
ERSTES KAPITEL
}

\section{NIKOLAUS CUSANUS}

\author{
I.
}

Jede Betrachtung, die auf die Erfassung der Philosophie der Renaissance als einer systematischen Einheit gerichtet ist, muß von der Lehre des Nikolaus Cusanus ihren Ausgangspunkt nehmen. Denn von all den philosophischen Richtungen und Bestrebungen des Quattrocento ist es diese Lehre allein, die die Hegelsche Forderung erfüllt, die einen ,einfachen Brennpunkt" darstellt, in dem die verschiedenartigsten Strahlen sich sammeln. Cusanus ist der einzige Denker der Zeit, der das Ganze ihrer Grundprobleme von ein em methodischen Prinzip aus erfaßt, und der es kraft dieses Prinzips meistert. Sein Denken umspannt noch, gemäß dem mittelalterlichen Ideal der Totalität, die Gesamtheit des geistigen und des physischen Kosmos und macht vor keiner Besonderung Halt. Er ist spekulativer Theologe, wie er spekulativer Mathematiker ist; er ist ebensowohl auf die Probleme der Statik und der allgemeinen Bewegungslehre, wie auf die Probleme der Astronomie und Kosmographie, auf die Probleme der Kirchengeschichte, wie auf die der politischen Geschichte, der Rechtsgeschichte, der allgemeinen Geistesgeschichte gerichtet. Aber so sehr er als Gelehrter und Forscher all diesen Gebieten angehört, und so sehr er fast jedes von ihnen durch eigene Leistungen bereichert hat, so fern liegt hier alle Gefahr der Spezialisierung, der Zersplitterung. Denn was Cusanus immer ergreift und bearbeitet, das fügt sich nicht nur einem intellektuellen Gesamtbild ein, das faßt sich nicht nur mit anderen Bestrebungen zu einer nachträglichen Einheit zusammen, sondern es ist von Anfang an nur die Entfaltung und Auslegung jenes einen Grund- und Hauptgedankens, den er in seiner ersten philosophischen Schrift, in der Schrift "de docta ignorantia“, durchgeführt hat. Der Gegensatz von complicatio und explicatio; - dieser Gegensatz, den Cusanus braucht, um durch ihn das Verhältnis Gottes zur Welt, wie das Verhältnis der Welt zum menschlichen Geist zu er- 
leuchten, läßt sich demnach auf seine eigene Lehre anwenden, die gleichfalls aus einem gedanklichen Keim erwächst, der sich fortschreitend auseinanderfaltet und in diesem Prozeß den ganzen Bestand und die gesamte Problematik des Wissens der Zeit in sich hineinnimmt.

Das Prinzip, auf dem die Philosophie des Cusanus beruht, stellt. sich ihm selbst als der Durchbruch einer neuen Grundwahrheit dar, die nicht durch syllogistische Schlüsse vermittelt ist, sondern die ihn als plötzliche Schau und mit der ganzen Gewalt einer großen Intuition überfällt. Er selbst hat geschildert, wie auf der Überfahrt von Konstantinopel als ein ,göttliches Geschenk" dieses Prinzip in ihm zuerst aufleuchtete. ${ }^{1}$ ) Versucht man, den Inhalt desselben auf einen abstrakten Ausdruck zu bringen, versucht man das, was sich für Cusanus selbst in dieser Weise als ein Unvergleichliches und Einzigartiges gibt, systematisch zu bestimmen und geschichtlich einzugliedern, so gerät man in Gefahr, die Originalität und Tiefe des neuen Gedankens zu verkennen. In der Tat scheint der Begriff der ,docta ignorantia“ und die Lehre von der "Koinzidenz der Gegensätze", die sich auf ihm aufbaut, nur Gedanken $\mathrm{zu}$ erneuern, die zum festen Bestand der mittelalterlichen Mystik gehörten. Auf die Quellen dieser Mystik, insbesondere auf die Schriften Eckharts und des Pseudo-Dionysius hat Cusanus fort und fort verwiesen. So scheint es schwer, wo nicht unmöglich, hier irgendeinen festen Trennungsstrich zu ziehen. Bestünde der eigentliche Kern von Cusanus' Schrift in dem Gedanken, daß Gott, daß das absolute Sein über jede Möglichkeit der positiven Bestimmung hinausliegt, daß er nur durch negative Prädikate zu bezeichnen und nur in dem Hinausgehen, in der Transzendenz über alle endlichen Maße, Proportionen und Vergleichungen zu fassen sei, so wäre damit kein neuer Weg und kein wesentlich neues Ziel bezeichnet gewesen. Denn wenn auch diese Richtung der „mystischen" Theologie ihrem letzten Grund nach der Scholastik widerstreiten mag, so bildet doch dieser Widerstreit einen charakteristischen Zug im geistigen Gesamtbild der Scholastik selbst. Diese hatte sich in ihren großen Führern die Lehre des Pseudo-Areopagiten längst zu eigen gemacht: nicht nur Johannes Eriugena geht auf seine Schriften zurück, sondern auch Albertus Magnus und Thomas von Aquin haben sie in eigenen Kommentaren behandelt und ihr damit einen festen Platz innerhalb des mittelalterlichen Lebens- und Lehrsystems gegeben.

I) De docta ignorantia III, I2: „Accipe nunc Pater metuende quaejamdudum attingere variis doctrinarum viis concupivi, sed prius non potui, quousque in mari ex Graecia rediens (credo superno dono a patre luminum, a quo omne datum optimum) ad hoc ductus sum, ut incompraehensibilia incompraehensibiliter amplecterer, in docta ignorantia, per transcensum veritatum incorruptibilium humaniter scibilium." 
Von hier aus also war dieses System nicht zu erschüttern: der alte Gedanke mußte zum mindesten eine neue Prägung und gewissermaßen einen neuen Accent erhalten, wenn er über seine Grenzen hinausgetrieben werden sollte.

Worin diese Prägung bestand, das läßt sich erst bezeichnen, wenn man sich zuvor die literarische und geistige Gesamtstruktur des Werkes des Areopagiten vergegenwärtigt hat. Schon der Titel der Schriften des Areopagiten weist auf diese Struktur hin - schon er deutet die Stellung an, die diese Schriften im Ganzen der mittelalterlichen Grundanschauung von Gott und der Welt einnehmen. Es ist das Problem der Hierarchie, das hier zum erstenmal in all seiner Schärfe und in all seiner metaphysischen Weite, in seinen Voraussetzungen und in seinen mannigfachen Abwandlungen vor uns hingestellt wird. Außer der Schrift von den gött-

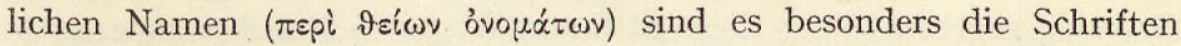

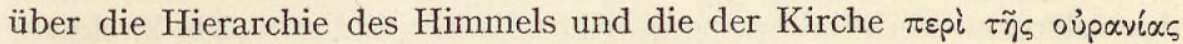

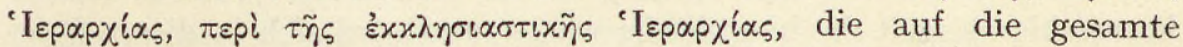
Folgezeit gewirkt haben. Die Bedeutung dieser Schriften liegt darin, daß hier zuerst die beiden geistigen Grundmächte und Grundmotive, auf denen der Glaube und die Wissenschaft des Mittelalters beruhen, einander begegnen und miteinander fest in eins wachsen - da $B$ hier die eigentliche Konkreszenz der christlichen Heilslehre mit der hellenistischen Spekulation sich vollzieht. Was diese Spekulation, was vor allem der Neuplatonismus dem Christentum darbot, war vor allem der Begriff und das allgemeine Bild des Stufenkosmos. Die Welt scheidet sich in eine niedere und höhere, eine sinnliche und intelligible Welt, die einander nicht nur gegenüberstehen, sondern deren Wesen eben in dieser ihrer gegenseitigen Verneinung, in ihrer polaren Gegensätzlichkeit besteht. Aber mitten über diesen Abgrund der Verneinung knüpft sich zwischen ihnen ein geistiges Band. Von dem einen Pol zum andern, von dem Über-Sein und Über-Einen, von dem Reich der absoluten Form bis hinab zur Materie als dem Absolut-Formlosen, führt ein stetiger Weg der Vermittlung. Das Unendliche geht auf diesem Wege in das Endliche über; das Endliche kehrt auf ihm zum Unendlichen zurück. Der gesamte Prozeß der Erlösung ist hierin beschlossen: er ist Menschwerdung Gottes, wie er Gottwerdung des Menschen ist. Immer bleibt hierbei ein ,Zwischen " zu überwinden - bleibt ein trennendes Medium, das sich nicht überspringen, sondern nur Schritt für Schritt, in einer streng geregelten Folge durchmessen läßt. Diese Stufenleiter, die vom Himmlischen zum Irdischen hinab, von diesem zu jenem hinaufführt, wird in den Schriften des Dionysius systematisch beschrieben und dargestellt. Zwischen Gott und den Menschen tritt die Welt der 
reinen Intelligenzen und der reinen himmlischen Kräfte, die in drei Kreise zerfällt, deren jeder sich in sich selber wiederum dreifach gliedert. In den ersten Kreis gehören die Seraphim, die Cherubim, die Throni; in den zweiten die Dominationes, Virtutes, Potestates; in den dritten die Principatus, Archangeli und Angeli. So geht alles Sein in bestimmten Graden der Ausstrahlung von Gott aus, um sich zuletzt wieder in ihm zusammenzufassen und in ihn zurückzunehmen. Wie alle Radien des Kreises vom Mittelpunkt ausstrahlen, so ist Gott Ausgangspunkt und Zielpunkt aller Dinge; wie diese Radien um so näher aneinanderrücken, je näher sie dem Mittelpunkt stehen, so überwiegt die Vereinigung der Wesen deren Trennung, je weniger sie von dem gemeinsamen Zentrum, dem Urquell des Seins und des Lebens, entfernt sind. Und damit ist auch die Rechtfertigung, ist die eigentliche Theodizee der kirchlichen Ordnung gegeben. Denn diese ist ihrem Wesen nach nichts anderes als das vollkommene Abbild der geistig-kosmischen Ordnung: die kirchliche Hierarchie spiegelt die himmlische wieder und wird sich in dieser Spiegelung ihrer eigenen unverbrüchlichen Notwendigkeit bewußt. 'Die mittelalterliche Kosmologie und der mittelalterliche Glaube, die Ansicht der Weltordnung und die der sittlich-religiösen Heilsordnung fließen hier in eine einzige Grundanschauung, in ein Bild von höchster Prägnanz und höchster innerer Konsequenz zusammen.

Nikolaus Cusanus hat dieses Bild nirgends bestritten; ja er scheint es in seiner gesamten Spekulation, besonders in der Spekulation der Frühzeit, unmittelbar vorauszusetzen. Und doch dringt schon in den ersten Sätzen der Schrift „De docta ignorantia“ ein Gedanke durch, der auf eine völlig neue geistige Gesamtorientierung hinweist. Vom Gegensatz zwischen dem Sein des Absoluten und des EmpirischBedingten, des Unendlichen und des Endlichen wird auch hier ausgegangen. Aber dieser Gegensatz wird nun nicht mehr schlechthin dogmatisch gesetzt, sondern er soll in seiner letzten Tiefe erfaßt, er soll aus den Bedingungen der menschlichen Erkenntnis begriffen werden. Diese Stellung zum Erkenntnisproblem charakterisiert Cusanus als den ersten modernen Denker. $\left.{ }^{1}\right)$ Sein erster Schritt besteht darin, daß er nicht sowohl nach Gott, als nach der Möglichkeit des Wissens von Gott fragt. Und in bezug auf diese Grundfrage genügt ihm keine der Antworten, die die Philosophie und die spekulative Theologie bisher auf sie gegeben

I) Näheres hierüber in meiner Schrift über das Erkenntnisproblem ${ }^{3}$ I, 2 Iff., auf die ich für das Folgende verweise. Auch die neueste eindringende Untersuchung der Lehre des Cusanus hat diesen Zusammenhang zwischen der Gotteslehre des Cusanus und seiner Erkenntnislehre bestätigt. ,, La clef de voûte du système philosophique de Nicolas de Cues - so urteilt Vansteen berghe (Le cardinal Nicolas de Cues, Paris 1920, S. 279) - et en cela il est bien moderne, est sa théorie de la connaissance." 
haben. Sie alle werden hinfällig, sobald man sich den einfachen Begriff des Wissens und die Voraussetzungen, die in ihm beschlossen sind, zum Bewußtsein bringt. Alles Wissen setzt ein Vergleichen voraus, das wiederum, schärfer gefaßt, nichts anderes als ein Messen ist. Sollen aber irgendwelche Inhalte aneinander und durcheinander gemessen werden, so gilt als erste unumgängliche Voraussetzung für diesen Prozeß die Bedingung der Homogeneität. Sie müssen auf ein- und dieselbe Maßeinheit zurückgeführt werden, sie müssen als derselben Größenordnung zugehörig gedacht werden können. Aber eben diese Bedingung wird unerfüllbar, sobald als Ziel der Erkenntnis und als ihr Gegenstand nicht mehr ein Endliches, Bedingtes, Einzelnes, sondern ein absoluter Gegenstand gesetzt wird. Dieser ist, seinem Wesen und seiner Definition nach, über alle Möglichkeit der Vergleichung und Messung und somit über alle Möglichkeit der Erkenntnis hinaus. Wenn alles empirische Erkennen und Messen dadurch bezeichnet ist, daß durch eine bestimmte Reihe von Operationen, durch eine endliche Folge von Denkschritten, eine Größe auf eine andere, ein Element auf ein anderes zurückgeführt wird, - so versagt dem Unendlichen gegenüber jede derartige Reduktion. „Finiti et infiniti nulla proportio“ - : der Abstand zwischen dem Endlichen und Unendlichen bleibt dersèlbe, so viele Mittelglieder wir zwischen beide auch einschieben mögen. Es gibt keine rationale Methodik des Denkens, kein ,diskursives“", Element an Element reihendes und Element für Element durchlaufendes Verfahren, das die Kluft zwischen beiden Extremen ausfüllen, das vom einen zum andern überführen könnte. ${ }^{1}$ )

In diesen knappen und schlichten Eingangssätzen der Schrift „,De docta ignorantia“ aber ist nun bereits eine entscheidende Wendung vollzogen. Denn jetzt ist mit einem einzigen scharfen Schnitt das Band gelöst, das bisher die scholastische Theologie und die scholastische Logik miteinander verbunden hatte. Die Logik in ihrer bisherigen Form hat aufgehört, ein Organon der spekulativen Gotteslehre zu sein. Hier hatte freilich schon die Entwicklung der Scholastik selbst dem Ergebnis des Cusanus vorgearbeitet: schon der Terminismus Wilhelm von Occams und die an ihn anknüpfende ,,moderne" Richtung der Scholastik hatte

I) S. De doct. ignor. I, I: ,Omnes . . investigantes in comparatione praesuppositi certi proportionabiliter incertum judicant. Comparativa igitur est omnis inquisitio, medio proportionis utens, ut dum haec quae inquiruntur propinqua proportionali reductione praesupposito possint comparari, facile est apprehensionis judicium; dum multis mediis opus habemus, difficultas et labor exoritur. Uti haec in Mathematicis nota sunt, ubi ad prima notissima principia priores propositiones facile reducuntur et posteriores, quoniam non nisi per medium priorum, difficilius. Omnis igitur inquisitio in comparativa proportione facili vel difficili existit, propter quid infinitum, ut infinitum, cum omnem proportionem aufugiat, ignotum est." 
die Verbindung zwischen Logik und Grammatik einerseits, zwischen Theologie und Metaphysik andererseits, wie sie in den klassischen Systemen des Realismus bestand, gelockert. ${ }^{1}$ ) Jetzt aber erfolgt eine weit radikalere Scheidung: denn die Aristotelische Logik, die auf dem Satz des ausgeschlossenen Dritten beruht, erweist sich eben damit für Cusanus als eine bloße Logik des Endlichen, muß also immer und notwendig versagen, wo es sich um die Anschauung des Unendlichen handelt. ${ }^{2}$ ) Alle ihre Begriffe sind Vergleichungsbegriffe: sie beruhen darauf, daß Gleiches und Ähnliches zusammengefaßt, Ungleiches und Unähnliches voneinander geschieden wird. Auf diesem Wege der Vergleichung und Unterscheidung, der Sonderung und Abgrenzung zerlegt sich uns alles empirische Sein in bestimmte Gattungen und Arten, die zueinander in einem festen Verhältnis der Über- oder Unterordnung stehen. Alle Kunst des logischen Denkens ist darauf gerichtet, dieses Ineinander der begrifflichen Sphären

I) $\mathrm{Da}$ diese Lockerung, wie sie durch Occams Grundlehre systematisch gefordert und innerhalb bestimmter Grenzen geleistet wird, dennoch zu keiner Ablösung der beiden Momente voneinander führte, daß vielmehr, auch im Lager der ,,moderni“, im herrschenden Schulbetrieb der Universitäten, die Grenzen, die Occam zu ziehen versucht hatte, sich alsbald wieder verwischten, haben neuerdings die gründlichen Untersuchungen Gerhard Ritters über den Kampf der ,via antiqua " und der ,via moderna“ im I4. und 15. Jahrhundert festgestellt (Studien zur Spätscholastik: I. Marsilius von Inghen und die okkamistische Schule in Deutschland. II. Via antiqua und via moderna auf den deutschen Universitäten des I5. Jahrhunderts, Sitzungsber. der Heidelb. Akad. der Wiss., Philos.histor. Kl., I92I/22.) "Wir haben Stück für Stück verfolgt" - so faßt Ritter, a. a. O., II, 86f. das Ergebnis seiner Untersuchungen zusammen _- „, wie sich die radikal erkenntnistheoretischen Sätze Okkams im Munde seiner Anhänger immer harmloser gestalteten. Zwar ein Johannes Gerson stand fast an der Grenze der Einsicht, die das stärkste Motiv der originalen Gedankenarbeit Okkams gebildet hatte: daß die religiöse Erkenntnis ihre eigenen Wurzeln in ganz anderen Bereichen des Geistes habe als im natürlichen Intellekt, und da $\beta \mathrm{ihr}$ die theologisch-metaphysische Spekulation darum mehr schaden als nützen könne. Wäre dieser Gedanke energisch durchgeführt worden, so hätte er in der Tat den Tod der Scholastik herbeiführen können. Aber dazu kam es noch lange nicht. Gerson selbst konnte sich nur mit halber Wendung von jener innigen Verflechtung religiös-dogmatischer und metaphysisch-logischer Betrachtungen losreißen, die den Kern alles scholastischen Denkens bildete. .... Er zweifelte nicht an der realen Bedeutsamkeit der abstrahierenden logischen Begriffsbildung. Und vollends die Untersuchung der philosophischen und theologischen Schriften des Marsilius von Inghen hat uns ein ganz geschlossenes wissenschaftliches System gezeigt, das auf nominalistischer Basis doch alle wesentlichen Positionen der hochscholastischen Metaphysik und Theologie behauptete." Hält man sich dieses Resultat von Ritters Untersuchungen vor Augen, so zeigt sich auch von dieser Seite her, wie weit Cusanus schon in seiner ersten Schrift über all das hinausgewachsen ist, was seine occamistischen Lehrer in Heidelberg ihm zu bieten vermochten.

2) Vgl. bes. Cusanus' Bemerkung gegen seinen scholastischen Gegner Johann Wenck aus Heidelberg: "Cum nunc Aristotelis secta praevaleat, quae haeresim putat esse oppositorum coincidentiam, in cujus admissione est initium ascensus in mysticam Theologiam, in ea secta enutritis haec via ut penitus insipida quasi proposito contraria ab eis procul pellitur, ut sit miraculo simile, sicuti sectae mutatio, rejecto Aristotele eos altius transsilire". Apol. doct. ign. fol. $64 \mathrm{f}$. 
sichtbar und deutlich zu machen. Wir müssen, um einen Begriff durch den anderen zu bestimmen, die ganze Folge der Mittelglieder, die zwischen ihnen stehen, durchlaufen - wir müssen diese Mittelglieder, wo sie sich dem natürlichen Denken nicht unmittelbar darbieten, kraft des syllogistischen Verfahrens entdecken, um auf diese Weise Abstraktes und Konkretes, Allgemeines und Besonderes in eine fest bestimmte Ordnung des Denkens zusammenzunehmen. Diese Ordnung ist der des Seins adaequat: sie stellt die Hierarchie des Seins in der hierarchischen Gliederung der Begriffe dar. Aber - so lautet nunmehr der Einwand des Cusanus - wenn auf diese Weise die Ähnlichkeiten und Verschiedenheiten, die Übereinstimmungen und Gegensätze des Endlichen erfaßt werden können, so läßt sich doch das Absolute und Unbedingte, das als solches über jede Vergleichung hinaus ist, niemals in dieses Netz der logischen Gattungsbegriffe einfangen. Der Inhalt des scholastischen Denkens widerspricht seiner. Form; beide schließen einander wechselseitig aus. Soll die Möglichkeit bestehen, das Absolute, das Unendliche zu denken, so kann und darf dieses Denken jedenfalls nicht an den Krücken der traditionellen ,Logik" einhergehen, durch die wir immer nur von einem Endlichen und Begrenzten zum andern geleitet, nicht aber über das gesamte Gebiet der Endlichkeit und Bedingtheit überhaupt hinausgeführt werden können.

So ist jetzt jegliche Art von ,rationaler" Theologie verworfen und an ihre Stelle tritt die ,mystische Theologie“. Aber wie Cusanus zuvor über den traditionellen Begriff der Logik hinausging, so wächst er jetzt auch über den traditionellen Begriff der Mystik hinaus. Denn mit der gleichen Bestimmtheit, mit der er die Erfassung des Unendlichen in logischen Abstraktionen und Gattungsbegriffen verneint, verneint er auch die Möglichkeit seiner Erfassung im bloßen Gefühl. In der mystischen Theologie des I5. Jahrhunderts stehen sich zwei Grundrichtungen scharf gegenüber, deren eine sich auf den Intellekt, deren andere sich auf den Willen als die Grundkraft der Seele und als das Organ ihrer Vereinigung mit Gott beruft. In diesem Streit tritt Cusanus entschlossen auf die erste Seite. Die echte Gottesliebe ist amor Dei intellectualis: sie schließt die Erkenntnis als notwendiges Moment und als notwendige Bedingung in sich. Denn niemand vermag zu lieben, was er nicht zuvor in irgendeinem Sinne erkannt hätte. Die Liebe schlechthin, als bloßer Affekt ohne jede Beimischung der Erkenntnis, wäre ein Widerspruch in sich: was immer geliebt wird, das wird damit unter die Idee des Guten gestellt, das wird „sub ratione boni" erfaßt. Dies Wissen um das Gute muß den Willen antreiben und beflügeln, wenngleich das Was, das einfache Wesen des Guten an sich, der Erkenntnis als solcher unzugänglich 
bleibt. So fällt auch hier Wissen und Nichtwissen in eins: so bewährt sich von neuem das Prinzip der docta ignorantia als ,,wissender Unwissenheit. " 1$)$ Und darin tritt zugleich das Moment hervor, das dieses Prinzip von jeglicher Art von ",Skepsis" scheidet. Denn wenn die ,docta ignorantia“ negativ den Gegensatz des Absoluten zu jeder Form der rationalen, der logisch-begrifflichen Erkenntnis betont, so liegt hierin zugleich eine positive Forderung beschlossen. Das unbedingte göttliche Sein, das sich der diskursiven Erkenntnis durch den bloßen Begriff verschließt, verlangt eine neue Erkenntnisweise und eine neue Erkenntnisform. Das wahrhafte Organ seiner Erfassung ist die intellektuelle Schau, die „visio intellectualis", in der alle Gegensätzlichkeit der logischen Arten und Gattungen aufgehoben wird, weil wir in ihr, über alle empirischen Unterschiede des Seins und über alle seine bloß begrifflichen Trennungen hinweg, in seinen einfachen Ursprung, in den Punkt, der vor aller Trennung und allem Gegensatz liegt, uns versetzt sehen. In dieser Art der Schau, und nur in ihr, wird die echte filiatio Dei erreicht, die die scholastische Theologie vergeblich auf dem Wege des diskursiven Begriffs zu erreichen und gewissermaßen zu erzwingen glaubte. ${ }^{2}$ ) Auch in diesem Gedanken der "filiatio" knüpft Cusanus überall an Grundmotive der mittelalterlichen Mystik an; aber wiederum ist es charakteristisch, daß er ihnen diejenige Wendung gibt, die seiner neuen Gesamtanschauung vom Verhältnis des Absoluten zum Endlichen entspricht. Wenn bei

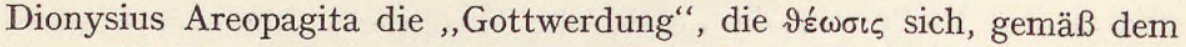
hierarchischen Prinzip, in einer ganz bestimmten Stufenfolge der Bewegung, der Erleuchtung und der schließlichen Einigung vollzieht, so ist sie für Cusanus ein einheitlicher Akt, in welchem der Mensch sich in ein unmittelbares Verhältnis zu Gott setzt. Auf der anderen Seite aber gewinnt er dieses Verhältnis nicht durch eine einfache Ekstase,

I) S. hierzu bes. Cusanus' Brief an Gaspard Aindorffer vom 22. Sept. 1452: „In sermone meo primo de spiritu sancto .. reperietis quomodo scilicet in dilectione coincidit cognitio. Impossibile est enim affectum moveri nisi per dilectionem, et quicquid diligitur non potest nisi sub ratione boni diligi... Omne enim quod sub ratione boni diligitur seu eligitur, non diligitur sine omni cognitione boni, quoniam sub ratione boni diligitur. Inest igitur in omni tali dilectione, qua quis vehitur in Deum, cognitio, licet quid sitid quod diligit ignoret. Est igitur coincidentia scientiae et ignorantiae, seu doctae ign orantiae." Der entgegengesetzte Standpunkt einer reinen Affekts- und Willensmystik wird gegenüber Cusanus in höchst charakteristischer Weise von seinem Gegner Vincent von Aggsbach vertreten. Nähreres über diesen Streit bei E. Vansteenberghe, Autour de la docte ignorance. Une controverse sur la théologie mystique au XVe siècle, Münster I9I5, wo auch die einzelnen Dokumente des Streites gesammelt sind. (Der angeführte Brief des Cusanus a. a. O. S. IIIf.)

2) Vgl. bes. die Schrift „De filiatione Dei“ (Opera fol. II9): „Ego autem ... non aliud filiationem Dei quam Deificationem quae et $\vartheta \hat{\varepsilon} \omega \sigma \iota \varsigma$ graece dicitur, aestimandum judico. Theosin vero tu ipse nosti ultimitatem perfectionis existere, quae et notitia Dei et verbi seu visio intuitiva vocitatur." 
durch eine Entrückung, sondern die visio intellectualis setzt die Selbstbewegung des Geistes, setzt eine in ihm selbst liegende ursprüngliche Kraft und deren Entfaltung in einer kontinuierlichen Denkarbeit voraus. Daher beruft sich Cusanus, um Sinn und Ziel der visio intellectualis zu bezeichnen, nicht sowohl auf die mystische Form der passiven Kontemplation, als er sich vielmehr auf die Mathematik beruft. Sie wird ihm zum eigentlichen, zum einzig wahrhaften und ,präzisen“ Symbol des spekulativen Denkens und der spekulativen Zusammenschau der Gegensätze. „Nihil certi habemus in nostra scientia nisi nostram mathematicam": wo die Sprache der Mathematik versagt, da gibt es für den menschlichen Geist überhaupt nichts Faßbares und nichts Erkennbares mehr. ${ }^{1}$ ) Wenn die Gotteslehre des Cusanus sich daher von der scholastischen Logik, von der Logik der Gattungsbegriffe, die unter dem Satz des Widerspruchs und des ausgeschlossenen Dritten steht, lossagt, so fordert sie dagegen einen neuen Typus der mathematischen Logik, die die Koinzidenz der Gegensätze nicht ausschließt, sondern die eben diese Koinzidenz selbst, eben dieses Zusammenfallen des AbsolutGrößten und des Absolut-Kleinsten, als ständiges Prinzip und als notwendiges Vehikel der fortschreitenden Erkenntnis braucht.

$\mathrm{Da}$ damit in der Tat einer neuer Weg der Theo-Logie beschritten wird, der dazu bestimmt war, die Grenzen der mittelalterlichen Denkart, und damit die Grenzen des mittelalterlichen Weltbildes zu überschreiten: das ergibt sich am deutlichsten, wenn man versucht, die Eigenart der Methode des Cusanus nicht nur systematisch zu erfassen, sondern ihr in dem universalgeschichtlichen Zusammenhang des Denkens, in dem Zusammenhang der Philosophiegeschichte und der allgemeinen Geistesgeschichte, ihren Platz zu bestimmen. Wie das gesamte Quattrocento, so steht Cusanus an jener Wende der Zeiten, an der die Geistesgeschichte sich vor eine große Entscheidung, vor die Entscheidung zwischen Platon und Aristoteles gestellt fand. Es schien freilich, als sei schon der ältere Humanismus mit dieser Entscheidung vorangegangen: schon Petrarca stellt im ,"Triumph des Ruhms" Platon als den ersten unter den Philosophen dar, dem Aristoteles erst in gemessener Entfernung folgt. ${ }^{2}$ ) Aber

I) S. Dial. de possest (Op. S. 259): ,Omnium operum Dei nulla est praecisa cognitio, nisi apud eum, qui ipsa operatur et si quam de ipsis habemus notitiam, illam ex aenigmate et speculo cognito mathematicae elicimus... Si igitur recte consideraverimus, nihil certi habemus in nostra scientia, nisi nostram mathematicam, et illa est aenigma ad venationem operum Dei." Vgl. bes. die Schrift de mathematica perfectione Opera, f. II 20 ff.

2) Petrarca, Trionfo della fama, cap. 3 :

Volsimi da man manca; e vidi Plato,

Al quale aggiunge, cui dal cielo è dato. Che in quella schiera andò piu presso al segno Aristotele, poi, pien d'alto ingegno. 
was ihn bei dieser Wahl leitet, das sind nicht prinzipielle, sondern literarisch-artistische Gründe: der ,göttliche Redestrom" Platons, dessen Kenntnis ihm durch Ciceros und Augustins Zeugnisse vermittelt wird, gibt ihm die sichere Gewähr für den Vorrang der Platonischen Philosophie. $\left.{ }^{1}\right)$ Cusanus dagegen ist vielleicht der erste abendländische Denker gewesen, dem es gegeben war, selbständige Einsicht in die Haupt- und Grundquellen der Platonischen Lehre zu gewinnen. Schon sein äußerer Lebensgang weist ihn auf diesen Weg: ist er doch der Führer jener Gesandtschaft gewesen, die sich vom Basler Konzil nach Griechenland begab, und die mit den führenden griechischen Denkern und Theologen der Zeit nach Italien zurückkehrte. Wie viel Cusanus, der schon von seiner ersten Studienzeit in Padua her das Griechische beherrschte, im Verkehr mit diesen Männern, mit Georgios Gemistos Plethon, mit Bessarion u. a. an Kenntnis und an unmittelbarer lebendiger Anschauung der Platonischen Quellen gewonnen haben muß, läßt sich leicht ermessen. Fortan zeigen ihn seine Schriften in fortdauernder Berührung mit diesen Quellen und in ständigem Gedankenaustausch mit ihnen. Insbesondere sind es - wie die Schrift ,De mente“, das dritte Buch des ,Idiota“, lehrt - die methodisch $\epsilon$ tscheidenden mittleren Bücher der Platonischen Republik gewesen, die aufs stärkste auf ihn gewirkt haben. ${ }^{2}$ ) Erwägt man ferner, daß diese Wirkung einen Geist traf, der sich von Anfang an in die Neuplatonische Spekulation versenkt, der sich an den Schriften des PseudoDionysius, an den Hermetischen Büchern, an Proklus genährt hatte, so begreift man das Problem, das hieraus erstehen mußte, und das nunmehr unaufhaltsam einer Lösung zudrängte. Die trübe Mischung platonischer und Neuplatonischer Gedankenmotive, wie sie im Wissen und Denken des Mittelalters allenthalben bestand, konnte nun nicht länger genügen. In einem Denker, der nicht nur durch die Schule der Philosophie und der Mathematik, sondern auch durch die Schule der humanistisch-philologischen Kritik hindurchgegangen war, der in eigener Arbeit wichtige erste Resultate dieser Kritik gefunden und sichergestellt hatte, - in einem solchen Denker gab es jetzt kein bloßes Neben einander Platonischer und Neuplatonischer Motive, sondern in ihm mußte nun alles zu einer Auseinandersetzung zwischen ihnen streben. Cusanus hat diese Auseinandersetzung nicht in expliziter literarischer Form gegeben, wie er sich auch an dem berühmten literarischen Streit, der durch

I) Näheres über Petrarcas Verhältnis zu Platon s. bei G. Voigt, Die Wiederbelebung des klass. Altertums, ${ }^{2}$ I, $82 \mathrm{ff}$.

2) In der uns erhaltenen Bibliothek des Cusanus befinden sich außer dem Staat der Phaedon, die Apologie, der Kriton, der Menon und Phaidros. Besonders viel scheint ferner Cusanus dem Parmenides zu verdanken, den er aus dem Kommentar des Proklog kannte. Näheres bei Vansteenberghe, a. a. O., S. $429 \mathrm{ft}$. 


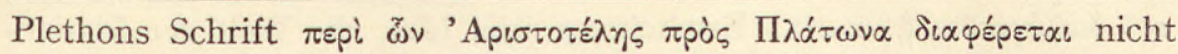
selbständig beteiligt hat. Aber statt der philologischen Kritik vollzieht er hier die tiefere und folgenreichere systematische Kritik. Die Spekulation des Cusanus wird zum Kampfplatz, auf dem sich nun Gedankenelemente, die in der mittelalterlichen Philosophie unterschiedslos ineinander übergehen, begegnen, auf dem sie sich erkennen und aneinander messen. Aus diesem Kampf - nicht aus dem literarischen Streit eines Plethon und Bessarion, eines Theodorus Gaza und Georg von Trapezunt - erwächst eine neue methodische Klärung des ursprünglichen Sinns des Platonismus, ergibt sich gleichsam eine neue geistige Demarkationslinie zwischen Platon und Aristoteles auf der einen, zwischen Platon und dem Neuplatonismus auf der anderen Seite.

Platons Weltbild ist gekennzeichnet durch den scharfen Schnitt, den es zwischen der sinnlichen und der intelligiblen Welt, zwischen der Welt der Erscheinungen und der der Ideen vollzieht. Beide Welten, die des ",Sichtbaren" und die des „Unsichtbaren“, die des óparòv und

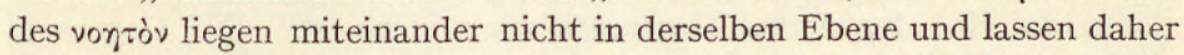
keinerlei unmittelbare Vergleichung zu. Vielmehr ist jede der volle Gegensatz, das š $\varepsilon$ pov der andern: alle Prädikate, die wir der einen zusprechen, müssen wir eben darum der andern absprechen. Alle Charaktere der "Idee" werden in dieser Weise antithetisch aus denen der Erscheinung abgeleitet. Wenn die Erscheinung durch das rastlose Fließen gekennzeichnet ist, so ist der Idee der dauernde Bestand eigen; wenn jene ihrer Natur nach niemals eine ist, sondern dem Blick, der sie festzuhalten versucht, in ein Vielfältiges, von Moment zu Moment anderes auseinandergeht, so beharrt diese in reiner Identität mit sich selbst. Wird die Idee durch die Forderung der Bedeutungskonstanz bezeichnet und durch sie durchgängig bestimmt, so entzieht sich die Welt der sinnlichen Phänomene jeder derartigen Bestimmung, ja ihrer bloßen Möglichkeit: nichts ist in ihr ein wahrhaft-Seiendes, ein wahrhaftEines, ein Etwas oder ein irgendwie-Beschaffenes. Auf dieser Grund-

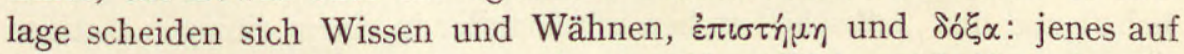
das immer-Seiende und immer in derselben Weise sich Verhaltende, dieses auf den bloßen Ablauf der Wahrnehmungen, der Vorstellungen, der Bilder in uns gerichtet. Alle Philosophie, die theoretische sowohl wie die praktische, die Dialektik wie die Ethik, besteht in dem Wissen um diesen Gegensatz: ihn aufheben, ihn in irgendeiner Weise versöhnen zu wollen hieße die Philosophie selbst aufheben. Wer diese Zweiheit verkennt, der vernichtet damit die Voraussetzung der Erkenntnis selbst, der zerstört den Sinn und die Bedeutung des Urteils und damit alle

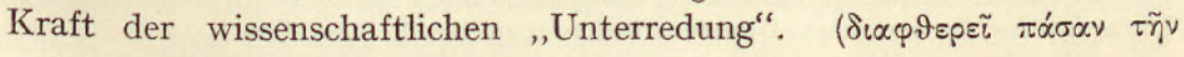




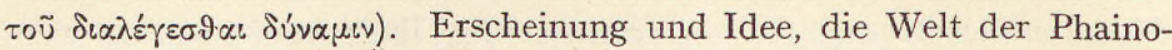
mena und die der Noumena, können denkend aufeinander bezogen, die eine kann und soll an der andern gemessen werden; aber niemals findet zwischen ihnen irgendeine "Mischung" statt, nirgends geht die Natur und das Wesen der einen in die der andern über, so daß irgendeine gemeinsame Grenzlinie bestünde, innerhalb deren beide

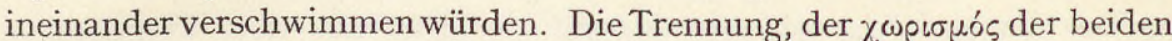

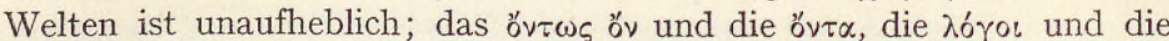
$\pi \rho \alpha ́ \gamma \mu \alpha \tau \alpha$ vereinen sich nicht, sowenig der reine "Sinn" der Idee als ein einzelnes „Daseiendes“ gegeben werden kann oder das bloße Dasein von sich aus eine ideelle Bedeutung, einen dauernden Sinngehalt oder Wertgehalt besitzt. ${ }^{1}$ )

Aristoteles' Kritik der Platonischen Ideenlehre geht von dem Anstoß aus, den er an dieser Trennung zwischen dem Gebiet des „Daseins" und dem des idealen ,Sinnes“ nimmt. Die Wirklichkeit ist eine: - wie wäre es möglich, sie in zwei verschiedenen Erkenntnisweisen zu fassen, von denen die eine der strikte Gegensatz zur andern ist? Der Gegensatz zwischen ",Stoff' und „Form“", zwischen „Werden " und ,,Sein", zwischen dem "Sinnlichen" und „Übersinnlichen" mag noch so weit gespannt werden - er kann gerade als Gegensatz nur gefaßt werden, wenn eine Vermittlung besteht, die von dem einen Pol zum andern überführt. So wird für Aristoteles der Begriff der Entwicklung zur Grundkategorie und zum durchgehenden Prinzip der Welterklärung. Was wir Wirklichkeit nennen, das ist nichts anderes als die Einheit ein und desselben Wirkungszusammenhangs, innerhalb dessen alles Verschiedene als eine bestimmte Phase und Stufe des Entwicklungsprozesses enthalten ist. Wo immer zwei noch so ,,heterogene "Seinsarten und Seinsweisen gegeben sind, da brauchen wir nur auf diesen einheitlichen dynamischen Prozeß hinzublicken, um sie in ihm verknüpft und in ihm versöhnt zu finden. Die Schranke zwischen „Erscheinung“" und „Idee“ in Platonischem Sinne fällt: denn das ,, Sinnliche" und das ,Intelligible“, das ,Niedere“ und das ,,Höhere“, das ,,Göttliche" und das „Irdische" stehen miteinander in einem einzigen stetigen Konnex des Wirkens. Die Welt ist eine in sich geschlossene Sphäre, in der es nur Gradabstufungen gibt. Von dem göttlichen unbewegten Beweger des Alls strömt die Kraft auf den äußersten Himmelskreis über, um sich von hier in stetiger und geregelter Folge auf das Ganze des Seins zu verteilen, um sich durch das Medium der ineinander geschachtelten himmlischen Sphären der niederen sublunarischen Welt mitzuteilen. So groß die Entfernung zwischen Anfang und Ende auch

I) Näheres in meiner Darstellung der griechischen Philosophie im Lehrbuch der Philosophie, hg. von Max Dessoir, Berlin 1925 , bes. I, S. $89 \mathrm{ff}$. 
sein mag, so gibt es doch in dem Weg vom einen zum andern nirgends einen Bruch, ein absolutes „Anheben“ oder "Aufhören“. Denn es ist ein endlicher und kontinuierlicher, ein in ganz bestimmten aufweisbaren Stadien durchmessbarer Raum, der beide voneinander trennt, um beide eben damit wieder miteinander zu verbinden.

Plotin und der Neuplatonismus suchen das Grundmotiv des Platonischen und des Aristotelischen Denkens zu vereinen; aber sie bringen es, systematisch betrachtet, nur zu einer eklektischen Mischung beider. Das Neuplatonische System ist beherrscht vom Platonischen Gedanken der „Transzendenz" - des absoluten Gegensatzes zwischen dem Intelligiblen und dem Sinnlichen, der ganz in Platonischen Wendungen beschrieben, ja der dem Ausdruck nach noch überboten wird. Aber indem nun gleichzeitig der Aristotelische Entwicklungsbegriff aufgenommen und angeeignet wird, löst sich die dialektische Spannung, die für das Platonische System unaufheblich war. Die Platonische Kategorie der Transzendenz und die Aristotelische der Entwicklung zeugen miteinander den Bastardbegriff der „Emanation“. Das Absolute bleibt als das Über-Endliche, als das Über-Eine und Über-Seiende, rein in sich selbst; aber nichtdestoweniger tritt es kraft des in ihm bestehenden Überflusses aus sich heraus und erzeugt in diesem Überfluß die Mannigfaltigkeit der Welten bis herab zur formlosen Materie, als der äußersten Grenze des Nicht-Seins. Die Betrachtung der Pseudo-Dionysischen Schriften hat uns gezeigt, wie das christliche Mittelalter diese Voraussetzung aufnahm, und wie es sie in seinem Sinne umbildete. Was es daraus gewann, war die Grundkategorie der stufenweisen Vermittlung, die auf der einen Seite die göttliche Transzendenz bestehen ließ, um sie auf der andern Seite, im Gedanken einer Hierarchie der Begriffe und einer Hierarchie der geistigen Kräfte, theoretisch wie praktisch zu bewältigen. Im Wunder der kirchlichen Heils- und Lebensordnung war jetzt die Transzendenz sowohl anerkannt wie besiegt - in ihm war für den Menschen das Unsichtbare sichtbar, das Unbegreifliche faßbar geworden.

Nikolaus Cusanus ist im ganzen seines Denkens und seiner Schriften noch aufs stärkste in dieser Gesamtanschauung des mittelalterlichen Geistes und des mittelalterlichen Lebens verwurzelt. Viel zu eng war das Band, das die Denkarbeit der Jahrhunderte zwischen dem Glaubensinhalt des Christentums und dem theoretischen Gehalt des Aristotelischen und Neuplatonischen Systems geknüpft hatte, als daß sich dieses Band für einen Denker, der so fest und sicher in diesem Glaubensinhalt stand, mit einem Schlage hätte lösen lassen. Und hierzu tritt für Cusanus noch ein anderes Moment, das seine Bindung an die vorausgegangenen großen scholastischen Systeme nicht nur erklärlich macht, sondern sie als fast 
unausweichlich erscheinen läßt. Diese Systeme hatten dem philosophischen Denken nicht nur seinen Gehalt, sondern auch seine Form gegeben: sie hatten die einzige und einzigartige Sprache geschaffen, in der es sich äußern konnte. Der Humanismus hatte freilich versucht, die Scholastik an diesem Punkte anzugreifen: er glaubte ihren Geist besiegen zu können, wenn er ihr die Fehler und Geschmacklosigkeiten ihres „,barbarischen" Latein vorhielt. Aber Cusanus ist dem Humanismus, so nahe er seinen Grundtendenzen stand, auf diesem Wege nicht gefolgt. Hier fühlte er sich, schon als Deutscher, von den großen Stilkünstlern, von den Meistern der humanistischen Beredsamkeit, voin Anfang an geschieden. Mit einem Enea Silvio Piccolomini, mit einem Lorenzo Valla, mit all jenen Männern, die ,,von Natur Lateiner" waren, konnte es für ihn, wie er empfand und aussprach, keinen Wettstreit geben. Aber er schämt sich dieses Mangels nicht: könne doch gerade in dem bescheideneren und niederen Ausdruck (humiliori eloquio) der lauterste und reinste Sinn sich äußern. ${ }^{1}$ ) Nun aber barg freilich eben dies Festhalten am "Stil“ der Scholastik für Cusanus auch eine innere sachliche Schwierigkeit und stellte ihn vor eine neue sachliche Aufgabe. Denn was jetzt von ihm gefordert wurde, war, daß er in den Grenzen der herrschenden philosophischen Begriffssprache, in den Grenzen der scholastischen Terminologie einen Gedanken aussprach, der seinem eigentlichen Gehalt und seiner Tendenz nach über die Schranken der Scholastik hinauswies. Cusanus' seltsames Latein, das auf der einen Seite dunkel, rätselhaft und schwerfällig erscheint, während es auf der andern Seite einen Reichtum von eigentümlichen neuartigen Wendungen in sich schließt, während es oft mit einem Wort, mit einem einzigen glücklich geprägten Terminus die ganze spekulative Tiefe der großen Grundprobleme, die ihn bewegen, blitzartig erhellt - dieses Latein ist nur aus der gesamten geistigen Situation, in der er sich gegenüber dem Mittelalter befand, verständlich. Das ständige Ringen mit dem Ausdruck, das für alle seine Schriften bezeichnend ist, ist nur ein Symptom dafür, wie jetzt die gewaltige Gedankenmasse der scholastischen Philosophie sich aus ihrer dogmatischen Erstarrung zu lösen beginnt wie sie keineswegs beiseite geworfen, aber doch in eine ganz neue $\mathrm{Be}$ -

I) ,Verum et eloquio et stilo ac forma litterarum antiqua videmus omnes delectari, maxime quidem Italos, qui non satiatuntur disertissimo (ut natura Latini sunt) huius generis latiali eloquio, sed primorum vestigia repetentes Graecis litteris maximum etiam studium impendunt. Nos vero Alemanni, etsi non longe aliis ingenio minores ex discrepanti stellarum situ essemus effecti: tamen in ipso suavissimo eloquii usu, aliis plerumque non nostro cedimus vitio, cum non nisi labore maximo, tamquam resistenti naturae vim facientes, Latinum recte fari valeamus." Aus der Vorrede zu Cusanus' Schrift „,De concordantia catholica", Op., fol. $683 \mathrm{f}$. 
wegung des Gedankens hineingezogen wird. Das eigentliche Ziel dieser Bewegung, das in Cusanus' Schriften bald nur in Andeutungen bezeichnet wird, bald wieder mit überraschender Klarheit vor uns hintritt, läßt sich dahin bezeichnen, daß nunmehr zwischen dem "Sinnlichen" und „Übersinnlichen“, zwischen der „,empirischen“" und der ,,intellektuellen“ Welt ein neues Verhältnis hergestellt wird: - ein Verhältnis, dessen systematische Betrachtung und Erfassung uns wieder auf die genuinPlatonischen Grundbegriffe, auf die Begriffe der Trennung und der

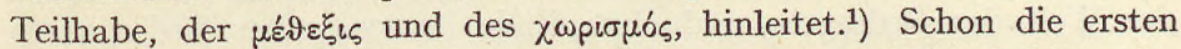
Sätze der Schrift „De docta ignorantia“" weisen darauf hin, daß hier der Schnitt, den das Denken durch die Welt des Seins legt, in einer anderen Weise und unter einem anderen Gesichtspunkt als in den klassischen Systemen der Scholastik geführt wird. Cusanus macht mit dem Plato-

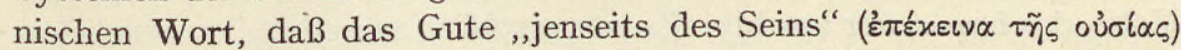
liege, wieder völligen Ernst. Keine Reihe von Schlußfolgerungen, die mit dem empirisch-Gegebenen beginnt, und die in stetigem Fortgang ein Empirisches an das andere reiht und auf ein anderes bezieht, vermag zu ihm hinaufzuführen. Denn jedes derartige Denken bewegt sich in einem bloßen Vergleich, also in der Sphäre des „Mehr" und „Weniger". Wie könnte aber durch einen solchen Vergleich jemals dasjenige gefaßt werden, was über allen Vergleich erhaben, was nicht nur relativ groß und größer, sondern das schlechthin Größte, das „Maximum“ ist? Der Ausdruck des Maximum darf hier nicht irre führen: es handelt sich nicht etwa darum, einen Superlativ zu schaffen, der auf einen vorangehenden Komparativ bezogen ist, sondern es soll vielmehr umgekehrt der unbedingte Gegensatz zu jeder auch nur möglichen Komparation, zu jedem bloß quantitativ-abstufenden Verfahren festgehalten werden. Das Maximum ist kein Größenbegriff, sondern ein rein qualitativer Begriff: es ist der absolute Grund des Seins, wie es der absolute Grund der Erkenntnis ist. $^{2}$ ) Kein bloß quantifizierendes Verfahren, keine graduelle Abstufung

I) $\mathrm{Daß}$ und warum diese Begriffe in ihrer ursprünglichen, in ihrer originär-platonischen Bedeutung dem gesamten Denken des Mittelalters fern bleiben und fern bleiben mußten, hat neuerdings Ernst Hoffmann in einem ausgezeichneten Aufsatz dargetan: ich begnüge mich hier damit, auf seine Darlegungen $\mathrm{zu}$ verweisen. (Platonismus und Mittelalter, Vorträge der Bibliothek Warburg, III, S. I 7 ff.)

2) Nebenher kann hier daran erinnert werden, da $\beta$ auch bei Platon die Idee des Guten, die zugleich der höchste Realgrund und der höchste Erkenntnisgrund ist, mit

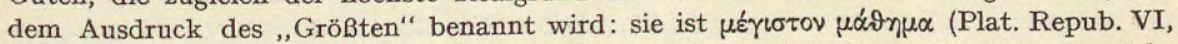
505 A). Ob Cusanus die Charakteristik des empirischen Seins als des Reiches des ,Mehr

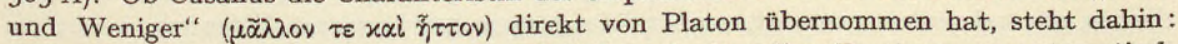
einen direkten Beweis dafür, daß er den Philebos, in dem diese Bestimmung systematisch durchgeführt wird, gekannt hat, finde ich in seinen Schriften nicht. Aber gerade wenn man annimmt, daß er den Gedanken wie den Ausdruck selbständig geformt hat, wirft dies auf den methodischen Zusammenhang, der hier herausgestellt werden soll, nur um 
vermag die Kluft zu füllen, die zwischen diesem Urgrund des Seins und dem empirischen Dasein besteht. Jede Messung, jede Vergleichung, jede Schlußfolgerung, die nur am Faden dieses Daseins fortläuft, endet auch in diesem Kreise: sie kann innerhalb des Empirischen in unbestimmbare Weite hin fortgesetzt werden, aber dieser grenzenlose Fortgang ins Unbestimmte faßt das Unendliche nicht, das vielmehr das absolute Maximum der Bestimmung ist. So treten ,Indefinites" und ,Infinites" bei Cusanus deutlich auseinander. Das einzige Verhältnis, das zwischen der Welt des Bedingten und ohne Ende immer weiter Bedingbaren und der Welt des Unbedingten besteht, ist das des völligen wechselseitigen Ausschlusses: die einzige zulässige Prädikation, die vom Unbedingten gilt, entsteht durch die Negation aller empirischen Prädikate. In aller Schärfe tritt damit das Motiv der "Andersheit", das Platonische

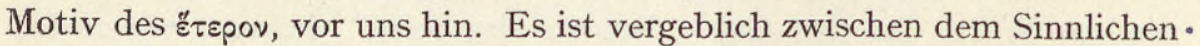
und dem Intelligiblen irgendeine Art von , Ähnlichkeit“" entdecken zu wollen. Der sinnliche Kreis, die sinnliche Kugel entsprechen niemals dem reinen Begriff beider, sondern bleiben notwendig hinter ihm zurück. Wir können das Sinnliche auf das Ideelle beziehen, wir können feststellen, daß ein gegebenes sichtbares Sein den an sich unsichtbaren Begriff der Kugel oder des Kreises mit größerer oder geringerer Genauigkeit erfüllt: aber der prinzipielle Unterschied zwischen „Abbild“ und "Urbild" wird dadurch nicht aufgehoben. Denn die reine Wahrheit des Urbilds ist eben dadurch bestimmt, daß es für sie kein "Mehr" oder "Weniger" gibt: wer ihr nur das Geringste abzuziehen oder von ihr wegzudenken sucht, der hat sie damit ihrer Wesenheit nach zerstört. Das Sinnliche hingegen erträgt nicht nur diese Unbestimmtheit, sondern es hat in ihr seine eigenste Natur; es ,,ist“, sofern ihm ein Sein zukommt, nur in eben dieser Grenzenlosigkeit des Werdens, des Hin- und Hergehens zwischen einem So-Sein und Anders-Sein. „Da es offenbar ist, daß zwischen dem Unendlichen und dem Endlichen kein Verhältnis stattfindet, so ist daraus auch völlig klar, daß, wo immer sich ein Überschreitendes und ein Überschrittenes findet, man nie zum Größten schlechthin gelangen kann: denn das Überschreitende, wie das Überschrittene, ist endlich, das schlechthin Größte aber ist notwendig unendlich. Gibt es also irgend

so helleres Licht. Im übrigen wird Platon von Cusanus als der einzige Denker gerühmt, der in bezug auf die Gotteserkenntnis den wahren Weg der ,,docta ignorantia“ gefunden habe: „Nemo ad cognitionem veritatis magis propinquat, quam qui intelligit in rebus divinis, etiam si multum proficiat, semper sibi superesse, quod quaerat. Vides nunc venatores Philosophos... fecisse labores inutiles: quoniam campum doctae ignorantiae non intrarunt. Solus a tem Plato, aliquid plus aliis Philosophis videns, dicebat, se mirari, si Deus inveniri et plus mirari, si inventus posset propolari". De venatione sapientiae, Cap. XII, fol. 307 . 
etwas, was nicht dieses Größte schlechthin ist, so kann offenbar zu ihm immer ein noch Größeres gefunden werden. So kann es nicht zwei oder mehrere Dinge geben, die einander so gleich oder ähnlich sind, daß nicht noch ähnlichere, und zwar ins Unendliche, gefunden werden könnten. So nahe also das Maß und das Gemessene einander kommen mögen, so bleibt zwischen ihnen doch immer ein Unterschied zurück. Der endliche Verstand kann demnach die Wahrheit der Dinge durch keine noch so große Ähnlichkeit in wirklicher Genauigkeit erkennen. Denn die Wahrheit ist weder mehr noch weniger, da sie in etwas Unteilbarem besteht.... Der Intellekt verhält sich somit zur Wahrheit, wie das Polygon zum Kreis: wie das Polygon, je mehr Winkel und Seiten es hat, sich um so mehr dem Kreise nähert, ohne jedoch, auch wenn man die Seiten und Winkel ins Unendliche wachsen läßt, dem Kreise gleich zu werden, so wissen wir auch von der Wahrheit nichts anderes, als daß sie, so wie sie ist, für uns in wahrhafter Genauigkeit nicht faßbar ist. Denn die Wahrheit ist die absoluteste Notwendigkeit, die weder mehr noch weniger sein kann als sie ist; unser Intellekt aber ist bloße Möglichkeit" 1 ).

Wie es gemäß diesen wenigen wuchtigen Sätzen keinen einfachen und stetigen Aufstieg vom Bedingten zum Unbedingten, keinen Fortgang von empirischen oder rationalen ,Wahrheiten" zu der einen absoluten Wahrheit geben kann, und wie dadurch die Form der scholastischen Logik und das Ziel der scholastischen Ontologie negiert wird, haben wir gesehen. Aber diese Folgerung schließt nun zugleich eine eigentümliche Umkehr in sich. Der Schnitt, der das Sinnliche vom Intelligiblen, der die Empirie und die Logik von der Metaphysik scheidet, zerschneidet nicht etwa den Lebensnerv der Erfahrung selbst: sondern gerade er ist es, der der Erfahrung ihr Recht sichert. Dies geschieht, indem Cusanus nunmehr mit der gleichen Entschiedenheit und Schärfe, wie zuvor den Gedanken der ,,Trennung“" den Gedanken der ,,Teilhabe“ herausarbeitet.

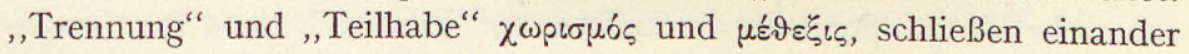
so wenig aus, daß vielmehr die eine nur durch die andere und mit bezug auf die andere gedacht werden kann. In der Definition des empirischen Wissens selbst sind notwendig beide Momente gesetzt und miteinander verknüpft. Denn kein empirisches Wissen ist möglich, ohne daß es sich auf ein ideales Sein und ein ideales So-Sein bezieht; aber kein empirisches Wissen ist derart, daß es die Wahrheit dieses Ideellen einfach enthält, daß es sie als Teilbestand in sich faßt. Der Charakter des Empirischen ist, wie wir gesehen haben, seine grenzenlose Bestimmbarkeit, derCharakter des Ideellen seine Geschlossenheit, seine notwendige und eindeutige Bestimmtheit. Aber die Bestimmbarkeit selbst ist nur in Hinblick auf die

I) De docta ignorantia I., 3, fol. 2 f. 
Bestimmtheit möglich, die ihr erst eine feste Form und Richtung gibt. So zielt alles Bedingte und Endliche auf das Unbedingte, ohne es doch jemals erreichen zu können. Das ist das zweite Grundmotiv, das im Begriff der docta ignorantia eingeschlossen liegt. Mit Rücksicht auf die Gotteslehre besagt dieser Begriff den Gedanken des wissenden Nichtwissens; mit Rücksicht auf die Erfahrung, auf die empirische Erkenntnis, besagt er den Gedanken des nichtwissenden Wissens. Die Erfahrung birgt echtes Wissen: - aber freilich muß dieses Wissen sich selbst darüber klar sein, daß es, soweit es auch fortschreiten mag, niemals ein absolutes, sondern immer nur ein relatives Ziel und Ende erreicht, daß in diesem Gebiete keine wahrhafte Exaktheit, keine praecisio herrscht, sondern daß jede noch so genaue Aussage oder Messung durch eine andere genauere überboten werden kann und überboten werden soll. In diesem Sinne bleibt all unser Erfahrungswissen „,Vermutung“; bleibt es ein Ansatz, eine Hypothesis, die sich von vornherein bescheidet, durch andere bessere und richtigere Ansätze überwunden werden zu können. In diesem Begriff der ,Vermutung“, der conjectura schließt sich jetzt der Gedanke der ewigen "Andersheit" zwischen Idee und Erscheinung mit dem Gedanken der Teilhabe der Erscheinung an der Idee unmittelbar in eins zusammen. Cusanus' Definition des empirischen Wissens ist nur durch diesen Zusammenschluß möglich: „conjectura est positiva assertio in alteritate veritatem uti est participans"1) So haben wir jetzt neben der negativen Theologie eine positive Erfahrungslehre, und beide widerstreiten einander nicht, sondern stellen nur ein und dieselbe Grundauffassung der Erkenntnis nach zwei verschiedenen Seiten dar. Die eine, in ihrem absoluten Sein ungreifbare Wahrheit kann sich für uns nur in der Sphäre der Andersheit darstellen; aber ebensogut gibt es für uns auch keine Andersheit, die nicht in irgendeiner Weise auf die Einheit hinweise und an ihr Teil hätte. ${ }^{2}$ ) Auf jede Identität, auf jedes Hineinragen der einen Sphäre in die andere, auf jede Aufhebung des Dualismus müssen wir verzichten; aber eben dieser Verzicht gibt unserer Erkenntnis ihr relatives Recht und ihre relative Wahrheit. Er zeigt, Kantisch gesprochen, daß unser Wissen zwar Grenzen hat, die es nie und nimmer zu übersteigen vermag, aber daß ihm innerhalb des Gebietes, das ihm

I) De conjecturis I, I3.

2) ,Identitas igitur inexplicabilis varie differenter in alteritate explicatur atque ipsa varietas concordanter in unitate identitatis complicatur... Potius igitur omnis nostra intelligentia ex participatione actualitatis divinae in potentiali varietate consistit. Posse enim intelligere actu veritatem ipsam uti est, ita creatis convenit mentibus sicut Deo proprium est, actum illum esse varie in creatis ipsis mentibus in potentia participatum... Nec est inccessibilis illa summitas ita aggredienda, quasi in ipsam accedi non possit, nec aggressa credi debet actu apprehensa, sed potius, ut accedi possit semper quidem propinquius, ipsa semper uti est inattingibili remanente" (ibid.). 
zugewiesen ist, keine Schranken gesetzt sind - daß es sich, in der Andersheit selbst, frei und unbehindert nach allen Seiten ausdehnen kann und soll. Die Trennung selbst ist es, die, indem sie den Zusammenfall verhütet, indem sie das Eine im anderen, das andere im Einen sehen lehrt, die Möglichkeit echter Teilhabe des Sinnlichen am Ideellen gewährleistet.

2.

Wir haben bisher nur das allgemeinste methodische Prinzip der Philosophie des Nikolaus Cusanus ausgesprochen - aber in eben diesem Prinzip liegt nun schon eine Reihe von Folgerungen beschlossen, die von entscheidender Bedeutung für das konkrete Weltbild, für die Auffassung des physischen wie des geistigen Kosmos sind. An die oben bezeichneten Sätze der beiden Schriften „De docta ignorantia“ und ,,de conjecturis" reiht sich unmittelbar die Darlegung des Prinzips der Relativität der Bewegung und die Lehre von der Eigenbewegung der Erde an. Cusanus gelangt zu diesen Sätzen, wie der Zusammenhang unverkennbar lehrt, nicht auf Grund physikalischer, sondern auf Grund spekulativer und allgemein-erkenntnistheoretischer Erwägungen: hier spricht nicht der Physiker, sondern der Methodiker des ,, wissenden Nichtwissens". Wenn dadurch, für den Historiker der empirischen Naturwissenschaft, seine Sätze etwas Befremdliches und Seltsames erhalten, wenn sie ihrer Ableitung und ihrer Form nach, nicht sowohl den Charakter der empirischen Forschung, als vielmehr den eines bloßen,, Aperçu “ zu tragen scheinen, so darf der Historiker der Philosophie sich hierdurch nicht beirren lassen. Seine Aufgabe ist es vielmehr, zu zeigen, wie in diesem scheinbaren Aperçu das Gan ze von Cusanus' Lehre vorausgesetzt ist, und wie eben dieses Ganze sich hier an einer bestimmten Sonderaufgabe bewährt.

Wir gehen auch hier, um die Eigenart von Cusanus' Sätzen und ihr originales gedankliches Motiv scharf zu erfassen, von dem Gegensatz gegen die mittelalterliche Physik aus. Diese stützt sich auf die Aristotelische Grundlehre von den vier Elementen, deren jedem im Aufbau des Kosmos ein ganz bestimmter Platz angewiesen ist. Feuer, Wasser, Luft und Erde stehen zueinander in einer fest geregelten räumlichen Beziehung, in einer bestimmten Ordnung des „Oben“ und „Unten“. Die Natur jedes Elements weist ihm einen bestimmten Abstand vom Mittelpunkt des Universums zu. Diesem zunächst steht die Erde; und jeder Teil von ihr strebt, wenn er einmal von seinem natürlichen Ort, von der unmittelbaren Nähe zum Weltmittelpunkt getrennt ist, in geradliniger Bewegung $\mathrm{zu}$ ihm zurück. Im Gegensatz hierzu ist die Bewegung des Feuers ,an 
sich" nach oben gerichtet, so daß es sich ständig vom Mittelpunkt zu entfernen strebt. Zwischen dem Ort der Erde und dem des Feuers lagert sich dann das Gebiet, dem Luft und Wasser angehören. Die allgemeine Form des physikalischen Wirkens ist durch diese Stellenordnung bestimmt. Alle physische Wirksamkeit vollzieht sich derart, daß eine Umwandlung von einem Element in ein anderes, ihm benachbartes stattfindet, so daß Feuer zu Luft, Luft zu Wasser, Wasser zu Erde wird. Dieses Prinzip der gegenseitigen Umwandlung, dieses Gesetz des Entstehens und Vergehens, prägt allem irdischen Geschehen seinen Stempel auf. Über der irdischen Welt aber erhebt sich die Sphäre, die diesem Gesetz nicht mehr unterworfen ist, die weder Entstehen noch Vergehen kennt. Die Materie der himmlischen Körper hat ein eigenes Sein, eine "quinta essentia", die von der Art der vier irdischen Elemente wesenhaft verschieden ist. Ihr kommt keine qualitative Umwandlung $\mathrm{zu}$, sondern sie besitzt nur noch eine mögliche Art der Veränderung: die reine Ortsbewegung. Und da von allen möglichen Formen der Bewegung dem vollkommensten Körper die vollkommenste zukommen muß, so ergibt sich, daß die himmlischen Körper reine Kreislinien um den Mittelpunkt der Welt beschreiben. Das ganze Mittelalter hindurch behauptet dieses System seine fast unbestrittene Herrschaft. Die Frage nach der ,,Substanz des Himmels" gibt freilich immer wieder zu Zweifeln Anlaß und unterliegt manchen Umgestaltungen im einzelnen: aber die Grundansicht selbst wird durch diese Wandlungen nicht wesentlich angetastet. Duns Scotus und Wilhelm von Occam greifen in diese Frage ein, indem sie die These verfechten, daß auch die himmlischen Körper aus einer Materie bestehen, die an sich, gleich der irdischen, die Möglichkeit des Werdens, des Übergangs in eine andere entgegengesetzte Form in sich schließt, daß aber keine natürlichen Kräfte bestehen, die die Macht besitzen, eine solche Veränderung auszulösen. So ist der Himmel, wenn nicht kraft logischer, so doch kraft tatsächlicher Notwendigkeit, wenn nicht begrifflich, so doch faktisch, dem Entstehen und Vergehen entrückt. Ein solches Entstehen oder Vergehen könnte immer nur durch einen unmittelbaren Eingriff Gottes in die Natur, nicht durch in ihr selbst liegende Kräfte erfolgen. ${ }^{1}$ )

Diese ,klassische" Aristotelische und scholastische Auffassung des Kosmos widerstreitet dem spekulativen Grundprinzip, das Cusanus in der Schrift „De docta ignorantia“ entwickelt hat, in zwiefacher Hinsicht. Sie ordnet auf der einen Seite das Element des Himmels und die vier

I) Vgl. hierzu, sowie für die weiteren Abwandlungen, die die Lehre von der Substanz des Himmels innerhalb der Scholastik erfahren hat: P. Duhem, Etudes sur Léonard de Vinci, $2^{c}$ serie, Paris r 909, S. $255 \mathrm{ff}$. 
irdischen Elemente nach einer räumlichen Abstufung, die zugleich eine Abstufung desWertes in sich schließt. Je höher ein Element in der kosmischen Stufenleiter steht, um so näher ist es dem unbewegten Beweger der Welt, und um so reiner und vollkommener ist demgemäß seine Natur. Cusanus aber kennt ein solches Verhältnis der Nähe und Ferne zwischen dem Sinnlichen und Übersinnlichen nicht mehr. Wo der Abstand als solcher unendlich ist, da heben sich die relativen endlichen Unterschiede auf. Jedes Element, jedes natürliche Sein ist daher, wenn wir es dem göttlichen Ursprung des Seins vergleichen, diesem Ursprung gleich fern und gleich nah. Es gibt jetzt kein „Oben“ und „Unten“ mehr, sondern nur noch einen einzigen in sich homogenen Kosmos, der als empirischer Kosmos dem absoluten Sein gegenübersteht, wie er andererseits als Ganzes am Absoluten Teil hat, so weit die Natur des Empirischen eine solche Teilhabe zuläßt. Weil diese Art der Teilhabe prinzipiell für alles Daseiende gilt, kann sie nicht einem seiner Bestandteile in höherem, einem anderen in geringerem Grade zukommen. Und damit ist mit einem Schlage der Wertgegensatz zwischen der niederen sublunaren und der höheren himmlischen Welt beseitigt. An die Stelle der Stufenleiter der Elemente, wie die Peripatetische Physik sie annimmt, tritt der Anaxagoreische Satz, daß in der körperlichen Natur ,,alles in allem " ist. Der Unterschied, den wir in den verschiedenen Weltkörpern anzunehmen haben, ist kein spezifischer Unterschied ihrer Substanz, sondern beruht auf dem verschiedenen Verhältnis der Mischung der überall gleichartigen, durch die ganze Welt verbreiteten Grundelemente. Könnten wir uns zur Sonne erheben, so würden wir auch in ihr neben dem Element des Feuers eine Schicht des Wassers, der Luft, der Erde finden - wie andererseits die Erde einem Beobachter, der sie von einem Standpunkt außer und über ihr betrachtete, als ein leuchtender Stern erscheinen würde. ${ }^{1}$ ) Und daran reiht sich eine zweite Erwägung, die für Cusanus dem kosmologischen System des Aristoteles und der Scholastik jeden Wahrheitswert raubt. Betrachtet man dieses System näher, so erkennt man, daß es aus zwei ungleichartigen und letzten Endes unvereinbaren Bestandteilen zusammengefügt ist. Ideelles mischt sich hier mit Empirischem, Empirisches mit Ideellem. Der vollkommenen Substanz des Himmels soll eine vollkommene Bewegung, die Bewegung in einer exakten Kreisbahn entsprechen. Aber das wahrhaft Exakte kann, wie das Prinzip der ,,docta

I) „In Sole si quis esset, non appareret illa claritas quae nobis: considerato enim corpore Solis, tunc habet quandam quasi terram centraliorem et quandam luciditatem quasi ignilem circumferentialem et in medio quasi aqueam nubem et aerem clariorem ... Unde si quis esset extra regionem ignis, terra... in circumferentia suae regionis per medium ignis lucida stella appareret, sicut nobis, qui sumus circa circumferentiam regionis Solis, Sol lucidissimus apparet." De doct. ign. II, I2 (fol. 39f.) 
ignorantia" uns gelehrt hat, niemals als tatsächlicher Bestand, als Vorhandenes und Aufweisbares in der Wirklichkeit der Dinge angetroffen werden. Es ist und bleibt ein Ideal, auf das wir die Körper und die körperlichen Bewegungen zwar um der Erkenntnis willen beziehen müssen, das sich aber nirgends unmittelbar in ihnen selbst, als ein wahrnehmbares Merkmal, vorfindet. $\left.{ }^{1}\right)$ Der Kosmos weist daher ebenso wenig eine vollkommene Kugel, wie eine streng genaue Kreisbahn auf: bleibt er doch, wie alles sinnlich Wahrnehmbare, in der Sphäre der Unbestimmtheit, des bloßen ,Mehr und Weniger". Von diesen methodischen Praemissen aus erreicht Cusanus die wesentlichen Sätze der neuen Kosmologie. Die Erde ist beweglich und von sphärischer Gestalt - doch ist weder ihre Gestalt noch ihre Bewegung derart, daß sie mit absoluter mathematischer Genauigkeit bestimmbar ist. Aber da sie dieses Zurückbleiben hinter der unbedingten Vollkommenheit des geometrischen Begriffs mit allem anderen, was es in der sichtbaren Natur gibt, teilt, so darf sieinnerhalb dieser Natur nicht länger als etwas Niederes oderVerwerfliches bezeichnet werden. Sie ist vielmehr ein edler Stern, dem Licht und Wärme und eine eigene von allen anderen Gestirnen unterschiedene Wirksamkeit zukommt, - wiedenn überhaupt imZusammenhang des Kosmos kein Teilentbehrlich ist, vielmehr jeder seine besondere Wirkungsart und demgemäß seinen eigenen unvergleichlichen Wert besitzt. ${ }^{2}$ ) Man erkennt in diesem Zusammenhange deut-

I) Auch diese Erwägung, kraft deren Cusanus das Aristotelische Weltgebäude gewissermaßen aus den Angeln hebt, findet sich in voller Klarheit und Schärfe bei Platon;

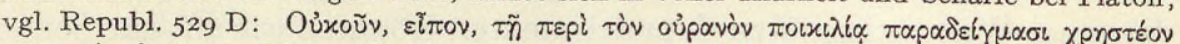

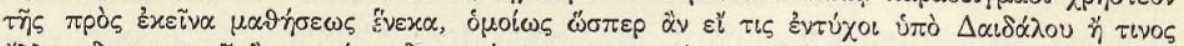

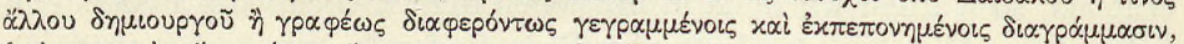

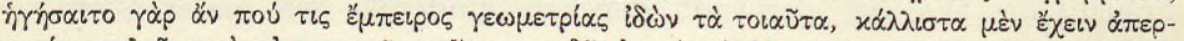

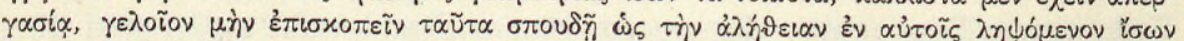

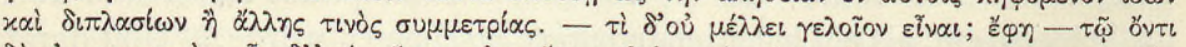

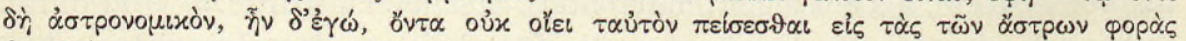

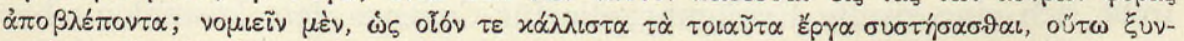

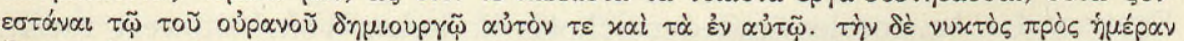

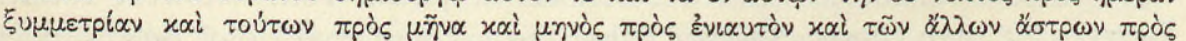

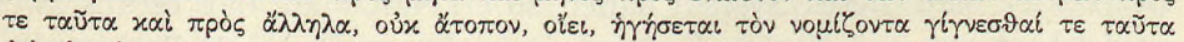

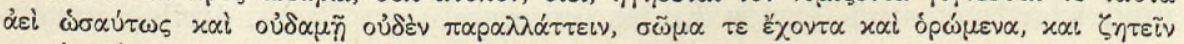

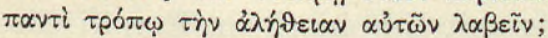

2) „Terrae igitur figura est mobilis et sphaerica et ejus motus circularis, sed perfectior esse posset. Et quia maximum in perfectionibus, motibus et figuris in mundo non est, ut ex jam dictis patet, tunc non est verum, quod terra ista sit vilissima et infima... Est igitur terra stella nobilis, quae lumen et calorem et influentiam habet aliam et diver$\mathrm{sam} \mathrm{ab}$ omnibus aliis stellis... Ita quidem Deus benedictus omnia creavit, ut dum quodlibet studet esse suum conservare, quasi quoddam munus divinum, hoc agat in communione cum aliis, ut sicut pes non sibi tantum, sed oculo ac manibus ac corpori et homini toti servit, per hoc quod est tantum ad ambulandum, et ita de oculo et reliquis membris: pariformiter de mundi partibus. Plato enim mundum animal dixit, cujus animam absque immersione Deum si concipis, multa horum, quae diximus tibi clara erunt." De doct. ign. II, I2. 
lich, wie die neue astronomische Orientierung, die zur Aufhebung des geozentrischen Weltbildes führt, für Cusanus nur die Folge und der Ausdruck einer veränderten geistigen Gesamtorientierung ist. Diese innere Verflechtung kommt schon in der Formel zum Vorschein, in die der Grundgedanke von Cusanus' Kosmologie in der Schrift ,de docta ignorantia“" gekleidet wird. Es ist vergeblich, für die Welt einen physischen Mittelpunkt zu suchen: denn wie sie keine fest umrissene geometrische Gestalt hat, sich vielmehr räumlich ins Unbestimmte erstreckt, so hat sie auch kein örtlich bestimmtes Zentrum. Die Frage nach ihrem Mittelpunkt kann daher, so fern sie überhaupt gestellt werden darf, nicht mehr von der Physik, sondern nur noch von der Metaphysik beantwortet werden: Gott ist das Zentrum der Erde und aller himmlischer Sphären, wie überhaupt all dessen, was es in der Welt gibt. Und wie als Mittelpunkt des Alls muß er auch als dessen unendlicher Umkreis bezeichnet werden, da sein Wesen das aller anderen in sich schließt. ${ }^{1}$ ) Diese Grundeinsicht aber schließt nun für Cusanus zugleich einen natürlichen wie einen geistigen, zugleich einen physischen und einen ,spirituellen" Sinn in sich. Wenn die neue Form der Kosmologie uns darüber belehrt, daß es in der Ordnung des Kosmos kein absolutes Oben oder Unten gibt, daß kein Körper dem göttlichen Urquell des Seins ferner oder näher steht, sondern daß jeder „,unmittelbar zu Gott" ist, - so entspricht diesem Gedanken jetzt eine neue Form der Religion und der religiösen Gesamtstimmung. In dieser Hinsicht lassen sich den kosmologischen Sätzen der Schrift „De docta ignorantia" die religionsphilosophischen Anschauungen, die Cusanus in der Schrift „De pace fidei“ (I454) entwickeit hat, unmittelbar an die Seite setzen. Beide Schriften bewegen sich, inhaltlich gesehen, auf ganz verschiedenen Gebieten; aber sie sind nichtsdestoweniger nur verschiedene Spiegelungen ein und derselben systematischen Grundansicht. Wie zuvor die Folgerungen aus dem Prinzip der ,,docta ignorantia“ für das Wissen von der Welt, so werden sie jetzt für das Wissen von Gott gezogen. Wie das Weltall sich in eine unendliche Mannigfaltigkeit unendlich verschiedenartiger Bewegungen auflöst, deren jede um ihren eigenen Mittelpunkt kreist, und die doch alle durch die Beziehung auf eine gemein-

I) „Non est igitur centrum terra, neque octavae aut alterius sphaerae, neque apparentia sex signorum super horizontem terram concludit in centro esse octavae sphaerae ... Neque etiam est ipsum mundi centrum plus intra terram quam extra. Neque etiam terra ista, neque aliqua sphaera habet centrum, nam cum centrum sit punctum aequedistans circumferentiae et non sit possibile verissimam sphaeram aut circulum esse, quin verior dari possit: manifestum est non posse dari centrum, quin verius etiam dari possit atque praecisius. Aequidistantia praecisa ad diversa extra Deum reperibilis non est, quia ipse solus est infinita aequalitas. Qui igitur est centrum mundi, scilicet Deus benedictus, ille est centrum terrae et omnium sphaerarum atque omnium quae in mundo sunt, qui est simul omnium circumferentia infinita." De doct. ign. II., rI, fol. $3^{8}$. 
same Ursache und durch den Anteil an ein und derselben universalen Gesetzlichkeit zusammengehalten werden, so gilt das Gleiche auch vom geistigen Sein. Jedes geistige Sein ist in sich zentriert: aber gerade in dieser Zentrierung, in dieser seiner unaufheblichen Individualität hat es seinen Anteil am Göttlichen. Die Individualität. bildet keine bloße Schranke, sondern sie stellt einen eigentümlichen Wert dar, der nicht nivelliert und nicht ausgelöscht werden darf, weil nur durch ihn das Eine, das ,,jenseits des Seins“ ist, für uns erfaßbar wird. Dieser Gedanke vermag nach Cusanus allein die Theodizee der religiösen Formen und Gebräuche zu leisten; denn kraft seiner erscheint die Vielheit, der Unterschied und die Heterogeneität dieser Formen nicht mehr als Widerspruch zur Einheit und Allgemeinheit der Religion, sondern als notwendiger Ausdruck eben dieser Allgemeinheit selbst. Die Schrift ,de pace fidei" stellt diese Grundauffassung in concreto vor uns hin. Die Abgesandten aller Völker und aller Religionsparteien erscheinen vor Gott, um ihn anzuflehen, den Streit, der sie entzweit, endlich zu schlichten. Was bedeutet dieser Streit, da doch alle Religionen auf das gleiche einheitliche Ziel und auf das gleiche einfache Sein Gottes abzwecken? „Was verlangt denn der Lebende, als zu leben; was verlangt der, der ist, anders als zu sein? Du also, der Du der Spender des Lebens und des Seins bist, bist auch derjenige, der in verschiedenen Riten auf verschiedene Weise gesucht zu werden scheint, der mit verschiedenen Namen genannt wird, und der doch, wie er ist, allen unbekannt und unaussprechlich bleibt. Denn Du, der Du die unendliche Kraft bist, bist nichts von dem, was Du geschaffen hast, noch kann das Geschöpf den Begriff Deiner Unendlichkeit fassen: denn zwischen dem Endlichen und Unendlichen findet kein Verhältnis statt. Du aber, allmächtiger Gott, der Du jedem Geiste unsichtbar bist, kannst Dich jedem auch sichtbar machen in der Art, auf welche Du begriffen werden kannst. Verbirg Dich also nicht länger, o Herr, sei gnädig und enthülle Dein Antlitz: und alle Völker werden zum Heil gelangen. Denn niemand entzieht sich Dir, außer weil er Dich nicht kennt. Wenn Du diese unsere Bitte erhörst, dann wird das Schwert, dann werden $\mathrm{HaB}$ und Neid und alle Übel schwinden und alle werden erkennen, daß es nur eine Religion in der Mannigfaltigkeit der Riten gibt. Kann also diese Mannigfaltigkeit der Riten nicht aufgegeben werden, oder erscheint es nicht gut, sie aufzuheben, damit die Verschiedenheit selbst zum Ansporn der Frömmigkeit werde und jedes Land seinen Gebräuchen, als den gottgefälligsten, mit um so größerem Eifer obliegt: so soll wenigstens, wie Du Einer bist, nur eine Religion und eine Gottesverehrung sein. "1) So wird der Anspruch auf eine Universalreligion,

I) De pace fidei, Cap. I (fol. 862 f.) 
der Anspruch auf eine weltumspannende ,Katholizität" aufrecht erhalten; aber er erhält jetzt, gegenüber der mittelalterlich-kirchlichen Auffassung, einen völlig neuen Sinn und eine neue Begründung. Der Glaubensinhalt selbst ist, soweit er immer und notwendig menschlicher Vorstellungsinhalt ist, zur ,conjectura“ geworden: er untersteht der Bedingung, das Eine Sein und die Eine Wahrheit nur in der Form der "Andersheit" aussprechen zu können. ${ }^{1}$ ) Dieser Andersheit, die in der Art und im Wesen der menschlichen Erkenntnis selbst gegründet ist, kann sich keine einzelne Glaubensform entziehen. Jetzt steht also nicht mehr einer allgemein-gültigen und einer allgemein-verbindlichen „Orthodoxie" eine Fülle bloßer „Heterodoxien“ gegenüber; sondern die Andersheit, das

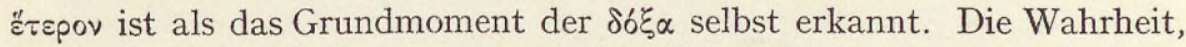
die in ihrem An-Sich ungreifbar und unfaßbar bleibt, kann nur in ihrer Andersheit gewußt werden: ,, cognoscitur inattingibilis veritatis unitas in alteritate conjecturali" ${ }^{2}$ ) Von dieser Grundansicht aus ergibt sich für Cusanus eine wahrhaft großartige „Toleranz", die aber alles andere als Indifferenz ist. Denn die Mehrheit der Glaubensformen wird jetzt nicht als ein bloßes empirisches Nebeneinander geduldet, sondern sie wird spekulativ gefordert und erkenntnistheoretisch begründet. In dem Dialog „,De pace fidei“ erhebt einer der Abgesandten der Völker, ein Tartare, gegen die geplante Glaubensvereinigung den Einwand, daß sie angesichts des radikalen Unterschieds nicht nur der theoretischen Grundanschauungen, sondern auch der Gebräuche und Sitten unvollziehbar sei. Kann es einen größeren Gegensatz geben, als daß die eine Religion die Vielweiberei erlaubt, ja gebietet, die andere sie zum Verbrechen macht, — daß im christlichen Meßopfer der Leib und das Blut Christi genossen wird, während eben dies jedem Nicht-Christen, als Verschlingen und Verzehren des Heiligsten, fluchwürdig und abscheulich erscheinen muß? „So begreife ich nicht, wie in all diesem, was nach Ort and Zeit wechselt, sich je eine Einigung ergeben sollte: und, solange dies nicht geschieht, wird auch die Verfolgung kein Ende nehmen. Denn die Verschiedenheit erzeugt Trennung und Feindschaften, $\mathrm{Haß}$ und Krieg." Aber gegen diesen Einwurf wird nun von dem göttlichen Wort Paulus zur Entscheidung angerufen. Es muß gezeigt werden - so fällt er diese Entscheidung daß die Erlösung der Seele nicht nach ihren Werken, sondern nach ihrem Glauben dargeboten wird; denn Abraham, der Vater aller Gläubigen, mögen sie nun Christen oder Araber oder Juden sein, glaubte an Gott und dies diente zu seiner Rechtfertigung. Hier fällt also jede äußere Schranke: ,,anima justi haereditabit vitam aeternam." Nimmt man dies an, so

I) S. De conjecturis I, I3 (ob. S. 24, Anm. 2).

2) De conjecturis $I, 2$ (fol. 76 ). 
bildet auch jene Verschiedenheit der Riten kein Hemmnis mehr: denn alle Einrichtungen und Gebräuche sind nur sinnliche Zeichen für die Wahrheit des Glaubens, und nur diese Zeichen, nicht das Bezeichnete, unterliegt dem Wechsel und der Veränderung. ${ }^{1}$ ) Es gibt keine noch so niedere, noch so verwerfliche Glaubensform, die nicht von dieser Grundeinsicht aus ihre relative Rechtfertigung fände. Auch der reine Polytheismus wird hier nicht ausgeschlossen: denn wo immer Götter verehrt werden, da wird der Gedanke, da wird die Idee des Göttlichen vorausgesetzt. ${ }^{2}$ ) Man sieht, wie der Kosmos der Religionen für Cusanus dieselbe Nähe und Ferne zu Gott, dieselbe unverbrüchliche Identität und dieselbe unaufhebliche Andersheit, dieselbe Einheit und dieselbe Besonderung aufweist, wie sie uns zuvor im Bilde des physischen Kosmos entgegengetreten sind.

Und dieser Gedanke greift noch weiter, indem er von der Besonderung, die uns in der Natur und in den geschichtlichen Formen des Geistes begegnet, zum letzten Besonderen, zum Individuum schlechthin weitergeht. Auch das Individuum bildet, religiös gesehen, keinen Gegensatz zum Allgemeinen, sondern vielmehr erst dessen wahrhafte Erfüllung. Die klarste Bestimmung und Durchführung dieser Grundanschauung hat Cusanus in der Schrift ,De visione Dei“" gegeben, die er den Mönchen von Tegernsee gewidmet hat. Wieder bricht hier jene Form der symbolischen Unterweisung durch, die für ihn bezeichnend ist. Wenn Goethe das Wesen des Symbols in der konkret-lebendigen Offenbarung des Unerforschlichen sieht, so hat Cusanus ähnlich gedacht und ähnlich empfunden. Immerwieder sucht er das Allgemeine und Allgemeinste an ein einzelnes, an ein Sinnlich-Unmittelbares anzuknüpfen. Er erinnert am Eingang der Schrift an ein Selbstbildnis Roger van der Weydens, das er im Rathaus zu Brüssel gesehen, und das die Eigenschaft besaß, daß es jedem Beschauer, wo immer er sich befinden mochte, stets den Blick direkt zuzukehren schien. ${ }^{3}$ )

I) De pace fidei Cap. I $_{5}$ : ,Oportet ut ostendatur non ex operibus, sed ex fide salvationem animae praesentari. Nam Abraham, pater fidei omnium credentium, sive Christianorum, sive Arabum, sive Judaeorum credidit Deo et reputatum est ei ad justitiam: anima justi haereditabit vitam aeternam. Quo admisso, non turbabunt varietates illae rituum, nam ut signa sensibilia veritatis fidei sunt instituta et recepta: signa autem mutationem capiunt, non signatum."

2) De pace fidei Cap. VI: ,Omnes qui unquam plures Deos coluerunt divinitatem esse praesupposuerunt. Illam enim in omnibus Diis tanquam in participantibus eandem adorant. Sicut enim albedine non existente non sunt alba: ita divinitate non existente, non sunt Dii. Cultus igitur Deorum confitetur Divinitatem."

3) Das Selbstporträt Roger van der Weydens ist, wie ich einer freundlichen Mitteilung Erwin Panofskys entnehme, heute nicht mehr vorhanden; erhalten hat sich jedoch eine alte Gobelinkopie von ihm, die sich im Museum in Bern befindet. Die Auffindung dieser Kopie auf Grund der Stelle in der Schrift ,,De visione Dei“ gelang H. Kauffmann, (Repertorium für Kunstgeschichte 19r6). Ein anderes Bild aus dem Nürnberger Rathaus, auf das Cusanus gleichfalls verweist, ist nicht mehr zu rekonstruieren. 


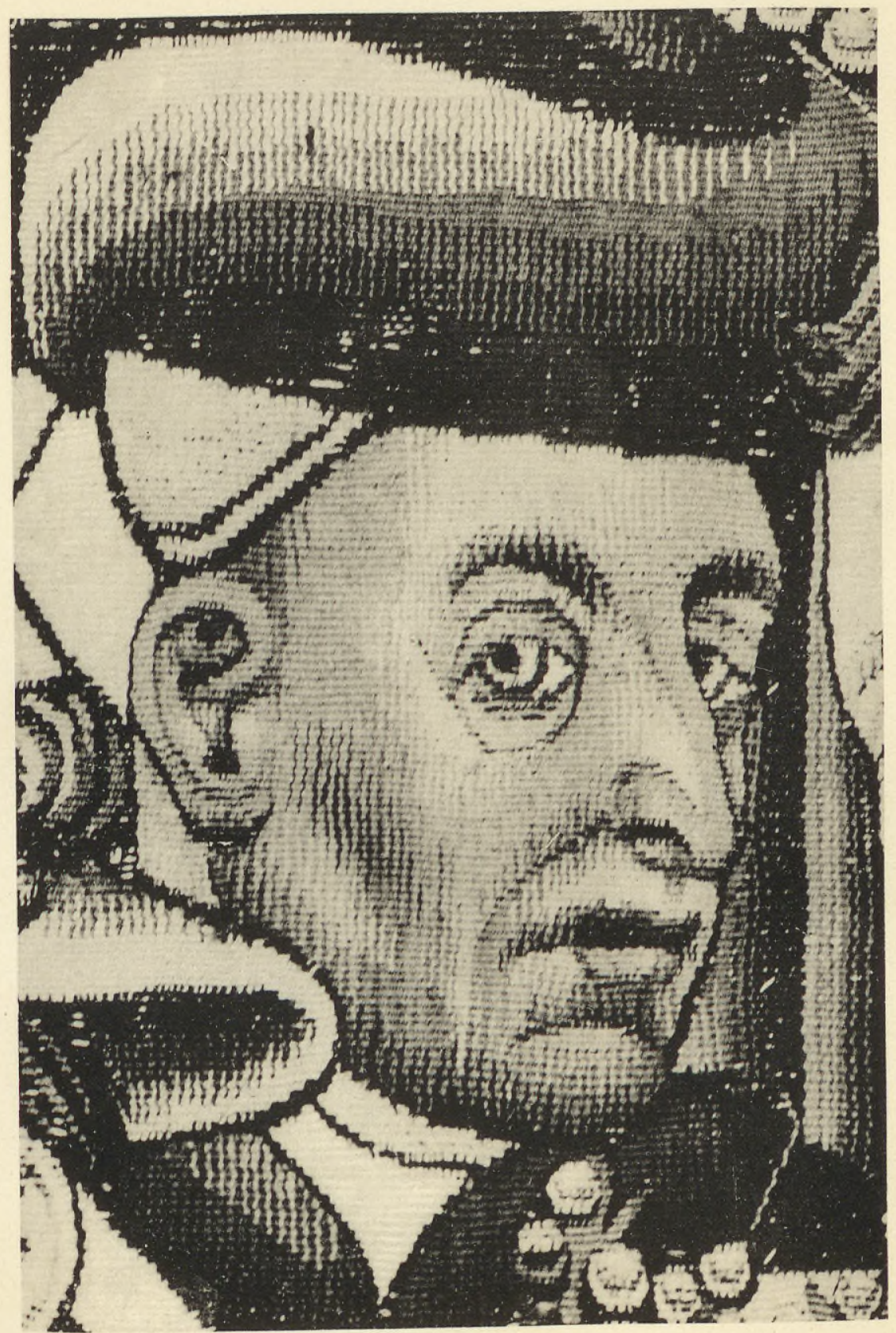

Selbstporträt Rogers v. d. Weyden

von der Gregorszene der Brüsseler Rathausbilder nach der Berner Kopie 


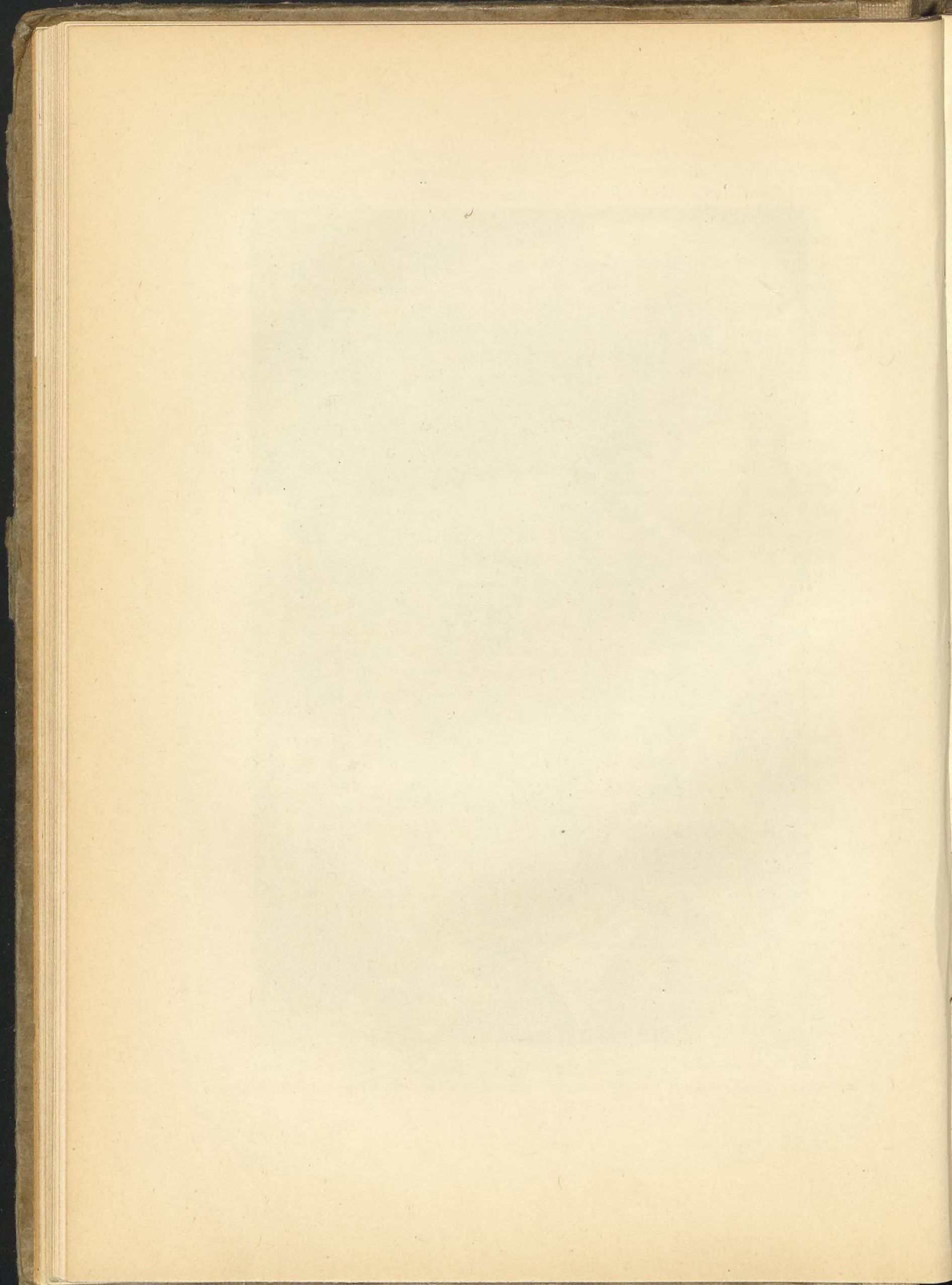


Man denke sich ein Bildnis dieser Art in der Sakristei des Klosters, etwa an der nördlichen Wand, aufgehängt und die Mönche im Halbkreis darum versammelt, so wird jeder von ihnen glauben, daß das Auge im Bilde direkt auf ihn gerichtet sei. Und nicht nur ein solches gleichzeitiges Sehen nach Süden, nach Westen und nach Norden werden wir dem Bild zusprechen müssen, sondern auch einen dreifachen Bewegungszustand. Denn während es für den ruhenden Beschauer ruht, folgt es dem bewegten mit dem Blick, so daß es, wenn es einer der Brüder von Ost nach West, ein anderer von West nach Ost umschreitet, an diesen beiden entgegengesetzten Bewegungen teilnimmt. Wir sehen also, daß ein und dasselbe unbewegliche Gesicht sich so nach Osten bewegt, daß es gleichzeitig nach Westen, und so nach Norden, daß es zugleich nach Süden vorrückt: daß es, in einem Ort verharrend, zugleich in allen anderen Orten ist und, in einer Bewegung begriffen, zugleich alle anderen mit vollzieht. Hier stellt sich uns, im sinnlichen Gleichnis, die Natur jenes Grundverhältnisses dar, das zwischen Gott, dem allumfassenden Sein, und dem Sein des Endlichen, des Letztbesonderen besteht. Jedes Besondere und Individuelle hat eine unmittelbare Beziehung auf Gott, - steht ihm gleichsam Auge in Auge gegenüber. Der wahrhafte Sinn des Göttlichen aber erschließt sich erst dann, wenn unser Geist nicht mehr bei einer dieser Beziehungen, noch auch bei ihrer bloßen Gesamtheit verweilt, sondern wenn er sie in die Einheit einer Schau, einer ,visio intellectualis" zusammennimmt. Wir begreifen alsdann, daß es für uns widersinnig ist, das Absolute an sich, ohne eine solche Bestimmung durch einen individuellen ,Blickpunkt", auch nur denken zu wollen - daß aber andererseits keiner dieser Blickpunkte vor dem andern den Vorrang hat, weil es eben erst ihre konkrete Totalität ist, die uns ein wahrhaftes Bild des Ganzen zu vermitteln vermag. In dieser Totalität ist jede Einzelansicht befaßt, ist sie zugleich in ihrer Zufälligkeit wie in ihrer Notwendigkeit erkannt. Und so gibt es denn für uns freilich keine Anschauung von Gott, die nicht ebenso sehr durch die Natur des ,Objekts", wie durch die des ",Subjekts" bedingt wäre - die nicht zugleich das Gesehene, wie die bestimmte Weise und Richtung des Sehens in sich schließt. Jeder vermag sich nur in Gott, ebenso aber Gott nur in sich zu sehen. Kein quantitativer Ausdruck, kein Ausdruck, der an den Gegensatz von ,,Teil “ und "Ganzem" gebunden ist, reicht aus, dieses reine Ineinander zu bezeichnen. „Dein wahres Gesicht ist frei von jeder Einschränkung, ist weder von dieser Größe, noch von dieser Beschaffenheit, weder räumlich noch zeitlich, denn es ist selbst die absolute Form, das Gesicht aller Gesichte. Wenn ich aber darauf achte, wie dies Gesicht die Wahrheit und das adaequateste $\mathrm{MaB}$ aller Gesichte ist, so gerate ich in Staunen. 
Denn dies Gesicht, das die Wahrheit aller Gesichte ist, ist nicht so und so groß, hat also kein Mehr oder Weniger, noch ist es irgendeinem gleich, weil es als absolut über jede Größe erhaben ist. So begreife ich denn, o Herr, daß Dein Antlitz vor jedem sichtbaren Antlitz vorhergeht, daß es die Wahrheit und das Musterbild aller Antlitze ist. Jegliches Gesicht, das in das Deine blickt, sieht daher nichts von sich selber Verschiedenes, weil es seine eigene Wahrheit sieht. Wie es mir also, wenn ich dies Gemälde hier von Osten anblicke, so erscheint, als blicke nicht ich das Bild, sondern als blicke mich das Bild an, und ebenso, wenn ich es von Süden oder Westen her anschaue, so ist Dein Antlitz allen, die Dich anblicken, zugewandt. Wer Dich also mit liebendem Blick anschaut, der fühlt Deinen Blick liebevoll auf sich gerichtet, - und mit je größerer Liebe er Dich anzublicken strebt, um so liebevoller wird Dein Blick ihm entgegenleuchten. Wer Dich im Zorne anblickt, der wird auch Dein Gesicht zornig, wer Dich froh anblickt, wird es froh finden. Denn wie dem körperlichen Auge, wenn es durch ein rotes Glas blickt, alles rot erscheint, so sieht das geistige Auge, in seiner Beschränkung, Dich, der Du das Ziel und Objekt der geistigen Betrachtung bist, gemäß der Natur seiner eigenen Eingeschränktheit. Denn der Mensch kann nicht anders als menschlich urteilen.... So würde auch ein Löwe, wenn er Dir ein Antlitz zuspräche, Dir das eines Löwen beilegen, das Rind das eines Rindes, der Adler das eines Adlers. O Herr, wie wunderbar ist Dein Gesicht, das der Jüngling jugendlich, das der Mann männlich, der Greis greisenhaft bilden muß, wenn er es begreifen will. In allen Gesichtern erscheint das Gesicht aller Gesichte verschleiert und wie im Rätsel enthüllt aber kann es nicht gesehen werden, solange nicht, über alle Gesichter hinaus, eingegangen wird in jenes geheime und dunkle Schweigen, in dem nichts mehr übrig bleibt von dem Wissen und dem Begriff des Gesichts. "1)

Mit diesen Sätzen aus der Schrift „De visione Dei“ stehen wir im Brennpunkt der Spekulation des Cusanus - und von diesem Punkt aus läßt sich nun auch am klarsten der Zusammenhang dieser Spekulation mit den geistigen Grundmächten der Epoche übersehen. Drei Mächte sind es gewesen, die schon auf Cusanus' Jugendbildung gewirkt, und die die Entwicklung seiner Lehre entscheidend bestimmt haben. Seine erste Erziehung hat er bei den „Brüdern vom gemeinsamen Leben“ in Deventer erhalten, in jenem Kreise, in dem ein neuer Typus persönlicher Frömmigkeit, in dem das Ideal der ,devotio moderna" zuerst lebendig wird. ${ }^{2}$ ) Hier wird Cusanus zuerst vom Geiste der deutschen Mystik, in

I) De visione Dei, cap. VI, fol. $18{ }_{5} f$.

2) Näheres über die "Brüder vom gemeinsamen Leben“ und über die religiöse 
seiner ganzen spekulativen Tiefe und in seiner sittlich-religiösen Urkraft, berührt. Auch geschichtlich lassen sich deutlich die Fäden verfolgen, durch die die Form des religiösen Lebens, die in Deventer gepflegt wird, mit der deutschen Mystik zusammenhängt: Gerard Groote, der Gründer der Bruderschaft vom gemeinsamen Leben, steht in naher Berührung mit Ruysbroeck ${ }^{1}$ ), dessen Grundanschauung wieder unmittelbar auf Eckhart zurückgeht. Cusanus' eigene Schriften bilden ein fortlaufendes Zeugnis dafür, wie stark und nachhaltig Eckharts Lehre auf ihn gewirkt und in welcher Richtung sich diese Wirkung bewegt hat. ${ }^{2}$ ) Die Umschmelzung des dogmatischen Gehalts des Christentums in seelischindividuellen Gehalt sah er hier mit einer Kraft der religiösen Empfindung und mit einer Kraft des sprachlichen Ausdrucks wie nie zuvor vollzogen. Das Geheimnis der Menschwerdung Gottes kann nicht durch irgendein Analogon aus der Welt der Natur oder der Welt der Geschichte enträtselt oder auch nur bezeichnet werden: sondern die Seele des Menschen, als diese, als individuelle Einzelseele, ist der Ort, an dem das Wunder dieser Menschwerdung sich vollzieht. Dies Wunder ist nicht vergangen, nicht in einem einzelnen Moment der objektiv-historischen Zeit geschehen und auf diesen Moment beschränkt, sondern es kann und muß in jedem Ich und zu jeder Zeit sich erneuern. In der Tiefe der Seele, in dem letzten Seelengrunde muß sich die Gottheit gebären; hier ist das wahrhafte „Kindbette der Gottheit“. Wo immer später der Mystiker Cusanus spricht - da hört man wieder diesen Grundklang Eckhartschen Glaubens und Eckhartscher Frömmigkeit heraus. Aber Cusanus bleibt an diesem Punkte nicht stehen. Der Schule der devotio moderna folgt zunächst die Schule des scholastischen Wissens und der scholastischen Theologie. An der Universität Heidelberg nimmt er die Grundsätze dieses Wissens in sich auf. Er folgt hier dem ",neuen Weg“, der via moderna, die in Heidelberg kurz zuvor durch Marsilius von Inghen, den Anhänger Occams, eingeführt war, und die in den ersten Jahrzehnten des fünfzehnten Jahrhunderts dort noch fast unangefochten galt. ${ }^{3}$ ) Und auch

Grundrichtung der "devotio moderna" s. in der Schrift von Mestwerdt, Die Anfänge des Erasmus. Humanismus und „Devotio moderna“. Leipzig I9I7, S. $86 \mathrm{ff}$., sowie bei Albert Hyma, The Christian Renaissance. A History of the "Devotio moderna", 2 Bd. Grand Rapids, Michigan, I924.

I) Über Gerard Groote und seine Beziehungen zu Ruysbroeck vgl. bes. Hyma a. a. O. I., IIf, s. jetzt auch Gabriele Dolezich, Die Mystik Jan van Ruysbroecks des Wunderbaren (Breslauer Studien znr historischen Theologie IV, Breslau I926) S. I ff.

2) Von den häufigen Erwähnungen Eckharts ist insbesondere die in der ,Apologia doctae ignorantiae" (Opera, fol. $69 \mathrm{ff}$.) wichtig. Näheres über sein Verhältnis zu Eckhart bes. bei Vansteenberghe, S. $426 \mathrm{ff}$. und Fiorentino a. a. O., S. Io8ff.

3) Näheres über den Heidelberger Universitätsbetrieb der damaligen Zeit s. bes. in Gerhard Ritters „Studien zur Spätscholastik“ (vgl. ob. S. I2, Anm. I). Merkwürdig 
von hier empfängt er starke und nachhaltige Antriebe: mit Recht gilt Cusanus später den Zeitgenossen als einer der besten , Kenner des Mittelalters" ". ${ }^{1}$ ) Aber die eigentlich entscheidende geistige Wendung vollzieht sich nicht hier, sondern erst in Cusanus' italienischer Epoche. Erst in der Berührung mit der Antike und mit deren Erneuerung im Italien des Quattrocento wird er ganz er selbst. Im Leben und Denken des ersten deutschen Systematikers der Philosophie hat Italien dieselbe Macht bekundet, die es später so oft im Leben der großen deutschen Künstler geübt hat. Und um so größer mußte diese Macht sein, als Cusanus nicht wie Goethe als fast Vierzigjähriger, sondern als Siebzehnjähriger den Boden Italiens betritt. Als er im Oktober I4I7 die Universität Padua bezieht, da umfängt ihn zum erstenmal die neue weltliche Bildung der Zeit. Jetzt ist er der Dumpfheit und Einsamkeit des mystischen Gefühls, wie der Enge des deutschen Gelehrtenlebens des Mittelalters entflohen jetzt berührt ihn weite Welt und freies Leben. Hier taucht er in den Strom der humanistischen Kultur ein; hier macht er sich die Kenntnis des Griechischen zu eigen, die ihn später wie zum tieferen Studium Platons, so auch zum Studium des Archimedes und der Grundprobleme der griechischen Mathematik befähigt hat. Denn sofort - und das unterscheidet Cusanus von den eigentlichen Humanisten, von einem Poggio oder Valla - nimmt sein Interesse an der Antike diese für ihn charakteristische Richtung, geht es, statt auf die Dichtung und Rhetorik, vielmehr auf die Philosophie und Mathematik des Altertums. So knüpft sich denn auch bereits in Padua das Band, das ihn fortan sein ganzes Leben lang mit einem der bedeutendsten italienischen Mathematiker und Physiker, mit Paolo Toscanelli verbunden hat. $\left.{ }^{2}\right)$ Von Toscanelli wird er in die

und interessant ist es, daß die Heidelberger ,moderni“ sich später, in ihrem Kampf gegen die "via antiqua“, auf Nikolaus Cusanus geradezu als auf einen der ihrigen berufen zu können glauben: vgl. den Schöfferschen Druck von I499, in dem Cusanus neben Okkam, Albert v. Sachsen, Joh. Gerson u. a. als ,,moderne“ Autorität erscheint. (Ritter, II, 77, Anm. 2.)

I) Als den ersten nachweisbaren Beleg für den Gebrauch des Wortes ,,Mittelalter' 'führt PaulLehmann in seiner Schrift ,,Vom Mittelalter und von der lateinischen Philologie des Mittelalters", München rgI4, S. 6, den Nachruf an, den Johannes Andrea, Bischof von Aleria, im Jahre I469, seinem Freunde Nicolaus Cusanus gewidmet hat. ,Vir ipse“ so heißt es hier — , quod rarum est in Germanis supra opinionem eloquens et Latinus; historias idem omnes non priscas modo, sed medie tempestatis tum veteres tum recentiores usque ad nostra tempora memoria retinebat." Im gleichen Sinne hat dann I493 Hartmann Schedel in seiner Weltchronik und I5I4 Faber Stapulensis in der Vorrede zu seiner Ausgabe der Werke des Cusanus diesen als "Kenner des Mittelalters" gerühmt.

2) Über Toscanelli vgl. Uzielli, Paolo dal Pozzo Toscanelli, - für Cusanus' Verhältnis zu ihm ist besonders die Widmung seiner Schrift: „De transmutationibus Geometricis“ bezeichnend. "Sed quanto me ab annis juventutis atque adolescentiae nostrae strictiori amicitiae nodo atque cordiali quodam amplexu indesinenter constrinxisti: tanto 
geographischen, kosmographischen und physikalischen Probleme der Zeit eingeführt; von ihm empfängt er die Anregungen, die er später an die deutschen Mathematiker und Astronomen, an Georg Peurbach und an Regiomontan weitergegeben hat, und die bis zu Copernikus fortwirken. Und alle diese drei großen Grundelemente der Bildung des Cusanus fordern nun einen geistigen Ausgleich, drängen zu einer Synthese, die auf den ersten Blick als eine wahrhafte ,coincidentia oppositorum " erscheinen kann, die aber, näher betrachtet, nichts anderes als der spezifische Ausdruck des eigentlichen geistigen Kernproblems der Renaissance ist.

$\mathrm{Da}$ die Renaissance mit all ihren geistig-produktiven Kräften auf eine Vertiefung des Problems des Individuums gerichtet ist, bedarf keines näheren Erweises. Burckhardts grundlegende Darstellung bleibt in diesem Punkte unerschüttert. Aber freilich hat Burckhardt nur eine Seite des großen Befreiungsprozesses geschildert, in dem der moderne Mensch zum Bewußtsein seiner selbst heranreift. „Im Mittelalter lagen die beiden Seiten des Bewußtseins - nach der Welt hin und nach dem Innern des Menschen selbst - wie unter einem gemeinsamen Schleier träumend oder halbwach. Der Schleier war gewoben aus Glauben, Kindesbefangenheit und Wahn; durch ihn hindurchgesehen erschienen Welt und Geschichte wundersam gefärbt, der Mensch aber erkannte sich nur als Race, Volk, Partei, Korporation, Familie oder sonst in irgendeiner Form des Allgemeinen. In Italien zuerst verwehte dieser Schleier in die Lüfte: es erwacht eine objektive Betrachtung und Behandlung des Staates und der sämtlichen Dinge dieser Welt überhaupt; daneben áber erhebt sich mit voller Wucht das Subjektive, der Mensch wird geistiges Individuum und erkennt sich als solches. "1) An dieser neu erwachenden objektiven Betrachtung, wie an dieser Vertiefung der Subjektivität hat Cusanus seinen vollen Anteil. Aber seine Größe und seine geschichtliche Tat besteht darin, daß er diese Wendung nicht im Gegensatz zu den religiösen Grundgedanken des Mittelalters, sondern aus dem Blickpunkt eben dieser Grundgedanken selbst vollzieht. Aus dem Zentrum des Religiösen selbst vollbringt er die „Entdeckung der Natur und des Menschen" und in diesem Zentrum sucht er sie zu befestigen und zu verankern. Der Mystiker und Theologe, der Cusanus ist und bleibt, fühlt sich Welt und Natur, fühlt sich der Geschichte und der neuen weltlichhumanen Bildung gewachsen. Er stößt sie nicht von sich ab, sondern wie er sich selbst immer mehr und mehr in ihren Kreis begibt, so schlingt

nunc accuratius emendationi animum adhibe et in communionem aliorum (nisi correctum) prodire non sinas".

I) Burckhardt, Kultur der Renaissance. ${ }^{8}$, I, I4I. 
er sie zugleich in seinen eigenen Gedankenkreis zurück. Von den ersten Schriften des Cusanus an läßt sich dieser Prozeß verfolgen. Und wenn in ihnen zunächst noch das Motiv des Platonischen „Chorismos“ überwiegt, so gewinnt in den späteren Werken das Motiv der ,Methexis“ mehr und mehr den Vorrang. Als der „Gipfel der Theorie“ erscheint Cusanus jetzt die Einsicht, daß die Wahrheit, die er anfangs im Dunkel der Mystik gesucht, die er als Gegensatz zu aller Vielheit und Veränderung bestimmt hat, nichtsdestoweniger mitten in diesem Bereich der empirischen Vielheit selbst sich offenbare, daß sie in den Straßen rufe. ${ }^{1}$ ) Immer stärker bricht bei Cusanus dieses neue Weltgefühl, und mit ihm sein charakteristischer religiöser Optimismus durch. Das Schlagwort des, „Pantheismus “ umschreibt dieses neue Weltgefühl nicht richtig: denn der Gegensatz zwischen dem Sein Gottes und dem Sein der Welt soll nicht verwischt, sondern in aller Strenge aufrecht erhalten werden. Aber wie die Schrift „,De visione Dei“" gelehrt hat, daß die Wahrheit des Allgemeinen und die Besonderung des Individuellen sich durchdringen, so daß das göttliche Sein nichtandersalsin den unendlich-mannigfaltigenindividuellen Blickpunkten erfaßt und gesehen werden kann, so können wir auch das Sein, das vor aller Einschränkung, vor aller ,,Kontraktion“ liegt, nur in eben dieser Einschränkung erblicken. Das Ideal, dem unsere Erkenntnis nachstreben kann, ist daher nicht, die Besonderung zu verleugnen und wegzuwerfen, sondern sie vielmehr zu ihrem ganzen Reichtum zu entfalten: denn nur die Totalität der Gesichte gibt uns die Eine Sicht des Göttlichen. Die Welt wird zum Symbol Gottes, nicht indem irgendein Teil von ihr herausgehoben und mit einem einzigartigen Wertzeichen versehen wird, sondern indem wir sie in der Gesamtheit ihrer Gestaltungen durchlaufen und uns ihrer Mannigfaltigkeit, ihren Gegensätzen frei hingeben. Daß Cusanus diese spekulative Forderung, die er stellt, in seiner eigenen Gedankenentwicklung erfüllt hat, - und da $\mathrm{B}$ er sie im Kreise der Kirche erfüllen durfte: das macht seine einzigartige Stellung in der Kirchengegeschichte und in der allgemeinen Geistesgeschichte aus. Als später die

I) De apice theorie (fol. $332 \mathrm{f}$.): Quidditas quae semper quaesita est et quaeritur et quaeretur, si esset penitus ignota, quomodo quaereretur ?.... Cum igitur annis multis viderim ipsam ultra omnem potentiam cognitivam, ante omnem varietatem et oppositionem, quaeri oportere: non attendi, quidditatem in se subsistentem esse omnium substantiarum invariabilem subsistentiam, ideo nec multiplicabilem nec pluralificabilem, et hinc non aliam et aliam aliorum entium quidditatem, sed eandem omnium hypostasim. Deinde vidi necessario fatendum ipsam rerum hypostasin seu subsistentiam posse esse. Et quia potest esse: utique sine posse ipso non potest esse, quomodo enim sine posse potest ... Veritas quanto clarior tanto facilior. Putabam ego aliquando ipsam in obscuro melius reperiri. Magnae potentiae veritas est, in qua posse ipsum valde lucet: clamitat enim in plateis, sicut in libello de Idiota legisti, valde certe se undique facile repertum ostendit." Vgl. bes. Idiotae lib. I, fol. I37f. 
katholische Kirche gegenüber dem Ansturm des Protestantismus sich genötigt sah, sich in sich selbst und im traditionellen Gehalt ihrer Dogmen zu verschließen, da mußte sie auch die neuen Gedanken und die neuen Tendenzen ausstoßen, die bei Cusanus noch religiös gefaßt und religiös bewältigt sind. Es sind die gleichen kosmologischen Lehren, die Cusanus im Jahre I440 in der Schrift ,,de docta ignorantia" aufstellt, für die mehr als anderthalb Jahrhunderte später Giordano Bruno den Tod, Galilei die kirchliche Verfolgung und den kirchlichen Bann erlitten hat. So steht Cusanus' Philosophie an einer schmalen Grenzscheide der Zeiten und der Denkweisen. Dies ergibt sich nicht nur, wenn man seine Lehre mit dem kommenden Jahrhundert, sondern auch, wenn man sie mit dem vergangenen zusammenhält. Es zeigt sich alsdann, daß hier in der Tat in einer einzigartigen und einmaligen Weise der religiöse Individualismus, dessen Grundquell in der Mystik, besonders in der deutschen Mystik eines Eckhart und Tauler, liegt, sich mit dem weltlichen Individualismus, mit dem Ideal der neuen Bildung und der neuen Humanität, begegnet und auseinandersetzt. Die ersten Anfänge dieser Auseinandersetzung reichen schon ins Trecento zurück. Petrarcas Leben und Philosophie bewegt sich ständig um diese beiden Brennpunkte, ringt immer von neuem nach einem Ausgleich zwischen den antik-humanen und den mittelalterlich-religiösen Forderungen. Aber ein Ruhepunkt in diesem Kampf, ein inneres Gleichgewicht zwischen den widerstreitenden Tendenzen wird bei ihm nicht erreicht. Aller Reiz und alle Lebendigkeit von Petrarcas Dialogen besteht vielmehr eben darin, daß sie uns mitten in den Kampf selbst stellen, daß sie das Ich ruhelos und haltlos den entgegengesetzten geistigen Mächten preisgegeben zeigen. Petrarcas innere Welt bleibt zwischen Cicero und Augustin geteilt. So muß er auf der einen Seite verwerfen, was er auf der anderen erstrebt; so muß er religiös entwerten, was für ihn den geistigen Gehalt und den geistigen Wert des Lebens ausmacht. Alle weltlich humanen Ideale, der Ruhm, die Schönheit, die Liebe, an denen er mit allen Fasern seines Ich hängt, verfallen diesem Verdikt. Und eben hieraus ergibt sich jene Zerrissenheit des geistigen Selbst, jene Krankheit der Seele, wie Petrarca sie in seiner persönlichreichsten und tiefsten Schrift, in dem Dialog „De secreto conflictu curarum suarum" gezeichnet hat. Als Ergebnis des Kampfes bleibt zuletzt nur der Verzicht, bleibt der Überdruß an der Welt, die „Acedia“ zurück. Das Leben, - so schildert Petrarca selbst diese Stimmung — wird zum Traum, zum Phantasma ${ }^{1}$ ): es sieht seine eigene Nichtigkeit, ohne sich ihr entziehen zu können. Von einem solchen inneren Widerstreit, von dem Pessimismus und der Askese, in denen Petrarca endet, findet sich bei

I) Epistolae rerum familiarium II 9, an Giacomo Colonna (vgl. Voigt, a. a. O., I, r 36). 
Cusanus keine Spur. Wenn er bisweilen, mitten in den schwersten Kämpfen, in jenem Konflikt mit dem Erzherzog Sigismund von Österreich, der schließlich zu seiner Gefangennahme führt, der Last der weltlichen Sorgen enthoben zu sein wünscht, wenn er eine Zelle im Kloster der befreundeten Brüder von Tegernsee für sich ersehnt ${ }^{1}$ ), so ist doch sein Leben als Ganzes durchaus auf aktive Wirksamkeit gestellt. Es ist von Anfang bis zu Ende erfüllt mit großen weltpolitischen Plänen und Aufgaben, mit praktischen Reformen und mit philosophisch-wissenschaftlicher Forschung. Und eben aus dieser mächtigen Aktivität bricht nun der Grundgedanke seiner Spekulation hervor. Was in seinem Tun getrennt erscheint, das soll sich in diesem Gedanken vereinen. Denn das eben ist das Wesen des Gedankens selbst, daß er die Gegensätze nur setzt, um sie zu versöhnen, um sie im Prinzip der ,coincidentia oppositorum“ aufzuheben und $\mathrm{zu}$ bewältigen.

An diesem Punkt, an dem es sich um die endgültige Entscheidung zwischen den religiösen Voraussetzungen des Cusanus und den weltlichen Idealen und Bildungsmächten, die auf ihn wirken, handelt, greift nun ein Lehrstück ein, das vielleicht als das merkwürdigste und schwierigste in seiner Philosophie bezeichnet werden muß. Die Entscheidung liegt für ihn in der einfachen Vertiefung in den Grundgehalt des Christentums selbst. Die Christus-Idee wird zur Rechtfertigung, zur religiösen Legitimation und Sanktion der Idee der Humanität aufgerufen. Man hat das dritte Buch der Schrift „De docta ignorantia“, in dem sich diese Wendung vollzieht, bisweilen so wenig verstanden, daß man es aus dem Ganzen der Philosophie des Cusanus auszuscheiden versuchte, daß man es als einen willkürlichen ,theologischen“ Anhang ansah, der einem rein dogmatischen Interesse seinen Ursprung verdanke. ${ }^{2}$ ) Aber derartige uns geläufige Trennungen lassen sich in die Lehre des Cusanus nicht einführen, ohne dadurch ihr ganzes inneres Gefüge zu zerschneiden, ohne ihre charakteristische geistige Struktur aufzuheben. In Wahrheit ist die Einführung und die spekulative Behandlung der Christus-Idee innerhalb der Schrift,,de docta ignorantia“" so wenig ein äußerer Annex, daß sie vielmehr die bewegende Kraft in Cusanus' Denken erst vollständig zur Entfaltung und Äußerung bringt. Hier stehen wir an dem eigentlichen Punkt des Übergangs, des dialektischen Umschlags seines Grundgedankens. Dieser war darauf gerichtet, zwischen dem Bedingten und Unbebedingten, dem Menschlichen und dem Göttlichen, dem Endlichen und

I) Vgl. den Brief an Gaspard Aindorffer vom I6. 8. I454 (bei Vansteenberghe, Autour de la docte ignorance, S. I39).

2) So urteilt neuerdings wieder T. Whittaker in einem Aufsatz Nicholas of Cusa, Mind, XXXIV (1925), S. $439 \mathrm{f}$. 
dem Unendlichen einen scharfen Schnitt zu vollziehen. Keines der beiden Momente ist auf das andere zurückführbar, keines durch das andere meßbar. So bleibt der endlichen, der menschlichen Erkenntnis gegenüber dem Absoluten kein anderes Verhalten als das der Resignation, der völligen Selbstbescheidung übrig. Aber gerade diese Resignation birgt nun ein positives Moment. Wenn die menschliche Erkenntnis zum NichtWissen des Absoluten gelangt, so gewinnt sie hierin das Wissen eben dieses Nicht-Wissens selbst. Sie erfaßt nicht die absolute Einheit in ihrem reinen „Was", aber sie erfaßt sich selbst in ihrer Unterscheidung von ihr, in ihrer durchgängigen ,Andersheit“. Und eben diese Andersheit schließt nun eine Beziehung zu diesem negativen Pol der Erkenntnis in sich. Das Wissen könnte sich ohne eine derartige Beziehung nicht einmal in seiner eigenen Nichtigkeit erkennen: es könnte - mit Hegel zu sprechen, dessen Grundgedanken Cusanus hier mit merkwürdiger Schärfe antizipiert - die Schranke nicht setzen, wenn es nicht über sie im gewissen Sinne schon hinaus wäre. Das Bewußtsein des Unterschieds schließt die Vermittlung des Unterschieds in sich. Aber diese Vermittlung kann wiederum nicht bedeuten, daß das Unendliche, das absolute Sein mit dem endlichen empirischen Selbstbewußtsein irgendein Verhältnis eingeht. Hier klafft nach wie vor ein Abgrund, der sich nicht überspringen läßt. An Stelle des empirischen Selbst muß vielmehr ein allgemeines Selbst, - an Stelle des Menschen als einer individuellen Sonderexistenz muß der geistige Gehalt der Menschheit treten. Und dieser geistig universelle Gehalt des Menschentums ist es, den Cusanus in Christus beschlossen sieht. Er allein ist daher die echte ,natura media", die Endliches und Unendliches in Eins faßt. Und diese Einheit ist keine zufällige, sondern eine wesentliche: sie besagt nicht, daß an sich Getrenntes eine bloß tatsächliche ,,Verbindung “ eingeht, sondern daß ein ursprünglicher und notwendiger Zusammenhang der beiden gegensätzlichen Momente zu fordern ist. Die geforderte ,mittlere Natur“ wird so geartet sein müssen, daß sie das Höhere wie das Niedere in seiner Ganzheit in sich schließt, - daß sie, als das Maximum der niederen Welt und als das Minimum der höheren, das gesamte Universum mit all seinen möglichen Gestaltungen in sich birgt und sie, wie der Cusanische Ausdruck lautet, in sich ,kompliziert". Damit wird diese Natur zum eigentlichen Bindeglied des Alls, zur „Klammer der Welt". ${ }^{1}$ ) Wie Christus der Ausdruck für die ganze Menschheit ist, wie er nichts anderes als ihre einfache Idee und Wesenheit bedeutet, so schließt andererseits der Mensch, in seiner Wesenheit betrachtet,

I) Excitat. Lib. IX (fol. 639): Et in hoc passu mediatio Christi intelligitur, quae est copula hujus coincidentiae, ascensus hominis interioris in Deum, et Dei in hominem. 
das All der Dinge in sich. In ihm als Mikrokosmos laufen alle Linien des Makrokosmos zusammen. ${ }^{1}$ ) Man sieht, wie hier das Mikrokosmos-Motiv, das von Cusanus ausdrücklich als antikes Motiv gekennzeichnet wird ${ }^{2}$ ), sich mit der religiösen Grundidee des Christentums in eigentümlicher Weise verschlingt. Im mittelalterlichen Denken bedeutet das Motiv der Erlösung im wesentlichen den Gedanken der Herauslösung aus der Welt: die Erhebung des Menschen über das niedere, sinnlich-irdische Dasein. Eine derartige Trennung zwischen Mensch und Natur aber kennt Cusanus nicht mehr. Faßt der Mensch als Mikrokosmos alle Naturen der Dinge in sich, so schließt seine Erlösung, seine Erhebung zum Göttlichen, auch die Erhebung der Gesamtheit der Dinge in sich. Es gibt nichts einzelnes, Abgetrenntes, gewissermaßen Ausgestoßenes mehr, das aus dem religiösen Grundprozeß der Erlösung schlechthin herausfiele. So ist es nicht nur der Mensch, der durch Christus zu Gott emporsteigt, sondern in ihm und kraft seiner vollzieht das All seinen Aufstieg. Das „regnum gratiae“ und das „regnum naturae" stehen sich nicht mehr fremd und feindlich gegenüber, sondern beide sind aufeinander und auf ihren gemeinsamen göttlichen Zielpunkt bezogen. Die Einigung hat sich nicht nur zwischen Gott und dem Menschen, sondern zwischen Gott und allem Geschaffenen vollzogen: der Abstand zwischen beiden ist gefüllt, indem zwischen das schaffende Prinzip und das Erschaffene, zwischen Gott und die Kreatur, der Geist der Menschheit, die humanitas, als ein zugleich Schaffendes und Erschaffenes tritt. ${ }^{3}$ )

I) De docta ign. III, 3: ,,Maximo autem, cui minimum coincidit, conveniet ita unum amplecti, quod et aliud non dimittat, sed simul omnia. Quapropter natura media, quae est medium connexionis inferioris et superioris, est solum illa, quae ad maximum convenienter elevabilis est potentia maximi infiniti Dei: nam cum ipsa intra se complicet omnes naturas, ut supremum inferioris et infimum superioris, si ipsa secundum omnia sui ad unionem maximitatis ascenderit, omnes naturas ac totum universum omni possibili modo ad summum gradum in ipsa pervenisse constat."

2) „Humana vero natura est illa, quae est supra omnia Dei opera elevata et paulominus Angelis minorata, intellectualem et sensibilem naturam complicans ac universa

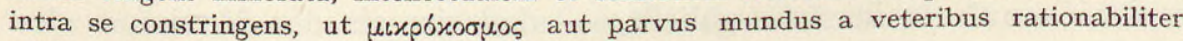
vocitetur." (ibid.)

3) De doct. ign. III, 2: „Oportet igitur ipsum tale ita Deum esse mente concipere, ut sit et creatura, ita creaturam ut sit et creator, creatorem et creaturam absque confusione et compositione. Quis itaque excelsum adeo elevari possit, ut in unitate diversitatem et in diversitate unitatem concipiat, supra omnem igitur intellectum haec unio esset." Vgl. bes. De visione Dei, cap. XX: ,Video in te Jesu filiationem divinam, quae est veritas omnis filiationis, et pariter altissimam humanam filiationem, quae est propinquissima imago absolutae filiationis ... Omnia igitur in natura humana tua video, quae et video in divina, sed humaniter illa esse video in natura humana, quae sunt ipsa divina veritas in natura divina ... Video, Jesu bone, te intra murum Paradisi quoniam intellectus tuus est veritas pariter et imago, et tu es Deus pariter et creatura, infinitus pariter et finitus, ... es enim copulatio divinae creantis naturae et humanae creatae naturae." 
Wenn Cusanus sich damit dem Ausdruck nach an die alte „Einteilung der Welt", an jene ,divisio naturae" anlehnt, wie sie schon Johannes Scotus gegeben hatte, indem er die Natur, welche schafft und nicht geschaffen wird, von derjenigen, welche geschaffen wird und schafft, von der, welche geschaffen wird und nicht schafft, und schließlich von der, welche weder schafft noch geschaffen wird, unterschied - so birgt doch jetzt dieser Ausdruck einen wesentlich neuen Gehalt in sich. Wenn Eriugena von dem geschaffenen und zugleich selbst schaffenden Wesen spricht, so versteht er darunter das zeitlose Hervorgehen der Dinge aus ihren Ideen, als ihren ewigen Prototypen und Urbildern. ${ }^{1}$ ) Bei Cusanus aber sind es nicht die Ideen, die, im Sinne des Neuplatonismus, als schöpferische Kräfte genommen werden: sondern er verlangt ein konkretes Subjekt als Mittelpunkt und Ausgangspunkt aller wahrhaft schöpferischen Betätigung. Und dieses Subjekt kann nach ihm nirgends anders als im Geiste des Menschen aufgewiesen werden. Dieser Gesichtspunkt ist es, aus dem sich zunächst und vor allem eine neue Wendung der Erkenntnislehre ergibt. Alles echte und wahrhafte Erkennen ist nicht auf ein bloßes Abbilden der Wirklichkeit gerichtet, sondern es stellt stets eine bestimmte Richtung geistigen Tuns dar. Alle Notwendigkeit, die wir in der Wissenschaft, die wir insbesondere in der Mathematik vor uns sehen, geht aus dem Grunde dieser freien Aktivität hervor. Der Geist gelangt nur dort zur wahrhaften Einsicht, wo er nicht ein äußeres Dasein abbildet, sondern wo er sich selbst und sein eigenes Wesen ,expliziert". In sich findet er den einfachen Begriff und das "Prinzip“ des Punktes, aus welchem er durch stetig wiederholte Setzung die Linie, die Fläche und schließlich die gesamte Welt der Ausdehnung hervorgehen läßt; in sich findet er den einfachen Gedanken des ,, Jetzt", aus dem sich ihm die Unendlichkeit der Zeitreihe entfaltet. Und wie die Grundformen der Anschauung, wie Raum und Zeit in diesem Sinne im Geiste ,,impliziert" sind, so ist es auch der Begriff von Zahl und Größe, so sind es alle logischen und mathematischen Kategorien. In der Entwicklung dieser Kategorien schafft er die Arithmetik, die Geometrie, die Musik und Astronomie. So ist auch alles Logische überhaupt, so sind die zehn Prädikamente, die fünf Universalien usf. in dieser Grundkraft des Geistes beschlossen. Sie sind die Bedingungen aller „Diskretion“, aller Scheidung des Mannigfaltigen nach Arten und Klassen und aller Zurückführung des empirisch-Veränderlichen auf fest bestimmte Gesetze. ${ }^{2}$ ) In dieser Grundlegung der

I) Vgl. bes. Johannes Scotus, De divisione naturae II, 2.

1) Vä. bes. Johannes über dieses Grundprinzip von Cusanus' Erkenntnislehre in m. Schrift über das Erkenntnisproblem³, I, 33 ff. - Vgl. bes. De ludo globi, Lib. II, fol. 23 If: 
Wissenschaften offenbart sich die Schöpferkraft der rationalen Seele in ihren beiden Grundmomenten: in ihr geht der Geist, indem er sich entfaltet, in die Zeit ein und bleibt nichtsdestoweniger über die Zeit als bloße Succession erhaben. Denn der Geist ist, als Ursprung und Schöpfer der Wissenschaft, nicht sowohl in der Zeit, als vielmehr die Zeit in ihm ist. Er ist es, der, vermöge seiner Kraft der Diskretion, erst feste Zeitabschnitte und Zeiteinteilungen schafft, der Stunden, Monate, Jahre gegeneinander abgrenzt. Wie Gott alle Wesensunterschiede hervorbringt, so ist es der menschliche Intellekt, der alle Begriffsunterschiede aus sich hervorgehen läßt, und der somit ein Urquell der Harmonie ist, die stets die Vereinigung des Entgegengesetzten ist. Erhat in Ptolemaeus das Astrolabium, in Orpheus die Lyra erschaffen: denn nicht von außen kommt die Erfindung, sondern sie ist nur die Verwirklichung des Begriffs in einer sinnlichen Materie. Wie das Auge zum Sehen, so verhält sich demnach die Zeit zur Seele: die Zeit ist das Organ, dessen sich die Seele bedient, um ihre Grundfunktion: die Funktion der Ordnung und Sichtung des Mannigfaltigen, vielfältig Verstreuten erfüllen zu können. ${ }^{1}$ ) Wie Cusanus

„Anima rationalis est vis complicativa omnium notionalium complicationum. Complicat enim complicationem multitudinis et complicationem magnitudinis, scilicet unius et puncti. Nam sine illis, scilicet multitudine et magnitudine, nulla fit discretio. Complicat complicationem motuum, quae complicatio quies dicitur: nihil enim in motu nisi quies videtur. Motus enim est de quiete in quietem. Complicat etiam complicationem temporis, quae Nunc seu praesentia dicitur. Nihil enim in tempore nisi Nunc reperitur. Et ita de omnibus complicationibus dicendum, scilicet quod anima rationalis est simplicitas omnium complicationum notionalium. Complicat enim vis subtilissima animae rationalis in sua simplicitate omnem complicitatem, sine qua perfecta discretio fieri non potest. Quapropter ut multitudinem discernat, unitati seu complicationi numeri se assimilat et ex se notionalem multitudinis numerum explicat. Sic se puncto assimilat, qui complicat magnitudinem, ut de se notionales lineas superficies et corpora explicet. Et ex complicatione illorum et illarum, scilicet unitate et puncto, mathematicales explicat figuras circulares et polygonias . Sic se assimilat quieti, ut motum discernat... Et cum hae omnes complicationes sint in ipsa unitae, ipsa tanquam complicatio complicationum explicatorie omnia discernit et mensurat, et motum et agros et quaeque quanta. Et invenit disciplinas, scilicet Arithmeticam, Geometricam, Musicam et Astronomicam et illas in sua virtute complicari experitur. Sunt enim illae disciplinae per homines inventae et explicatae... Unde et decem praedicamenta in (animae rationalis) vi notionali complicantur; similiter et quinque Universalia et quaeque logicalia et alia ad perfectam notionem necessaria, sive illa habeant esse extra mentem, sive non, quando sine ipsis non potest discretio et notio perfecte per animam haberi."

I) ,Annus, mensis, horae sunt instrumenta mensurae temporis per hominem creatae. Sic tempus, cum sit mensura motus, mensurantis animae est instrumentum. Non igitur dependet ratio animae a tempore, sed ratio mensurae motus, quae tempus dicitur, ab anima rationali dependet. Quare anima rationalis non est tempori subdita, sed ad tempus se habet anterioriter, sicut visus ad oculum: qui licet sine oculo non videat, tamen non habet ab oculo, quod est visus, cum oculus sit organum ejus. Ița anima rationalis, licet non mensuret motum sine tempore, non tamen propterea ipsa subest tempori, sed potius e converso: cum utatur tempore pro instrumento et organo ad discretionem motuum faciendam" (ibid.) Vgl. bes. Idiot. Lib. III, De mente, cap. I 5, fol. I 7 I. 
in dieser idealistischen Auffassung den Grund zu dem modernen, mathematisch-physikalischen Zeitbegriff legt, der später bei Kepler und bei Leibniz hervortritt ${ }^{1}$ ), so eröffnet er damit zugleich eine neue Aussicht und eine neue Wertung der Geschichte. Auch die Deutung des geschichtlichen Daseins wird jetzt dem Grundgegensatz der ,complicatio“ und "explicatio“ unterstellt. Auch dieses Dasein ist nicht schlechthin ein äußeres „,Geschehen“, sondern es stellt sich als die eigenste Tat des Menschen dar. Nirgend anders als in seiner Geschichte kann der Mensch sich als wahrhaft schöpferisch und frei bewähren. Hier erweist sich, daß er in allem Gang der zufälligen Begebenheiten und unter allem Zwang der äußeren Umstände doch immer der ,geschaffene Gott" bleibt. Ganz in die Zeit, ja ganz in die Besonderheit des jeweiligen Moments eingeschlossen, ganz in die Bedingungen des Augenblicks verstrickt, zeigt er sich dem allen gegenüber doch stets als "Deus occasionatus“. Er verharrt in seinem eigenen Sein, er geht über die Grenzen seiner spezifisch-menschlichen Natur nirgends hinaus: aber eben indem er sie allseitig entwickelt und darstellt, stellt er damit das Göttliche in der Form und in den Schranken des Menschlichen dar. ${ }^{2}$ ) Denn wie jedes Wesen hat er das Recht, seine Form zu vollenden und zu verwirklichen. ${ }^{3}$ ) Er darf diese Form, diese seine Begrenzung bejahen, ja er muß es, denn nur, indem er dies tut, kann er in ihr Gott verehren und lieben, kann er die Reinheit seines Ursprungs bekunden. ${ }^{4}$ ) Es ist als hätte damit das Dogma

I) Auf die Lehre des ,göttlichen Cusanus“ (divinus mihi Cusanus) weist Kepler schon in seiner ersten Schrift, im Mysterium Cosmographicum, hin. S. Cap. II, Opera (ed. Frisch) I, I22; vgl. ferner Opera II, 490 und 595.

2) De conjecturis II, I4.

3 ) ,Quis ista intelligere posset, quomodo omnia illius unicae infinitae formae sunt imago, diversitatem ex contingenti habendo, quasi creatura sit Deus occasionatus... quoniam ipsa forma infinita non est nisi finite recepta, ut omnis creatura sit quasi infinitas finita aut Deus creatus, ut sit eo modo quo hoc melius esse possit ... Ex quo subinfertur omnem creaturam ut talem perfectam, etiam si alterius respectu minus perfecta videatur. Ouiescit omne esse creatum in sua perfectione, quam habet ab esse divino liberaliter, nullum aliud creatum esse appetens tanquam perfectius, sed ipsum quod habet a maximo nullum aliud creatum esse appetens tanquam pediligens, quasi quoddam divinum munus, hoc incorruptibiliter perfici et conservari optans." De doct. ign. II, 2.

4) Seinen klarsten und schärfsten Ausdruck hat dieser Gedanke in der Schrift: „De dato patris luminum" erhalten; vgl. z. B. Cap. I: ,Omnis vis illa quae se esse cognoscit ab optimo, optime se esse cognoscit. Cognoscit igitur esse suum, cujus nullam vellet ullo unquam tempore corruptionem aut mutationem in aliud esse extra speciem propriam, sibi datum non quidem ab alio aliquo, quod non est de sursum, super omnia in altitudine omnis optimitatis. Nam non credit intellectus humanus naturam suam sibi potuisse dari ab aliquo, cujus bonitas non sit altissima de sursum, super omne bonum. Neque quiesceret aliquod ens in data natura, si a diminuto et creato bono esset, sed quia ab optimo et maximo magistro, quo nihil altius, sortitum est esse suum, omne id quod est quiescit in specifica natura sua ut in optima ab optimo." 
der Erbsünde, so wenig Cusanus es bestreitet $^{1}$ ), die Kräfte verloren, die es auf das gesamte mittelalterliche Denken und auf das mittelalterliche Lebensgefühl ausgeübt hat. Jetzt erwacht wieder jener Pelagianische Geist, in dessen scharfer Bekämpfung durch Augustin die mittelalterliche Glaubenslehre erwachsen war. Die Lehre von der Freiheit des Menschen wird in aller Schärfe betont: denn nur durch die Freiheit vermag der Mensch sich Gott anzugleichen, vermag er das Gefäß Gottes (capax Dei) zu werden. ${ }^{2}$ ) Und wenn der Mensch sein Sein völlig von Gott zu Lehen trägt, so gibt es nichtsdestoweniger eine Sphäre, in der er als freier Schöpfer wirkt, in der er autonom schaltet. Diese Sphäre ist die des Wertes. Ohne die menschliche Natur gäbe es nichts wie einen Wert, gäbe es kein Prinzip der Schätzung der Dinge nach ihrer größeren oder geringeren Vollkommenheit. Man denke sich diese Natur aus dem Ganzen der Dinge ausgestrichen - und mit ihr würde auch jeder Wertvorzug des einen vor dem andern verschwinden. Gott ist freilich der Münzmeister, der die Münze schlägt; aber der menschliche Geist erst bestimmt, wie viel sie gilt. „Denn obwohl der menschliche Intellekt dem Wert nicht das Sein gibt, so ließe sich doch ohne ihn kein Wert unterscheiden. Setzt man also den Intellekt bei Seite, so läßt sich nicht wissen, ob es einen Wert gibt. Ohne die Kraft der Beurteilung und des Vergleichens hört jegliche Schätzung auf, und mit ihr müßte auch der Wert wegfallen. Hieraus ergibt sich die Köstlichkeit des Geistes, da ohne ihn alles Geschaffene ohne Wert gewesen wäre. Wollte also Gott seinem Werke Wert verleihen, so mußte er neben anderen Dingen die intellektuelle Natur erschaffen. " ${ }^{3}$ ) In diesen Sätzen findet der religiöse Humanismus und der religiöse Optimismus des Cusanus seine Vollendung: denn wie könnte das wertlos, wie könnte es dem Verderben und der Sünde verfallen sein, was vielmehr Prinzip und Quell alles Wertes ist? Wie zuvor die Natur durch das Medium der Menschheit zu Gott emporgehoben wurde, so hat jetzt die menschliche Kultur ihre wahrhafte Theodizee erfahren. In ihr bewährt sich die Freiheit des menschlichen Geistes, die das Siegel seiner Göttlichkeit ist. Die Stimmung der Weltflucht ist besiegt; das Mißtrauen gegen die Welt ist geschwunden. Denn

I) Zu Cusanus' Lehre vom Sündenfall vgl. z. B. die Predigt: Coelum et terra transibunt, Excitat. Lib. V, fol. 495 .

2) „Creavit autem Deus naturam magis suae bonitatis participem, scilicet intellectualem, quae in hoc, quod habet liberum arbitrium est creatori similior et est quasi alius Deus... Ista natura intellectualis capax est Dei, quia est in potentia infinita: potest enim semper plus et plus intelligere. ... Nulla natura alia potest fieri melior ex se, sed est id quod est sub necessitate, quae ipsam sic tenet. Sola intellectualis natura habet in se principia, per quae potest fieri melior et ita Deo similior et capacior." Excitat. Lib. V, fol. 498.

3) De ludo globi, Lib. II, fol. 236f.; vgl. hierzu Erkenntnisproblem ${ }^{3}$, I, $57 \mathrm{ff}$. 
nur indem er sich der Welt ohne Rückhalt aufschließt, indem er sich ihr ganz hingibt, kann der Geist zu sich selber und zum Maß seiner eigenen Kräfte gelangen. Auch die sinnliche Natur wie die sinnliche Erkenntniskraft ist jetzt nichts schlechthin Niederes mehr, da sie es vielmehr ist, die den ersten Antrieb und Anreiz für alle Betätigung des Intellekts bildet. Der Geist ist die lebendige Beschreibung der ewigen und unendlichen Weisheit, aber sein Leben gleicht in uns dem eines Schlafenden, bis es durch die Bewunderung, die aus der Betrachtung des Sinnlichen erwächst, zur Bewegung angeregt wird. ${ }^{1}$ ) Diese Bewegung hat im Geist selbst ihren Anfang wie ihr Ende; aber sie führt mitten durch das Gebiet des Sinnlichen hindurch. Immer ist es der Geist selbst, der sich dem Sinnlichen „,assimiliert", der etwa der Farbe gegenüber zum Sehen, dem Ton gegenüber zum Hören wird. ${ }^{2}$ ) Dieser Abstieg in die Welt der Wahrnehmung gilt jetzt nicht mehr als Abfall, als eine Art Sündenfall der Erkenntnis; in ihm vollzieht sich vielmehr der Aufstieg der Sinnenwelt selbst, die nunmehr aus der Mannigfaltigkeit zur Einheit, aus der Beschränkung zur Allgemeinheit, aus der Zerstreuung zur Klarheit sich erhebt. ${ }^{3}$ ) Der menschliche Geist - in diesem prägnanten Symbol faßt sich für Cusanus das Ganze dieser Gedanken zusammen -, ist ein göttlicher Same, der in seiner einfachen Wesenheit die. Gesamtheit alles überhaupt Wissbaren in sich faßt; aber damit dieser Same aufgehen und Frucht tragen kann, muß er in das Erdreich des Sinnlichen versenkt werden. $\left.{ }^{4}\right)$ In solcher Versöhnung von Geist und Welt, von Intellekt und Sinnlichkeit liegt der

I) Idiotae Lib. III: De mente, cap. 5: „Mens est viva descriptio aeternae et infinitae sapientiae. Sed in nostris mentibus ab initio vita illa similis est dormienti, quousque admiratione, quae ex sensibilibus oritur, excitetur, ut moveatur. Tunc motu vitae suae intellectivae in se descriptum reperit, quod quaerit."

2) Idiotae Lib. III, cap. 7: „Mens est adeo assimilativa, quod in visu se assimilitat visibilibus et in auditu audibilibus, in gustu gustabilibus, in odoratu odorabilibus, in tactu tangibilibus et in sensu sensibilibus, in imaginatione imaginabilibus et in ratione rationabilibus."

3) De conjectur. II, 16 : „Intellectus autem iste in nostra anima eapropter in sensum descendit, ut sensibile ascendat in ipsum. Ascendit ad intellectum sensibile ut intelligentia ad ipsum descendat. Hoc est enim intellectum descendere ad sensibile quod sensibile ascendere ad intellectum: visibile enim non attingitur per sensum visus absente intentione intellectualis vigoris... Intellectus autem qui secundum regionem intellectualem in potentia est, secundum inferiores regiones plus est in actu. Unde in sensibili mundo in actu est, nam in visu visibile et in auditu audibile actualiter appraehendit... Unit enim alteritates sensatorum in phantasia, varietatem alteritatum phantasmatum unit in ratione, variam alteritatem rationum in sua unit intellectuali simplici unitate."

4) „Quia mens est quoddam divinum semen sua vi complicans omnium rerum exemplaria notionaliter: tunc a Deo, a quo hanc vim habet, eo ipso quod esse recepit est simul et in convenienti terra locatum, ubi fructum facere possit et ex se rerum universi-tatem notionaliter explicare, alioqui haec vis seminalis frustra data ipsi esset, si non fuisset addita opportunitas in actum prorumpendi." Idiot. Lib. III, cap. 5 (fol. I 54). 
Grundcharakter jener ,,kopulativen Theologie“, nach der Cusanus strebt, und die er aller bloß ,disjunktiven“, aller negierenden und trennenden Theologie mit vollem methodischen Bewußtsein gegenüberstellt. ${ }^{1}$ )

I) Vgl. bes. seinen Brief an die Mönche von Tegernsee vom I4. Sept. I453, gedruckt bei Vansteenberghe, Autour de la docte ignorance (S. II3ff.) S. ferner De filiatione Dei (fol. r25): ,Una est... Theologia affirmativa, omnia de uno affirmans, et negativa omnia de eodem negans, et dubia neque negans neque affirmans, et disjunctiva, alterum affirmans, alterum negans, et copulativa opposita affirmative connectens ... Oportet deinde studentem non negligere, quomodo in hac schola sensibilis mundi in modorum varietate quaeritur unum, quod omnia, sed parto jam magisterio in caelo intelligentiae pure in uno omnia sciuntur." 
ZWEITES KAPITEL.

\section{CUSANUS UND ITALIEN.}

I.

Die starke Wirkung, die Cusanus' Persönlichkeit und Lehre auf Italien und das italienische Geistesleben des Quattrocento geübt hat, wird uns schon von den Zeitgenossen bezeugt. ${ }^{1}$ ) Die Geschichte der Philosophie und die allgemeine Kulturgeschichte der Renaissance hat jedoch die Zusammenhänge, die hier bestehen, bisher nicht in wirklicher Schärfe erkannt und herausgearbeitet. Was Cusanus' Bedeutung für die Geschichte der italienischen Philosophie betrifft, so tritt sie klar und unverkennbar erst bei Giordano Bruno hervor. Bruno selbst hat nie einen Zweifel darüber gelassen, wieviel er den beiden Denkern, die er als seine eigentlichen geistigen Befreier preist, wieviel er dem ,göttlichen Cusaner" und Copernicus verdankt. Aber zwischen dem Erscheinungsjahr der „,docta ignorantia" und Brunos philosophischen Hauptschriften liegt ein Zeitraum von fast anderthalb Jahrhunderten. Sollen wir annehmen, daß während dieses Zeitraums Cusanus' spekulative Grundgedanken im Dunkel geblieben sind, daß sie keinerlei unmittelbare Wirkung auf ihre eigene Epoche geübt haben? Fast scheint diese Annahme notwendig, wenn man erwägt, daß die eigentlich repräsentativen philosophischen Systeme der Zeit sich nirgends auf diese Grundgedanken berufen, ja daß ihnen selbst der Name ihres Urhebers fremd geworden zu sein scheint. Weder bei Pomponazzi und bei den Denkern der Schule von Padua, noch in dem Kreise der Florentiner Platoniker, in den Schriften Ficins und Picos wird Nikolaus von Kues erwähnt. ${ }^{2}$ ) Alle Fäden, die

I) Vgl. Apol. doct. ignorantiae, (fol. 75) : , Jam dudum audivi per Italiam ex hoc semine per tuam sollicitam culturam studiosis ingeniis recepto magnum fructum effluxisse."

2) In den Werken Picos scheint der Name des Cusanus überhaupt nicht vorzukommen; bei Ficin begegnet er uns nur ein einziges Mal in den Briefen, und zwar merkwürdigerweise in entstellter Form. Hier wird in einer Aufzählung philosophischer Schriften, die dem Platonischen Gedankenkreis angehören, außer auf Bessarions Verteidigung der Platonischen Lehre auch auf ,gewisse Spekulationen" des Cusanus verwiesen (quaedam

Studien der Bibliothek Warburg to: Cassirer 
man hier etwa zu knüpfen sucht, drohen daher zu zerreißen: die einfache Betrachtung der Tatsachen scheint jeden ,konstruktiven“ Versuch, einen Zusammenhang zwischen dem System des Cusanus und den Grundlehren der italienischen Philosophie des I5. Jahrhunderts herzustellen, von vornherein auszuschließen. In der Tat haben besonders die italienischen Historiker der Philosophie in ihrer großen Mehrzahl diesen Schluß gezogen. In diesem Urteil spricht auch jene nationale Grundstimmung mit, die in der philosophischen Literatur Italiens, namentlich in der des letzten Jahrzehnts, in immer stärkerem Maße zu Tage tritt. Die Gedankenwelt der Renaissance, wie ihre Kulturwelt überhaupt, sollte aus ihrem eigenen nationalen Mutterboden hergeleitet, sollte als autochtone Schöpfung des italienischen Geistes erkannt werden. Nur aus Tendenzen dieser Art heraus wird es verständlich, wenn etwa ein Forscher wie Gentile in seinen Studien über Giordano Bruno und in seiner Abhandlung über den „Begriff des Menschen in der Renaissance“ mit keinem Wort auf Cusanus' Lehre eingeht. ${ }^{1}$ ) Und doch hat schon vor vier Jahrzehnten einer der führenden italienischen Philosophiehistoriker das Verhältnis, das zwischen Cusanus und Italien besteht, klar und unzweideutig formuliert. „Man würde sich täuschen" - so heißt es gleich zu Anfang von Fiorentinos nachgelassenem Werk "Il risorgimento filosofico nel Quattrocento“ — ,wenn man glaubte, daß unsere Renaissance eine einfache Wiederkehr antiker Ideen bedeutet: denn, abgesehen davon, daß die Geschichte sich niemals wiederholt, wurde jetzt auf den alten italisch-griechischen Stamm ein neues Reis: der deutsche Gedanke gepfropft. Wenn man den neuen Faktor, der damit in die Geschichte des spekulativen Denkens eintritt, vernachlässigen, oder wenn man seine Bedeutung aus falsch verstandenem nationalem Ehrgeiz abschwächen wollte, so würde man ein ungenaues und ungerechtes Urteil fällen und sich das Verständnis des wahren Anfangs der neuen Philosophie verschließen". Es wäre ein außerordentlicher Gewinn für die Erkenntnis der gedanklichen Ursprünge und der gedanklichen Grundmotive der Renaissance gewesen, wenn Fiorentino, der einer der besten Kenner der Renaissancephilosophie gewesen ist, diese seine These im einzelnen hätte belegen und durchführen können. Nun aber, da sein Werk leider Fragment geblieben ist - es bricht genau an dem Punkt ab, an dem der nähere quellenmäßige Nachweis jenes Grundverhältnisses

speculationes Nicolai Caisii (sic!) Cardinalis). S. Epistol., Lib. IX, Op. fol. 899 . Daß Ficin gleichwohl die Werke des Cusanus gekannt hat, ist zweifellos. (Vgl. z. B. G. Saitta, La filosofia di Marsilio Ficino, Messina I923, S. 75 und die weiter unten gegebenen näheren Nachweise).

I) Giov. Gentile, Giordano Bruno e il pensiero del Rinascimento, Firenze 1923. 
hätte einsetzen müssen - liegt es der objektiven Geschichtschreibung ob, wenigstens die methodische Mahnung und Warnung Fiorentinos zu beherzigen. Man versteht die Geschichte einer großen geistigen Bewegung, zumal einer philosophischen Bewegung nicht, wenn man sie von vornherein unter einseitig nationalen Blickpunkt stellt. Jeder wahrhaft große, jeder in einem tieferen Sinne ,nationale" Genius zwingt uns sofort, die Enge einer derartigen Betrachtungsweise aufzugeben. Für Cusanus gilt dies in doppelter Hinsicht. Was er selbst Italien verdankt, wie er durch die Berührung mit der italienischen Kultur des I5. Jahrhunderts erst ins Helle und Weite geführt wurde, und wie erst hierdurch sein Gedanke die feste Form und Bestimmung gewonnen hat - das hat sich uns bereits gezeigt. Aber der Stärke und Kraft dieser Wirkung entspricht nun die der Rückwirkung. Mag diese Rückwirkung nicht sofort in abgeschlossenen Gebilden für uns sichtbar werden: sie ist dennoch vorhanden. Aber um sie zu erfassen, dürfen wir freilich die Philosophie der Renaissance nicht lediglich nach ihrem „Schulbegriff“ beurteilen, sondern wir müssen sie nach ihrem „Weltbegriff" zu nehmen suchen. In diesen gehen die Grundmotive von Cusanus' Lehre überall ein; und sie zeigen sich um so stärker wirksam, je weniger es sich hier um eine einfache Übernahme einzelner Gedanken und um eine bloße Aneignung einzelner Resultate handelt. Nicht derartige feste Resultate, sondern Tendenzen und Antriebe sind es, die Cusanus der italienischen Philosophie seiner Zeit gegeben hat, - Tendenzen, die sich deutlicher, als in festen dogmatischen Lehrmeinungen, in einer neuen Richtung der Gesamtauffassung und in neuen $Z$ ielen, auf die jetzt Spekulation und Leben hindrängen, kenntlich machen.

Um die Bedeutung und den Umfang der Fortwirkung von Cusanus' Lehre zu ermessen, müssen wir uns daher in erster Linie nicht an die Philosophie und an die philosophischen Schulhäupter, sondern an die Laienwelt und an ihre intellektuellen Vertreter wenden. Burckhardt hat als einen charakteristischen Grundzug der Renaissance ,,die Zunahme völlig ausgebildeter Menschen" in der Zeit des I5. Jahrhunderts bezeichnet. Diese ,Vielseitigen“ und „Allseitigen“ aber, wie er sie uns geschildert hat, konnten der Philosophie ihrer Zeit, die mehr oder weniger in den Formen des scholastischen Denkens und der scholastischen Gelehrsamkeit gebunden blieb, die Elemente ihrer geistigen Gesamtausbildung nicht mehr entnehmen. Wie schon Petrarca, um seinen persönlichen Lebensstil und sein persönliches Bildungsideal festzuhalten, sich heftig den Anforderungen der philosophisch-gelehrten Bildung widersetzen mußte ${ }^{1}$ ), wie er ihr gegenüber mit Stolz sein Nichtwissen bekannte und

I) Vgl. besonders die Schrift: De sui ipsius et aliorum ignorantia. 
behauptete, so steht Leonardo da Vinci in einem ständigen Kampfe gegen Autorität und Tradition. Erst in diesem Kampfe grenzt sich ihm jene neue Idee des Wissens ab, der er zustrebt, und für die er erst die methodischen Voraussetzungen zu schaffen hat. Die Grenzscheide der Geister liegt für Leonardo in dem Gegensatz zwischen den ursprünglichen Entdeckern und den Nachbildern und „Kommentatoren“. Die ersten großen Denker, - die ,Primitiven“" nach Leonardos Ausdruck, kannten nur ein Muster und Vorbild für ihre Forschungen, die Erfahrung, und verdienen deshalb den Namen der Erfinder, während ihre Nachfolger die Natur und die Wirklichkeit verließen, um sich in eine Welt bloß begrifflicher Distinktionen (discorsi) zu verlieren. Hier kann nur der Rückgang auf den ,,natürlichen“ Menschenverstand - auf die Kraft des unverbildeten Geistes helfen. „Le bone lettere son nate da un bono naturale, e perchè si dee piu laudare la cagion che l'effetto, più lauderai un bon naturale sanza lettere che un bon letterato sanzo naturale". 1 ) Kein Denker der Zeit hat diesen Satz, der die Gesamtstimmung und die Wegrichtung von Leonardos Forschung ausspricht, schärfer formuliert und eindringlicher begründet, als es Nikolaus Cusanus getan hatte. Dem Ideal der Laienfrömmigkeit, der ,,devotio moderna“, wie er es bei den Brüdern vom gemeinsamen Leben kennen gelernt und sich zu eigen gemacht hatte, stellt Cusanus ein neues Ideal des Laienwissens zur Seite. Der Darstellung und Rechtfertigung dieses Ideals ist eine seiner wichtigsten Schriften gewidmet, die schon in ihrem Titel den Hinweis auf diesen Grundgedanken enthält. Den drei Dialogen „De sapientia“, "De mente" und "De staticis experimentis" hat Cusanus den gemeinsamen Obertitel des „Idiota“ gegeben: denn in allen dreien ist es der Laie, der Ungelehrte, der als Lehrer des Redners, wie des Philosophen auftritt. Er stellt die entscheidenden Fragen, mit denen die Lösung schon bestimmt, schon im gewissen Sinne vorweggenommen ist. Die Schrift beginnt damit, daß der Laie auf dem Forum in Rom einem Redner begegnet, dem er vorhält, daß die wahrhafte Nahrung des Geistes nicht in den Schriften anderer bestehen, daß die echte Weisheit nicht in der Hingabe an irgendeine Autorität gefunden werden könne. „Du hältst Dich für weise, ohne es zu sein, und bist stolz auf diese Deine Weisheit; ich erkenne mich als Unwissenden und bin eben darum vielleicht wissender als Du“. Denn die Weisheit bedarf keiner gelehrten Zurüstungen: sie ruft auf den Straßen. Mitten im Geräusch und Getümmel des Marktes, in den alltäglichen Verrichtungen der Menschen, ist sie für den, der zu hören versteht, vernehmlich. Im Verkehr zwischen Käufer und Verkäufer, im Abwiegen der Waren, im Zählen des Geldes stellt sie sich uns

I) Il codice Atlantico di Leonardo da Vinci, Roma - Milano I894 ff., fol. 75. 
unmittelbar dar: beruht doch dies alles auf der Grundkraft des Menschen, auf der Kraft des Messens, des Wägens und Zählens. In dieser Kraft liegt das Fundament für alle Tätigkeit der Vernunft, liegt das auszeichnende Merkmal des Geistes; es genügt, sich in sie und in ihre einfachsten und gewöhnlichsten Äußerungen zu vertiefen, um an diesen Äußerungen das Wesen unserer geistigen Natur und ihr Geheimnis zu erfassen. ${ }^{1}$ ) Aus dieser Grundanschauung heraus wird erst die Wirkung verständlich, die Cusanus gerade auf die genialen „Laien“ ausgeübt hat. Seit Duhems eindringenden Forschungen, die die Quellen für Leonardos Denken aufgedeckt haben, wissen wir, wie eng die sachlichen Beziehungen zwischen Nikolaus Cusanus und Leonardo sind. Duhem hat im einzelnen dargelegt, wie Leonardo eine große Zahl von Problemen unmittelbar aus đen Händen des Cusanus empfangen und wie er sie genau an der Stelle aufgenommen hat, an der dieser sie verlassen hatte. ${ }^{2}$ ) Jetzt erschließt sich uns der tiefere Grund für dieses geschichtliche Verhältnis. Wenn Leonardo auf Cusanus zurückgreifen, wenn er an vielen Stellen gewissermaßen unmittelbar sein Erbe antreten konnte, so geschah es, weil er sich mit ihm in der methodischen Gesinnung einig fühlte. Er ist für ihn nicht sowohl der Vertreter eines bestimmten philosophischen Systems, als vielmehr der Repräsentant einer neuen Forschungsart und Forschungsrichtung. Und hieraus läßt sich denn auch begreifen, wie die Beziehung, die sich hier herstellt, über alle Grenzen des bloß-Individuellen hinauswächst. Cusanus wird gewissermaßen zum Exponenten des geistigen Gesamtkreises, dem Leonardo angehört, - jenes Kreises, der im Italien des I5. Jahrhunderts neben der absteigenden scholastischen und der aufsteigenden humanistischen Bildung eine dritte spezifisch-moderne Form des Wissens und des Erkenntniswillens darstellt. Hier soll nicht ein fester religiöser Gehalt wissenschaftlich fixiert und begriffen werden, hier soll nicht auf die große antike Tradition zurückgegangen und

I) Idiota (ad Oratorem): ,Traxit te opinio auctoritatis, ut sis quasi equus, natura liber, sed arte capistro alligatus praesepi, ubi non aliud comedit, nisi quod illi ministratur. Pascitur enim intellectus tuus, auctoritati scribentium astrictus, pabulo alieno et non naturali. Orator: $\mathrm{Si}$ non in libris sapientum est sapientiae pabulum; ubi tunc est? Idiota. Non dico ibi non esse, sed dico naturale ibi non reperiri. Qui enim primo se ad scribendum de sapientia contulerunt, non de librorum pabulo, qui nondum erant, incrementa receperunt, sed naturali alimento in virum perfectum perducebantur et ii caeteros, qui ex libris se putant profecisse, longe sapientia antecedunt... Scribit aliquis verbum illud, cui credis. Ego autem dico tibi, quod sapientia foris clamat in plateis et est clamor ejus, quomodo ipsa habitat in altissimis. Orator. Ut audio, cum sis Idiota, sapere te putas? Idiota. Haec est fortassis inter te et me differentia: tu te scientem putas, cum non sis, hinc superbis; ego vero Idiotam me esse cognosco, hinc humilior, in hoc forte doctior existo" etc.(Idiot. de sapientia lib. I, fol. 137).

2) Etude sur Léonard de Vinci, ceux qu'il a lus et ceux qui l'ont lu, Seconde série, Paris I909, S. $99 \mathrm{ff}$. 
in ihr die Erneuerung des Menschentums gesucht werden: sondern hier wird überall an konkrete technisch-künstlerische Aufgaben angeknüpft, für die eine „Theorie“ gesucht wird. Mitten in der schöpferischen Kunstbetätigung erhebt sich die Forderung einer tieferen Besinnung dieser Tätigkeit auf sich selbst - und sie läßt sich nicht erfüllen, ohne in die letzten Gründe des Wissens, insbesondere des mathematischen Wissens, zurückzugehen. Neben Leonardo ist es besonders Leon Battista Alberti, der diese neue Gestalt und diese neue Problematik des geistigen Lebens in sich verkörpert: und auch er ist nicht nur durch persönliche Beziehungen mit Cusanus verbunden, sondern weist auch in seinen theoretischen Hauptschriften auf dessen mathematisch-philosophische Spekulationen, insbesondere auf die methodischen Bemühungen um das Problem der Quadratur des Kreises, zurück. ${ }^{1}$ ) Man erkennt auch von dieser Einzelfrage her, in welchem entscheidenden Gedanken sich die Männer dieses Kreises mit Cusanus begegnen. ${ }^{2}$ ) Die Schrift ,,de docta ignorantia" war davon ausgegangen, alles Erkennen als ein Messen zu bestimmen: und sie hatte demgemäß in dem Begriff der Proportion, der die Bedingung der Möglichkeit der Messung in sich schließt, das Medium

I) Näheres bei Mancini, Vita di Leon Battista Alberti, 2. Aufl., Firenze rgog und bei Olschki, Geschichte der neusprachlichen wissenschaftlichen Literatur, I, Heidelb. r919, S. 8Iff.

2) Als einen weiteren Beweis für die starke Fortwirkung, die die Lehre des Cusanus in Italien geübt habe, führt Vansteenberghe in seiner Biographie (S. $448 \mathrm{ff}$.) die Tatsache an, daß in Italien eine ,kleine Cusanische Schule" bestand, die noch gegen Ende des Jahrhunderts eine ,akademische Versammlung" abgehalten habe. Daß, nach dem Bericht Paciolis in der Vorrede zu seiner Schrift „Divina proportione”, an dieser Versammlung außer ,einer Menge gelehrter Bewunderer des großen Kardinals", auch Leonardo da Vinci teilgenommen habe, sei eine neue Bestätigung für Duhems These. Hier aber scheint freilich ein Irrtum vorzuliegen. Das Widmungsschreiben der Schrift „Divina proportione" enthält, so viel ich sehe, nichts, was auf die Existenz einer solchen "Cusanischen Gemeinde schließen ließe. Es berichtet über eine Zusammenkunft, die am 9. Februar 1498 im Mailänder Schloß in Gegenwart des Herzogs Lodovico Maria Sforza stattgefunden habe, und zählt unter denen, die bei dieser Versammlung anwesend waren, neben Ambrogio da Rosate, Marliani, Pirovano, Leonardo da Vinci u. and. auch Andrea Novarese und Niccolò Cusano auf; von dem letzteren wird dann als von einem Manne gesprochen, der von allen Anwesenden wegen seiner Kenntnisse in der Medizin u. der Astronomie bewundert und verehrt worden sei. (E dali prefati molto in tutti premesse (discipline) admirato e venerato Nicolo cusano: cf. Luca Pacioli, Divina proportione, Neuausg. in den Quellenschriften für Kunstgeschichte und Kunsttheorie des Mittelalters und der Neuzeit, N. F. Bd. II, Wien I889, S. 32.) Von einer Bewunderung für die Person und die Lehre des Philosophen Nicolaus Cusanus im Kreise der Versammelten ist hier also nicht die Rede; der erwähnte Niccolò Cusano ist vielmehr ein Arzt gleichen Namens, der eine Professur in Pavia inne hatte. (Vgl. über ihn sowie über die andern in der Vorrede Paciolis genannten Männer Gustavo Uzielli, Ricerche interno a Leonardo da Vinci, Serie prima, Torino 1896 , S. $368 \mathrm{ff}$.). Was die Versammlung selbst betrifft, so handelte es sich um eine Zusammenkunft der sog. "Academia Leonardo Vinci“, über die Näheres aus Uzielli (a. a. O. S. 34 Iff.) und aus Olschki (a. a. O. I, 239 ff.) zu entnehmen ist. 
der Erkenntnis überhaupt fixiert. „Comparativa est omnis inquisitio, medio proportionis utens ".1) Aber die Proportion ist nicht nur ein logischmathematischer, sie ist vor allem auch ein ästhetischer Grundbegriff. So wird der Gedanke des Maßes zum Bindeglied, in dem sich der Erforscher der Natur mit dem Künstler, dem Schöpfer einer zweiten „Natur" begegnet. Die Proportion ist - wie es Luca Pacioli, der Freund Leonardos, ausspricht - nicht nur Mutter des Wissens, sondern „,Mutter und Königin der Kunst“. In ihrem Begriff durchdringen sich nunmehr die spekulativ-philosophischen, die technisch-mathematischen und die künstlerischen Tendenzen der Zeit - und eben diese Durchdringung ist es, kraft deren das Problem der Form zu einem der Zentralprobleme der Renaissancekultur wird.

Wieder kann man sich hier jenen eigentümlichen Prozeß der ,,Säkulasierung" deutlich machen, den die religiösen Motive des mittelalterlichen Denkens seit Beginn der Renaissance durchlaufen. Denn selbst der neue Begriff der „Natur" und der "Naturwahrheit", wie er sich jetzt herauszubilden beginnt, geht seinem geschichtlichen Ursprung nach auf diese Motive zurück. Die Wendung zur Natur - wenn man dieses Wort nicht in seinem modern-ästhetischen oder in seinem modern-wissenschaftlichen, sondern im religiösen Sinne nimmt - tritt unverkennbar bereits in jener großen Wendung der Frömmigkeit zu Tage, die sich in der mittelalterlichen Mystik vollzieht. In diesem Punkte hat Thode in seiner Schrift über Franz von Assisi zweifellos richtig gesehen. Bei Franz von Assisi erwacht das neue christliche Liebesideal, das die dogmatisch-starre Scheidung zwischen „Natur" und "Geist" durchbricht und überwindet. Indem das mystische Gefühl sich auf die Allheit des Daseins richtet, um sie mit sich selbst zu durchdringen, schwinden vor dieser Allheit die Schranken der Besonderung und Vereinzelung dahin. Die Liebe wendet sich nicht mehr allein Gott, als dem Ursprung und dem transzendenten Urgrund des Seins zu - und sie bleibt ebensowenig auf das Verhältnis von Mensch zu Mensch, als immanent-sittliches Verhältnis, beschränkt. Sie überträgt sich auf alle Geschöpfe schlechthin, - auf die Tiere und Pflanzen, auf Sonne und Mond, auf die Elemente und Naturkräfte. Sie alle sind nicht mehr für sich stehende und abgelöste ,Teile“ des Seins, sondern werden durch die Glut der mystischen Liebe mit dem Menschen und mit Gott zu einer Einheit zusammengeschmolzen. Die Kategorie der spezifischen und der individuellen Dinglichkeit, vermöge deren das Leben der Natur sich in fest bestimmte Arten trennt und sich in bestimmte Grade abstuft, hält vor der mystischen Kategorie der Brüderlichkeit nicht stand: wie die Fische und Vögel, die Bäume und

I) De doct. ign. I, I. 
Blumen, so sind auch Wind und Wasser für Franz von Assisi zu „,Brüdern und Schwestern" des Menschen geworden. In dieser Form der franziskanischen Mystik beginnt der mittelalterliche Geist das große Werk der Erlösung der Natur und ihrer Befreiung vom Makel der Sünde und der Sinnlichkeit. Aber noch fehlt die Erkenntnis, die dieser Art der Liebe gemäß ist, und die ihr gerecht zu werden vermöchte. Wir sahen, wie diese Erkenntnis bei Nikolaus Cusanus einsetzt - wie er, selbst von der Mystik herkommend, nun auch die spekulative Rechtfertigung der Natur fordert und sucht. Und hierfür mußte freilich ein anderer Weg beschritten werden: hier mußte der Mystiker den Logiker zu Hilfe rufen. Aber es ist nicht mehr die alte Logik der Schule, die Logik der „Aristotelischen Sekte", wie Cusanus sie nennt, auf die jetzt zurückgegriffen wird: denn ihr Grundprinzip selbst war es, das der Philosoph der ,,coincidentia oppositorum" verwarf. ${ }^{1}$ ) An ihre Stelle, an die Stelle der formalen Syllogistik, tritt vielmehr die Logik der Mathematik. Sie soll fortan das Mittel abgeben, kraft dessen wir uns über die Sphaere des mystischen Gefühls in die des intellektuellen Schauens erheben. Hier erst gelangt die Gottesliebe des Mystikers zu ihrer Erfüllung und zu ihrem wahrhaften Ziel: denn es gibt für Cusanus keine wahrhafte Liebe ohne einen Akt der Erkenntnis, auf den sie sich stützt. ${ }^{2}$ ) So ergibt sich jetzt das merkwürdige, in der Geschichte der Philosophie einzigartige Schauspiel, daß die Exaktheit der Mathematik nicht um ihrer selbst willen, noch zur Begründung der Naturerkenntnis, sondern zur Begründung und Vertiefung der Gotteserkenntnis gesucht wird. Alle Weisen und alle göttlichsten und heiligsten Lehrer - so erklärt die Schrift ,,de docta ignorantia" - kämen darin überein, daß alles Sichtbare ein Abbild jenes Unsichtbaren sei, das nicht anders denn im Spiegel und im Rätsel von uns gesehen werden könne. Wenn aber auch das Geistige an sich uns unzugänglich bleibt und wenn es von uns niemals anders als im Sinnbild, im Symbol erfaßt werden kann, so ist doch zum mindesten dies zu fordern, daß das Sinnbild selbst nichts Zweifelhaftes oder Unklares in sich birgt: denn der Weg zum Ungewissen kann nur durch das Gewisse und Sichere hindurchführen. ${ }^{3}$ ) Das ist das Neue, daß von den Symbolen, in denen das Göttliche uns fassbar wird, nicht nur sinnliche Fülle und Kraft, sondern daß von ihnen vor allem gedankliche Bestimmtheit und Sicherheit verlangt wird. Die Art der Beziehung zwischen Welt und Gott, zwischen dem Endlichen und dem Unendlichen erfährt damit eine

I) Apologia doctae ignorantiae, vgl. ob. S. 12, Anm. 2.

2) Vgl. ob. S. I 9.

3) De doct. ign. I, I I : „Dicimus, cum ad divina non nisi per symbola accedendi nobis via pateat, quod tunc mathematicalibus signis propter ipsorum incorruptibilem certitudinem convenientius uti poterimus." 
durchgreifende Wandlung. Für die mystische Gedankenstimmung kann schlechthin jeder Punkt des Seins zum Anknüpfungspunkt für diese Beziehung werden: denn in jeglichem einzelnen läßt sich die ",Spur Gottes“ erkennen, läßt er selbst sich, im Abglanz des Endlichen, erschauen. Auch Cusanus wiederholt diese Wendung ${ }^{1}$ ), aber er stellt sie in einen neuen universellen Zusammenhang hinein. Ihm ist die Natur nicht nur der Widerschein des göttlichen Seins und der göttlichen Kraft, sondern sie wird ihm zum Buch, das Gott mit seinem Finger geschrieben hat. ${ }^{2}$ ) Hier stehen wir noch fest auf religiösem Boden: aber zugleich ist jetzt mit Schelling zu reden - der Durchbruch in das freie, offene Feld objektiver Wissenschaft vollzogen. Denn der Sinn des Buches der Natur kann nicht lediglich im subjektiven Gefühl und in der mystischen Ahnung angeeignet, sondern er muß erforscht, er muß Wort für Wort, Buchstabe für Buchstabe enträtselt werden. Die Welt darf nicht länger bloß als göttliche Hieroglyphe, als heiliges Zeichen vor uns stehen bleiben, sondern dieses Zeichen bedarf der Auslegung, der systematischen Interpretation. Je nach der Richtung, die diese Auslegung nimmt, führt sie entweder zu einer neuen Metaphysik oder zu einer exakten Wissenschaft der Natur. Den ersteren Weg hat die Naturphilosophie der Renaissance eingeschlagen. Sie nimmt den Grundgedanken, daß die Natur das „,Buch Gottes" sei, auf, um ihn in immer neuen Variationen abzuwandeln. Campanella baut auf diesem Fundament geradezu seine gesamte Erkenntnislehre und seine gesamte Metaphysik auf. „Erkennen“ heißt ihm nichts anderes als das Lesen der göttlichen Schriftzeichen in der Natur: ,intelligere" bedeutet nichts anderes als ,intus legere“. „Die Welt ist das Standbild, der lebendige Tempel und der Codex Gottes, in den er Dinge von unendlicher Würde, die er in seinem Geiste trug, eingeschrieben und eingezeichnet hat. Selig, wer in diesem Buche liest und von ihm die Beschaffenheiten der Dinge erlernt, nicht aber sie nach eigenem Gutdünken oder nach fremden Meinungen erdichtet."3) Hier drückt sich in einem Gleichnis, das als solches nicht neu ist, sondern das sich über Nikolaus Cusanus bis in die mittelalterliche Philosophie, bis Augustin und Thomas zurückverfolgen läßt, dennoch ein spezifisch-neues Naturgefühl aus; aber es ist bezeichnend, daß diese Sätze sich am Schluß einer Schrift finden, die den Titel: ,,De sensu rerum et magia" führt.

I) Vgl. z. B. de doct. ign. II, 2: „Creaturae esse non possit aliud esse quam ipsa resplendentia (Dei), non in aliquo alio positive recepta, sed contingenter diversa."

2) Vgl. Idiota, Liber I de sapientia, (fol. I37): ,, Orator: Quomodo ductus esse potes ad scientiam ignorantiae tuae, cum sis Idiota? Idiota: Non ex tuis, sed ex Dei libris. Orat: Qui sunt illi ? Id: Quos suo digito scripsit. Orat: Ubi reperiuntur? Id: Ubique...."

3) Campanella, De sensu rerum et magia, ed. Tob. Adami, Frankfurt 1620, S. 37of. (Näheres s. Erkenntnisproblem ${ }^{3}$, I, S. 268f., 282.) 
Denn das Band, das die Natur im Innersten zusammenhält und das sie mit dem Menschen verknüpft, ist hier noch durchaus als magischmystisches Band gedacht. Der Mensch kann die Natur nicht anders verstehen, als dadurch, daß er sein eigenes Leben unmittelbar in sie hineinlegt. Die Grenzen seines Lebensgefühls, die Schranken, die der unmittelbaren Nachempfindung der Natur gezogen sind, sind daher zugleich die Grenzen seines Wissens von ihr. Die entgegengesetzte Form der Deutung zeigt jene Richtung der Naturbetrachtung, die, von Cusanus anhebend, über Leonardo da Vinci zu Galilei und Kepler weiterführt. Sie begnügt sich nicht mit der bildlich-sinnlichen Eindringlichkeit der Zeichen, in denen wir die geistige Struktur des Universums lesen, sondern sie verlangt von diesen Zeichen, daß sie in sich selbst ein System, einen durchgängig-geordneten Zusammenhang bilden. Der "Sinn“ der Natur soll nicht nur mystisch gefühlt; er soll als logischer Sinn gedacht werden. Und diese Forderung ist nicht anders als durch das Medium der Mathematik erfüllbar. Sie allein richtet gegenüber der Willkür und Unsicherheit der Meinungen den Maßstab der Notwendigkeit und den der Eindeutigkeit auf. So wird für Leonardo die Mathematik zur Grenzscheide zwischen Sophistik und Wissenschaft. Wer ihre höchste Gewißheit schmäht, nährt seinen Geist von Verwirrung. Indem er an einzelnen Worten haftet, verfällt er damit auch der Unbestimmtheit und Vieldeutigkeit, die dem Einzelwort eignet, sieht er sich in grenzenlose Wortstreitigkeiten verwickelt. ${ }^{1}$ ) Die Mathematik allein vermag diesen Streitigkeiten ein Ziel zu setzen, indem sie die Wortbedeutungen fixiert und indem sie ihre Verknüpfungen bestimmten Regeln unterwirft, indem sie, statt eines bloßen Aggregats von Worten, ein strenges syntaktisches Gefüge von Gedanken und Sätzen vor uns hinstellt. Galilei geht diesen Weg der Betrachtung zu Ende. Für ihn wird selbst die einzelne sinnliche Wahrnehmung, mit welcher Intensität und Eindringlichkeit sie uns immer gegeben sein mag, zum bloßen „Namen“, der an sich nichts „besagt", der keine objektiv-bestimmte Bedeutung in sich faßt. ${ }^{2}$ ) Eine solche kommt vielmehr erst zustande, wenn der menschliche Geist den Inhalt der Wahrnehmung auf jene Grundformen der Erkenntnis bezieht, deren Urbild er in sich selbst trägt. Kraft dieser Beziehung und dieses Ineinander wird uns das Buch der Natur erst lesbar und verständlich. So gelangen wir von Cusanus' Grundgedanken der ,unzerstörlichen Gewißheit" (incorruptibilis certitudo), die unter allen Sym-

I) Leonardo da Vinci, Scritti letterari, ed. Jean Paul Richter, London $188_{3}$, No. II 57 (II, 289).

2) Vgl. Galilei, Il saggiatore (Opere ed. Albèri IV, 334): Per lo che vo io pensando, che questi sapori, odori, colori etc., per la parte del suggetto, nel quale ci par che riseggano, non sieno altro che puri nomi, ma tengano solamente lor residenza nel corpo sensitivo etc. 
bolen, deren der menschliche Geist fähig und bedürftig ist, allein den mathematischen Zeichen eigne, in kontinuierlicher geschichtlicher Folge zu jenen berühmten Haupt- und Leitsätzen, in denen Galilei das Ziel und die Eigenart seiner Forschung bestimmt. Und der Prozeß der Säkularisierung vollendet sich, indem weiterhin die Offenbarung des „Buchs der Natur" der biblischen Offenbarung gegenübergestellt wird. Zwischen beiden kann kein prinzipieller Gegensatz bestehen, da beide denselben geistigen Sinn in verschiedener Form darstellen, da sich in ihnen die Einheit des göttlichen Urhebers der Natur manifestiert. Wenn aber trotzdem dem Anschein nach ein solcher Widerstreit sich für uns auftut, so kann sein Ausgleich nur in der Weise erfolgen, daß wir der Offenbarung im Werk vor der im Wort den Vorzug geben: denn das Wort ist ein Vergangenes und Überliefertes, während das Werk als Vorhandenes und Dauerndes, als ein unmittelbar und gegenwärtig zu Befragendes vor uns steht. ${ }^{1}$ )

In dieser Entwicklung des Naturbegriffs, in dieser seiner stetigen Emanzipation von den religiös-theologischen Voraussetzungen, in denen er zunächst noch wie eingehüllt erschien, wirken jene beiden Grundkräfte mit, die überall in das geistige Leben der Renaissance entscheidend eingreifen, und die es allmählich in eine neue Richtung lenken. Die neue geistige Grundform der Renaissance wird überall mitbestimmt durch die neuen Ausdrucksmöglichkeiten, die jetzt in der Sprache wie in der Technik geschaffen werden. Wenn Nikolaus Cusanus im „Idiota“ klar und bestimmt das Ideal eines neuen Laienwissens aufstellt, so fehlt doch diesem Wissen zunächst noch die ihm gemäße, die adaequate Ausdrucksform. Der „Laie“ unternimmt es, den Redner wie den Philosophen seiner Unwissenheit zu überführen, er rührt an die Grundvoraussetzungen des scholastischen wie des humanistischen Wissensbegriffs, aber er selbst spricht noch das Latein der Schule. Wie sehr diese Bindung

I) S. bes. Galileis Brief an Diodati vom I5. Januar 1633: „,Se io domanderò al Fromondo di chi sono opera il sole, la luna, la terra, le stelle, le loro disposizioni e movimenti, penso, che mi risponderà essere fattura d'Iddio. E domandato di chi sia dettatura la Scrittura Sacra, so che risponderà essere dello Spirito Santo, cioè parimente d'Iddio. Il mondo dunque sono le opere, e la Scrittura sono le parole del medesimo Iddio. Dimandato poi se lo Spirito Santo sia mai usato nel suo parlare di pronunziare parole molto contrarie in aspetto al vero e fatte così per accomodarsi alla capacità del popolo, per lo più assai rozzo e incapace, sono ben certo che mi risponderà, insieme con tutti i sacri scrittori, tale essere il costume della Scrittura. . . Ma se io gli dimanderò se Iddio per accomodarsi alla capacità e opinione del medesimo volgo ha mai usato di mutare la fattura sua, o... ha conservato sempre e continua di mantenere suo stile circa i movimenti, figura e disposizione delle parti dell' universo, son certo che egli risponderà che la luna fu sempre sferica, sebbene l'universale tenne gran tempo ch' ella fosse piana, e in somma dirà nulla mutarsi giammai dalla natura per accomodare la fattura sua alla stima e opinione degli uomini." (Edizione nazionale XV, 23). 
an die Sprache, an die Terminologie des Mittelalters bei Cusanus selbst die freie Entfaltung seines originalen Grundgedankens beschränkt, haben wir gesehen (vgl. ob. S. 20). Die Männer aber, die jetzt in Italien seine Gedanken aufnehmen und weiterführen, sind von dieser Beschränkung frei. Sie, die Mathematiker, die Techniker und Künstler lehnen mit dem Inhalt des traditionellen Wissens auch seine Form ab. Sie wollen Erfinder, nicht Kommentatoren sein: und dies bedingt, daß sie wie mit ihrem eigenen Kopfe denken, so auch in ihrer eigenen Sprache sprechen wollen. ,Wenn ich nicht wie sie die Autoren anführen kann — so hält Leonardo den Scholastikern und den Humanisten seiner Zeit entgegen so werde ich eine weit größere und würdigere Sache anführen, indem ich mich auf die Erfahrung, die Meisterin ihrer Meister, berufe. Sie gehen aufgeschwellt und pomphaft einher, gekleidet und geschmückt nicht durch eigene Mühe, sondern durch die Mühen anderer und wollen mir selbst die meine nicht gönnen; - aber wenn sie mich, den Erfinder, verachten, um wieviel mehr werden dann sie, die nicht Erfinder, sondern nur Trompeten und Rezitatoren der Werke anderer sind, getadelt werden können .... Sie werden sagen, daß ich, weil ich ohne Bildung bin (per non avere lettere) nicht gut und richtig von dem sprechen kann, was ich behandeln will: wissen sie denn nicht, daß meine Dinge mehr durch Erfahrung, als durch die Worte anderer zu behandeln sind? Wie diese die Lehrmeisterin all jener war, die gut geschrieben haben, so nehme auch ich sie zur Lehrmeisterin und werde sie in allen Fällen anführen. "1) Und doch hätte selbst diese Wendung zur Erfahrung nicht fruchtbar werden und nicht zu einer wahrhaften Befreiung von der Scholastik führen können, wenn sie sich nicht ein neues Organ geschaffen hätte. Olschki hat in seiner "Geschichte der neusprachlichen wissenschaftlichen Literatur" vortrefflich gezeigt, wie beide Aufgaben ineinandergriffen; wie sie nur miteinander lösbar waren. Die Ablösung vom mittelalterlichen Latein, der allmähliche Aufbau und Ausbau des „Volgare“ als einer selbständigen wissenschaftlichen Ausdrucksform war die notwendige Vorbedingung für die freie Entwicklung des wissenschaftlichen Denkens und seiner methodischen Grundideale. Wieder zeigt sich hierin die Wahrheit und Tiefe von Humboldts Grundanschauung, nach der die Sprache dem Gedanken nicht einfach folgt, sondern nach der sie selbst eines der wesentlichen Momente der Bildung des Gedankens ist. Auch der Unterschied des scholastischen Latein vom modernen Italienisch ist keine bloße ,Verschiedenheit von Schällen und Zeichen“, sondern es drückt sich in ihm

I) Il codice Atlantico di L. da Vinci fol. II $5^{\mathrm{r}}, \operatorname{II} 7^{\mathrm{v}}$; wie nahe Leonardo auch in dieser Formulierung und Begründung seines methodischen Grundgedankens dem Cusanus steht, zeigt ein Blick auf den Eingang des "Idiota“" (s. ob. S. 53 Anm. I). 
eine „Verschiedenheit der Weltansichten“ aus. Auch hier diente die Sprache nicht einfach zum Gefäß der neuen Weltansicht, sondern trieb sie aus sich hervor und ließ sie, zugleich mit ihrer eigenen Formung und Gestaltung, erstehen. In die gleiche Richtung wie das sprachliche Denken aber weist hier das technische Denken der Renaissance. ${ }^{1}$ ) Auch hier war - was auf den ersten Blick überraschend genug ist - Nikolaus Cusanus vorangegangen. Denn in seiner Philosophie ist dem technischen Geist, dem Geist der „Erfinder“, eine ganz neue Bedeutung gegeben, eine ganz neue Stellung erobert. Wo Cusanus seine Grundansicht des Wissens aufstellt und verteidigt, wo er darlegt, daß alles Wissen nichts anderes sei, als die Entfaltung und Explikation dessen, was komplikativ in dem einfachen Wesen des Geistes beschlossen liegt: da weist er nicht nur auf die Grundbegriffe der Logik, der Mathematik und der mathematischen Naturwissenschaft, sondern auf die Elemente des technischen Wissens und des technischen Schaffens hin. Wie der Geist aus dem Prinzip des Punktes, das in ihm liegt, den Raum, wie er aus dem einfachen "Jetzt" die Zeit, wie er aus der Einheit die Zahl entfaltet, so muß auch all seinem Wirken auf die Natur ein idealer „Entwurf" vorausgehen. Alle Künste und Fertigkeiten wurzeln in einem solchen Entwurf. Neben den Praedikamenten der Logik, neben den Begriffen der Geometrie und Arithmetik, der Musik und der Astronomie werden daher die technischen Errungenschaften, wird die Leier des Orpheus und das Astrolabium des Ptolemäus als Zeugnis der Selbständigkeit und der Ewigkeit des Geistes angeführt. ${ }^{2}$ ) Und daß hierbei der Geist, indem er seine eigene Schöpferkraft betätigt, nichtsdestoweniger nicht einfach in sich selbst bleibt, daß er sich einer sinnlichen "Materie" zuwendet, die er bildet und umgestaltet, bedeutet keinen Abfall von seiner rein intellektuellen Natur und Wesenheit. Denn auch hier gilt, daß der Weg nach oben und der nach unten derselbe ist: der Intellekt steigt nur zum Sinnlichen herab, um die Sinnenwelt zu sich emporzuheben. Sein Wirken auf eine scheinbar entgegengesetzte stoffliche Welt ist die Bedingung dafür, daß er seine eigene Form erkennt und daß er sie verwirklicht - daß er sie aus dem potentiellen Sein in ihr aktuelles Sein überführt. ${ }^{3}$ ) Man versteht von

I) Für die nähere Darlegung dieses Zusammenhangs muß hier auf Olschki's Schrift (I, 3 ff., 30 ff., 53 ff. u. ö.) verwiesen werden.

2) Vgl. bes. De ludo globi, Lib. II (fol. 232) „Creat anima sua inventione nova instrumenta, ut discernat et noscat: ut Ptolemaeus astrolabium et Orpheus lyram et ita de multis. Neque ex aliquo extrinseco inventores crearunt illa, sed ex propria mente. Explicarunt enim in sensibili materia conceptum." Vgl. bes. Excitat. Lib. V, fol. 498: "In ista natura (intellectuali) Deus voluit magis ostendere divitias gloriae suae: videmus enim, quomodo intellectus omnia ambit et assimilat et artes de se exserit assimilativas, ut est fabrilis et pictoria" (vgl. ob. S. 43 ff.).

3) De conjecturis II, I6 (s. ob. S. 47 , Anm. 3). 
hier aus, wie gerade von dem I dealismus des Cusanus eine starke ,,realistische" Wirkung ausgehen - wie der Erneuerer der Platonischen Anamnesis-Lehre zum Führer der großen „Empiristen“, der Begründer der modernen Erfahrungswissenschaft werden konnte. Denn auch für sie besteht zwischen „Apriorismus" und „Empirismus“ kein Gegensatz, da es die Notwendigkeit, da es die Vernunft selbst ist, die sie in der Erfahrung suchen. Wenn Leonardo sich der Erfahrung zuwendet, so geschieht es, um in ihr selbst die ewige und unwandelbare Gesetzlichkeit der Vernunft aufzuweisen. Den eigentlichen Gegenstand bildet auch für ihn nicht sowohl die Erfahrung selbst, als die Vernunftgründe, die „,ragioni“, die in ihr verborgen und gewissermaßen verkörpert sind. Und er spricht es aus, daß die Natur voll solcher ,Vernunftgründe" ist, die niemals in die Erfahrung getreten sind: la natura è piena d'infinite ragioni che non furono mai in isperienza. ${ }^{1}$ ) Auch Galilei geht keinen anderen Weg: so sehr er sich als Vorkämpfer des Rechtes der Erfahrung fühlt, so sehr betont er, daß der Geist das eigentliche, das notwendige Wissen nicht anders denn aus seinem eigenen Grunde (da per se) zu schöpfen vermag. Aus dieser Gedankenstimmung ihrer führenden Geister heraus wird es verständlich, daß die neue Wissenschaft der Natur, indem sie sich von der Scholastik löste, das Band, das sie mit der antiken Philosophie und mit den Versuchen $\mathrm{zu}$ ihrer Erneuerung verband, nicht $\mathrm{zu}$ zerschneiden brauchte, sondern daß sie es nur um so fester zu knüpfen vermochte.

2.

Mit den letzten Betrachtungen sind wir indes schon weit über die Epoche hinausgeschritten, der Cusanus' Lehre und deren unmittelbare Wirkung angehört. Blicken wir jetzt wieder zurück, so drängt sich vor allem die Frage auf, welche Bedeutung diese Lehre für den Fortgang und die Umgestaltung der eigentlich ,,philosophischen“ Probleme im Zeitalter des Quattrocento besessen hat. Aber hier bleiben, wie wir gesehen haben, die geschichtlichen Zeugnisse stumm. Der Mathematiker Cusanus hat sofort einen festen Kreis von Schülern um sich gesammelt. Diesem Kreise gehören nicht nur die Deutschen Peurbach und Regiomontan sondern auch eine große Zahl der italienischen Mathematiker an: besaß doch das Italien der damaligen Zeit keinen wahrhaft führenden Geist auf dem Gebiete der Mathematik, keinen Denker, der an Originalität und Tiefe der Problemstellung Cusanus zu vergleichen gewesen wäre. „Als genialer Kopf mit dem Stempel des Erfinders ausgezeichnet — so

I) Les manuscrits de L. de Vinci, ed. Charles Ravaisson, Paris I88Iff., J. fol. $18^{\mathrm{r}}$; vgl. bes. Cod. Atlant. f. $147^{\mathrm{v}} .:$, ,Nessuno effetto è in natura sanza ragione, intendi la ragione e non ti bisogna esperienzia." 
urteilt M. Cantor in seiner Darstellung der Mathematik des I5. Jahrhunderts - war nur einer, nur Cusanus, und für die Mängel seiner Erfindungen ist vielleicht verantwortlich, daß er nicht ausschließlicher Mann der Wissenschaft, in erster Linie Mathematiker sein durfte. "1) Die Philosophie der Zeit war dagegen, so sehr sie in der Vergangenheit wurzelte, reich an eigenen und eigenartigen Ansätzen. Ihr begannen sich, dank der fortschreitenden Arbeit der Quellenkritik und der Übersetzung, allmählich der ,,echte“ Aristoteles und der ,echte“ Platon zu erschließen. Und nicht als bloß historische Größen treten jetzt Aristoteles und Platon vor die Zeit hin, sondern die Platonische Liebeslehre, die Ideenlehre und die neu gestaltete Aristotelische Seelenlehre greifen als unmittelbar wirksame Kräfte in das Denken der Epoche ein. Hier herrscht somit überall eine lebendige Bewegung, die über jeden erreichten Punkt und über jede feste Systematik alsbald wieder hinausdrängt. Auch Cusanus' Lehre wird in diese Bewegung hineingezogen. Aber wenn - wie sich uns bei näherer Betrachtung zeigen wird - ihre Fortwirkung auch in diesem Kreise unverkennbar ist, so geht diese Wirkung doch nicht mehr von dem System als Ganzem, sondern nur von einzelnen seiner Grundprobleme und Grundmotive aus. Diese Probleme werden aufgenommen, diese Motive werden fortgesponnen, soweit sie sich der Gesamtheit der neuen philosophischen Aufgaben, die jetzt in den Blickpunkt getreten sind, einfügen lassen. Und diese Einfügung selbst geschieht nicht ohne Schwierigkeiten und Hemmungen. Diese Hemmungen werden begreiflich, wenn man sich die inneren Wandlungen vergegenwärtigt, die der Geist der "Renaissance“ von der Mitte des I5. Jahrhunderts bis zu seinem Ende erfährt. Nur ein Menschenalter trennt die philosophischen Hauptwerke des Cusanus von denen Ficins oder Picos, - und doch wird, sobald man sie einander gegenüberstellt, alsbald der Wandel spürbar, der sich nicht nur in der abstrakten Problematik, sondern auch in der Gedankenstimmung selbst, in der geistigen Gesamthaltung vollzogen hat. Es zeigt sich auch von dieser Seite her, wie irrig der Glaube ist, als habe sich die Loslösung der Renaissance vom „Mittelalter" in der Art einer geradlinigen, stetig fortschreitenden Entwicklung vollzogen. Nirgends handelt es sich hier um eine solche ruhige und gleichmäßige Entfaltung, um ein einfaches Wachstum von innen heraus. In dem Kampf der Kräfte, der sich hier vollzieht, kommt es immer nur $\mathrm{zu}$ einem vorübergehenden, $\mathrm{zu}$ einem durchaus labilen Gleichgewicht. Auch Cusanus' System hatte in der großen Auseinandersetzung, die es zwischen dem religiösen und dem philosophischen Wahrheitsbegriff, zwischen Glauben und Wissen, zwischen Religion und weltlicher Bildung vollzog, ein solches Gleichgewicht be-

I) M. Cantor, Vorles. über Geschichte der Mathematik² II, 2 II. 
deutet. Aber der religiöse Optimismus des Cusanus, der sich getraute, das Ganze der Welt zu umspannen, der den Menschen und den Kosmos, der die Natur wie die Geschichte in sich hineinzog und in sich zu versöhnen suchte, hatte die Gewalt der Gegenkräfte, die hier bewältigt und gebunden werden sollten, unterschätzt. Dieser tragische Irrtum offenbart sich nicht sowohl in der Philosophie des Cusanus, als er in seinem Leben, in seiner politischen und kirchlichen Wirksamkeit zutage tritt. Er beginnt diese Wirksamkeit mit dem Kampf gegen die absolute Gewalt des Papsttums, der er in der Schrift „De concordantia catholica“ die Lehre von der Souveränität der Gesamtkirche entgegenstellt. Diese steht, sofern sie in einem allgemeinen Konzil verkörpert ist, über den Bischöfen und über dem Papst. Der Papst repräsentiert die Einheit der katholischen Kirche; er ist das Bild der Einen Kirche, wie die Kirche selbst das Bild Christi ist: aber wie das Urbild dem Abbild, wie Christus der Kirche, so ist auch diese dem Papst überlegen. ${ }^{1}$ ) Aber diese theoretische Grundüberzeugung leidet schon während der Kämpfe des Basler Konzils Schiffbruch. Hier bereits sieht sich Cusanus, um sein Ideal der kirchlichen Einheit aufrechtzuerhalten, um die Kirche vor dem Schisma und dem Verfall $\mathrm{zu}$ bewahren, genötigt, in das gegnerische Lager überzugehen. Er wendet sich der päpstlichen Partei zu, der er fortan dauernd verbunden bleibt, und zu deren stärksten Stützen er von nun ab zählt. Sein ganzes Leben, seine politische wie seine intellektuelle Wirksamkeit bewegt sich in diesem Kreise der kirchlichen Hierarchie. Im Namen dieser Hierarchie nimmt er den Kampf gegen widerstreitende weltliche Ansprüche auf, um ihn mit Gefährdung von Freiheit und Leben, bis zum äußersten durchzuführen. ${ }^{2}$ ) So erkennt man schon bei ihm selbst, wie die widerstreitenden Gewalten, die er in seinem Denken zu verknüpfen und zu systematischer Einheit und Harmonie zusammenzuschließen versucht, im Leben, in der unmittelbaren Wirklichkeit, in der er steht, wieder auseinanderstreben. Wenn Cusanus mitten in diesen Enttäuschungen der große Optimist und der große Ireniker blieb, wenn er fort und fort an die mögliche und notwendige ,,Koinzidenz" der Gegensätze glaubte, so schien doch der weitere Fortgang der Geschichte diese Hoffnung mehr und mehr zu enttäuschen. Er zeigte, daß die neuen Mächte, die jetzt das klare Bewußtsein ihrer selbst zu erringen begannen, sich in ihrer Entwicklung nicht beschränken und einengen ließen, daß jede von ihnen die volle Selbständigkeit für sich in Anspruch nahm. Diesem Anspruch gegenüber konnte die Philosophie

I) ,Unde sicut Christus est veritas, cujus figura et significatio est petra sive Ecclesia: ita petra est veritas, cujus significatio et figura est Petrus. Ex quo clare patet, Ecclesiam. supra Petrum esse, sicut supra illam est Christus. " De concord. Catholica II, I8; fol. 739 .

2) Näheres bei A. Jaeger, Der Streit des Kardinals Nikolaus von Cusa mit dem Herzoge Sigmund v. Österreich, 2. B., Innsbruck r86r. 
sich in doppelter Weise verhalten. Sie konnte ihn fördern und unterstützen, indem sie das Fundament des alten Gedankenbaus, den die Scholastik errichtet hatte, Stück für Stück abtrug - oder sie mußte versuchen, diesen Bau mit den Mitteln, die ihr die klassisch-humanistische Bildung darbot, zu erneuern. Zwischen diesen beiden Tendenzen ist die Philosophie des Quattrocento geteilt: aber die rückläufige Bewegung, der Versuch der ,Restauration“ der scholastischen Gedankenformen gewinnt in ihr allmählich mehr und mehr an Ausbreitung und Stärke. In den letzten Jahrzehnten des I5. Jahrhunderts, in der Epoche, die durch die Herrschaft der Platonischen Akademie in Florenz bezeichnet ist, hat diese Bewegung ihren Höhepunkt erreicht. Die Philosophie wird zur Schutzwehr gegen die von allen Seiten andrängenden weltlichen Kräfte. Aber sie kann diese Aufgabe nicht erfüllen, ohne die ersten Ansätze zu einer selbständigen und spezifischen Methodik, die bei Cusanus erreicht waren, wiederum zu gefährden, - ohne sich mehr und mehr in „Theologie“ zurückzuverwandeln. Es ist kein Zufall, daß Marsilius Ficinus seinem Hauptwerk den Titel „Theologia Platonica“ gegeben hat, daß Pico von Mirandula seine philosophische und literarische Tätigkeit mit dem „Heptaplus", einem allegorischen Kommentar zur mosaischen Schöpfungsgeschichte, beginnt. Wenn in den großen idealistischen Systemen der neueren Zeit der Platonismus als Grundlage der wissenschaftlich en Philosophie verstanden wird, wenn er bei einem Denker wie Leibniz zur Forderung einer "perennis quaedam philosophia" führt - so hat sich der Florentinische Platonismus mit der Forderung einer ,pia quaedam philosophia" begnügt. ${ }^{1}$ ) Und der Glaube soll hierbei ganz in seiner mittelalterlich-kirchlichen Form, als "fides implicita" erneuert werden: ",ego certe - so heißt es in einem Brief Ficins - malo divine credere, quam humane scire. "2) Man spürt in dieser zugespitzten Formel, wie sehr sich jetzt die Spannung zwischen Glauben und Wissen wieder verschärft hat. Wenn Cusanus im Prinzip der ,,docta ignorantia“ diese Spannung als solche bezeichnete, so war er sich doch bewußt, in ebendiesem Prinzip zugleich das Mittel zu besitzen, um sie auf philosophischem, auf spekulativem Wege zu überwinden. Auch Ficin und Pico versuchen diesen Weg der Spekulation zu gehen: aber den Anfang und das Ende desselben, seinen Ausgangspunkt und seinen Zielpunkt, kann nicht mehr das Wissen

I) „Non absque divina providentia volente omnes pro singulorum ingenio ad se mirabiliter revocare factum est, ut pia quaedam Philosophia quondam et apud Persas sub Zoroastre et apud Aegyptos sub Mercurio nasceretur, utrobique sibimet consona. Nutriretur deinde apud Thraces sub Orpheo atque Aglaophemo. Adolesceret quoque mox Pythagora apud Graecos et Italos. Tandem vero a divo Platone consummaretur Athenis." Ficin, Epistolae, lib. VIII, Opera, Basil. o. J., fol. 87x.

2) Epistolae, Lib. V., a. a. O. fol. 783 .

Studien der Bibliothek Warburg ro: Cassirer 
als solches, sondern nur die Offenbarung sichern - eine Offenbarung, die in einem halb mythischen, halb historischen Sinne verstanden wird. -

So würde man ein durchaus einseitiges Bild von der Lebensstimmung des Florentiner Kreises gewinnen, wenn man sie vornehmlich nach den Hymnen des Lorenzo Magnifico, oder gar nach seinen Canti carnascialeschi beurteilen wollte. Wenn hier der Kultus der Kunst und der Schönheit zu einem Kultus der Welt und der Sinnlichkeit wird, wenn die Freude am reinen „Diesseits“ der Dinge sich stark und unbefangen ausspricht, so mischten sich doch in die Aussprache dieses Grundgefühls alsbald andere Klänge. Noch vor dem Auftreten Savonarolas und vor seiner eigentlichen geschichtlichen Wirksamkeit ist gleichsam der Schatten Savonarolas in diesem Kreise zu spüren. Daß die Florentiner Akademie in ihren eigentlich führenden Geistern zuletzt Savonarola erlag, daß sie sich vor ihm fast ohne Widerstand beugte: das wird nur verständlich, wenn man auf die asketischen Züge achtet, die sich von Anfang an in ihr Weltbild einmischen. Im Leben Ficins sind es eben diese Züge, die mehr und mehr die geistige Form und die sittliche Gesamthaltung bestimmen. Ficin selbst hat berichtet, wie er in einer schweren Krankheit, die ihn in seinem 44. Jahre befiel, vergebens Trost in der Philosophie und in der Lektüre der profanen Schriftsteller gesucht habe. Die Heilung sei erst erfolgt, nachdem er der Maria ein Gelübde getan und sie um ein Zeichen der Genesung gebeten habe. Jetzt deutet er diese Krankheit als ein göttliches Zeichen, daß die Philosophie für sich allein nicht zum wahren Heil der Seele genüge: er wirft seinen Kommentar zum Lukrez ins Feuer, um nicht an der Verbreitung heidnischer Irrtümer mitschuldig zu werden und beschließt, seine ganze philosophische und literarische Wirksamkeit ausschließlich in den Dienst der Religion, der Festigung und Verbreitung des Glaubens zu stellen. ${ }^{1}$ ) Auch auf das Bild Picos von Mirandula, der den Zeitgenossen so licht und glänzend, der ihnen als ein wahrhafter „Phoenix der Geister“ erschien, fallen allmählich immer tiefere und dunklere Schatten. Nach der ersten verheißungsvollen Epoche des Aufstiegs, die von einem fast unbegrenzten Vertrauen in die Kraft des menschlichen Geistes und der humanistischen Lebens- und Bildungsideale erfüllt ist, mehren sich auch hier die asketischen Züge. Insbesondere in dem Briefwechsel Picos treten diese Accente der Weltverneinung und Weltverachtung stark und unverkennbar hervor. $\left.{ }^{2}\right)$ Um keine Seele hat Savonarola hartnäckiger, leidenschaftlicher, fanatischer gekämpft als um die

I) S. Ficin, Epistolae lib. I (fol. 644); cf. L. Galeotti, Saggio intorno alla vita ed agli scritti di Marsilio Ficino, Arch. storico italiano, N. S., T. IX, p. 33 f. $344 \mathrm{ff}$.

2) Vgl. bes. Picos Briefe an seinen Neffen Giovan Francesco Opera S. $340 \mathrm{ff}$,, 
Picos - und in diesem Kampf ist ihm zuletzt der Sieg geblieben. Unmittelbar vor seinem Tode steht Pico im Begriff, der immer wiederholten Mahnung Savonarolas zu folgen und in das Kloster von San Marco einzutreten. So steht auch am Ende dieses Lebens ein Verzicht - eine resignierte Rückkehr nicht nur zum religiösen Dogma, sondern auch zu den Sakramenten der Kirche und $\mathrm{zu}$ den christlich-mittelalterlichen Lebensformen.

Dennoch wäre die starke und unmittelbare Wirkung, die die Platonische Akademie auf all die großen Florentiner geübt hat - eine Wirkung, die zeitweise selbst den skeptisch-kühlen Geist Macchiavellis ergreift nicht erklärbar, wenn wir es hier lediglich mit einer rückläufigen Bewegung zu tun hätten. So sehr das religiös-theologische Interesse hier die gesamte Haltung und die gesamte Entwicklung des philosophischen Gedankens bestimmt, so ist doch der religiöse Geist selbst inzwischen in eine neue Phase eingetreten. Die gedankliche Arbeit der ersten Hälfte des Quattrocento, aus der ein neuer, ein ,,moderner" Begriff der Religion selbst herauswuchs, ist nicht verloren. So schwer es für uns ist, die Fäden, die die Platonische Akademie mit dieser Arbeit verbinden, im einzelnen aufzuzeigen und $\mathrm{zu}$ verfolgen, so klar tritt andererseits der allgemeine, der mittelbare Zusammenhang überall hervor. Die Lehre Ficins ist mit der Lehre des Cusanus nicht nur durch wichtige Bestimmungen in der Stellung und Lösung des Erkenntnisproblems verknüpft. Mehr noch als in diesen logischen Grundfragen, wird der Zusammenhang in den Grundfragen der Metaphysik und der Religionsphilosophie ersichtlich. Das neue Verhältnis zwischen Gott und W elt, das durch die Spekulation des Cusanus festgestellt war, und das dieser Spekulation ihren auszeichnenden Charakter verlieh, bleibt trotz aller gedanklichen Gegenströmungen auch bei Ficin in Kraft. Und es gewinnt jetzt von einem Motiv her, das Cusanus relativ fern lag, eine neue Bestätigung. Wenn dieser in seiner religiösen ,Rechtfertigung“ der Welt wesentlich an mathematische und kosmologische Probleme anknüpft - so geht die Florentinische Akademie immer wieder auf das Wunder der Schönheit, auf das Wunder der künstlerischen Form und der künstlerischen Gestaltung zurück. In ihm ist auch ihre Theodizee gegründet. Die Schönheit des Universums ist es, die den Hinweis auf seinen göttlichen Ursprung und die letzte und höchste Beglaubigung für seinen geistigen Wert in sich schließt. Sie erscheint als ein durchaus Objektives: als $\mathrm{Maß}$ und Form, als Verhältnis und Harmonie an den Dingen selbst - aber eben dieses Objektive erfaßt der Geist als sich selbst angehörig, als aus seinem Wesen hervorgegangen. Wenn selbst der gemeine und ungebildete Verstand Schönes von Häßlichem unterscheidet, wenn er Formloses flieht und sich dem Gestalteten 
zuwendet, so folgt daraus, daß er, unabhängig von aller Erfahrung und Lehre, eine feste Norm des Schönen in sich trägt. "Jeder Geist lobt die runde Gestalt, sobald sie ihm zum ersten Male in den Dingen begegnet, und weiß doch nicht, warum er sie lobt. Und so loben wir auch an Bauwerken die Ebenmäßigkeit der Wände, die Anordnung der Steine, die Gestalt der Fenster und Türen, und ebenso am menschlichen Leibe die Proportion der Glieder oder in einer Melodie den Zusammenklang der Töne. Wenn jeder Geist dies alles gutheißt und wenn er es, ohne den Grund dieser Billigung zu kennen, gutheißen muß, so kann dies nur durch einen natürlichen und notwendigen Instinkt geschehen... Die Gründe dieser Urteile sind also dem Geiste eingeboren." ${ }^{1}$ ) So wird die Harmonie zum Siegel, das Gott auf sein Werk gedrückt hat, und vermöge dessen er dies Werk geadelt, vermöge dessen er es in eine innerliche und notwendige Beziehung zum menschlichen Geiste gesetzt hat. Indem der menschliche Geist mit seinem Wissen um die Schönheit, mit dem Maßstab, den er in sich selbst findet, zwischen Gott und die Welt tritt, schließt er beides damit erst wahrhaft zu einer Einheit zusammen. Wieder begegnet uns hier der Mikrokosmos-Gedanke in jener charakteristischen Prägung, die er durch Cusanus erfahren hatte. Bei diesem erscheint der Mensch als das Band der Welt - nicht nur, weil er alle Elemente des Kosmos in sich vereinigt, sondern weil sich in ihm gewissermaßen das religiöse Schicksal des Kosmos entscheidet. Da er der Repräsentant des Alls und der Auszug aller seiner Kräfte ist, so kann er selbst nicht zum Göttlichen erhoben werden, ohne daß sich kraft dieses Prozesses und in ihm zugleich die Erhebung des Alls vollzieht. Die Erlösung des Menschen bedeutet also nicht seine Loslösung von der Welt, die selbst als die schlechthin niedere sinnliche Sphäre liegen bliebe sondern sie erstreckt sich nunmehr auf das Ganze des Seins. Diesen Gedanken nimmt die Florentinische Akademie auf, - und er wird zu einem der wichtigsten und wirksamsten Motive in der Religionsphilosophie Ficins. Auch bei Ficin erscheint die Seele als die geistige "Mitte“ der Welt, als das ,dritte Reich" zwischen der Welt des Intelligiblen und der des Sinnlichen. Sie ist über der Zeit, weil sie die Zeit in sich selbst enthält, zugleich aber ist sie unter den Dingen, die an der Zeit keinen Anteil haben; sie ist beweglich und unbeweglich, einfach und vielfältig. ${ }^{2}$ ) Sie enthält das Höhere, - doch so, daß sie das Niedere nicht verläßt; denn sie geht niemals in einer einzigen Bewegung auf, sondern bewahrt, mitten in dieser Bewegung begriffen, die Möglichkeit der Umkehr und

I) Ficinus, Theologia Platonica sive de immortalitate animae, Lib. XI, Cap. V (fol. 255).

2) Vgl. Theol. Platonica Lib. I, cap. 3 ff. 
Umwendung. Auf diese Weise faßt die Seele das All nicht sowohl statisch, als vielmehr dynamisch in sich: sie ist nicht aus den einzelnen Teilen, die den Makrokosmos bilden, zusammengesetzt, sondern sie ist der Intention nach auf sie alle gerich tet, ohne je in einer dieser Zielrichtungen ausschließlich zu verharren und aufzugehen. ${ }^{1}$ ) Und diese Richtung stammt nicht von außen, sondern aus ihr selbst. Die Seele wird weder durch ein übermächtiges Fatum, durch eine bloße Naturgewalt zum Sinnlichen herabgezogen, noch wird sie durch die Wirksamkeit der göttlichen Gnade, die sie schlechthin passiv zu empfangen hat, zum Übersinnlichen emporgehoben. An diesem Punkte trennt sich Ficin von Augustin, der fast überall sonst für ihn - ähnlich wie für Petrarca - als höchste religiöse Autorität gilt. Und wieder bedeutet diese Trennung eine Hinwendung zu Cusanus. Denn dieser war es gewesen, der gemäß der Grundstimmung, von der seine philosophische Lehre beherrscht wird, dem PaulinischAugustinischen Dogma von der Gnadenwahl entgegentreten mußte. So wenig er versucht, die Wirksamkeit der Gnade zu bestreiten oder zu beschränken, so steht doch für ihn fest, da $\beta$ der eigentliche religiöse Impuls nicht von außen, sondern aus dem Innern der Seele stammt. Denn das Wesen der Seele selbst ist die Fähigkeit zur Selbstbewegung und Selbstbestimmung. „Niemand sieht Dich" - so spricht in der Schrift „De visione Dei“ die Seele zu Gott — ,wer Dich nicht hat; niemand faßt Dich, wenn Du Dich ihm nicht gibst. Wie aber könnte ich Dich haben, wie kann mein Wort zu Dir, dem schlechthin Unzugänglichem gelangen? Wie soll ich Dich erbitten: denn gibt es etwas Absurderes, als daß Du Dich mir gibst, der Du alles in allem bist - und wie könntest Du Dich mir geben, ohne mir zugleich den Himmel, die Erde und alles, was in ihnen ist, zu geben?" Aber die Antwort, die die Seele von Gott erhält, löst diesen Zweifel: „,Sei Du Dein und ich werde Dein sein“. In der Freiheit des Menschen liegt es, sich selbst zu wollen oder nicht zu wollen - und nur wenn er sich für das Erste selbsttätig entscheidet, wird ihm Gott zuteil. Die Wahl, die letzte Entschließung steht bei ihm selbst. ${ }^{2}$ ) An

I) „In universo Dei opere connexio partium est ponenda, ut unius Dei unum quoque sit opus. Deus et corpus extrema sunt in natura et invicem diversissima. Angelus haec non ligat; nempe in Deum totus erigitur, corpora negligit. ... Qualitas etiam non connectit extrema, nam declinat ad corpus, superiora relinquit, relictis incorporeis fit corporalis. Hucusque extrema sunt omnia seque invicem superna et inferna fugiunt, competentia carentia vinculo. Verum essentiali ista tertia interjecta talis existit, ut superiora teneat, inferiora non deserat. ... Est enim immobilis, est et mobilis. Illinc cum superioribus, hinc cum inferioribus convenit. Si cum utrisque convenit, appetit utraque. Quapropter naturali quodam instinctu ascendit ad supera, descendit ad infera. Et dum ascendit inferiora non deserit, et dum descendit, sublimia non relinquit. Nam si alterutrum deserat, ad extremum alterum declinabit, neque vera erit ulterius mundi copula." - Theol. Platon. III, 2, fol. II9.

2) De visione Dei cap. VII: „Cum sic in silentio contemplationis quiesco, tu Domine 
dieser Grundanschauung hält auch Ficins Schrift „,De christiana religione“ fest. ${ }^{1}$ ) Und auch sie gibt von hier aus dem Erlösungsmotiv eine Wendung, durch die nunmehr auch das All, auch die Sinnenwelt selbst in religiösem Sinne gerettet erscheint. Die Erlösung des Menschen hat nicht nur ihm selber ein neues Sein, sondern kraft desselben auch dem Universum eine neue Form gegeben. Diese Umbildung, diese ,,reformatio" kommt einer geistigen Neuschöpfung gleich. Indem der Mensch seiner eigenen Göttlichkeit bewußt wird, indem er das Mißtrauen gegen seine Natur überwindet, schwindet damit auch das Mißtrauen gegen die Welt. In seiner Menschwerdung hat Gott erklärt und bewirkt, daß es in der Welt nichts Formloses, nichts schlechthin Verächtliches mehr gibt. $\left.{ }^{2}\right)$ Er vermochte den Menschen nicht zu sich zu erheben, ohne in ihm auch die Welt zu adeln. Je tiefer der Mensch seine eigene Natur erfaßt, je mehr er sich in der reinen Geistigkeit seines Ursprungs begreift, um so höheren Wert muß er demnach der Welt verleihen - wie andererseits die Erschütterung seines Glaubens an sich selber ihn wie den gesamten Kosmos wieder ins Nichts, in die Sphäre der Sterblichkeit, zurückstoßen würde. Diese Fassung des Erlösungsgedankens weiß, wie Ficin ausdrücklich betont, nichts mehr von einer hierarchischen Stufung oder Vermittlung. Wie Gott sich ohne Mittelglied (absque medio) dem Menschen verbunden hat, so müssen wir uns bewußt sein, daß unser Heil darin besteht, daß wir ihm ohne Mittler anhaften. ${ }^{3}$ ) Wenn wir hier auf dem Wege der Reformation stehen, so ist es doch auf der anderen Seite ein echtes Grund-

intra praecordia mea respondes, dicens: sis tu tuus, et ego ero tuus. O Domine . . posuisti in libertate mea ut sim, si voluero, mei ipsius. Hinc nisi sim mei ipsius, tu non es meus.... Et quia hoc posuisti in libertate mea, non me necessitas, sed expectas, ut ego eligam mei ipsius esse."

I) S. z. B. Cap. 35 (fol. 74): „Non cogit ad salutem Deus homines quos ab initio liberos procreavit, sed assiduis inspirationibus singulos allicit, quod si qui ad eum accesserint, hos durat laboribus, exercet adversitatibus, et velut igne aurum, sic animum probat difficultate" etc. Vgl. ferner Epist. Lib. II (fol. 683). "Si quis autem dixerit, mentem $\mathrm{ab}$ alienis vel extrinsecis ad intelligentiam non moveri, sed ipsam et propria et mirabili quadam virtute suas sibi species, sua objecta concipere, dicemus ex eo sequi mentem esse incorpoream penitus et aeternam, si nequaquam ab alio, sed a seipsa movetur."

2) De christ. relig. Cap. XVIII (fol. 22): „Non minus ferme est deformia reformare, quam formare simpliciter ab initio. ... Decuit igitur Deum omnium effectorem perficere quae defecerant, quemadmodum per insensibile verbum omnia creaverat. ... Quid sapientius quam universi decorem miram primae et ultimae rationis copulam fieri? ... Sic ergo et declaravit et fecit ut nihil esset in mundo deforme, nihil penitus contemnendum, cum regi coelorum terrena conjunxit atque ea quodammodo coelestibus adaequavit."

3) ,Proinde quia Deus homini absque medio se conjunxit, meminisse oportet, nostram felicitatem in eo versari, ut Deo absque medio haereamus. . . Desinant igitur, jam desinant homines suae divinitati diffidere, ob quam diffidentiam mortalibus se ipsos immergunt". De christian. relig. Cap. XIX (fol. 23). 
motiv der Renaissance, durch das diese Wendung sich vorbereitet. Denn die Selbstbejahung des Menschen ist es, die jetzt zugleich zur Weltbejahung wird: die Idee der ,humanitas“ gibt auch dem Makrokosmos einen neuen Gehalt und Sinn. Und von hier aus läßt sich erst ganz die tiefe Wirkung verstehen, die die Platonische Akademie auf die großen $\mathrm{K}$ ünstler der Renaissance ausüben mußte. Alle scheinbare Unform aus der Welt auszutilgen, alles Gestaltlose als der Gestalt teilhaft zu erkennen - dies ist nach Ficin die Summe der religiös-philosophischen Erkenntnis. Aber diese Erkenntnis kann beim bloßen Begriff nicht stehen bleiben; sie muß sich in Tat umsetzen und sich in ihr bewähren. Hier setzt die Leistung des Künstlers ein. Die Forderung, die die Spekulation nur zu stellen vermochte, wird von ihm erfüllt. Daß die Sinnenwelt Form und Gestalt hat - dessen kann sich der Mensch nur dadurch versichern, daß er ihr fortschreitend Form gibt: Alle Schönheit der sinnlichen Welt stammt zuletzt nicht aus ihr selbst, sondern liegt darin begründet, daß sie gewissermaßen zum Medium wird, an dem die freie Schöpferkraft des Menschen sich betätigt, und in dem sie sich selbst als solche erkennt. So betrachtet aber liegt die Kunst nicht nur nicht außerhalb des religiösen Blickpunktes, sondern sie wird zu einem Moment des religiösen Prozesses selbst. Ist die Erlösung als Erneuerung der Form des Menschen und der Form der Welt, als echte ,,reformatio" gefaßt ${ }^{1}$ ), so liegt der Brennpunkt des geistigen Lebens gewissermaßen an der Stelle, an der die "Idee“ Körperlichkeit gewinnt, an der die unsinnliche Gestalt, die im Geist des Künstlers vorhanden ist, in die Welt des Sichtbaren herausbricht und sich in ihr verwirklicht. Alle Spekulation muß daher notwendig fehlgreifen, wenn sie ihren Blick bloß auf das Gestaltete heftet, statt sich in den Grundakt des Gestaltens selbst zu versenken. „O Erforscher der Dinge - so heißt es bei Leonardo - rühme Dich nicht des Wissens um die Dinge, die die Natur in ihrem gewöhnlichen Lauf hervorbringt: sondern freue Dich, das Ziel und Ende derjenigen Dinge zu kennen, die von

I) In eindringenden wort- und ideengeschichtlichen Untersuchungen hat Konrad Burdach gezeigt, wie die Begriffe der Wiedererneuerung und Wiedergeburt, des renasci und der reformatio, im religiösen Gedankenkreis wurzeln und wie sie erst allmählich aus dieser Sphäre in die weltliche Sphäre übertragen werden. (Sinn und Ursprung der Worte Renaissance und Reformation, Sitzungsber. der Berl. Akademie d. Wiss. I910; wieder abgedr. in der Schrift Reformation, Renaissance, Humanismus, Berl. 1918). Auf die philosophische Literatur der Renaissance ist Burdach hierbei leider nicht eingegangen: und doch bildet gerade sie in dem von ihm dargestellten Prozeß eines der wichtigsten Mittel- und Bindeglieder. Eine Stelle, wie die aus Ficins Schrift „De christiana religione“", die wir oben (S. 7o, Anm. 2) angeführt haben, führt uns gewissermaßen den Umschlag des Gedankens unmittelbar vor Augen: das ,,reformare " bedeutet die geistige Neuschöpfung des Seins durch den Prozeß der Erlösung und gleichzeitig liegt in ihr jene ,Entdeckung der Welt und des Menschen “, wie sie sich durch die neu eindringenden weltlichen Bildungselemente vollzieht. 
Deinem Geist entworfen sind." 1 ) Von dieser Art sind ihm Wissenschaft und Kunst: denn die Wissenschaft ist eine zweite Schöpfung der Natur, die durch die Vernunft, die Kunst, eine zweite Schöpfung der Natur, die durch die Einbildungskraft hervorgebracht wird. ${ }^{2}$ ) Und beide, Vernunft und Einbildungskraft stehen sich hier nicht mehr fremd gegenüber: sind sie doch nur verschiedene Offenbarungen derselben Urkraft des Menschen zur Gestaltung überhaupt.

Blicken wir auch hier wieder auf die Vorgeschichte dieses Gedankens zurück, so werden wir zu der wichtigen Wendung hingeleitet, die Cusanus' Lehre in dem Grundmotiv der „Ebenbildlichkeit" des menschlichen Geistes mit Gott vollzogen hatte. Diese kann keinerlei sachlich-inhaltliche „Ähnlichkeit" zwischen ihnen mehr bedeuten: denn eine solche wird durch das Prinzip der ,docta ignorantia“, durch den Satz: ,, finiti et infiniti nulla proportio" von Anfang an ausgeschlossen. So gleichen sich Gott und Mensch weder in ihrem Sein noch in ihrem Werk. Denn wenn aus Gottes Schöpfung die Dinge selbst hervorgehen, so hat es der menschliche Geist immer nur mit ihren Zeichen, mit ihren Symbolen zu tun. Diese sind es, die er vor sich hinstellt, auf die er sich in seiner Erkenntnis bezieht, und die er nach festen Regeln miteinander verknüpft. Wenn Gott die Wirklichkeit der Dinge erschafft, so baut der Mensch die Ordnung des Idealen auf: wenn jenem die "vis entificativa", so kommt diesem die ,vis assimilativa“ zu. ${ }^{3}$ ) Aber wenn demgemäß der göttliche und der menschliche Geist gewissermaßen verschiedenen Dimensionen angehören, wenn sie in ihrer Existenzform und in dem Gegenstand ihrer Hervorbringungen einander disparat sind, so besteht doch der $\mathrm{Zu}$ sammenhang zwischen ihnen in der Weise des Produzierens selbst. Hier allein liegt das echte tertium comparationis. Das Verhältnis ist auf keine Weise durch irgendeinen Vergleich zu fassen, den wir der fertigen Dingwelt selbst entnehmen, weil es sich in ihm um kein statisches, sondern um ein dynamisches Verhältnis handelt. Nicht irgendeine Wesensgleichheit der Substanz ist hier zu fordern und zu suchen: wohl aber eine Entsprechung im Akt, in der Operation. In der Tat würde das Abbild, wie viel wir ihm auch vom substantiellen Wesen des Urbildes mitteilen wollten, darum doch nicht aufhören, ein totes Abbild zu sein. Erst die Über-

I) Leonardo da Vinci (ed. Ravaisson) G fol. $47 \mathrm{r}$.

2) Trattato della pittura (ed. Manzi) S. 38 .

3) , $\mathrm{Si}$ mentem divinam universalitatem veritatis rerum dixeris: nostram dices universalitatem assimilationis rerum, ut sit notionum universitas. Conceptio divinae mentis est rerum productio, conceptio nostrae mentis est rerum notio. Si mens divina est absoluta entitas, tunc ejus conceptio est entium creatio et nostrae mentis conceptio est entium assimilatio: quae enim divinae menti ut infinitae conveniunt veritati, nostrae conveniunt menti, ut propinquae ejus imagini." Idiotae lib. III, de mente; Cap. 3, vgl. bes. Cap. 7 . 
einstimmung in der Form des Wirkens gibt ihm die Form des Lebens. Setzen wir Gott, der die Schaffenskraft schlechthin ist, als die ,,absolute Kunst", so würde für diese, falls sie den Entschluß faßte, sich selbst in einem Bild zu verkörpern, ein doppelter Weg möglich sein. Sie könnte einmal ein Bild schaffen, das so viel an Vollkommenheit enthielte, als das Geschaffene überhaupt aufzunehmen vermag, das aber andererseits, eben weil es bereits an der Grenze der möglichen Vollkommenheit steht, diese Grenze nicht mehr zu überschreiten vermöchte. Oder aber sie könnte ein an sich unvollkommeneres Bild hervorbringen, diesem aber die Kraft mitgeben, sich selbst ständig zu steigern und sich dem Urbild ähnlicher und ähnlicher zu machen. Welches von diesen beiden Bildern vor dem andern den Vorzug verdiente, kann keine Frage sein: würde sich doch das erste zum zweiten verhalten, wie das von einem Maler entworfene Bild eines Menschen, das in allen Zügen dem Original gliche, aber stumm und tot dastünde, zu einem anderen, das, an sich weniger ähnlich, doch von seinem Schöpfer die Gabe erhalten hätte, sich zu bewegen. Und in eben diesem Sinne ist unser Geist das vollkommene und lebendige Bild der unendlichen Kunst. Denn wie weit er auch im Anfang der Schöpfung in dem, was er aktuell ist, hinter dieser unendlichen Kunst zurückbleibt, so besitzt er doch eine angeborene $\mathrm{Kraft}$, durch die er sich ihr immer gemäßer gestalten kann. ${ }^{1}$ ) Der Beweis seiner spezifischen Vollkommenheit besteht also darin, daß er bei keinem erreichten Ziel Halt macht, sondern beständig über dasselbe hinausfragen und hinausstreben muß. Wie das sinnliche Auge durch nichts Sichtbares je befriedigt und begrenzt wird - denn niemals kann sich das Auge am Sehen ersättigen, - so sättigt sich das intellektuelle Schauen niemals im Sehen der Wahrheit. An dieser Stelle hat vielleicht die Faustische Grundstimmung der Renaissance ihren klarsten philosophischen Ausdruck und ihre tiefste philosophische Rechtfertigung erhalten. Der Drang ins Unendliche, das Nichtverharrenkönnen bei irgendeinem Gegebenen und Erreichten, ist keine Schuld, keine Hybris des Geistes, sondern er ist das Siegel seiner göttlichen Bestimmung und seiner Unzerstörbarkeit. ${ }^{2}$ ) Schritt für Schritt läßt sich verfolgen, wie dieses charakteristische Grundmotiv in alle Sphären des geistigen Lebens der Renaissance eingreift und wie es sich in ihnen umbildet. Es steht im Mittelpunkt von Leonardos

I) S. Idiot. Lib. III, De mente, cap. I3, fol. I69.

2) ,Sicut vis visiva sensibilis est infinibilis per omne visibile (nunquam enim satiatur oculus visu), sic visus intellectualis nunquam satiatur visu veritatis. Semper enim acuitur et fortificatur vis videndi: sicut experimur in nobis, quod quanto proficimus plus in doctrina, tanto capaciores sumus et plus proficere appetimus, et hoc est signum incorruptibilitatis intellectus." Excitat. lib. V (Ex. serm.: Si quis sermonem meum servaverit), fol. 488 . 
Theorie der Kunst $^{1}$ ), wie es im Mittelpunkt von Ficins philosophischer Unsterblichkeitslehre steht. Cusanus hatte eine dreifache Richtung und eine dreifache Bedeutung des Unendlichkeitsbegriffs unterschieden: denn Gott als dem Absolut- Unendlichen, als dem Maximum schlechthin, das als solches für den menschlichen Intellekt unerreichbar bleibt, stehen zwei Formen des Relativ- Unendlichen gegenüber. Die eine stellt sich uns in der Welt, die andere im menschlichen Geiste dar. Dort wird die Unendlichkeit des Absoluten dadurch im Bilde dargestellt und widergespiegelt, daß das Universum ohne räumliche Grenzen ist, daß es sich in unbestimmte Weiten erstreckt - hier drückt sich die Beziehung darin aus, daß der Geist in seinem Fortgang kein ,ne plus ultra“, keine Schranke seines Strebens anerkennt. Wenn diese Grundanschauung nach ihrer kosmologischen Seite hin erst weit später, erst in der Naturphilosophie des 16 . Jahrhunderts, insbesondere bei Giordano Bruno, wirksam wird, so wird sie nach der Seite der spekulativen Psychologie von der Schule von Florenz aufgenommen und weitergebildet. Ficins Hauptwerk: die "Theologia Platonica" ist völlig auf sie gestellt. So sehr dieses Werk sich an antike und mittelalterliche Vorbilder anlehnt, so sehr es alle Argumente erneuert, die bei Platon und Plotin, bei den Neuplatonikern und Augustin für die Unzerstörlichkeit der Seele angeführt worden waren, so fällt doch aller Nachdruck der Beweisführung und alles Pathos der Erkenntnis auf die Erwägung, daß der Geist kein Ende in der Zeit haben kann, weil er selbst alle zeitlichen Grenzen, alle Abteilungen des kontinuierlichen Flusses des Werdens in bestimmte Abschnitte und Perioden, erst hervorbringt. Dieses Wissen um die Zeit, um ihren unendlichen Fortgang wie um die festen Maßbestimmungen, kraft deren dieser Fortgang gewissermaßen aufgehalten und vermittelst des Denkens ,festgestellt" wird, ist das, was den Geist ein für allemal über die Zeit hinaushebt. ${ }^{2}$ ) Und zu dem gleichen Schluß

1) Vgl. z. B. Leonardo, Tratt. della pittura 28: „Li semplici naturali sono finiti e l'opere che l'occhio commanda alle mani sono infinite; come dimostra il pittore nelle finzioni d'infinite forme d'animali et erbe, pianti e siti."

2) ,,(Mens) corpora dividit in partes plurimas partiumque particulas, numeros auget supra numeros absque fine. Figurarum modos mutuasque illarum proportiones atque etiam numerorum comparationes innumerabiles invenit, lineas supra coelum ultra terminum undique protendit. Tempus in praeteritum absque principio, in futurum absque fine producit. Neque solum ultra omne tempus aliquid antiquius cogitat, verum etiam ultra omnem locum alium semper cogitat ampliorem. ... Illud ... mihi videtur vim mentis ... interminatam prae ceteris demonstrare, quod ipsam infinitatem esse invenit, quidve sit et qualis definit. Cum vero cognitio per quandam mentis cum rebus aequationem perficiatur, mens cognitae infinitati aequatur quodammodo. Infinitum vero oportet esse, quia aequatur infinitati. Ac si tempus, quod successione quadam metitur motum, infinitum esse oportet, si modo motus fuerit infinitus, quanto magis infinitam esse oportet mentem, quae non modo motum tempusque stabili notione, sed infinitatem ipsam quoque metiatur? Cum necesse sit mensuram ad id quod 
werden wir von seiten des Willens geführt: denn dieser wird zum wahrhaft menschlichen Willen erst dadurch, daß er über alle endlichen Zwecksetzungen hinausgreift. Wenn alles natürliche Dasein und Leben sich in einem bestimmten Kreise befriedigt, wenn es in seinem Zustand verharren will, so erscheint dem Menschen alles Erreichte geringfügig, solange es noch irgend etwas zu erwerben gibt. Für ihn gibt es keinen Zeitpunkt, in dem er ausruhen, keinen Ort, an dem er stillestehen könnte. $\left.{ }^{1}\right) \mathrm{Zu}$ seiner vollen Bedeutung gelangt dieser Gedanke, indem er von der individuellen Natur des Menschen auf seine spezifische Natur übertragen wird, - indem der Kreis der psychologischen Betrachtung zu dem der geschichtsphilosophischen Betrachtung erweitert wird. Und auch hier ist es der Grundgedanke von Ficins Religionsphilosophie, der die Brücke zwischen diesen beiden Gebieten schlägt. Wie für Cusanus die Gesamtheit der Menschen in Christus zur Einheit zusammengefaßt ist, wie demnach jedes Individuum ,unus Christus ex omnibus“ ist²), so gibt auch Ficin der Christus-Idee eine Wendung, durch die sie unmittelbar in die Idee der Humanität, im antik-stoischen Sinne des Wortes, übergeht. ${ }^{3}$ ) Von hier aus wird eine Geschichtsphilosophie möglich, die, so sehr sie im dogmatischen Gedankenkreis des Christentums verbleibt, doch jede dogmatische Enge mehr und mehr überwindet, sofern es ihr gelingt, den Begriff der Religion nicht ausschließlich in einer einzelnen Glaubensform, sondern in der Gesam theit der historischen Glaubensformen verkörpert zu sehen. Damit aber ist die klassische Form der

ipsa metitur habere proportionem, finiti vero ad infinitum sit nulla proportio." (Theol. Plat. VIII, I6, fol. zoof.). Die letzten Sätze enthalten ein direktes Zitat aus der Schrift "de docta ignorantia", zum Zusammenhang mit Cusanus vgl. im übr. De ludo globi, Lib. II u. Idiot. Lib. III, I5 (oben S. 44, Anm. I).

I) „Non certa quaedam rerum aliquarum possessio aut species aliqua voluptatis sufficit homini, quemadmodum caeteris animantibus, sed paulum quid in is adeptum se putat, donec restat aliquid vel minimum acquirendum. ... Homo solus in praesenti hoc vivendi habitu quiescit nunquam, solus hoc loco non est contentus". Theol. Plat. XIV, 7, fol. 3I5. Vgl. ibid. XVIII, 8 fol. 4II: „Solemus ... in nullo cognitionis modo quiescere priusquam, quid sit res ipsa secundum substantiam, cognoverimus. Praeterea rationi naturalis est continua per rationes discursio, quousque ad summam perveniat rationem, quae quoniam infinita sit, ideo sola rationis discursum ex se absque fine frustra pervagaturum sistere possit. Siquidem ultra finitum quodlibet mens semper aliquid ulterius machinatur".

2) „Una (est) Christi humanitas in omnibus hominibus et unus Christi spiritus in omnibus spiritibus, ita ut quodlibet in eo sit, ut qui sit unus Christus ex omnibus. Et tunc qui unum ex omnibus, qui Christi sunt, in hac vita recipit, Christum recipit, et quod uni ex minimis fit, Christo fit." De doct. ign. III, I2; vgl. ob. S. 42, Anm. I.

3) ,Singuli namque homines sub una idea et in eadem specie sunt unus homo. $\mathrm{Ob}$ hanc ut arbitror rationem sapientes solam illam ex omni virtutum numero hominis ipsius nomine, id est humanitatem appellaverunt, quae omnes homines quodammodo seu fratres ex uno quodam patre longo ordine natos diligit atque curat." Ficin us, Epistol. Lib. I, fol. 635 . 
christlichen Geschichtsphilosophie, wie sie Augustin in der Schrift „De civitate Dei" geschaffen hatte, gesprengt. Wenn in dieser die Betrachtung ausschließlich auf das $\mathrm{Ziel}$ der Geschichte gerichtet ist, in welchem ihr Sinn erst sichtbar hervortritt, wenn Sündenfall und Erlösung die beiden religiösen Pole sind, von denen auch alles besondere Geschehen erst seine theologische Deutung erhält, so kann jetzt der Blick auf der Breite dieses Geschehens selbst ruhen. Und damit ist der Gedanke der Entwicklung in den Kreis des Religiösen aufgenommen, ist die Mannigfaltigkeit der Formen und Phasen der Gottesverehrung aus der Einheit der Gottesidee selbst gerechtfertigt. Das echte Christentum verlangt nicht, daß die Gegner des Glaubens vertilgt, sondern daß sie durch die Vernunft überzeugt, durch Unterricht bekehrt oder aber ruhig geduldet werden. ${ }^{1}$ ) Denn die göttliche Vorsehung läßt es nicht $\mathrm{zu}$, daß es $\mathrm{zu}$ irgendeiner Zeit irgendein Gebiet der Erde gibt, dem jede Form der Gottesverehrung fremd ist. Ihr ist mehr daran gelegen, daß sie überhaupt verehrt, als da $\beta$ sie in diesen oder jenen Riten und Gesten verehrt wird; ihr ist noch die scheinbar niedrigste und törichste Art des Glaubens und des Kults wohlgefällig, sofern sie nur eine men schliche Form und ein Ausdruck der menschlichen Natur in ihrer notwendigen Beschränkung ist. ${ }^{2}$ ) Man erkennt hier, wie die Philosophie Ficins bei all ihrer Bindung an den theologischen Begriff der Offenbarung doch im Innern ebendieses Begriffs selbst einen dialektischen Umschlag vorbereitet. Wenn alle geistigen Werte, die die Menschheitsgeschichte in sich birgt, auf eine einheitliche Offenbarung reduziert und in ihr gegründet werden, so liegt darin umgekehrt der Gedanke, daß eben diese gesuchte Einheit der Offenbarung nicht anders als im Ganzen der Geschichte und in der Totalität ihrer Gestaltungen zu suchen ist. An der Stelle der abstrakten Einfachheit, wie sie sich in einer allgemein verbindlichen dogmatischen Formel darstellen läßt, tritt jetzt die konkrete Allgemeinheit der Form des religiösen Bewußtseins, die die Verschiedenheit der Symbole, in denen dies Bewußtsein sich äußert, zum notwendigen $\mathrm{K}$ orrelat hat.

I) De christ. relig. Cap. 8, fol. II.

2) De christ. relig. cap. 4; ,Nihil Deo magis displicet quam contemni, nihil placet magis quam adorari. . . Idcirco divina providentia non permittit esse aliquo in tempore ullam mundi regionem omnis prorsus religionis expertem, quamvis permittat variis locis atque temporibus ritus adorationis varios observari. Forsitan vero varietas hujus modi, ordinante Deo, decorem quendam parit in universo mirabilem. Regi maximo magis curae est revera honorari, quam aut his aut illis gestibus honorari. ... Coli mavult quoquo modo, vel inepte, modo humane, quam per superbiam nullo modo coli." Vgl. hrz. Cusanus in einem Briefe an Aindorffer vom 22. Sept. I452: „Inexplicabilis divinae scripturae fecunditas per diversos diverse explicatur, ut in varietate tanta ejus infinitas clarescat; unum tamen est divinum verbum in omnibus relucens." S. bes. ob. S. 29 ff. 
DRITTES KAPITEL.

\section{FREIHEIT UND NOTWENDIGKEIT IN DER PHILO- SOPHIE DER RENAISSANCE.}

I.

Als gegen Ende des Jahres I5or die ferraresische Gesandtschaft in Rom erschien, die dazu bestimmt war, Lucrezia Borgia zu ihrer Hochzeit mit Alfonso von Este nach Ferrara zu geleiten, da befand sich unter den Festspielen, die im päpstlichen Palast zu Ehren dieser Gesandtschaft gegeben wurden, auch eines, in dem ein Kampf zwischen Fortuna und Herkules dargestellt war. Juno sendet gegen ihren alten Feind Herkules die Fortuna aus, die aber, statt ihn zu besiegen, von ihm überwunden, ergriffen und gefesselt wird. Auf Junos inständige Bitte gibt Herkules die Fortuna zwar frei; aber nur unter der Bedingung, daß weder sie selbst noch jene je wieder etwas Feindliches gegen das Haus der Borgia oder der Este unternehmen, vielmehr beide den zwischen beiden Häusern geschlossenen Ehebund begünstigen sollten. ${ }^{1}$ ) Es ist nur ein höfiches und ganz in die Sprache höfischer Konvention gekleidetes Spiel, das wir hier vor uns haben; - und auch die Wahl des Herkules-Symbols scheint auf den ersten Blick nicht viel mehr als eine Anspielung auf den Namen des regierenden Herzogs von Ferrara, Ercole d'Este, des Vaters Alfonsos, zu bedeuten. Um so mehr muß es überraschen, daß uns der gleiche allegorische Gegensatz, den hier das Festspiel darstellt, nicht nur in der Literatur der Zeit immer wieder begegnet, sondern daß er selbst in die Philosophie eindringt. In der Tat kehrt noch gegen Ende des Jahrhunderts in der moralphilosophischen Hauptschrift Giordano Brunos das gleiche Motiv wieder. In Brunos ,,Spaccio della bestia trionfante" (I584) wird dargestellt, wie Fortuna vor Zeus und vor die Versammlung der olympischen Götter hintritt, um von ihnen den Platz zu verlangen, den bisher Herkules in der Reihe der Sternbilder

I) Näheres über dieses Festspiel z. B. bei Ferd. Gregorovius, Lucrezia Borgia I9II, S. I $8{ }_{3} f$. 
eingenommen hat. Aber ihr Anspruch wird als nichtig erklärt. Ihr selbst, der Schweifenden und Unbeständigen, wird zwar keine einzelne Stelle im Universum verwehrt; sie mag sich nach Belieben überall im Himmel und auf Erden zeigen. Die Stelle des Herkules aber wird der T a p f erkeit verliehen, weil dort, wo die Wahrheit, das Gesetz und das rechte Urteil herrschen soll, die Tapferkeit nicht fehlen darf. Sie ist der Hort aller anderen Tugenden, das Schild der Gerechtigkeit und der Turm der Wahrheit: uneinnehmbar von den Lastern, unbesiegbar durch Leiden, ausdauernd gegen Gefahren, streng gegen die Begierden, eine Verächterin des Reichtums und die Bezwingerin der Fortuna. ${ }^{1}$ ) Wir dürfen uns nicht scheuen, den höfischen Ausdruck des Gedankens hier unmittelbar neben den philosophischen zu stellen: denn eben dies, daß eine solche Beziehung und ein solches Beieinander möglich ist, ist für die Kultur der Renaissance und für ihre geistige Gesamthaltung bezeichnend. Wieviel die Geselligkeit der Renaissance, wieviel die Form ihrer Feste und Spiele uns von ihrem Geiste verrät, hat Burckhardt uns gezeigt. Und eine Gestalt wie Giordano Bruno lehrt, daß die allegorischen Masken, die diese Spiele beherrschen, ihre Wirkung bis weit in ein Gebiet erstrecken, das, unseren Denkgewohnheiten gemäß, nur dem abstrakten, dem begrifflich-bildlosen Denken vorbehalten sein sollte. In einer Zeit, in der das Leben sich überall von geistigen Formen beherrscht und mit ihnen durchdrungen zeigt, in der die Grundgedanken über die Stellung des Menschen zur Welt, über Freiheit und Schicksal bis in das festliche Spiel hinein sich wirksam erweisen - in einer solchen Zeit bleibt auch der Gedanke nicht lediglich in sich selbst beschlossen, sondern strebt nach sichtbaren Symbolen. Giordano Bruno ist der deutlichste Exponent dieser Grundanlage und dieser Grundstimmung der Renaissancephilosophie. Von seinen frühesten Schriften, von der Schrift: „De umbris idearum" an, hat er den Gedanken festgehalten, daß für die menschliche Erkenntnis sich die Ideen nicht anders als in bildhafter Form darstellen und verkörpern lassen. Mag diese Darstellung dem ewigen transzendenten Gehalt der Ideen gegenüber noch so schattenhaft erscheinen: sie ist dennoch die unserem Denken und unserem Geist allein gemäße. Wie der Schatten nicht schlechthin Dunkelheit, sondern eine Mischung von Licht und Dunkel ist, so sind die Ideen, in menschliche Form gefaßt, nicht Trug und Schein, sondern die Wahrheit selbst, soweit sie einem begrenzten und endlichen Wesen faßbar ist. ${ }^{2}$ ) Für eine solche Denkart ist die Allegorie kein bloßes

I) Bruno, Spaccio della bestia trionfante, Dial. II, terza parte; Opere italiane (ed. Lagarde, Göttingen I888) S. $486 \mathrm{ff}$.

2) Bruno, De umbris idearum, Intentio secunda, Opera latina (ed. Tocc, Iombriani etc.) Vol. II, S. 2 If. 
äußeres Beiwerk, keine zufällige Hülle, sondern sie wird zum Vehikel des Gedankens selbst. Die Ethik Brunos insbesondere, die es nicht sowohl mit der Form des Universums, als mit der des Menschen zu tun hat, greift überall nach diesem spezifisch-menschlichen Ausdrucksmittel. Brunos Spaccio ist die allseitige Entwicklung jener ethisch-allegorischen Formelsprache, die die Verhältnisse der inneren Welt durch Gestalten des sichtbaren, des räumlichen Kosmos zu verdeutlichen sucht. Die Kräfte, die das Innere des Menschen bewegen, werden als kosmische Potenzen, die Tugenden und Laster werden als Sternbilder angeschaut. Aber wenn in dieser Betrachtung die fortezza in den Mittelpunkt rückt, so darf sie doch nicht lediglich in ihrer ethischen Bedeutung und in ihrer ethischen Einengung verstanden werden. Sie bedeutet - dem etymologischen Ursinn der ,,virtus “ gemäß, deren Begriff sie hier ausdrückt - die Kraft der Mannhaftigkeit überhaupt, die Kraft des menschlichen Willens, die zur Bändigerin des Schicksals, zur ,domitrice della fortuna“ wird. Es ist - um den Ausdruck zu brauchen, den Warburg in einer anderen Sphäre geprägt hat - eine neue und doch echt-antike Pathosformel, die wir hier heraushören; es ist ein heroischer Affekt, der seine Sprache und seine gedankliche Rechtfertigung sucht. -

Will man die philosophischen Lehren über das Verhältnis von Freiheit und Notwendigkeit, wie sie in der Renaissance hervortreten, in ihrer eigentlichen Tiefe fassen, so muß man überall bis zu dieser ihrer letzten Wurzel zurückgehen. Den rein dialektischen Motiven dieses ewigen und in seiner Grundform unveränderlichen Problems hat die Philosophie der Renaissance nur wenig hinzugefügt. Eine Schrift wie die des Pomponatius „De Fato, libero arbitrio de praedestinatione“ stellt in vollständiger Aufzählung und in schulmäßiger Gründlichkeit alle diese Motive noch einmal vor uns hin. Sie verfolgt die Frage in all ihren Verzweigungen; sie geht sorgsam allen begrifflichen Distinktionen nach, durch die die antike Philosophie und die Scholastik die Vereinbarkeit des göttlichen Vorherwissens mit der Freiheit des menschlichen Wollens und Handelns zu erweisen versucht hatte. Sie selbst aber bringt weder eine prinzipiell neue Entscheidung, noch scheint sie sie auch nur zu suchen. Man muß auf die anderen philosophischen Hauptschriften Pomponazzis, insbesondere auf seine Schrift über die Unsterblichkeit der Seele zurückgreifen, um seine eigene Stellung klar zu bestimmen. Dann aber bemerkt man freilich - insbesondere in der neuen Grundlegung der Ethik, die die Schrift „De immortalitate animae“ enthält - wie auch hier die Starrheit der traditionellen Begriffe und Formeln, die in ihrem ganzen Umfang mitgeführt werden, sich zu lösen beginnt. Wir stehen hier vor einem ähnlichen Prozeß, wie er sich in den Wandlungen des Fortuna-Sym- 
bols in der bildenden Kunst der Renaissance verfolgen läßt. Wie Warburgs und Dorens Untersuchungen uns diesen Prozeß erschlossen, wie sie uns gezeigt haben, daß die festgewordenen mittelalterlichen Formen der Fortuna noch lange erhalten bleiben, daß aber neben ihnen immer stärker andere Motive hervortreten, die, in ihrer Wurzel antik, jetzt doch mit einem neuen Geist und einem neuen Leben erfüllt werden - so gilt das gleiche auch innerhalb der intellektuellen Sphäre. Auch hier kommt es nicht sofort zu neuen Lösungen; sondern es muß, bevor diese einsetzen können, zunächst gleichsam ein neuer Spannungszustand des Gedankens erzeugt werden. Nirgends tritt ein eigentlicher Bruch mit der philosophischen Vergangenheit ein; wohl aber kündet sich eine veränderte Dynamik des Denkens, kündet sich - mit Warburg zu sprechen - das Streben nach einem neuen ,energetischen Gleichgewichtszustand “ an. Wie die bildende Kunst nach plastischen Ausgleichsformeln, so sucht die Philosophie nach gedanklichen Ausgleichsformeln ,zwischen mittelalterlichem Gottvertrauen und dem Selbstvertrauen des Renaissancemenschen “. ${ }^{1}$ ) Dieses Streben tritt nicht minder deutlich als in der eigentlichen ,philosophischen“ Literatur der Zeit in jenen halb philosophischen, halb rhetorischen Traktaten hervor, die die literarische Signatur des neuen humanistischen Zeitalters bilden. Von Petrarcas Schrift „De remediis utriusque fortunae“ führt hier der Weg über Salutati zu Poggio und zu Pontano weiter. Poggio versucht die Lösung, daß er die einander entgegengesetzten Kräfte, die das Leben des Menschen gestalten, in ihrer Vorherrschaft den verschiedenen Epochen des menschlichen Daseins zuweist. Die Gefahren, die dem Menschen von außen, von den Schicksalsgewalten drohen, sind am stärksten, solange sein eigentliches Selbst sich noch nicht herausgebildet hat, solange er noch in der Kindheit oder in der ersten Jugend steht. Sie treten zurück, sobald dieses Selbst erwacht ist, und sobald es sich durch die Grundkräfte freien Menschentums, durch die Energie des sittlichen und des intellektuellen Strebens, zu seiner vollen Wirksamkeit entfaltet. So sind es ,virtus " und ,studium", die zuletzt auch alle feindlichen Mächte des Himmels besiegen. ${ }^{2}$ )

I) $\mathrm{Zu}$ den Wandlungen des Fortuna-Symbols in der bildenden Kunst der Renaissance s. A. Warburg, Francesco Sassetti's letztwillige Verfügung (Kunstwissensch. Beiträge, August Schmarsow gewidmet, Leipzig 1907 , S. I29ff.) und A. Doren, Fortuna im Mittelalter und in der Renaissance Vortr. der Bibl. Warburg, hg. von Fritz Saxl, 1922/23, Teil I, Leipzig 1924 , S. 7 Iff. Doren's literarische Belege und Nachweise werden neuerdings ergänzt durch H. R. Patch, The tradition of the Goddess Fortuna in Medieval Philosophy and Litterature; Smith College Studies in Modern Languages, Juli 1922.

2) Poggio Epist. II, I95: ,Verissimum quidem est, quod scribis neque sidera neque coelorum cursus praestantes hominum naturas bonarum artium studiis et optimis moribus corroboratas pervertere ac depravare posse: sed ante assumptum robur, ante adeptos optimos mores, antequam bonarum artium institutis homines firmentur . . plus sidera 
Wendungen dieser Art zeigen eine neue Richtung des Glaubens - aber in ihr zugleich eine neue seelische $Z$ wiespältigkeit. $Z u$ der plastischgedanklichen Einheit von Dantes Fortunabild, das in einer großen Synthese alle widerstreitenden Motive zusammenzwingt, das die Fortuna als ein Wesen eigenen Seins und eigener Prägung bestehen läßt und sie nichtsdestoweniger dem geistig-göttlichen Kosmos einfügt - zu dieser Einheit ist es nicht wieder gekommen. Aber gerade diese Unsicherheit bedeutet gegenüber der Sicherheit unḍ Geborgenheit des mittelalterlichen Vorsehungsglaubens eine neue Befreiung. In der mittelalterlichen $Z_{w e i-}$ weltenlehre und in all den Dualismen, die sie zur Folge hat, steht der Mensch den Kräften, die um ihn ringen, einfach gegenüber, ist er ihnen gewissermaßen preisgegeben. Er erlebt den Widerstreit dieser Kräfte; aber er greift nicht selbst in diesen Widerstreit ein. Er ist der Schauplatz des großen Weltendramas - aber er ist noch nicht zum wahrhaften selbständigen Gegenspieler geworden. Die Renaissance jedoch zeigt uns immer deutlicher ein andres Bild. Aus der Fortuna mit dem Rad, das den Menschen ergreift und das ihn mit sich umwälzt, das ihn bald erhebt, bald in den Abgrund stürzt; wird die Fortuna mit dem Segel - und nicht nur sie ist es, die das Schiff geleitet, sondern der Mensch selber ist es, der am Ruder sitzt. $\left.{ }^{1}\right)$ Die Äußerungen der Theoretiker, die nicht sowohl vom schulmäßigen Wissen als von einer bestimmten Sphäre des Handelns oder des geistigen Schaffens herkommen, weisen in die gleiche Richtung. Für Macchiavelli beherrscht das Glück die Hälfte aller menschlichen Handlungen, aber es gibt sich nicht dem tatenlos Zuschauenden, sondern dem Handelnden, rasch und kühn Zupackenden; für Leon Battista Alberti reißt der Strom der Fortuna den nicht mit fort, der sich in ihm, der eigenen Kraft vertrauend, als tüchtiger Schwimmer seinen Weg bahnt. ${ }^{2}$ ) „La fortuna per sè, non dubitare, sempre fu e sempre sarà inbecillissima et debolissima, a chi se gli opponga " ${ }^{3}$ ) Beide, Macchiavell und Alberti, sprechen hier aus der Stimmung ihres Florentiner Kreises heraus - aus jener Stimmung, die nicht nur die Politiker, die Männer der Tat, wie Lorenzo Magnifico, sondern auch die spekulativen Denker beherrschte, bevor ihre Kraft und ihr Vertrauen durch Savonarola gebrochen war. Wenn Ficin in einem Briefe an Rucellai es für das Beste et coelos valere arbitror ad disponendum animum nostrum quam hominum praecepta et suasiones". Näheres bei Ernst Walser, Poggius Florentins, Leipzig und Berlin r9r4, S. $196,236 \mathrm{ff}$.

I) Vgl. hierzu das Bildmaterial in Warburgs Sassetti-Aufsatz (S. I4I) und bei Doren a. a. O., Tafel VI, Abb. I4 und 16.

2) Macchiavelli, Principe, cap. 25; L. B. Alberti Intercoenales (Op. ined. ed. Mañcini, S. I36ff.); näheres s. b. Doren, a. a. O., S. II7f., I32f.

3) L. B. Alberti, Della tranquillità dell' animo Lib. III, Opere volgari I, II 3 f. (s. Patch, a. a. O., S. 217).

Studien der Bibliothek Warburg 10: Cassirer 
erklärt, mit der Fortuna Frieden und Waffenstillstand zu schließen, unseren Willen dem ihren anpassend, damit sie uns nicht mit Gewalt in einen uns unwillkommenen Weg zieht ${ }^{1}$ ) - so klingt.die Losung des jüngeren Führers der Platonischen Akademie, Pico della Mirandola, schon um vieles kühner und freier. „Die Wunder des Geistes sind größer als der Himmel. . . . Es gibt nichts Großes auf der Erde außer dem Menschen, nichts Großes im Menschen außer seinem Geist und seiner Seele. Wenn Du zu ihnen aufsteigst, so steigst Du über den Himmel hinaus. "2) Mitten in der strenggläubigen, ja in der streng-kirchlichen Welt des Florentiner Platonismus bricht jetzt jener ,heroische Affekt" durch, der in der Folge zu Giordano Brunos Dialog ,Degli eroici furori" führen wird. -

Wir gehen jedoch hier diesen Wandlungen in der geistigen Stimmung nicht nach, sondern wir suchen sie lediglich in dem systematischen Ausdruck zu erfassen, den sie sich in der philosophischen Theorie geschaffen haben. Die theoretische Erörterung über die Willensfreiheit wird durch Lorenzo Vallas Schrift „De libero arbitrio“ eingeleitet. Was dieser Schrift ihre Bedeutung gegeben, was sie aus der Menge der scholastisch-mittelalterlichen Traktate über den gleichen Gegenstand sofort herausgehoben hat: das ist weit mehr als ihr Inhalt die Form, in die dieser Inhalt gekleidet ist. In ihr bekundet sich in der Tat nicht nur ein neuer literarischer Stil, sondern ein neuer Stil des Denkens. Zum erstenmal seit den Tagen der Antike wird jetzt wieder das Freiheitsproblem vor ein rein weltliches Forum, vor den Richterstuhl der ,natürlichen Vernunft" zitiert. Zwar hat Valla das Dogma nirgends direkt bekämpft, sondern er hat sich - wie vor dem Inquisitionstribunal, vor das er eines Tages in Neapel zitiert wurde ${ }^{3}$ ), - am Ende immer halb gläubig, halb ironisch den Entscheidungen der „Mutter Kirche“ gefügt. Und doch spürt man überall in seinen Schriften das Walten des neuen kritisch-modernen Geistes, der sich seiner Macht und seines gedanklichen Rüstzeugs bewußt $\mathrm{zu}$ werden beginnt. Valla hat als erster jene Form der Dogmenkritik geschaffen, wie sie im siebzehnten Jahrhundert durch Bayle, ja wie sie im achtzehnten noch durch Lessing geübt wird. Mag er die Entscheidung immerhin einer anderen Instanz überlassen - er fordert, daß die Untersuchung ausschließlich vom Standpunkt der Vernunft und mit ihren Mitteln geführt werde. Die Vernunft ist der ",beste Autor“, der durch kein anderes Zeug-

I) Den Text des Briefes von Ficin an Rucellai s. bei Warburg, Sassetti-Aufsatz S. 149 .

2) Pico della Mirandola, In astrologiam, Lib. III, cap. 27, Op. fol. 5 I9.

3) Über Vallas Verhalten gegenüber den kirchlichen Inquisitoren vgl. z. B. die Schilderung bei Voigt, Wiederbelebung des klass. Altertums ${ }^{2}$, I, $476 \mathrm{ff}$. 
nis überwunden werden kann. ${ }^{1}$ ) Mag daher der Inhalt des Glaubens unangetastet bleiben, ja mag Valla, wie später Bayle, versichern, daß es ihm nur darum zu tun sei, diesen Inhalt rein herauszuschälen und ihn aus der gefährlichen Verbindung mit der „Philosophie“ zu lösen: so werden doch jetzt die traditionellen Begründungen dieses Inhalts kritisch geprüft und kraft dieser Prüfung Schicht für Schicht abgetragen. Die Kritik richtet sich zunächst auf die moralischen und auf die rechtlichen Grundlagen des hierarchischen Systems. Durch den Angriff auf die Konstantinische Schenkung, den schon Cusanus in seiner Schrift ,De concordiantia catholica" eingeleitet hatte, der aber jetzt mit neuen Waffen und in weit größerer Schärfe wieder aufgenommen wird, wird der rechtliche Anspruch der Kirche auf die weltliche Herrschaft in seiner Nichtigkeit erwiesen. ${ }^{2}$ ) Und dieser juristischen Bestreitung der Fundamente der Hierarchie entspricht die ethische, die Valla in der Schrift ,de professione religiosorum" durchgeführt. Auch hier wird der religiöse Gehalt als solcher nirgends angetastet; aber heftig wendet sich Valla gegen den Anspruch, daß dieser Gehalt in einer einzelnen Lebensform und in einer besonderen sozialen Form ausschließlich oder vorzugsweise verkörpert sei. Das Ideal des mönchischen Lebens, der Wertvorzug des Klerikers wird entschlossen beseitigt. Das Wesen der Religion und der Frömmigkeit besteht in einem freien Verhältnis, das sich das Ich, das Subjekt des Glaubens und Willens, zur Gottheit gibt. Die Eigenart dieses Verhältnisses wird verkannt, ja vernichtet, wenn man es im Sinne einer äußerlich rechtlichen Verpflichtung nimmt; wenn man glaubt, die reine Innerlichkeit der Gesinnung dadurch in ihrem Werte erhöhen zu können, daß man ihr ein bestimmtes äußeres Verhalten hinzu'ügt. Es gibt kein solches Verhalten, es gibt kein Tun oder Lassen, das der Hingabe des Selbst verglichen werden könnte oder das sie in ihrer ethisch-religiösen Bedeutsamkeit zu steigern vermöchte: omnia dat, qui se ipsum dat. Für diese vom Subjekt, nicht vom Objekt her, vom "Glauben“ nicht von den „Werken“ her orientierte Auffassung gibt es keine ständische Vertretung des Religiösen mehr: „,non enim in solis cucullatis vita Christi custoditur". ${ }^{3}$ ) Und

I) Vgl. Valla, Confutat. prior in Benedictum Morandum Bononiensem, Opera, Basil. I 543 , S. $445 \mathrm{ff}$. "Sed omissis utrinque criminibus inspiciamus civiliter, quid mihi objectas. Nempe quod Livium ausus sum reprehendere, an tu eum nusquam reprehendi posse existimas? ... Et in Demosthene atque Cicerone summis oratoribus nonnulla desiderantur, et in Platone Aristotele, philosophis maximis, aliqua notantur . . . Numquid deterius est rationis, quam hominis testimonium? ... An melior ullus autor est quam ratio ?"

2) S. Valla, De falso credita et ementita Constantini donatione declamatio, Op. fol. $76 \mathrm{rff}$

3) S. Vallas Apologia contra calumniatores ad Eugenium IV, Opera fol. 799 v. „Via a Christo tradita nulla est tutior, sicut nec melior, in qua nulla professio nobis injungi- 
durch diese Befreiung aus hierarchischer Enge erhält nunmehr, wie das Tun, so auch das Denken eine ganz neue Schwingungsweite. Zwar bleibt der Anspruch des Christentums, die Wahrheit schlechthin zu enthalten, unbestritten - aber mehr und mehr muß sich der Inhalt des christlichen Glaubens eine Deutung gefallen lassen, die ihn den Ansprüchen des natürlichen Verstandes gemäß macht. Am unverhülltesten tritt dies in Vallas erster Schrift, in dem Dialog „De voluptate“ hervor. Die Lust soll hier nicht nur als das höchste Gut, sondern als das Gute schlechthin, als das erhaltende Prinzip alles Lebens, und damit als Grundprinzip alles Wertes erwiesen werden. Aber diese Erneuerung des Hedonismus tritt dem Glauben nicht feindlich gegenüber, sondern sie stellt sich unter den Schutz des Glaubens selbst. Das Christentum - so lautet Vallas Grundthese - ist dem Epikureismus nicht feind: ist es doch selbst nichts anders als ein gesteigerter und gleichsam sublimierter Epikureismus. Denn was bedeutet die Seligkeit, die es seinen Anhängern verheißt, anders als die höchste und vollkommenste Form der Lust ?') Wie man schon in diesem Jugendwerk Vallas überall spürt, daß es ihm nicht sowohl um den Erweis der These selbst, als vielmehr um die Freude am Kampf zu tun ist, so gilt das Gleiche für alle seine philosophischen Schriften. Für Valla gilt in vollem Maße das Wort Lessings: das Vergnügen der Jagd ist ihm allezeit mehr wert als der Fang. Eben dies gibt auch seiner Schrift über die Freiheit des Willens ihr literarisches und ihr gedankliches Gepräge. Der Erfolg dieser Schrift und ihre geschichtliche Wirksamkeit, die noch bei Leibniz in voller Stärke hervortritt, war nicht zum mindesten darin gegründet, daß hier ein Problem, das die Scholastik in unendliche Unterfragen, in immer neue dialektische Distinktionen zerlegt hatte, wieder einmal in seiner Ganzheit angegriffen und auf den prägnantesten, auf den stilistisch und gedanklich geschliffensten Ausdruck gebracht wurde. Hier steht der Humanist Valla dem Philosophen zum mindesten gleich. Nur ein Humanist und ein genialer Literat konnte die äußere Form schaffen, in die jetzt das Problem gekleidet wird. Statt den Begriff des göttlichen Vorherwissens und der göttlichen Allmacht zu erörtern und beide dem Begriff der menschlichen Willensfreiheit gegenüberzustellen, geht Valla von einer Verkörperung der Begriffe aus.

tur. At vita ipsorum, inquiunt, ab illa Christi non discrepat. Sane vero, sed ne aliorum quidem, nec enim in solis cucullatis vita Christi custoditur." Vgl. bes. die Schrift "de professione religiosorum“. (ed. Vahlen, Laurentii Vallae opuscula tria, Wien r869, bes. S. I6off.).

I) Vgl. bes. Valla, De voluptate Lib. III, cap. 9 (op. fol. 977) „Beatitudinem quis dubitat aut quis melius possit appellare quam voluptatem ? ... Ex quo debet intelligi non honestatem, sed voluptatem propter seipsam esse expetendam, tam ab is qui in hac vita, quam ab iis qui in futura gaudere volunt." 
Der antike Mythos erhält jetzt eine neue Rolle zugewiesen: er wird zum Vehikel der logischen Denkarbeit. Das göttliche Vorherwissen wird in der Gestalt Apollons, die göttliche Allmacht in der Gestalt Jupiters dargestellt. Beide Potenzen widerstreiten einander nicht: denn das Wissen um ein Künftiges bringt dieses Künftige so wenig hervor, wie das Wissen um ein Gegenwärtiges es erschafft. Die Sicherheit, mit der ein zukünftiges Ereignis vorausgesehen wird, erhält daher in keiner Weise einen Realgrund für sein wirkliches Eintreten. Und somit ist Apollo, der Seher, der dem Sextus Tarquinius seine Freveltat voraussagt, an dieser Tat selbst nicht schuldig. Er darf den Sextus vor das Forum des Jupiter verweisen, der ihm diese Anlage, diese Richtung des Willens gegeben hat. An diesem Punkte bricht freilich Vallas Untersuchung ab. Wie es möglich ist, daß der Mensch als Geschöpf das Ganze seines Seins Gott verdankt, und daß er nichtsdestoweniger mit der Freiheit der Willensentscheidung begabt und kraft dieser Freiheit für seine Taten verantwortlich ist: diese Frage duldet nach Valla keine philosophische Lösung mehr. Hier bleibt nur der Verzicht, nur die Flucht in das Mysterium übrig. ${ }^{1}$ ) Man braucht in diesem Verzicht kein bloses Ausweichen vor gefährlichen theologischen Konsequenzen zu sehen: denn er entspricht dem Ganzen von Vallas Geistesart. Hier wie überall will er keine fertige Lösung geben: er begnügt sich damit, die Frage in ihrer schärfsten Zuspitzung vor uns hinzustellen, um uns sodann mit eben dieser Frage zu entlassen.

Ein völlig anderer Geist herrscht in dem Werk Pomponazzis „De fato, libero arbitrio et praedestinatione." An die Stelle der aphoristischen Behandlung, die das Problem der Willensfreiheit und der Praedestination durch Valla erfahren hatte, begegnet uns hier wieder die echt scholastische Gründlichkeit und Nüchternheit der Analyse. Nur dadurch macht sich der Abstand von der Scholastik fühlbar, daß die Benutzung der Quellen vorsichtiger und kritischer geworden ist. Überall wird der Rückgang auf den ,,reinen“, den quellenmäßigen Aristoteles gefordert: und er, dem Valla ausdrücklich die Gefolgschaft versagt hatte ${ }^{2}$ ), gilt nun wieder als die höchste Autorität des weltlichen Wissens. Aber eine Vereinbarung dieser Autorität, eine Vereinbarung der menschlichen Vernunft, die sich für Pomponazzi in Aristoteles verkörpert, mit dem Glauben wird nicht mehr erwartet. Der Gegensatz zwischen beiden wird nicht nur nicht zu verdecken gesucht; er wird geflissentlich betont und verschärft. Die Lehre von der "doppelten Wahrheit" bleibt so der Weisheit letzter Schluß.

I) S. die Schrift De libero arbitrio, Opera, fol. Ioo4ff.

2) Vgl. bes. Vallas „Dialecticae disputationes“, Opera fol. 645 ff. - bes. charakteristisch auch De libero arbitrio fol. 1004: Antonio: Hic te teneo. An ignoras praeceptum esse philosophorum, quicquid possibile est, id tanquam esse debere concedi? ... Laurentius: Philosophorum mecum formulis agis? quasi eis contradicere non audeam! 
Dabei wird freilich deutlich, daß gegenüber dem Mittelalter die innere geistige und seelische Haltung gegenüber dieser Lehre sich verändert hat. So sehr die dogmatischen Entscheidungen der Kirche anerkannt, so wenig der Begriff der fides implicita angetastet wird, so spürt man doch, - wenn man diese Anerkennung etwa mit der des Occamismus vergleicht - wie sehr der Schwerpunkt sich jetzt zugunsten der „Vernunft" verschoben hat. Man hat Pomponazzi den ,letzten Scholastiker" genannt - aber man kann ihn ebensowohl den ersten Aufklärer nennen. Es ist in der Tat Aufklärung in scholastischem Gewand, was seine Werke durchgehend darbieten. Er führt die Untersuchung überall in Strenge und Nüchternheit, in begrifflicher Reinheit und Präzision durch; er läßt dem Wissen allein das Wort - um dann freilich vor den letzten Ergebnissen und Konsequenzen Halt zu machen. Er läßt die transzendente Welt des Kirchenglaubens stehen - aber er selbst macht kein Hehl daraus, daß er ihrer weder zum Aufbau der Wissenschaft, zum Aufbau der Psychologie und Erkenntnislehre, noch zu dem der Ethik bedarf. Beides ruht für ihn auf eigenem, auf autonomem Grunde: es ist von der Form der Theologie unabhängig geworden. Auch die Schrift über die Willensfreiheit zeigt diese charakteristischen Grundzüge seines Denkens. Wenn Vallas Werk ein Werk der gedanklichen und literarischen Konzentration war, wenn er das Problem auf wenige Seiten zusammenzudrängen sucht, so führt Pomponazzi noch einmal die ganze Reihe der Beweise und Gegenbeweise, der Definitionen und Distinktionen vor uns vorüber. Die Schrift hat die Form eines Kommentars zu der Abhandlung des Alexander von Aphrodisias $\pi \varepsilon p \grave{~}$

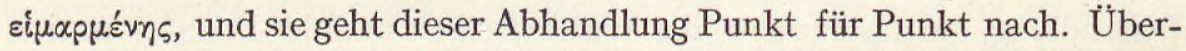
all ist hier ein grübelnder Verstand, eine scharfe Dialektik am Werke, die jeden Satz bis in seine letzten Folgerungen durchzudenken, jedem Argument sein Gegenargument gegenüberzustellen sucht. Pomponazzis eigenes systematisches Urteil bleibt dabei freilich in der Schwebe. Scharf und bestimmt wird nur das eine Moment betont und herausgearbeitet, auf das auch Valla den Nachdruck gelegt hatte: - das göttliche Vorherwissen steht mit der Freiheit der menschlichen Handlungen in keinem notwendigen Widerstreit. Denn wenn Gott die künftigen Handlungen kennt, so kennt er sie doch nicht aus ihren Gründen heraus, was mit der Annahme der Freiheit in der Tat unvereinbar wäre, sondern er kennt sie nach ihrer einfachen Faktizität, nach ihrem bloßen „Daß“. Wenn der Mensch Vergangenes und Gegenwärtiges nach seinem „,Daß“, Zukünftiges dagegen immer nur gemäß seinem Wissen um das ,Warum“ zu erfassen vermag, weil eben die Zukunft ihm nicht unmittelbar gegeben, sondern nur aus ihren Ursachen erschließbar ist: so gilt diese Differenz eines unmittelbaren und mittelbaren, eines gegebenen und erschlossenen Wissens nicht 
für die göttliche Erkenntnis. Denn diese ist eben dadurch charakterisiert, $\mathrm{da} ß$ in ihr die Unterschiede der Zeitform, die für unser Begreifen der Welt wesentlich sind, verschwinden: daß das W issen des Künftigen also keiner Vermittlung, keines diskursiven Durchlaufens der Bedingungen, kraft deren es eintreten wird, bedarf. $\left.{ }^{1}\right)$ Ist damit die Frage der Praeszienz der menschlichen Handlungen ähnlich wie bei Valla entschieden, so hat das andere Problem, das bei diesem stehen blieb, das Problem der Vereinbarkeit der göttlichen Allmacht mit der Freiheit und Selbstverantwortung des Menschen für Pomponazzi viel von seinem Gewicht verloren. Denn so wenig er sich über diesen Punkt unzweideutig zu erklären wagt, so neigt doch sein eigenes Urteil unverkennbar dem strengen Determinismus zu. In seiner naturphilosophischen Schrift ,,de naturalium effectuum admirandorum causis" wird die Kausalität des Geschehens in streng astrologischem Sinne verstanden, wird die Welt der Geschichte, wie die der Natur als notwendiges Ergebnis der Wirksamkeit der Himmelskörper angesehen. Und auch sonst bleibt für Pomponazzi, wo er sich frei ausspricht, das Fatum in seiner stoischen Fassung die relativ-befriedigendste, die der menschlichen Vernunft gemäßeste Lösung. Was die Annahme dieser Lösung erschwert, das sind nach ihm nicht sowohl logische, als vielmehr ethische Widerstände - und eben der Beseitigung dieser Widerstände ist ein wesentlicher Teil seines Werkes gewidmet. Wenn Valla in seiner Schrift ,de voluptate" die Form der religiösen Metaphysik der Form seiner durchaus weltlich gerichteten Ethik anzugleichen bestrebt war, so zerschneidet Pomponazzi mit einem energischen Schnitt das Band, das bisher Metaphysik und Ethik miteinander verknüpft hatte. Beide sind voneinander prinzipiell völlig unabhängig. Wie das Urteil über den Wert des menschlichen Lebens nicht von den Vorstellungen abhängt, die wir uns über seine Fortdauer, über die Unsterblichkeit der menschlichen Seele machen, so gehört auch die Frage nach dem Wert oder Unwert unserer Handlungen einer völlig anderen Betrachtungsweise, als die nach ihrer Verursachung an. Wie immer wir die letztere entscheiden mögen, so bleibt das ethisch-praktische Urteil frei - und diese Freiheit, nicht eine chimärische Ursachlosigkeit ist es, deren wir allein bedürfen. -

Pomponazzis Schrift ist von der Vallas durch einen Zeitraum von mehr als acht Jahrzehnten getrennt: jene ist 1520 abgefaßt, diese scheint gegen 1436 geschrieben zu sein. ${ }^{2}$ ) In eben diese Jahrzehnte fällt die

I) Zum Ganzen s. Pomponazzi's Schrift: De fato, libero arbitrio et de praedestinatione, Basel, ${ }_{5} 67$ f.; bes. Lib. V, S. $9 r_{3}$ ff.

2) Zur Datierung von Vallas Dialog „De libero arbitrio“ vgl. M. von Wolff, Lorenzo Valla, Lpz. 1893 , S. $36 \mathrm{f}$.; Pompona z zi's Traktat ist zum erstenmal Basel 1567 als Anhang der Schrift „De admirandorum effectuum causis“ gedruckt, aber, wie eine Bemerkung am Schluß ergibt, schon ${ }^{5} 520$ vollendet worden. 
Umgestaltung, die das philosophische Denken der Renaissance durch den Platonismus der Florentiner Akademie erfährt. Und nicht nur zeitlich, sondern auch systematisch steht die Lehre der Akademie mitten inne zwischen dem Humanismus und jener Nachblüte der Scholastik, die sich in der Schule von Padua darstellt; zugleich aber macht sich in ihrer Gestaltung durchgehend die tiefe Einwirkung geltend, die der Florentiner Platonismus durch Cusanus erfahren hat. Picos bekannte Rede, die seiner Verteidigung der 900 Thesen in Rom als Einführung dienen sollte, läßt diese geistige Filiation der Gedanken klar erkennen. Wenn Pico das Thema von der "Würde des Menschen“ in den Mittelpunkt stellt, so nimmt er damit zunächst nur bestimmte Motive auf, die schon der ältere Humanismus immer wieder rhetorisch abgewandelt hatte. Schon der Tractat „De dignitate et excellentia hominis“, den Giannozzo Manetti um das Jahr $\mathrm{I}_{452}$ verfaßt hatte, ist nach dem gleichen formalen und gedanklichen Schema gebaut, dem auch Picos Rede folgt. Er stellt der Welt der Natur, als einer Welt des bloß Gewordenen, die geistige Welt des Werdens, die Welt der Kultur gegenüber. In ihr allein ist der Menschengeist heimisch; in ihr erweist er seine Würde und seine Freiheit, „Nostra namque, hoc est humana, sunt, quoniam ab hominibus effecta, quae cernuntur: omnes domus, omnia oppida, omnes urbes, omnia denique orbis terrarum aedificia. Nostrae sunt picturae, nostrae sculpturae, nostrae sunt artes, nostrae scientiae, nostrae ... sapientiae. Nostrae sunt ... omnes adinventiones, nostra omnium diversarum linguarum ac variarum litterarumgenera, dequarum necessariis usibusquanto magismagisque cogitamus, tanto vehementius admirari et obstupescere cogimur" ${ }^{1}$ ) Wenn diese Sätze Manettis im wesentlichen auf antik-stoisches Gedankengut zurückgehen, so tritt in Picos Rede ein neues Element hinzu. Denn seine gesamte Anschauung ist durchdrungen von jener charakteristischen Umwandlung des Mikrokosmos-Motivs, die sich bei Cusanus und nach ihm bei Ficin, vollzogen hatte (s. ob. S. $68 \mathrm{ff}$.). Dadurch erst wächst seine Rede über ein bloßes oratorisches Prunkstück hinaus. Ihr rhetorisches Pathos schließt zugleich ein spezifisch-modernes gedankliches Pathos in sich. Nicht im Sein des Menschen kann seine Würde beruhen - nicht auf der Stelle, die ihm ein für allemal im kosmischen Gefüge angewiesen ist. Wenn das hierarchische System die Welt in Stufen abteilt und jedem Wesen eine dieser Stufen als den ihm zukommenden Platz im Universum zuweist - so faßt gerade diese Grundanschauung den Sinn und das

I) Die Sätze aus Giannozzo Manettis Traktat „De dignitate et excellentia hominis“ (I452) nach der ausführlichen Analyse, die Gentile, Il concetto dell'uomo nel rinascimento (wieder abgedr. in: Giordano Bruno e il pensiero del Rinascimento, S. I I ff.) ron der Schrift Manettis gegeben hat. 
Picos Rede über die „Würde des Menschen“"

Problem der menschlichen Freiheit nicht. Denn dieses liegt in der Umkehr des Verhältnisses, das wir überall sonst zwischen Sein und Wirken anzunehmen pflegen. In der Dingwelt mag der alte scholastische Satz, der Satz: "operari sequitur esse" gelten; die Menschenwelt hat ihre Natur und ihre Eigenart darin, daß in ihr die entgegengesetzte Bestimmung gilt. Nicht das Sein schreibt hier der Art der Gestaltung eine ein für allemal feststehende Richtung vor - sondern die ursprüngliche Richtung der Gestaltung bestimmt und setzt erst das Sein. Das Sein des Menschen folgt aus seinem Tun: und dieses Tun geht nicht lediglich in der Energie des Willens auf, sondern umfaßt die Gesamtheit seiner bildenden Kräfte. Denn jedes echte schöpferische Bilden schließt mehr als ein bloßes Wirken auf die Welt in sich; es setzt voraus, daß das Wirkende sich vom Gewirkten, daß das Subjekt des Tuns sich von seinem Gegenstand unterscheidet und sich ihm mit Bewußtsein entgegensetzt. Und diese Entgegensetzung ist kein einmaliger Prozeß, der mit einem bestimmten Resultat abschließt, sondern sie muß stets aufs neue vollzogen werden. Das Sein des Menschen wie sein Wert hängt von diesem Vollzug $a b,-$ kann demnach immer nur dynamisch, nicht statisch bezeichnet und bestimmt werden. Wir mögen uns in der hierarchischen Stufenleiter der Wesen noch so hoch erheben, wir mögen bis $\mathrm{zu}$ den himmlischen Intelligenzen, ja bis zum göttlichen Ursprung alles Seins aufsteigen: so lange wir bei irgendeiner Sprosse dieser Leiter stehen bleiben, so finden wir in ihr den spezifischen Wert der Freiheit nicht. In dem starren hierarchischen System muß dieser Wert immer als ein Fremdling, als ein Inkommensurables und „Irrationales" erscheinen: denn diese Ordnung des bloßen Seins faßt den Sinn und die Bewegung des reinen Werdens nicht. Mit diesem Gedanken ist, - so sehr Picos Lehre in ihrer Gesamtform durch die aristotelisch-scholastische Tradition einerseits, durch die Neuplatonische Tradition andererseits bestimmt wird - ein neuer Durchbruch erfolgt. Denn jetzt zeigt sich, daß weder die Kategorie der Schöpfung noch die der Emanation hinreicht, um das Verhältnis zu bezeichnen, das zwischen Gott und dem Menschen, wie zwischen dem Menschen und der Welt besteht. Die Schöpfung im gewöhnlichen Sinne kann nicht anders verstanden werden, als daß durch sie dem Geschaffenen nicht nur ein bestimmt-abgegrenztes Sein mitgeteilt, sondern daß ihm zugleich ein bestimmter Umkreis des Wollens und Vollbringens vorgeschrieben wird. Der Mensch jedoch durchbricht jede derartige Schranke: sein Wirken wird ihm nicht durch seine Wirklichkeit schlechthin diktiert, sondern schließt immer neue, über jeden endlichen Kreis prinzipiell hinausgehende Möglichkeiten in sich. Dies ist das Geheimnis seiner Natur, um das ihn nicht nur die niedere Welt, sondern auch die Welt der Intelligenzen be- 
neidet. Denn in ihm allein ist die überall sonst waltende Regel der Schöpfung, ist ihr fester "Typus" aufgehoben. Am Ende der Schöpfung - so schildert es der Mythos, mit dem Picos Rede beginnt - ward in dem Demiurgen der Wunsch rege, ein Wesen zu bilden, das imstande sein sollte, den Grund seines Werkes zu erkennen und es um seiner Schönheit willen zu lieben. „Aber in den ewigen Musterbildern der Dinge war kein Vorbild mehr für einen neuen Sproß, noch besaß der Schöpfer unter seinen Schätzen eine Gabe, die er dem neuen Sohn als Mitgift verleihen konnte, noch ließ sich ein Platz im gesamten Weltkreis ausfindig machen, an dem der Betrachter des Alls seinen Sitz hätte nehmen können. Denn das All war erfüllt und jedem Kreis, dem höchsten sowohl wie dem untersten und dem mittleren, waren Wesen der entsprechenden Ordnung zugeteilt. So beschloß der höchste Meister, daß das Geschöpf, dem er kein besonderes Gut mitgeben konnte, statt dessen all das, womit er jedes Einzelwesen ausgestattet, gemeinsam mit ihnen besitzen sollte. Er formte den Menschen nach einem allgemeinen, keine Sonderungen in sich schließenden Bilde und sprach zu ihm, indem er ihn mitten in die Welt stellte: ,Keinen festen Sitz, keine Dir eigene Gestalt, kein besonderes Erbe haben wir Dir, Adam, gegeben, damit Du welchen Sitz immer, welche Gestalt immer, welche Gaben immer, die Du Dir nach Deinem Wunsch und Deinem Entschluß erwählst, zu eigen haben mögest. Alle anderen Wesen haben eine festbestimmte Natur erhalten und werden von uns unter vorher bestimmten Gesetzen festgehalten. Dich allein bindet keine Schranke, es sei denn, daß Du selber nach Deinem Willen, den ich Dir verliehen, sie Dir vorschreibst. Mitten in die Welt habe ich Dich gestellt, damit Du um so leichter um Dich schauest und sehest alles, was darinnen ist. Ich schuf Dich als ein Wesen, weder himmlisch noch irdisch, weder sterblich noch unsterblich allein, damit Du Dein eigener freier Bildner und Überwindner seiest und jedwede Form, die Du für Dich erwählst, annehmen könnest. Du kannst zum Tier entarten und zum Göttlichen Dich wiedergebären. . . . Die Tiere bringen . . aus dem Mutterleib mit, was sie haben sollen; die höheren Geister sind von Anfang an oder doch bald hernach, was sie in Ewigkeit bleiben werden. Dem Menschen dagegen hat sein Vater bei der Geburt die Samen und Keime jeglichen Lebens mitgegeben. Welche von ihnen er ausbildet, die werden in ihm wachsen und Frucht tragen. Sind es die pflanzlichen Keime, so wird er zur Pflanze, folgt er der Sinnlichkeit, so wird er zum Tier, bildet er das Vermögen der Vernunft in sich aus, so wird er zum himmlischen Lebewesen, folgt er der Intelligenz, so wird er zum Engel und zum Sohn Gottes. " 1 ) Burckhardt

I) Pico Oratio de hominis dignitate Op. fol. 3I4ff. (Die Übersetzung zum Teil in Anlehnung an Burckhardts Übertragung: Kult. der Renaiss. ${ }^{8}$, II 73). Der Gedanke, 
hat die Rede Picos eines der edelsten Vermächtnisse der Kulturepoche der Renaissance genannt - und in der Tat faßt sich in ihr in großartiger Einfachheit und Prägnanz das Ganze ihres Wollens und das Ganze ihres Erkenntnisbegriffs zusammen. Klar treten sich hier die beiden Pole gegenüber, auf deren Gegensatz die sittlich-intellektuelle Spannung beruht, die dem Geist der Renaissance eigentümlich ist. Was vom Willen des Menschen und von seiner Erkenntnis gefordert wird, ist die totale Hinwendung zur Welt und die totale Unterscheidung von ihr. Wille und Erkenntnis dürfen, ja müssen sich jedem Teil des Universums hingeben; denn nur indem er den Gesamtkreis des Alls durchläuft, durchmißt der Mensch den Kreis seiner eigenen Bestimmung. Aber diese volle Aufgeschlossenheit gegen die Welt darf auf der anderen Seite niemals ein Aufgehen in ihr, ein mystisch-pantheistisches Sich-Verlieren, bedeuten. Denn der menschliche Wille besitzt sich nur, indem er sich bewußt wird, daß ihn kein einzelnes Ziel, das menschliche Wissen besitzt sich nur, indem es weiß, daß kein einzelner Inhalt es jemals erfüllen kann. So schließt die Wendung zum Ganzen des Kosmos immer zugleich die Fähigkeit in sich, sich in keinem seiner Teile zu binden. Der Kraft der totalen Hinwendung entspricht die der totalen Rückwendung. Die Dualität zwischen Mensch und Welt, zwischen ,,Geist“ und ,Natur“" wird streng festgehalten - und doch ist andererseits diese Dualität nicht bis zu einem absoluten Dualismus von scholastisch-mittelalterlichem Gepräge weitergeführt. Denn die Polarität ist nicht absolute, sondern relative Gegensätzlichkeit: der Unterschied der beiden Pole ist nur dadurch möglich und nur dadurch faßbar, daß er zugleich eine wechselseitige Beziehung zwischen ihnen in sich schließt. Hier haben wir eine der Grundkonzeptionen des Florentiner Platonismus vor uns, die durch andere entgegengesetzte Gedankenbestimmungen, durch den Zug zur ,Transzendenz“ und zur Askese, der sich in ihm allmählich immer stärker geltend machte, nie völlig überwunden oder ausgelöscht werden konnte. So stark Ficin und Pico überall sonst unter dem Einfluß neuplatonischer Motive stehen: hier bricht der echt-Platonische Grundsinn der Begriffe des ,Chorismos“ und der ,Methexis“ wieder durch. Die „Transzendenz“ selbst ist es, die die "Teilhabe", die „Teilhabe“ ist es, die die ,Transzendenz" setzt und fordert. Diese Wechselbestimmung mag, objektiv betrachtet, noch so rätselhaft und noch so paradox erscheinen: sie erweist sich sofort als notwendig und als einsichtig klar, sofern wir von der Natur des Ich, des

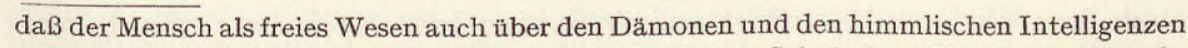
stehe, stammt aus hermetischer Tradition, die in der Schule von Florenz stark nachwirkt: Marsilius Ficinus hat das alte Corpus der hermetischen Schriften ins Lateinische übersetzt. Näheres über diesen Zusammenhang bei Konrad Burdach im Kommentar zum Ackermann aus Böhmen. (Vom Mittelalter zur Reformation III, I, S. 293 ff., 325 ff.). 
wollenden und erkennenden Subjekts ausgehen. In dem freien Akt des Willens und im freien A kt des Wissens knüpft sich unmittelbar zusammen, was sich im bloßen Dasein ewig zu fliehen scheint. Denn diesem Akt eignet zugleich die Kraft der Sonderung, wie die der Vereinigung: er allein vermag die Unterscheidung bis zur höchsten Schärfe zu bringen, ohne damit das Unterschiedene in eine absolute Trennung auseinanderfallen $\mathrm{zu}$ lassen. -

Und wenn hier die Beziehung des Ich auf die Welt, des Subjekts auf das Objekt echt Cusanisch wieder als eine "coincidentia oppositorum" gefaßt wird: so tritt dieser Zusammenhang noch deutlicher hervor, wenn wir die geschlichtliche Weiterwirkung der Gedankenmotive verfolgen, die Pico in seiner Rede über die „Würde des Menschen" angeschlagen hatte. Schon in Picos Rede selbst hören wir deutlich den Nachklang der Cusanischen Spekulation. „Humanitatis unitas - so heißt es in der Schrift „De conjecturis“ - cum humaniter contracta existat, omnia secundum hanc contractionis naturam complicare videtur. Ambit enim virtus unitatis ejus universa atque ipsa intra suae regionis terminos adeo coercet, ut nihil omnium ejus aufugiat potentiam. ... Homo enim Deus est, sed non absolute, quoniam homo. Humanus est igitur Deus. Homo etiam mundus est, sed non contracte omnia, quoniam homo. Est igitur Homo $\mu \iota x \rho o ́ x о \sigma \mu о \varsigma$ aut humanus quidem mundus. Regio igitur ipsa humanitatis Deum atque universum mundum humanali sua potentia ambit. Potest igitur homo esse humanus Deus atque Deus humaniter, potest esse humanus angelus, humana bestia, humanus leo aut ursus, aut aliud quodcumque. Intra enim humanitatis potentiam omnia suo existunt modo. In humanitate igitur omnia humaniter, uti in ipso universo universaliter, explicata sunt, quoniam humanus existit mundus. Omnia denique in ipsa complicata sunt humaniter, quoniam humanus est Deus. Nam humanitas unitas est, quae est et infinitas humaniter contracta... Non ergo activae creationis humanitatis alius extat finis quam humanitas. Non enim pergit extra se dum creat, sed dum ejus explicat virtutem ad se ipsam pertingit nequequicquam novi efficit, sed cuncta quae explicando creat, in ipsa fuisse comperit."1) Auf diese fundamentalen Sätze mußte der Humanismus überall zurückgreifen, wo er über eine bloße Gelehrtenbewegung hinauswuchs, wo er sich eine philosophische Form und eine philosophische Begründung zu geben suchte. So finden wir denn auch ihre Wirksamkeit nicht auf einen einzelnen Kreis beschränkt, sondern über die nationalen Grenzen und über die Grenzen der philosophischen Schulen hinausgehend. Sie sind der Anfangspunkt einer geistigen

I) Cusanus, De conjecturis II, I4 (vgl. ob. S. 45). 
Bewegung, die von Italien nach Frankreich, von dem philosophischen Humanismus Platonischer Prägung auf den Aristotelischer Prägung übergreift. Hier tritt für uns nicht nur der sachlich-systematische Zusammenhang der Gedanken deutlich hervor, sondern es lassen sich auch die einzelnen geschichtlichen Fäden klar voneinander sondern. Denn Jakob Faber Stapulensis, der der eigentliche Erneuerer der Aristotelischen Studien und der Schöpfer der "Aristotelischen Renaissance" in Frankreich ist, ist zugleich der Herausgeber der ersten Gesamtausgabe der Werke des Nikolaus Cusanus. Und wie von Cusanus, den er überall mit größter Bewunderung und Verehrung nennt, hat er auch von der Platonischen Akademie in Florenz entscheidende Anregungen erhalten. ${ }^{1}$ ) So vereint sich denn auch beides in dem Werk seines Schülers Carolus Bovillus (Charles de Bouelles), das die unmittelbare Weiterbildung und die systematische Durchführung des Grundgedankens von Picos Rede bildet. $^{2}$ ) Dieses Werk - die Schrift „De sapiente“ vom Jahre I509ist vielleicht die merkwürdigste und in mancher Hinsicht charakteristischste Schöpfung der Renaissance-Philosophie. Denn wohl nirgends sonst findet sich Altes und Neues, findet sich Überlebtes und Zeugungskräftiges auf so engem Raume nebeneinander, wie es hier der Fall ist. Noch herrscht fast ungezügelt jener Grundtrieb des mittelalterlichen Denkens, der das Ganze des Kosmos, das Ganze der physischen wie der geistigen Welt, mit einem dichten Gewebe von Analogien zu überspinnen und in dem Netzwerk dieser Analogien einzufangen sucht. Ein und dasselbe immer wiederholte Grundschema ist es, das uns die Ordnung des Mikrokosmos und des Makrokosmos, die Ordnung der Elemente und Naturkräfte wie

I) Daß die Lehren der Platonischen Akademie schon frühzeitig in Frankreich, besonders an der Pariser Universität, Eingang gefunden haben, zeigt ein Brief Gaguins an Ficin vom I. September I496. „Virtus et sapientia tua, Ficine, - so heißt es hier tanta in nostra Academia Parisiensi circumfertur, ut cum in doctissimorum virorum collegiis, tum in classibus etiam puerorum tuum nomen ametur atque celebretur." (Rob. Gaguini Epistolae et Orationes, ed. Thuasne, Paris I903/4 II, 20f.); cit. nach P. Mestwerdt, Die Anfänge des Erasmus, S. 165. - Über die Wirkung des Florentiner Platonismus auf die philosophische Entwicklung des Faber Stapulensis vgl. bes. A. Renaudet Préréforme et Humanisme à Paris pendant les premières guerres d'Italie (1494-1 ${ }_{5} \mathrm{I}_{7}$ ), Paris 1916 , S. $138 \mathrm{ff}$. u. ö.

2) Wie nahe die Schrift des Bovillus ihrem Thema nach dem Thema von Picos Rede ,De hominis dignitate" steht, zeigt z. B. eine Stelle, wie Cap. XXIV: „Hominis nichil est peculiare aut proprium, sed ejus omnia sunt communia, quecunque aliorum propria. Quicquid hujus et hujus, illius et alterius et ita singulorum est proprium, unius est hominis. Omnium enim in se naturam transfert, cuncta speculatur, universam naturam imitatur. Sorbens enim hauriensque quicquid est in rerum natura, omnia fit. Nam neque peculiare ens homo est, hoc vel hoc, neque ipsius est hec aut hec natura, sed simul omnia est." (Die Schrift De sapiente ist ${ }_{5} 09$ verfaßt und im Jahre ${ }_{5}$ Io, zugleich mit anderen Werken des Bovillus, in Paris erschienen. Näheres über diese Ausgabe und über die Grundlagen von Bovillus' Erkenntnislehre, auf die hier nicht eingegangen werden konnte, s. Erkenntnisproblem ${ }^{3}, \mathrm{I}, 66 \mathrm{ff}$.). 
die der sittlichen Kräfte, die logische Welt der Syllogismen und die metaphysische der realen Gründe und Folgen enträtseln und aufschließen soll. Aber mitten in diese schematisch-allegorische Darstellung des Weltganzen sind nun Gedanken von so echt spekulativem Gehalt und von so eigenartig neuer Prägung verwoben, daß man bisweilen unmittelbar an die großen Systeme des modernen philosophischen Idealismus, an Leibniz oder Hegel gemahnt wird. Der Aufbau der Welt vollzieht sich nach Bovillus in vier voneinander verschiedenen Stufen, die gleichsam den Weg vom „Objekt" zum ,,Subjekt", den Weg vom bloßen „Sein“" zum „Selbstbewußtsein“ darstellen. Das Sein als das abstrakteste Element, ist allen Wesen gemeinsam; das Selbstbewußtsein, als das konkreteste und entwickeltste, kommt nur dem höchsten Geschöpf, dem Menschen zu. Und zwischen diesen beiden äußersten Polen steht die Natur als Vorstufe und als Potenz des Geistes. Sie verkörpert in sich die verschiedenartigen Formen des Lebens, aber sie führt nur bis an die Schwelle der Vernunft, des reflexiven, auf sich selbst bezogenen Wissens heran. Esse, Vivere, Sentire, Intelligere: das sind demnach die verschiedenen Stadien, die das Sein durchläuft, um zu sich selbst, zu seinem eigenen Begriff zu gelangen. Die unterste dieser Stufen, die Existenz als solche, eignet jedem Daseienden: dem Stein sowohl wie der Pflanze, dem Tier sowohl wie dem Menschen. Aber über diesem Fundament der bloßen Substantialität erheben sich nun die verschledenen Ordnungen des subjektiven Lebens. ${ }^{1}$ ) Bovillus antizipiert hier geradezu die Hegelsche Formel, nach der Sinn und Ziel des geistigen Entwicklungsprozesses darin besteht, daß die ,,Substanz" zum ,,Subjekt" wird. Die Vernunft im Menschen ist diejenige Kraft, durch welche die „Mutter Natur“ in sich zurückkehrt, durch die sie ihren Kreislauf vollendet und sich selbst zurückgegeben wird. ${ }^{2}$ ) Aber sie findet sich nach dieser Rückkehr nicht mehr in derselben Gestalt vor, von der sie ausgegangen war. Nachdem einmal die erste Trennung im Menschen gesetzt, nachdem er aus der Einfachheit seines ursprünglichen Zustandes herausgetreten ist, kann er zu dieser ungebrochenen Einfachheit nicht wieder zurückgehen. Er muß durch den Gegensatz hindurch, um über ihn hinwegschreitend die wahrhafte Einheit seines Wesens zu finden; jene Einheit, die die Differenz nicht ausschließt, sondern setzt und fordert. Denn dem einfachen Sein als solchem wohnt

I) S. "de sapiente" Cap. I und 2.

2) ,Fit iterum ut rite diffiniri a nobis possit ipsa ratio adulta esse et consumata nature filia, sive altera quedam natura prime nature speculatrix et que ad prioris nature imitationem omnia in semetipsa effingit cunctaque sapienter (vires supplens matris) moderatur. Rationem quoque eam vim diffinimus, qua mater natura in seipsam redit, qua totius nature circulus absolvitur quave natura sibi ipsi restituitur." De sapiente, cap. V. 
keine Kraft inne: es wird erst wahrhaft fruchtbar, wo es sich in sich selbst entzweit und sich aus dieser Entzweiung in seiner Einheit wiederherstellt. ${ }^{1}$ ) In der Durchführung und im Ausdruck dieses Gedankens folgt Bovillus ersichtlich der spekulativen Deutung der Trinitätslehre, die Cusanus gegeben hatte. Wie dieser legt er allen Nachdruck darauf, daß die wahrhafte Drei-Einheit nicht statisch, sondern dynamisch zu verstehen sei $\mathrm{da} ß$ sie nicht als das Nebeneinander dreier "Naturen" in einer an sich einfachen Substanz, sondern als die kontinuierliche Einheit einer Entwicklung zu fassen sei, die von der bloßen ,,Möglichkeit“ zur ,Wirklichkeit“, von der ,,Potenz" zur vollen und vollständigen ,Aktuierung" führt. Indem diese Grundauffassung von Gott auf den Menschen übertragen wird, ergibt sich, daß die wahrhafte Wirklichkeit des Menschen nur dort besteht, wo er die einzelnen Stadien dieses Prozesses durchlaufen hat. In diesem Werden allein vermag er sein spezifisches Sein zu erreichen und $\mathrm{zu}$ verstehen. Was wir „Weisheit" nennen, das ist daher seinem eigentlichen Begriff nach nicht ein Wissen von äußeren Gegenständen, sondern ein Wissen von unserem eigenen Selbst: nicht die Natur, sondern die humanitas bildet ihr eigentliches Objekt. Der Weise ist derjenige, der die Gegensätze, die im Wesen des Menschen beschlossen liegen, durchmessen, der sie erkannt und der sie damit überwunden hat. Er ist homo in potentia und homo in actu, homo ex principio und homo ex fine, homo existens und homo apparens, homo inchoatus und homo perfectus, homo a natura und homo ab intellectu. ${ }^{2}$ ) Und in dieser Definition der Weisheit ist für Bovillus zugleich die Formulierung und die Lösung des Freiheitsproblems enthalten. Denn Freiheit bedeutet für ihn nichts anderes, als daß der Mensch sein Sein nicht, gleich dem der übrigen Wesen, fertig von der Natur erhält und es gleichsam von ihr dauernd zu Lehen trägt, sondern daß er es sich erwerben, daß er es durch virtus und ars gestalten muß. Von der größeren oder geringeren Kraft zu dieser Gestaltung hängt sein Selbstwert ab. Hier gliedert sich daher dem System der spekulativen Metaphysik bei Bovillus ein vollständiges System der Ethik ein, das auf den gleichen Grundlagen wie dieses beruht. Wie das Sein sich in das Esse, Vivere, Sentive und Intelligere abstuft, so kann der Mensch nach freier Wahl entweder das Ganze dieser Stufenreihe durchmessen, oder aber auf einer einzelnen Stufe verharren und stehen bleiben. Er kann,

I) „Natura sapienti simplex esse condonavit. Ipse vero sibi ipsi compositum esse: hoc est bene beateque esse progenuit ... Accepit enim sapiens a natura substantialis munus hominis, ex cujus fecunditate studiosum hominem parturivit. Insipiens vero parem quoque ac substantialem hominem mutavit a natura, sed nullo virtutis fenore splendescit. Hic igitur homo rite habere et non habere, ille vero habere et habere predicatur." (De sap. Cap. VI u. VII.)

2) De sapiente, Cap. VI. 
wenn er dem Laster der Trägheit, der mittelalterlichen ,,acedia“, verfällt, bis zu der Stufe herabsinken, auf der ihm nur noch das nackte Dasein ohne eine Form und somit ohne ein Bew $\mathrm{B}$ ts ein dieses Daseins bleibt er kann bis zur höchsten sich erheben, auf der er durch das Medium der eigenen Selbsterkenntnis die Erkenntnis des Kosmos gewinnt. ${ }^{1}$ ) Denn das eine ist nur durch das andere erreichbar. Selbsterkenntnis und Welterkenntnis sind nur scheinbar voneinander unterschiedene und einander entgegengerichtete Prozesse. In Wahrheit findet das Ich sich selbst nur, indem es sich der Welt hingibt, indem es sie vollständig in sich hineinzuziehen und sie in der Gesamtheit ihrer Formen, ihrer ,,Species" nachzubilden strebt. Aber diese Nachbildung, die eine bloß passive Leistung, eine Funktion des Gedächtnisses zu sein scheint, enthält in Wahrheit schon alle Kräfte des Intellekts, der denkenden Betrachtung und Reflexion in sich. So wird der ",major mundus", indem er in den ,,minor mundu s“ eingeht, in ihm erst in seiner Wahrheit erfaßt. Die Welt enthält die Gesamtheit der Dinge, aber der Mensch erst weiß diese Gesamtheit; sie umfaßt den Menschen als einen Teil, aber er begreift sie in ihrem Prinzip. So kann er, verglichen mit der Welt, das Größte wie das Kleinste genannt werden: das Kleinste, wenn wir mit dem Maßstabe der Substanz, das Größte, wenn wir mit dem des Wissens messen. „Mundus maxima substantia, scientia nullus. Homo scienta amplissimus, substantia pusillus. Uterque stat in utroque; uterque utriusque capax. Hominis enim substantia versatur in mundo, mundi vero scientia in homine. Mundus substantialis mundus est, homo rationalis mundus. Quanta in mundo substantiarum discretio quantaque rerum differitas, tantum in homine rationum discrimen. In utroque sunt omnia, in quolibet quodlibet et in utroque nihil. In homine substantia nulla: in mundo ratio itidem et conceptio nulla. Vacuus uterque est et plenus uterque. Inops rerum homo: rationum dives est. Mundus vero rerum plenus, inanis rationum“ “. $\left.{ }^{2}\right)$ Deutlicher kann der Gegensatz der „Substantialität“ und der ,,Subjektivität", des ,An-Sich-Seins" und des ,,FürSich-Seins" kaum ausgesprochen werden. ${ }^{3}$ ) Und wie Hegel so fordert
I) Ibid, Cap. I u. II.
2) Ibid. Cap. XIX.

3) Vgl, noch Cap. XXIV: „In omni quippe mundana substantia: aliquid delitescit humanum, aliqua cuivis substantie indita est hominis atomus, homini propria, qua componendus est et conflandus studiosus homo, quam sibi vendicare et ingenii vi abstrahere a materia natus est homo... Qui igitur conflatus est et perfectus a natura homo, (homo, inquam, noster situs in mundi medio) matris imperio per mundum (circumferri iussus): exquirit a singulis que sua sunt, abstrahit a qualibet mundi substantia proprie speciei atomum. Illam sibi vendicat atque inserit et ex plurium specierum atomis suam elicit profertque speciem, que naturalis et primi nostri hominis fructus seu acquisitus studiosusve homo nuncupatur. Hec itaque hominis est consumatio: cum ad hunc modum ex substantiali scilicet homine rationalem, ex naturali acquisitum et ex sim. plici compositum, perfectum, studiosum." 
Bovillus, daß auch dieser Gegensatz noch in einer höchsten spekulativen Synthese überschritten wird. Der Mensch der „Natur“, der homo schlechthin muß zum Menschen der ,Kunst“, zum homo-homo werden; aber indem diese Differenz in ihrer Notwendigkeit erkannt ist, ist sie damit auch schon überwunden. Über den beiden ersten Gestaltungen erhebt sich jetzt die letzte und höchste; die Dreieinheit des homo-homo-homo, in der der Gegensatz von Potenz und Akt, von Natur und Freiheit, von Sein und Bewußtsein, zugleich befaßt und aufgehoben ist. ${ }^{1}$ ) In ihr erscheint der Mensch nicht mehr als Teil des Alls, sondern als dessen Auge und Spiegel: und zwar als ein Spiegel, der die Bilder der Dinge nicht von außen empfängt, sondern der sie vielmehr in sich selbst formt und bildet. ${ }^{2}$ )

I) De sap. Cap. XXII ,Manifestum ... est sapientiam esse quendam hominis numerum, discrimen, fecunditatem, emanationem eamque consistere in hom in is dyade, genita ex priore monade. Primus enim nativus noster et sensibilis homo ipsiusque nature mutuum monas est et totius humane fecunditatis fons atque initium. Artis vero homo, humanave species arte progenita, dyas est et primi quedam hominis emanatio, sapientia, fructus et finis. Cuius habitu qui a natura homo tantum erat, artis fenore et uberrimo proventu reduplicatus homo vocatur et homohomo. Et non modo ad dyadem, sed et ad usque tryadem humane sapientie vis hominis numerum extendit humanitatemque propagat. Sine quippe medio extrema sunt nulla; sine propinquitate nulla distantia; sine concordia dissociatio nulla et sine concurrentia nulla disparata. Sunt autem monas et dyas, Natura item et ars quedam extrema. Similiter et nature homo et artis homo, seu substantialis homo et vera ejus imago virtute progenita; nature mutuum sive naturale donum et hominis acquisitum. Horum igitur extremorum symplegma est aliquod, concordia et concurrentia aliqua. Aliquis amor, pax, vinculum: et medium aliquod amborum, proventus, unio, fructus, emanatio. Juncta etenim invicem monas et dyas tryadem eliciunt proferuntque, suam copulam, unionem et concordiam. Itaque sapientia quedam est trina hominis sumptio, hominis trinitas, humanitas tryas. Est enim trinitas totius perfectionis emula, cum sine trinitate nulla reperiatur perfectio."

2) „Homo nichil est omnium et a natura extra omnia factus et creatus est, ut multividus fiat sitque omnium expressio et naturale speculum abjunctum et separatum ab universorum ordine: eminus et e regione omnium collocatum, ut omnium centrum. Speculi etenim natura est, ut adversum et oppositum sit ei, cujus in sese ferre debet imaginem. ... Et in quocunque loco cuncta mundi statueris entia: in ejus opposito abs te collocandus et recipiendus est homo, ut sit universorum speculum. ... Verus igitur et speculi et hominis locus est in oppositione, extremitate, distantia et negatione universorum, ubi inquam omnia non sunt, ubi nichil actu est. Extra omnia, in quo tamen fieri omnia nata sunt. ... Nam consumatis et perfectis omnibus, postquam actus singuli sua loca sortiti sunt, vidit Deus deesse omnium speculatorem et universorum oculum.... Viditque nullum supremo huic oculo inter cetera superesse locum. Plena quippe actuum erant omnia; quodlibet suo gradu, loco et ordine constiterat. Et ex actibus diversis disparatisque speciebus aut rerum differentiis et mundi luminaribus (que per se intermisceri, confundi, concurrere et fas et possibile non est) fieri homo haudquaquam poterat. Extra igitur cunctorum differentias et proprietates in opposito omnium loco, in conflage mundi, in omnium medio coaluit homo: tanquam publica creatura, que quod relictum erat in natura vacuum potentiis, umbris, speciebus, imaginibus et rationibus supplevit." (de sap. Cap. 26). Diese Sätze sind geschichtlich von besonderer Bedeutung, weil sie den charakteristischen .,Umschlag" zeigen, den das Mikrokosmos-Motiv innerhalb der Philosophie der Renaissance erfährt, Bei Bovillus sowohl, wie bei Pico und Cusanus, schlieBt dieses Motiv nicht nur die Einheit von Mensch und Welt in sich; sondern in eben dieser Einsicht selbst, in der 
Es entspricht der Wesensart der Renaissancephilosophie, daß sie sich nicht mit dem abstrakten Ausdruck dieser Gedanken begnügt, sondern daß sie für sie einen bildhaft-symbolischen Ausdruck sucht. Wie von selbst bietet sich hierfür der antike Prometheus-Mythos dar, der nunmehr eine Art Auferstehung und geistige Neubelebung erfährt. Das Prometheus-Motiv gehört $\mathrm{zu}$ jenen mythischen Urmotiven, an die schon die antike Philosophie immer wieder angeknüpft hatte. An seiner allegorischen Auslegung hatte sich Platon im Protagoras, hatte sich Plotin und der Neuplatonismus versucht. Jetzt begegnet dieses Motiv dem christlichen Adam-Motiv, um entweder mit ihm zu verschmelzen oder um sich mit ihm auseinanderzusetzen und es kraft des Gegensatzes, in den es $\mathrm{zu}$ ihm tritt, innerlich umzuformen. Burdach hat den Weg und die Entwicklung des Adam-Motivs im einzelnen verfolgt und gezeigt, wie fruchtbar und treibkräftig sich dasselbe in der Zeit des Übergangs vom Mittelalter zur Renaissance erwiesen hat. Die Gestalt des Urmenschen, wie ihn die kirchliche Anschauung nach biblischer Darstellung geformt hatte, gewinnt jetzt unter Mitwirkung Platonisch-Augustinischer und Neuplatonisch-hermetischer Gedanken eine neue Bedeutung. Indem der Urmensch zum Ausdruck des geistigen Menschen, des ,homo spiritualis" wird, fassen sich in seine Gestalt alle geistigen Tendenzen der Epoche zusammen, die auf eine Erneuerung und Wiedergeburt, auf eine Regeneration des Menschen gerichtet sind. ${ }^{1}$ ) Diese Wendung prägt sich in der englischen Literatur in William Langlands Gedicht „Piers the Plowman", in der deutschen in dem Dialog zwischen dem Ackermann und dem Tod aus, den Johannes von Saaz um I40o verfaßt hat. Dieser Dialog, den Burdach das größte dichterische Kunstwerk der ganzen Epoche in Deutschland genannt hat, läßt schon in seiner Gestaltungskraft und in seiner gewaltigen Sprachkraft die neuen ideellen Mächte erkennen, die jetzt zur Aussprache drängen. Es ist Dichtung, nicht Lehre, die wir hier vor uns haben - aber eine Dichtung, die ganz beseelt und durchdrungen ist von dem Hauch eines neuen Gedankens. Und dieser steht hier ohne alle Verquickung mit scholastischem Beiwerk gleichsam im freien Raum des Denkens vor uns. Es ist nicht die abstrakte philosophische Betrachtung, die die Probleme aufwirft und fortspinnt, sondern es ist das Leben selbst, das sich die ewige Frage nach seinem Ursprung und nach seinem Wert stellt. So wandeln sich alle Gegensätze aus bloß dialek-

Korrelation, wird jetzt das Moment des Gegensatzes, die Polarität von ",Subjekt“ und "Objekt" betont. Damit stehen wir unmittelbar an der Schwelle der Leibnizischen Monadenlehre: denn auch die Monade muß sich, ihrer Natur und Wesenheit nach, vom Universum der Phaenomene abscheiden, um eben dieses Universum vollständig ausdrücken, um zum ,lebendigen Spiegel“ desselben werden zu können.

I) Vgl. Burdach, Reformation, Renaissance, Humanismus, S. I 7 Iff. 
tischen in dramatische Gegensätze um. Nur diese Gegensätze selbst, nicht ihre Lösung, stellt der Dialog vor uns hin. In dem Streit zwischen dem Ackermann und dem Tod, zwischen der Schicksalsmacht der Vernichtung und dem Geist des Menschen, der sich gegen diese Macht auflehnt, kommt es scheinbar zu keiner Entscheidung. Das Urteil Gottes, mit dem der Dialog schließt, spricht dem Tod den Sieg, aber dem Kläger, dem Ackermann, die Ehre des Streites zu. „Der krieg ist nicht gar one sache: ir habt beide wol gefochten; den twinget leit zu clagen, disen die Anfechtung des clagers die warheit zu sagen. Darumb, clager, habe ere! Tot, sige!"‘1) Und doch ist dieser Sieg des Todes zugleich seine Niederlage: denn wenn jetzt seine physische Gewalt bestätigt und besiegelt wird, so ist zugleich seine geistige Macht gebrochen. Die Vernichtung des Lebens, der Umstand, daß Gott es dem Tode preisgibt, bedeutet nicht länger die Nichtigkeit dieses Lebens. Denn wenn es in seinem Sein zerstört wird, so bleibt ihm doch ein unzerstörlicher Wert: der Wert, den der freie Mensch sich selber und der Welt gibt. In diesem Glauben der Menschheit an sich selbst liegt die Gewähr ihrer Wiedergeburt. Die allegorische Form der Dichtung wirkt nur wie ein leichter Schle er, durch den hindurch wir diese große Linie der künstlerischen Gestaltung und der Gedankenführung klar und scharf erblicken. Und in ihr erkennen wir d utlich die Grundanschauung der kommenden Renaissance. Mit Recht findet Burdach in der großen Anklagerede des Landmanns gegen den Tod, in dieser Rede, die den Menschen als die vollkommenste und herrlichste, weil als die freieste Schöpfung Gottes preist, den Geist wieder, der sich mehr als zwei Menschenalter später in Picos Rede über die Würde des Menschen ausspricht. ,Engel, teufel, schretlein, clagemuter, das sint geiste in gotes twangwesen: der mensche ist das aller achtberest, das aller behendest und das aller freieste gotes werkstuck. "2) Und wenn weiter als der charakteristische Grundzug dieser Anklagerede hervorgehoben wird, daß sie die pessimistischen Züge des christlichen Dogmas entschlossen beiseite schiebt, daß sie in ihrem unerschütterlichen Glauben an die Eigenkräfte des Menschen und an seine gottgewollte gute Natur, ein pelagianisches Element in sich schlie $\left.\beta t:^{3}\right)$ so hat sie auch damit eine Anschauung antizipiert, die sich kurz darauf in der deutschen Philosophie ihren begrifflichen Ausdruck und ihre begriffliche Rechtfertigung gegeben hat. Wie hier der Dichter des Ackermanns aus Böhmen die durch Adams Fall verschuldete, durch den göttlichen Fluch deklarierte, auf das gesamte Menschengeschlecht

I) Der Ackermann aus Böhmen, hg. von Bernt und Burdach, Berlin I9r7. (Vom Mittelalter zur Reformation. Forschungen zur Gesch. der deutschen Bildung III, I) Cap. XXXIII (S. 85)

2) Ackermann aus Böhmen, Cap. XXV, S. 58 ; vgl. Burdachs Commentar S. 323 .

3) Burdach, a.a. O., S. 3I5. 
mit jeder neuen Zeugung sich neu vererbende Verderbnis der Menschennatur ignoriert: so wird bald nachher, und fast mit den gleichen Worten, Nikolaus von Kues sich gegen diese Lehre erklären. „Omnis vis illa quae se esse cognoscit ab optimo, optime se esse cognoscit. Omne id, quod est, quiescit in specifica natura sua, ut in optima ab optimo. Datum igitur naturale qualecumque in omni eo quod est, est optimum ...de sursum igitur est ab omnipotentia infinita." 1 )

Und damit stehen wir an dem Punkt, an dem das AdamMotiv jene innere Umwandlung erfährt, durch welche es fähig wird, unmittelbar in das Prometheus-Motiv überzugehen. Es bedarf, um diesen Übergang zu vollziehen, keiner Veränderung im Inhalt des Gedankens; es genügt eine leichte Verschiebung des Accents. Der Mensch ist Geschöpf, - aber was ihn vor allen anderen Geschöpfen bezeichnet, ist, daß ihm von seinem Urheber die Gabe der Schöpfung selbst mitgegeben worden ist. Er erreicht seine Bestimmung, er vollendet sein Sein erst, indem er diese seine Grund- und Urkraft betätigt. Der Mythos vom menschenbildenden Künstler Prometheus war auch dem mittelalterlichen Denken nahe geblieben: er kehrt bei Tertullian, bei Lac$\tan z$ und bei Augustin wieder. Aber die mittelalterliche Anschauung ergreift in diesem Mythos im wesentlichen den negativen Zug: sie sieht in ihm nur die heidnische Travestie des biblischen Schöpfungsmotivs, das sie, dieser Verkehrung gegenüber, wieder in aller Strenge aufzurichten sucht. Der wahre Prometheus, - der, den der christliche Glaube allein kennen und zulassen darf - ist nicht der Mensch, sondern der einzige Gott: „Deus unicus qui universa condidit, qui hominem de humo struxit, hic est verus Prometheus."2) Demgegenüber bedeutet es schon einen Wechsel der Grundstimmung, wenn Boccaccio in der euhemeristischen Deutung der Prometheus-Sage, die seine ,Genealogia deorum“ gibt, eine zweifache Schöpfung unterscheidet: die eine, durch die der Mensch ins Dasein gerufen worden ist, die andere, durch die diesem Dasein erst ein geistiger Gehalt verliehen wurde. Der rohe und unwissende Mensch, der aus den Händen der Natur hervorging, konnte seine Vollendung nicht anders als durch einen neuen Schöpfungsakt erhalten: wenn der erste ihm seine physische Wirklichkeit gab, so hat ihm erst der zweite seine spezifische Form gegeben. Prometheus ist hier ein menschlicher

I) Cusanus, De dato patris luminum, Cap. I (Op. fol. 284 f.); vgl. ob. S. 45 , Anm. 4.

2) Zur Gestaltung des Prometheus-Motivs im Mittelalter, insbesondere bei Lactanz (Divin. Institut. II, II) und bei Tertullian (Apolog. I8; Adv. Marc., I, I) vgl. die näheren Nachweise bei J. Toutain, Artikel: Prometheus in Daremberg-Saglio, Dictionnaire des antiquités IV, 684. Für die Wiederaufnahme des Motivs in der bilden den Kunst der Renaissance s. Georg Habich, Über 2 Prometheus-Bilder angeblich von Piero di Cosimo, Sitzungsber. d. Bayer. Akad. d. Wiss.: Philos.-philol. Klasse, I920. 
Kulturheros, der Bringer des Wissens und der staatlich-sittlichen Ordnung, der kraft dieser Gaben die Menschen im eigentlichen Sinne ",reformiert" , d. h. ihnen eine neue Form und Wesenheit aufgeprägt hat. ${ }^{1}$ ) Aber auch über diese Fassung des Motivs wächst nun die RenaissancePhilosophie mehr und mehr hinaus, indem sie die Formgebung immer entschiedener in die Aktivität des einzelnen Subjekts verlegt. Jetzt stellt sich neben die Tätigkeit des Schöpfers und die des Heilbringers die des Individuums selbst. Selbst in die Gedankenwelt des „,christlichen Platonismus" dringt diese Grundansicht ein: selbst bei Ficin bricht zuweilen dieser heroische Individualismus durch. Auch für ihn ist der Mensch kein Sklave der schaffenden Natur, sondern ihr Nebenbuhler, der ihre Werke vollendet, verbessert und läutert: „humanae artes fabricant per se ipsas quaecumque fabricat ipsa natura, quasi non servi simus naturae, sed aemuli."2) Wir sahen, wie dieser Gedanke sich sodann bei Bovillus verschärft und potenziert. Und auch er greift jetzt in der Darstellung der Schrift „De sapiente“ auf die Prometheus-Sage zurück. Sie erfährt dabei jene Deutung und Umbildung, die der Naturphilosophie des Bovillus und seiner Metaphysik entspricht. Wenn diese Metaphysik sich vierfach gliedert, wenn sie alles Sein in die Grundordnungen des Esse, Vivere, Sentire und Intelligere aufteilt, so entspricht in dem Analogienspiel, von dem

I) Boccaccio, De genealogia Deorum, Lib. IV, cap. IV. „Verum qui natura producti sunt rudes et ignari veniunt, immo ni instruantur, lutei agrestes et beluae. Circa quos secundus Prometheus insurgit, id est doctus homo et eos tanquam lapideos suscipiens quasi de novo creat, docet et instruit et demonstrationibus suis ex naturalibus hominibus civiles facit moribus, scientia et virtute insignes, adeo ut liquide pateat alios produxisse naturam et alios reformasse doctrinam."

2) Ficinus, Theologia Platonica XIII, 3; fol. 295. Die Spannung, die im Begriff der ,humanitas" bei Ficin bestehen bleibt, drückt sich u. a. bei ihm auch in der Erklärung des Wortes aus, das er bisweilen, in der Art des Mittelalters etymologisch spielend, mit humus zusammenstellt (homo dicitur ab humo Epistol. I, fol. 64I) während er an anderen Stellen diese Ableitung ausdrücklich bestreitet: „(humanitatem) cave ne quando contemnas forte existimans humanitatem humi natam. Est enim humanitas ipsa praestanti corpore nympha, coelesti origine nata Aethereo ante alias dilecta Deo." (Epist. Lib. V., fol. 805.) Auch hier wird wieder jener Gegensatz deutlich, der seine künstlerische Gestaltung schon zu Anfang des Jahrhunderts in den Wechselreden zwischen dem Ackermann und dem Tod erfahren hatte. (S. bes. Cap. XXIV u. XXV. des Ackermanns aus Böhmen.) Burdachs Kommentar (S. 3Io, 3I 7) nimmt als mittelbare oder unmittelbare Quelle für die Gestaltung der Reden des Todes die Schrift Innocenz' III. "De contemptu mundi sive de miseria conditionis humanae" an. Bewährt sich dieser Zusammenhang, so zeigt sich auch von dieser Seite her wieder, wie eng im Zeitalter der Renaissance der religiöse, der philosophische und der humanistische Gedankenkreis ineinander greifen. Denn eben diese Schrift ist es gewesen, der Giannozzo Manetti seinen Traktat „De dignitate et excellentia hominis“ (1452) entgegengestellt hatte: welch letzterer wieder in vielen Punkten für Ficins Apologie der ,Humanität" das direkte litterarische Vorbild gebildet zu haben scheint. (Näheres bei Gentile, a. a. O., S. I53ff.; s. ob. S. 88). 
die gesamte Lehre des Bovillus beherrscht wird, von den kosmischen Elementen die Erde der ersten, das Wasser der zweiten, die Luft der dritten Stufe, während das Feuer, das den obersten Rang einnimmt, damit zu einem Analogon und Ebenbild der ,Vernunft" wird. Hier haben sich stoische Grundgedanken mit einer Form der „Lichtmetaphysik" verbunden, die aus Neuplatonischen Quellen stammt, und die später in der Naturphilosophie der Renaissance, insbesondere bei $\mathrm{Pa}$ trizzi, noch einmal eine systematische Erneuerung erfahren hat. ${ }^{1}$ ) So kann jetzt das Prometheus-Motiv für Bovillus das Bindeglied bilden, das seine Philosophie der Natur mit seiner Philosophie des Geistes verknüpft. Indem der Weise aus dem irdischen Menschen den himmlischen, aus dem potentiellen Menschen den aktuellen, aus der Natur den Intellekt erzeugt, ahmt er damit dem Prometheus nach, der in den Himmel aufstieg, um das allbelebende Feuer von den Göttern herabzuholen. Er wird sein eigener Schöpfer und Meister, - er erwirbt und besitzt sich selbst, während der bloß ,natürliche“ Mensch stets einer fremden Macht gehört und ihr ewiger Schuldner bleibt. ${ }^{2}$ ) Die zeitliche Ordnung zwischen dem Menschen der ,Natur“ und dem der „Kunst“, zwischen dem ,,primus homo" und dem ,,secundus homo", erfährt also, sobald wir zur Ordnung des Wertes fortschreiten, ihre Umkehr: das der Zeit nach Zweite wird zum Ersten des Wertes. Denn der Mensch erreicht seine Bestimmung erst dadurch, da $\beta$ er sie sich selber gibt - da $\beta$ er, wie Pico es in seiner Rede ausspricht, $\mathrm{zu}$ seinem eigenen freien Bildner (sui ipsus quasi arbitrarius honorariusque plastes et fictor) wird. Völlig losgelöst von seinem anfänglichen religiösen Urgrund, ja in bewußter Abkehr von ihm, tritt uns dieser Gedanke sodann bei Giordano Bruno entgegen. Bei ihm herrscht nur noch der ins Heroische und Titanische gesteigerte Affekt der Selbstbehauptung des Ich. Wenn das Ich ein Trans-

I) Vgl. Patrizzis Pancosmia, Lib. IV (Nova de universis Philosophia, Ferrariae I59 I, P. IV, fol. $73 \mathrm{ff}$.)

2) ,Sapiens .. celestem hominem inde profert, e tenebris emendicat elicitque splendorem: ex potentia actum, ex principio finem, ex insita vi opus, ex natura intellectum, ex inchoatione perfectum, ex parte totum et ex denique semine fructum. Hac enim in parte celebrem illum Prometheum imitatur, qui (ut poetarum fabule canunt) aut divum permissione aut mentis et ingenii acumine admissus nonnunquam in ethereos thalamos, posteaquam universa celi palatia attentiore mentis speculatione lustravit, nichil in eis igne sanctius, preciosius ac vegetius reperit. Hunc ergo quem dii tantopore mortalibus invidebant illico suffuratus mortalium indidit orbi eoque luteum ac figulinum hominem (quem fixerat prius) animavit. Ita et sapiens vi contemplationis sensibilem mundum linquens penetransque in regiam celi conceptum ibidem lucidissimum sapientie ignem immortali mentis gremio in inferiora reportat eaque sincera ac vegetissima flamma naturalis ipsius tellureusve homo viret, fovetur, animatur. Sapiens nature munera studioso homine compensat, seipsum insuper acquisivit seque possidet ac suus manet. Insipiens vero ... manet perpes nature debitor, substantiali homine oberatus et nunquam suus." Bovillus, De sapiente, Cap. VIII. 
zendentes, über alle Grenzen der menschlichen Fassungskraft Hinausliegendes anerkennt, so will es doch dieses Übersinnliche nicht als ein bloßes Geschenk der Gnade empfangen. Wem ein solches Geschenk zuteil wird, der mag an sich ein größeres Gut besitzen, als der, der aus eigener Kraft zur Erkenntnis des Göttlichen zu gelangen sucht: aber dieses objektiv-Gute wiegt den spezifischen Wert des selbständigen Strebens und Handelns nicht auf. Denn nicht als Gefäß und als bloßes Werkzeug, sondern als Künstler und als wirkende Ursache soll der Mensch das Göttliche tassen. So scheidet Bruno die bloß gläubigEmpfangenden von denen, die in sich selbst den Trieb des Aufstiegs und die Kraft des Aufschwungs, den „impeto razionale“ zum Göttlichen verspüren: ,gli primi hanno più dignità, potesta et efficacia in sè, perchè hanno la divinità; gli secondi son essi più degni, più potenti et efficaci, et son divini. Gli primi son degni come l' asino che porta li sacramenti: gli secondi come una cosa sacra. Nelli primi si considera et vede in effetto la divinità et quella s'admira, adora et obedisce, negli secondi si considera et vede l'eccellenza della propria humanitade. “1) Hält man mit diesen Sätzen aus Brunos Dialog, ,Degli eroici furori“ die Sätze zusammen, in denen Nikolaus Cusanus in der Schrift "De docta ignorantia“ den Begriff und das Ideal der humanitas definiert hatte, so umspannt man damit das Ganze der Gedankenbewegung des I5. und I6. Jahrhunderts. Cusanus versucht nicht nur dieses Ideal dem religiösen Gedankenkreis einzugliedern, sondern es bedeutet ihm geradezu die Vollendung und Erfüllung der Grundlehren des Christentums: die Idee der Humanität fließt mit der Idee Christi in eins zusammen. Aber je weiter die philosophische Entwicklung fortschreitet, um so mehr lockert sich dieses Band, um sich zuletzt ganz zu lösen. Giordano Brunos Formulierung läßt in charakteristischer Bestimmtheit die Kräfte erkennen, die auf eine solche Lösung hindrängten. Das Ideal der Humanität schließt das Ideal der Autonomie in sich; und je mehr dieses letztere an Stärke gewinnt, um so mehr sprengt es den religiösen Kreis, in den Cusanus und in den die Florentinische Akademie den Humanitätsbegriff zu bannen suchte.

2.

Die bisherige Betrachtung hat uns die allmähliche Umbildung des Freiheitsproblems und das immer stärkere Vordringen des Freiheitsprinzips innerhalb der religiösen Gedankenwelt der Renaissance gezeigt. Schritt für Schritt mußte bei diesem Vordringen der theologischen Dogmatik der Boden abgewonnen werden: ein Prozeß, der um so schwie-

I) Bruno, De gli heroici furori, Dial. III; Opere ital., ed. Lagarde, S. 64 I. 
riger war, als der Begründer dieser Dogmatik auch der Renaissancephilosophie noch durchaus als klassischer Autor, als philosophische und religiöse Autorität gilt. Petrarca war in dieser Verehrung Augustins vorangegangen - er hatte ihn aus der Schar der großen antiken Vorbilder herausgehoben und ihn als den ihm ,unter Tausenden Teuersten " erkannt. ${ }^{1}$ ) Den gleichen Weg geht die florentinische Akademie, die in Augustin überall das eigentliche Vorbild des ",christlichen Platonikers“ sieht. Erst wenn man sich dies geschichtliche Verhältnis vergegenwärtigt, ermißt man ganz die Größe der Widerstände, die hier zu überwinden waren. Und doch hätte selbst die Wegräumung dieser Widerstände für sich allein nicht genügt, um den Sieg des Freiheitsgedankens zu entscheiden. Denn, bevor dies geschehen konnte, galt es den Kampf gegen eine andere Macht aufzunehmen, die mit dem geistigen Leben der Renaissance durch tausend Fäden verbunden war. Leibniz hat in der Theodizee eine dreifache Form des Fatum unterschieden: dem „Fatum Christianum" stellt er das „Fatum Mahumetanum" und das "Fatum Stoicum" gegenüber. Alle drei Grundrichtungen des Denkens, die sich in diesen Begriffen ausprägen, sind in der Renaissance noch durchaus lebendige Kräfte. Mit nicht minderer Stärke als die christliche Gedankenwelt wirkt hier die Gedankenwelt der Astrologie, die sich aus heidnischen und aus arabischen Quellen nährt. Und wenn gegen die christlichmittelalterliche Tradition und gegen die christlich-mittelalterliche Dogmatik die Antike aufgerufen werden konnte, so blieb sie gegenüber dem neuen Gegner zunächst machtlos, ja sie schien dessen Kraft nur zu verstärken. Denn der Weg zu der ,,klassischen“ Epoche der griechischen Philosophie ist der Renaissance zunächst verschlossen. Sie kann diese Philosophie nicht anders als in hellenistischer Umhüllung und Verkleidung sehen; sie erblickt die Lehre Platons nur durch das Medium des Neuplatonismus. So rückt ihr mit der Erneuerung der antiken Begriffswelt auch die antike Mythenwelt wieder unmittelbar nahe. Noch bei Giordano Bruno spürt man, wie diese Welt keineswegs endgültig versunken ist, sondern wie sie überall bestimmend in das philosophische Denken selbst eingreift. Und noch weit kräftiger und tiefer mußte diese Wirkung sich dort darstellen, wo nicht das begriffliche Denken, sondern das künstlerische Gefühl oder der Affekt die Auseinandersetzung zwischen Ich und Welt, zwischen Individuum und Kosmos suchte. Je selbständiger diese Kräfte in der Renaissance heraustreten, je ungehemmter sie sich auswirken können, um so mehr fallen die Widerstände, die das Mittelalter dem System der Astrologie entgegengesetzt hatte. Auch das christliche Mittelalter hatte dieses System nicht entbehren und hatte es niemals völlig

I) Petrarca, De secreto conflictu curarum suarum, Praefatio. 
überwinden können. Es nimmt dasselbe auf, wie es überhaupt die antikheidnischen Grundvorstellungen duldet und weiterführt. Die alten Göttergestalten leben weiter; aber sie werden zu Dämonen, zu Geistern niederen Ranges herabgesetzt. So stark das primitive Gefühl der Dämonenfurcht sich im Menschen behaupten mag, so ist es jetzt doch beschwichtigt und in Schranken gehalten durch das Vertrauen in die Allmacht des einzigen Gottes, dessen Willen alle Gegenkräfte sich beugen müssen. Wenn daher das "Wissen" des Mittelalters, wenn insbesondere die mittelalterliche Medizin und die mittelalterliche Naturwissenschaft durchweg mit astrologischen Elementen durchsetzt ist, so bietet doch der mittelalterliche Gla ube ein ständiges Korrektiv gegen sie dar. Er leugnet und er beseitigt sie nicht: aber er unterstellt sie der Macht der göttlichen Vorsehung. Kraft dieser Unterordnung kann die Astrologie als Prinzip des weltlichen Wissens unangetastet bleiben. Selbst Dante nimmt sie in diesem Sinne an; ja er gibt, im Convivio, ein vollständiges System des Wissens, das Stück für Stück dem System der Astrologie entspricht. Den sieben Planetensphären sind die sieben Wissenschaften des Trivium und des Quadrivium zugeordnet: die Grammatik entspricht der Sphäre des Mondes, die Dialektik der des Merkur, der Rhetorik die Venus, der Sonne die Arithmetik, dem Mars die Musik, dem Jupiter die Geometrie, dem Saturn die Astronomie. ${ }^{1}$ ) Was sodann den Humanismus betrifft, so läßt er in seiner ursprünglichen Form noch keine veränderte Haltung zur Astrologie erkennen. Petrarca fügt sich hier noch völlig der christlichen Grundansicht ein: seine Stellung zur Astrologie ist von der Augustins, auf dessen Argumente er sich ausdrücklich beruft, nicht verschieden. ${ }^{2}$ ) Und wenn Salutati in seiner Jugend zum Glauben an das astrologische Fatum neigt, so hat er in seiner späteren Schrift „De fato et fortuna" diese Anfechtung überwunden und diesen Glauben ausdrücklich bekämpft. Den Gestirnen eignet keine selbständige Macht: nur als Werkzeuge in der Hand Gottes dürfen sie betrachtet werden. ${ }^{3}$ ) Aber je weiter man fortschreitet, um so mehr fühlt man, wie gerade das Vordringen des weltlichen Geistes und der weltlichen Bildung die Hinneigung $\mathrm{zu}$ den astrologischen Grundlehren verstärkt. In Ficins sonst so gemessenes und gleichmäßiges Leben kommt durch das zwiespältige geistig-sittliche Verhältnis zur Astrologie ein Moment der Unruhe und der ständigen inneren Spannung. Auch er unterwirft sich der christlich-

I) Dante, Convivio, trattato secondo, Cap. XIV.

2) Petrarca, Epist. rerum familiarium III, 8 (näheres bei Voigt, Wiederbel. des klass. Altert. $\left.{ }^{2}, \mathrm{I}, 73 \mathrm{ff}.\right)$.

3) Näheres über Salutatis Schrift "De fato et fortuna" (I396) bes. bei A.v. Martin, Coluccio Salutati und das humanistische Lebensideal, Leipzig u. Berl. rgr6, S. $69 \mathrm{ff} ., 283 \mathrm{ff}$. 
kirchlichen Grundanschauung; auch er betont, daß die Himmelskörper zwar Macht über den Körper des Menschen besitzen, daß sie aber keinen Zwang auf seinen Geist und auf seinen Willen ausüben können. ${ }^{1}$ ) Und er bekämpft von hier aus den Versuch, mit den Mitteln der Astrologie die Zukunft enträtseln zu wollen: ,,si diligentius rem ipsam consideramus, non tam fatis ipsis, quam fatuis fatorum assertoribus agimur".${ }^{2}$ ) Und doch ist unverkennbar, daß diese theoretische Überzeugung, zu der er sich durchringt, den Kern seines Lebensgefühls nicht zu ändern vermag. Dieses wird nach wie vor durch den Glauben an die Macht der Gestirne beherrscht; vor allem durch den Glauben an die Macht des Unheilbringers Saturn, der im Aszendenten von Ficins eigenem Heroskop stand. ${ }^{3}$ ) Der Weise kann nicht versuchen, sich der Kraft seines Sternes zu entziehen: nur das eine bleibt ihm, daß er diese Kraft zum Guten lenkt, indem er die wohltätigen Einflüsse, die von ihr ausgehen, in sich verstärkt, die schädlichen nach Möglichkeit abwendet. Die Formgebung des Lebens beruht auf dieser Fähigkeit, es innerhalb des vorgeschriebenen Kreises zur Einheit und zur Vollkommenheit zu gestalten: und über diese Schranke kann und soll auch unser höchstes Streben nicht hinausgreifen. Im dritten Buche seiner Schrift „De triplici vita", dem er den Titel: „De vita coelitus comparanda" gegeben hat, hat Ficin ein vollständiges bis ins einzelne durchgeführtes System der Lebensgestaltung gemäß der Bestimmung und der Kraft der Gestirne entwickelt. ${ }^{4}$ ) An einem Beispiel dieser Art erkennt man mit besonderer Klarheit, daß es zwei verschiedene Grundmächte waren, gegen die das neue Lebensgefühl der Renaissance, und gegen die ihr Begriff und ihr Ideal der Humanität sich durchzusetzen hatte. Jedem Versuch der Befreiung des Ich steht eine Notwendigkeit von zwiefacher Art und Prägung gegenüber: wie auf der einen Seite das ,regnum gratiae“, so fordert auf der anderen Seite das ,regnum naturae" von ihm die Anerkennung und Unterwerfung. Je stärker der erste Anspruch zurückgedrängt wurde, um so mehr mußte der zweite sich erheben und sich als allein gültig erklären. Der transzendenten Bindung stellt sich jetzt die immanente, der reli-

I) Ficin an Cavalcanti, Epistol. Lib. I., Op. fol. 633. „Corpus . nostrum a corpore mundi fati viribus tanquam particula quaedam a tota sui mole violento quodam impetu trahitur, nec in mentem nostram fati vis penetrat, nisi ipsa se sua sponte prius in corpus fato subjectum immiserit.... Recipiat a corporis peste seipsum animus quisque et in mentem suam se colligat, tunc enim vim suam fortuna explebit in corpore, in animum non transibit."

2) Ficin, Epistol. Lib. IV, fol. 781.

3) S. Ficins Briefe an Cavalcanti; Epist. Lib. III, fol. 73 I und 732.

4) Über Ficins Schrift „De vita triplici“ und über seine Stellung zur Astrologie vgl. bes. Panofsky-Saxl, Dürers Melancolia I (Stud. der Bibl. Warburg Nr. II) Leipzig und Berlin I923, S. $32 \mathrm{ff}$. 
giösen und theologischen die naturalistische gegenüber. Und sie war schwerer zu überwinden und zu besiegen: nährte sich doch der Naturbegriff der Renaissance zuletzt aus denselben geistigen Kräften, aus denen auch ihr Begriff des Geistes und ihr Begriff des Menschen erwuchs. Was hier gefordert wurde, war somit nichts Geringeres, als da $B$ diese Kräfte sich gewißermassen gegen sich selbst kehren, und daß sie sich selber ihre eigene Grenzen setzen sollten. Richtete sich der Kampf gegen die Scholastik und gegen die mittelalterliche Dogmatik nach außen, so war jetzt ein Kampf nach innen zu bestehen. Man begreift, wie schwierig und hartnäckig dieser Kampf sich gestalten mußte. In der Tat ist die gesamte Naturphilosophie der Renaissance, wie sie im I5. Jahrhundert entsteht, um bis ins I6., ja bis in die Anfänge des I7. Jahrhunderts fortzuleben, mit der magisch-astrologischen Grundanschauung der Kausalität aufs engste verflochten. Die Natur ,nach eigenen Prinzipien“ (juxta propria principia) $\mathrm{zu}$ begreifen: dies schien nichts anderes $\mathrm{zu}$ bedeuten, als sie aus den in ihr selbst liegenden eingeborenen Kräften zu erklären. Wo aber lagen diese Kräfte deutlicher zutage, wo zeigten sie sich faßbarer und allgemeiner, als in der Bewegung der Himmelskörper? Wenn irgendwo, so mußte hier das immanente Gesetz des Kosmos, die allumfassende universelle Regel auch für alles besondere Geschehen ablesbar sein. Astrologie und Magie stehen daher in der Epoche der Renaissance so wenig in Widerstreit gegen den ,modernen" Naturbegriff, daß sie vielmehr beide zu seinem mächtigsten Vehikel werden. Die Astrologie und die neue empirische "Wissenschaft" der Natur treten zueinander in eine ebensowohl persönliche wie sachliche Union. Man muß sich diese Union in dem Bild der einzelnen Denker selbst vorstellig machen, man muß sie etwa in der Form betrachten, in der sie uns in der Selbstbiographie eines Mannes wie Cardano entgegentritt, um die Macht, die sie über das Leben selbst, über seine theoretische Auffassung wie über seine praktische Gestaltung ausübt, ganz zu ermessen. Erst Copernicus und Galilei haben dieses Band gelöst: und doch stellt auch diese Lösung keinen bloßen Sieg der „Erfahrung“ über das „Denken“, des Rechnens und Messens über die Spekulation dar. Damit sie gelingen konnte, mußte sich vielmehr zuvor ein Wandel der Denkart selbst vollzogen, mußte eine neue Logik des Naturbegreifens sich gebildet haben. Nichts ist wichtiger für die Erkenntnis der großen systematischen Zusammenhänge innerhalb der Renaissancephilosophie, als dem Werden dieser Logik nachzugehen. Denn nicht das Resultat als solches, sondern der Weg, auf dem es erreicht wurde, ist hier das Entscheidende und Wesentliche. Wenn dieser Weg uns mitten durch ein Gewirr phantastischen Aberglaubens zu führen scheint, wenn noch bei Denkern, 
wie Bruno oder Campanella die Grenze zwischen Mythos und Wissenschaft, zwischen „Magie" und „Philosophie“ sich nirgends sicher ziehen läßt - so blicken wir hier doch um so tiefer in die Dynamik des geistigen Prozesses hinein, durch den erst, langsam und stetig, die ,Auseinandersetzung" zwischen beiden Gebieten sich vollzogen hat.

Diese Stetigkeit ist freilich nicht so zu verstehen, daß hier die zeitliche Abfolge der Gedanken zugleich ihre systematische Abfolge repräsentiert und wiedergibt. Nirgends handelt es sich um einen kontinuierlichen zeitlichen ,Fortschritt', der in gerader Linie zu einem bestimmten Ziel führt. Altes und Neues geht nicht nur auf lange Zeitstrecken nebeneinander her, sondern beides fließt ständig ineinander über. Von einer „Entwicklung“ kann daher hier nur in dem Sinne gesprochen werden, daß sich die einzelnen Gedankenmotive, in eben diesem fluktuierenden Hin und Her, allmählich immer schärfer gegen einander absondern, daß sie in bestimmten, typischen Gestaltungen heraustreten. An solchen typischen Bildungen wird der immanente Fortgang des Gedankens klar, der keineswegs seinem zeitlich-empirischen Verlauf zu entsprechen braucht. Zwei verschiedene Stufen in der Überwindung des astrologischen Weltbildes lassen sich vor allem unterscheiden: die eine besteht in der Negation des Inhalts dieses Weltbildes, die andere in dem Versuch, diesen Inhalt in eine neue Form zu kleiden und ihm damit eine neue methodische Begründung zu geben. Der letztere Versuch ist charakteristisch für jene Art der Naturbetrachtung, die nicht unmittelbar von den Phänomenen selbst herkommt, sondern die Erscheinungen durch das Medium der Aristotelisch-scholastischen Naturbegriffe $\mathrm{zu}$ betrachten und sie dem System dieser Begriffe einzufügen sucht. Hier ergibt sich eine eigenartige Mischform, eine Art scholastischer Astrologie und astrologischer Scholastik, die in einzelnen mittelalterlichen Systemen, vor allem im Averroismus, ihr Vorbild hat. In der italienischen Renaissance hat dieser Denktypus in Pomponazzis Werk ,De naturalium effectuum admirandorum causis sive de in-

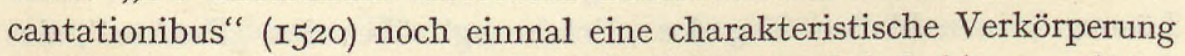
erfahren. Betrachtet man dieses Werk auf seinen Inhalt hin, so scheint es auf dem ersten Blick nichts anderes als ein Kompendium antiken und mittelalterlichen Aberglaubens zu sein. Die mannigfachen Arten der Vorzeichen und der Wundererscheinungen, die verschiedenen Formen der Mantik und Magie sind hier zusammengefaßt und nach Gruppen geordnet. Wenn Pomponazzi sich gegen einzelne dieser Wunderberichte kritisch und skeptisch verhält, so tastet er doch nirgends die Wahrheit und die Glaubwürdigkeit der Gattung selbst an. Diese Wahrheit gilt ihm durch die ,Erfahrung“ verbürgt, welch letztere der philosophische 
Kritiker einfach hinzunehmen hat, ohne ihren Inhalt zu verändern. Mag daher irgendeine Art der Wirkung noch so seltsam und unwahrscheinlich sein, so darf doch die Theorie, die den Beobachtungen keine Vorschriften $\mathrm{zu}$ machen, sondern die eben diese Beobachtungen $\mathrm{zu}$ „,retten“ hat, das reine „Daß“, die Tatsächlichkeit dieser Wirkungen nicht bestreiten, sondern sie hat vielmehr zu diesem „Daß“ das ,Warum“, zu dem Phänomen den ,Grund“ zu suchen. Dieser läßt sich freilich nur finden, wenn wir die Vereinzelung, in der die Phänomene uns zunächst gegeben sind, aufheben, wenn wir jede besondere Wirkung, so rätselhaft sie als solche erscheint, auf eine allgemeine Form der Gesetzlichkeit überhaupt zurückführen. Und eben diese Form ist es nun, die für Pomponazzi in der Wirksamkeit der Himmelskörper, in der astrologischen Kausalität gegeben ist. Diese letztere ist ihm daher nicht mehr und nicht weniger als das Grundpostulat, auf das sich alle Erklärung des Naturgeschehens stützen muß. Kein Geschehen kann als vollständig begriffen gelten, so lange es nicht in dieser Weise mit den letzten erkennbaren Ursachen alles Seins und alles Werdens in Zusammenhang gebracht ist: und andererseits gibt es keine Tatsache der Natur, die sich nicht, wenigstens dem Prinzip und der Möglichkeit nach, durch die Einwirkung der Sterne auf die niedere Welt erklären ließe. Alle besonderen „Wunder" gehen daher für Pomponazzi auf das eine dieser Einwirkung zurück. Überall sucht er zu erweisen, daß es zur Erklärung der angeblichen Zauberwirkungen, der Phänomene der Magie, der Traumdeutung, der Chiromantie und Nekromantie usf. keiner andern Kraft als dieser bedarf. Wenn der Volksglaube sich diese Erscheinungen nur dadurch verständlich machen kann, daß er in ihnen den Ausfluß persönlicher Kräfte und persönlicher Willensakte sieht, so muß der Theoretiker diese Voraussetzung, die das Naturgeschehen der Willkür preisgibt, verwerfen. Für ihn gibt es keine unmittelbar-dämonischen oder unmittelbar-göttlichen Eingriffe, die das Gesetz dieses Geschehens durchbrechen. Denn selbst die Einwirkung Gottes auf die Welt erfolgt nicht anders als durch das Medium der Himmelskörper. Diese sind nicht nur Zeichen des göttlichen Willens, sondern sie sind dessen echte und unentbehrliche Mittelursachen. ${ }^{1}$ ) Ob wir für jedes besondere Geschehen diese Mittelursachen aufweisen, und ob wir sie in lückenloser Reihe verfolgen können, gilt hierbei gleichviel: genug, daß wir wissen, daß diese

I) „Et certe (cognosces) superos in haec inferiora non operari nisi mediantibus corporibus coelestibus.... Ex quibus concluditur omnem effectum hic inferius aut per se aut per accidens reduci ad coelum et experitia corporum coelestium miranda et stupenda posse cognosci et pronuntiari." Pomponazzi, De naturalium effectuum admirandorum causis seu de incantationibus, Cap. X, Ausg. Basel ${ }_{5} 67$, S. I22f. 
Reihe besteht, daß sie unbedingt gefordert ist. $\left.{ }^{1}\right)$ Der philosophische Verstand darf in keinem Einzelfall von dieser Forderung abgehen, darf sich bei keiner Erklärung beruhigen, die das Medium der astrologischen Kausalität überspringt oder ihre Erforschung vorzeitig abbricht. Denn würde auch nur eine einzige Ausnahme von dieser Grundregel zugelassen, so verlöre damit die Naturordnung jeglichen inneren Halt. Könnten Engel oder Dämonen ohne die himmlischen Körper einen direkten Einfluß auf die Naturobjekte und auf die Menschenwelt ausüben, so wäre die Bedeutung und die Notwendigkeit eben dieser kosmischen Körper selbst, so wäre die Funktion, die sie im Ganzen der Welt zu erfüllen haben, nicht mehr verständlich zu machen. ${ }^{2}$ ) Man sieht: es ist eine eigenartige Form und eine eigenartige Begründung der Astrologie, die wir hier vor uns haben. Denn hier herrscht weder der Affekt, der in die Zukunft hinausgreifen und ihr ihr Geheimnis abzwingen will, noch die empirische Betrachtung oder die mathematische Theorie: hier ist eine Logik am Werke, die gewissermaßen die Form der Astrologie, als die unserer Naturerkenntnis allein aedaquate, a priori zu deducieren sucht. Die astrologische Kausalität wird, um einen modernen Ausdruck zu gebrauchen, zur ,Bedingung der Begreiflichkeit der Natur.“ Sie bedeutet für Pomponazzi nicht den Sprung in den Wunderglauben, sondern die einzige Rettung vor ihm, die einzig sichere Bürgschaft für die unbedingte Geltung der Naturgesetze. So ist es - wie paradox dies auf den ersten Blick erscheinen mag - eine durchaus "rationale" Astrologie, die wir hier vor uns haben. Die unbedingte Herrschaft der Gestirne über alles Irdische wird behauptet, um den unbedingten Primat der wissenschaftlichen Vernunft aufrecht $\mathrm{zu}$ erhalten. Pomponazzi verfolgt hier dasselbe Ziel, dem all seine anderen philosophischen Schriften zustreben. Er will das „Wissen“ an die Stelle des „,Glaubens" setzen; er sucht, statt nach einer transzendenten, nach einer rein ,immanenten“" Erklärung. In diesem Sinne ist seine Ethik orientiert, die er, unabhängig von jeder Annahme über die Unsterblichkeit und ein künftiges Leben, auf eigenem Grunde festzustellen und aus einer ursprünglichen autonomen Gewißheit der Vernunft abzuleiten versucht; in diese Richtung weist seine Psychologie, die den dualistischen Gegensatz von

I) ,Ultimo supponitur, quod in rebus difficilibus et occultis responsiones magis ab inconvenientibus remotae ac magis sensatis et rationibus consonae sunt magis recipiendae quam oppositae rationes.... His modo sic suppositis tentandum est sine daemonibus et angelis ad objecta respondere.... Effectus inferior immediate non fit a Deo super nos, sed tantum mediantibus ejus ministris. Omnia enim Deus ordinat et disponit ordinate et suaviter legemque aeternam rebus indidit quam praeterire impossibile est." Ibid. S. I3I, I34; vgl. Cap. I2, S. 223 u. ö.

2) S. a. a. O., Cap. X, S. I42; Cap. I3, S. 299 u. ö. 
"Seele" und „Geist" bekämpft und nachzuweisen sucht, daß auch die höchsten geistigen Funktionen nicht anders denn in organischer Verbindung mit der Sinnlichkeit, und demnach mit den Funktionen des Körpers, $\mathrm{zu}$ verstehen sind. Was Pomponazzi in der Schrift ,De immortalitate animi“ für die Ethik und für die Psychologie angestrebt hatte: das will die Schrift „de incantationibus" für die Naturphilosophie durchführen. Sie sucht zu zeigen, daß auch alle ,magischen“ Wirksamkeiten, die ihrer Tatsächlichkeit oder Möglichkeit nach nicht bestritten werden, den Rahmen der Einen immanenten Naturkausalität nicht zu sprengen vermögen. Die Natur als solche kennt nichts Gewöhnliches und nichts Ungewöhnliches; nur unsere Fassungskraft ist es, die solche Unterschiede setzt. So führt uns denn auch alles, was anfangs über ihren Kreis hinauszuleiten scheint, bei tieferer Forschung um so mehr in diesen Kreis zurück. Das Zufällige und Individuelle löst sich in das Notwendige und Allgemeine auf. Wenn dies Ergebnis auf der einen Seite als Triumph der astrologischen Weltansicht erscheint, so zeigt sich doch andererseits bei genauerer Betrachtung, daß diese Weltansicht selbst bereits eine eigentümliche Zersetzung erfahren hat. Die Astrologie zeigt - wie Warburg an ihrer Geschichte dargetan hat - von Anfang an ein geistiges Doppelantlitz. Als Theorie sucht sie die ewigen Gesetze des Weltalls in nüchterner und klarer Linienführung vor uns hinzustellen, während ihre Praxis im Zeichen der Dämonenfurcht, der ,,primitivsten Form religiöser Verursachung “ steht ${ }^{1}$ ). Die geistesgeschichtliche Bedeutung von Pomponazzis Schrift ,de incantationibus“ besteht darin, daß sie, selbst noch ganz im Bannkreis der astrologischen Anschauung stehend, zwischen den beiden Grundmomenten, die sich in ihr bisher unlöslich verschlungen hatten, zuerst eine scharfe und bewußte Trennung vollzieht. In diesem Sinne enthält die Schrift, die zunächst wie ein Arsenal des Wunderglaubens erscheint, echte kritische Denkarbeit in sich. Das rein ,primitive“, das dämonische Element im Sternenglauben wird abgestreift, und an seiner Statt bleibt nur der Gedanke der Einen unverbrüchlichen Gesetzlichkeit des Geschehens zurück, die keine Ausnahme oder Zufälle kennt: die ,dämonische“ Kausalität des Glaubens weicht der Kausalität der Wissenschaft. ${ }^{2}$ ) Diese selbst bleibt freilich da es für Pomponazzi noch keine mathematische Naturwissen-

I) S. A. Warburg, Heidnisch-antike Weissagung in Wort und Bild zu Luthers Zeiten, Sitzungsber. der Heidelberg. Akad. d. Wissensch. Philos.-hist. Klasse, Jahrg. I9I9, S. 24,70 .

2) Vgl. hrz. bes. die Entgegensetzung des „philosophischen“ (Peripatetischen) Ursachenbegriffs und des „religiösen" Ursachenbegriffs: De incantat. Cap. X, S. I98, Cap. XIII, S. 306f. u. ö; s. auch Douglas, The philosophy and psychology of Pietro Pomponazzi, Cambridge I9Io, S. $270 \mathrm{ff}$. 
schaft gibt - noch durchaus in dem traditionellen Vorstellungskreis der Astrologie gebunden. Aber es läßt sich schon hier voraussehen, daß, wenn einmal dieser Rahmen gesprengt, wenn der astrologische Ursachenbegriff durch den mathematisch-physikalischen ersetzt sein wird, der Gestaltung dieses letzteren keine inneren Hemmungen mehr entgegenstehen werden. In diesem durchaus mittelbaren Sinne hat selbst Pomponazzis so seltsames und abstruses Werk in rein methodischer Hinsicht der neuen exakt-wissenschaftlichen Grundauffassung des Naturgeschehens den Weg bereiten helfen.

Aber diese Leistung schloß zugleich eine andere Konsequenz in sich. Der Durchbruch zum strengen Naturalismus, der sich bei Pomponazzi vollzieht, war nur damit zu erkaufen, daß der naturalistischen Grundanschauung auch die Macht und die alleinige Herrschaft über das Ganze des Geisteslebens eingeräumt wurde. Hier durfte es keine Schranken und keinen Trennungsstrich geben, so wahr mit der Forderung Ernst gemacht werden sollte, daß der Zusammenhang von Ursachen und Wirkungen als ein schlechthin einzigartiger und eindeutiger zu denken sei. Diese Einzigkeit des Kausalnexus schließt es aus, daß neben der Sphäre der durchgängigen Determination, die wir "Natur" nennen, irgendeine Region übrig bleibt, die sich außerhalb dieser Determination hält. Auch das geistige Leben mit alledem, was uns in ihm als ein Gebiet freien Werdens und schöpferischer Produktivität zu gelten pflegt, kann nur dann als wahrhaft begriffen angesehen werden, wenn wir es auf dieselben allumfassenden Gesetze zurückgeführt haben, auf denen alle Ordnung und Verknüpfung der Erscheinungswelt überhaupt beruht. In Pomponazzi's Sprache bedeutet dies nichts anderes, als daß die astrologische Kausalität nicht nur das Prinzip für alle Erklärung des Naturgeschehens, sondern auch das konstitutive Prinzip der G eschich te bildet. Wie alles natürliche Sein und Werden, so steht alle geschichtliche Entwicklung unter der Macht der Sterne. Von hier empfängt sie ihren ersten Anstoß; von hier aus wird all ihr weiterer Fortgang entscheidend bestimmt. Der Radikalismus dieses Gedankens tritt vor allem in seiner Anwendung auf die Religionsgeschichte zutage. Pomponazzi steht in dieser Anwendung nicht allein; er spricht in ihr vielmehr nur eine Folgerung aus, zu der das System der Astrologie seit jeher hingedrängt hatte. Daß wie die Naturformen, so auch die Glaubensformen je ihre eigenen „Epochen“, ihre Zeiten des Aufblühens und Verwelkens, haben und daß diese sich am Himmel ablesen lassen, ist eine der Astrologie vertraute Anschauung. So wurde der jüdische Glaube auf die Konjunktion des Jupiter mit dem Saturn, der chaldäische auf die des Jupiter mit dem Mars, auf die mit der Sonne der ägyptische, auf die mit der Venus der mohammedanische 
Glaube zurückgeführt. Und auch vor dem Christentum machte diese astrologische Geschichtskonstruktion nicht Halt: Cecco d'Ascoli hat im Jahre I327 den Versuch, die Nativität Christi zu stellen, mit dem Tode auf dem Scheiterhaufen gebüßt. Burckhardt sagt von diesen Versuchen, daß sie in ihren weiteren Folgen ,eine förmliche Verfinsterung alles Übersinnlichen " mit sich führen mußten. ${ }^{1}$ ) Ebendiese Folgerung tritt vielleicht nirgends mit so bewußter Absicht wie in dem Werk Pomponazzis hervor. Er braucht geradezu diese „Verfinsterung“, damit sich ihr gegenüber um so deutlicher und heller die Autarkie und Autonomie der Naturgesetze abhebe. So geht er denn hier bis an die äußersten Grenzen; so zieht er Konsequenzen, die vielleicht nie zuvor mit solcher Schärfe und Rückhaltlosigkeit. formuliert worden waren. Die Wandlungen am Himmel sind es, die zugleich mit innerer Notwendigkeit einen „Gestaltwandel der Götter" nach sich ziehen. Zwar scheinen wir uns hier auf einem völlig ,irrationalen“, der Kausalität der Natur unzugänglichem Gebiet zu befinden: denn liegt nicht der letzte Grund der Religionen in der Offenbarung, in den unmittelbaren Inspirationen, die ihre Verkünder und Propheten erhalten? Aber eben hier setzt wieder Pomponazzis eigentümliche Methodik ein. So wenig er die Offenbarung leugnet, so sehr fordert er andererseits, daß selbst sie sich dem allgemeinen Gang und Gesetz der Natur einfügt. Der Grundsatz, daß das Göttliche auf die niedere irdische Welt niemals unmittelbar, sondern stets nur durch bestimmte Mittelursachen hindurch wirke, darf auch an diesem Punkte nicht durchbrochen werden. Auch alles Werden der Religionsformen ist, so wahr es empirisch-zeitliches Werden ist, an solche Mittelursachen gebunden. Die Erweckung des Religionsstifters selbst setzt eine natürliche "Anlage" in ihm voraus, und sie fordert weiterhin bestimmte Bedingungen, unter denen allein sie wirksam werden kann. Fassen wir diese natürlichen Umstände zusammen und suchen wir bis $\mathrm{zu}$ ihrem letzten einheitlichen Grund zu dringen, so werden wir wiederum auf die Macht der Sterne zurückgeführt. Die Konstellation ist es, an der auch alles geistige Sein und Geschehen hängt: denn sie ruft, wie den Künstler und Poeten, so auch den religiösen Seher, den vates hervor. Auch hier ist alle Vorstellung einer äußeren, einer göttlichen oder dämonischen „Besessenheit“ fernzuhalten. Mag Gott letzten Endes, wie der Ursprung alles Geschehens, so auch der Ursprung der Erleuchtung des Sehers sein, so richtet sich doch diese Erleuchtung selbst nach der kosmischen Weltlage, die ihrerseits durch die Disposition der Himmelkörper bezeichnet wird. Diese letztere ist es also, durch die die Kraft des Propheten erweckt und durch die ihr Erfolg oder Mißerfolg

I) Vgl. Burckhardt, Kultur der Renaissance ${ }^{8}$, II, 243.

Studien der Bibliothek Warburg 10: Cassirer 
bestimmt wird. ${ }^{1}$ ) Keine Glaubensform darf somit den Anspruch erheben, als ewige Wahrheit gleichsam über der Zeit zu stehen, sondern jede erweist sich als zeitbestimmt und zeitgebunden. Der Glaube hat gleich allem natürlichen Dasein eine Periode des Blühens und Welkens, des Entstehens und Vergehens. Auch das Heidentum hat seinen Welttag gehabt, während dessen seinen Göttern die Herrschaft, seinen Gebeten und Anrufungen volle Wirksamkeit zukam. Und das gleiche gilt für das Judentum und den Islam: läßt sich doch nicht leugnen, daß ebenso wie die Sendung Christi, so auch die Sendung des Mose und Mahomet durch bestimmte „Wunder" verkündigt und beglaubigt wurde. Aber in solchen Wahr- und Vorzeichen handelt es sich nirgends um Wunder im absoluten Sinne, handelt es sich nicht um Phänomene, die schlechthin gegen die Natur sind und außerhalb ihrer Ordnung stehen. Was wir Mirakel nennen, sind vielmehr nur jene seltenen und ungewöhnlichen, nur in langen Zeitabständen sich wiederholenden Erscheinungen, die mit jeder großen geistigen Umwälzung in der Welt verbunden sind. Sie zeigen sich am reichsten und am wirksamsten beim Aufstieg eines neuen Glaubens, um welk und schwach zu werden, so bald er selbst zu altern beginnt und durch einen anderen, kräftigeren besiegt wird. Wie von den Göttern, so gilt es daher von ihren Äußerungen, von ihren Verkündigungen und Orakeln, daß sie ihre bestimmte, in den Sternen geschriebene Stunde haben: ,neque enim signum vel scriptura, vel vox hoc ex se facere possunt, sed virtute corporum coelestium hoc fit faventium tali legislatoribus et ejus stigmatibus. ... Nam veluti nunc orationes factae valent ad multa, sic tempore illorum deorum hymni dicti in eorum laudem proficiebant tunc: proficiebant autem, quia tunc sidera illis favebant, nunc vero non favent, quoniam propitia sunt istis qui nunc sunt. “2) Auch das Christentum steht nach Pomponazzi nicht über diesem Kreis des Werdens und Vergehens, sondern mitten in ihm. Auch in ihm finden wir nicht sowohl einen schlechthin ewigen Bestand, als vielmehr die Bewährung der überall gültigen Regel des Entstehens und Herabsinkens. Und Pomponazzi scheut sich nicht, die Zeichen der Zeit so zu deuten, daß sie auf das nahe Ende des christlichen Glaubens hinweisen. Auch dem Zeichen des Kreuzes, das einst die heidnischen Götter und die heidnischen

I) „Illa oracula non semper reperiuntur vera: quoniam stellae non sunt semper secundum eundem et unum motum: et vulgares attribuebant hoc numinibus iratis, cum veram causam ignorarent. Sed haec est consuetudo vulgi, ascribere daemonibus vel angelis quorum causas non cognoscunt.... Deus autem non tantum unius est causa, verum omnium; quare et omnium vaticiniorum causa est, secundum tamen alteram et alteram dispositionem coelorum ... dat unum vaticinium et secundum alteram alterum.... Modo quis est tam philosophiae expers, qui nesciat secundum dispositionem varietatem et effectus variari."Pomponazzi, De incantat.,Cap. 12, S. $230 f$.

2) Ibid., Cap. 12, S. $287 \mathrm{f}$. 
Kulte überwunden hat, ist keine unbeschränkte Kraft und Geltung beschieden: gibt es doch in dieser irdischen Welt so wenig im Geistigen, wie im Natürlichen, irgend etwas, dem nicht zugleich mit seinem Anfang sein Ende vorgeschrieben wäre. ${ }^{1}$ )

Hier eröffnet uns das Werk Pomponazzis zugleich den Ausblick auf die allgemeinsten Probleme, mit denen die Philosophie der Renaissance $\mathrm{zu}$ ringen, und auf die Gegensätze, die sie in sich $\mathrm{zu}$ bewältigen hat. Ein neuer Begriff der Natur und ein neuer Begriff des Menschentums ist es, der hier entstehen will. Aber beide können sich nicht unmittelbar miteinander verbünden: denn sie scheinen nicht nur verschiedene, sondern einander direkt entgegengesetzte Tendenzen des Geistes in sich zu verkörpern. Je klarer und schärfer sie bestimmt werden, um so unerbittlicher tritt auch der Konflikt zwischen ihnen hervor. Vom Standpunkte der "Natur" gesehen, bleibt die Welt der Freiheit stets ein Mysterium, eine Art von Wunder. Dieses Wunder kann nicht anerkannt werden, ohne daß eben damit der spezifische Sinn des Naturbegriffs, wie die Renaissance ihn faßt, verloren ginge. Denn dieser Sinn besteht in nichts anderen als in Gedanken der Einheit und der Einzigkeit der Naturerklärung. Dieser methodische Monismus scheint vorerst jeden Dualismus in den Inhalten des Seins auszuschließen. Die geistig-geschichtliche Welt darf nicht neben der natürlichen als ein ",Staat im Staate“ stehen bleiben, sondern $m u ß$ in sie zurückgenommen und auf ihre Grundgesetze reduziert werden. Aber gegen diese Reduktion, die vom Standpunkte des Erkenntnisbegriffs der Renaissance unausweichlich scheint, lehnt sich das Lebensgefühl der Renaissance immer von neuem auf. In Pomponazzis Schrift ,de incantationibus“ sehen wir gewissermaßen den einen Pol dieser Bewegung, in Picos Kampfschrift gegen die Astrologie ihren anderen $\mathrm{Pol}$ vor uns. Aber daneben fehlt es nicht an Versuchen, zwischen den polaren Gegensätzen einen Ausgleich und eine Vermittlung zu schaffen. Eine solche schien sich darzubieten, sobald man auf ein Grundmotiv der Renaissance-Philosophie, auf das Motiv des „,Mikrokosmos" zurückgriff. Denn hier befand man sich von Anfang an in einer mittleren Sphäre, in der der Naturbegriff der Renaissance und ihr Begriff der ,humanitas" sich begegneten und sich wechselseitig bestimmten. Als Symbol, als Bild der Natur ist der Mensch ebenso auf sie bezogen, wie er von ihr unterschieden ist. Er faßt sie

I) ,Ita est in talibus legibus veluti in generabilibus et corruptibilibus. Videmus enim ista et sua miracula in principio esse debiliora, postea augeri, deinde esse in culmine, deinde labefactari, donec in nihil revertantur. Quare et nunc in fide nostra omnia frigescunt, miracula desinunt, nisi conficta et simulata: nam propinquus videtur esse finis.... Non enim influit aliqua virtus de coelo nisi in quodam tempore, et non ultra: ita est etiam de virtutibus imaginum." (Ibid. Cap. I2, S. 286.) 
in sich, ohne andererseits in ihr aufzugehen; er enthält alle ihre Kräfte, denen er nichtsdestoweniger eine spezifisch-neue, die Kraft der „Bewußtheit", hinzufügt. Von hier aus dringt auch in die astrologische Gedankenwelt ein neues Motiv ein, das sie allmählich von innen her umbildet. Die Weltansicht der Astrologie war nicht nur mit dem MikrokosmosGedanken von alters her verbündet, sondern sie schien nichts anderes als die einfache Konsequenz und Durchführung desselben zu sein. Ficins Darstellung des Systems der Astrologie in der Schrift „De vita triplici" beginnt mit dem Gedanken, daß es, so wahr die Welt kein Aggregat toter Elemente, sondern ein beseeltes Wesen ist, in ihr nirgends bloße „Teile" geben könne, die neben dem Ganzen und außer ihm ein selbständiges Dasein besitzen. Was wir äußerlich betrachtet als Teil des Universums ansehen, das ist vielmehr, tiefer erfaßt, als Organ zu begreifen, das im Lebenszusammenhang des Kosmos seine bestimmte Stelle und seine notwendige Funktion besitzt. Die Einheit des universellen Wirkungszusammenhangs muß sich in eine solche Mannigfaltigkeit von Organen gliedern: aber diese Differenzierung bedeutet keine Absonderung des Teils vom Ganzen, sondern nur den jeweilig verschiedenen Ausdruck des Ganzen, je eine besondere Seite seiner Selbstdarstellung. Andererseits wäre indes diese Geschlossenheit des Kosmos, diese "concordia mundi" nicht möglich, wenn nicht in dem wechselseitigen Ineinandergreifen der besonderen Kräfte zugleich eine bestimmte hierarchische Ordnung zwischen ihnen bestünde. Die Wirksamkeit des Universums wahrt nicht nur eine bestimmte Form, sondern sie weist auch durchgängig eine bestimmte Richtung auf. Der Weg führt von oben nach unten, vom Reich des Intelligiblen zum Reich des Sinnlichen. Aus der oberen himmlischen Sphäre strömen fortwährend die Ausflüsse herab, durch die das irdische Sein nicht nur erhalten, sondern ständig von neuem befruchtet wird. Aber diese emanatistische Form der Physik, die Ficin noch ganz im Sinne älterer Darstellungen, insbesondere im Sinne des Picatrix, des klassischen Handbuchs der späthellenistischen Magie und Astrologie vorträgt ${ }^{1}$ ), läßt sich auf die Dauer nicht festhalten. Denn ihre festeste Grundlage ist zerstört, seit das philosophische Denken des Quattrocento die entscheidende Kritik am Begriff des Stufenkosmos vollzogen hat. In der neuen Kosmologie, die mit Nikolaus Cusanus einsetzt, gibt es kein absolutes „Oben“ und ,Unten“", gibt es somit auch keine schlechthin einsinnige Richtung des Wirkens mehr. Der Gedanke des Weltorganismus ist hier dahin erweitert, daß jedes Weltelement mit gleichem Recht als Mittelpunkt des

r) Zum „Picatrix" s. Hellmut Ritter, Picatrix, ein arabisches Handbuch hellenistischer Magie, Vortr. der Bibl. Warburg I, (I92I/ 22), S. $94 \mathrm{ff}$. 
Alls angesehen werden kann (vgl. ob. S. 28 f.). Das bisherige einseitige Abhängigkeitsverhältnis zwischen der niederen und höheren Welt nimmt jetzt mehr und mehr die Form eines reinen Korrelationsverhältnisses an. Und damit muß, auch dort, wo die allgemeinen Voraussetzungen des astrologischen Denkens in Kraft bleiben, der Typus dieses Denkens und seine Begründung sich allmählich umgestalten. In Deutschland tritt diese Umgestaltung am deutlichsten in der Naturphilosophie des Paracelsus zutage. Der Zusammenhang und die durchgängige Entsprechung zwischen der ,,großen " und der ,,kleinen“"Welt ist hier durchaus festgehalten. Er bildet für Paracelsus die Voraussetzung aller Arzneikunde. Wie die Philosophie ,,der erste Grund der Arznei“, so ist die Astronomie ihr ,,ander Grund“. „Erstlich sol der arzt wissen, das er den menschen in dem andern halben teil, was astronomicam philosophiam betrift, verstande und das er den menschen da herein bring und den himel in in, sonst wird er kein arzt sein des menschen, dan der himel in seiner sphaer halt innen den halben leib, auch die halbe zal der krankheiten. Wer will ein arzt sein, dem die krankheiten dieses halben teils nit zustünden ? . . Was ist ein arzt, der nit beschleußt mit der cosmographei, deren er sonderlich ein wissen sol haben ... dan alle erkantnus gebüren sich in der cosmographei und ohne dieselbigen geschicht nichts". Dennoch wird die Harmonie zwischen der Welt und dem Menschen, deren Erkenntnis die Hauptaufgabe aller theoretischen Arzneiwissenschaft bildet, jetzt nicht mehr im Sinne einer einfachen Dependenz verstanden. „Zween Zwilling, die einander gleich sehen, welcher hatts vom anderen, daß er dem anderen gleich sicht? Keiner. Was wollten wir dann uns Jovische Kinder heißen und Monische, dieweil wir sind gegeneinander wie die Zwilling." Wollte man hier überhaupt die Ähnlichkeitsbeziehung auf eine Kausalbeziehung zurückdeuten, so müßte der Schwerpunkt derselben vom ,„äußeren“ Sein nach dem ,inneren“, vom Sein der Dinge in das des "Gemüts" verschoben werden. Denn billiger sage man, daß der Mars dem Menschen, als daß der Mensch dem Mars nacharte: „denn der Mensch ist mehr als Mars und andere Planeten “. ${ }^{1}$ ) Wieder erkennt man hier, wie in den festgefügten naturalistischen Gedankenkreis der Astrologie ein neues und im Grunde fremdartiges Motiv eindringt. Die rein kausale Betrachtungsweise schlägt in die teleologische Betrachtungsweise um - und durch sie erhalten jetzt alle Bestimmungen über das Verhältnis zwischen Mikrokosmos und Makrokosmos, auch wenn sie ihrem Inhalt nach aufrecht erhalten bleiben, gewissermaßen ein verändertes Vor-

I) Theophrast v. Hohenheim, gen. Paracelsus, medizinische, naturwissenschaftliche und philosophische Schriften, hg. von Karl Sudhoff, Band VIII (München I924), S. $68 \mathrm{ff}$., 9 Iff., I03f. u.s. 
zeichen. Dem Schicksalsmotiv der Astrologie tritt auch hier das ethische Selbstbewußtsein des Menschen gegenüber. Schon im äußeren Aufbau von Paracelsus' Arzneikunde und Naturphilosophie bekundet sich diese eigenartige Mischung. Das „Buch Paragranum", das die ,vier Columnae“ der Heilkunde aufzeigen will, nennt neben den drei Säulen der Philosophia, Astronomia und Alchimia die ,Virtus": ,die vierte seul sei die tugend und bleibe beim arzet bis in den tot, die da beschlie $\beta$ und erhalt die anderen drei seulen."1) Der Mikrokosmos-Gedanke - in der Fassung, die ihm die Renaissance-Philosophie gegeben hatte - gestattet eine

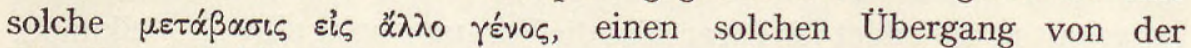
Physik zur Ethik nicht nur, sondern er fordert geradezu zu ihm heraus: denn in ihm hat sich von Anfang an die Kosmologie nicht nur mit der Physiologie und Psychologie, sondern auch mit der Ethik verbunden. Wenn dieser Gedanke verlangt, daß das Ich des Menschen aus der Welt erkannt wird, so schließt er andererseits die Forderung in sich, daß die echte und wahrhafte Welterkenntnis durch das Medium der Selbsterkenntnis hindurchgehen muß. Beide Forderungen stehen bei Paracelsus noch unmittelbar nebeneinander. Auf der einen Seite ist ihm der Mensch nichts anderes als ,,ein bildnus in eim spiegel, gesezt hinein durch die vier element", und ,,gleicherweis wie der im spiegel niemants mag seins wesens verstand geben, niemants zu erkennen geben, was er sei, dan allein es stat da wie eine tote bildnus, also ist der mensch an im selbs auch, und aus ime wird nichts genomen, allein was aus der eußeren erkantnus kompt, des figur er im spiegel ist." $\left.{ }^{2}\right)$ Und doch faßt dieses ,tote Bildnis', alle Kräfte der reinen Subjektivität, alle Kraft des Erkennens und des Wollens, in sich, und wird eben damit in einem neuen Sinn, zum Kern und Mittelpunkt der Welt. „Dann es ist ein solch groß Ding umb des Menschen gemüth, also das es niemandt möglich ist auszusprechen: Und wie Gott selbs und Prima Materia und der Himmel, die Drey ewig und unzergänglich sindt; also ist auch das Gemüth des Menschen. Darumb wird der Mensch selig durch und mit seinem Gemüth. . . Und wann wir Menschen unser Gemüth recht erkennten, so wäre uns nichts unmöglich auf dieser Erden."3)

So zeigt sich auch dort, wo das astrologische Weltbild im ganzen unangefochten bleibt, das deutliche Bestreben, der Subjektivität innerhalb dieses Weltbildes selbst eine neue Stellung zu erobern. Paracelsus nimmt hier nur die Gedanken des Mannes auf, den er, der sonst mit

I) Paracelsus, Das Buch Paragranum, a. a. O. Ausg. Sudhoff, S. 56 .

2) Paracelsus, Buch Paragranum, a. a. O. S. 72.

3) Paracelsus, Liber de imaginibus, Cap. XII Werke, hg. von Joh. Huser, Basel ${ }^{589}$ ff. IX, $389 f$. 
dem Lob von Vorgängern kargt, als den ,besten italienischen Arzt“ bezeichnet hat. ${ }^{1}$ ) Diese seine Anerkennung Ficins bezieht sich ersichtlich auf dessen drei Bücher „de vita“, in denen der Versuch gemacht ist, einen Gesamtaufbau der Medizin auf astrologischer Grundlage zu geben. Aber die Lehre von den Strahlungen der Gestirne, die durch ihre Einwirkung das Ganze des physischen und sittlichen Habitus des Menschen bestimmen, hat schon in dieser Schrift Ficins eine eigentümliche Lockerung erfahren. Zwar ist das Band, das jeden Menschen von seiner Geburtsstunde an mit ,seinem" Planeten verbindet, nach Ficin unzerreißbar. Unablässig klagt er selbst über den Einfluß, den das Unheilsgestirn, das im Aszendenten seines Horoskops steht, auf ihn und auf die gesamte Führung seines Lebens ausübt. Die Leichtigkeit und Sicherheit der Lebensführung, die anderen der Jupiter als Geschenk gewährt, ist ihm, dem "Saturnkind“ versagt. Und doch schließt diese Anerkennung des astrologischen Fatums für Ficin keinen endgültigen Verzicht auf die selbständige Gestaltung des Lebens in sich. Die müde und schmerzliche Resignation, mit der er sich in den Willen des Schicksals ergibt, weicht allmählich einem neuen und freieren Ton. So wenig es dem Menschen vergönnt ist, sein Gestirn, und mit ihm seine physischsittliche Natur, sein Temperament, zu wählen: - so steht es ihm doch frei, innerhalb der Schranken, die dieses Gestirn ihm vorschreibt, seine Wahl zu treffen. Denn jedes Gestirn enthält in seinem eigenen Kreise eine Mannigfaltigkeit verschiedener, ja gegensätzlicher Lebensgestaltungen und läßt die endgültige Entscheidung zwischen ihnen dem Willen offen. Wie der Saturn der Dämon der Trägheit und des in sich selbst versunkenen, unfruchtbaren Trübsinns ist, so ist er andererseits der Genius der intellektuellen Betrachtung und Versenkung, der Intelligenz und Kontemplation. Diese Polarität, die in den Gestirnen selbst liegt, und die gerade im System der Astrologie ihre Anerkennung und ihren deutlich-sichtbaren Ausdruck gefunden hatte, macht nun die Bahn für die Willensentscheidung des Menschen frei. Wenn der Kreis des Wollens und Vollbringens für den Menschen fest abgesteckt ist, so ist es doch nicht die Richtung dieses Wollens. Je nachdem diese Richtung auf die hohen oder niederen, auf die geistigen oder sinnlichen Kräfte geht, die der Planet als indifferente Möglichkeiten in sich faßt, ergeben sich nicht nur verschiedene, sondern entgegengesetzte individuelle Lebensformen. Und wie die Gestalt des Lebens, so hängt auch sein Glück oder Unglück von diesem Impuls des Willens ab. Derselbe Planet kann zum Freund oder Feind des Menschen werden, kann seine segenspendenden oder unheilbringenden Kräfte entfalten, je nach der inneren Stellung, die der Mensch

I) Brief an Christoph Clauser, Werke ed. Huser, Bd. VII. 
sich zu ihm gibt. So wird Saturn zum Feind aller derer, die ein gemeines Leben führen, aber zum Freund und Schützer derjenigen, die die tiefsten in ihm liegenden Gaben zu entfalten suchen, die sich mit ganzer Seele der göttlichen Kontemplation überlassen. Somit behält Ficin den Gedanken der „Planetenkindschaft" bei: aber neben der natürlichen $\mathrm{Ab}$ stammung von dem Planeten kennt er nun auch eine geistige, kennt er, wie man gesagt hat, eine „Wahl-Planeten-Kindschaft“. Mag der Mensch immerhin unter einem bestimmten Planeten geboren sein und unter seiner Herrschaft sein Leben führen müssen: bei ihm steht es, welche Möglichkeiten und Kräfte, die dieser in sich faßt, er in sich entfalten und zu voller Reife bringen will. Ja, er kann sich je nach den geistigen Neigungen und Bestrebungen, die er in sich walten läßt und fördert, bald unter den Einfluß des einen, bald unter den eines anderen Gestirns begeben. ${ }^{1}$ ) Auf diesem Wege versucht Ficin, die Grundlehren der Astrologie in sein theologisches System einzubauen. Es gibt für ihn eine dreifache Ordnung der Dinge, die er durch die Namen providentia, fatum, natura bezeichnet. Die Vorsehung ist das Reich der Geister, das Fatum das Reich der Seelen, die Natur das Reich der Körper. Wenn die Körper in ihren Bewegungen unter dem Zwang der Naturgesetze stehen, wenn die ,rationale" Seele, solange sie mit dem Leib verbunden ist und ihm als bewegende Kraft innewohnt, die ständige Rückwirkung der Körperwelt erfährt und dadurch in ihre Notwendigkeit verstrickt wird - so besitzt das rein geistige Prinzip im Menschen die Fähigkeit, sich von allen derartigen Bindungen zu lösen. Was wir die „Freiheit" des Menschen nennen, ist dies, daß er, wenngleich er unter dieser dreifachen Ordnung steht, sich doch aus der einen in die andere versetzen kann. Mögen wir durch unseren Geist der Vorsehung, durch unsere Imagination und Sinnlichkeit dem Fatum, durch unsere besondere Natur der allgemeinen Natur des Universums unterstehen, so sind wir doch kraft unserer Vernunft Herren über uns selbst (nostri juris) und von jeder Fessel gelöst, da wir bald die eine, bald die andere auf uns nehmen können. ${ }^{2}$ ) Hier mündet selbst das astrologische System Ficins in jenen

I) Auf Einzelheiten von Ficins Schrift „De vita triplici“ gehe ich hier nicht ein, sondern verweise auf die Darstellung bei Panofsky u. Saxl Dürers Melencolia I, S. 32, in der (im IV. Anhang) auch umfangreiche Proben aus dem Werk Ficins wiedergegeben sind.

2) S. Ficin, Theologia Platonica, Lib. XIII (fol. 289f.): „Iis quasi tribus rudentibus toti machinae colligamur, mente mentibus, idolo idolis, natura naturis... Anima per mentem est supra fatum, in solo providentiae ordine tanquam superna imitans et inferiora una cum illis gubernans. Ipsa enim tanquam providentiae particeps ad divinae gubernationis exemplar regit se, domum, civitatem, artes et animalia. Per idolum est in ordine fati similiter, non sub fato... Per naturam quidem corpus est sub fato, anima in fato naturam movet. Itaque mens super fatum in providentia est, idolum in fato 
Gedankenkreis der Florentiner. Akademie ein, in dem sich Picos Rede „,über die Würde des Menschen“ bewegt. Der Mensch hat in jeglicher Ordnung des Seins nur die Stelle, die er sich in ihr gibt. Seine individuelle Bestimmtheit hängt letzten Endes von seiner Bestimmung ab und diese ist nicht sowohl eine Folge seiner Natur, als sie eine Folge seiner freien Tat ist. -

Aber wenn es hier, trotz Ficins ständigem Ringen mit dem Problem, bei einer bloßen Scheinlösung und bei einem Kompromiß bleibt, so stehen wir mit Picos Streitschrift gegen die Astrologie auf einem völlig neuen Boden. Der Bannkreis der Astrologie ist hier mit einem Schlage gebrochen. $\mathrm{Daß}$ Pico eine solche Leistung gelingen konnte, das muß auf den ersten Blick als eine seltsame historische Anomalie erscheinen: steht doch seine gesamte Lehre noch ganz unter dem Zwang des magisch-kabalistischen Denkens, das, wie seine Naturphilosophie, so auch seine Religionsphilosophie beherrscht. Unter den 900 Thesen, mit deren Verteidigung er seine philosophische Laufbahn beginnt, finden sich nicht weniger als $7 \mathrm{I}$, die dieser Sphäre angehören, die von Pico selbst ausdrücklich als kabalistische Schlußfolgerungen bezeichnet werden. ${ }^{1}$ ) Es ist daher verständlich, wenn einer der besten Kenner der Geschichte der Astrologie, Franz Boll, seine Verwunderung darüber äußert, daß gerade Pico, in dessen zwiespältiger Natur mehr noch als der Trieb zu scharfer Kritik die neuplatonische und neupythagoreische Mystik Gewalt hatte, die Astrologie so unbedingt verwarf; während er doch auf der anderen Seite geradezu alle philosophischen Grundtendenzen vertrat, aus denen der astrologische Glaube sich ständig nährte und vertiefte. $\left.{ }^{2}\right)$ Daß eine solche Lösung gelang, kann jedoch - wenn man die geistige Eigenart von Picos Schrift berücksichtigt - nicht mit Boll auf einen äußeren Anstoß, auf den erschütternden Eindruck von Savonarolas Predigt, zurückgeführt werden. Hier wirken vielmehr innere und selbständige Kräfte, die ihren letzten Grund freilich nicht in Picos Naturanschauung, sondern in seiner ethischen Gesamtansicht haben. Wenn Pico in seiner Metaphysik, in seiner Theologie, in seiner Naturphilosophie noch durch unzerreißbare Bande mit der Vergangenheit verknüpft ist, so ist er in der Ethik zu einem der ersten Verkünder und Bahnbrecher

super naturam, natura sub fato, supra corpus. Sic anima in providentiae, fati, naturae legibus non ut patiens modo ponitur, sed ut agens.... Denique facultas illa rationalis quae proprie est animae verae natura, non est ad aliquid unum determinata. Nam libero motu sursum deorsumque vagatur. ... Quamobrem licet per mentem, idolum, naturam quodammodo communi rerum ordini subnectamur, per mentem providentiae, per idolum fato, per naturam singularem universae naturae, tamen per rationem nostri juris sumus omnino et tanquam soluti, modo has partes, modo illas sectamur."

I) Joh. Pici Mirandulae Conclusiones DCCCC; s. Opera, fol. 63 ff., Io $7 \mathrm{ff}$.

2) Fr. Boll, Sternglaube und Sterndeutung, 2. Aufl., Lpz. I919, S. 50. 
des echten Renaissancegeistes geworden. Und auf diesem Fundament der ethischen Humanität baut auch seine Schrift gegen die Astrologie auf. Der Gedanke, der Picos Rede über die "Würde des Menschen“" beherrschte, findet in dieser Schrift seinen vollen und reinen Ausklang. „Nihil magnum in terra praeter hominem, nihil magnum in homine praeter mentem et animum, huc si ascendis, coelum transcendis, si ad corpus inclinas et coelum suspicis, muscam te vides et musca aliquid minus. " 1 ) In diesen Sätzen wird ein echt-Platonisches Motiv wieder lebendig und wirksam. Was hier verlangt wird, ist eine Art der "Transzendenz", die keinen räumlichen Maßstab mehr anerkennt, weil sie über die Form des Raumes überhaupt hinausgeht. So einfach und schlicht dieser Gedanke erscheint, so richtet er sich doch gegen eine der Grundvoraussetzungen, auf denen die hellenistisch-neuplatonische wie die christlichmittelalterliche Anschauung der Welt beruht. Denn das eben charakterisiert diese Anschauung, daß sie das Jenseits-Motiv, das Platonische é $\pi \varepsilon ́ \varkappa \varepsilon เ v \alpha$, zugleich räumlich und geistig nimmt, und daß sie beide Bedeutungen untrennbar ineinander verwebt. So sehr Pico überall sonst im Banne des Neuplatonismus und seiner synkretistischen Vermischung der Gedankenmotive steht: hier ist es ihm gelungen, dieser Vermischung Herr zu werden und die Grenzen scharf zu ziehen. Und damit ist zugleich eine Bereicherung und Vertiefung in der Gesamtauffassung der antiken Geisteswelt erreicht. Der erste Schritt auf dem langen und mühsamen Wege, der von Plotin zu Platon, vom Hellenismus zum klassischen Griechentum zurückführen sollte, ist getan. Schon die ersten Sätze von Picos Schrift enthalten den charakteristischen Hinweis, daß die Astrologie im ganzen der echthellenischen, der klassisch-griechischen Gedankenwelt ein Fremdling sei. Plato und Aristoteles täten ihrer nicht einmal Erwähnung: und sie haben sie durch dieses verächtliche Schweigen mehr als durch eine umständliche Widerlegung verurteilt. ${ }^{2}$ ) Diesem geschichtlichen Argument reihen sich sodann die eigentlich entscheidenden systematischen Argumente an. Hier muß Pico, um seine Grundthese durchzuführen, zum Kritiker der Erkenntnis werden - muß er die Form der mathematisch-physikalischen Kausalität von der der astrologischen Kausalität scheiden. Wenn diese letztere auf der Annahme okkulter Qualitäten beruht, so begnügt die erstere sich mit dem, was die Erfahrung, was die empirische Anschauung uns lehrt. Nicht irgendwelche geheimnisvolle „Ausflüsse“ der Sterne, die durch Sympathie das jedem einzelnen Gestirn Verwandte ergreifen, gelten ihr als Band, das den Himmel mit der Erde verknüpft. An die Stelle solcher chimärischer Erdichtungen setzt sie vielmehr das einzige Phä-

I) Pico della Mirandola, In astrologiam libri XII, Lib. III, cap. 27 , fol. 519.

2) Pico, In astrologiam, Lib. I (fol. 4I5). 
nomen, was sich der Beobachtung unmittelbar darbietet, was empirisch beglaubigt und erwiesen werden kann. Wenn Ficin s astrologische Physik alle irdisch-natürlichen Wirkungen durch Strahlungen der Sterne bedingt sein ließ, in denen das allbelebende Pneuma sich von der höheren Welt auf die niedere fortpflanzt, so verwirft Pico diese Erklärung nicht nur im einzelnen, sondern im ganzen, nicht nur inhaltlich, sondern methodisch. Denn alle Erscheinungen seien aus ihren eigen en Prinzipien (ex propriis principiis), aus ihren nächsten und partikularen Ursachen zu begreifen. Die nächste Ursache für all das, was der Himmel an realen Wirkungen in sich schließt, aber brauchen wir nicht weit zu suchen: besteht sie doch in nichts anderem als in den Kräften des Lichts und der Wärme, also in allbekannten, sinnlich-aufzeigbaren Erscheinungen. Sie allein bilden das Vehikel aller himmlischen Einwirkungen und das Medium, durch welches das örtlich noch so weit Getrennte sich dynamisch aneinander knüpft. ${ }^{1}$ ) Was Pico hier gibt, scheint auf den ersten Blick nichts anderes als eine naturphilosophische Theorie zu sein, wie sie uns später etwa bei Telesio oder Patrizzi begegnen wird. Sieht man jedoch auf den Zusammenhang, in dem diese Theorie steht, so erkennt man, daß sich in ihr weit mehr verbirgt. Denn was hier gefunden und bestimmt aufgestellt wird: das ist nichts Geringeres, als jener Begriff der ,vera causa“, an den Kepler und Newton anknüpfen, und auf den sie ihre Grundauffassung der Induktion stützen werden. Selbst der direkte geschichtliche Zusammenhang scheint hier gesichert: denn Kepler hat sich von seiner ersten methodischen Hauptschrift, von seiner Apologie Tychons an, auf Pico und dessen Widerlegung der Astrologie berufen. Nicht jeder Grund, den wir rein begrifflich für die Erklärung eines Naturphänomens ersinnen mögen, ist ,wahr": er wird es erst, indem er sich als verifizierbar, als durch Beobachtung und Messung feststellbar erweist. Wenn Pico dieses Prinzip nicht in der gleichen Klarheit, wie die Begründer der mathematischen Naturwissenschaft ausspricht, so wird es doch von ihm überall als immanentes Kriterium verwertet. Mit seiner Hilfe wendet er sich als einer der ersten gegen die Annahme von Kräften, die am bloßen Orte haften. Der Ort ist eine geometrisch-ideelle, keine physikalisch-reale Bestimmung, von der also keine konkreten physischen Wirkungen ausgehen können. ${ }^{2}$ ) Und nicht nur Ideelles, sondern rein Fiktives

I) In astrol. Lib. III, Cap. V (fol. 46I): „Praeter communem motus et luminis influentiam nullam vim caelestibus peculiarem inesse". Vgl. bes. Lib. III, Cap. XIX (fol. 503). „Pastores, agricolae et ipsum saepe vulgus ineruditum statum aeris praecognoscunt non a stellis, sed ab aeris ipsius dispositione.... Q Quare raro fallunt, aerem scilicet ex aere, sicut medici aegrum ex aegro praejudicantes, hoc est ex propriis principiis, non quod faciunt astrologi, ex remotis et communibus in universalibus, imo, quod pejus est, fictis imaginariis fabulosis."

2) In astrologiam, Lib. VI, Cap. 3 , fol. 584 f. 
ist es, was die Astrologie als Reales verkennt und mit realen Kräften ausstattet. Die Linien, die der Astrolog zum Zweck der Orientierung am Himmel zieht, die einzelnen Häuser, in die er ihn einteilt, dieser ganze Apparat des rechnenden Denkens unterliegt in der Astrologie einer seltsamen Hypostase: er wird zu einem Sein sui generis, das mit dämonischer Gewalt begabt ist. Aber alle diese Gebilde schwinden dahin, wenn man sich klar macht, daß sie keinerlei ontologische, sondern lediglich signifikative Bedeutung haben. Auch die echte Naturwissenschaft kann freilich, ebenso wie die Astrologie, das Signifikative, die Operation mit bloßen Zeichen nicht entbehren. Aber für sie sind diese Zeichen nichts Endgültiges, geschweige etwas selbständig Existierendes, sondern sie bilden nur ein Medium des Gedankens; - sie sind eine Etappe auf dem Wege, der von der sinnlichen Erfassung der Phänomene zu der denkenden Erfassung ihrer Ursachen führt. Eine solche aber setzt mehr als eine vage Entsprechung, eine bloß analogische Beziehung zwischen räumlich und zeitlich getrennten Seinselementen voraus. Wir müssen die kontinuierliche Folge der Veränderungen, die von einem bestimmten Punkte des Universums ihren Ausgang nehmen, Schritt für Schritt, Glied für Glied verfolgen können, wir müssen ein einheitliches Gesetz, dem alle diese kontinuierlichen Änderungen gehorchen, aufzustellen imstande sein, um von einer wirklichen kausalen Verknüpfung sprechen zu dürfen. Wo wir nicht eine derartige Form der Wirksamkeit des Himmels empirisch nachweisen können, da ist es müßig, ihn als Zeichen des künftigen Geschehens betrachten und seine Zeichen enträtseln zu wollen. Denn der Himmel bezeichnet in Wahrheit nur das, was er wirkt: ,non potest coelum ejus rei signum esse, cujus causa non sit." ${ }^{1}$ ) Mit diesen Kernsätzen greift Pico über die bloße Kritik der Astrologie hinaus: er zieht die scharfe Grenzlinie, die die magischen Zeichen der Astrologie von den intellektuellen der Mathematik und der mathematischen Naturwissenschaft trennt. Fortan steht der Weg offen, die „Chiffreschrift der Natur" durch mathematisch-physikalische Symbole zu deuten, die zugleich als Symbole begriffen werden, die dem Geist nicht mehr als fremdartige Gewalten, sondern als seine eigenen Schöpfungen gegenüberstehen.

Die letzten Wurzeln von Picos Kritik der Astrologie liegen jedoch nicht in derartigen logischen oder erkenntniskritischen Erwägungen. Das $\mathrm{Pa}-$ thos, das seine Schrift gegen die Astrologie beseelt, ist seinem eigentlichen Ursprung nach nicht sowohl gedankliches als ethisches Pathos. Es ist die Grundanschauung seines ethischen Spiritualismus, die er der Astro-

I) In astrolog. ,Lib. IV, cap. I2, fol. 543: „Non potest igitur coelum significare inferioria, nisi quatenus causa effectum indicat suum, quare qui causam quidem non esse victi ratione fatentur, signum tamen esse contendunt, hi vocem suam ignorant." 
logie immer wieder entgegenstellt. Die Astrologie annehmen, heißt nicht sowohl die Seinsordnung als vielmehr die Wertordnung der Dinge verkehren, - heißt die ,Materie" zur Herrscherin über den ,Geist" erklären. Dieser Einwand scheint freilich hinfällig zu werden, wenn man die Grundform der Astrologie und ihren geschichtlichen Ursprung erwägt. Denn eben das kennzeichnet ja diese Grundform, daß hier die Himmelskörper keineswegs als etwas bloß Stoffliches, als kosmische Massen, angesehen werden, sondern daß diese Massen belebt sind von geistigen Prinzipien, von den Intelligenzen, die sie beseelen und ihren Lauf bestimmen. Indem das menschliche Schicksal dem Himmel unterworfen wird, wird somit das Sein des Menschen nicht an ein materielles Prinzip geknüpft und gebunden: sondern es wird diesem Sein nur in der Hierarchie der intelligiblen Kräfte, die das All durchwalten, seine feste Stelle bestimmt. Aber eben an diesem Punkte greift nun jene Fassung und Bestimmung des Freiheitsbegriffs ein, wie Pico sie in der Rede „De dignitate hominis" gègeben hatte. Dieser Freiheitsbegriff ist verletzt: - nicht nur wenn der Geist des Menschen der Kausalität der Natur, sondern auch wenn er irgendeiner anderen Art der Bestimmung unterworfen wird, die er nicht selbst gesetzt hat. Das eben bezeichnete den Vorrang, den der Mensch nicht nur vor den übrigen Naturwesen, sondern den er selbst im „Reich der Geister", im Reich der Intelligenzen behauptet, daß er sein Wesen nicht von Anfang an fertig empfängt, sondern da $B$ er es kraft freier Entscheidung gestaltet. Diese Gestaltung widerspricht jeder Determination von außen - mag diese selbst nun als ,,stofflich" oder als ,,geistig“, als materiell oder als spirituell angesehen werden. Der Glaube an die reine Schöpferkraft des Menschen und an die Autonomie dieser Schöpferkraft: dieser echt humanistische Glaube ist es daher, der bei Pico die Astrologie besiegt. So findet er die entscheidenden Beweise für seine These vor allem dort, wo er der astrologischen Welt die Welt der menschlichen Kultur gegenüberstellt. Diese ist kein Erzeugnis kosmischer Kräfte, sondern sie ist das Werk des Genies. Im Genie scheint uns freilich eine ,irrationale", eine in ihre Elemente und ihre kausalen Ursprünge nicht weiter auflösbare Macht entgegenzutreten, so daß wir mit seiner Anerkennung wieder nur vor eine Grenze des Begreifens geführt werden. Aber diese Grenze ist menschlicher, nicht mystischer Art. Bei ihr dürfen wir stehen bleiben: denn sind wir einmal zu ihr vorgedrungen, so haben wir damit den Kreis des menschlichen Seins und den der menschlichen Bestimmung durchmessen. Wir stehen bei jenen letzten Gründen, die für uns allein faßbar sind, weil sie unser eigenes Wesen ausdrücken. Wer diese Gründe noch an ein anderes, ihnen Vorausliegendes anknüpfen will, wer sie aus kosmischen Potenzen und Einflüssen „,er- 
klären" zu können glaubt, der täuscht mit dieser Erklärung nur sich selbst. Nicht die Kraft der Sterne, sondern die der Menschheit ist es, die wir im Werk der großen Denker, der Staatsmänner und Künstler zu erkennen und $\mathrm{zu}$ verehren haben. Was Aristoteles und Alexander über all ihre Zeitgenossen emporgehoben, was ihnen ihre Bedeutung und Macht gegeben hat, warnicht ihr besserer Stern, sondernihr besseres, ,In genium “: und dieses geht nicht auf das Gestirn, nicht auf eine körperliche Ursache, sondern unmittelbar auf Gott als den Quell und Ursprung alles geistigen Seins zurück. Die Wunder des Geistes sind größer als die des Himmels: es heißt nicht sie begreifen, sondern sie leugnen und nivellieren, wenn man sie auf diese zurückführen sucht. ${ }^{1}$ )

So sind es nicht in erster Linie empirisch-naturwissenschaftliche Gründe, so sind es nicht die neuen Methoden der Beobachtung und der mathematischen Rechnung gewesen, die das astrologische Weltbild überwunden haben. Der entscheidende Schlag war gefallen, ehe diese Methoden ihre volle Ausbildung erfahren hatten. Nicht die neue Anschauung der Natur, sondern die neue Anschauung vom Selbstwert des Menschen war das eigentliche Motiv der Befreiung. Der Kraft der ,Fortuna“ tritt die Kraft der ,virtus", dem Schicksal tritt der seiner selbst gewisse und sich selbst vertrauende Wille gegenüber. Das was im eigentlichen und wahrhaftesten Sinne als das Geschick des Menschen zu bezeichnen ist: das fließt ihm nicht von oben, von den Sternen herab, sondern es steigt aus den letzten Tiefen seines Inneren empor. Wir selbst sind es, die die Fortuna zur Göttin machen und sie an den Himmel anheften, während in Wahrheit das Schicksal die "Tochter der Seele“ ist: „sors animae fili $a^{\prime \prime} .^{2}$ ) Es ist bezeichnend für die Art, wie innerhalb der Renaissancephilo-

I) In Astrol. Lib. III, cap. 27, fol. 5I ff. „Admiraris in Aristotele consummatam scientiam rerum naturalium, ego tecum pariter admiror. Causa coelum est, inquis, et constellatio, sub qua natus est; non accedo, non tam vulgata ratione, quod nati eodem astro multi non fuerunt Aristoteles, quam quod praeter coelum, sub quo tanquam causa universali et Boetiae sues et philosophi... pariter germinant, causae proximae sunt Aristoteli propriae et peculiares, ad quas singularem ejus profectum referamus. Primum utique... sortitus est animam bonam, et hanc utique non a coelo, siquidem immortalis et incorporeus animus, quod ipse demonstravit nec astrologi negant. Tum sortitus est corpus idoneum, ut tali animae famularetur, nec hoc etiam a coelo, nisi tanquam a communi causa, sed a parentibus. Elegit philosophari. Hoc et principiorum opus quae diximus, hoc est animi et corporis, et sui arbitrii fuit; profecit in philosophia, hic arrepti propositi et suae industriae fructus... At profecit plus longe quam coaetanei et quam discipuli. Sortitus erat non astrum melius, sed ingenium melius: nec ingenium ab astro, siquidem incorporale, sed a Deo, sicut corpus a patre, non a coelo... Quod vero ad id attinet, quod principaliter hic tractatur, nego quicquam in terris adeo magnum fieri vel videri, ut autorem coelum mereatur. Nam miracula quidem animi (ut diximus) coelo majora sunt, fortunae vero et corporis, utcumque maxima sint, coelo collata minima deprehenduntur."

2) In astrol., Lib. IV, cap. 4 , fol. 53 I. 
sophie die einzelnen verschiedenen Gedankenkreisen entstammenden Motive ineinander greifen und sich wechselseitig befruchten, daß wiederum kein Geringerer als Kepler hier den Gedanken Picos unmittelbar aufnimmt und weiterführt. Kepler steht als Naturforscher, als Mathematiker und Astronom, noch keineswegs völlig außerhalb des Bannkreises der Astrologie. Ganz allmählich setzt sich bei ihm die Loslösung durch: und in diesem Prozeß lassen sich all jene Vermittlungen und Übergänge wieder aufzeigen, die wir innerhalb der Entwicklung der Philosophie der Renaissance verfolgt haben. Was diese Loslösung erschwert und hintanhält, das sind nicht lediglich die Gründe sozialer und ökonomischer Natur, die noch zu Zeiten Keplers die Personalunion zwischen dem Astronomen und Astrologen verlangten. Kepler hat von der ,närrischen Tochter Astrologie" gesprochen, die die höchst weise, aber arme Mutter Astronomie ernähren müsse. ${ }^{1}$ ) Aber nicht immer zeigen seine Äußerungen über die Astrologie die gleiche ironisch-heitere Überlegenheit. Den Konjunktionen der Planeten hat er, noch in einer Schrift des Jahres I623, wenn nicht eine unmittelbare Einwirkung auf die niedere Welt, so doch einen „Stachel und Antrieb“ zugesprochen. Und von diesem Gedanken der, wenn auch nur mittelbaren, Ka usalität, zieht er sich weiterhin auf den Gedanken der bloßen ,Entsprechung“ zurück: das Verhältnis von „Ursache" und „Wirkung“ wird durch ein Verhältnis der Korrelation ersetzt. Der Himmel macht keinen neuen Handel: aber er ,,schlägt die Trommel" zu denen, die aus natürlichen Gründen, aus physischen Ursachen und aus menschlichen Affekten und Leidenschaften, entstehen. ${ }^{2}$ ) Das eigentlich entscheidende Argument gegen die Astrologie aber entnimmt auch Kepler nicht sowohl der Welt des natürlichen Geschehens als vielmehr der des geistigen Schaffens. Auch für ihn ist es die Rückbesinnung auf die Urkraft des Geistes, auf die Kraft des „Genies“", die hier die letzte Entscheidung herbeiführt. Nicht Merkur und Mars so spricht er es in der „Harmonia mundi“ aus - sondern Copernicus und Tycho de Brahe seien seine Gestirne gewesen. Vergebens werde der Astrolog in seinem Horoskop die Gründe dafür suchen, daß er im Jahre I596 die Proportionen zwischen den Abständen der Planeten oder daß er im Jahre I604 und I6I8 die Gesetze der Bewegung der Planeten ge-

I) Kepler, De stella nova in pede Serpentarii (I606) Cap. XII. (Opera, ed. Frisch, II, $656 \mathrm{f}$.). , Quod astrologica attinet, equidem fateor, virum illum (Fabricium) auctoritati veterum et cupiditati praedictionum, ubi haec duo conspirant, alicubi succumbere et quodam quasi enthusiasmo praeter rationem abripi: verum ista cum ingenti doctorum virorum turba communia habet. Quo nomine vel solo veniam meretur. Quid ringeris, delicatule philosophe, si matrem sapientissimam sed pauperem stulta filia, qualis tibi videtur, naeniis suis sustentat et alit."

2) S. Keplers Discurs von der großen Conjunction und allerlei Vaticiniis über das I623. Jahr, Op. VII, 697ff., vgl. bes. VII, $706 \mathrm{f}$. 
funden habe. „Non influxerunt ista cum charactere coeli in flammulam illam facultatis vitalis nuper incensae inque actum productae, sed partim intus in penitissima animae essentia latebant secundum Platonicam doctrinam ..., partim alia via per oculos nimirum, introrsum recepta sunt; sola et unica thematis genethliaci opera fuit ista, quod et emunxit illos ingenii judiciique igniculos et instigavit animum ad laborem indefessum auxitque desiderium sciendi; breviter: non inspiravit animum, non ullam dictarum hic facultatum, sed excivit."1) So empfängt hier jene Wechselbestimmung, die schon in Picos Schrift gegen die Astrologie hervorgetreten war, ihre Bestätigung. Das Freiheitsproblem schließt sich aufs engste mit dem Erkenntnisproblem zusammen: die Fassung des Freiheitsbegriffs bestimmt den Erkenntnisbegriff, wie umgekehrt dieser durch jene bestimmt wird. Denn die Spontaneität und Produktivität der Erkenntnis ist es, die zuletzt zum Siegel für die Überzeugung von menschlicher Freiheit und menschlicher Schöpferkraft wird. Wir haben früher die Bedeutung aufgewiesen, die das Prometheus-Motiv, wie es sich im Denken der Renaissance fortschreitend entfaltet, für die allmähliche Umgestaltung des mittelalterlich-theologischen Weltbildes besitzt: jetzt zeigt sich, $\mathrm{da} ß$ es im Grunde das gleiche Motiv ist, das im Kampf gegen die Astrologie, gegen die Weltanschauung der ausgehenden Antike, die treibende Kraft bildet, und das zuletzt den Sieg über sie entscheidet. Giordano Bruno hat im ,,Spaccio della bestia trionfante“ für diese geistige Gesamtbewegung das charakteristische Symbol geschaffen. Die Sternbilder des Tierkreises, die dem in Wahn und Aberglauben befangenen Menschen als die höchsten Herrscher über sein Geschick erscheinen, sollen gestürzt und durch andere Mächte ersetzt werden. Eine neue Moralphilosophie soll gegründet werden, die den Gegenstand rein nach dem ,,inneren Licht darstellt, das auf der Warte oder am Steuer unsrerer Seele sitzt. Dies Prinzip des Gewissens und des Selbstbewußtseins: das Prinzip der ,,Sinderesis ", wie Bruno es nennt ${ }^{2}$ ), tritt an die Stelle der unbewußt wirkenden, kosmisch-dämonischen Kräfte. , ,Ordnen wir vor allem jenen Himmel, der geistig in uns selber liegt (che intellettualmente è dentra noi) - und dann jenen sichtbaren, der sich körperlich unsern Augen darstellt. Nehmen wir aus dem Himmel unseres Geistes die Bärin der Roheit, den Pfeil des Neides, das Füllen der Leichtfertigkeit, den Hund der üblen Nachrede, die Hündin der Schmeichelei hinweg; verbannen wir den Herkules der Gewalttätigkeit, die Leier der Verschwörung ... den Cepheus der Hartherzigkeit. Wenn wir so unsere Behausung gereinigt und unseren Himmel neu geschaffen haben werden: dann werden auch neue Konstellationen,

I) Kepler, Harmonice mundi, Lib. IV, cap. 7 (Op. V, 262 f.).

2) Bruno, Lo spaccio della bestia trionfante; Opere ital., ed. Lagarde, S. 4$^{\text {I2 }}$. 
neue Einflüsse und Kräfte, neue Geschicke herrschen: denn von dieser oberen Welt hängt alles ab und aus entgegengesetzten Ursachen fließen notwendig entgegengesetzte Wirkungen. O wir Glücklichen, wir wahrhaft Seligen, wenn wir nur unseren Geist und unser Denken in der rechten Weise anbauen. Wollen wir unseren Zustand ändern, so ändern wir unsere Sitten; wollen wir, daß dieser gut und besser wird, so dürfen letztere nicht schlechter werden. Reinigen wir den Trieb in unserem Inneren: so wird es nicht schwer sein, von dieser Neugestaltung der inneren Welt zur Umformung der sinnlichen und äußeren zu gelangen" (purghiamo l'interiore affetto: atteso che dall' informatione di questo mondo interno non sarà difficile di far progresso alla riformatione di questo sensibile et esterno). ${ }^{1}$ ) So trägt selbst bei dem Denker, den man als typischen Vertreter der ,naturalistischen “Tendenzen der Renaissance anzusehen pflegt, die Naturphilosophie und Kosmologie ein ausgesprochen ethisches Gepräge: nur durch den heroischen Affekt, der sich in ihm selbst entzündet, wird der Mensch der Natur gewachsen und zur Anschauung ihrer Unendlichkeit und Unermeßlichkeit reif.

I) Bruno, Spaccio a. a. O., S. $439 \mathrm{f}$. 


\section{VIERTES KAPITEL}

\section{DAS SUBJEKT-OBJEKT-PROBLEM IN DER PHILO- SOPHIE DER RENAISSANCE}

I.

Die doppelseitige und doppelsinnige Beziehung, in der die Renaissance zum Mittelalter, wie zur Antike steht, zeigt sich nirgends deutlicher als in der Stellung, die sie zum Problem des Selbstbewußtseins einnimmt. In diesem Zentralproblem fließen alle geistigen Quellen, aus denen sie sich nährt, zusammen. Aber aus dieser vielfältigen und gegensätzlichen historischen Bedingtheit heraus ergeben sich nun zugleich neue systematische Fragen. Die bewußte Formulierung dieser Fragen ist freilich eines der spätesten Ergebnisse der Renaissancephilosophie: sie wird erst bei Descartes, ja im gewissen Sinne erst bei Leibniz erreicht. Hier wird erst der neue ,Archimedische" Punkt gefunden und bestimmt, von dem aus die Begriffswelt der scholastischen Philosophie aus den Angeln gehoben wird. Und so pflegt man denn auch von hier, von Descartes' Prinzip des „Cogito“ an, den Anfang der modernen Philosophie zu datieren. Dieser Anfang erscheint in keiner Weise geschichtlich vermittelt: er beruht, wie Descartes selbst es empfunden und ausgesprochen hat, auf einer freien Tat des Geistes, der mit einem Schlage, mit einem einmaligen selbständigen Willensentschluß alles Vergangene von sich abwerfen und den neuen Weg der denkenden Selbstbesinnung beschreiten muß. Hier handelt es sich nirgends um eine allmähliche Evolution, sondern um eine echte „,Revolution der Denkart". Aber der Wert und die Bedeutung dieser Revolution wird nicht geschmälert, wenn man das Werden und das stetige Anwachsen der intellektuellen und der allgemeingeistigen Kräfte verfolgt, aus denen sie zuletzt hervorbricht. Diese Kräfte bilden zunächst keine Einheit und weisen keine straffe Organisation auf. Sie wirken eher gegeneinander als miteinander: sie scheinen, wie sie ganz verschiedene Ansatzpunkte haben, auch auf verschiedene intellektuelle Zielpunkte gerichtet zu sein. Und doch stimmen sie alle in einer negativen 
Leistung überein: sie bedeuten gewissermaßen die Auflockerung des Erdreichs, aus dem die neue, die spezifisch-moderne Grundanschauung des Verhältnisses von „,Subjekt" und „Objekt“ hervorgehen sollte. Es gibt kaum irgendeine Richtung der Renaissancephilosophie, die an dieser Arbeit nicht beteiligt wäre. In sie greift nicht nur die Metaphysik, sondern auch die Naturphilosophie und die empirische Naturerkenntnis, nicht nur die Psychologie, sondern auch die Ethik und die Ästhetik ein. Auch die Differenzen zwischen den verschiedenen Schulrichtungen finden hier ihren Ausgleich: denn die Bewegung, die aus dem Platonismus hervorgeht, konvergiert an diesem Punkte mit der, die von dem erneuerten und reformierten Aristotelismus ihren Ausgang nimmt. Das geschichtliche Bewußtsein der Epoche wie ihr systematisches Bewußtsein sieht sich hier vor die gleichen Grundfragen gestellt und auf bestimmte sachliche Entscheidungen hingedrängt. -

Es gehört $\mathrm{zu}$ den fundamentalen Leistungen der griechischen Philosophie, daß es ihr zuerst gelingt, den Begriff des Selbstbewußtseins, wie den Begriff der Welt, aus der Sphäre des mythischen Denkens herauszuarbeiten. Beide Aufgaben bedingen einander wechselseitig: denn erst das neue Bild des Kosmos, das das griechische Denken entwirft, schafft der neuen Anschauung vom Ich, die hier ersteht, Raum. Noch tiefer und fester als die Anschauung der Dingwelt schien freilich die Anschauung vom Ich mit mythischen Bestandteilen und Voraussetzungen verwoben. Denn noch bei Platon ist das Problem des Ich unlöslich mit dem der Seele verknüpft: derart, daß selbst Platons philosophische Sprache keine anderen Ausdrücke für dieses Problem kennt, als solche, die in irgendeiner Weise auf die Grundbedeutung der $\psi v \chi \eta_{n}^{\prime}$ zurückgehen. Bei Platon selbst drückt sich dies Verhältnis in einer dauernden Spannung aus, die seine gesamte Lehre vom Anfang bis zu Ende beherrscht. Denn jetzt müssen selbst die neuen Grundeinsichten, die der Dialektiker Platon auf seinem Wege, auf dem Weg der fortschreitenden Analyse und der immer tieferen Fundamentierung des Wissens gewinnt, sich in die Sprache von Platons metaphysischer Psychologie kleiden. Die Begriffsbestimmung des ,Apriori“ und der Aufweis seines Notwendigkeitsgrundes erfolgt in der Form der Platonischen Anamnesis-Lehre; die Unterscheidung der Grade und der Arten der Gewißheit sucht in der Absonderung verschiedener Seelenteile ihre Stütze. Auf dem Höhepunkt der Platonischen Spekulation, der durch die Altersdialoge Platons bezeichnet wird, scheint freilich die sichere und scharfe Abgrenzung der einzelnen Problemkreise erreicht. Noch der Theaetet definiert die Einheit des Bewußtseins

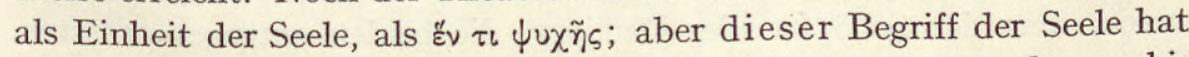
alle primitiv-mythischen Bestandteile, alle Erinnerungen an den orphi- 
schen Seelenbegriff und Seelenglauben von sich abgestreift. Er steht gewissermaßen nur noch als Symbol für den fortschreitenden Prozeß und die fortschreitende Funktion der Vereinigung, die das reine Denken an den Inhalten der Wahrnehmung vollzieht. Nichtsdestoweniger besteht auch jetzt die Polarität der Motive und die Polarität der Darstellungsmittel fort. Platons Philosophie kennt zwei einander scharf entgegengesetzte Darstellungsformen, deren eine für das Reich des Seins, deren andere für das Reich des Werdens gilt. Nur vom immer Seienden, von dem, was mit sich selbst identisch bleibt und was sich stets in der gleichen Weise verhält, ist ein strenges Wissen möglich. Das Werdende, das zeitlich Bedingte und von Moment zu Moment Veränderliche aber ist einer solchen Erfassung durch das Wissen nicht fähig: es kann, wenn überhaupt, so nur in der Sprache des Mythos beschrieben werden. Fragt man jedoch, gemäß dieser Grundunterscheidung der Platonischen Erkenntnislehre, welches Erkenntnismittel das für die Auffassung und Darstellung der Seele gemäße und adaequate ist: so läßt diese Frage keine eindeutige Antwort zu. Denn die Seele durchbricht die ursprüngliche Platonische Scheidung: sie gehört sowohl dem Reich des Seins, wie dem des Werdens, und sie gehört in gewissem Sinne weder dem einen noch dem anderen an. Sie ist ein $Z$ wischen- und Zwitterwesen: gleich unfähig, auf das reine Sein der Idee, wie auf die Welt der Erscheinung und des Werdens zu verzichten. Jede menschliche Seele hat ihrer Natur nach das Seiende geschaut und bleibt der Erfassung der reinen Seinsverhältnisse fähig: aber jede trägt zugleich die Richtung, die Tendenz, das Streben zur sinnlichenVielheit und zum sinnlichen Werden in sich. Diese doppelte Bewegung ist es, worin ihr Bestand, ihre eigentliche Wesenheit sich ausdrückt. So bleibt sie ein ,Mittleres" zwischen Werden und Sein, zwischen Erscheinung und Idee. Sie ist auf beide Pole, auf das Seiende und Wërdende, auf das Identische und das Verschiedene bezogen, ohne in das eine oder andere Gebiet einzugehen, ohne ihm verhaftet zu sein. Vielmehr bleibt sie sowohl der reinen Idee gegenüber, wie gegenüber den Phänomenen, den Inhalten der sinnlichen Wahrnehmung, ein Eigenes und Selbständiges. Als ",Subjekt" des Denkens und des Wahrnehmens fällt sie nicht mit dem Inhalt des Wahrgenommenen oder mit dem Inhalt des Gedachten zusammen. Die mythische Sprache des Platonischen Timäus muß freilich diesen Unterschied verwischen: denn wie sie nur die eine Dimension des zeitlichen Geschehens kennt, so muß sie auch alle qualitativen Unterschiede in Unterschiede des zeitlichen Ursprungs und der zeitlichen Schöpfung umsetzen. So wird hier die Seele zu einem Mischwesen, dem der Schöpfer, der Demiurg, die beiden entgegengesetzten

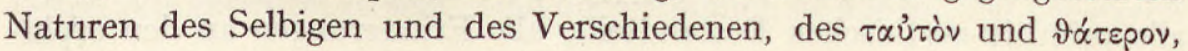


aufgeprägt und gewissermaßen eingeschmolzen hat. Eine ideale Bedeutungsdifferenz wird, wie es dem Wesen und der Eigenart des mythischen Ausdrucks entspricht, in eine ontologische Differenz des Seins und der Abstammung umgesetzt. Und wesentlich in dieser Form hat die Platonische Seelenlehre auf die Folgezeit gewirkt. Das ganze Mittelalter hindurch bleibt der Timäus ein philosophisches Grundbuch, bleibt er fast der einzige Platonische Dialog, der, in der Übersetzung des Chalcidius, gekannt und gelesen wird. So kann hier der Sokratisch-Platonische Seelenbegriff, der die Seele als Prinzip der Subjektivität erfaßt, nur in mythischer Umhüllung und in mythischer Objektivierung gedacht werden. Schon im antiken Denken selber hatte dieser Prozeß der Objektivierung eingesetzt. Aristoteles deutet die Seele als die F orm des Leibes: aber als solche ist sie zugleich die in ihm wirksame, die ihm immanente Kraft der Bewegung. Sie ist ebensowohl die $Z$ weckursache, die die ideale „Bestimmung“" des Leibes ausdrückt, wie sie die bewegende Ursache ist, durch welche der Leib in fortschreitender Entwicklung dieser seiner Bestimmung zugeführt wird. In dieser Auffassung der Seele als der ,Entelechie" des Körpers wird sie wiederum zur reinen Naturpotenz, zur Kraft des organischen Lebens und der organischen Gestaltung. Zwar sieht sich Aristoteles selbst, an einem entscheidenden Punkt seiner Lehre, zu einer Umbildung und Erweiterung seinès ursprünglichen Seelenbegriffs hingedrängt. Denn wenn dieser die Phänomene des Lebens umfaßt und erklärt, so genügt er nicht, um alle Bestimmungen des Wissens zu umfassen. Das Wissen ist in seiner höchsten und reinsten Form nicht mehr auf ein Individuelles, sondern auf ein schlechthin Allgemeines, nicht mehr auf einen ,stofflichen“, sondern auf einen rein intelligiblen Inhalt bezogen. Und so muß die seelische Kraft, die dieses Wissen in sich verwirklicht, mit dem Gegenstand von gleicher Art sein, so muß auch sie als von allem

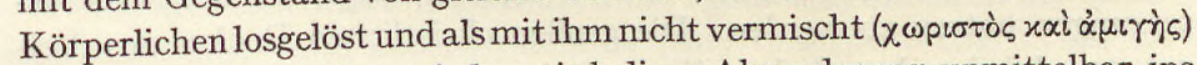
gedacht werden. Aber wieder wird diese Absonderung unmittelbar ins Metaphysisch-Ontologische übersetzt. Der Aristotelische voũ $\zeta$, der das Subjekt des reinen Denkens, des Denkens der „,ewigen Wahrheiten“ ist, ist ebenso ein objektives ,Geistwesen“, wie die Seele als Form des organischen Körpers ein Naturwesen ist. Wie diese bewegende Kraft ist, so ist er denkende Kraft, die von außen her ( $\vartheta$ úpa $\vartheta \varepsilon v)$ in den Menschen eintritt. Der Neuplatonismus nimmt diese Bestimmung auf: aber er entkleidet zugleich die Denkkraft jenes spezifischen Sondercharakters, der ihr bei Aristoteles zukam, indem er sie wieder der allgemeinen Hierarchie der Kräfte, die vom Einen zum Vielen, vom Intelligiblen zum Sinnlichen hinabführt, einordnet und ihr innerhalb derselben einen festen Platz anweist. Je weiter hier die Entwicklung fortschreitet, um so mehr drängen sich zwi- 
schen die Denkkraft als solche und die Form, in der sie im Menschen, als konkretem Individuum, erscheint, eine Fülle von halb-göttlichen, halbdämonischen $Z$ wischenwesen. Ihren Abschluß und ihre folgerechte systematische Formulierung hat diese Entwicklung in der arabischen Philosophie des Mittelalters, vor allem in der Averroistischen Lehre erhalten. Indem hier die Seele wieder ganz in den Kreis der objektiv-metaphysischen Kräfte zurückgenommen wird, wird damit nicht nur das Prinzip der Subjektivität, sondern auch das der Individualität aufgegeben. Die Grundkraft des Denkens ist über jede Art der Individuation erhaben: denn der Intellekt als solcher ist kein vielfach geteilter, sondern er bildet eine absolute Einheit. Der Akt des Denkens besteht eben darin, daß das Ich aus der Isolierung, die ihm als bloßem Lebewesen anhaftet, herausgeht: daß es sie überwindet und daß es mit dem Einen absoluten Intellekt, dem ,intellectus agens" verschmilzt. Die Möglichkeit dieser Verschmelzung wird jetzt nicht nur vom Standpunkt der Mystik, sondern sie muß von dem der Logik gefordert werden: denn sie allein scheint den Prozeß des Denkens real erklären und ihn in seiner notwendigen Geltung begründen zu können. Das wahrhafte Subjekt des Denkens ist nicht das Individuum, nicht das ,Selbst“, sondern es ist ein allen Denkenden gemeinsames unpersönliches, substantielles Sein, dessen „Verbindung“ mit dem einzelnen Ich eine äußere und zufällige bleibt.

Aber an diesem Punkte gerät nun das logisch-metaphysische System, das sich aus dem Ineinandergreifen des Aristotelismus und Neuplatonismus entwickelt hatte, mit dem System des Glaubens, dessen sicherste Stütze es bisher zu sein schien, in offenen Widerstreit. Der christliche Glaube zum mindesten kann von dem Prinzip des "Subjektivismus", von dem Prinzip der Selbständigkeit und des Selbstwertes der Einzelseele nicht lassen, ohne damit seinen eigenen religiösen Grundvoraussetzungen untreu zu werden. Die großen christlichen Denker des dreizehnten Jahrhunderts haben diesen $Z$ wiespalt gefühlt - und sie haben, um ihm zu entgehen, die systematischen Konsequenzen, die der Averroismus gezogen hatte, fort und fort bekämpft. Thomas von Aquino hat ihrer Widerlegung eine eigene Schrift: „De unitate intellectus contra Averroistas" gewidmet. Der Grundgedanke dieser Schrift besteht darin, daß die Averroistische These das Phänomen des Denkens, das sie zu erklären vorgibt, in Wahrheit vielmehr vernichtet. Was der Intellekt an sich, was er seinem allgemeinen Wesen nach ist, diese Frage selbst läßt sich nicht stellen, ohne daß wir die F unktion des Denkens ausüben: diese Funktion selbst aber kennen wir empirisch nicht anders als in individueller Form, in der Beziehung auf ein denkendes Selbst. Dieses Selbst ausschalten heißt also das Faktum vernichten, auf dem alle Theorie des 
Wissens sich aufbauen muß. Und noch weit mehr als die Theorie des Wissens wird die religiöse Selbstgewißheit durch den Averroismus in ihrer Eigenart und in ihrem innersten Kern bedroht. Denn diese Gewißheit fordert, daß die beiden Glieder des religiösen Grundverhältnisses, daß Gott und Ich in ihrer Selbständigkeit erhalten werden. Der allgemeine, der absolute Gehalt des Glaubens kann nicht anders ergriffen und angeeignet werden, als dadurch, daß wir uns in das Zentrum des religiösen Lebens versetzen: für dieses aber bildet die Persönlichkeit keine bloße zufällige Schranke und Hemmung, sondern in ihm wirkt sie als unumgängliches, als konstitutives Prinzip. Schon der erste große Systematiker des Christentums, schon Augustin hatte diese Folgerung in aller Schärfe gezogen. Es ist bekannt, daß sein religiöser Subjektivismus ihn unmittelbar zu jenen Grundergebnissen hinführt, die Descartes später als Logiker und als Kritiker der Erkenntnis formuliert. Es ist ein und dasselbe Prinzip der Verinnerlichung, der Reflexion auf sich selbst, auf dem sein religiöser Idealismus und auf dem Descartes' logischer Idealismus beruht. "Noli foras ire, in te ipsum redi: in interiore homine habitat veritas". Das eigene Sein, Wissen und Wollen, das eigene esse, nosse und velle bildet den unerschütterlichen Ausgangspunkt aller Theorie: denn nichts weiß der Geist so gut, wie das, was ihm gegenwärtig ist und nichts kann ihm gegenwärtiger sein, als er sich selber ist. ${ }^{1}$ ) In diesen Sätzen wird der Primat der religiösen Erfahrung gegenüber allen dogmatischen Konsequenzen einer metaphysischen Seelen- und Gotteslehre festgestellt. Die Einordnung des Ich in ein konstruktives Schema der objektiven Erkenntnis hört auf: denn eben diese mittelbare Bestimmung reicht an sein spezifisches Wesen und an seinen spezifischen Wert, der durchaus ein Wert sui generis ist, nicht heran.

Man muß sich diesen Gegensatz, diese Spannung, die schon im mittelalterlichen Lehr- und Lebenssystem besteht, vergegenwärtigen, um die Wendung zu verstehen, die mit der Philosophie der Renaissance einsetzt. Der Averroismus schien im vierzehnten und fünfzehnten Jahrhundert, trotz aller Angriffe, die er in den klassischen Systemen der Scholastik erfahren hatte, in seinen theoretischen Grundlagen noch unerschüttert zu sein. Lange Zeit bildet er an den italienischen Universitäten die herrschende Lehre. In dem eigentlichen gelehrten Zentrum der scholastischen Studien, in Padua, hat die Averroistische Doktrin sich von der ersten Hälfte des vierzehnten Jahrhunderts bis ins sechzehnte und siebzehnte Jahrhundert behauptet. ${ }^{2}$ ) Aber allmählich setzt immer deutlicher die Gegenbewegung gegen sie ein. Es ist charakteristisch, daß diese Gegen-

I) Augustinus, De trinitate XIV, 7., De vera religione, Cap. 39 u. ö.

2) Näheres bei Ernest Renan, Averroes et l'Averroisme, 3e. edit., Paris 1866. 
bewegung keineswegs auf den Kreis der Schule beschränkt bleibt, sondern daß sie ihre stärksten Antriebe von anderer Seite her empfängt. Es sind die Männer des neuen humanistischen Bildungsideals und des neuen Persönlichkeitsideals der Renaissance, die zuerst zum Kampf gegen den Averroismus aufrufen. Petrarca geht auch auf diesem Wege voran. Die leidenschaftliche Fehde, die er sein Leben lang gegen den Averroismus geführt hat, ist von theoretischen Mißverständnissen nicht frei : aber diese tun ihrem Wert nur geringen Eintrag. Denn hier handelt es sich um mehr als um bloß spekulativ-theoretische Erörterungen; hier ist es eine geniale Persönlichkeit, die sich aus dem Recht ihres ursprünglichen Lebensgefühls heraus gegen Folgerungen, die dieses Recht beschränken und die es zu verkümmern drohen, auflehnt. Der Künstler und Virtuose der "Individualität", der sie zuerst wieder in ihrem unerschöpflichen Reichtum und in ihrem unerschöpflichen Wert entdeckt hat, setzt sich gegen eine Philosophie zur Wehr, für die alle Individualität etwas schlechthin Zufälliges, etwas rein „Accidentelles“ bedeutet. Und für diesen Kampf wird ihm Augustin zum eigentlichen Gewährsmann. Wie Petrarca, als einer der Ersten, die geschichtlichen Schöpfungen des Geistes nicht mit ihrem bloßen objektiven Gehalt auf sich wirken läßt, sondern wie er hinter ihnen das Leben ihrer Schöpfer erfühlen und mitleben will, so tritt er kraft dieser Gabe, über die Jahrhunderte hinweg, mit Augustin in unmittelbare Berührung. Das lyrische Genie der Individualität entzündet sich an dem religiösen Genie der Individualität: denn Lyrik und Religion fließen in der charakteristischen Form von Petrarcas Mystik in eins zusammen. Diese Mystik ist nicht, gleich der Averroistischen, kosmologisch, sondern sie ist rein psychologisch orientiert. Und so sehr sie die Einheit der Seele mit Gott sucht und ersehnt, so ist ihr doch diese Einheit nicht das einzige und wesentliche Ziel, in dem sie ausruhen will; sondern immer wieder vertieft sie sich in die Anschauung der inneren Bewegtheit des Ich, um sie in ihrer Mannigfaltigkeit zu bewundern und sie, eben in ihrer Gegensätzlichkeit, zu genießen. Man begreift von hier aus, wie Petrarca in seinem Kampf gegen den Averroismus beständig seine Gläubigkeit betonen, wie er sich in ihm ganz als orthodoxer Christ fühlen kann, der die Einfalt des Glaubens gegen die Anmaßungen der menschlichen Vernunft verteidigt - und wie doch andererseits dieses Christentum bei ihm eine ganz persönliche, eher ästhetische als religiöse Prägung gewinnt. Die philosophische Reflexion mußte, wenn sie des Averroismus Herr werden wollte, einen anderen Weg einschlagen; sie mußte, statt sich in das Gefühl und in den Genuß der Individualität zu versenken, ein neues tieferes Prinzip für sie aufzustellen suchen. Wir sahen, daß es die Lehre des Nikolaus Cusanus ist, in der zuerst dies 
Prinzip gewonnen wird. In der Zeit, in der Cusanus in Padua studiert, steht der Averroismus der Schule von Padua auf dem Höhepunkt seiner Entwicklung. Aber nichts weist darauf hin, daß er von ihm irgendeine wesentlich gedankliche Anregung erhalten hat. In seinen späteren systematischen Hauptschriften hat er seine Grunddoktrin ausdrücklich bekämpft; - und zwar mit Beweisgründen, die nicht sowohl seiner Metaphysik, als vielmehr seiner Erkenntnislehre entstammen. Diese erkennt zwischen dem Reich des Sinnlichen und des Intellektuellen keine absolute Trennung an: denn wenngleich Sinnliches und Intellektuelles einander entgegengesetzt sind, so bedarf doch der Intellekt eben dieses Gegensatzes und Gegenhaltes der sinnlichen Wahrnehmung, weil er nur durch ihn zu seiner eigenen Vollendung, zu seiner vollen Aktualität gelangen kann. (Vgl. ob. S. 47 f.) So läßt sich denn auch keine geistige Funktion denken, die schlechthin losgelöst vom sinnlichen Material vollzogen werden könnte. Der Geist erfordert, um wirksam werden zu können, einen ihm entsprechenden und ,,adaequaten" Körper : und darin liegt weiterhin, daß die Differenzierung und Individualisierung des Denkakts mit der der körperlichen Organisation gleichen Schritt halten muß. „Wie nämlich das Sehen Deines Auges, nicht das Sehen irgendeines anderen sein könnte, auch wenn es von Deinem Auge losgelöst und mit dem Auge eines andern verbunden würde, weil es jenes $\mathrm{Maß}$, das es in Deinem Auge besitzt, in dem eines andern nicht wiederfinden kann, - und wie die Unterscheidung, die in Deinem Sehen ist, nicht die Unterscheidung im Sehen eines anderen sein kann: so läßt sich auch nicht ein Intellekt in allen Menschen denken." Hier bricht ein Gedanke durch, der seine vollständige systematische Durchführung und Ausgestaltung erst bei Leibniz erfahren wird. Der reine Denkakt hat das Sinnliche und Körperliche nicht einfach zum gleichgültigen und indifferenten Substrat, noch bedient er sich desselben als eines bloßen Organs, das ihm selbst wie ein totes Werkzeug gegenübersteht: sondern die Kraft und die Leistung dieses Aktes besteht eben darin, $\mathrm{da} \beta$ er die im Sinnlichen gelegenen Unterschiede als solche erfaßt und vollständig in sich repräsentiert. Das principium individuationis kann demgemäß nicht in der bloßen „Materie“ des Denkens gesucht werden, sondern es muß in seiner reinen Form gegründet sein. Die Seele, als aktive Denkkraft, ist nicht nur im Leibe, wie in einer äußeren Behausung eingeschlossen, sondern sie drückt alle in ihm bestehenden Differenzen und alle in ihm vorgehenden Veränderungen mit größerer oder geringerer Deutlichkeit aus. So besteht zwischen Seele und Leib nicht nur ein Verhältnis der Verbindung, sondern der durchgehenden „Angemessenheit“: der durchgängigen Proportion, 
wie Cusanus es nennt. ${ }^{1}$ ) Wenn er hierbei die entgegengesetzte Auffassung nicht nur bei Averroes, sondern auch in der Lehre bestimmter Neuplatoniker vertreten findet, so ist es für den Neuplatonismus der Renaissance, für die Florentinische Akademie, bezeichnend, daß sie in diesem entscheidenden Problem mit Cusanus durchaus auf gleichem Boden steht. Auch Ficin hat in seinem Hauptwerk, der ,Theologia Platonica" und in seinen Briefen die Lehre von der Einzigkeit des ",aktiven Intellekts" ständig bekämpft. Auch er beruft sich hierfür auf die unmittelbare Erfahrung, die uns das, was wir unser Ich und was wir unser Denken nennen, immer nur in schlechthin individueller Form zeige. Zwischen dem Wesen des Selbst und dem, als was es sich uns im unmittelbaren Bewußtsein gibt, kann aber keine prinzipielle Verschiedenheit bestehen: ,quid enim menti naturalius, quam sui ipsius cognitio? ‘ $\left.{ }^{2}\right)$

Aber diesem Prozeß, der auf die Herausarbeitung der the or et isch en Grundlagen und Bedingungen des Begriffs der ",Subjektivität" hinzielt, steht nun ein anderer gegenüber, der uns erst die eigentlichen Kräfte deutlich macht, durch welche diese gesamte geistige Bewegung letzten Endes bestimmt und beherrscht wird. Das Fundament, auf dem Ficin seine Seelenlehre und seine Lehre von der individuellen Unsterblichkeit aufbaut, ist nicht sowohl seine Grundansicht von der menschlichen Erkenntnis als vielmehr seine Grundansicht vom menschlichen Willen. Die Lehre vom Eros ist der eigentliche Angelpunkt von Ficins Psychologie. Sie wird zum Mittelpunkt aller philosophischen Bestrebungen der Florentinischen Akademie; sie bildete - wie Christoforo Landinos Disputationes Camaldulenses uns zeigen $\left.{ }^{3}\right)$ - das ewigunerschöpfliche Thema der akademischen Gespräche. Von diesem Zentrum gehen all die Wirkungen aus, die die Akademie auf das geistige Gesamtleben der Zeit, die sie auf die Literatur und auf die bildende Kunst des Quattrocento geübt hat. Zugleich findet hier eine ständige Wechselwirkung statt: wie Girolamo Benivieni in seiner "Canzone dell" amor celeste e divino" den Grundgedanken von Ficins Liebestheorie in poetische Form kleidet; so hat Pico von Mirandula durch den

I) Cusanus, Idiota lib. III de mente, Cap. I2, fol. 167 f.: „Sicut enim visus oculi tui non posset esse visus cujuscunque alterius, etiam si a tuo oculo separaretur et alterius oculo jungeretur, quia proportionem suam, quam in oculo tuo reperit, in alterius oculo reperire nequiret: sic nec discretio, quae est in visu tuo, posset esse discretio in visu alterius. Ita nec intellectus discretionis illius posset esse intellectus discretionis alterius. Unde hoc nequaquam possibile arbitror unum esse intellectum in omnibus hominibus."

2) Ficinus, Epistol. Lib. I., fol. 628 .

3) Über Landinos "Disputationes Camaldulenses" und den Wert, den sie als Quelle für die Geschichte der Florentinischen Akademie besitzen, vgl. bes. della Torre, Storia dell' Academia Platonica di Firenze, Firenze 1902, S. $579 \mathrm{ff}$. 
Kommentar, den er zu Benivienis Gedicht geschrieben, diese Gedanken wieder in die rein philosophische Sphäre zurückgewandt. ${ }^{1}$ ) Pico und Ficin scheinen hierbei von keinem anderen Bestreben geleitet, als die Platonische Theorie des Eros so getreu als möglich zu reproduzieren: beide schließen sich unmittelbar der Darstellung des Platonischen Gastmahls an, die Ficin in einem eigenen Werke aufs eingehendste kommentiert hat. Und doch tritt vielleicht nirgends so deutlich, wie eben hier, die Besonderheit und Eigenart des ,christlichen“" Platonismus der Florentiner Akademie hervor. "Mitto ad te" — so schreibt Ficin in einem Brief an Luca Controni, mit dem er die Übersendung seines Symposion-Kommentars und seiner Schrift „De christiana religione“ begleitet — ,amorem, quem promiseram. Mitto etiam religionem ut agnoscas et amorem meum religiosum esse et religionem amatoriam. "2) In der Tat ist die Eros-Lehre Ficins der Punkt, an dem seine Psychologie und seine Theologie sich begegnen, und an dem beide unlöslich miteinander verschmelzen. Auch bei Platon gehört der Eros einem mittleren Reich des Seins an: zwischen dem Göttlichen und dem Menschlichen, der intelligiblen Welt und der sinnlichen Welt stehend, ist er dazu bestimmt, beide aufeinander zu beziehen und aneinander zu binden. Diese Bindung vermag er nur zu vollziehen, sofern er selbst nicht ausschließlich einer der beiden Welten angehört. Er selbst ist weder Fülle, noch Mangel, weder wissend, noch unwissend, weder unsterblich noch sterblich: sondern aus all diesen Gegensätzen ist sein "dämonisches“ Wesen gemischt. Diese in sich selbst zwiespältige Natur des Eros bildet das eigentlich bewegende Moment des Platonischen Kosmos. Hier dringt in das statische Gefüge desselben zuerst ein dynamisches Motiv ein. Die Welt der Erscheinung und die der Liebe stehen nicht mehr einfach einander gegenüber: sondern die Erscheinung selbst ,strebt" nach der

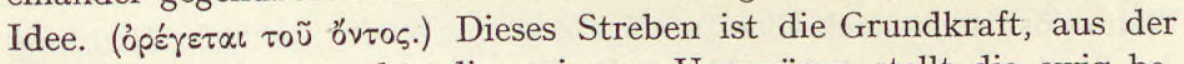
alles Werden hervorgeht; dieses innere Ungenügen stellt die ewig belebende „Unruhe“ dar, die allem Geschehen eine bestimmte Richtung, die Richtung auf das unwandelbare Sein der Idee, vorschreibt. Aber innerhalb des Platonischen Systems ist diese Richtung nicht umkehrbar.

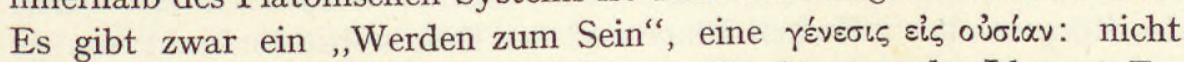
dagegen gibt es ein Wirken vom Sein zum Werden, von der Idee zur Erscheinung hin. Hier bleibt vielmehr das Motiv des $\chi \omega$ pır ós $_{\text {in }}$ aller Strenge erhalten: die Idee des Guten ist „Ursache“ des Werdens lediglich in dem Sinne, daß sie dessen Ziel und Ende darstellt, nicht in dem Sinne, daß sie als bewegende Kraft in das Getriebe der empirisch-sinn-

I) Pico della Mirandola, Opera fol. $734 \mathrm{ff}$.

2) Ficinus, Epistol. Lib. I, fol. 632 . 
lichen Wirklichkeit eingreift. Dieses methodische Verhältnis erfährt sodann im System des Neuplatonismus seine metaphysische Deutung und seine metaphysische Hypostasierung. Auch hier eignet allem bedingten und abgeleiteten Sein der Trieb zur ersten Ursache zurüchäzukehren. Aber diesem Streben des Bedingten zum Unbedingten entspricht auf der Seite des letzteren kein Gegenstreben. Das Überseiende und das Über-Eine des Neuplatonismus steht auch ,,über dem Leben“

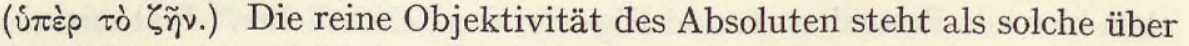
der Sphäre des subjektiven Bewußtseins, mag dieses als praktisches oder als theoretisches Bewußtsein gefaßt werden. Denn wie die Bestimmung des Strebens, so ist auch die des Erkennens vom Absoluten fernzuhalten. Alles Erkennen setzt die Beziehung auf ein anderes voraus, welche der reinen Autarkie des Absoluten, seiner Geschlossenheit in sich selbst widerstreiten würde. ${ }^{1}$ )

Ficins Theorie der Liebe durchbricht diesen Gedankenkreis, sofern sie den Prozeß $\beta$ der Liebe als einen durchaus wechselseitigen Prozeß faßt. Das Streben des Menschen zu Gott, das sich im Eros darstellt, wäre nicht möglich ohne ein Gegenstreben Gottes zum Menschen. Hier ist es der Grundgedanke der christlichen Mystik, der in Ficin lebendig wird, und der auch seinem Neuplatonismus eine neue Prägung gibt. Gott, das absolute objektive Sein ist ebenso in die Subjektivität verstrickt und an sie, als Korrelat, als notwendiges Gegenüber, gebunden, wie alle Subjektivität auf ihn bezogen und gerichtet ist. Die Liebe selbst kann sich nicht anders denn in dieser doppelten Form verwirklichen: sie ist ebensowohl der Drang des Höheren zum Niederen, des Intelligiblen zum Sinnlichen, wie sie die Sehnsucht des Niederen nach dem Höheren ist. Wie sich Gott in einem freien Liebesakt der Welt zuneigt, wie er in einer freien Tat seiner Gnade den Menschen und die Welt erlöst, so ist auch allen Intelligenzen eine solche zwiefache Richtung des Strebens wesentlich. „Es ist die Eigenheit aller göttlichen Geister, daß sie, indem sie das Höhere schauen, nicht aufhören, auf das Niedere $\mathrm{zu}$ blicken und für dasselbe zu sorgen. Dies ist auch die Eigentümlichkeit unserer Seele, die sich nicht nur des eigenen Körpers, sondern auch des Körpers aller irdischen Dinge und der Erde selbst annimmt, um sie zu pflegen und zu fördern." In dieser Pflege, in dieser „Kultur" des Sinnlichen liegt ein Grundmoment und eine Grundaufgabe des Geistigen selbst. Diese Fassung der Eros-Lehre rückt das Problem der Theodizee, mit dem auch der Neuplatonismus ständig gerungen hatte, in ein neues Licht. Jetzt erst wird eine Theodizee im strengen Sinne möglich: denn jetzt ist die Materie nicht mehr als bloßer Gegensatz zur Form, und somit

I) Vgl. bes. Plotin, Ennead. VI, 7,35, VI, 7, 4I u. ö. 
als das „Böse“ schlechthin, sondern als das gefaßt, woran alle Wirksamkeit der Form anzusetzen, und worin sie sich zu bewähren hat. Der Eros ist im eigentlichen Sinne zum „Band der Welt" geworden; denn er ist es, der alle Ungleichartigkeit ihrer verschiedenen Elemente und Bereiche überwindet, indem er jedes von ihnen in seinen Kreis aufnimmt; indem er die substantielle Verschiedenheit der Seinselemente dadurch versöhnt und aufhebt, daß er sie als Subjekte und als Mittelpunkte ein und derselben dynamischen Funktion erkennen läßt. Die Liebe ist es, vermöge deren der Geist zum Sinnlich-Körperlichen herabsteigt, und sie ist es, die ihn wieder aus diesem Gebiet sich erheben läßt: aber in beiden Bewegungen ist es kein fremder Antrieb, kein fatalistischer Zwang, sondern der eigene freie Entschluß, dem er folgt. „Animus nunquam cogitur aliunde, sed amore se mergit in corpus, amore se mergit e corpore. "1) Hier zeigt sich ein geistiger Kreislauf, ein ,circuitus spiritualis", der keines äußeren Zweckes bedarf, weil er sein Ziel und seine Grenze in sich selbst hat, weil er in sich sowohl das Prinzip der Bewegung, wie das der Ruhe findet. ${ }^{2}$ )

Die Philosophie der Renaissance hat diese Grundgedanken der spekulativen Liebeslehre Ficins aufgenommen und sie für die Naturphilosophie wie für die Ethik, für die Kunsttheorie wie für die Erkenntnistheorie fruchtbar zu machen gesucht. Was die Lehre von der Erkenntnis betrifft, so hatte schon die Neuplatonisch-mystische Literatur des Mittelalters Erkenntnis und Liebe unlöslich miteinander verknüpft: denn der Geist vermag sich keinem Objekt in rein theoretischer Betrachtung zuzuwenden, es sei denn, daß er durch einen Akt der Liebe zu ihm

I) Ficinus, Theolog. Platonica, Lib. XVI, cap. 7., fol. $3^{82}$. Dieses entscheidende Moment in Ficins Theorie der Liebe ist von Saitta, La filosofia di Marsilio Ficino, Messina I923, S. 217ff. richtig hervorgehoben worden; aber Saitta hat hier, wie in vielen andren Punkten, die Originalität Ficins gegenüber Nikolaus Cusanus erheblich überschätzt. "Cio che differenzia il Ficino dai filosofi precedenti - so schreibt er - compreso il Cusano, è l'intuizione travolgente dell' amore come spiegamento assoluto, infinito di libertà. ... Il vero mistico s'appunta nella assoluta indistinzione o indifferenza, laddove il pensiero di Ficino respira nell' atmosfera sana della libertà come continua differenziazione “ (a. a. O. ,S. 256). Aber gerade diese "Atmosphäre der Freiheit" ist es, in der Cusanus' Schöpfungsbegriff und sein Begriff der göttlichen Liebe sich bewegt. Vgl. z. B. De beryllo, Cap. XXIII, fol. 275: „Ad omnem essendi modum sufficit abunde primum principium unitrinum: licet sit absolutum et superexaltatum, cum non sit principium contractum, ut natura, quae ex necessitate operatur, sed sit principium ipsius naturae. Et ita supernaturale, liberum, quod voluntate creat omnia.... Istud ignorabant tam Plato quam Aristoteles: aperte enim uterque credidit conditorem intellectum ex necessitate naturae omnia facere, et ex hoc omnis eorum error secutus est. Nam licet non operetur per accidens, sicut ignis per calorem .. (nullum enim accidens cadere potest in ejus simplicitatem) et per hoc agere videatur per essentiam: non tamen propterea agit quasi natura, seu instrumentum necessitatum per superiorum imperium, sed per liberam voluntatem, quae est essentia ejus."

2) Ficinus, Theol. Platonica IX, 4 ; fol. 2 Ir. 
hingetrieben werde. Diese Grundanschauung erfährt in der RenaissancePhilosophie ihre Erneuerung und ihre systematische Durchführung in Patrizzis Lehre. Der Akt der Erkenntnis und der Liebesakt haben ein und dasselbe Ziel: denn beide gehen darauf aus, die Trennung der Seinselemente aufzuheben und zum Punkt ihrer ursprünglichen Einheit zurückzudringen. Das Wissen ist nichts anderes als eine bestimmte Etappe auf diesem Wege der Rückwendung. Es ist selbst eine Form des Strebens: denn jedem Wissen ist die "Intention“ auf sein Objekt (intensio cognoscentis in cognoscibile) wesentlich. Der höchste Intellekt ist durch nichts anderes zum Intellekt, zum denkenden Bewußtsein geworden, als dadurch, daß er sich, durch die Liebe getrieben, in sich selbst entzweit hat, daß er sich eine Welt von Wissensobjekten als Gegenstände der Betrachtung gegenübergestellt hat. Aber der Wissensakt, der diese Entzweiung, diese Hingabe der ursprünglichen Einheit an die Vielheit setzt, ist es auch, der sie wieder überwindet. Denn ein Objekt erkennen, heißt die Distanz, die zwischen ihm und dem Bewußtsein besteht, negieren und mit ihm im gewissen Sinne eins werden: „cognitio nihil est aliud, quam Coitio quaedam cum suo cognobili“. ${ }^{1}$ ) Stärker und tiefer jedoch, als auf die Theorie der Erkenntnis hat die Lehre vom Eros, wie Ficin sie erneuert hat, auf die Anschauung der Renaissance vom Wesen und Sinn der Kunst gewirkt. Die Leidenschaft, mit der viele der großen Künstler der Renaissance die spekulative Grundlehre der Florentinischen Akademie ergreifen, erklärt sich dadurch, daß sie ihnen weit mehr als bloße Spekulation bedeutete. Hier sahen sie nicht nur eine Theorie des Kosmos vor sich, die ihrer Grundanschauung entgegenkam, sondern hier fanden sie vor allem das Geheimnis ihres eigenen Schaffens gedeutet und ausgesprochen. Die rätselhafte Doppelnatur des Künstlers, seine Hingabe an die Welt der sinnlichen Erscheinung und sein ständiges Hinweggreifen und Hinausstreben über sie, schien nun begriffen und in diesem Begreifen erst wahrhaft gerechtfertigt. Die Theodizee der Welt, die Ficin in seiner Lehre vom Eros gegeben hatte, war zugleich zur eigentlichen Theodizee der Kunst geworden. Denn das eben ist die Art des Künstlers, wie es die des Eros ist, daß er Geschiedenes und Entgegengesetztes ständig ineinanderknüpfen muß: daß er im "Sichtigen“ das "Unsichtige“, im "Sinnlichen“ das ,Intelligible" sucht. Wenn sein Schauen und Bilden durch den Hinblick auf die reine Form bestimmt wird, so hat er andererseits eben diese reine Form erst wahrhaft, wenn es ihm gelingt, sie in der Materie zu verwirklichen. Tiefer als jeder andere empfindet der Künstler diese Span-

I) Francisci Patricii Panarchias Lib. XV: De intellectu (Nova de universis philosophia, Ferrar. I59I, fol. 3I). 
nung, diesen polaren Gegensatz der Seinselemente, aber zugleich weiß und fühlt er sich als seinen Vermittler. Hier liegt der Kern aller ästhetischen Harmonie, aber zugleich das ewige Ungenügen, das aller Harmonie, aller Schönheit anhaftet, sofern sie nicht anders als am Materiellen sich offenbaren kann. In dieser Gestalt und in dieser Vertiefung tritt uns die Liebeslehre Ficins in Michelangelos Sonetten entgegen. Vergleicht man diese ihre Fortwirkung mit der Weiterbildung, die sie in der Erkenntnislehre durch Patrizzi, in der Ethik durch Giordano Bruno erfährt, so begreift man erst völlig, worauf die außerordentliche Fruchtbarkeit dieser Lehre beruht. Auch der Platonismus der Schule von Florenz faßt die Ideen noch durchaus als Kräfte, als objektiv-kosmische Potenzen auf: aber daneben entdeckt er, in seiner Lehre vom Eros, einen neuen Begriff des geistigen Selbstbewußtseins. Dieses tritt jetzt in seiner Einheit und seiner Vielfältigkeit, in seiner Besonderung in die Grundtätigkeiten des Erkennens, des Wollens und des ästhetischen Schaffens, wie in seiner immanenten Geschlossenheit und Gleichförmigkeit hervor. Das Selbst, der ,,subjektive Geist“, gliedert sich in die verschiedenen Schaffensrichtungen, aus denen die Mannigfaltigkeit der Kultur, das System des „objektiven Geistes“ hervorgeht. Auch Giordano Bruno beruft sich, unter Hinweis auf Plotin, auf den Eros als denjenigen, der uns das Reich der Subjektivität erst wahrhaft erschließt. Solange unser Auge noch der bloßen Anschauung deswahrgenommenen Gegenstandeshingegeben ist, kann das Phänomen der Schönheit, wie das der Liebe nicht entstehen: beide treten erst hervor, sobald sich der Geist von den äußeren Formen des Bildes zurückzieht und sich in seiner eigenen, nicht-teilbaren und aller Sichtbarkeit entrückten Gestalt begreift. ${ }^{1}$ )

Wenn es hier der Spiritualismus der Renaissance ist, durch den ihre Auffassung des Problems der Seele und des Problems des Selbstbewußtseins bestimmt wird, so nimmt die Entwicklung beider Probleme scheinbar einen völlig anderen Weg, wenn man sie im Rahmen des Naturbegriffs und der naturalistischen Psychologie betrachtet. Die Hinwendung zum Naturalismus, der Versuch, das Prinzip der "Seele" dem allgemeinen Naturzusammenhang einzufügen und es rein immanent aus ihm heraus zu erklären, bildet die Grundtendenz in der kritischen Erneuerung der Aristotelischen Psychologie, die um die Wende des I6. Jahrhunderts von der Schule von Padua versucht wird. Pomponazzis Schrift „De immortalitate animi“ stellt den ersten systematischen Ab-

I) Vgl. Giordano Bruno, De umbris idearum (Opera latina, ed. Imbriani, II,48): ,Notavit Platonicorum princeps Plotinus. Quamdiu circa figuram oculis dumtaxat manifestam quis intuendo versatur, nondum amore corripitur: sed ubi primum animus se ab illa revocans figuram in se ipso concipit non dividuam, ultraque visibilem, protinus amor oritur." 
schluß dieser Entwicklung dar. Wieder steht hier der Kampf gegen den Averroismus im Mittelpunkt der Betrachtung. Die averroistische Lehre glaubt die Einheit des Intellekts nur dadurch retten zu können, daß sie sie mit seiner Allgemeinheit zusammenfallen läßt, daß sie die Individualität des denkenden Prinzips nicht als eine ursprüngliche, sondern nur als eine zufällige Bestimmung desselben ansieht. Aber es ist nicht mehr Psychologie, sondern Metaphysik, wenn man, statt die Phänomene des seelischen Lebens in ihrer reinen Gegebenheit $\mathrm{zu}$ beschreiben, nach ihrer transzendenten Ursache fragt, und wenn man die letztere so bestimmt, daß darüber der unterscheidende empirische Charakter aller seelischen Vorgänge verloren geht. Diesen Charakter gilt es zünächst anzuerkennen, ehe man ihn in der einen oder anderen Weise zu erklären versucht. Der Averroismus aber fehlt gerade gegen diese methodische Grundmaxime: er erklärt das denkende Bewußtsein in einer Weise, daß er es damit, als Bewußtsein, vielmehr zum Verschwinden bringt. Sein einheitlicher ,tätiger Verstand" kann allenfalls als ein kosmisches Sein und eine kosmische Kraft angesehen werden: aber es fehlt dieser Kraft eben dasjenige Moment, was sie erst zum Selbstbewußtsein, was sie aus einem bloßen An-Sich zu einem „,Für-Sich-Seienden“ machen könnte. Weil Bewußtsein nur in dieser Form des,,Für-Sich " möglich ist, darum ist es immer nur in konkreter Besonderung denkbar: denn die eine Bestimmung schließt die andere in sich. Von hier aber geht die Beweisführung Pomponazzis einen Schritt weiter. Die Besonderung des Subjekts des Bewußtseins läßt sich nicht denken, ohne daß wir ihr eine entsprechende objektive Besonderung zur Seite stellen. Eine individuelle Seele kann als solche nur begriffen werden, wenn sie als Form eines individuellen Leibes gedacht wird. Ja, man kann geradezu sagen, daß das, was wir die Beseelung eines Leibes nennen, in nichts anderem als in dieser seiner durchgehenden Individualisierung besteht. Durch sie unterscheidet sich der Leib von der bloßen „Materie“; durch sie wird er zum organischen Leib, der in seiner individuellen Bestimmtheit der Träger eines bestimmten, konkret-individuellen Lebens ist. Die "Seele" tritt demgemäß zum „Körper“ nicht als ein äußerlich-bewegendes und äußerlich-belebendes Prinzip hinzu, sondern sie ist dasjenige, was den Körper erst gestaltet, was ihn zu einem in sich unterschiedenen und in dieser Unterscheidung gegliederten Ganzen macht. Und diese streng- korrelative Beziehung läßt nun auch den umgekehrten Ausdruck zu. Ist die Seele nicht bloße ,forma assistens", sondern echte ,forma informans", so ist klar, daß ihre Funktion der Formung stets nur an einem bestimmten physischen Substrat vollzogen werden kann. Denken wir das letztere aufgehoben, so würde mit ihm die Funktion nicht nur ihre 
Stütze, sondern geradezu ihren Sinn verlieren. An diesem Punkte trennt sich daher Pomponazzi nicht nur vom Averroismus, sondern von jeder Art spiritualistischer Psychologie. So wenig die Seele sich als ein separates Wesen vom Leib, dessen Form sie ist, ablösen läßt: so wenig gibt es in ihr selbst eine absolute Trennung, die ihre ,,höheren " Funktionen schlechthin von den "niederen" scheidet. Sie ist nur insoweit ,Intellekt" oder "Geist", als sie zugleich "Leben“ ist: und sie kann sich als Leben immer nur an einem bestimmten organischen Körper erweisen. Daraus ergibt sich, daß, - wenn wir nicht sowohl der Offenbarung, als den reinen Vernunftgründen folgen - alle Beweise für die Unsterblichkeit der Seele, für ihre selbständige vom Körper gelöste Fortdauer entfallen. Denn diese Beweise beruhen, näher betrachtet, sämtlich auf einer bloßen petitio principii. Sie schließen von der Allgemeinheit der Denkfunktion, von der selbständigen Leistung, die dem „,reinen“ Denken gegenüber der sinnlichen Wahrnehmung zukommt, auf die selbständige Existenz, auf die mögliche Abtrennung der denkenden Substanz. Weil es allgemeine ideelle B ed eu t ung en, weil es von der Sinneserfahrung unabhängige logische und ethische Geltungswert e gibt: darum wird eine unabhängige Denkkraft als Träger dieser Werte postuliert. In Wahrheit aber zeigt eben die schärfere Analyse des Denkakts selbst, daß diese Forderung hinfällig ist: denn der Geist erfaßt den Sinn eines allgemeinen Begriffs oder einer allgemeinen Regel immer nur dadurch, $\mathrm{da} ß$ er diesen Sinn in einem Besonderen, in einem Inhalt der Wahrnehmung oder der sinnlichen Phantasie, anschaut. Ohne diese konkrete Erfüllung, ohne die Beziehung auf das Besondere, bliebe der universelle Gedanke leer. So weisen Logik und Psychologie hier auf die gleiche Folgerung hin, die mit dem Inhalt der christlichen Lehre freilich in einem unaufheblichen Widerstreit steht. Pomponazzi versucht nirgends diesen Gegensatz zu überbrücken: er stellt ihn in größter Bestimmtheit hin, um sich sodann auf die Lehre der ,doppelten Wahrheit“ zurückzuziehen. Aber diese rein formelle Einschränkung läßt den Radikalismus seiner inhaltlichen These nur um so schärfer hervortreten. Wenn er im Kampf gegen den Averroismus beständig von den Beweisgründen Gebrauch macht, mit denen Thomas von Aquino die Lehre von der Einzigkeit des Intellekts in allen Menschen bekämpft hatte, so wendet sich jetzt seine Argumentation gegen Thomas selbst, und damit gegen die Grundlage der gesamten scholastischen Psychologie. Mit wirklicher Meisterschaft wird hier vor allem der Widerstreit aufgedeckt, der zwischen den Platonischen und den Aristotelischen Elementen des Thomistischen Seelenbegriffs bestehen bleibt. Der Platonismus, für den Seele und Körper ursprünglich-getrennte und in ihrer Wesenheit verschiedene 
Substanzen sind, bleibt nach Pomponazzi in diesem seinem strengen metaphysischen Dualismus wenigstens sich selbst treu. Er faßt die "Verbindung" von Leib und Seele nicht als Korrelation, als eine innere und wesentliche Bezogenheit auf, sondern er sieht in der Seele lediglich ein von außen Bewegendes. Die Einheit von „Körper" und „Geist", von "Sinnlichkeit" und "Intellekt", die wir im menschlichen Selbstbewußtsein unmittelbar $\mathrm{zu}$ erfahren glauben, wird damit freilich im Grunde als Täuschung erklärt: sie wäre keine andere, als sie etwa zwischen dem Ochsen und der Pflugschar besteht. Aber wie könnte ein Aristoteliker sich mit einer derartigen Einheit zufrieden geben, da doch nach Aristoteles' grundlegender Definition die Seele nichts als die Wirklichkeit, die „Entelechie“ des Körpers selbst ist? Zwischen dieser Erklärung und der Annahme, daß die Seele einer doppelten Daseinsweise fähig ist, der einen, die ihr während des irdischen Lebens, der andern, die ihr nach der Abtrennung vom Körper als separater Substanz zukommt, klafft ein Widerspruch. Denn da uns niemals die Substanz in ihrem absoluten Sein, in ihrem reinen ,An-Sich“ gegeben ist, sondern da wir sie nur in ihren Operationen, in ihrer Wirkungsweise erkennen, so folgt daraus, daß wir nicht ein und derselben Substanz zwei völlig verschiedene und disparate Formen des Wirkens zuschreiben können. Sprechen wir also der Seele neben der empirisch-bedingten und der empirisch-bekannten Art des Wirkens, die sie als „Form des Körpers“ besitzt, noch eine andere $\mathrm{zu}$, die sie unabhängig von diesem auszuüben vermag, - so behalten wir damit statt ihrer behaupteten realen Identität in Wahrheit nur eine verbale übrig. Wir setzen zwei Substanzen, zwei begrifflich und definitorisch verschiedene Wesenheiten, die wir jedoch willkürlich mit demselben Namen belegen. Und eben dies ist der Grundmangel, an dem die Thomistische Lehre leidet. Thomas kann nicht umhin, das erkenntnistheoretische Fundament der Aristotelischen Lehre anzuerkennen. Er stützt sich wie diese auf den Satz, daß kein Denken, keine Ausübung irgendeiner rein intellektuellen Funktion möglich sei, ohne daß dieses Denken sich irgendwie auf sinnliche Vorstellungen bezieht. Der mittelbare, der "repräsentative" Akt des Denkens bedarf stets der Stütze in etwas Unmittelbar-Gegebenem und dem Bewußtsein direkt Gegenwärtigem: und diese Gegenwart kommt allein den „Phantasmen“, den Bildern der Wahrnehmung und der sinnlichen Einbildungskraft zu. Aber diese erkenntnistheoretischnotwendige Konsequenz wird von dem Metaphysiker Thomas von Aquino verleugnet und umgestoßen. Die Lösung der Seele vom Körper bedeutet, daß ihr das Substrat, an dem sie ihre Funktion allein auszuüben vermochte, entzogen wird. Und doch soll diese Veränderung der Voraus- 
setzungen ihres Denkens nicht etwa dieses Denken selbst aufheben, sondern dieses nur in eine neue, von der früheren radikal-verschiedene Form umprägen. Aber eine solche Form ist erdacht, nicht erfahren, noch überhaupt in irgendeinem Sinne erfahrbar. Hier versagt jede Hilfe der Empirie; hier bewegen wir uns nicht mehr im Gebiet der psychologischen oder logischen Analyse, sondern im leeren Feld der Spekulation. Aristoteles, der Analytiker und Psychologe, kennt nirgends einen solchen Übergang einer Wirkungsweise der Seele in eine andere, ihr diametralentgegengesetzte ${ }^{1}$ ): welcher Übergang - da der Begriff des Seins nach dem des Wirkens zu bestimmen ist - in der Tat nichts anderes als eine Art mythischer Metamorphose, eine Verwandlung wie in einer Ovidischen Wundererzählung bedeuten würde. ${ }^{2}$ ) Schärfer als es hier geschieht, kann der Bruch mit der Psychologie der Scholastik kaum vollzogen werden. Die gesamte scholastische Seelen-Metaphysik wird jetzt zur bloßen SeelenFabel: zu einer Fiktion, die sich auf keine tatsächliche Gegebenheit, auf kein ",natürliches" Kriterium und Zeichen berufen kann. Wer ein doppeltes Sein der Seele, im Körper und losgelöst von ihm, behauptet, der hätte zwei spezifisch-verschiedene Erkenntnisweisen von ihr aufzuweisen, in deren einer sie auf Sinnliches bezogen, in deren anderer sie gänzlich von ihm abgelöst ist: für eine derartige Ablösung aber bietet uns die Betrachtung der psychischen Erscheinungen selbst nirgends einen Beleg dar. Und um die Deutung und „Rettung“ dieser Erscheinungen, nicht um die willkürliche Annahme einer anderen ,Welt" und eines Zustandes der Seele in ihr, der, von uns aus betrachtet, schlechthin transzendent und unbegreiflich bleibt, kann es sich für die rationale Erklärung allein handeln. Die ,Vernunft" kann hier keine andere Entscheidung treffen, als sie der wahre, der richtig-interpretierte Aristoteles gefällt hat. Für beide ist und bleibt die menschliche Seele nichts anderes als die Form des organischen Leibes, und als solche ,,ihrer Natur nach sterblich" (simpliciter mortalis), wenngleich sie in einer bestimmten Hinsicht, sofern sie sich nämlich durch das Individuelle hindurch auf das Allgemeine, durch das Sinnlich-Vergängliche hindurch auf Zeitloses

I) „Ridiculum videtur dicere animam intellectivam ... duos habere modos intelligendi, scilicet et dependentem et independentem a corpore, sic enim duo esse videtur habere". "Neque plures modi cognoscendi ab Aristotele in aliquo loco sunt reperti, neque consonat rationi“. Pomponazzi, De immortalitate animi (I5I6); Cap. IV, IX u. ö.

2) a. a. O. Cap. IX: „Dicere enim ... ipsum intellectum duos habere modos cognoscendi, scilicet sine phantasmate omnino, et alium cum phantasmate, est transmutare naturam humanam in divinam.... Sic anima humana simpliciter efficeretur divina, cum modum operandi divinorum assumeret, et sic poneremus fabulas Ovidii, scilicet naturam in alteram naturam transmutari." 
und Ewiges zu richten vermag, als ,bedingt-unsterblich" (secundum quid immortalis) genannt werden darf. ${ }^{1}$ )

Hier scheint zugleich der äußerste Gegensatz zu der Seelenlehre der Florentinischen Akademie erreicht: wie denn in der Tat Pomponazzis Traktat ,De immortalitate animi“ überall als der negative Pol zu Ficins gleichnamiger Schrift erscheint. Und doch besteht über diesen Gegensatz hinweg noch eine Gemeinsamkeit des systematischen Interesses. Beide, Pomponazzi wie Ficin, ringen mit dem Problem der Individualität; beide suchen das Phänomen des „,Selbst" zum Zentrum der Psychologie zu machen. Aber sie verfolgen dieses Ziel auf völlig getrennten Wegen. Für Ficin ist es die rein geistige Natur des Menschen, die ihn allein zu einem ,,Selbstwesen“ im strengen Sinne gestalten, die ihn über den Kreis alles bloß-Dinglichen emporheben kann. Die Freiheit des Menschen, in der sein wahrhaftes Ich zum Ausdruck kommt, setzt die Möglichkeit der Befreiung der Seele vom Körper voraus. Für Pomponazzi dagegen soll die Individualität nicht gegen die Natur behauptet, sondern sie soll aus ihr gefolgert und erwiesen werden. Sie bildet nach ihm nicht erst eine Prärogative des "Geistes", sondern sie stellt den Grundcharakter alles Lebens dar. „Leben“ heißt nichts anderes als das Dasein in individueller Form und in durchgängig-individueller Gestaltung. Wie Ficin in seinem Kampf für das Recht und die Eigenart des individuellen Ich den Supranaturalismus und die Transzendenz, so ruft Pomponazzi in dem gleichen Kampf den Naturalismus und die Immanenz zu Hilfe. Ihm liegt der letzte Grund des Individuellen und seine eigentliche Rechtfertigung nicht jenseit, sondern diesseit der Natur: denn als eigentliches Beispiel, als Prototyp der „Individuation" steht ihm der organische Leib vor Augen. So bringt er den Biologen Aristoteles gegen den Metaphysiker Aristoteles wieder zu Ehren; so sucht er eine Seelenlehre, die sich ihren Prinzipien nach von der Körperlehre nicht unterscheidet, sondern die gradlinige Fortsetzung und die Vollendung derselben ist. Das Bild der "Außenwelt" scheint das der ,inneren“ Welt nach sich zu formen: aber zugleich ist umgekehrt die Grunderfahrung des individuellen seelischen Lebens zum Schlüssel für die gesamte Natur geworden. Doch ist es weder der Weg Ficins, noch der Pomponazzis gewesen, auf dem die moderne Grundanschauung der Natur und die moderne Anschauung des Selbstbewußtseins erreicht wurde. Die eigentlichen Quellen dieser Anschauung finden wir vielmehr in einer gedank-

I) Zum Ganzen vgl. außer der Schrift ,,De immortalitate animi“" bes. den Commentar Pomponazzis zu Aristoteles' de anima (hg. von Ferri, Rom I876). Weitere Belege s. in meiner Schrift über das Erkenntnisproblem ${ }^{3}, \mathrm{I}, \mathrm{S}$. I05ff., sowie bei Douglas, The philosophy and psychology of Pietro Pomponazzi, Cap. 4 u. 5 . 
lichen Bewegung, die weder das "Subjekt" dem "Objekt", noch das "Objekt" dem "Subjekt" unterordnen will, sondern die gewissermaßen nach einem neuen ideellen Gleichgewicht zwischen beiden sucht. Wenn dieses Gleichgewicht sich herstellen, wenn in einem neuen Begriff der Natur auch ein neuer Begriff des Intellekts und des Geistigen überhaupt gewonnen und sichergestellt werden sollte, - so war hierzu erforderlich, daß der Weg der Metaphysik, wie der der bloßen Psychologie verlassen wurde. Nicht die supranaturalistische Metaphysik, noch die naturalistische Psychologie, sondern die exakt-wissenschaftliche und die künstlerische Betrachtung der Wirklichkeit haben dieses Ziel erreicht, - haben einen Begriff der Naturnotwendigkeit und Naturgesetzlichkeit geschaffen, der zur Freiheit und Autonomie des Geistes nicht mehr im Widerstreit stand, sondern ihr vielmehr zum Halt und zur sichersten Bestätigung wurde.

3.

Die Psychologie der Renaissance zeigt uns in ihrer philosophischwissenschaftlichen Form nur die ersten Ansätze jener großen geistigen Gesamtbewegung, aus der der neue tiefere Begriff der ",Subjektivität" hervorwachsen sollte. Sie selbst vermag das Ganze des neuen Problems, das hier entsteht, noch nicht zu umspannen und zu formulieren: denn es gelingt ihr nicht, die beiden gegensätzlichen Momente, aus denen es sich aufbaut, zu einer wahrhaften Einheit zusammen zu schauen. Der alte Kampf, der Kampf zwischen ,Spiritualismus' und ,Naturalismus' war auf diesem Boden nicht zu entscheiden. Die psychologischen Systeme der Frührenaissance besitzen hier im wesentlichen nur das Verdienst, daß sie den Grundgegensatz auf seinen schärfsten Ausdruck bringen. Noch einmal ringt jetzt der Begriff der "Natur" und der Begriff des "Geistes" um die Herrschaft über die "Seele" des Menschen. Die theoretische Seelenlehre bleibt zwischen zwei divergierenden Grundansichten gespalten. Wo sie, wie in der Florentinischen Akademie, den Weg des Spiritualismus verfolgt, da muß sie zuletzt den Wert der Natur tief herabwürdigen; wo sie, wie in der Psychologie Pomponazzis, ,,Seele“ und „Leben“ als eine Einheit faßt, da geht ihr jede Sonderstellung des Geistes und der ,höheren“ intellektuellen und ethischen Funktionen verloren. Die Anschauung von der Ewigkeit und Unzerstörlichkeit des Geistes muß die Natur, die Anschauung von der Einzigkeit und Geschlossenheit des Naturzusammenhangs muß die Unsterblichkeit negieren. Und der letzte Grund für diesen wechselseitigen Ausschluß liegt darin, daß der Gegensatz zunächst noch rein substantiell gefaßt wird. Solange "Natur" und "Geist" noch als zwei „Teile" des Seins gedacht sind, 
kann die Frage nicht zur Ruhe kommen, welcher von beiden den anderen umfaßt, welcher von ihm umfaßt wird. In ständigem Wettstreit machen sie sich gewissermaßen den Gesamtraum der Wirklichkeit streitig. Der Geist wird bei Telesio zu einem Sondergebiet der Natur, das durch ihre allgemeinen Kräfte, die Kräfte der Wärme und Kälte, beherrscht und durch sie bewegt wird; die Natur wird bei Ficin zu der untersten Stufe des Seins, die unter dem Reich der Gnade, unter der Stufe der ,Providentia', wie unter der des ,Fatum' steht. Für den Naturalismus bildet das Geistige eine einzelne „Provinz" des Seins, die nicht als "Staat im Staate" angesehen werden darf, sondern in dessen allumfassenden Gesetzen gleichsam eingebettet liegt - für den Spiritualismus ist die Natur das letzte Glied der Kette, die die Welt der ,Form' mit der der ,Materie' verknüpft. ${ }^{1}$ ) In Bildern dieser Art, die mehr als Bilder, die typische Ausprägungen einer gemeinsamen Grundform der Betrachtung sind, schreitet die Untersuchung fort. Hier tritt ein Wandel erst ein, als sich allmählich die Voraussetzung, unter der sowohl die spiritualistische, wie die naturalistische Psychologie der Renaissance stehen, zu verschieben beginnt; - als an Stelle des substantiell-dinglichen Verhältnisses von „Leib" und "Seele", von "Natur" und „Geist" ein funktiona les Verhältnis tritt. Aber die Metaphysik der Zeit vermochte dieses neue Verhältnis nicht aus eigener Kraft zu erringen und $\mathrm{zu}$ gestalten. Sie hätte die scholastische Grundform, die keineswegs allein im Spiritualismus, sondern auch im Naturalismus der Renaissance fortwirkt, nicht zu sprengen vermocht, wäre ihr nicht von anderer Seite her eine entscheidende Hilfe erwachsen. Diese wird ihr auf der einen Seite von der exakten und empirischen Forschung, auf der anderen von der Kunsttheorie her zuteil. Die Vereinigung beider bildet eines der markantesten und eines der fruchtbarsten Momente in der geistigen Gesamtentwicklung der Renaissance. Die Theorie der Naturerkenntnis und die Theorie der künstlerischen Gestaltung weisen jetzt nicht nur der Philosophie einen neuen Weg, sondern sie gehen ihr auf diesem Wege vor-

I) Auch der Humanismus hat im allgemeinen die mittelalterliche Stufen- und Rangordnung der Wissenschaften, die den Wissenschaften von der Natur die unterste Stufe zuweist, nicht überwunden. So steht etwa für Salutati die Jurisprudenz höher als die Medizin, weil jene sowohl in ihrer Grundlage, im Begriff der aequitas, als in der Form der Gesetze ein direktes Zeugnis der göttlichen Weisheit ist, während diese, die auf Werdendes und Vergehendes gerichtet ist, eher einer Kunst als einer Wissenschaft gleich zu achten ist. Sie strebt nicht nach dem Guten, sondern bloß nach dem untergeordneten Wahren - sie pflegt, indem sie sich rein empirisch der "experientia et instrumenta“" bedient, lediglich das zeitlich-Daseiende, statt durch Spekulation zu den ewigen Vernunftgründen der Dinge vorzudringen. (Näheres bei Paul Joachimsen, Aus der Entwicklung des italienischen Humanismus, Histor. Zeitschrift, Bd. I2I (I920), S. I96f und bei Ernst Walser, Poggius Florentinus, S. 250ff.). 
an: sie erschaffen einen neuen Sinn der Naturgesetzlichkeit. Und damit tritt auch die Grundfrage von ,Freiheit' und ,Notwendigkeit' in ein neues Stadium. Die Wissenschaftstheorie wie die Kunsttheorie der Renaissance konnten an dieser geistigen Zentralfrage der Epoche nicht vorbeigehen, aber sie finden jetzt für sie eine Lösung, die jenseit des Bereichs der metaphysischen Schulgegensätze steht. Die Antinomie von Freiheit und Notwendigkeit wandelt sich zur Korrelation. Denn das ist der gemeinsame Zug, der die Welt der reinen Erkenntnis mit der des künstlerischen Schaffens verbindet, $d a ß$ in beiden, wenngleich in verschiedener Weise, ein Motiv der echten geistigen Zeugung waltet: daß sie, Kantisch gesprochen, über alle ,kopeyliche“ Betrachtung des Gegebenen hinausgehen und zu einem ,,architektonischen“ Aufbau des Kosmos werden müssen. Je mehr die Wissenschaft wie die Kunst sich dieser ihrer gestaltenden Urfunktion bewußt werden, um so mehr begreifen sie das Gesetz, unter dem sie stehen, als den Ausdruck ihrer wesentlichen Freiheit selbst. Und damit gewinnt auch der Begriff der Natur, gewinnt die gesamte Gegenstandswelt eine neue Bedeutung. Der ,,Gegenstand" ist jetzt etwas anderes als der bloße Gegensatz und gleichsam der Gegenwurf zum Ich - er ist das, worauf alle produktiven, alle eigentlichbildenden Kräfte des Ich gerichtet sind und worin sie erst ihre eigentliche konkrete Bewährung finden. In der Notwendigkeit des Gegenstands erkennt das Ich sich selbst, erkennt es die Kraft und Richtung seiner Spontaneität. Dieser Grundgedanke des philosophischen Idealismus ist bereits von Nikolaus Cusanus in aller Schärfe und in seiner ganzen Tiefe erfaßt; aber nicht die abstrakte Spekulation, sondern die neue Form der wissenschaftlichen Erkenntnis und die neue Form der künstlerischen Anschauung ist es gewesen, in der er seine eigentliche Nachwirkung und seine lebendige Erfüllung erfahren hat.

Das erste Zeugnis der entscheidenden Umbildung des Naturbegriffs ist freilich nicht in der bloßen Theorie zu suchen, mag sie sich nun auf philosophische, auf wissenschaftliche oder auf künstlerische Probleme beziehen; sondern es liegt in jener Wandlung vor uns, die das Naturgefüh1 seit dem I3. Jahrhundert erfährt. Petrarcas Lyrik löst zuerst den Bann, unter dem die Natur in der dogmatisch-mittelalterlichen Anschauung verschlossen lag. Alles Fremdartige, alles unheimlich Dämonische fällt jetzt von ihr ab; denn die lyrische Stimmung ergreift in ihr nicht den Gegensatz zur seelischen Wirklichkeit, sondern sie fühlt in ihr überall die Spur und den Nachklang der Seele. So wird für Petrarca die Landschaft zum lebendigen Spiegel des Ich. Darin liegt freilich nicht nur eine Befreiung, sondern zugleich eine Schranke des Naturgefühls: denn eben in dieser ihrer 
Funktion, das Seelische widerzuspiegeln, besitzt die Natur selbst eine nur mittelbare und gleichsam reflektierte Wirklichkeit. Nicht um ihrer selbst willen wird sie gesucht und dargestellt: sondern ihr Wert liegt darin, daß der moderne Mensch in ihr ein neues Ausdrucksmittel für sich selbst, für die Lebendigkeit und die unendliche Vielgestaltigkeit seines Innern gefunden hat. In den Briefen Petrarcas tritt diese eigentümliche Polarität seines Naturgefühls bisweilen mit überraschender Klarheit und Bewußtheit zutage. Wenn es ihn von der Aussprache des Innern zur Darstellung der Natur treibt, so fühlt er sich eben in ihrer Anschauung wieder auf sich selbst, auf das eigene Ich zurückgewiesen. Die Landschaft verliert ihm jetzt den selbständigen Wert und den eigenen Gehalt. Das Naturgefühl sinkt wieder zur bloßen Folie des Selbstgefühls herab: quid enim habet locus ille gloriosius habitatore Francisco'? ${ }^{1}$ ) Die Naturschilderungen Petrarcas zeigen überall diese Doppelheit und diese eigentümliche Oszillation. Auch in der berühmtesten dieser Schilderungen, in der Erzählung seiner Besteigung des Mont Ventoux, tritt sie unverkennbar hervor. Man kennt die charakteristische Szene: wie Petrarca, nachdem er unter unsäglichen Mühen den Berggipfel erreicht hat, nicht in der Anschauung des Bildes, das sich ihm hier darbietet, verweilt, sondern wie sein Blick auf das Buch fällt, das sein ständiger Begleiter ist, - wie er in Augustins Confessionen auf die Stelle trifft, die davon spricht, daß die Menschen hingehen und hohe Berge und weite Meeresfluten und den Lauf der Gestirne bewundern, sich selbst aber darüber vergessen. ${ }^{2}$ ) Hier drängt sich der typische Gegensatz der Denkart und der Gesamtstimmung in einen Satz zusammen. Der Drang zur Natur, das Verlangen nach ihrer unmittelbaren Anschauung wird hintangehalten durch die Augustinische Mahnung, die in dieser Hinwendung nur die Gefahr sieht, die daraus für das einzig wahrhaftunmittelbare Verhältnis, für das Verhältnis der Seele zu Gott, erwächst. ,Noli foras ire, in te ipsum redi, in interiore homine habitat veritas ${ }^{3}$ ): dieses Augustinische Motto scheint jeden direkten Zugang zur Natur, zur Welt der ,äußeren' Anschauung zu verwehren. So verharrt Petrarcas Naturgefühl zuletzt in derselben Spannung, die für sein gesamtes Weltgefühl charakteristisch ist. Er sieht die Natur wie den Menschen, er sieht Welt und Geschichte in einem neuen Glanze: aber dieser Glanz selbst erscheint ihm immer wieder wie eine Verblendung und Verführung. Dem Buch, das von diesem Widerstreit seines Innern handelt, das die

I) Petra rca, Append. litt. epist. 6, ed. Fracassetti, vgl. Voigt, Wiederbel. d.klass. Altert. ${ }^{2}, \mathrm{I}, \mathrm{II}_{3}$.

2) Petrarca, Epistolae famil. IV, 1; vgl. die Darstellung Burckhardts, Kult. d. Ren. ${ }^{8}$, II, I $8 f$.

3) Augustinus, De vera religione, cap. 39. 
Beichte über diesen ,geheimen Kampf seiner Herzenssorgen" ablegt, diesem Buch, das man vielleicht die erste Darstellung der modernen Seele und des modernen Menschen nennen kann, hat er zugleich den echt-mittelalterlichen Titel: ,De contemptu mundi‘ geben können. Petrarca steht zur Natur, wie er zum Weltleben und zum Ruhm, der für ihn der Kern alles weltlichen Lebens ist, steht: er fühlt sich leidenschaftlich und unwiderstehlich zu ihnen hingezogen, aber er vermag sich ihnen nicht unbefangen und mit freiem Gewissen hinzugeben. So entsteht hier kein naives, sondern ein durchaus ,sentimentalisches' Verhältnis zur Natur: nicht aus sich selbst, sondern nur als dunkler oder lichter Hintergrund zum Ich kann sie verstanden, kann sie empfunden und genossen werden. -

Die Folgezeit, die Zeit des Quattrocento und Cinquecento, mußte hier einen anderen Weg einschlagen. Ihr entstand die Aufgabe, den Naturbegriff zunächst auf sich selbst zu stellen, ihm einen festen, streng,objektiven' Bestand $\mathrm{zu}$ sichern. Erst nachdem diese Leistung vollzogen war, durfte und mußte die Frage sich erneuern, wie dieses neue selbständige Gebiet sich zur Welt des "Bewußtseins' und des ,Geistes" verhält. Abermals wird jetzt eine „Entsprechung“, eine „Harmonie“ dieser beiden Welten gesucht: aber diese setzt nunmehr das Eigenrecht und die selbständige Bestimmtheit der beiden Glieder, die in dieses Verhältnis eingehen, voraus. Es ist die nächstliegende und die in der Philosophiegeschichte, wie in der Kultur- und Geistesgeschichte noch heute fast unbestritten herrschende Ansicht, daß die Renaissance dieses Eigenrecht der Natur auf dem Wege der unmittelbaren, der sinnlichempirischen Anschauung entdeckt und erkämpft hat. Burckhardt hat in einem der glänzendsten Kapitel seines Werkes diese fortschreitende „Entdeckung der Welt" geschildert. Es schien genug, die Gestalten dieser Welt, statt sie lediglich auf den Menschen zu beziehen, rein und objektiv zu empfangen, sie nach ihrer einfachen sinnlichen Bestimmtheit hinzunehmen und sie gemäß dieser zu beschreiben und zu gliedern, um damit ein neues Bild der Wirklichkeit, als reiner Erfahrungswirklichkeit, zu gewinnen. Ansätze zu einer solchen Betrachtungsweise treten im Italien des I4. und I5. Jahrhunderts überall hervor und gewinnen immer mehr an Kraft und an Umfang. Immer gewaltiger wächst die Fülle des anschaulichen Materials, aus dem das neue Bild der Welt hervorwächst; immer deutlicher legen sich die großen Hauptzüge dieses Bildes wie die feinen und feinsten Umrisse des einzelnen auseinander. Und dem Drang zum eigenen Sehen entspringt und entspricht der Drang zur systematischen Beschreibung und Gliederung. Der Sammlersinn, der schon früh zur Anlage botanischer und zoologischer Gärten führt, legt zugleich den ersten Grund zu 
einer neuen exakten Form der Naturbeschreibung. Ca esa lpins Werk „De plantis“ ( $\mathrm{I}_{583}$ ) eröffnet, indem es zuerst ein ,natürliches System“ der Pflanzenwelt aufzustellen versucht, den Weg zu einer wissenschaftlichen Botanik. Auch die Naturphilosophie der Renaissance scheint zunächst diesen rein empirischen Weg einzuschlagen. Wie später Bacon, so fordert Telesio, daß die Natur nicht durch das Medium der abstrakten Aristotelischen Kategorien gesehen, sondern daß sie aus ihr selbst erkannt, daß sie gemäß ihren eigenen Prinzipien (juxta propria principia) erforscht werde. Diese eigenen Prinzipien liegen nicht in den logischen Begriffen von ,Form“ und ,Stoff', von ,Aktualität" und „Potentialität", von "Wirklichkeit" und „Beraubung“", sondern sie sind in konstanten und überall gleichbleibenden konkreten Naturerscheinungen zu suchen. Als solche Urphänomene, die in direkter sinnlicher Anschauung zu erfassen sind, sondert Telesio die Grundkräfte des Warmen und Kalten aus. Indem diese Kräfte sich gegenseitig die Wage halten, indem sie der Materie, die hierbei jedoch nicht als bloß-logisches Subjekt der Veränderung, sondern als deren reales physisches Substrat zu denken ist, successiv verschiedene Gestaltungen aufprägen, entsteht daraus alle Mannigfaltigkeit des Geschehens, die andererseits durch ebendiese Rückführung auf die Trias der Prinzipien zugleich als streng-gesetzliche Einheit erkannt ist. Als das entscheidende Grundmittel dieser Erkenntnis aber wird hierbei von Telesio überall die sinnliche Empfindung proklamiert. Sie muß aller Arbeit des Intellekts, des denkenden Ordnens und Vergleichens der Einzeltatsachen, vorangehen: denn sie allein vermag den Kontakt zwischen "Subjekt" und "Objekt", zwischen Erkenntnis und Wirklichkeit herzustellen. Telesios System der Natur und sein System der Erkenntnis versteht diesen Kontakt in durchaus wörtlichem Sinne. Jede denkende Erfassung eines Gegenstandes setzt die sinnliche Berührung mit ihm voraus. Denn das Bewußtsein eines Objekts haben wir nicht anders als dadurch, daß dieses Objekt auf uns wirkt, ja daß es kraft dieser Wirkung in uns eingeht. Was wir ,Geist' nennen, ist eine bewegliche Substanz, die in ihrem Bewegungszustand durch äußere Einwirkungen bestimmt und modifiziert wird - und jede sinnliche Wahrnehmung stellt je eine eigene Art dieser Modifikation dar. Was hierbei verschieden ist, ist die Art der Fortpflanzung des ursprünglichen Anstoßes, die durch die Natur des Mediums, das als Träger dieser Fortpflanzung dient, mitbedingt ist. Die Kräfte des Warmen und Kalten werden bei der Gesichtsempfindung durch Vermittlung des Lichts, bei der Gehörsempfindung durch Vermittlung der Luft übertragen, die auch für die Geruchsempfindung als Vehikel dient. Aber da all diese mittelbare Übertragung zuletzt in einer unmittelbaren 
Berührung enden muß, so wird für Telesio der Tastsinn zum Sinn aller Sinne. Auch alle „höheren“ geistigen Funktionen sind letzten Endes auf ihn zurückführbar; auch all unser Denken und Schließen stellt sich gleichsam als ein ,"Tasten in die Ferne“ dar. Denn der Akt der vernünftigen Schlußfolgerung besteht in nichts anderem als darin, daß der Geist die von außen kommenden Eindrücke, die Modifikationen des Kalten und Warmen, nicht nur empfängt, sondern daß er sie auch in sich bewahrt; daß er fähig ist, einen Bewegungszustand, der einmal durch äußere Einwirkung in ihm hervorgebracht worden ist, unter bestimmten Bedingungen wieder in sich zu erneuern. So gelangt er zu einer Wiederholung früherer Impressionen und damit zu einer Art Verknüpfung seines gegenwärtigen und seines vergangenen Zustandes, was ihn weiterhin dazu befähigt, auch in die Zukunft vorauszugreifen und kommende Eindrücke $\mathrm{zu}$ antizipieren. Diese Form der Rückwendung zum Vergangenen und der Hinwendung auf das Künftige ist es, was wir als die reflexive Kraft des Denkens, als die Kraft des ,Vernunftschlusses“ $\mathrm{zu}$ bezeichnen pflegen. Aber hierin äußert sich nicht eine eigene losgelöste Kraft eines selbständigen , ,aktiven Intellekts“"; sondern hier haben wir nur die gleichsam mechanische Fortsetzung der einmal in uns gewirkten Bewegungen vor uns. Wenn Aristoteles das Gedächtnis aus dem Sinn, die Erfahrung aus dem Gedächtnis, die Erkenntnis aus der Erfahrung hervorgehen läßt, so erkennt er implizit dieses Grundverhältnis der einzelnen seelischen Funktionen und ihr Zusammenwirken im Aufbau des Wissens an - wenngleich er explizit, in seiner Lehre vom voũ , dieses Verhältnis wieder verleugnet hat. In Wahrheit kann es zwischen Empfinden und Vorstellen, zwischen Vorstellen und Erinnern, zwischen Erinnern und Wissen keine anderen als fließende Unterschiede geben; der Intellekt selbst ist nur ein mittelbarer und abgeleiteter Sinn, der eben infolge dieser Mittelbarkeit notwendig unvollkommen bleibt und von der wirklichen Beschaffenheit des Eindrucks nur noch eine Art Abschattung, nur noch ein Analogon und Gleichnis bewahrt. ${ }^{1}$ )

So scheint der Naturalismus der Renaissance dort, wo er zuerst als geschlossenes System auftritt, eine streng empiristische und sensualistische Richtung einzuschlagen. Seine ganze Begründung scheint darin $\mathrm{zu}$ bestehen, daß er sich der empirischen Beobachtung als alleiniger Führerin überläßt, - daß er aus dem Bilde der Natur alles ausschaltet, was sich nicht auf das direkte Zeugnis der sinnlichen Wahrnehmung stützen läßt. Und doch tritt, wenn man die Weiterwirkung von Telesios Grundgedanken innerhalb der Naturphilosophie der Renaissance verfolgt,

I) Telesio, De rerum natura juxta propria principia; vgl. bes. Lib. VIII, Cap. 3 u. II, Ausg. Neapoli $1_{587}$, fol. $3^{1} 4$ f., $326 \mathrm{f}$. 
alsbald ein merkwürdiger Umschwung ein. Schon die nächsten Nachfolger Telesios, schon die Männer, die sich als seine unmittelbarenSchüler fühlen, haben den Weg der exakten Beobachtung der Natur und die Methodik der streng deskriptiven Erkenntnis verlassen. Telesios Grundtendenz ist nicht nur gegen die Aristotelisch-scholastische Naturerklärung, sondern sie ist, mit nicht minderer Bestimmtheit, gegen die ,okkulten Wissenschaften gerichtet. Wenn er die Erklärung der Natur aus ihren „eigenen Prinzipien“ fordert, so sind damit auch die Geheimwissenschaften der Astrologie und Magie verworfen. Aber diese Selbständigkeit der empirischen Wissenschaft geht, kaum daß sie erreicht schien, alsbald wieder verloren. Nirgends gelingt es der Naturphilosophie der Renaissance, die Magie von ihrem Pfad zu entfernen. In den Schriften Giordano Brunos nehmen die Probleme der ,natürlichen Magie“ einen so breiten Raum ein, daß sie die spekulativ-philosophischen Probleme beständig zu überwuchern drohen. Und Campanella, der sich in der Gesamttendenz seiner Naturlehre und seiner Erkenntnislehre Telesio am nächsten anschließt, kann seiner naturphilosophischen Hauptschrift wieder den Titel „De sensu rerum et magia" geben. Man sieht: der ,Empirismus', der hier verkündet und geprägt wird, besitzt aus sich allein nicht die Kraft, zu einem System der ,,reinen Erfahrung“ vorzudringen und es von allen phantastischen Zutaten frei zu halten. Überall schlägt er unvermittelt in sein Gegenteil: in Theosophie und Mystik um. Von dem Naturbegriff Telesios zu dem der modernen Wissenschaft führt kein direkter Weg. Campanella war in einer Selbsttäuschung befangen, wenn er, als Vertreter der Telesianischen Prinzipien, zugleich als Apologet Galileis auftreten zu können glaubte. $\left.{ }^{1}\right)$ Denn eben hier zeigt sich der scharfe Trennungsstrich in der Methode der Naturerkenntnis. Der Weg Leonardos und Galileis, der in der Erfahrung die ,Vernunft", der in ihr die ,ragioni" des Wirklichen sucht, scheidet sich klar und scharf von dem Weg der sensualistischen Naturlehren. Wenn jener immer klarer und bestimmter zum mathematischen Idealismus hinlenkt, so führt dieser immer wieder zu den primitiven Formen des Animismus zurück. Und diese Wendung ist kein Zufall und kein bloßer historischer Rückfall; sie ist nicht bloß in dunklen Affekten und Leidenschaften, kraft deren der Mensch zur Herrschaft über die Natur strebt, sondern sie ist in den allgemeinen theoretischen Voraussetzungen der italienischen Naturphilosophie gegründet. Ein Ding ,erkennen' - das ist das gemeinsame Prinzip, von dem sie überall ausgeht - heißt, mit ihm eins werden: diese Einheit aber ist nur dann möglich, wenn Subjekt

I) Vgl. Campanellas Schrift Apologia pro Galileo mathematico florentino, Frankfurt 1622 . 
und Objekt, wenn der Erkennende und Erkannte von gleicher Natur, wenn sie Glieder und Teile ein und desselben Lebenszusa mmenhanges sind. Jede sinnliche Wahrnehmung ist der Akt einer solchen Verschmelzung und Wiedervereinigung. Der Gegenstand wird wahrgenommen, wird in seinem eigentlichen, echten Sein nur dann erfaßt, wenn wir in ihm das gleiche Leben, dieselbe Art der Bewegung und Beseelung spüren, wie sie uns in der Selbsterfahrung unseres Ich unmittelbar gegeben und gegenwärtig ist. So ergibt sich der Panpsychismus hier als einfaches Korollar der Erkenntnislehre - wie umgekehrt diese von Anfang an die Farbe des Panpsychismus trägt. So eng ist dieser Zusammenhang, daß $\mathrm{Pa}$ trizzi seine Darstellung der Theorie des Wissens einem Werk angliedern kann, dem er den Titel ,Panpsychia' gegeben hat. Was er hier Aristoteles vorhält, ist, daß er den Grundgedanken des Panpsychismus nur halb durchgeführt, daß er die Welt zum Monstrum gemacht habe, indem er nur die himmlische Welt der Gestirne als beseelt, alles andere aber als unbeseelt ansehe. In Wahrheit aber kennt die Einheit des Lebens keine solchen Trennungen und Schranken. Sie ist, ganz und ungeteilt, in allem scheinbar bloß-Materiellen enthalten: sie wirkt im Größten und Kleinsten, im Höchsten und Niedersten, in den Sternen sowohl wie in den einfachen Elementen. Denn alles wirkliche Sein und aller wahrhafte Wert läßt sich nur Beseeltem zusprechen: die Elemente müßten beides entbehren,wenn ihnen jedes eigene Leben abgesprochen würde. $\left.{ }^{1}\right)$ Schon Telesios Erkenntnislehre sucht die Einheit von Intellekt und Sinnlichkeit dadurch zu erweisen, daß sie alle Funktionen des Denkens und des ,rationalen Schließens in der einen Funktion der Analogiebildung wurzeln läßt: intellectionis cujusvis principium similitudo est sensu percepta. ${ }^{2}$ ) Jetzt wird diese Art der Analogiebildung näher $\mathrm{zu}$ bestimmen gesucht, indem sie gewissermaßen einen metaphysischen Unterbau erhält. Der theoretische Schluß der „Analogie“ wurzelt in der ursprünglichen Wesensgemeinschaft alles Seienden und wäre ohne sie hinfällig. Alles Begreifen, alles vermittelnde Folgern geht zuletzt auf einen ursprünglichen Akt der Einfühlung zurück, in welchem wir uns der Gemeinschaft, die uns mit allem Sein verknüpft, versichern. Auch Cardans Naturlehre is.t ganz von solchen analogischen Spielen des Denkens, die mehr als dies, die ein unmittelbares intuitives Erfassen der Naturzusammenhänge sein wollen, beherrscht. Die Metalle sind ihm nichts anderes als ,,begrabene Pflanzen“, die ihr Dasein unter der Erde führen; die Steine haben ihre Entwicklung,

I) S. Franciscus Patritius, Panpsychia (Novae de universis Philosophiae tomus III). Ferrariae I59ז, Lib. IV, fol. $54 \mathrm{ff}$.

2) Telesio, De rerum natura, VIII, 3; näheres über Telesios Erken ntnislehre s. Erkenntnisproblem ${ }^{3}, \mathrm{I}, 232 \mathrm{ff}$. 
ihr Wachstum und ihre Reife. $\left.{ }^{1}\right)$ Diese Grundansicht duldet nicht nur die Magie, sondern sie fordert sie geradezu: sie sieht in ihr die eigentliche Erfüllung aller Naturwissenschaft. Wenn Pico in seinen 900 Thesen und in der ,Apologie', die er zur Verteidigung dieser Thesen gegen die Anklage der Ketzerei verfaßt hat, die Magie als die Summe aller natürlichen Weisheit und als den praktischen Teil aller Naturwissenschaft definiert, so spricht er damit nur eine gemeinsame Grundüberzeugung der Naturphilosophie der Renaissance aus. Für diese ist die Magie nichts anderes als die aktive Seite der Naturerkenntnis: was in dieser theoretisch als verwandt, als zusammengehörig erkannt wird, das wird in jener tätig miteinander verknüpft und einem gemeinsamen Ziel zugeführt. So wirkt die Magie nicht selbst Wunder, sondern sie unterstützt nur als emsige Dienerin die Kräfte der wirkenden Natur. , ,Sie erforscht den Zusammenhang des Universums, den die Griechen ,Sympathie' nennen; sie bohrt sich hinein in das Verständnis des Wesens aller Dinge, sie zieht aus dem Schoße der Erde und aus deren geheimnisvollen Vorratskammern die verborgenen Wunder hervor und bringt sie, als hätte sie sie selber geschaffen, ans Licht. Wie der Landmann die Ulme mit dem Weinstock, so vermählt der Magier Himmel und Erde und bringt das Niedere mit den Kräften der höheren Welt in Berührung. "2) Die Magie kann hier ihrem vollen Umfang nach anerkannt werden: - unter der einen Bedingung, daß der Grund ihrer Wirksamkeit nicht mehr außerhalb der Natur oder über ihr, sondern mitten in ihr selbst gesucht wird. Nicht der Eingriff dämonischer Mächte, sondern die Beobachtung des Laufes des Geschehens selbst und der ihm innewohnenden Regel ist es, was allem magischen Wirken seine Richtung weist und sein Ziel setzt. In diesem Sinne hat Giambattista Porta in seinem Werk über die ,,natürliche Magie“ ihren Begriff fixiert. Die Natur ist nicht sowohl das Objekt der Magie, als sie vielmehr ihr Subjekt ist: sie ist, vermöge der Anziehung des Gleichen und der Abstoßung des Ungleichen, die in ihr herrscht, der Ursprung und Same aller magischen Kraft. ${ }^{3}$ ) Campanella knüpft in seiner Schrift ,De sensu rerum et magia' an diese Grundbestimmungen Portas an - : aber er sucht, wenn dieser von der einfachen Tatsache des $\sigma \dot{u} \mu \pi \nu \circ \iota \alpha \pi \dot{\alpha} v \tau \alpha$, von dem ,Faktum“ der allgemeinen Sympathie, ausgeht,

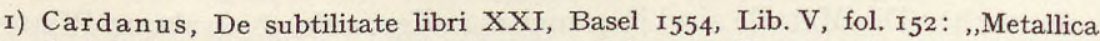
vivere etiam hoc argumento deprehenditur, quod in montibus non secus ac plantae nascuntur, patulis siquidem ramis, radicibus, truncis ac veluti floribus ac fructibus, ut non aliud sit metallum aut metallica substantia quam planta sepulta."

2) Pico della Mirandola, Apologia, Opera fol. I7of.; vgl. bes. die Rede ,de hominis dignitate" ibid., fol. 327 f. (die Übersetzung $z$. T. nach Lieberts deutscher Übertragung, S. 210).

3) Joh. Baptista Porta, Magiae naturalis Libri viginti, Lib. I, cap. 2. 
dieses Faktum selbst auf seinen spekulativen ,Grund' zurückzuführen. So wird er - in jener paradoxen Mischung der Motive, wie sie für die Philosophie der Renaissance bezeichnend ist - zum rationalen Methodiker der Magie. Ausdrücklich bezeichnet er es als seine Aufgabe, die natürliche Magie, die Porta in seinem Werk historisch-faktisch als einen Umkreis bestimmter Tatsachen aufgestellt habe, auf ihre letzten Ursachen zurückzuführen und ihr damit erst ihre wahrhaft-rationale Gestalt zu geben. ${ }^{1}$ ) Wenn Portas Schrift sich in die Fülle der Analogien vertieft, die zwischen Makrokosmos und Mikrokosmos, zwischen der Welt des Menschen und der der Elemente, der Pflanzen und Tiere bestehen, so will Campanella diese gesamte Mannigfaltigkeit auf ein einziges Prinzip zurückführen. Er begnügt sich nicht mit der Tatsache dieser Übereinstimmungen, sondern er fragt nach ihrem ,Warum ' - und er glaubt dieses Warum gefunden zu haben, indem er als Grund aller Verknüpfung, aller Ähnlichkeit und Unähnlichkeit, aller Sympathie und Antipathie, die Fähigkeit der sinnlichen Empfindung aufweist, die allen Teilen des Seins, wie immer sie im einzelnen beschaffen sein mögen, wenngleich in verschiedener gradueller Abstufung, zukommt, und die eben darum sie alle nicht bloß mittelbar, sondern unmittelbar, nicht bloß empirisch, sondern gewissermaßen a priori verknüpft. Der Sinn wird zu einer schlechthin ursprünglichen ontologischen Wesensbestimmung alles Seins, die jenseit aller individuellen Differenzen liegt, und die daher alle Losgelöstheit der Seinselemente voneinander, all ihre scheinbare Disparatheit, überbrückt. Er entsteht nicht und vergeht nicht; er findet sich nicht nur in einzelnen organischen Bildungen der Natur, sondern er ist all ihren Gestalten gemeinsam: denn so wahr in der Wirkung nichts sein kann, was nicht in der Ursache präformiert ist, so wahr kann aus Unbelebtem, nicht Sinnbegabtem nichts mit Empfindung und Leben Begabtes hervorgehen. ${ }^{2}$ )

Wir haben es an dieser Stelle nicht mit den metaphysischen Konsequenzen zu tun, zu denen diese Lehre im System Campanellas hinführt; wir betrachten sie vielmehr nur nach den meth odisch en Bestimmungen, die sie in sich schließt. Und in dieser Hinsicht zeigt sich nunmehr mit aller Schärfe, daß die Hinwendung zur sinnlichen Fülle der Erscheinungswelt und das Streben, sie unmittelbar zu ergreifen und gewissermaßen auszuschöpfen, den neuen, den spezifisch-modernen Begriff der ,Natur

I) Campanella, De sensu rerum et magia, ed. Tob. Adami, Frankfurt I620, Lib. IV, cap. I, S. 260: „Conatus est bis . . . studiosissimus Porta hanc scientiam revocare, sed historice tantum, nullas reddendo dictorum suorum causas. (Ex quo autem hunc librum meum vidit, audio ipsum rationalem magiam struere)."

2) Campanella, Universalis philosophiae seu metaphysicarum rerum juxta propria dogmata partes tres, Paris 1638 , P. II, Lib. VI, cap. 7 ; zum Verhältnis Campanellas zu Giambattista Porta vgl. Fiorentino, Bernardino Telesio, Firenze I872ff., II, I23ff. 
nicht nur nicht geschaffen, sondern daß sie ihn vielmehr hintangehalten und gehemmt hat. Solange nicht, durch das Medium der Mathematik und durch die neuen Denkmittel, die aus ihm hervorgingen, bestimmte Kriterien der Erfahrung selbst geschaffen waren, solange fehlte es dem Empirismus der Renaissance an jedem objektiven Wertmaßstab und an jedem Prinzip der Auswahl unter den sich zudrängenden Beobachtungen. In bunter Fülle, aber zugleich in völlig chaotischer Regellosigkeit, reihen sich jetzt die einzelnen „,Tatsachen" aneinander. Die Berufung auf die Erfahrung bietet solange keinen Halt, als ihr eigener Begriff noch völlig heterogene Bestandteile in sich faßt. Die Naturlehre des fünfzehnten und sechzehnten Jahrhunderts legt den ersten Grund zur exakten Deskription und zum exakten Experiment: aber unmittelbar neben beiden stehen die Versuche zu einer Begründung der ,empirischen Magie“. Denn das eben unterscheidet die ,natürliche“ Magie von der ,dämonischen“ (1), da $\beta$, wenn diese auf der Annahme übernatürlicher Kräfte beruht, jene sich ganzim Rahmen der Natur und ihrer empirischen Gleichförmigkeit halten will, daß siekeineanderen Methoden als die derinduktiven Beobachtung und Vergleichung der Phänomene für sich in Anspruch nimmt. Aber diese Form der „Induktion“ kennt noch keinerlei Beschränkung durch analytisch-kritische Gesichtspunkte, wie sie dem echten „Experiment" jederzeit voraus und zugrunde liegen. So grenzt hier die Welt der Erfahrung nicht nur an die des Wunders an, sondern beide gehen ständig ineinander über und ineinander auf. Die ganze Atmosphäre dieser „Wissenschaft“ der Natur ist mit dem Wunder erfüllt und gesättigt. Giambattista Porta wird von Kepler als Entdecker des Fernrohrs gerühmt, und er hat, wie immer es sich mit diesem Anspruch verhalten mag, um die Grundlegung der wissenschaftlichen Optik entscheidende Verdienste; aber er ist es zugleich, der in der ,Accademia dei Secreti, die er in Neapel begründete, die erste große Sammelstätte der ,okkulten" Wissenschaften geschaffen hat. In unermüdlicher Sammler- und Forschertätigkeit, auf langen Reisen, die ihn durch ganz Italien, durch Frankreich und Spanien führten, hat er alles zusammengetragen, was sich auf die Erforschung der geheimen Kräfte der Natur bezieht, hat er sein Kompendium der natürlichen Magie, das er schon als Fünfzehnjähriger verfaßt hat, unab-

I) Diese Unterscheidung der ,natürlichen “ von der ,dämonischen“ "Magie geht in der Renaissancephilosophie durch: sie findet sich. wie in Picos 900 Thesen und in seiner "Apologie", z. B. in Ficins Schrift „De vita triplici" und bei Pomponazzi, De admirandorum effectuum causis sive de incantationibus (Lib. I, cap. 5, S. 74): „Nemini dubium est ipsam (magiam naturalem) in se esse veram scientiam factivam et subalternatam philosophiae naturali et Astrologiae, sicut est medicina et multae aliae scientiae; et in se est bona et intellectus perfectio... et, ut sic, non facit hominem habenten ipsam malum esse hominem." 
lässig zu erweitern und zu bereichern gesucht. Hier, wie später bei Campanella, führt daher der Empirismus nicht zu einer Überwindung der Magie, sondern nur zu ihrer Kodifizierung. Wo man die Erfahrung selbst als bloßes Aggregat auffaßte, wo man sie mit Campanella geradezu als ,experimentorum multorum coacervatio' definierte, da gab es keine Sichtung ihrer Bestandteile, keine Bewertung des einzelnen für den systematischen Aufbau der „Natur“. Eine solche konnte erst eintreten, nachdem von anderer Seite her eine Scheidung ihrer Grundelemente gewonnen war, nachdem in der Erfahrung selbst eine innere „Krisis" sich vollzogen hat. Diese Scheidung, die das ,Notwendige“ vom ,Zufälligen“, das Gesetzliche vom phantastisch-Willkürlichen trennt, hat nicht der Empirismus und Sensualismus der Naturphilosophie, sondern der Intellektualismus der Mathematik vollzogen. Und doch sind es nicht rein intellektuelle Motive gewesen, die in diesem Kampf wirksam waren und die ihn allein entschieden haben, sondern - und dies ist für das geistige Gesamtbild der Renaissance charakteristisch und entscheidend $\%$ die Logik der Mathematik geht hier mit der Kunsttheorie Hand in Hand. Erst aus dieser Vereinigung und aus diesem Bündnis wächst der neue Begriff der ,Notwendigkeit“ der Natur heraus. Die Mathematik und die Kunst begegnen sich jetzt in derselben grundlegenden Forderung: in der Forderung der ",Gestalt". In dieser gemeinsamen Aufgabe fällt die Scheidewand zwischen der Theorie der Kunst und der der Wissenschaft. Leonardo da Vinci kann hier unmittelbar an Cusanus anknüpfen - und Galilei hat sich in einer berühmten Stelle der Dialoge über die beiden großen Weltsysteme zum Erweis seiner Auffassung des menschlichen Intellektes und der Rolle, die ihm im Aufbau des Erfahrungswissens zukommt, auf Michelangelo, auf Raffael und Tizian berufen. ${ }^{1}$ ) Hier stellt sich eine neue Synthese innerhalb der Welt des Geistes und mit ihr zugleich eine neue Korrelation von ,Subjekt' und ,Objekt' her: die Reflexion auf die Freiheit des Menschen, auf seine ursprüngliche Schöpferkraft, verlangt den Begriff der immanenten ,Notwendigkeit“ des Naturgegenstandes als ihre Ergänzung und als ihre Bestätigung.

In voller Klarheit tritt dieser Doppelprozeß in Leonardos Manuskripten hervor. Die Aufzeichnungen Leonardos sind durchzogen von dem steten Kampf gegen die ,lügnerischen“ Wissenschaften, die dem Menschen mit falschen Hoffnungen schmeicheln, die ihm die unmittelbare Herrschaft über die Natur und ihre geheimen Kräfte vortäuschen. Was er diesen Wissenschaften vorhält, ist, daß sie den echten Weg der Vermittlung, daß sie das einzig wahrhafte Medium der Naturerkenntnis,

I) Galilei, Dialogo sopra i due massimi sistemi del mondo, Ed. nazionale VII, r29f. Studien der Bibliothek Warburg ro: Cassirer 
das in der Mathematik liegt, verschmähen. „Wer die höchste Weisheit der Mathematik tadelt, nährt sich von Verwirrung und wird niemals Schweigen auferlegen den Widersprüchen der sophistischen Wissenschaften, durch die man nur ein ewiges Geschrei erlernt. "1) Mit diesem Wort scheidet sich Leonardo ein für allemal von den ",Schwarmgeistern" der Naturphilosophie, von den ,vagabundi ingegni ${ }^{\prime}$, wie er selbst sie nennt. Mögen diese scheinbar zu den höchsten Zielen greifen und in die letzten Gründe der Natur hinabdringen, so kann die Größe des Objekts ihrer Wissenschaft doch niemals über die Unsicherheit des Fundaments dieses Wissens hinwegtäuschen. ,Du aber, der Du von Träumen lebst : Dir gefallen besser die sophistischen Gründe und die Gaunereien der Ballaufbläser in den großen und unsicheren Dingen als die sicheren natürlichen, die nicht von solcher Höhe sind.' $\left.{ }^{2}\right)$ Jetzt ist mit einem Schlage der Wertmaßstab, der im mittelalterlichen System den Rang der einzelnen Wissenschaften bestimmte, verändert. Wir erinnern uns, wie noch bei Salutati die Jurisprudenz höher als die Medizin stand, weil sie es mit dem Gesetz, also mit einem Geistigen und Göttlichen, zu tun hat, während die Medizin, wie die Naturwissenschaft überhaupt, sich nur mit niederen materiellen Dingen befaßt. "Nos curamus temporalia“ - so spricht in Salutatis Schrift ,De nobilitate legum et medicinae' die Medizin — ,sed leges aeterna, ego de terra creata sum, lex vero de mente divina“. Die Gesetze sind ,notwendiger als die Medizin“, so wahr sie unmittelbar von Gott abstammen. ${ }^{3}$ ) Jetzt aber ist ein anderer Begriff und eine andere Norm der Notwendigkeit geschaffen, nach welcher sie nicht mehr von der Höhe und Erhabenheit des Gegenstandes des Wissens, sondern von der Wissensform, von der spezifischen Qualität der Gewißheit abhängt. Diese, die ,certezza', wird zum eigentlichen, ja einzigen ,fundamentum divisionis'. Und damit rückt die Mathematik in den Brennpunkt der Erkenntnis: denn Gewißheit ist nur dort vorhanden, wo sich eine der mathematischen Wissenschaften anwenden oder wo sich der Gegenstand der Frage in Zusammenhang mit mathematischen Prinzipien erörtern läßt. ${ }^{4}$ ) Der Durchgang durch die Form der mathematischen Demonstration wird zur conditio sine qua non für alle wahrhafte Wissenschaft: ,nessuna investigazione si po' dimandare vera scienza, s'essa non passa per le mathematiche dimostrazioni ${ }^{\prime}{ }^{5}$ ) Freilich, so bestimmt dieser

I) The literary works of Leonardo da Vinci, ed. Jean Paul Richter, 2 vol., London I883, Nr. II 57 (die Übersetzungen z. T. in Anlehnung an die Übertragung von Marie Herzfeld, Leon. da Vinci, der Denker, Forscher und Poet, Lpz. I904).

2) Leonardo da Vinci, (Richter) Nr. II68.

3) S. ob. S. 150 Anm. I; vgl. bes. Walser, Poggius Florentinus, S. $250 f$.

4) Les manuscrits de Léonard de Vinci, publ. par Charles Ravaisson-Mollien, G. fol. 96 verso. 5) Trattato della pittura, ed. Ludwig, Lpz. I882, I, 33. 
Grundsatz aufgestellt ist, so kann es, wenn man das Ganze von Leonardos Aufzeichnungen überblickt, bisweilen scheinen, als ob in Hinblick auf das eigentliche methodische Fundament der Naturerkenntnis der Gedanke zwischen zwei entgegengesetzten Bestimmungen hin und her ginge. Denn bald ist es die Mathematik, bald ist es die „Erfahrung", die hier als Grundprinzip ausgezeichnet wird. Die Weisheit ist die Tochter der Erfahrung; das Experiment der einzige wahrhafte Dolmetsch zwischen der kunstreichen Natur und der menschlichen Spezies. ${ }^{1}$ ) Der Irrtum wurzelt somit niemals in der Erfahrung, in den Daten der Sinne, sondern nur in der Reflexion, in dem falschen Urteil, das wir über sie fällen. Daher beklagen sich die Menschen mit Unrecht über die Erfahrung und geben ihr Schuld, trügerisch zu sein. „Aber lasset selbige Erfahrung nur stehen und kehret solche Lamentation wider eure Unwissenheit, welche euch dazu übereilen läßt, mit euren eitlen und törichten Wünschen euch von jener Dinge zu versprechen, die in ihrer Macht nicht sind. “2) Dennoch ist mit diesen Sätzen nicht etwa ein zweites Prinzip der Gewißheit anerkannt, das neben oder über der Mathematik stünde. Denn eben dies ist hier das Entscheidende, daß ein solcher Dualismus zwischen dem Abstrakten und Konkreten, zwischen der ,Vernunft" und der ,Erfahrung " für Leonardo nicht länger fortbesteht. Beide Momente sind aufeinander bezogen und aneinander gebunden: die Erfahrung vollendet sich erst in der Mathematik, wie die Mathematik erst in der Erfahrung ,zu ihrer Frucht kommt". Hier herrscht kein Wettstreit, geschweige ein Widerstreit, sondern ein rein komplementäres Verhältnis. Denn es gibt keine wahrhafte Erfahrung ohne Analyse der Erscheinungen, ohne Auflösung des Gegebenen und Komplexen in seine Grundbedingungen; und es gibt kein anderes Mittel, diese Analyse durchzuführen als das der mathematischen Demonstration und der mathematischen Rechnung. Ist doch das, was wir die Welt der Tatsachen nennen, selbst nichts anderes als ein Gewebe von „Vernunftgründen“, von Bestimmungselementen, die im konkreten Sein und Geschehen unendlich vielfältig ineinander eingreifen und sich übereinander lagern, und die nur durch die Kraft des Denkens voneinander gesondert und einzeln in ihrer Bedeutung und Geltung aufgezeigt werden können. Das Experiment selbst hat seinen eigentlichen Wert darin, daß es diese Analyse leistet; daß es die einzelnen Faktoren, die in eine komplexe Erscheinung eingehen, für sich sichtbar macht und sie gesondert in ihrer Wirksamkeit verfolgt. So ist die Erfahrung, Aristo-

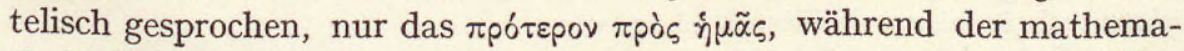

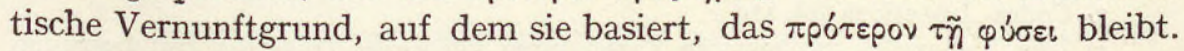

I) Il codice Atlantico di L. da Vinci, Milano, 1894, fol. $86^{x}$.

2) ibid. (Codex Atlanticus) fol. I $54 \mathrm{r}$. 
Und es besteht kein $Z$ weifel, daß das, was uns die Erfahrung, was uns die Welt der Phänomene tatsächlich zeigt, immer nur Bruchstück, immer nur ein endlicher Ausschnitt aus dem an sich unendlich-vielfältigen Bereich der Vernunftgründe ist. Die Natur birgt zahllose Gründe in sich, die niemals in die sinnliche Erscheinung getreten sind. ${ }^{1}$ ) Das also ist der echte Weg der Forschung, daß durch die ständige Beziehung der Erfahrung auf die Mathematik die schwankende Fülle der Erscheinungen auf ein bestimmtes $\mathrm{Maß}$ und eine feste Regel gebracht, daß das empirisch $\mathrm{Zu}$ fällige in ein gesetzlich Notwendiges verwandelt wird. Jetzt ist jenes Kriterium gefunden, zu dem die Naturphilosophie der Renaissance nicht vorzudringen vermochte, jetzt ist die Grenze zwischen der methodischen Richtung der Erfahrung und der bloßen ,,Spekulation“" streng gezogen. ${ }^{2}$ ) Die Regeln sind aufgestellt, die das Wahre vom Falschen unterscheiden lassen, die das wissenschaftlich Erreichbare vom Unmöglichen und Phantastischen trennen. Der Mensch begreift jetzt das Ziel seines Wissens, wie dessen Grenze, und ist nicht länger in Unwissenheit eingehüllt, die nur zur Folgehaben kann, daß er, ohne eine Wirkung erzielt zu haben, sich zuletzt verzweifelnd der Skepsis überantworten muß. ${ }^{3}$ )

Man pflegt, wenn man nach Leonardos Anteil an der Begründung der exakten Wissenschaft fragt, von den Einzelergebnissen der modernen Statik und Dynamik auszugehen, die er in seinen Aufzeichnungen vorweggenommen hat. Und wirklich finden sich hier überall Andeutungen verstreut, die auf die Grundprinzipien der Galileischen Bewegungslehre vorausweisen. Solche Andeutungen gehen ebensowohl auf das Trägheitsgesetz, wie auf den Satz der Gleichheit von Wirkung und Gegenwirkung, auf das Problem des Kräfteparallelogramms und des Geschwindigkeitsparallelogramms, auf das Hebelprinzip und auf das Prinzip, das La g rang e später als das „Prinzip der virtuellen Geschwindigkeit" formuliert hat. Aber all dies, so wichtig und grundlegend es ist, ${ }^{4}$ ) erschöpft keineswegs das Ganze von Leonardos theoretischer Leistung. Diese liegt nicht sowohl in den Resultaten, als vielmehr in der neuen Fragestellung: in dem neuen Begriff der „Naturnotwendigkeit", den er aufstellt und den er allseitig zur Geltung bringt. In seiner Definition der "Notwendigkeit" hat er wahre methodische Kernworte geprägt. „La neciessità è maestra e tutrice della natura, la neciessità è tema e inventrice della natura e freno e regola

I) Litterary works (Richter) Nr. II5I.

2) „Fuggi i precetti di speculatori che le loro ragioni non son confermate dalla sperienzia" (Ravaisson- Mollien, B fol. I4. v.).

3) Codex Atlanticus fol. Ix $\mathrm{r}$.

4) Über Leonardos mechanische Forschungen vgl. außer Duhems grundlegenden Arbeiten jetzt die neueste Schrift von Ivor B. Hart, The mechanical investigations of L. da Vinci, London 1925 . 
eterna“.1) In solcher Aufstellung des Problems, des „Themas“ der exakten Wissenschaft liegt Leonardos eigentliche gedankliche Größe. Die Natur wird beherrscht von der Vernunft, als dem Gesetz, das ihr innewohnt und das sie nie und nimmer brechen kann. ${ }^{2}$ ) Jetzt ist es nicht mehr der Sinn, ist es nicht die Empfindung oder das unmittelbare Lebensgefühl, mit dem wir uns der Natur angleichen, und mit denen wir ihr ihr Geheimnis ablauschen können. Das Denken allein, der "Satz vom Grunde", den Leonardo als Satz der mathematischen Begründung versteht, erweist sich der Natur als wahrhaft gewachsen. Eben hier liegt der Punkt, von dem aus sich Leonardos Wirkung auf Galilei erst ganz in ihrer Bedeutung erfassen und würdigen läßt. Der Ausspruch der ein zeln en Naturgesetze mag bei Leonardo bisweilen noch schwankend und zweideutig sein:aber was bei ihm feststeht, ist der Gedanke und die Definition des Naturgesetzes selbst. Hier knüpft Galilei unmittelbar an ihn an; hier setzt er nur fort und expliziert er nur, was Leonardo begonnen. Auch für Galilei „hat" die Natur nicht sowohl Notwendigkeit, als sie vielmehr Notwendigkeit ist. Diese ist das entscheidende Merkmal, durch das sich, was wir Natur nennen, vom Reich der Fiktion und der poetischen Erdichtung unterscheidet. Wenn Galilei ebensowohl gegen die spekulative Naturphilosophie seiner Zeit, wie gegen Aristoteles und die Scholastik kämpft, so geschieht es, weil beide in ihren Erklärungen diese Grenze beständig verwischen. Sie sehen - wie Galilei es im ",Saggiatore“ ausspricht - die Philosophie wie ein Buch an, wie ein Erzeugnis der Phantasie, gleich der Ilias oder dem ",rasenden Roland", in dem es am wenigsten darauf ankommt, ob das, was in ihm geschrieben steht, wahr ist. „Aber nicht so verhält es sich: sondern die Philosophie ist in dem großen Buch der Natur geschrieben, das uns beständig vor Augen liegt, das aber niemand zu lesen vermag, es sei denn, daß er zuvor die Chiffern, in denen es verfaßt ist, d. h. die mathematischen Figuren und deren notwendige Verknüpfung zu verstehen gelernt hat.“3) Nur in dieser Art der Verknüpfung, in der streng-eindeutigen Beziehung der "Ursache" auf die „Wirkung", der „Wirkung“" auf die „Ursache“, erschließt sich uns der logisch-mathematische Zusammenhang des Seins und des Geschehens. Dennoch sind Leonardo und Galilei, so nahe sie sich inihrer Betrachtung der Natur stehen, nicht auf dem gleichen Wege zu diesem Ergebnis gelangt. Denn wenn Galilei den Trennungsstrich zwischen der objektiven Wahrheit der Natur und der Welt der Fabel und der Fiktion zieht, so tritt auch die Dichtung

I) Richter Nr. II33.

2) "La natura è costretta dalla ragione della sua legge che in lei infusamente vive". (Ravaisson-Mollien, C fol. $23 \mathrm{v}$.)

3) Galilei, Il saggiatore, Ed. naz. VI, 232. 
so tritt die K unst auf die letztere Seite. Für Leonardo dagegen bedeutet die Kunst niemals eine bloße Ausgeburt der subjektiven Phantasie, sondern sie ist und bleibt ihm ein echtes und unentbehrliches Organ der Wirklichkeitserfassung selbst. Ihr immanenter Wahrheitswert steht dem der Wissenschaft nicht nach. Denn Leonardo läßt so wenig in der einen wie in der anderen ein Moment der subjektiven Willkür zu, sondern verehrt in beiden die allwaltende Notwendigkeit als Thema und Entdeckerin der Natur, als ihr Zügel und ihre ewige Regel. Wie für Goethe, ist ihm der künstlerische "Stil" von jeglicher bloß zufälligen individuellen „Manier" scharf geschieden: wie für diesen ruht er ihm ,,auf den tiefsten Grundfesten der Erkenntnis, auf dem Wesen der Dinge, insofern uns erlaubt ist, es in sichtbaren und greiflichen Gestalten zu erkennen". Diese Sicht- und Greifbarkeit der Gestalt ist es, an der auch der Forscher Leonardo festhält. Sie ist die Schranke, an die nach ihm auch alles menschliche Erkennen und Begreifen gebunden bleibt. Das Reich der anschaulichen Gestalten vollständig zu durchmessen, jede dieser Gestalten in ihrem klaren und sichern Umriß zu erfassen, und sie sich in voller Bestimmtheit mit dem äußeren und inneren Blick zu vergegenwärtigen: das ist das höchste Ziel, das Leonardos Wissenschaft kennt. Die Grenze des Schauens ist ihm daher notwendig zugleich die Grenze des Begreifens. So ist, was er als Künstler wie als Forscher umspannt, immer die ,Welt des Auges" ; aber diese soll nicht stückweise und fragmentarisch, sondern vollständig und systematisch vor ihm stehen. ${ }^{1}$ )

Verkennt man diese Grundform von Leonardos Frage, schiebt man ihm andere Probleme unter, die erst die spätere mathematische Naturwissenschaft gestellt hat und stellen konnte, so gerät man in Gefahr, seinen Begriff des Wissens und seine wissenschaftliche Leistung an einem falschen Maßstab zu messen. Von zwei verschiedenen Seiten her ist neuerdings dieser Begriff angefochten und in seiner Bedeutung für die Geschichte der Erkenntnis zu beschränken gesucht worden. Croce rückt in einer Abhandlung über ,Leonardo als Philosoph“ Leonardo nahe an die großen modernen Naturforscher, an Galilei und Newton heran, spricht ihm aber den Blick für die innere Welt, für die eigentliche Sphäre des Geistes und der spekulativen Erkenntnis ab. ${ }^{2}$ ) Den entgegengesetzten Vorwurf hat Olschki in seiner "Geschichte der neusprachlichen wissenschaftlichen Literatur" erhoben. „Es ist - so schreibt er - als ob er vor einer wissenschaftlich brauchbaren, auf deduktivem oder induktivem Wege zu er-

I) Über dieses Verhältnis von „Sehen“ und „Erkennen“" bei Leonardo vgl. z. B. die Darstellung von Farinelli, La natura nel pensiero e nell' arte di Leonardo da Vinci (Michelangelo e Dante, Torino, I9I8, S. 3 I 5 ff.).

2) Croce, Leonardo filosofo (Saggi filosofici, Paris I9r3, III). 
langenden Generalisierung sich scheue, als ob er sich auch zum Verharren in der nächstliegenden Abstraktion unfähig fühle und sich mit den durch Zeichnungen erhaltenen intuitiven Beweisen zufrieden gäbe." Aber beide Urteile: das eine, das Leonardo an der Norm eines spekulativen Idealismus, das andere, das ihn an der Norm des modernen Positivismus mißt, vergessen, daß es nach Goethes Wort auch eine ,exakte sinnliche Phantasie" gibt, die ihre eigenen Regeln und ihre eigenen immanenten Maße hat. Was diese Form der exakten Phantasie für die empirische Forschung zu leisten vermag: das eben hat Leonardo wie kein Zweiter erwiesen. Nichts ist irriger, als wenn man in seinem wissenschaftlichen Werk eine bloße Mischung von scharf beobachteten Tatsachen und phantasievollen ,Schwärmereien“ sieht. ${ }^{1}$ ) Denn die Phantasie tritt hier nicht zur Wahrnehmung hinzu, sondern sie ist selbst das lebendige Vehikel der Wahrnehmung; sie weist ihr ihren Weg und gibt ihr ihre Prägnanz, ihre Schärfe und Bestimmtheit. So ist es freilich zutreffend, daß auch Leonardos Wissenschaftsideal auf nichts anderes als auf die Vollendung des Sehens, auf das ,saper vedere" gerichtet ist, daß das darstellend bildnerische Material auch in seinen mechanischen, optischen und geometrischen Aufzeichnungen überwiegt, daß ,Abstraktion" und ,Vision" in ihm untrennbar zusammenwirken. ${ }^{1 \mathrm{a}}$ ) Aber eben diesem Zusammenwirken verdankt seine Forschung die höchsten Resultate. Er selbst hat erklärt, daß er die Verengung und Ausdehnung der Pupille je nach der einfallenden Lichtmenge zuerst als Maler beobachtet und dann erst als Theoretiker behandelt habe. ${ }^{2}$ ) So erweist sich Leonardos Bild der Natur überall als ein methodisch-notwendiger Durchgangspunkt: die künstlerische ,Vision“" erst ist es gewesen, die der wissenschaftlichen Abstraktion ihr Recht erkämpft und die ihr den Weg bereitet hat. Die ,exakte Phantasie“ des Künstlers Leonardo ist ebensosehr über das chaotische Wallen und Wogen des subjektiven Gefühls, dem alle Gestalten in eine unterschiedslose Einheit zu verschwimmen drohen, hinaus - wie sie andererseits, allen bloß begrifflichen und abstrakten Distinktionen gegenüber, mit aller Kraft am anschaulich Wirklichen festhält. In der Anschauung, nicht unter oder über ihr, wird die wahrhafte, die objektive Notwendigkeit entdeckt. Und damit erhält sie einen neuen Sinn und einen neuen Klang. Wenn bisher die Notwendigkeit, als das regnum naturae, dem Reich der Freiheit und dem des Geistes als Gegensatz gegenüberstand, so wird sie jetzt zum

I) Olschki, Geschichte der neusprachlichen wissenschaftlichen Literatur, Heidelb. I9I9, I, 26r: I, 30of. u. ö.

Ia) Olschki, a. a. O., I, 342, 379 .

2) Ravaisson-Mollien, D fol. I $_{3} \mathrm{r}$; vgl. Solmi, Nuovi studi sulla filosofia naturale di L. da Vinci, p. 39: ,Analizzare un fatto col discorso o analizzarlo con disegno non sono (per Leonardo) che due modi diversi di un medesimo processo." 
Siegel des Geistes selbst. „O wunderbare Notwendigkeit — so schreibt Leonardo - Du zwingst mit höchster Vernunft alle Wirkungen an ihren Ursachen teilzunehmen und jede natürliche Handlung gehorcht Dir gemäß einem höchsten und unwiderruflichen Gesetz auf die kürzeste Weise. . . . Wer vermöchte dieses Wunder zu erklären, das den menschlichen Verstand zur göttlichen Anschauung erhebt? ... O mächtiges Werkzeug der kunstreichen Natur, Dir kommt es zu, dem Gesetz zu gehorchen, das Gott und die Zeit der schaffenden Natur gegeben haben. " 1 ) Diese Herrschaft der Notwendigkeit und diesen ihren tiefsten Gehalt hat erst die künstlerische Anschauung wahrhaft erschlossen. Das Wort Goethes, daB das Schöne eine Manifestation geheimer Naturgesetze sei, die uns ohne dessen Erscheinung ewig verborgen geblieben wären; dieses Wort ist ganz in Leonardos Sinn gesprochen und drückt den Kern seines Gedankens aus. Die Proportion in ihrer innersten Gesetzlichkeit ist für ihn das wahrhafte Mittelglied und Bindeglied zwischen Natur und Freiheit: in ihr ruht der Geist, als in einem Bestehenden und Objektiven, und in ihr findet er doch zugleich sich selbst und seine eigene Regel wieder.

Es verlohnt sich, bei diesem durchgehenden Parallelismus von Kunst theorie und Wissenschaftstheorie länger zu verweilen: denn ihn ihm erschließt sich uns eines der tiefsten Motive in der geistigen Gesamtbewegung der Renaissance. Man kann sagen, daß fast alle großen Errungenschaften der Renaissance sich hier wie in einem Brennpunkt zusammenfassen, daß sie fast alle in einer neuen Stellung zum Problem der Form und in einer neuen Empfindung für die Form wurzeln. Die Dichtung und die bildende Kunst weisen hier auf das gleiche Grundverhältnis zurück. Borinski hat gezeigt, welche Bedeutung die Poetik der Renaissance für das Ganze ihres menschlich-geistigen Lebensideals besitzt. „Dieser Umschwung in der geistigen Weltaneignung ... vermag auch zuerst die Bedeutung einleuchtend zu machen, die das klassische Altertum für die... neue geistige Ära besitzt. Beziehungen zum Altertum hat das Mittelalter ... gewiß genug gehabt. In dieser Hinsicht ist dank der die Antike ablösenden Kulturmacht, der Kirche, eigentlich nie ein völliger Bruch mit ihr, eher, wie im Karolingischen, Ottonischen, Hohenstaufischen Zeitalter, Ansätze zu Vorausnahmen der großen Geistesbewegung eingetreten. Allein im großen Ganzen bleibt die Einwirkung des Altertums auf die Zeit, wie man es treffend im weitesten Sinne bezeichnet hat, st offlich. Und diese "stoffliche Antike" wirkt noch lange genug in die eigentliche Renaissancezeit hinein nach. Jener Umschwung in der Stellung der Persönlichkeit zum Altertum aber äußert sich in der Form: von der Form des eigenen Daseins in Fühlen, Denken, Leben

I) Cod. Atlant. fol. $345 \mathrm{r}$. 
angefangen bis zur antik-klassischen Formgebung in Dichtung und Kunst, Gesellschaft und Staat." $\left.{ }^{1}\right)$ Es gibt kaum ein geistiges Gebiet, in dem sich nicht dieser Zusammenhang, dieser eigentümliche Primat, den die Form im Denken und im Leben der Renaissance gewinnt, aufweisen ließe. Die Lyrik geht hier voran; sie wird zum ersten und mächtigsten Vehikel des neuen Formwillens. In Dantes Vita nuova und in Petrarcas Sonetten eilt gewissermaßen das Formgefühl dem Lebensgefühl voraus: wenn dieses noch im mittelalterlichen Gefühls- und Anschauungskreis gebunden erscheint, so wird jenes zur eigentlich befreienden und lösenden Kraft. Hier beschreibt der lyrische Ausdruck nicht nur eine fertige, in sich bereits gestaltete innere Wirklichkeit, sondern er entdeckt und erschafft diese Wirklichkeit selbst. Der neue lyrische Stil wird zum Quellgebiet des neuen Lebens. Geht man den philosophischen Quellen dieses Stils nach, so wird man auf die mittelalterliche Philosophie, insbesondere auf den Averroismus zurückgeführt. Der Gehalt der Probleme, wie die gesamte allegorische Begriffssprache dieser Lyrik, wird erst verständlich, wenn man sie aus ihren geschichtlichen Voraussetzungen, aus der poetischen Tradition der Troubadours und aus der wissenschaftlichen Tradition der Scholastik herleitet. ${ }^{2}$ ) Die neue Form, in die dieser traditionelle Gehalt gegossen wird, aber war dazu bestimmt, ihn selbst fortschreitend zu verändern. Und das gleiche Verhältnis von Gehalt und Ausdruck wie in der lyrischen Sphäre zeigt sich in der logischen Sphäre. Denn auch hier wirkt das neue Sprachgefühl der Renaissance, das im Kreise des Humanismus erwächst, überall als eine unmittelbare Triebkraft des Denkens. Das Streben nach Reinheit der Sprache, nach Befreiung aus den ,,barbarischen“ Mißbildungen des scholastischen Latein, führt zu einer Neugestaltung der Dialektik. Vallas Elegantien der lateinischen Sprache stellen sich dasselbe Ziel wie seine dialektischen Disputationen: beide streben nach Klarheit, nach Vereinfachung, nach Reinigung des Sprechens, die von selbst und unmittelbar zur Schlichtheit und Reinheit des Gedankens führen soll. Die Lehre von der Gliederung der Rede wird zur Lehre von der allgemeinen Struktur des Gedankens fortgebildet: die Stilistik wird zum Vorbild und zur Führerin der Kategorienlehre. Was die Philosophie, was die Logik und Dialektik an echtem Gehalt besitzen, das tragen sie von der ,Königin Rede“ zu Lehen: ,omnia quae philosophia sibi vendicat" - so spricht der Humanist und Rhetor Antonio Panormita in Vallas Dialog über die Lust - ,nostra sunt ${ }^{\text {‘3 }}$.)

x) Borinski, Der Streit um die Renaissance (vgl. ob. S. 6, Anm. I); S. 20 f.

2) Näheres hierzu bei Karl Voßler, Die philosophischen Grundlagen zum ,süßen neuen Stil“ des Guido Guinicelli, Guido Cavalcanti und Dante Alighieri, Heidelberg I904.

3) Valla, De voluptate, Lib. I, Cap. X; Opera fol. 907. 
Und so hat man vom Humanismus überhaupt gesagt, daß seine innerste Wurzel und das große gemeinsame Band, das alle Humanisten umspannt, weder Individualismus noch Politik, Philosophie oder religiöse gemeinsame Ideen, sondern lediglich das künstlerische Empfinden gewesen sei. ${ }^{1}$ ) Jetzt zeigt sich, daß dieses künstlerische Empfinden es gewesen ist, das auch dem neuen Begriff der Natur, der sich in der Wissenschaft der Renaissance herausbildet, seine konkrete Bestimmung gegeben hat. Zwischen Leonardos künstlerischem Schaffen und seiner wissenschaftlichen Leistung besteht nicht nur, wie man zumeist annimmt, eine Art Personalunion, sondern eine echt sachliche Union. Kraft dieser gelangt er zu einer neuen Grundanschauung von dem Zusammenhang von „Freiheit“ und „Notwendigkeit", von ",Subjekt" und "Objekt", von "Genie" und „Natur". Es schien, als habe die ältere Kunsttheorie der Renaissance, auf der Leonardo fußt und die er weiterführt, zwischen beiden eine Art Kluft aufgerissen. In Leon Battista Albertis "Trattato della pittura" wird der Künstler geradezu davor gewarnt, sich, statt sich in das große Vorbild der ,Natur“ zu versenken, auf die Kraft des eigenen Genies (ingegno) zu verlassen. Er soll den Weg jener Toren meiden, die, stolz auf ihr Talent, sich ohne jegliches der Natur entnommene Beispiel, dem sie mit den Augen oder mit dem Verstande folgen, Lob in der Malerei verdienen zu können glauben. ${ }^{2}$ ) Bei Leonardo hingegen hat dieser Gegensatz seinen Ausgleich gefunden. Die Schöpferkraft des Künstlers steht ihm ebenso wie die des theoretischen, des wissenschaftlichen Denkens fest. Die Wissenschaft ist eine zweite Schöpfung, die mit dem Verstande, die Malerei ist eine zweite Schöpfung, die mit der Phantasie gemacht ist (la scienza è una seconda creazione fatta col discorso, la pittura è una seconda creazione fatta colla fantasia). Aber beide Schöpfungen erhalten ihren Wert eben dadurch, daß sie sich nicht von der Natur, von der empirischen Wahrheit der Dinge entfernen, sondern daß sie eben diese Wahrheit erfassen und aufdecken. Ein solches eigentümliches Wechselverhältnis zwischen „Natur“ und ,Freiheit" war nicht möglich, solange der Gegensatz zwischen beiden lediglich unter ethischen und religiösen Kategorien gedacht wurde. Denn hier, im Gebiet des Willens, handelte es sich um eine Alternative, vor die das sittlich-religiöse Ich sich gestellt sah. Es konnte den einen oder den anderen Standpunkt wählen: es könnte sich gegen die Freiheit und Gnade

I) Ernst Walser, Studien zur Weltanschauung der Renaissance, S. I2.

2) Leon Battista Alberti, Trattato della pittura, Lib. III (ed. Janitschek, Wien 1877 , S. I5 I) : Ma per non perdere studio et faticha, si vuole fuggire quella consuetudine d' alcuni sciocchi, i quali presuntuosi di suo ingegnio, senza avere essemplo alcuno dalla natura quale con occhi o mente seguano, studiano da se ad se acquistare lode di dipigniere. Questi non imparano dipigniere bene, ma assuefanno se a suoi errori . Fuggie l'ingegni non periti quella idea delle bellezze, quale i beni exercitatissimi appena discernono'. 
für die Natur, oder für das ,regnum gratiae“ für die Freiheit und die Providenz gegen die Natur entscheiden. Über diesen Widerstreit, wie er z. B. das Grundthema von Picos Rede über die Würde des Menschen bildet, aber ist Leonardo von Anfang an hinaus. Denn ihm bedeutet die Natur nicht länger das Reich des Gestaltlosen, die bloße Materie, die sich dem Prinzip der Form und ihrer Herrschaft widersetzt. Sie ist für ihn nicht das Gestaltfremde, sondern sie ist ihm, der sie nicht anders als durch das Medium der Kunst erblickt, vielmehr das Reich der vollkommenen und durchgehenden Gestaltung selbst. So herrscht in ihr freilich die Notwendigkeit als ihr Band und ihre ewige Regel - aber diese Notwendigkeit ist nicht die des bloßen Stoffes, sondern sie ist die der reinen „Proportion“, die dem Geist innerlichst verwandt ist. Proportion ist nicht bloß in den Zahlen und Maßen aufzufinden, sondern auch in den Tönen, Gewichten, Zeiten und Orten, und in welcher Kraft immer es sei. ${ }^{1}$ ) Durch sie, durch das innere $\mathrm{Maß}$ und die Harmonie, ist jetzt die Natur gleichsam erlöst und geadelt. Nicht mehr als feindliche oder fremde Macht steht sie dem Menschen gegenüber; denn, wenngleich sie für uns unerschöpfbar, wenngleich sie schlechthin unendlich ist, sind wir doch sicher, daß diese Unendlichkeit keine andere als die der ,infinite ragioni" der Mathematik ist, die wir, wenngleich wir sie ihrem Umfang nach niemals zu überschauen vermögen, doch in ihren letzten Gründen, in ihren Prinzipien erfassen. Die Idealität der Mathematik hebt den Geist zu seiner höchsten Höhe und bringt ihn $\mathrm{zu}$ seiner eigentlichen Vollendung: - sie beseitigt die Schranke, die die mittelalterliche Anschauung zwischen der Natur und dem Geist einerseits, zwischen dem menschlichen und dem göttlichen Intellekt andererseits aufgerichtet hatte. Galilei wird auch diese kühne Folgerung ausdrücklich ziehen. Der Maßstab des Wissens - so führt er in den Dialogen über die beiden Weltsysteme aus - kann in doppeltem Sinne verstanden werden, je nachdem man das Wissen in intensiver oder extensiver Bedeutung nimmt. Wählt man das letztere, geht man von der Vielheit des Wißbaren aus, so ist mit ihr verglichen der menschliche Verstand gleich einem Nichts zu erachten. Anders aber, wenn man, statt die Objekte des Wissens ins Auge zu fassen, auf seinen Grund und sein Prinzip, auf das, was es zum Wissen macht, zurückgeht. „Denn hier sage ich, daß der menschliche Geist einiges so vollkommen versteht, und von ihm eine so absolute Gewißheit besitzt wie die Natur selbst: und von dieser Art sind die reinen mathematischen Wissenschaften. Zwar erkennt der göttliche Intellekt die mathematischen Wahrheiten in unendlich größerer Fülle als der unsere (denn er weiß siealle); aber von den wenigen, die der menschliche Intellekt erfaßt, glaube ich, daß ihre Erkenntnis an

I) Ravaisson-Mollien fol. 49 r. (Ausg. Herzfeld, S. 26). 
objektiver Gewißheit der göttlichen gleichkommt, da der Mensch dazu gelangt, ihre Notwendigkeit einzusehen, über welche hinaus es keinen höheren Grad von Sicherheit geben kann."1)

Und damit ist nun auch das wahrhafte Grundverhältnis zwischen der künstlerischen Phantasie und der Wirklichkeit, zwischen dem ",Genie“ und der „Natur" festgestellt. Zwischen beiden besteht nirgend ein Widerstreit: die echte künstlerische Phantasie strebt nicht über die Natur hinaus ins Reich der bloßen Fiktionen und Einbildungen, sondern sie ergreift deren eigene ewige und immanente Gesetze. Denn - auch darin stimmt Leonardo mit Goethe überein - : ,,das Gesetz, das in die Erscheinung tritt, in der größten Freiheit nach seinen eigensten Bedingungen, bringt das objektiv Schöne hervor, welches freilich würdige Subjekte finden muß, von denen es aufgefaßt wird. ${ }^{\text {“2 }}$ ) Die Schöpferkraft des Künstlers, seine Phantasie, die eine ,zweite Natur" hervorbringt, besteht nicht darin, daß er dieses Gesetz erfindet, daß er es wie aus dem Nichts erschafft, sondern da $\beta$ er es entdeckt und aufweist. Im Akt des künstlerischen Sehens und der künstlerischen Darstellung scheidet sich das Zufällige und Notwendige: in ihm tritt das Wesen der Dinge hervor, das in ihrer Form seinen sichtbaren Ausdruck findet. Auch hier wird die wissenschaftliche Theorie der Erfahrung, wie sie von Galilei und Kepler geprägt wird, unmittelbar an jenen Grundbegriff und an jene Grundforderung der „Exaktheit“ anknüpfen, wie ihn die Kunsttheorie aufgestellt und sichergestellt hatte. Und beide: die Kunsttheorie und die Erkenntnistheorie der exakten Wissenschaft durchlaufen hier genau die gleichen Phasen des Denkens. Man hat mit Recht als eines der bedeutsamsten Momente in der Kunsttheorie der Renaissance den Umstand angeführt, daß in ihr ,,das Band zwischen dem Pulchrum und dem Bonum ", das das ganze Mittelalter hindurch die Kunst in der theologisch-metaphysischen Sphäre festhielt, sich hier zum erstenmal zu lockern beginnt, und daß damit die Autonomisierung des ästhetischen Gebiets eingeleitet wird, die erstnach mehrals drei Jahrhunderten theoretisch begründet werden sollte. ${ }^{3}$ ) Aber dieser Lockerung entspricht auf der anderen Seite eine Befestigung: denn je mehr das „Pulchrum“ sich vom „Bonum“ loslöst, um so fester schließt es sich mit dem ,V Verum“ zusammen. Wie Leonardo den Künstler davor warnt, , die Manier eines anderen nachzuahmen“, - wie er jene, die nur die Autoren studieren, und nicht die Werke der Natur, nicht als Kinder der Natur, sondern nur als deren Enkel gelten läßt $\left.{ }^{1}\right)$ : so steht

I) Galilei, Dialogo sopra i due massimi sistemi del mondo, I, Ed. naz. VII, I29.

2) Goethe, Maximen und Reflexionen, hg. von Max Hecker, Nr. 1346.

3) Erwin Panofsky, Idea, Ein Beitrag zur Begriffsgeschichte der älteren Kunsttheorie (Studien der Bibl. Warburg, hg. von Fritz Saxl, V), Lpz. 1924, S. 29. 
Galilei in stetem Kampfe gegen jene scholastische Methode, die an Stelle der Auslegung und Interpretation der Phänomene die Auslegung der Schriftsteller setzt. Aber wie Leonardo, so betont auch Galilei andererseits unablässig, daß das Gesetz, das die Erscheinungen beherrscht, daß die ,ragioni“, die ihnen zugrunde liegen, nicht unmittelbar durch sinnliche Wahrnehmung aus ihnen abzulesen sind, sondern daß es, um sie zu entdecken, der Spontaneität des mathematischen Verstandes bedarf. Denn das Ewige und Notwendige in den Dingen lernen wir nicht durch eine bloße Anhäufung und Vergleichung sinnlicher Erfahrungen kennen: vielmehr muß der Geist es ,,von sich aus “ erfaßt haben, um es in den Erscheinungen wiederzufinden. Die wahren und notwendigen Dinge, d. h. diejenigen, die sich unmöglich anders verhalten können, weiß jeder Verstand aus sich (da per sè); - oder es ist unmöglich, daß er sie jemals wisse. ${ }^{2}$ ) So setzt auch jedes Experiment, jede Frage an die Erfahrung, einen intellektuellen „Entwurf“ des Gedankens - ein „,mente concipio", wie Galilei es nennt, voraus. In ihm antizipieren wir eine Gesetzlichkeit der Natur, um sie nachträglich, durch Prüfung an der Erfahrung, zur Gewißheit zu erheben. Auch hier wird also das objektiv-Gesetzliche, werden die festen Grundmaße, die alles Naturgeschehen bestimmen und beherrschen, nicht einfach der Erfahrung entnommen, sondern sie werden als „Hypothesen“ der Erfahrung zugrunde gelegt, um durch sie bestätigt oder widerlegt zu werden. Das ist das neue Verhältnis von ,Verstand“ (discorso) und Sinn, von Erfahrung und Denken, auf dem nach Galilei alle Wissenschaft der Natur beruht: ein Verhältnis, das, wie man sieht, das strenge Analogon bildet zu jener Beziehung, die nach der Kunsttheorie der Renaissance zwischen der Phantasie des Malers und der ,objektiven“ Wirklichkeit der Dinge besteht. Die Kraft des Geistes, des künstlerischen wie des wissenschaftlichen Ingeniums, besteht nicht darin, daß beide sich in ungebundener Willkür ergehen, sondern daß sie uns den ,,Gegenstand“ in seiner Wahrheit, in seiner höchsten Bestimmtheit erst sehen und erkennen lehren. Das Genie im Künstler und im Denker findet die Notwendigkeit der Natur. Noch währt es jahrhundertelang, ehe dieser Gedanke in theoretischer Bestimmtheit ausgesprochen werden, ehe die ,Kritik der Urteilskraft" den Satz prägen kann, daß das Genie diejenige Naturgabe sei, durch welche die „Natur im Subjekte“ der Kunst die Regel gebe. Aber

r) Codex Atlanticus fol. I4I r. (vgl. Ausgabe von M. Herzfeld, S. I37f.).

2) Galilei, Dialogo sopra i due massimi sistemi del mondo, Ed. naz. VII, I83: „Posso bene insegnarvi delle cose che non son nè vere nè false; ma le vere, cioè le necessarie, cioè quelle che e impossibile ad esser altrimenti, ogni mediocre discorso o le sa da sè o è impossibile che ei le sappia mai." 
der Weg zu diesem Ziele ist jetzt deutlich gewiesen. ${ }^{1}$ ) Und auf diesem Wege erst ist es der Renaissance gelungen, die Magie und die Mystik, sowie den gesamten Komplex der ,okkulten“ Wissenschaften zu überwinden. Der Zusammenschluß von Mathematik und Kunsttheorie hat hier geleistet, was die Hingabe an die empirisch-sinnliche Beobachtung und die unmittelbare gefühlsmäßige Versenkung in das , Innere derNatur“ nicht zu leisten vermochten. Jetzt entsteht die neue, die eigentlich-moderne Idee der Natur, wie sie sich, als eine Synthese des theoretischen und des künstlerischen Geistes der Renaissance, am vollkommensten in Keplers Werk über die Weltharmonie darstellt. Kepler selbst spricht hierbei das Verhältnis in rein Platonischen Begriffen aus: die Gesetze der Harmonie sind ihm die Grundbestimmungen, die wir im Empirischen, im sinnlich-Sichtbaren nur deshalb wiederfinden, weil alles Sichtbare nach den ewigen „Archetypen“ der Ordnung und des Maßes, der Arithmetik und Geometrie geschaffen ist. Aber auch Galilei, auch der große wissenschaftliche Analytiker, der überall darauf ausgeht, Empirisches

I) Auf den Gegensatz zwischen der ,,Spontaneität" des Genies und der „,Objektivität" der ,Regeln', wie er in der Poetik der Renaissance aufgestellt wird, gehe ich hier nicht näher ein: einiges neue Material für die Darstellung und Beurteilung dieses Gegensatzes ist jetzt bei Edgar Zilse1, Die Entstehung des Geniebegriffs, Tübingen 1926, und in einer Hamburger Dissertation von Hans Thüme, Beiträge zur Geschichte des Geniebegriffs in England (Einleitung) gegeben. Auch in diesem Problemkreis, auch in dem Streit zwischen ,imitatio' und ,inventio - wie er auf der einen Seite von Polizian, dem jüngeren Pico und von Erasmus, auf der anderen Seite von Cortese und Bembo geführt wird wird eine klare und sichere Abgrenzung der Prinzipien zwar nirgends erreicht, aber andererseits nimmt die Renaissancephilosophie bereits jene prägnante Formulierung vorweg, die dann, durch Vermittlung der englischen Psychologie und Ästhetik, auf Lessing und auf Kant gewirkt hat. Giordano Bruno spricht es aufs schärfste aus, daß nicht die Poesie aus den Regeln, sondern die Regeln aus der Poesie entstehen, denn es gebe so viel Gattungen und Arten echter Regeln, als es Gattungen und Arten wahrhafter Poeten gebe (Eroici furori I. Opere ital. (Lagarde) S. 625). Im übrigen betont Pan ofsky (a. a. O., S. 38) mit Recht, daß die ,eigentliche Renaissance“ "von einem Widerspruch zwischen Genie und Regel ebensowenig wie von einem Widerspruch zwischen Genie und Natur" etwas weiß, und daß gerade ihr Begriff der Idee ,,die Versöhntheit dieser noch gar nicht auseinandergetretenen Gegensätze besonders deutlich zum Ausdruck bringt, indem er die Freiheit des künstlerischen Geistes den Ansprüchen der Wirklichkeit gegenüber zugleich gesichert und eingeschränkt zeigt." Dies stimmt mit dem Resultat unserer Untersuchung völlig überein: nur möchte ich nicht mit Panofsky sagen (a.a. O., S. 56), daß das Denken der Renaissance die künstlerische Idee im allgemeinen und die Idee der Schönheit im besonderen „empirisiert und aposteriorisiert" habe. Das Eigentümliche und das Entscheidende scheint mir hier vielmehr darin zu liegen, daß beide, die Naturtheorie wie die Kunsttheorie, am ,Apriori ' der Idee festhalten und nichtsdestoweniger, kraft eben dieses Apriori selbst, die Idee in ein neues Verhältnis zur Erfahrung rücken. Denn die mathematische Idee, das ,Apriori' der Proportion und der Harmonie, ist es, was jetzt als der gemeinsame Grund der empirischen Wahrheit sowohl, wie der künstlerischen Schönheit aufgewiesen wird: die "eingeborene" Idee der Zahl und die "eingeborene" Idee des Schönen haben Kepler, wie er selbst immer wieder betont hat, zur Aufstellung der drei Grundgesetze der Planetenbewegung geführt. 
von Metaphysischem, Logisches von Ästhetischem sorgsam zu scheiden: auch er ist sich doch einer gemeinsamen Wurzel des künstlerischen und des wissenschaftlichen Geistes bewußt. Beide bedeuten ihm verschiedene Weisen der Gestaltung, wobei er der Kraft der Gestaltung, die in den großen Künstlern lebt, unbedenklich und neidlos den Vorrang vor der rein theoretischen Betrachtung einräumt. An derselben Stelle, an der er die kühne Gleichsetzung des menschlichen und des göttlichen Intellekts vollzieht, beruft er sich, um diesen Adel des menschlichen Geistes zu erweisen, vor allem auf die Produktivität des bildenden Künstlers, die der des Theoretikers unendlich überlegen sei. „Wenn ich die vielen wunderbaren Entdeckungen der Menschheit in Künsten und Wissenschaften durchgehe und dann an mein Wissen denke, das mich so ganz und gar nicht befähigt, eine neue ausfindig zu machen, ja auch nur das Gefundene zu begreifen, dann bin ich verwirrt vor Staunen, niedergeschlagen vor Verzweiflung, und halte mich fast für unglücklich. Wenn ich eine vortreffliche Statue betrachte, sage ich bei mir: Wann wirst du lernen, aus einem Marmorblock einen solchen Kern herauszuschälen, die herrliche Form zu entdecken, die er verbarg? oder verschiedene Farben mischen und sie auf einer Leinwand, einer Mauerfläche ausbreiten, so daß sie das ganze Reich des Sichtbaren darstellen, wie ein Michelangelo, ein Rafael, ein Tizian ?"1) Abermals tritt uns hier, im Zusammenhang der Kunsttheorie und der Erfahrungstheorie, ein Grundmotiv entgegen, das uns zuvor im Kreise der ethisch-religiösen Spekulation begegnet ist. Wieder erweist sich jetzt der Geist des Menschen als ein zweiter Schöpfer, als ein ,,wahrer Prometheus unter Jupiter". Es zeigt sich, wie die Renaissance, von den verschiedensten Seiten her und auf mannigfach-verschlungenen Wegen immer wieder zu diesem Bilde zurückkehrt, das für sie offenbar mehr als eine bloße Allegorie bedeutet, das ihr zum Symbol dessen wird, was sie als geistige Gesamtbewegung ist und erstrebt.

Und zugleich mit dieser Entdeckung des neuen Naturbegriffs, ja eben in dieser Entdeckung selbst, hat nun die Renaissance eine neue Bereicherung und Vertiefung ihres geschichtlichen Bewußtseins erfahren. Denn jetzt hat sie einen neuen Zugang zur klassisch-griechischen Gedankenwelt, hat sie den Weg von der spätantiken hellenistischen Philosophie zum Idealismus Platons zurückgefunden. In diesem Prozeß handelt es sich nicht um eine bloße Aneignung des echt-Platonischen Gedankengutes, sondern um eine wahrhafte „Anamnesis“ der Platonischen Lehre: um ihre Erneuerung aus dem eigenen Grunde des Denkens selbst. Um sich diesen Prozeß deutlich und durchsichtig zu

1) Galilei, Dialogo sopra i due massimi sistemi, Ed. naz. VII, Ir8. (deutsche Übers. von Emil Strau $B, L_{p z}$ 1892, S. IIO). 
machen, braucht man nur an jene bekannte Stelle in Platons Phaedon $\mathrm{zu}$ erinnern, in der die innersten Motive der Platonischen Ideenlehre und ihre eigentliche Genesis sich vor uns enthüllen. Auch für Platon war der Zugang zu seinem Grundprinzip daran geknüpft, daß sich ihm ein völlig neuer Weg der Erforschung des Seins erschloß, daß ein Bruch mit der gesamten Methodik der Vorsokratischen Philosophie erfolgte. Auch er - so berichtet er - habe in seiner Jugend ein wundergroßes Bestreben nach jener Weisheit gehabt, welche man Naturkunde nennt: dünkte es ihm doch etwas Herrliches, die Ursachen von allem zu erkennen, wodurch jegliches ist und wodurch es entsteht und vergeht. Und gleich den Naturphilosophen habe auch er dieses Streben dadurch zu befriedigen gesucht, da $\beta$ er sich der Führung der Wahrnehmung überlie $B$, da $B$ er mit dem Auge und dem Ohr und mit jedem einzelnen Sinn die Dinge unmittelbar zu erfassen suchte. Aber je weiter er auf diesem Wege fortschritt, um so deutlicher sei ihm zum Bewußtsein gekommen, daß auf ihm die Wahrheit vom Seienden ( $\tau \tilde{\omega} \nu$ ơv $\tau \omega \nu \dot{\eta} \dot{\alpha} \lambda \dot{\eta} \vartheta \varepsilon \iota \alpha$ ) nicht gewonnen werden könne. ,Es bedünkte mich nämlich, nachdem ich müde geworden war, die Dinge unmittelbar zu betrachten, ich müsse mich hüten, daß mir nicht begegne, was denen, welche die Sonne bei einer Verfinsterung beobachten, oft zu begegnen pflegt. Viele nämlich verderben sich die Augen, wenn sie nicht im Wasser oder irgendworin sonst nur das Bild der Sonne, statt ihrer selbst, anschauen. So etwas merkte ich auch, und ich fürchtete, ich möchte ganz und gar an der Seele geblendet werden, wenn ich meine Augen unmittelbar auf die Gegenstände richtete und mit jedem Sinn versuchte, sie zu treffen. Sondern mich dünkte, ich müßte zu den Gedanken meine Zuflucht nehmen und in diesen das wahre Wesen der Dinge anschauen. Doch vielleicht trifft das Gleichnis auf die Weise, wie ich es aufgestellt habe, nicht zu: denn das möchte ich garnicht zugeben, daß, wer das Seiende in Gedanken betrachtet, es mehr in Bildern betrachtet, als wer in den Naturdingen. Also dahin wendete ich mich, und indem ich jedesmal den Logos zugrunde legte, den ich für den stärksten hielt, setzte ich, was mir mit ihm übereinzustimmen schien, als wahr; was aber nicht, als unwahr." Hier liegt der Kernpunkt der neuen Denkart Platons und deren Gegensatz zur Denkart der gesamten griechischen Naturphilosophie offen zutage. Es ist bekannt, daß Platon auch Anaxagoras in dieses Urteil einbezogen hat: daß nach ihm auch der voũ des Anaxagoras diesen Namen nicht verdient, weil er sich bei näherer Betrachtung lediglich als eine bewegende Kraft, also als eine bloße Naturpotenz erweise. Die Abkehr von der unmittelbar-sinnlichen Erfassung der Naturdinge, die „Flucht in den Logos“ führt allein zur Schau des Seienden. Diese Flucht in den Logos aber bedeutet für Platon die 
Flucht in die Mathematik. Und damit ist die „zweite Fahrt" bezeichnet,

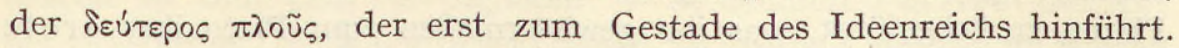
Vergleicht man diese Entwicklung mit der Entwicklung des Naturbegriffs der Renaissance, so sieht man, in wie überraschender Weise sich hier die einzelnen Phasen wiederholen. ${ }^{1}$ ) Auch die Renaissance beginnt mit dem ersten Weg: mit dem Versuch der unmittelbar-sinnlichen Erfassung der Natur. Telesios Bestimmung, daß alle Erkenntnis sich letzten Endes auf eine Berührung zwischen dem Ich und den Dingen zurückführen lasse, erinnert unmittelbar an Platos Spott über jene, die da glaubten,

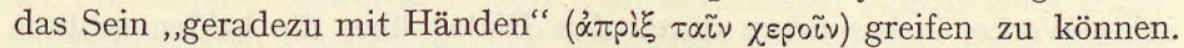
Aber ebendieses Streben ist es gewesen, das die Naturphilosophie zuletzt für die eigentümliche ,Wahrheit“ der Natur, für ihre universelle Gesetzlichkeit blind gemacht, das sie ins Dunkel der Mystik und der Theosophie zurückgeführt hat. Und wieder war es die Rückwendung zum "Logos“, die erst die Bahn zu einer Wissenschaft der Natur frei machte. Was

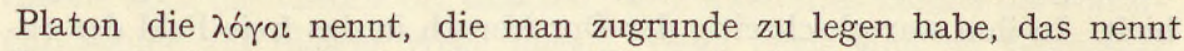
Leonardo die „,ragioni“, die unser Wissen in der Erfahrung bloßzulegen habe. Und auch er zögert nicht, ihnen bei all seiner unbedingten Wertschätzung der Empirie den Vorrang vor der bloß sinnlichen Beobachtung zuzuschreiben. „Nessuno effetto è in natura sanza ragione; intendi la ragione e non ti bisogna esperienzia" ${ }^{2}$ ) Auch Galileis Forschung ist von dem gleichen Motiv beherrscht. Die Grundgesetze der Natur sind nach Galilei nicht Gesetze von unmittelbar Gegebenem, von faktisch Aufweisbarem, sondern sie beziehen sich durchweg auf ideale Fälle, die in der Natur niemals in voller Strenge verwirklicht sein können. Aber das tut ihrer Wahrheit, ihrer „Objektivität" keinen Eintrag. Es ist kein Einwand gegen das Trägheitsprinzip, daß die Natur uns niemals einen „,sich selbst überlassenen Körper“ zeigt - so wenig es den Sätzen des Archimedes über die Spirale Abbruch tut, daß sich in der Natur kein Körper findet, der eine spiralförmige Bewegung besitzt. Wenn wir diese systematische Übereinstimmung zwischen Leonardo und Galilei einerseits und Plato andererseits feststellen, so verliert ihr gegenüber die Frage an Gewicht, auf welchen vielfältig verschlungenen Wegen die Kenntnis der echten Platonischen Grundgedanken beiden geschichtlich vermittelt war. Es gehört nicht zu den geringsten Wundern in dem an Wundern so reichen Geiste Leonardos, daß er, der im Florenz des Quattrocento, der mitten in der Atmosphäre des Neuplatonismus lebt, vom Geist des Neuplato-

I) Vgl. hierzu und zum folgenden die näheren Belege im Erkenntnisproblem ${ }^{3}$ I, 3 I 4 f, wo jedoch die Bedeutung, die dem ästhetischen Faktor in der Entdeckung des modernen Naturbegriffs zukommt, noch nicht scharf genug erfaßt ist.

2) Leonardo, Cod. Atlant. fol. I 47 v.

Studien der Bibliothek Warburg 10: Cassirer 
nismus so gut wie unberührt geblieben ist. Was ihn zu dem historischen Platon zurückgeführt, was ihn gewissermaßen zum Platoniker trotz Ficin und trotz der Florentinischen Akademie gemacht hat: das war die Tatsache, daß er als Künstler, als Kunsttheoretiker und als wissenschaftlicher Forscher wieder ganz im Banne des Platonischen Wortes:

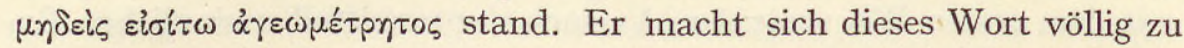
eigen: ,,non mi legga chi non è matematico nelli mia principi.“ " $)$ In voller Bewußtheit und Klarheit tritt sodann dies neue Verhältnis zur Platonischen Lehre bei Galilei hervor. Wie ein roter Faden zieht sich durch seine Werke, insbesondere durch den Dialog über die beiden größten Weltsysteme, die Berufung auf die Platonische Theorie des Wissens. Ihrer

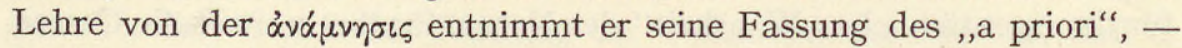
des da per sè. Mit diesem Wort, das die Spontaneität des Geistes, das die Autonomie der theoretischen Vernunft verkündet, war der magische Bann gebrochen, der die Naturphilosophie der Renaissance gefangen hielt. In ihm war gleichzeitig der Durchbruch in das freie Feld der objektiven Naturerkenntnis und der Rückgang vom Hellenismus zur klassischen Antike vollzogen. „Wir sind im Zeitalter des Faust - so faßt Warburg in seiner Luther-Schrift die Entwicklung der astrologischen Ideen innerhalb der Renaissance zusammen -, wo sich der moderne Wissenschaftler zwischen magischer Praktik und kosmologischer Mathematik den Denkraum der Besonnenheit zwischen sich und dem Objekt zu erringen versuchte. Athen will eben immer neu aus Alexandrien zurückerobert sein.“2) Diese „Rückeroberung Athens aus Alexandrien“ war das Ziel, in dem sich die Kunsttheorie der Renaissance und die Theorie der exakten Wissenschaft zusammenfanden. Der ,Denkraum der Besonnenheit" wurde wiedergewonnen, indem man sich auf den Platonischen

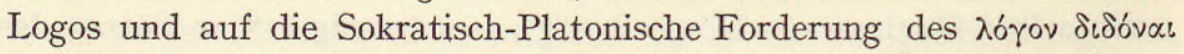
zurückbesann. So entspringt die neue Auffassung der Natur einer neuen Auffassung vom Sinn und Ziel der Erkenntnis. Die Naturphilosophie der Renaissance hatte nichts Geringeres als eine erkenntnistheoretische Begründung und Rechtfertigung der Magie versucht. Die Möglichkeit der Magie folgt nach Campanella aus demselben Prinzip wie die Möglichkeit der Erkenntnis. Denn auch ,,erkennen“ könnten wir nicht, wenn nicht Subjekt und Objekt, Mensch und Natur ursprünglich und wesentlich eins wären. Wir erkennen einen Gegenstand nur dort wahrhaft, wo wir mit ihm verschmelzen, wo wir geradezu $\mathrm{zu}$ ihm werden. „Cognoscere est fieri rem cognitam“ - so definiert Campanella , ,cog-

I) Leonardo, (ed. Richter, Nr. 3).

2) Warburg, Heidnisch-antike Weissagung in Wort und Bild zu Luthers Zeiten, S. 70 . 
noscere est coire cum suo cognobili" - so definiert Patrizzi den Akt der Erkenntnis. Die Magie drückt diesen Sachverhalt, der sich im Wissen theoretisch darstellt, nur nach der praktischen Seite aus: sie zeigt, wie auf Grund der Identität von Subjekt und Objekt das Subjekt das Objekt nicht nur begreifen, sondern auch beherrschen kann, wie es die Natur nicht nur seinem Verstande, sondern auch seinem Willen unterwirft. Damit ist die Magie - als "natürliche“, nicht als ,dämonische" gedacht - zum edelsten Teil der Naturerkenntnis und zur „Vollendung der Philosophie" geworden. Darf man irgendeinen Begriff nach seiner vollkommensten Darstellung und Verkörperung benennen - so folgert Pico von Mirandola - so dürfen wir den Namen der Magie mit dem gleichen Recht auf die gesamte Wissenschaft und die gesam te Philosophie anwenden, wie wir auch Rom ,die“ Stadt, Vergil ,den“ Dichter, Aristoteles ,,den" Philosophen zu nennen pflegen. ${ }^{1}$ ) Aber weder die Kunsttheorie noch die Theorie der exakten Naturerkenntnis konnte der Naturphilosophie auf diesem Wege folgen. Denn beide sind im Gegensatz zur mystisch-magischen Naturanschauung von ein und derselben geistigen Grundtendenz, von dem Willen zur reinen Gestalt beherrscht. Alle Gestalt aber - mag sie nun im theoretischen oder ästhetischen Sinne verstanden werden - verlangt Begrenzung und Bindung, verlangt einen festen und klaren Umriß der Dinge. Wo die Natur im Bilde geformt oder im Denken als gesetzlich-notwendige gefaßt werden soll, da genügt der Pantheismus und der Panentheismus des Gefühls nicht mehr. Dem Drang zur Versenkung in ihre All-Einheit tritt jetzt der entgegengesetzte Trieb: der Drang zur Besonderung, zur Spezifikation gegenüber. Weder die Kunst noch die Mathematik kann das Subjekt in das Objekt eingehen und dieses in jenes aufgehen lassen: denn nur durch die Festhaltung der Distanz zwischen beiden wird, wie der ästhetische Bildraum, so auch der logisch-mathematische Denkraum möglich.

Und dieses Zusammenwirken der beiden geistigen Grundkräfte der Renaissance trägt nun noch eine andere Frucht: es führt zu einer Umgestaltung und zu einer radikalen Neugestaltung der theoretischen Auffassung der „Sinnlichkeit“. Wir sahen bereits, wie Leonardos gesamte Naturanschauung aus der spezifischen Urkraft seines Wesens, aus seiner exakten sinnlichen Phantasie erwächst. Wenn für Pico die Magie zum „,Gipfel der Philosophie“ (apex et fastigium totius philosophiae) geworden war, so scheint in Leonardos ,Trattato della pittura' die Malerei

r) ,Si ergo Magia idem est quod sapientia, merito hanc practicam scientiae naturalis, quae praesupponit exactam et absolutam cognitionem omnium rerum naturalium, quasi apicem et fastigium totius philosophiae, peculiari et appropriato nomine Magiam, id est sapientiam, sicut Romam urbem, Virgilium poetam, Aristotelem philosophum dicimus, appellare voluerunt.' Pico della Mirandola, Apologia (Opera fol. I7o). 
diesen Rang für sich in Anspruch nehmen zu wollen. Wer die Malerei mißachtet, der liebt weder die Philosophie noch die Natur. ${ }^{1}$ ) Hier, in dieser Auffassung vom Wert und Sinn der bildenden Kunst, scheidet sich der Weg der Renaissance auch von demjenigen Platons, der in ihr fast ausschließlich das ,mimetische" Element, das Element der Nachahmung des Gegebenen, gesehen und sie daher als Kunst der Idole von der echten Schau der Ideen ausgeschlossen hatte. ${ }^{2}$ ) Und es ist charakteristisch dafür, wie tief dieser Gegensatz im Wesen der Renaissance wurzelt, daß auch der spekulative Idealismus selbst die neue Forderung, die hier gestellt war, aufnimmt und ihr zur systematischen Anerkennung verhilft. Die Lehre des Nikolaus Cusanus hat keine selbständige Ästhetik entwickelt, aber in ihrer Erkenntnistheorie hat sie der Sinnlichkeit, gegenüber der Platonischen Auffassung, einen neuen Platz und eine ganz neue Wertschätzung erobert. Es ist bedeutsam und bezeichnend, daß Cusanus, wo er sich auf Platon beruft und wo er unmittelbar an ihn anknüpft, diese Anknüpfung genau an derjenigen Stelle vollzieht, an der Platon selbst der sinnlichen Wahrnehmung mehr als sonst entgegenzukommen, an der er ihr einen, wenngleich nur bedingten und relativen, Erkenntniswert zuzugestehen scheint. Er zitiert die Sätze der Platonischen Republik, in denen dargetan wird, daß einzelne Klassen der sinnlichen Wahrnehmung, eben wegen der inneren Widersprüche, die sie in sich tragen, mittelbar das Ziel der Erkenntnis fördern: sind es doch eben diese Widersprüche, die es nicht zulassen, daß die Seele sich in der bloßen Wahrnehmung beruhigt. Gerade sie fordern das Denken heraus und werden zu seinem „Parakleten“" der Widersinn im Sinnlichen treibt dazu, den echten und wahrhaften Sinn an einer anderen Stelle, im Gebiet der Sí́voı $\alpha$, zu suchen. ${ }^{3}$ ) Aber was Platon hier nur einer besonderen Art der Sinneswahrnehmung zugestand, das dehnt Cusanus nunmehr auf die Gattung aus. Nicht nur dieser oder jener Art der Wahrnehmung, sondern der sinnlichen Erfahrung als Ganzem eignet diese belebende und erweckende Kraft. Der Intellekt gelangt nicht zum Bewußtsein dessen, was er ist und was er vermag, bevor er nicht durch die Kräfte der Sinnlichkeit zu der ihm eigentümlichen Be wegung angetrieben wird. Wenn dieser Antrieb ihn dazu bestimmt, sich der sinnlichen Sphäre zuzuwenden, so geschieht es freilich nicht, um in ihr unterzugehen, sondern um sie zu sich emporzuheben. Sein scheinbarer Abstieg zum Sinnlichen bedeutet vielmehr dessen Aufstieg zu ihm. S. 134 .)

I) Leonardo, ed. Ravaisson-Mollien, Ash. fol. 20 r. (Herzfeldsche Ausgabe,

2) Näheres in meinem Vortrag ,Eidos und Eidolon. Das Problem des Schönen und der Kunst in Platons Dialogen". Vorträge der Bibliothek Warburg 1922/23. I, S. Iff. 3) Pla ton, Republ. 523 Aff.; cf. Cusanus, Idiota, Lib. III, 4. 
Denn in der ,Andersheit' der sinnlichen Welt findet er jetzt seine eigene unverrückbare Einheit und Identität; in der Hingabe an das, was ihm wesensfremd $\mathrm{zu}$ sein scheint, findet er seine eigene Vollkommenheit, seine Selbstentfaltung und Selbsterfassung. $\left.{ }^{1}\right)$ Die Erfahrung bildet jetzt nicht mehr den Widerstreit und Gegenpol zur Grundkraft der theoretischen Erkenntnis, zur wissenschaftlichen Vernunft, sondern sie bildet ihr eigentliches Medium: das Feld ihrer Betätigung und ihrer Bewährung. Bei Leonardo wie bei Galilei ist der Gegensatz in ein reines Wechselverhältnis aufgelöst. Der Unterschied zwischen Vernunft und Erfahrung ist kein anderer als ein Unterschied der Richtung. „Meine Absicht - so heißt es in einer Untersuchung Leonardos über das Hebelprinzip - ist, zuerst das Experiment vorzubringen und dann mit der Vernunft zu zeigen (colla ragione dimonstrare), weshalb solches Experiment notwendig in dieser und keiner anderen Weise wirken muß. Und dieses ist die wahre Art, wie die Erforscher der Wirkungen der Natur vorgehen müssen: denn wenngleich die Natur mit dem Grunde beginnt und mit der Erfahrung endet, wir müssen den entgegengesetzten Weg verfolgen, d. h. beginnen mit dem Experiment und mit diesem den Grund (ragione) untersuchen ". ${ }^{2}$ ) Hier, wie in Galileis Unterscheidung und in seiner korrelativen Vereinigung der ,resolutiven' (analytischen) und der ,kompositiven' (konstruktiven) Methode findet also ein echter Kreisprozeß statt: von der Erscheinung wird zu ihren ,Gründen“, von diesen wieder zu den Erscheinungen zurückgegangen. Die scharfe Sonderung, die Platon zwischen dem Weg des Dialektikers und dem des Mathematikers vollzieht ${ }^{3}$ ), ist damit aufgehoben. Der Weg des Dialektikers „,nach oben" und der des Mathematikers „,nach unten" ist derselbe, sofern jeder von ihnen nur je eine verschiedene Etappe in dem zyklischen Prozeß der Erkenntnis darstellt. Und damit stellt sich auch die Beziehung zwischen der reinen Theorie und ihren Anwendungen in einem neuen Lichte dar. Auch Platons Lehre von der Erkenntnis kennt eine ",angewandte" Mathematik und weist ihr im systematischen Stufengang des Wissens eine ganz bestimmte Stelle zu. Ja, man kann sagen, daß Platon durch die bekannte Forderung, die er an die Astronomen seiner Zeit gestellt hat, durch die Aufgabe, die Phaenomene am Himmel kraft ihrer Beziehung und Rückführung auf geordnete und streng gleichförmige Bewegungen zu ,,retten “, erst dem Begriff einer ,,Anwendung“ der Mathematik auf die Natur einen ganz scharfen, methodisch-prägnanten Sinn gegeben hat. Nichtsdestoweniger ist die Erkenntnis der Natur,

I) Cusanus, De conjecturis II, II; II, I6; (zum Ganzen vgl, oben S. 47 f.).

2) Leonardo, (Ravaisson-Mollien E., fol. 55 r; vgl. Ausg. von M. Herzfeld S. 6).

3) Platon, Republ. 533 Cff. 
ist das Wissen um die sinnlichen Erscheinungen als solche, hierbei nicht Selbstzweck: sondern dieses Wissen soll nur dazu dienen, der reinen Theorie als Vorwurf zu dienen. Der Dialektiker wendet sich an die Astronomie nicht um ihres Gegenstands willen, sondern um der Probleme willen, die sie dem Mathematiker und damit dem reinen Denken stellt. Er will sich nicht in die Betrachtung und Bewunderung der ,bunten Arbeit am Himmel" versenken, sondern er läßt die Dinge am Himmel stehen, wenn anders es ihm darum zu tun ist, wahrhaft der Sternenkunde sich befleißigend, das von Natur Vernünftige in seiner Seele aus Unbrauchbarem brauchbar zu machen. ${ }^{1}$ ) Das Absehen des echten, des philosophischen Astronomen ist demgemäß nicht empirisch, sondern es ist propädeutisch: es zielt nicht auf die Sinnenwelt selbst, sondern auf jene „Umkehr" der Seele ab, die sie von der Sinnenwelt zur reinen Gedankenwelt führt. Dieser Grundansicht gegenüber bedeutet das Denken der Renaissance, auch dort, wo die echt-Platonischen Motive in ihm wieder unmittelbar lebendig werden, einen entscheidenden Umschwung Jetzt erst wird der Erfahrungswelt ihr wahrhaftes Eigenrecht erkämpft. Der empirische Gehalt und die mathematische Form bleiben nach wie vor streng aufeinander bezogen; aber diese Beziehung hat jetzt gewissermaßen ein entgegengesetztes Vorzeichen erhalten. Das Empirische soll nicht schlechthin im Ideellen aufgehoben und damit seines spezifischen Charakters entkleidet werden. Sondern umgekehrt ist es das Ideelle, das im Empirischen erst seine wahrhafte Erfüllung, und damit seine Bewährung und Rechtfertigung, finden soll. Wenn für Platon die Bewegungslehre nur ein ,Paradeigma', ein notwendig- unvollkommenes Beispiel für abstrakte mathematische Verhältnisse war — so erhält sie jetzt nicht nur Selbstwert, sondern sie wird geradezu zum Ziel, dem alle reine Mathematik zustrebt. Die Mechanik ist nach Leonardo ,,das Paradies der mathematischen Wissenschaften", weil man erst in ihr zur "Frucht" der Mathematik gelangt.2) Galilei bezeichnet den Schlußpunkt dieser Entwicklung - und er gibt ihr zugleich den klarsten methodischen Ausdruck, sofern für ihn die Bewegung selbst zur Idee geworden ist. Sie gehört nicht mehr dem Schattenreich des Werdens, der Platonischen réveaıs an, sondern ist zum reinen Sein emporgehoben, sofern ihr eine strenge Gesetzlichkeit und damit Konstanz und Notwendigkeit eignet. Die Bewegung, ja die materielle Masse selbst besitzt, als Gegenstand des Wissens genommen, Idealität: denn an beiden lassen sich gewisse unveränderliche Bestimmungen, die immer in der gleichen Weise sich ver-

I) Platon, Republ. 630 Aff.

2) Leonardo, Ravaisson-Mollien E. fol. 8 v. 
halten, lassen sich somit echte mathematische Wesensgesetze aufweisen. ${ }^{1}$ ) Damit erst war die Erfahrung selbst zur strengen Erkenntnis erhoben, war, wie Galilei im Eingang zu den entscheidenden Untersuchungen der Discorsi über die örtliche Bewegung sagt, ,,über einen sehr alten Gegenstand eine ganz neue Wissenschaft" gewonnen. ${ }^{2}$ ) In diesem Ergebnis findet ebensowohl die realistisch-empiristische, wie die idealistische Tendenz der Renaissance ihrenadäquaten Ausdruck. Wenn die Wissenschaftstheorie der Renaissance der Sinnlichkeit eine neue Stelle zuweist, so geschieht es, weil sie sich ihr jetzt erst als Theorie wahrhaft geistig gewachsen fühlt, weil sie die ideellen Grundmittel erarbeitet hat, vermöge deren sich die bloße sinnliche Empfindung zur reinen Anschauung gestalten läßt. Die gleiche Grundrichtung der Betrachtung und der gleiche charakteristische Übergang ist es, der auch der Kosmologie der Renaissance ihr Gepräge gibt. Die veränderte Grundauffassung von der Natur der Bewegung forderte und erschuf aus sich heraus einen neuen Weltbegriff. Je mehr das Bewegungsproblem in den geistigen Brennpunkt der Betrachtung rückt und je schärfer es in seiner neuen Gestalt erfaßt wird, um so entschiedener drängt es zu einer radikalen Umformung der Lehre von den Elementen und der Lehre vom Universum hin.

4 .

Die Behauptung, daß der logische und wissenschaftliche Primat, den das Problem der Bewegung in der Philosophie der Renaissance gewinnt, den Keim und Ursprung der modernen Kosmologie in sich schließt, enthält freilich auf den ersten Blick eine geschichtliche Paradoxie. Denn war nicht eben diese zentrale Stellung des Bewegungsbegriffs von alters her gesichert - bildete nicht die Aristotelische Auffassung der Bewegung den Kernpunkt und das begriffliche Zentrum der gesamten Aristotelischen Naturtheorie? Die Peripatetische Physik baut sich auf der Grundunterscheidung auf, die sie zwischen den Urformen der Bewegung annimmt. Wenn Aristoteles den Begriff der xívnoıs in dem weiten Sinne faßt, gemäß dem unter ihn nicht nur die Ortsveränderung, sondern auch die qualitative Veränderung ( $\left.\alpha^{\lambda} \lambda \lambda_{0}^{\prime} \omega \sigma \iota \varsigma\right)$, das quantitative

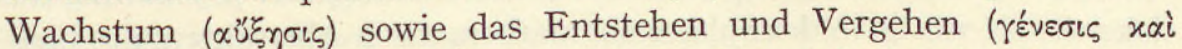
$\varphi \vartheta \circ \rho \grave{)}$ fällt, - so steht doch auch für ihn fest, daß die reine Ortsver-

I) Vgl. z. B. Galilei, Discorsi e dimostrazioni matematiche intorno a due nuove scienze I (Op., ed. Albèri, XIII, 7): „E perchè io suppongo la materia esser inalterabile, cioè sempre l'istessa, è manifesto che di lei come di affezione eterna e necessaria si possono produr dimostrazioni non meno dell' altre schiette e pure matematiche." Für die Bewegung wird das gleiche Prinzip z. B. in Galileis Schrift gegen Vincenzo di Grazia (s. z. B. Op. XII, 507 ff.) formuliert.

2) Galilei, Discorsi, Giornata terza. Op. XIII, I48. 
änderung, gegenüber allen anderen Formen, die erste und grundlegende,

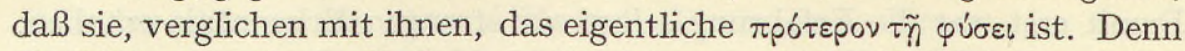
die Differenz, die in ihr hervortritt, ist es, auf der die Natur und Beschaffenheit der Subjekte beruht, die diese Differenz an ich tragen. Die vier Elemente, aus denen sich der Kosmos aufbaut, das Element der Erde, des Wassers, der Luft und des Feuers, erweisen ihre spezifische Verschiedenheit eben darin, daß jedem eine eigene spezifische Art der Bewegung zukommt. Jedes dieser Elemente hat im Aufbau des Ganzen seinen natürlichen Ort, an dem es zu der ihm eigentümlichen Vollkommenheit gelangt, und dem es daher, wenn es von ihm getrennt wird, notwendig zustrebt. Aus dieser Grundtendenz heraus erwächst bei den irdischen Elementen die Bewegung in gerader Linie, während die unzerstörbare und vollkommene Substanz der himmlischen Körper als die einzige ihr angemessene Form der Bewegung den Umschwung in einer reinen Kreislinie zuläßt. Kraft seiner Natur, kraft seiner ursprünglichen absoluten Schwere strebt das Element der Erde zum Mittelpunkt der Welt hin, wie das Element des Feuers sich kraft seiner absoluten Leichtigkeit von ihm zu entfernen strebt. Das Element des Äthers aber, aus dem die Substanz des Himmels besteht, kennt Gegensätze dieser Art nicht mehr. In ihm herrscht die reine und vollkommene Gleichförmigkeit; die Einheit des göttlichen Bewegers, der die himmlischen Sphären in Umlauf versetzt, muß ihr Abbild in der Form dieses Umlaufs selbst besitzen, der daher nicht anders als streng regelmäßig und streng kreisförmig sein kann.

So wird für Aristoteles die Bewegung zum eigentlichen Einteilungsgrund der Welt, zum fundamentum divisionis im physischen wie im metaphysischen Sinne. Aber sie kann nur insofern als ein ursprüngliches Moment der Bestimmung des Seins dienen, als sie selbst nach ihrer rein qualitativen Seite, als absolute Seinsbestimmung, genommen ist. Was Aristoteles in ihr sieht, das ist daher keine bloß ideelle Beziehung, die innerhalb der beiden universellen Stellenordnungen des Raumes und der Zeit zu definieren wäre. Eine solche Beziehung würde nach der Grundanschauung des Aristotelischen Systems in keiner Weise ausreichen, um der Bewegung eine reale, eine ontologische Bedeutung zu sichern. Sie würde in der Sphäre des mathematisch-Abstrakten, des bloß Gedanklichen stehen bleiben, und somit das konkrete Was, das Wesen des Naturgegenstandes, nicht bezeichnen, geschweige erschöpfen. Die Tatsache, daß in alle unsere Aussagen über ein konkretes ,Was" stets zugleich Aussagen über ein ,Wo" eingehen, daß es nicht möglich ist, qualitative Bestimmungen an physischen Körpern zu treffen, ohne sich auf örtliche Bestimmungen zu stützen: diese Tatsache muß demnach von Aristoteles so gedeutet werden, daß er dem Orte selbst eine bestimmte 
substantielle Bedeutung gibt. Orte haben ihre Natur und Eigenart in derselben oder doch in analoger Weise, wie Körper sie haben. Und zwischen diesen beiden Naturen besteht ein ganz bestimmtes Verhältnis der Gemeinschaft oder des Widerstreits, der Sympathie oder Antipathie. Der Körper verhält sich zu dem Ort, in dem er sich befindet und der ihn umschließt, keineswegs gleichgültig, sondern er steht $\mathrm{zu}$ ihm in einer realursächlichen Beziehung. Jedes physische Element sucht „seinen“, ihm zugehörigen und ihm entsprechenden Ort, während es einen anderen, ihm entgegengesetzten flieht. So erscheint der Ort selbst, relativ zu bestimmten Elementen, mit Kräften begabt, - aber wiederum nicht mit solchen, die wir etwa als anziehende oder abstoßende Kräfte im Sinne der modernen Mechanik definieren könnten. Denn in ihnen handelt es sich nicht um mathematisch-physikalische Größen, die sich nach einem Prinzip des „Mehr" oder ,Weniger" gegeneinander abstufen lassen. Statt solcher relativen Größenwerte haben wir vielmehr auch hier überall absolute Seinswerte vor uns. Aristoteles stellt sich im Aufbau seiner Kosmologie die Frage, ob die Tendenz, vermöge deren ein bestimmtes Element zu seinem natürlichen Ort hinstrebt, sich wie eine quantitativabstufbare Eigenschaft an ihm denken lasse, die etwa, gemäß der wechselnden Entfernung des Elements von seinem natürlichen Ort, einen verschiedenen Grad aufweise. Aber er muß gemäß den Grundvoraussetzungen seiner Physik und seiner Kosmologie diese Frage ausdrücklich verneinen. Es erscheint ihm widersinnig, daß ein schwerer Körper zum Zentrum der Welt umso stärker hingezogen wird, je näher er sich ihm befindet: denn die Distanz als solche ist eine rein äußerliche Bestimmung, die außer Betracht bleiben muß, wenn es sich darum handelt, die Wirkungen festzustellen, die aus der ,Natur" eines Dinges, aus seinem Wesen hervorgehen. Dieses Wesen und die durch dasselbe bedingte Bewegungstendenz eignet jedem Körper in schlechthin unveränderlicher Art, also unabhängig von einem so äußerlichen und zufälligen Umstand, wie es

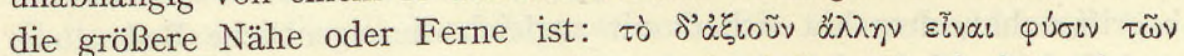

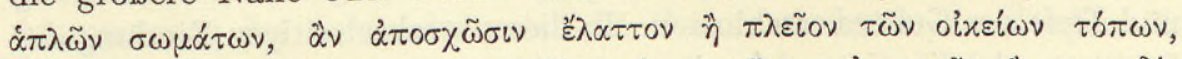

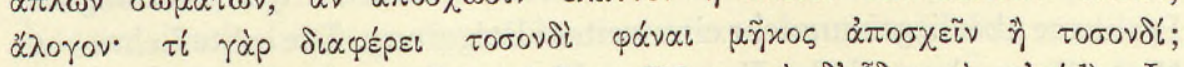

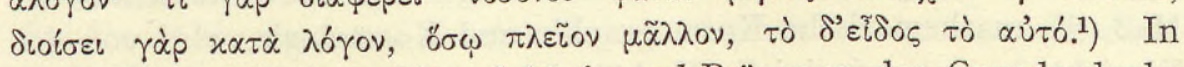
diesen Sätzen ist in größter Schärfe und Prägnanz der Grundgedanke der Physik der ,,substantiellen Formen " formuliert. Wenn für die moderne Physik die eigentlich objektivierende und realisierende Bedeutung gewissen unveränderlichen Relationen zukommt, wenn alle Bestimmtheit des physischen Seins und Geschehens auf ihnen, als dem Ausdruck der allgemeinen Naturgesetze, beruht, derart, daß die einzelnen

I) Aristoteles, тepi oủpavoũ A 8. 
Relationsglieder, die Körper und die Orte, überhaupt erst durch diese Gesetze definierbar werden: - so herrscht bei Aristoteles durchaus

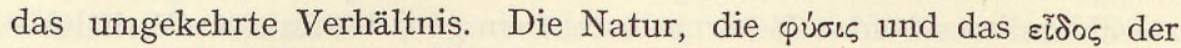
Orte ,an sich" und der Körper, der Elemente ,an sich" bestimmen den architektonischen Bau des Kosmos und die Form des Geschehens in ihm.

Die scholastische Physik hat diese Grundvoraussetzung überall festgehalten. Duhem hat gezeigt, wie im I4. Jahrhundert auch innerhalb dieser scholastischen Physik ein neuer Geist sich zu regen beginnt, wie insbesondere die Schriften Alberts von Sachsen bestimmte Probleme formulieren, die, wenn man rein die Form der Fragest ellung betrachtet, der modernen Kosmologie, der Lehre Keplers und Newtons, den Weg bereitet haben. ${ }^{1}$ ) Aber eine Antwort auf diese Fragen konnte erst gefunden werden, nachdem das Fundament der Aristotelischen Physik abgetragen, nachdem die Lehre vom Ort und vom Raum in ihren Grundfesten erschüttert war. Jnnerhalb der spekulativen Philosophie bezeichnet hier die Schrift, De docta ignorantia ' den eigentlichen Durchbruchspunkt. Denn hier ist der Kernpunkt der Aristotelischen Lehre angegriffen. Die kosmologische Bedeutung der Cusanischen Schrift beruht nicht in erster Linie darauf, daß in ihr die antike, insbesondere die Pythagoreische Lehre der Erdbewegung erneuert wird, sondern auf dem Prinzip, aus dem heraus diese Erneuerung erfolgt. Hier zuerst wird in wirklicher Schärfe der Grundgedanke der Relativität des Ortes und der Bewegung formuliert - und dieser Gedanke erscheint selbst als bloßes Korollar jenes allgemeineren Postulats, von dem die Erkenntnislehre des Cusanus beherrscht wird. Um den Begriff der objektiven Wahrheit zu bestimmen, muß sich Cusanus, spekulativ und philosophisch, in die Prinzipien der Messung vertiefen: denn alles Erkennen erscheint ihm als ein bloßer Sonderfall der universellen Funktion des Messens. ,Mens' und ,mensura' gehören zusammen: wer das Wesen des Messens begriffen hat, dem hat sich damit zugleich die eigentliche Bedeutung und Tiefe des Geistes erschlossen. In dieser wechselseitigen Bindung der Probleme aber liegt nunmehr eine weitere Folgerung. Die echte Lehre vom $\mathrm{MaB}$, die mathematische Kosmographie und Kosmologie, wird von der Einsicht in das prinzipielle Verhältnis von "Subjekt" und ,Objekt" abhängig. Wer die wahren, die objektiven Maße des Alls finden will, der muß sich vor allem auf das Verfahren und die Grundform der Messung überhaupt zurückbesinnen, der muß zur vollen Klarheit über die Bedingungen des Messens durchgedrungen sein. Eine wesentliche Bedingung alles Messens aber, insbesondere aller örtlichen und zeitlichen Ver-

I) Vgl. D uhem, Etudes sur Léonard de Vinci, Seconde série, II 82 ff. u. ö. 
gleichung, besteht nach Cusanus darin, daß zunächst bestimmte Punkte als fest und unveränderlich angenommen werden. Ohne die Setzung solcher festen Punkte, ohne die Bestimmung gewisser Pole oder Centra, wäre jede Beschreibung physischer Bewegungen unmöglich. So unentbehrlich diese Setzung ist, so fordert jedoch andererseits das Prinzip der ,docta ignorantia', daß wir sie eben als Setzung begreifen: daß wir sie als hypothetische und ideelle, nicht als absolute und ontologische Bestimmung verstehen. Der messende Geist kann der festen Punkte und Zentren nirgends entraten: aber die Wahl dieser Punkte ist ihm nicht ein für allemal durch die objektive Natur der Dinge vorgeschrieben, sondern sie ist in seine eigene Freiheit gestellt. Kein physischer "Ort" genießt hier vor dem anderen irgendeinen natürlichen Vorrang. Was vom Standpunkt des einen Betrachters aus ruht, das kann von dem eines anderen als bewegt angesehen werden - und umgekehrt. Der Begriff des absoluten Ortes und der absoluten Bewegung verliert damit seinen Sinn. Wenn sich ein Beobachter am Nordpol der Erde, ein anderer an dem der Himmelskugel befände, so würde jenem der Pol und diesem der Mittelpunkt im Zenith erscheinen - und beide würden das Recht haben, den Ort, in dem sie stehen, als Mittelpunkt anzusehen und auf ihn alles übrige zu beziehen. Aufgabe des Verstandes ist es, alle diese verschiedenen sinnlichen Aspekte miteinander zu verknüpfen und ,komplikativ' in eins zu fassen: einer solchen Zusammenfassung aber erscheint die Welt wie ein Rad im Rade, eine Kugel in der Kugel, die nirgends einen Mittelpunkt besitzt, der vor irgendeinem anderen den Vorzug verdient. ${ }^{1}$ )

Gegenüber der Aristotelischen Welt mit ihren festen Orten und Maßen kann dieser Relativismus auf den ersten Blick wie eine völlige Auflösung erscheinen. Aber auch hier dient die scheinbare Skepsis der ,docta ignorantia' nur als Vorbereitung und als Vehikel für die Erfassung einer ganz neuen positiven Aufgabe. Im System der Peripatetischen Physik herrscht gewissermaßen eine wechselseitige Verklammerung der Grundelemente: die Orte sind durch die Körper, die Körper durch die Orte, die zu ihnen gehören, festgelegt. Die räumliche Sphäre ist hierdurch auf dieselbe Weise und gemäß den gleichen Gesichts-

I) „Complica igitur istas diversas imaginationes ut sit centrum Zenith et e converso: et tunc per intellectum (cui tantum servit docta ignorantia) vides mundum et ejus motum ac figuram attingi non posse, quoniam apparebit quasi rota in rota, sphaera in sphaera, nullibi habens centrum vel circumferentiam, ut praefertur." Cusanus, De doct. ign. II, II ; zur geschichtlichen Bedeutung und Fortwirkung dieser Lehre vgl. bes. E. F. Apelt, die Reformation der Sternkunde, Jena 1852 , S. I 8 ff. Für den systematischen Zusammenhang, der zwischen der Metaphysik des Cusanus und seiner Kosmologie besteht, kann jetzt auf die Darstellung in einer demnächst erscheinenden Hamburger Dissertation von Hans Joachim Ritter verwiesen werden. 
punkten wie die dingliche Sphäre geteilt. Wie die Dinge sich in ewige und veränderliche, in vollkommene und unvollkommene scheiden, so geht eine analoge Scheidung durch die räumliche Welt. Wie dort die Eigenschaften, so sind hier die Stellen unvertauschbar: das "Oben“ ist vom "Unten“, die ",höhere" himmlische Welt von der ,niederen" sublunaren durch eine unübersteigliche Kluft geschieden. Mit der Aufhebung dieser Scheidung scheint zunächst auch jede sichere räumliche Fixierung, jede klare und eindeutige Grenzsetzung bedroht. Das á $\pi \varepsilon \iota p o v$, nicht nur im Sinne des quantitativ-Unendlichen, sondern im Sinne des qualitativ-Bestimmungslosen, scheint wieder Herr über das $\pi \varepsilon e_{p} \alpha_{\zeta}$, das Chaos scheint Herr über den Kosmos geworden zu sein. Und doch setzt eben an diesem Punkte die neue unendlich-fruchtbare positive Forderung ein. Das neue Erkenntnisprinzip, das in der Philosophie des Cusanus lebendig wird, die neue Norm der Gewißheit, die hier aufgestellt wird, zerstört das Bild der Aristotelischen Welt mit ihren festen Mittelpunkten und ihren ineinander greifenden Sphären, indem es dasselbe als bloßes Bild begreift. Aber eben aus dieser Zerstörung erwächst jetzt um so dringlicher die Aufgabe, die Gesamtordnung des Seins und Geschehens aus der eigenen Kraft und mit den eigenen Mitteln des Intellekts wieder aufzubauen. Der Intellekt muß lernen, sich ohne sinnliche Hilfe und Stütze in seinem eigenen Medium, im freien Äther des Gedankens zu bewegen, um kraft dieser Bewegung der Sinnlichkeit Herr zu werden und sie zu sich emporzuziehen. Damit kehrt sich, verglichen mit der Aristotelisch-scholastischen Physik, die Ordnung der Probleme um. Was für diese als Anfangspunkt galt, das wird jetzt zum End- und Zielpunkte der kosmologischen Betrachtung. Ist einmal die Relativität aller Ortsbestimmung prinzipiell erkannt, so kann die Frage nicht mehr lauten, wie wir zu festen Punkten im Universum gelangen können, sondern nur noch, wie sich in dem Bereich der durchgängigen Wechselbeziehung und der grenzenlosen Variabilität, in dem wir jetzt stehen, nichtdestoweniger feste Gesetze der Veränderung gewinnen lassen. Die Bestimmung irgendwelcher „Orte" setzt jetzt ein System universeller Regeln der Bewegung voraus und kann nur innerhalb dieses Systems erfolgen. Auf der Einheit dieser Regeln beruht die Einheit des Universum als eines „Universum contractum". Denn das eben unterscheidet jene ,zusammengezogene "Einheit, die wir ,Welt" nennen, von der absoluten Einheit Gottes, daß hier die Identität niemals als substantiale Einerleiheit, sondern daß sie nur relativ, nur in bezug auf die „Andersheit", sich darstellen kann. Nur durch das Medium der Vielheit kann hier die Einheit, nur durch das Medium der Veränderung kann die Konstanz erfaßt werden. Und beide Bestimmungen scheiden sich nicht 
in der Art, daß sie sich auf verschiedene Sphären des Universum verteilen, in deren einer dieVeränderlichkeit, in deren anderer dieEinheit und Gleichförmigkeit herrscht. Eine solche räumliche Sonderung würde dem begrifflichen Prinzip der Korrelativität, wie es jetzt festgestellt ist, widerstreiten. Im Kosmos des Cusanus gibt es kein einzelnes Dasein mehr, das nicht beide Bestimmungen: das der ,Einheit“ und der ,Andersheit", der Dauer und des steten Wechsels, unlöslich in sich verknüpfte. Hier befindet sich daher auch kein einzelner Teil mehr ,außerhalb" der andern oder steht ,über" oder ,unter" ihnen, sondern hier gilt der Satz, daß ,alles in Allem" (quodlibet in quolibet) ist. Ist das All als ein Ganzes von Bewegungen erkannt, die nach festen Gesetzen ineinandergreifen, so gibt es in ihm kein „Oben“ und „Unten“ mehr, kein Ewiges und Notwendiges, das sich vom Zeitlichen und Zufälligen scheidet. Vielmehr ist alle empirische Wirklichkeit eben dadurch gekennzeichnet, daß sie die Koinzidenz ebendieser Gegensätze ist. Diese Koinzidenz kann, als qualitatives Ineinander, nur sein oder nicht sein; sie kann nicht hier in geringerem, dort in höherem Grade bestehen. Zwischen den Teilen der Welt besteht somit eben dieselbe symbolische Beziehung, wie sie nach Cusanus zwischen der Welt und Gott besteht. Wie das absolute Maximum im relativen Maximum, wie die absolute Unendlichkeit Gottes in der Schrankenlosigkeit des Universum ihr Abbild besitzt, so wird das Ganze der Welt in jedem ihrer Einzelglieder erkannt, so spiegelt sich die Verfassung dieses Ganzen in jeder besonderen Bestimmung und in jedem einzelnen Zustand von ihm ab. Wenn kein Teil mehr schlechthin das Ganze ist, wenn er dessen Vollkommenheit und Vollendung nicht in sich zu fassen vermag, so hat doch jeder den gleichen Anspruch, diese Vollendung in sich zu repräsentieren. Aus dieser metaphysischen Grundkonzeption heraus erwächst bei Cusanus der neue kosmologische Begriff der Gleichförmigkeit. Die Einsicht in die Gleichförmigkeit wird, kraft des Prinzips der docta ignorantia, dadurch erreicht, daß der Abstand des Empirischen von der Welt der ,,absoluten “ Form ins Unendliche vergrößert wird, daß aber eben damit innerhalb der bedingten, der sinnlich-empirischen Wirklichkeit die Unterschiede sich relativieren und aufheben. Jeder Teil des Kosmos ist, was er ist, immer nur im Zusammenhang des Ganzen: eben dieser Zusammenhang selbst aber ist jetzt zugleich derart gefaßt, daß in ihm kein Glied entbehrt werden kann, ohne damit die Funktion des Ganzen zu vernichten. Auf dieser inneren Wechselbezogenheit all seiner Teile, nicht auf einem Anstoß, der ihm von außen her erteilt würde, beruht auch die Bew eg ung des Kosmos: sie bedarf keines Impulses von außen, keines göttlichen Bewegers mehr, sobald einmal eingesehen ist, daß es nichts anderes als die Wechselbezüglichkeit 
der Dinge, also ihre eigene immanente „Wirklichkeit" ist, die sich in ihr manifestiert. In der Totalität, in der unendlichen Verschiedenheit der einzelnen Bewegungen und in dem universellen Gesetz, das sie nichtsdestoweniger als einheitliches Prinzip umfaßt, bestimmt und erschöpft sich der Begriff der Natur: die „Natur" ist nichts anderes als die „Komplikation“ all dessen, was in der Bewegung und durch sie geschieht.

Der Grund zu einer neuen Dynamik war damit gelegt: aber freilich vermochte das spekulative Denken, das in Cusanus diese Aufgabe mit überraschender Sicherheit ergriffen hatte, sie mit seinen eigenen Mitteln nicht zur Lösung zu bringen. Das Ziel, das hier von fern her bezeichnet und gesehen war, mußte sich, ehe es erreicht wurde, Schritt für Schritt die ihm gemäßen Mittel, die adaequaten Denkformen schaffen. Hier ist es vor allem Kepler, der nicht nur durch die konkrete Fassung der Grundgesetze der Planetenbewegung, sondern vor allem auch durch deren methodische und prinzipielle Begründung, sich als Schöpfer eines neuen Wissenschaftsbegriffs erweist. Der Ort - so betont er - ist nichts an sich Bestimmtes und Gegebenes, sondern alle örtliche Bestimmung ist ein Werk des Geistes: „omnis locatio est mentis seu mavis sensus communis opus."1) Dieser Grundsatz ist es, der sowohl Keplers theoretische Astronomie, wie seine Optik und seine Wahrnehmungstheorie beherrscht, und der alle drei zu einer geistigen Einheit zusammenschließt. Erst von hier aus läßt sich ganz begreifen, welche Dienste der Einblick in das Prinzip der Relativität des Ortes und der Bewegung dem modernen Denken geleistet hat. An diesem Prinzip wird ein neues Grundverhältnis zwischen „Natur" und „,Geist“, zwischen „Objekt" und „Subjekt" erfaßt. Jetzt tritt der ideelle Faktor, der in aller Gegenstandssetzung, in aller räumlichen Objektivierung selbst enthalten ist, klar hervor. Gerade darum, weil der Ort nicht mehr als eine unmittelbar gegebene dingliche Beschaffenheit angesehen werden kann, weil er als reine Beziehung gefaßt ist, entsteht die Aufgabe, dieser Beziehung im Ganzen der Naturerkenntnis ihre feste Stelle zuzuweisen und sie in ihrem eigentümlichen und charakteristischen "Gefüge" $\mathrm{zu}$ begreifen. Auch das Verhältnis des einzelnen ,,Ortes“ zum ,Raum“ erfährt damit eine wesentliche Umbildung. Wenn Aristoteles alle einzelnen örtlichen Bestimmungen in einem einheitlichen Gesamtraum vereinigt sein läßt, so ist doch bei ihm auch dieses Grundverhältnis eher physisch, als mathematisch gedacht. Denn die Verknüpfung, um die es sich hierbei handelt, ist nicht sowohl ideell, als vielmehr dinglich $\mathrm{zu}$ denken: der eine allumschließende Raum enthält die besonderen Orte als seine Be-

I) Kepler, Opera, ed. Frisch II, 55 . 
standteile in sich. Allgemein besteht zwischen dem Ort, den ein Körper einnimmt, und diesem Körper selbst ein durchaus dingartiges Verhältnis. Aristoteles vergleicht die Beziehung, die hier statthat, derjenigen, die etwa zwischen einem Gefäß und einer Flüssigkeit, die in dasselbe eingeschüttet wird, stattfindet. Wie derselbe Krug oder Schlauch bald Wein, bald Wasser in sich fassen kann, so kann derselbe Ort bald diesen, bald jenen Körper in sich aufnehmen. Was wir Raum nennen, ist freilich ebensowenig der Stoff des Körpers, wie es der Körper selbst ist: denn diese beiden sind das Umfaßte, während wir im Begriff des Raumes nicht dieses, sondern vielmehr das Umfassende denken. Aber unter dem Letzteren sind wiederum nicht die eigenen Grenzen des Körpers oder seine Gestalt zu verstehen: denn die Gestalt des Körpers ist mit ihm zugleich beweglich, so daß sich, wenn wir sie als Ausdruck des Raumes ansehen würden, der Körper nicht im Raume, sondern mit dem Raume bewegen würde. So kann der Raum nur als die Grenze des umschließenden Körpers gegen den umschlossenen bestimmt werden. Der Ort jedes einzelnen Körpers wird durch die innere Grenze des nächsten ihn umfassenden bezeichnet, während unter dem Raum als Ganzem die Grenze der äußersten Himmelsphäre zu denken ist. ${ }^{1}$ ) Hierbei soll freilich die Grenze selbst als geometrische Linie, nicht als ein Materielles verstanden werden; aber nichtsdestoweniger gleicht die Gesamtheit eben dieser geometrischen Bestimmungen eher einem bloßen Aggregat, als einem

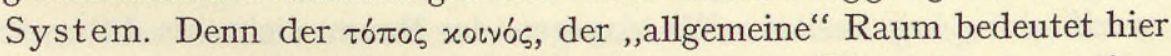
keineswegs die Bedingung für die Setzung der Einzelräume, sondern er steht zu den besonderen Räumen, als das sinnlich-Umschließende, in einem analogen Verhältnis, wie diese zu den einzelnen Körpern stehen.

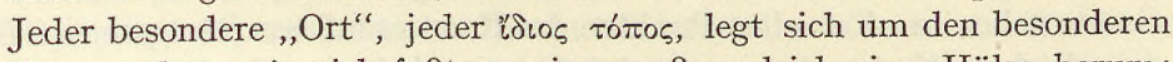
Körper, den er in sich faßt, gewissermaßen gleich einer Hülse herum; und der allgemeine Raum bedeutet in diesem Ineinander, in dieser fortgesetzten Einschachtelung nur die letzte und äußerste Schale, jenseits deren es so wenig mehr einen Raum wie einen Körper geben kann. Denn der Begriff des ,leeren Raumes“ ist im System der Peripatetischen Physik ohne jeden bestimmten Sinn: da der Raum nur als eine Bestimmung a $\mathrm{m}$ Körper, nur als dessen Grenze gefaßt ist, so haftet er notwendig an diesem, so daß dort, wo kein Körper ist, auch die Möglichkeit des Raumes entfällt. Ein leerer Raum wäre als ein Umschließendes, das nichts umschließt, nichts Geringeres als eine contradictio in adjecto. Auch die Stetigkeit des Raumes wandelt sich demgemäß aus einer geometrisch-idealen in eine Art dinglicher Bestimmung. Wie wir die Körperwelt darum stetig nennen, weil sich in der unmittelbaren Nachbar-

I) Vgl. Aristoteles, Physik IV, cap. 5-7, De coelo IV, 3 u. ö. 
schaft jedes Körpers immer wieder ein anderer befindet, so daß hier nirgends eine Lücke besteht, so läßt sich auch in der Verbindung der einzelnen individuellen Orte zum Gesamtraum kein hiatus denken. Die Kontinuität des Raumes ist hier nicht, wie etwa in den idealistischen Raumtheorien, in seiner „Form" und seinem "Prinzip" begründet, sondern sie folgt aus dem, was er dinglich-substantiell, was er als Substrat ist.

Gegenüber dieser Grundansicht bestand eine der wesentlichsten Aufgaben der Renaissance-Philosophie und der Renaissance-Mathematik darin, Schritt für Schritt die Vorbedingungen für einen neuen Raumbegriff zu schaffen: den Aggregat-Raum durch den System-Raum, den Raum als Substrat durch den Raum als Funktion zu ersetzen. Der Raum mußte gleichsam seiner Dinghaftigkeit, seiner substantiellen Natur entkleidet, er mußte als freies ideales Liniengefüge entcleckt werden. ${ }^{1}$ ) Der erste Schritt auf diesem Wege bestand darin, daß der allgemeine Grundsatz der Homogeneität des Raumes festgestellt wurde. Eine solche hat im System der Aristotelischen Physik keinen Platz: denn hier besteht zwischen den "Orten“ derselbe durchgreifende Unterschied, wie er zwischen den physischen Elementen besteht. Wenn ein bestimmtes Element gemäß seiner Natur nach oben, ein anderes gemäß seiner Natur nach unten strebt, so ist damit gesagt, daß dieses ,Oben“ und „Unten' selbst eine eigene feststehende Beschaffenheit, daß es eine spezifische ழúaıs besitzt. Wo dagegen der Raum nicht als Inbegriff solcher gegebenen Beschaffenheiten gefaßt, sondern als systematisches Ganze konstruktiv erzeugt werden soll: da muß vor allem gefordert werden, daß die Form dieser Konstruktion einem streng einheitlichen Gesetz gehorcht. Von allen Punkten des Raumes müssen jetzt prinzipiell die gleichen Konstruktionen möglich sein, jeder muß als Ausgangspunkt wie als Zielpunkt für jegliche überhaupt mögliche geometrische Operation gedacht werden können. Dieses Postulat ist es, das in seiner Allgemeinheit schon bei Nikolaus Cusanus erfaßt wird, das aber seine wahrhafte konkrete Erfüllung erst in Galileis Bewegungslehre erhalten hat. Man begreift jetzt, warum Galilei in der Kritik der Peripatetischen Philosophie und Physik immer wieder auf dieses Kernproblem zurückkommt. Denn in ihm ist nichts Geringeres als eine völlige Umkehrung des bisherigen Begriffs der Natur geleistet. „Natur" bedeutet jetzt

I) Wie diese Entdeckung sich nicht nur in der Mathematik und in der Kosmologie, sondern auch in der bildenden Kunst und in der Kunsttheorie der Renaissance vollzieht, ja wie die Theorie der Perspektive hier die Resultate der modernen Mathematik und Kosmologie antizipiert, hat Pan ofs ky soeben gezeigt: vgl. seinen Vortrag: ,Die Perspektive als symbolische Form". (Vorträge der Bibl. Warburg, IV, I924/25). 
nicht mehr die Welt der substantiellen Formen, noch den Grund der Bewegung und Ruhe der Elemente, sondern sie bezeichnet jene allgemeine Gesetzlichkeit der Bewegung, der kein besonderes Sein, wie immer es im einzelnen beschaffen sein mag, sich entziehen kann, weil es sich erst durch sie und kraft ihrer einer universellen Ordnung des Geschehens einfügt. Indem wir diese Ordnung zunächst als mathematischideelle konzipieren, indem wir sie sodann mit den Daten der sinnlichen Erfahrung vergleichen und an ihnen bewähren, entsteht uns damit zwischen beiden eine immer festere Verknüpfung. Diese ist, dem Prinzip nach, an keinerlei Beschränkung gebunden: es gibt in der Welt Galileis keine Schranke, die dem "Ideellen" die volle Anwendbarkeit auf das ,Wirkliche", die dem „Abstrakten“ die volle Geltung für das „Konkrete“" verwehrt. So folgt für ihn aus der notwendigen Homogeneität des geometrischen Raumes die Homogeneität der Welt. Die Bewegung hört auf, ein eigentümliches „,Quale“ $\mathrm{zu}$ sein, das sich an verschieden gearteten Körpern in verschiedener Beschaffenheit vorfindet; sie wird bestimmbar durch ein und dasselbe allgemein-gültige Maß- und Größengesetz. Die Verknüpfung, die Synthesis von Bewegungen folgt jetzt keinem anderen Prinzip mehr als die Synthesis reiner Zahlen oder die konstruktive Zusammenfassung verschiedener geometrischer Operationen. Eine solche Zusammenfassung war, solange man an den Grundvoraussetzungen der Aristotelischen Physik festhielt, nicht möglich: denn hier besteht zwischen den verschiedenen Bewegungsformen wie eine reale, so auch eine Art logischer Opposition. Zwar kennt auch Aristoteles neben den einander entgegengesetzten Grundformen der Bewegung, der geradlinigen und der kreisförmigen, eine ,gemischte" Bewegung, die an ihnen beiden Anteil hat; aber eine solche Mischung ist nach ihm nur dort denkbar, wo wir es mit keinem einheitlichen Subjekt der Bewegung zu tun haben, das Bewegliche also kein einfacher, sondern ein aus verschiedenartigen Bestandteilen zusammengesetzter Körper ist. Gehen wir dagegen bis zum wahrhaft Einfachen zurück, so entspricht jeder „Natur" eines Elements eine und nur eine Bewegung: ihm deren mehrere zuzusprechen, hieße seine eigene eindeutige Bestimmtheit leugnen. Ein ,einfacher" Körper, dem ebensowohl die kreisförmige, wie die geradlinige, die Bewegung zum Mittelpunkt hin, wie die vom Mittelpunkt weg zukäme, wäre in der Tat vom Standpunkt der Aristotelischen Physik ein hölzernes Eisen: denn in ihm müßten zwei einander entgegengesetzte substantielle Formen vereinigt gedacht werden. Galilei dagegen kehrt an diesem Punkte die Aristotelisch-scholastische Regel, den Satz: operari sequitur esse um. Statt die Form des Wirkens aus einer dogmatischen Annahme über die Form des Seins zu erschließen, geht er 
von den empirischen Gesetzen des Wirkens aus, um dadurch mittelbar den Ansatz für die Bestimmung des Seins zu gewinnen. ${ }^{1}$ ) Und diese seine Auffassung von der Form des Wirkens ist wiederum bedingt und getragen von seiner Grundansicht über die Form des Wissens. Für ihn folgt die Einheit der Natur, die Einheit der Physis aus der Einheit der Physik: und diese letztere selbst gilt ihm wiederum durch die Einheit der Geometrie und der Mathematik verbürgt. Weil es eine allgemeine Axiomatik des Messens, der exakten und empirischen Größenbestimmung, gibt, enthält auch die Welt des Meßbaren keine schlechthin unüberbrückbaren Gegensätze. Es sind dieselben ideellen Grundnormen, nach denen wir den Fall des Steines und den Umlauf der Gestirne verstehen müssen, nach denen wir die irdische wie die himmlische Welt zu bestimmen haben. In dieser Wendung läßt sich von neuem, nach der systematischen wie nach der historischen Seite hin, die entscheidende Bedeutung des Methodenproblems für das Seinsproblem erfassen. Im Mittelalter spiegelt sich der methodische Dualismus, der Gegensatz zwischen Theologie und Physik, in einem dualistischen Begriff der Materie wider. Thomas von Aquino betont geradezu, daß zwischen der irdischen und der himmlischen Materie keinerlei Gemeinschaft des Wesens, sondern lediglich eine solche des bloßen $\mathrm{Namens}$ bestehe. Die moderne Anschauung, die auf der Voraussetzung der Einheit des Intellekts, auf dem Gedanken der,Mathesis universalis', wie Descartes ihn begründet, beruht, muß hier die entgegengesetzte Folgerung ziehen: die Substanz der Körperwelt ist eine, weil und sofern das empirische und rationale Wissen, wie verschieden immer sein Gegenstand sein mag, denselben Regeln und Prinzipien untersteht.

Aber wenn es hier die ideellen Normen der mathematischen Erkenntnis sind, die auf die Gestaltung der empirischen Physik, auf die Fassung des Bewegungsbegriffs, entscheidenden Einfluß gewinnen,- - so läßt sich nunmehr auch der umgekehrte Prozeß beobachten. Die neue Einheit, die zwischen Geometrie und Physik geschaffen ist, wirkt sich zugleich in dem Sinne aus, daß die Bewegung, als mathematische Idee betrachtet, in die Behandlung der Geometrie eindringt. Auf dem Wege von der antiken zu der modernen Mathematik, von der ,synthetischen" Geometrie der Griechen zur analytischen Geometrie und zur Analysis des Unendlichen, bedeutet dieser Schritt eine der wichtigsten Etappen. Erst durch ihn wird es möglich, zu einer klaren Scheidung der Raumanschauung von der empirischen Dinganschauung zu gelangen, - den „Dingraum“ in den reinen „Systemraum“ umzubilden. Der Raum der Aristotelischen Physik, der als die Grenze des umfassenden Körpers

I) Näheres s. Erkenntnisproblem ${ }^{3}$ I. 4 or ff. 
gegenüber dem umfaßten definiert wird, zeigt eben in dieser Definition, daß er selbst noch verhaftet an den Körpern klebt, daß er eine bloße Bestimmung an und von Körperlichem bedeutet. In ihm herrscht demnach auch keine wahrhafte Freiheit der Bewegung und des gedanklichen Fortschritts. Nicht nur daß hier keine Linie im eigentlichen Sinne ins Unendliche verlängert werden kann - denn das aktuell-Unendliche schließt einen inneren Widerspruch in sich - so kann auch die Bewegung überhaupt nicht ohne Einschränkung in jeder beliebigen Richtung weitergeführt gedacht werden. Denn der spezifische Charakter des Beweglichen setzt dieser Weiterführung von vornherein feste Schranken: bestimmten Elementen sind bestimmte Orte und bestimmte Richtungen gemäß und natürlich, während andere ihrer Natur widerstreiten. Die moderne Dynamik kehrt diesen Sachverhalt um, indem sie die Bewegung, die sie in voller Allgemeinheit und Weite nimmt, zu einem Vehikel der räumlichen Erkenntnis, der Bestimmung geometrischer Gebilde, macht. Am klarsten stellt sich diese Umkehr in Keplers stereometrischen Untersuchungen dar. Kepler stellt das Maßverhältnis zwischen komplizierten körperlichen Gebilden dadurch fest, daß er diese nicht einfach als fertige und gegebene einander gegenüberstellt, sondern daß er, statt ihrer selbst, die Regel betrachtet, nach der sie als entstehend gedacht werden können. Jede körperliche Gestalt erscheint jetzt als eine Gesamtheit aus unendlich vielen einzelnen Lagebestimmungen, die sie in diesem ihrem genetischen Aufbau durchläuft: und es ist die Aufgabe des mathematischen Denkens, für diese Totalität einen einheitlichen Maßbegriff zu finden. So erscheint etwa in dieser Betrachtungsweise der Kreis als ein Inbegriff von unendlich vielen und unendlich schmalen gleichschenkligen Dreiecken, deren Spitzen in seinem Mittelpunkt zusammentreffen, und analog wird die Kugel als ein Ganzes aus unendlich vielen Kegeln gedacht und berechnet. Und nicht nur auf solche bekannte geometrische Grundgebilde erstreckt sich Keplers Untersuchung, sondern er läßt durch die Bewegung verschiedener sphärischer und konischer Flächen um bestimmte Achsen, Durchmesser und Ordinaten eine Fülle neuer Gestalten hervorgehen, deren körperliche Inhalte er nach allgemeinen Methoden zu bestimmen sucht. ${ }^{1}$ ) Indem auf diese Weise der Begriff des Unendlichen als ein nicht nur legitimes, sondern geradezu als ein notwendiges Erkenntnismittel der Mathematik erwiesen wird, erfährt dadurch auch der Weltbegriff, erfährt der Begriff des Erkenntnisobjekts eine Neugestaltung. Denn jedes ,bestimmte Integral“ - und Keplers Methode besteht

I) Näheres über die Methode von Keplers „Stereometria doliorum" s. bei Zeuthen, Geschichte der Mathematik im I6. und 17 . Jahrhundert, sowie bei Gerhardt, Die Entdeckung der höheren Analysis, Halle 1855 . S. I 5 ff. 
geradezu darin, geometrische Gebilde als bestimmte Integrale zu fassen und auf sie zu reduzieren - schließt unmittelbar die Verknüpfung zweier Momente in sich, die bisher miteinander unvereinbar schienen. Das

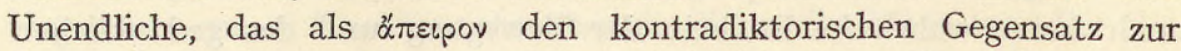
Grenze, zum $\pi$ śpas zu besagen scheint, wird in der neuen Form der mathematischen Analysis in den Dienst der quantitativen Bestimmung gestellt, ja als eines ihrer wichtigsten Werkzeuge erwiesen. Seine metaphysische Transzendenz wandelt sich in logische Immanenz. Der Begriff des Raumes streift den letzten Rest des Stofflichen von sich ab; er wird zu einem reinen Ordnungsgefüge. Am klarsten kündigt sich diese Wendung in der Einführung des Koordinatenbegriffs an, die jetzt durch Fermat und Descartes erfolgt. Descartes' analytische Geometrie baut sich auf einem ähnlichen logisch-geometrischen Grundprinzip wie Keplers „Stereometria doliorum“ auf. Denn auch Descartes behandelt die Kurven, die er betrachtet, nicht einfach als sinnlich-anschauliche Gegebenheiten, sondern er läßt sie aus einem geordneten Komplex von Bewegungen entstehen. Die Form der Kurve wird analytisch auf das Gesetz dieser Bewegungen reduziert. Die Einsicht in den relativen Charakter aller Bewegung führt dann weiter dahin, daß jede noch so komplexe Bewegung dem Prinzip nach in Elementarbewegungen zerlegt werden kann, - welche Elementarbewegungen die einfachste Form annehmen, wenn wir sie längs zwei aufeinander senkrecht stehenden Achsen vor sich gehend denken. Das verschiedene Geschwindigkeitsverhältnis, das zwischen diesen beiden Bewegungen - der längs der Abszissenachse und der längs der Ordinatenachse - besteht, bestimmt in eindeutiger Weise die geometrische Form der resultierenden Kurve und macht alle ihre Eigenschaften vollständig erkennbar. Und zugleich ist es innerhalb des reinen Relations- und Systemraumes, der jetzt geschaffen ist, völlig in die Freiheit des mathematischen Denkens gestellt, welche Punkte es als ruhend, welche es als beweglich ansehen will. Denn von jedem Koordinatensystem läßt sich, gemäß einer einfachen Regel der Transformation, zu jedem anderen übergehen, ohne daß dabei die Gesetze der Bewegung, ohne daß die Gleichungen, durch die bestimmte Kurven ausgedrückt werden, eine andere als eine rein formelle Änderung erfahren. Hier liegt einer der wesentlichsten Fortschritte der modernen analytischen Geometrie gegenüber der griechischen Mathematik. Auch in dieser letzteren finden sich ganz bestimmte Ansätze zur Verwendung des Koordinatenbegriffs; aber immer lehnt sich hierbei die Betrachtung aufs engste an die jeweilig gegebene einzelne Figur an, ohne sich zu wahrhafter Allgemeinheit zu erheben. Stets muß hier der Anfangspunkt der Koordinaten der betrachteten Figur selbst angehören oder in nächster 
Beziehung zu ihr und ihren geometrischen Grundeigenschaften stehen. Erst Fermat schafft demgegenüber eine Methode, die von all solchen Beschränkungen frei ist, die es gestattet, das Zentrum des Bezugssystems beliebig in der Ebene der Kurve anzunehmen. Auch die Richtung der Abszissen- und der Ordinatenachse läßt jetzt Verschiebungen und Drehungen aller Art zu; statt der rechtwinkligen Koordinaten können auch schiefwinklige benutzt werden, kurz es wird jetzt dem Koordinatensystem eine völlig freie Lage zur Kurve gegeben. In seiner Schrift , $A d$ locos planos et solidos isagoge hat Fermat diesen methodischen Vorzug seines Verfahrens gegenüber dem der Alten ausdrücklich hervorgehoben, indem er es als seine Grundaufgabe bezeichnet, , ,diesen Wissenszweig einer ihm eigens angepaßten Analyse zu unterwerfen, damit in Zukunft ein allgemeiner Zugang zu den Örtern offen stehe“ ${ }^{1}$ ) Diesen Universalismus der Raumanschauung hätte auch die reine Mathematik nicht zu erkämpfen vermocht, wenn nicht zuvor von anderer Seite her, insbesondere von Seiten der Kosmologie und Naturphilosophie, eine Lockerung und Lösung des Aristotelisch-scholastischen Raumbegriffs erfolgt wäre.

In der Tat kündet sich dieser Wandel lange bevor er in der Methodik der exakten Wissenschaft sichtbar wird, gewissermaßen in einer neuen Stimmung und Tönung des gesamten Weltg efühls an. Giordano Bruno ist der typische Zeuge für diese Umkehr in der Richtung der Betrachtung. Das Unendliche als ein Instrument der exakten wissenschaftlichen Erkenntnis ist ihm noch fremd: ja er hat es in seiner Lehre vom Minimum in dieser seiner Funktion ausdrücklich bekämpft und abgewehrt. Aber so wenig er die logische Struktur des neuen mathematisch-Unendlichen durchschaut, so sehr umfaßt er den unendlichen Kosmos mit der ganzen Glut eines leidenschaftlichen Affekts. Dieser heroische Affekt ist es, der sich jetzt gegen das "Ne plus ultra" der mittelalterlichen dogmatischen Glaubenslehre wie der Aristotelisch-scholastischen Kosmologie zur Wehr setzt. Der freie Flug der Phantasie und der freie Flug des Denkens darf nirgends durch feste räumlich-dingliche Schranken gehemmt werden. So wendet sich Bruno vor allem und immer von neuem gegen die Kon-

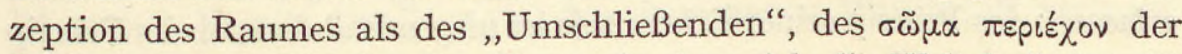
Peripatetischen Physik. Der Raum, in dem sich die Welt befindet, ist ihm nicht die äußerste Umgrenzung, in der sie gewissermaßen eingehüllt und eingebettet ruht: er ist vielmehr das freie Medium der Bewegung, die sich ungehindert über jede endliche Grenze und nach allen Richtungen hin erstreckt. Diese Bewegung kann und darf kein Hemmnis in der

I) Vgl. hierzu z. B. Wieleitner, Die Geburt der modernen Mathematik, Historisches und Grundsätzliches I: Die analytische Geometrie, Karlsruhe I924, S. $36 \mathrm{ff}$. 
„Natur" irgendeines Einzeldinges oder in der allgemeinen Beschaffenheit des Kosmos finden: denn sie selbst, in ihrer Universalität und ihrer Schrankenlosigkeit, ist es vielmehr, die die Natur als solche konstituiert. Der unendliche Raum wird erfordert als das Vehikel der unendlichen Kraft: und diese ist wiederum nichts anderes als ein Ausdruck des unendlichen Lebens des Universum. Diese drei Momente sind für Brunos Denken nirgends scharf geschieden: wie in der stoischen und neuplatonischen Physik, auf die er sich stützt, so fließt auch bei ihm der Begriff des Raumes mit dem des Äthers und dieser wieder mit dem Begriff der Weltseele zusammen. Auch hier ist es somit ein dynamisches Motiv, das die Starrheit des Aristotelisch-scholastischen Kosmos durchbricht und überwindet. Aber es ist nicht, wie bei Kepler und Galilei, die Form der neuen Wissenschaft der Dynamik, sondern ein neues dynamisches Weltgefühl, das hier den Ausschlag gibt. Auch in Kopernikus sieht Bruno nicht sowohl den rechnenden Astronomen, als vielmehr den Heros dieses Weltgefühls. „Wer vermöchte nach Gebühr den Großsinn dieses Deutschen zu preisen, der unbekümmert um das Urteil der törichten Menge und gegen den Strom der entgegengesetzten Meinung, zuerst der wahren Ansicht zum Sieg verholfen hat - jener Ansicht, die unser Wissen aus dem engen Kerker erlöst hat, in welchem es nur wie durch einzelne Öffnungen die Sterne erblickte, die die Luft durchmessen, den Himmel durchdrungen und die eingebildeten Mauern der ersten, der achten, neunten und zehnten Sphäre zerbrochen hat?"1) Aus Sätzen dieser Art erkennt man, daß für Giordano Bruno das Raumproblem nicht ausschließlich und nicht in erster Linie dem Kreis der kosmologischen und naturphilosophischen Probleme, sondern daß es vor allem dem Kreis der ethischen Grundfragen angehört. Diese eigenartige Verknüpfung ergibt sich daraus, daß für Bruno die Unendlichkeit des Raumes nirgends auf das einfache Zeugnis der empirischen oder mathematischen Anscha ung behauptet wird - denn der Sinn und die Anschauung als solche sind nach ihm überhaupt außer Stande, auf den wahren Begriff des Unendlichen hinzuführen. Wir erfassen vielmehr das Unendliche mit dem gleichen Organ, mit dem wir auch unser eigenes geistiges Sein und Wesen erfassen: das Prinzip seiner Erkenntnis ist nirgends anders, als im Prinzip

x) Bruno, La cena de la ceneri, Op. italiane (Lagarde) S. I24ff.; vgl. De Immenso et Innumerablibus, Lib. I, cap. I. (Op. latina I, I, S. 20I).

,Intrepidus spatium immensum sic findere pennis

Exorior, neque fama facit me impingere in orbes,

Quos falso statuit verus de principio error,

Ut sub conficto reprimamur carcere vere,

Tanquam adamanteis cludatur moenibus totum.

Nam mihi mens melior ..." 
des Ich, im Prinzip des Selbstbewußtseins zu suchen. ${ }^{1}$ ) So läßt sich denn, wenn wir zu seinem wahren Wesen durchdringen wollen, nicht bei der passiven Betrachtung, bei der bloßen sinnlichen oder ästhetischen Kontemplation stehen bleiben, sondern immer bedürfen wir, um uns $z u$ ihm $z u$ erheben, eines freien Aktes und eines freien Aufschwungs des Geistes. In diesem Akt, in dem sich das Ich seiner eigenen inneren Freiheit versichert, ersteht ihm, gleichsam als Gegenpol dieser seiner intellektuellen Selbstanschauung, die Anschauung vom unendlichen Universum. Das Wissen vom Subjekt und das vom Objekt sind hier unlöslich ineinander verwoben. Wer nicht in sich selbst den heroischen Affekt der Selbstbehauptung und der schrankenlosen Selbsterweiterung findet, der bleibt auch für den Kosmos und seine Unendlichkeit blind. In Brunos Dialog „Degli eroici furori“ ist es daher die Form der Renaissance-Psychologie und die Form der Renaissance-Ethik, die sich überall als das entscheidende Motiv der neuen Kosmologie erweist. Die Anschauung des Unendlichen wird hier durchweg als eine Tat des Ich beschrieben und als eine Tat des Ich gefordert. Auch der mittelalterlichen Spekulation war der Gedanke einer Mehrheit, ja einer Unendlichkeit der Welten nicht fremd. Sie hat die theoretische Möglichkeit dieses Gedankens nach allen Seiten hin erwogen, wenngleich sie sich in Übereinstimmung mit den Beweisgründen, die Aristoteles in der Schrift „De coelo“ für die Einheit des Kosmos anführt, zumeist gegen diese Möglichkeit entschied. ${ }^{2}$ ) Und auch hier erkennt man in der Form der Abwehr, $\mathrm{da} ß$ in ihr nicht ausschließlich intellektuelle, sondern ethisch-religiöse Motive wirksam sind. Mit der Preisgabe des Gedankens der Einzigkeit der Welt schien auch der Gedanke des einzigartigen Wertes des Menschen preisgegeben, schien der religiöse Proze $\beta$ um sein eigentliches und einheitliches Zentrum gebracht zu sein. Noch in den führenden Geistern der Frührenaissance wirkt diese Grundstimmung nach: noch Petrarca hat in der Schrift „De sui ipsius et aliorum ignorantia“ die These von der Unendlichkeit der Welten ausdrücklich als den ",Gipfel der Torheit“ bezeichnet und sie als philosophische Ketzerei gebrandmarkt. Für Bruno hingegen ist es eben die intellektuelle und die sittliche Würde des Ich, ist es sein Begriff der Person, der einen neuen Weltbegriff verlangt.

I) Bruno, De l'infinito, universo e mondi. Dial. I, Op. ital. S. 307: „Non è senso che vegga l'infinito, non è senso da cui si richieda questa conclusione, perche l'infinito non puo essere oggetto del senso: et però chi dimanda di conoscere questo per via di senso, è simile a colui che volesse veder con gl'occhi la sustanza e l'essenza: et chi negasse per questo la cosa, perche non è sensibile, o visibile, verebe a negar la propria sustanza et essere."

2) Näheres über den Stand der Frage in der scholastischen Physik des I2. und I3. Jahrhunderts s. bei Duhem, Léonard de Vinci et les deux Infinis, (Etudes sur L. de Vinci II). 
Überall spürt man in der Verkündung seiner kosmologischen Grundansicht dieses subjektive Pathos; überall liegt bei ihm der eigentliche Accent nicht sowohl auf dem Universum, als auf dem Ich, das die Anschauung des Universums in sich zu erzeugen hat. Die neue Weltansicht stellt sich durchweg in der Form eines neuen Impulses, eines neuen Antriebes und Auftriebes, dar. Der Mensch findet sein wahres Ich erst, indem er das unendliche All in sich hinein zieht, und indem er auf der anderen Seite sich selbst $\mathrm{zu}$ ihm erweitert. Hier verwischt sich auch die Grenze von Tod und Leben: denn im Tode, im Aufgeben der individuellen Daseinsform, wird erst die eigentliche Wahrheit und Universalität des Lebens selbst erfaßt. Nicht der Philosoph freilich, sondern der Dichter Giordano Bruno ist es gewesen, der in den Sonetten, die dem Dialog „Degli eroici furori“" eingefügt sind, dieser Grundkonzeption ihren reinsten und stärksten Ausdruck gegeben hat:

Poi che spiegat' ho l'ali al bel desio

Quanto più sott' il piè l'aria mi scorgo,

Più le veloci penni al vento porgo,

Et spreggio il mondo, et vers' il cielo m'invio.

$\mathrm{Ne}$ del figliuol di Dedalo il fin rio

Fa che più pieghi, anzio via più risorgo.

Ch'i' cadrò morto a terra ben m'accorgo,

Ma qual vita pareggia al morir mio?

La voce del mio cor per l'aria sento,

Ove mi porti temerario? china,

Che raro è senza duol tropp'ardimento.

Non temer, respond'io, l'alta ruina.

Fendi sicur le nubi, et muor contento.

S'il ciel si illustre morte ne destina. ${ }^{1}$ )

Wenn hier das Raumproblem wieder in das allgemeine philosophische Grundproblem der Renaissance: in die Frage nach dem Verhältnis von „Subjekt" und,,Objekt" einmündet, so tritt eben damit freilich von neuem jene Dialektik hervor, mit der die Renaissance-Philosophie dauernd $\mathrm{zu}$ ringen hat. Ja, sie erscheint jetzt, indem sie sich uns in der konkretesten Form, in der Sprache der räumlichen Anschauung, darstellt, erst auf ihren schärfsten Ausdruck gebracht. Der Mensch erscheint dem Universum, das Ich erscheint der Welt gegenüber zugleich als das Umfaßte und als das Umfassende. Beide Bestimmungen sind gleich unentbehrlich, um sein Verhältnis zum Kosmos auszusprechen. Und so findet denn

I) Eroici furori, Dial. III, Op. ital. p. 648 . 
zwischen ihnen eine ständige Gegenwirkung und ein ständiges Umschlagen statt. Wenn die Unendlichkeit des Kosmos das Ich nicht nur zu beschränken, sondern völlig zunichte zu machen droht, so liegt doch andererseits eben in ihr die Quelle seiner steten Selbsterhöhung: denn der Geist gleicht der Welt, die er begreift. Von den verschiedensten Ausgangspunkten her ergreift die Renaissance-Philosophie dieses Grundmotiv, um es ständig neu $\mathrm{zu}$ variieren. „Ich erfülle und durchdringe und enthalte den Himmel und die Erde" - so spricht Gott in einem Dialog zwischen Gott und der Seele, den Ficin nach dem Vorbild Augustins verfaßt hat. „Ich erfülle und werde nicht erfüllt, weil ich die Fülle selbst bin. Ich durchdringe und werde nicht durchdrungen, weil ich die Kraft des Durchdringens selbst bin. Ich umfasse und werde nicht umfaßt, weil ich selber das Vermögen des Umfassens bin. "1) Aber all diese Prädikate, die hier die Got theit für sich in Anspruch nimmt, werden nun in gleicher Weise der menschlichen Seele selbst zugesprochen. Auch sie enthält, sofern sie als Subjekt des Erkennens genommen wird, die objektive Wirklichkeit, statt von ihr umfaßt $\mathrm{zu}$ werden. Ihr Primat gegenüber allem bloß Dinglichen ist damit ein für allemal sicher gestellt. Das Ich ist dem unendlichen Kosmos gewachsen, sofern es in sich selbst die Prinzipien findet, nach welchen es ihn, als unendlich, weiß. Aber dieses Wissen selbst ist nicht von bloß abstrakter, rein diskursiver Art; es ist eine intuitive Gewißheit, die, statt aus dem logischen Verstand, vielmehr aus dem spezifischen Lebensgrund des Ich stammt und aus ihm beständig aufs neue hervorquillt. Gleich Goethes Ganymed steht der Mensch der Renaissance der Gottheit und dem unendlichen Universum ,umfangend-umfangen“ gegenüber. Die dialektische Antinomie, die in diesem Doppelverhältnis beschlossen liegt, hat die RenaissancePhilosophie nicht bewältigt; aber es bleibt ihr unbestrittenes Verdienst, da $\beta$ sie das Problem zuerst bezeichnet und daß sie es in einer neuen Fassung den folgenden Jahrhunderten, den Jahrhunderten der exakten Wissenschaft und der systematischen Philosophie, überliefert hat. fol. 610).

I) Ficinus, Dialogus inter Deum et animam Theologicus. Epistol. Lib. I. (Opera 


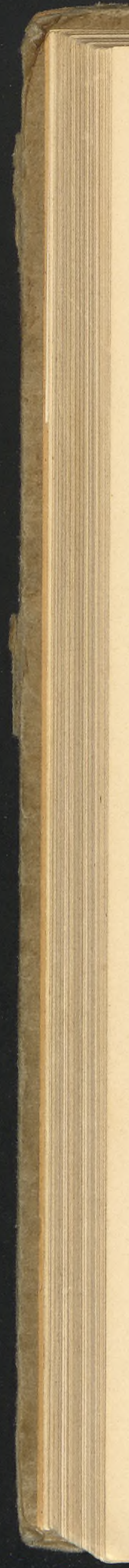




\section{VORBEMERKUNG}

Der Anhang besteht aus zwei Stücken:

I. dem Liber de Mente des Nicolaus Cusanus. [Text und Übersetzung.]

2. dem Liber de Sapiente des Carolus Bovillus. [Text.]

Die Edition des lateinischen Textes des Cusanus wurde durch Dr. Joachim Ritter besorgt, die Übersetzung des Textes rührt von cand. phil. Heinrich Cassirer her. Der Bovillus-Text ist von cand. phil. Raymond Klibansky herausgegeben.

\section{NICOLAUS CUSANUS}

\section{LIBER DE MENTE}

Herausgegeben von Joachim Ritter, übersetzt von Heinrich Cassirer.

Die Textausgabe des Cusanus erfolgte nach der noch heute in Cues befindlichen Handschrift Cod. Cus. 2I8, deren Randnotizen nach M arx (Verzeichnis der Handschriften-Sammlung des Hospitals zu Cues S. VI) zum Teil von Nicolaus Cusanus selbst herrühren.

Die Wiedergabe des Textes folgt der Handschrift. Die Orthographie ist im allgemeinen beibehalten. In Einzelfällen, wo Änderungen notwendig waren, ist dies unter dem Text ausdrücklich bemerkt. Dagegen sind die Eigennamen sowie der Gottesname entgegen der Handschrift überall stillschweigend in großer Schreibung gegeben. Die Interpunktion ist, soweit es möglich war, nach modernen Gesichtspunkten behandelt. 


\section{NICOLAI CUSANI LIBER DE MENTE.}

Quomodo philosophus ad ydiotam, ut proficeret de menII 5 r. tis natura, accessit; quomodo mens sit per se mens, ex officio anima et dicta sit a mensurando. Capitulum primum Ydiote de mente.

$5 \quad$ Multis ob iubileum ${ }^{1}$ ) Romam mira devocione accurrentibus auditum est philosophum omnium, qui nunc vitam agunt, precipuum in ponte reperiri transeuntes admirari. Quem orator quidam sciendi avidissimus solicite querens ac ex faciei pallore, toga, talari et ceteris cogitabundi viri gravitatem presignantibus cognoscens blande salutans inquirit, que 10 eum causa eo loco $^{\text {a) }}$ fixum teneat.

Philosophus. Admiracio, inquit.

Orator. Admiracio stimulus videtur esse omnium quamcunque rem scire querentium. Hinc opinor, cum precipuus habearis inter doctos, maximam eam esse admirationem, que te adeo solicitum tenet. ${ }^{b}$ )

15 Philosophus. Bene ais, amice. Nam cum ex universis pene clymatibus magna cum pressura innumerabiles populos transire conspiciam, admiror omnium fidem unam in tanta corporum diversitate. Cum enim nullus alteri similis esse possit, una tamen omnium fides est, que eos tanta devocione de finibus orbis advexit.

$20 \quad$ Orator. Certe Dei donum esse necesse est ydiotas clarius fide attingere quam philosophos racione. Nam tu nosti, quanta inquisicione opus habet mentis immortalitatem racione pertractans, quam tamen nemo ex hiis omnibus sola fide pro indubitata non habet, cum omnium cura et labor ad hoc tendat, ut anime post mortem nullo peccato obtenebrate ${ }_{25}$ in lucidam atque desideratissimam vitam rapiantur.

Philosophus. Magnam rem et veram narras, amice. Ego enim omni tempore mundum peragrando sapientes adii, ut de mentis inmortalitate cercior fierem, cum apud Delphos precepta sit cognicio, ut ipsa se mens cognoscat coniunctamque cum divina mente se senciat, sed
a) loci $H s$.
b) teneat, korr. tenet $\mathrm{Hs}$.
I) 1450 . 


\section{DES NICOLAUS CUSANUS SCHRIFT VOM GEIST.}

I. Kapitel.

Der Philosoph kommt zum Laien, um seine Erkenntnis über die Natur des Geistes zu vertiefen. Der Geist ist an sich Geist, vermöge der ihm zugewiesenen Aufgabe Seele und heißt Geist (mens) weil er mißt (mensurat).

Zu der Zeit, als zur Feier des Jubeljahres viele Menschen von wundervoller Gottergebenheit erfüllt nach Rom eilten, stand, wie uns berichtet wird, der hervorragendste aller jetzt lebenden Philosophen auf einer Brücke und wunderte sich über die Schar der Vorüberziehenden. Ihn befragte ein Redner, ein Mann voll des höchsten Dranges nach Wissen, mit lebhafter Anteilnahme, da er ihn an seinem bleichen Antlitz, an seinem Talar, und anderen Kennzeichen, welche die ernsthafte Würde eines Denkers anzeigten, erkannte, mit ehrerbietigem Gruße, aus welchem Grunde er an dieser Stelle wie fest gebannt stehen bleibe.

Philosoph. Das Erstaunen bewegt mich dazu.

Redner. Das Erstaunen scheint der Antrieb für alle Menschen zu sein, die überhaupt nur irgend etwas wissen wollen; so glaube ich denn, $\mathrm{da} ß$ es nur der höchste Grad des Erstaunens sein könne, der Dich mit solcher Anteilnahme an diesem Orte festhält, wirst Du doch für den hervorragendsten Mann unter den Gelehrten gehalten.

Philosoph. Du sprichst die Wahrheit mein Freund; denn, da ich beinahe aus aller Herren Länder eine unzählbare Menge Menschen hier zusammen kommen sehe, erfüllt von tiefer Bewegung des Gemütes, bin ich von Bewunderung ergriffen, daß sie alle ein em Glauben anhangen, bei solcher großen Verschiedenheit ihrer äußeren Gestalt. Wenngleich keiner dem anderen ähnlich sein kann, ist es doch der eine Glaube, von dem sie alle ergriffen sind, der sie von allen Grenzen des Erdkreises hergeführt hat, mit einer solchen Ergebenheit gegen ihren Gott.

Redner. Notwendig muß dies ein Gnadengeschenk Gottes sein, daß ungelehrte Laien durch den Glauben mit größerer Klarheit begreifen, als die Philosophen durch das vernünftige Denken. Denn Du weißt ja, welcher Fülle mühseliger Forschung es bedarf, wenn man mit der Hilfe des vernünftigen Denkens über die Unsterblichkeit des Geistes handelt, die doch allein kraft des Glaubens keiner von diesen allen in Zweifel zieht. Ist es doch ihrer aller Bestrebung und Bemühung, daß ihre Seelen nach dem Tode, von keiner Sünde verdunkelt, zu einem lichten, sehnlichst erstrebten Leben emporgetragen werden.

Philosoph. Da sprichst du eine große Wahrheit aus, mein Freund; denn ich habe Zeit meines Lebens die Welt durchreist und die Weisen gehört damit ich über die Unsterblichkeit des Geistes gewisser würde, da von dem delphischen Orakel die Selbsterkenntnis vorgeschrieben wurde, damit der Geist sich selbst erkenne, und sich mit dem Geiste Gottes ver- 
hactenus nondum ${ }^{2}$ ) quesitum adeo perfecte ac lucida racione attigi, quemadmodum hic ignorans populus fide.

Orator. Si phas est, dicito, quid te impulit Romam advenire, qui Peripateticus videris, an putas aliquem, a quo proficias, reperire.

$5 \quad$ Philosophus. Audiveram ex templo menti per T. Attilium Crassum in Capitolio dedicato multas sapientum de mente scripturas hoc loco reperiri. Adveni fortassis frustra, nisi tu, qui michi bonus civis et sciens videris, auxilium prestes.

Orator. Templum menti dedicasse Crassum illum certum est, sed 10 an de mente fuerint $t^{b}$ ) in eo templo libri et qui fuerint, nemo ${ }^{c}$ ) post tot Romanas clades scire poterit. Verum ne doleas frustra advenisse, hominem ydiotam meo iudicio admirandum, de qua re volueris, audies.

Philosophus. Oro quantocius hoc fieri.

Orator. Sequere.

15 Et cum prope templum eternitatis in subterraneum quendam locellum descenderent, ydiotam ex ligno coclear exprimentem alloquitur orator: Erubeo, ydiota, inquit, te per hunc maximum philosophum hiis rusticis operibus implicatum reperiri. Non putabit a te se theorias aliquas auditurum.

20 Ydiota. Ego in hiis exerciciis libenter versor, que et mentem et Ir 5 v. corpus indesinenter pascunt. Credo, | si hic, quem adducis, philosophus est, non me spernet, quia arti coclearie operam do.

Philosophus. Optime ais. Nam et Plato intercise pinxisse legitur, quod nequaquam fecisse creditur $^{d}$ ), nisi quia speculacioni non ad25 versabatur.

Orator. Ob hoc fortassis erant Platoni de arte pingendi familiaria exempla, per que res grandes faciles reddidit.

Ydiota. Immo in hac mea arte id, quod volo, symbolice inquiro et mentem depasco, commuto coclearia et corpus reficio; ita quidem omnia 30 michi necessaria, quantum sufficit, attingo.

Philosophus. Est mea consuetudo, cum hominem fama sapientem accedo, de hiis, que me angunt, in primis sollicitum esse et scripturas in medium conferre et inquirere earundem intellectum. Sed cum tu sis

\footnotetext{
a) nundum $H s$.

b) fuerint über der Zeile ergänzt Hs.

c) Danach nemo durch Streichung getilgt Hs.

d) creditur am Rand ergänzt Hs.
} 
bunden fühle. Aber bisher bin ich noch nicht in solcher Vollendung und Klarheit zu dem gesuchten Ergebnis vermöge meines Denkens gekommen, wie es dieses unwissende Volk vermöge seines Glaubens vermocht hat.

Redner. Wenn die Frage erlaubt ist, so sage mir doch, aus welchem Beweggrunde $\mathrm{Du}$ nach Rom gekommen bist, $\mathrm{Du}$, der Du doch der peripatetischen Schule anzugehören scheinst. Glaubst Du etwa, hier jemanden zu finden, der Dir einen geistigen Gewinn brächte?

Philosoph. Ich hatte gehört, daß sich in dem Tempel, welchen Titus Attilius Crassus dem Geiste auf dem Capitol geweiht hat, viele Schriften weiser Männer über den Geist befänden; vielleicht aber bin ich dennoch vergebens hergekommen, es sei denn, daß Du, der Du ein geachteter Bürger und ein gebildeter Mann zu sein scheinst, mir Deine Hilfe gewährst.

Redner. Es ist gewiß richtig, daß jener Crassus dem Geiste einen Tempel geweiht hat; niemand jedoch kann wissen, ob in diesem Tempel jemals Schriften über den Geist gewesen sind, und welche das gewesen sein könnten, wird vollends niemand wissen können, nachdem inzwischen so viele Kriegsstürme über Rom hereingebrochen sind. Damit $\mathrm{Du}$ jedoch nicht unmutig seist, da $B$ Du vergebens hierher gekommen bist, sollst Du einen, wenigstens nach meiner Meinung, bewunderungswürdigen Laien reden hören. schehe.

Philosoph. Es ist mein Wunsch, daß das so bald als möglich ge-

Redner. Folge mir nur.

Und als sie nahe dem der Ewigkeit geweihten Tempel in einen kellerartigen Raum hinabgestiegen waren, sprach der Redner einen Laien, welcher aus Holz einen Löffel schnitzte, mit folgenden Worten an:

Redner. Ich erröte, daß Dich dieser große Philosoph mit solch bäurischer Arbeit beschäftigt findet; denn er wird nicht glauben wollen, $\mathrm{da} B$ er von Dir irgendwelche theoretischen Erörterungen wird hören können.

Laie. Ich befasse mich gern mit derartigen Beschäftigungen, die in gleicher Weise unablässig Geist und Körper bereichern. Ich glaube aber, wenn der Mann, den Du hierher bringst, ein Philosoph ist, dann wird er mich nicht verachten, weil ich auf die Kunst des Löffelschnitzens Mühe verwende.

Philosoph. Da hast Du völlig Recht. Denn auch Platon hat, wie wir lesen, bisweilen gemalt, was er doch wohl niemals, wie wir glauben müssen, getan hätte, wenn es dem Geist der Spekulation entgegen wäre.

Redner. Vielleicht hatte Platon deshalb vertraute Beispiele aus der Malkunst zur Hand, mit deren Hilfe er schwierige Dinge deutlich machte.

Laie. So ist es. In dieser meiner Kunst suche ich im Bilde das auf, was ich im Sinne habe, erfreue meinen Geist, drechsle meine Löffel und schaffe meinem Körper Erholung. So erreiche ich in genügender Weise alles, dessen ich bedarf.

Philosoph. Wenn ich einen Mann besuche, der in dem Rufe steht, weise zu sein, so pflegt es meine erste Sorge zu sein, ihn in betreff der Dinge, die mich in geistige Unruhe setzen, zu befragen und ihm Schriften 
ydiota, ignoro, quomodo te ad dicendum excitem, ut, quam habeas de mente intelligenciam, experiar.

Y diota. Arbitror neminem facilius me cogi posse, ut dicat ${ }^{\mathrm{a}}$ ), que sentit. Nam cum me ignorantem fatear ydiotam, nichil respondere perti5 mesco; literati philosophi ac famam sciencie habentes merito cadere formidantes gravius deliberant; tu igitur, quid a me velis, plane si dixeris, nude recipies.

Philosophus. Paucis exprimere nequeo. Si placet consedentes passim loquamur.

10 Ydiota. Placet, inquit ${ }^{\mathrm{b}}$ ) et positis in trigono scabellis ${ }^{\mathrm{c}}$ ) ipsisque tribus ex ordine locatis orator aiebat.

Orator. Vides, philosophe, viri huius simplicitatem, qui nichil horum in usu habet, que ad recipiendum tanti ponderis virum decencia petit. Fac in hiis experimentum, que magis, ut aiebas, te angunt. Nichil enim 15 de hiis, que sciverit, te latebit. Experieris, puto, te non vacue adductum.

Philosophus. Adhuc omnia placent, ad rem descendam. Tu interim taciturnus sis queso, nec te prolixior turbet collocucio.

Orator. Experieris me continuacionis sollicitatorem pocius quam ${ }^{\mathrm{d}}$ ) fastidientem.

20 Philosophus. Dic igitur, ydiota, - ita tu tibi ${ }^{\mathrm{e}}$ ) nomen esse ais si quam de mente habes coniecturam.

Y diota. Puto neminem esse aut fuisse hominem perfectum, qui non de mente aliqualem saltem fecerit conceptum. Habeo quidem et ego mentem esse, ex qua omnium rerum terminus et mensura; mentem \$5 quidem a mensurando dici conicio.

Philosophus. Putas ne aliud mentem, aliud animam.

Y diota. Puto certe. Nam alia est mens in se subsistens, alia in corpore. Mens in se subsistens aut infinita est aut infiniti ymago. Harum autem, que sunt infiniti ymago, cum non sint maxime et absolute seu 30 infinite in se subsistentes, posse aliquas ${ }^{f}$ ) animare humanum corpus admitto, atque tunc ex officio easdem animas ${ }^{\mathrm{g}}$ ) esse concedo.

Philosophus. Concedis igitur eandem esse mentem et hominis $\operatorname{animam}^{\mathrm{h}}$ ), mentem per se, animam ex officio.

$\mathrm{Y}$ diota. Concedo, uti ${ }^{\mathrm{i}}$ ) una est vis sensitiva et visiva oculi in animali.
a) dica korr. dicat $H s$.
b) inquam $H s$.
c) danach ac durch Streichung getilgt Hs.
e) tibi tu umgestellt $H s$.
d) über quam quam hinzugefügt $H s$.
g) eanden animam korr. easdem animas $H s$.
f) aliquas am Rand ergänzt Hs.
i) danach enim getilgt $H s$.
b) danach esse getilgt Hs. 
vorzulegen, um sie in ihrem Sinne zu erforschen; doch, da Du ja ein Laie bist, weiß ich nicht, wie ich Dich zum Sprechen bringen kann, um zu erfahren, welche Einsicht Du in die Natur des Geistes besitzest.

Laie. Ich glaube, daß niemand leichter als ich dazu bewogen werden könne, zu sagen, was er meint. Denn, da ich offen mich als unwissenden Laien bekenne, fürchte ich mich nicht zu antworten; die Schulphilosophen dagegen, die einen wissenschaftlichen Ruf besitzen, scheuen sich mit gutem Grunde, einen Fehler zu machen, und müssen daher ängstlich erwägen. Du wirst also von mir ohne Umschweife hören, was ich meine, sobald Du nur klar auseinandersetzest, worüber Du mich hören willst.

Philosoph. Mit wenigen Worten kann ich es nicht ausdrücken. Setzen wir uns also und besprechen die Sache der Reihe nach.

Laie. Es ist mir recht.

Und sie setzten ihre Stühle so, daß sie ein Dreieck bildeten. Darauf sagte der Redner:

Redner. Du siehst, Philosoph, die Einfalt dieses Mannes, der nichts von dem tut, was sich schickt, um einen so bedeutenden Mann wie Dich zu empfangen. Versuch es also zunächst mit den Dingen, die Dich, wie Du sagst, vor allem in geistige Unruhe versetzen. Nichts nämlich von dem, was er darüber weiß, wird Dir verborgen bleiben, und du wirst, wie ich glaube, gewahr werden, daß Du nicht umsonst hierher gekommen bist.

Philosoph. Das alles ist mir sehr recht, und ich werde zur Sache kommen. Du aber bitte, schweige indessen und laß Dich durch die Länge des Gesprächs nicht verdrießlich machen.

Redner. Du wirst bemerken, daß ich eher auf die Fortsetzung des Gesprächs dringen werde, als daß ich seiner überdrüssig würde.

Philosoph. Sag also Laie, denn so willst $\mathrm{Du}$ ja genannt werden, ob Du eine Vermutung über das Wesen des Geistes hast.

Laie. Ich glaube, daß es keinen vollkommenen Menschen gibt, noch gegeben hat, der sich nicht irgendeinen Begriff vom Geiste gebildet hätte. So habe denn auch ich einen und meine, daß es der Geist sei, von dem Maß und Grenze aller Dinge herstamme. Ich vermute also, da $\beta$ das Wort „,mens" sich vom Worte ",mensurare" herleite. einerlei?

Philosoph. Hältst Du Geist und Seele für verschieden oder

Laie. Ich glaube, daß sie verschieden seien; denn man muß unterscheiden zwischen dem Geiste, der in sich besteht, und dem, der im Körper ist. Der Geist, der in sich besteht, ist entweder unendlich, oder ein Bild des Unendlichen. Von den Geistern aber, welche nur ein Bild des Unendlichen sind, da-sie nicht auf die größte und absolute Weise an sich sind, können, wie ich zugebe, einige einen menschlichen Körper beleben (animare) und dann nenne ich sie infolge dieses ihres Amtes Seelen (animas).

Philosoph. Du gibst also zu, daß beim Menschen Geist und. Seele identisch seien, und du redest vom Geist, wenn er an sich ist, von Seele, wenn er seine Aufgabe, den Körper zu beleben, erfüllt.

Laie. Ja, wie ja auch das empfindende und das sehende Vermögen des Auges in einem Lebewesen eines sind.

Stu die I der Bibliothek Warburg ro: Cassirer. 
Secundus tractatus. Capitulum secundum.

Quomodo est vocabulum naturale et aliud impositum secundum illud citra precisionem; et quomodo est principium simplex, quod est ars arcium; et quomodo complicas.tur ars eterna philosophorum ${ }^{\mathrm{a}}$.)

Philoso phus. Aiebas mentem a mensurando dici. Hanc partem neminem legi tenuisse inter varias verbi dirivaciones; primo oro, ut causam dicti apperias.

Y diota. Si de vi vocabuli diligencius scrutandum est, arbitror vim | I $6 \mathrm{r}$. illam, que in nobis est, omnium rerum exemplaria nocionaliter compli11 cantem, quam mentem appello, nequaquam proprie nominari. Quemadmodum enim racio humana quidditatem operum Dei non attingit, sic nec vocabulum. Sunt enim vocabula motu racionis imposita. Nominamus enim unam rem vocabulo uno et per certam racionem et eandem alio ${ }_{15}$ per aliam $^{b}$ ), et una lingua habet propriora, alia magis barbara et remociora vocabula. Ita video, quod, cum proprietas vocabulorum recipiat magis et minus, vocabulum precisum ignorari.

Philosophus. Ad alta properas, ydiota, nam secundum illa, que dicere videris, ob hoc vocabula sunt minus propria, quia ad placitum opi${ }_{20}$ naris instituta, prout cuique imponenti ex racionis motu ocçurrebat.

Y diota. Volo, ut me profundius intelligas. Nam, et si fatear omne vocabulum eo ipso unitum, quo forma materie advenit, et verum sit formam adducere vocabulum, ut sic vocabula sint non ex imposicione, sed $a b$ eterno, et imposicio sit libera, tamen non arbitror aliud quam ${ }^{c}$ ) ${ }_{25}$ congruum nomen imponi, licet illud non sit precisum.

Philosophus. Fac te queso planiorem, ut quod velis capiam.

Ydiota. Perlibenter, et nunc me ad hanc artem cocleariam converto et primum volo, scias me absque hesitacione asserere omnes humanas artes ymagines quasdam esse infinite et divine artis; nescio, si tibi so idipsum videatur.

Philosophus. Tu alta exigis; neque phas est ad illa passim respondere.

Ydiota. Miror, si umquam philosophum legeris, qui hoc ignoraverit, cum de se pateat. Manifestum est enim nullam humanam artem

\footnotetext{
a) Secundus Tractatus - philosophorum am Rand ergänzt Hs.

b) per aliam am Rand hinzugefügt Hs.

c) quam über quam ergänzt Hs.
} 


\section{Kapitel.}

Es gibt ein Wort, das von Natur besteht und eines, das jenem entsprechend gesetzt ist, jedoch hinter der absoluten Bedeutung zurückbleibt, und es gibt ein einfaches Prinzip, das die Kunst der Künste ist, und es wird zu zeigen sein, auf welche Weise die ewige Kunst der Philosophen zur Einheit kommt.

Philosoph. Du sagtest, daß das Wort ,,mens“" sich von ,"mensurare" herleitet. Ich habe niemals gelesen, da $\beta$ jemand bei den doch so verschiedenen Ableitungen des Wortes diese Ansicht vertreten hätte; zunächst wünsche ich, daß Du mir den Grund dessen, was du sagtest, eröffnest.

Laie. Wenn es unsere Aufgabe ist, über die Bedeutung dieses Wortes tiefere Nachforschungen anzustellen, so glaube ich, daß jenes Vermögen in uns, das die Urbilder aller Dinge auf begriffliche Weise in sich befaßt, und das ich durch das Wort Geist bezeichne, niemals im eigentlichen Sinne benannt werden könne. Wie nämlich der menschliche Verstand die Wesenheit der göttlichen Werke niemals erreichen kann, so erreicht sie auch das Wort nicht. Denn die Worte sind durch einen Akt des Verstandes gesetzt. Wir benennen nämlich eine Sache durch ein bestimmtes Wort in einem bestimmten Sinne und dann dieselbe Sache durch ein anderes Wort und in einem anderen Sinne. Und die eine Sprache hat Worte, die mehr den eigentlichen Sinn treffen, die andere Worte von gröberer und undeutlicherer Prägung. So meine ich, daß darum, weil es die Eigentümlichkeit des Wortes ist, eines „,Mehr" und „Weniger" fähig zu sein, das präzise Wort nicht gewußt werden kann.

Philosoph. Zu großen Dingen versteigst Du Dich da, Laie; denn nach dem, was Du sagst, sind darum die Worte weniger genau und treffend, weil sie, wie Du meinst, nach Willkür festgesetzt sind, je nachdem, wie es dem, der sie infolge eines Verstandesaktes prägte, in den Sinn kam.

Laie. Ich wünschte, daß du mich tiefer verstündest. Denn ich muß bekennen, daß jedes Wort durch eben das geeint ist, wodurch die Form an die Materie herantritt, und daß die Form das Wort hervorbringt, so $\mathrm{da} B$ auf diese Weise die Worte nicht von einer Setzung herstammen, sondern von Ewigkeit sind, während die Setzung frei ist. Ich glaube demnach, daß jeder Name der Sache, die er bezeichnet, in irgend einer Weise angemessen ist, wenngleich er nicht präzis zu sein braucht.

Philosoph. Drück Dich noch deutlicher aus, damit ich verstehe, was Du meinst.

Laie. Sehr gern; und zwar werde ich mich jetzt der Betrachtung der Kunst des Löffelschnitzens zuwenden. Zunächst also wisse, daß ich ohne Zögern behaupte, daß alle menschlichen Künste Abbilder seien der unendlichen und göttlichen Kunst. Und ich weiß nicht, ob es sich für Dich auch so darstellt.

Philosoph. Das ist eine schwierige Frage, und es geht nicht an, auf solche Dinge nebenhin zu antworten.

Laie. Ich sollte mich wundern, wenn Du jemals einen Philosophen gelesen hättest, der das nicht gewußt hätte, da es doch aus sich selbst klar ist. Denn es ist doch klar, daß keine menschliche Kunst die Genauig- 
perfeccionis precisionem attigisse, omnemque finitam esse et terminatam. Terminatur enim ars una in suis terminis, alia in aliis suis, et quelibet est alia ab aliis, et nulla omnes complicat.

Philosophus. Quid ex hoc inferes ${ }^{a}$ ).

$5 \quad$ Ydiota. Artem omnem humanam finitam.

Philosophus. Quis hesitat.

Y diota. Impossibile est autem plura esse infinita realiter distincta.

Philosophus. Et hoc ipsum fateor, quoniam alterum foret in altero finitum.

10 Ydiota. Si igitur hoc sic est, nonne solum absolutum principium est infinitum, quia ante principium non est principium, ut de se patet, ne principium sit principiatum. Hinc eternitas est ipsa sola infinitas seu principium absolutum.

Philosophus. Admitto.

15 Ydiota. Est igitur sola et unica absoluta eternitas ipsa infinitas, que est sine principio. Quare omne finitum principiatum ab infinito principio.

Philosophus. Negare nequeo.

Ydiota. Omnis ergo ars finita ab arte infinita; sicque necesse erit 20 infinitam artem omnium artium exemplar esse principium, medium ${ }^{\text {b) }}$, finem, metrum, mensuram, veritatem, precisionem et perfeccionem.

Philosophus. Prosequere, ad que properas, quia nemo hiis dissentire potest.

Ydiota. Applicabo igitur ex hac coclearia arte symbolica para${ }_{25}$ digmata, ut sensibiliora fiant, que dixero.

Philosophus. Rogo sic agas; video enim te viam tenere ad ea, ad que anhelo.

Y diota sumpto cocleari ad manum aiebat: Coclear extra mentis r16 v. nostre ydeam | aliud non habet exemplar. Nam, et si statuarius aut 30 pictor trahat exemplaria a rebus, quas figurare satagit, non tamen ego, qui ex lignis coclearia et scutellas et ollas ex luto educo; non enim in hoc ymitor figuram cuiuscunque rei naturalis; tales enim forme cocleares, scutellares et ollares sola humana arte perficiuntur. Unde ars mea est magis perfectoria quam ${ }^{c}$ ) ymitatoria figurarum creatarum et in hoc 35 infinite arti similior.

Philosophus. Placet idipsum.
a) infers korr. inferes $\mathrm{Hs}$.
b) danach et getilgt Hs.
c) über quam quam hinzugefügt $H s$. 
keit der Vollendung erreicht, daß vielmehr jede von ihnen begrenzt und beschränkt ist. Denn jede Kunst hat Grenzen, die ihr speziell zugemessen sind und keine einzelne Kunst umfaßt alle Künste.

Philosoph. Was schließt du daraus?

Laie. Daß alle menschliche Kunst endlich sei.

Philosoph. Wer könnte daran zweifeln?

Laie. Es ist aber unmöglich, daß es mehrere Unendliche geben könnte, die voneinander real unterschieden wären.

Philosoph. Auch das gebe ich zu, da dann das Eine in dem Anderen begrenzt sein würde.

Laie. Wenn dem also so ist, ist dann nicht allein das absolute Prinzip unendlich, da es vor einem Prinzip kein Prinzip geben kann, wie es sich von selbst versteht, damit das Prinzip nicht wiederum unter einem Prinzip stehe? Darum ist nur die Ewigkeit selbst Unendlichkeit oder absolutes Prinzip.

Philosoph. Ich gebe es zu. Es gibt also eine alleinige und einzig absolute Ewigkeit, die Unendlichkeit selbst, die unter keinem Prinzip steht. Daher steht alles Endliche unter einem unendlichen Prinzip.

Philosoph. Ich räume es ein.

Laie. Alle endliche Kunst stammt also von einer unendlichen Kunst $a b$, und so ergibt es sich denn notwendig, daß die unendliche Kunst das Urbild aller Künste sei, ihr Anfang, ihre Mitte und ihr Ende, ihr Maß und ihr Maßstab, ihre Wahrheit, Genauigkeit und Vollendung.

Philosoph. Verfolge dein Ziel, da niemand Deinen Behauptungen widersprechen kann.

Laie. So werde ich denn symbolische Beispiele aus der Kunst des Löffelschnitzens verwenden, damit meine Worte faßlicher werden.

Philosoph. Ich bitte Dich, das zu tun; denn ich sehe, daß Du auf das ausgehst, was ich erstrebe.

Der Laie nahm einen Löffel zur Hand und sprach:

Laie. Der Löffel hat außer der Idee in unserem Geiste kein anderes Urbild; denn, wenngleich der Bildhauer wie der Maler ihre Vorbilder von den Dingen hernehmen, die nachzuahmen sie bestrebt sind, so trifft auf mich das nicht zu, der ich aus Holz Löffel, Schalen und Töpfe aus Lehm verfertige; denn bei dieser Tätigkeit ahme ich keine Gestalt von irgendeinem natürlichem Dinge nach; denn solche Formen von Löffeln, Schalen und Töpfen werden allein vermöge der menschlichen Kunst zustande gebracht. Daher ist meine Kunst vollkommener, als die Kunst, welche Gestalten von Geschöpfen nachahmt, und darum der unendlichen Kunst näher verwandt.

Philosoph. Das ist von selbst klar. 
Y diota. Esto igitur, quod artem explicare et formam coclearitatis, per quam coclear constituitur, sensibilem facere velim, que cum in sua natura nullo sensu sit attingibilis, quia nec alba nec nigra aut alterius coloris vel vocis vel odoris vel gustus vel tactus, conabor tamen eam modo, 5 quo fieri potest, sensibilem facere. Unde materiam, puta ${ }^{a}$ ) lignum, per instrumentorum meorum, que applico, varium motum dolo et cavo, quousque in eo proporcio debita oriatur, in qua forma coclearitatis convenienter resplendeat. Sic vides formam coclearitatis simplicem et insensibilem in figurali proporcione huius ${ }^{b}$ ) ligni quasi in ymagine eius resplendere. ${ }_{10}$ Unde veritas et precisio coclearitatis, que est immultiplicabilis et incommunicabilis, nequaquam potest per quecunque eciam instrumenta et quemcunque hominem perfecte sensibilis fieri, et in omnibus coclearibus non nisi ipsa simplicissima forma varie relucet, magis in uno et minus in alio et in nullo precise. Et quamvis lignum recipiat nomen ab adventu 15 forme, ut orta proporcione, in qua coclearitas resplendet, coclear nominetur, ut sic nomen sit forme unitum, tamen imposicio nominis fit ad beneplacitum, cum aliud imponi posset, sic, et si ad beneplacitum ${ }^{\mathrm{c}}$ ), tamen non aliud et penitus diversum a naturali nomine forme unito, sed vocabulum naturale post forme adventum in omnibus variis nominibus per 20 quascunque naciones varie impositis relucet. Imposicio igitur vocabuli fit motu racionis, nam motus racionis est circa res, que sub sensu cadunt, quarum discrecionem, concordanciam et differenciam racio facit, ut nichil sit in racione, quod prius non fuit in sensu. Sic igitur vocabula imponit et movetur racio ad dandum hoc nomen uni et aliud alteri rei. 25 Verum, cum non reperiatur forma in sua veritate in hiis, circa que racio versatur, hinc racio in coniectura et opinione occumbit. Unde genera et species, ut sub vocabulo cadunt, sunt encia racionis, que sibi racio fecit ex concordancia et differencia sensibilium. Quare, cum sint posterius natura rebus sensibilibus, quarum sunt similitudines, tunc sensibilibus so destructis remanere nequeunt. Quicunque igitur putat nichil in intellectum cadere posse, quod non cadat in racione, ille eciam putat nichil posse esse in intellectu, quod prius non fuit in sensu, et hic necessario dicere habet rem nichil esse, nisi ut sub vocabulo cadit et huius ${ }^{b}$ ) studium est in omni inquisicione quid nominis profundare. Et hec inquisicio grata est ho-

\footnotetext{
a) puto korr. puta $H s$.

b) hius $H s$.

c) bene am Rand ergänzt Hs.
} 
Laie. Gesetzt also den Fall, daß ich eine Kunst entfalten und die Form der Löffelheit, durch welche ein Löffel entsteht, sinnlich machen will - obwohl diese Form ihrer Natur nach durch keinen der Sinne erfaßbar ist, da sie weder weiß noch schwarz noch von irgendeiner anderen Farbe ist, noch von irgendeinem Ton oder Geruch, Geschmack oder Gefühl - so bin ich doch bestrebt, sie, soweit das möglich ist, sinnlich zu machen. Daher bearbeite ich die Materie, d. h. in diesem Falle das Holz, und höhle es aus vermöge der verschiedenartigen Bewegungen meiner Werkzeuge, die ich in Anwendung bringe, bis in ihm das gebührende Verhältnis der Masse entsteht, in dem sich die reine Form der Löffelheit angemessen widerspiegelt. So siehst Du denn, daß die einfache und unsinnliche Form der Löffelheit in dem Maßverhältnis dieses Holzes sich widerspiegelt, gleichsam wie in einem Bilde. Daher kann das wahre Sein und die wahre Bestimmtheit der Löffelheit, die nicht vervielfältigt werden und nicht wirklich übertragen werden kann, niemals durch irgendwelche Werkzeuge, noch durch irgendeinen Menschen in wahrhafter Vollendung sinnlich gemacht werden. Und in allen einzelnen Löffeln leuchtet nur die einfachste Form selbst auf verschiedene Weise hervor, mehr in dem einen, weniger in dem anderen und in keinem in voller Entsprechung. Und obwohl das Holz selbst seinen Namen von der an es herangebrachten Form hat, so daß, wenn diejenigen Maßverhältnisse zustande gekommen sind, in denen sich die reine Löffelheit widerspiegelt, man dann von einem Löffel redet, dergestalt, daß hier reine Form und Name in eins gesetzt worden sind, so geschieht dennoch die Namensaufprägung nach Gutdünken, weil ein andrer Name geprägt werden könnte. Denn obschon der Name nach Gutdünken gewählt ist, so ist er dennoch im Hinblick auf den natürlichen Namen, der mit der Form eins ist, nicht etwas völlig anderes und gänzlich verschiedenes, sondern der natürliche Name (vocabulum) leuchtet nach Hinzutreten der Form in allen verschiedenen Namen, welche doch durch alle Völker verschieden geprägt wurden, wieder auf. Die Prägung des Namens geschieht also durch einen Akt des Verstandes; denn die Tätigkeit des Verstandes bezieht sich auf die Dinge, die den Sinnen erscheinen. Der Verstand bewirkt nur deren Unterscheidung, Übereinstimmung und Verschiedenheit, so, daß es nichts im Reiche des Verstandes gibt, was nicht vorher in den Sinnen gewesen wäre. So also prägt der Verstand Namen, und wird dazu veranlaßt, dem einen Dinge jenen, dem anderen einen anderen Namen zu verleihen. Da aber die reine Form in ihrer Wahrheit nicht in dem aufgefunden wird, worauf sich der Verstand bezieht, so verfällt daher der Verstand der Vermutung und der Meinung. Von diesem Gesichtspunkte aus sind Arten und Gattungen, so wie sie unter einem Namen begriffen werden, Geschöpfe des Verstandes, die sich der Verstand gebildet hat, aus der Übereinstimmung und der Verschiedenheit der Sinnendinge. Daher können sie nicht bestehen bleiben, wenn die Sinnendinge zerstört sind, da sie ihrer Natur nach später sind als die Sinnendinge und bloß deren Ähnlichkeiten darstellen. Wer also glaubt, daß nichts in die Vernunft eingehen könne, was nicht in den Verstand eingeht, der glaubt auch, daß nichts in der Vernunft sein könne, was nicht vorher in den Sinnen gewesen sei; und der muß notwendig sagen, 
I17 r. mini, | quia motu racionis discurrit; hic negaret formas in se et in sua veritate separatas esse aliter, quam ut sunt encia racionis, et exemplaria ac ydeas nichili faceret. Qui vero in mentis intelligencia aliquid esse admittunt, quod non fuit in sensu nec in racione, puta exemplarem et in${ }^{5}$ communicabilem $^{\text {a) }}$ veritatem formarum, que in sensibilibus relucent, hii dicunt exemplaria natura precedere sensibilia sicut veritas ymaginem, et ordinem dant talem, ut primo ordine nature sit humanitas in se et ex se scilicet absque preiacenti materia, deinde homo per humanitatem et quod ibi cadat sub vocabulo, deinde species in racione. Unde destruc10 tis omnibus hominibus humanitas, ut est species, que sub vocabulo cadit et est ens racionis, quod racio venata est ex similitudine hominum, subsistere nequit, nam ab hominibus dependebat, qui non sunt, sed propter hoc non desinit esse humanitas, per quam fuerunt homines; que quidem humanitas non cadit sub vocabulo speciei, prout vocabula motu racionis ${ }^{15}$ sunt imposita, sed est veritas speciei illius sub vocabulo cadentis. Unde ymagine destructa manet in se veritas. Et hy omnes negant rem non aliud esse, quam $^{\mathrm{b}}$ ) ut cadit sub vocabulo; eo enim modo, ut sub vocabulo cadit, de rebus fit logica et racionalis consideracio. Quare illam logice inquirunt, profundant et laudant, sed ibi non quiescunt, quia racio ${ }^{20}$ seu logica circa ymagines formarum tantum versatur ${ }^{\mathrm{c}}$ ), sed res ultra vim vocabuli theologice intueri conantur et ad exemplaria et ydeas se convertunt. Arbitror non posse plures inquisicionum modos dari, si tu, qui es philosophus, alias legisti, scire potes, ego sic conicio. ${ }^{d}$ )

Philosophus. Mirabiliter omnes omnium tangis philosophorum 25 sectas, Peripatheticorum et Achademicorum.

Y diota. Hee omnes et quotquot cogitari possent modorum differencie facillime ${ }^{\mathrm{e}}$ ) resolvuntur eț concordantur, quando mens se ad infinitatem elevat. Nam sicut orator hic presens tibi lacius ex hiis, que a me habet, explanabit, tunc infinita forma est solum una et simplicissima, que in ${ }_{30}$ omnibus rebus resplendet tamquam omnium et singulorum formabilium adequatissimum exemplar. Unde verissimum erit non esse multa separata exemplaria ac multas rerum ydeas, quam quidem infinitam formam nulla racio attingere potest. Hinc per omnia vocabula racionis motu

a) incommunicabilem über der Zeile korr. Hs.

b) über quam quam hinzugefügt $H s$. c) versantur korr. versatur $H s$.

d) Connicio Hs. Am Rand Capitulum tertium. Quomodo intelligantur et concordentur philosophi; et de nomine Dei et precisione; ac quomodo uno preciso nomine cognito omnia cognoscuntur; et de sufficiencia scibilium; et quomodo differunt conceptus Dei et noster. getilgt $H s . \quad$ e) facilime $H s$. 
daß ein Ding nur dann etwas sei, wenn es unter ein Wort fällt und dessen Bestrebung muß es sein, immer tiefer in den Sinn des Namens zu dringen. Und eine solche Art der Forschung ist dem Menschen angenehm, weil er vermöge dieser Bewegung des Verstandes die Erscheinungen durchläuft. Ein solcher Mensch würde leugnen, daß es Formen an sich gäbe, die in ihrer eigentümlichen Wahrheit für sich bestünden, auf eine andere Weise, als daß sie bloße Wesenheiten des Verstandes seien, und er würde Urbilder und Ideen für nichts achten. Die aber, welche zugeben, daß es in der Vernunft des Geistes etwas gibt, das nicht in den Sinnen noch im Verstande gewesen ist, d. h. daß es ein Urbild und eine nicht ablösbare Wahrheit der reinen Form gibt, welche in den Sinnendingen wieder aufleuchtet, die sagen, daß die Urbilder ihrer Natur nach den Sinnendingen vorausgehen, wie die Wahrheit ihrem Nachbilde vorausgeht. Und sie ordnen in der Weise, daß an erster Stelle der natürlichen Ordnung die Menschheit in sich und an sich selbst steht, $d$. h. ohne zugrunde liegende Materie, an zweiter der Mensch, insofern er durch die Menschheit bestimmt ist und somit unter den Namen fällt, an dritter der Artbegriff, wie der Verstand ihn bildet. Daher hört nach Vernichtung aller einzelnen Menschen die Menschheit als bloßer Artbegriff, der unter den Namen fällt und bloß ein Werk des Verstandes ist, auf. Denn diesen Begriff hat der Verstand nur zufolge bloßer Ähnlichkeit unter den Einzelmenschen gebildet. Der Begriff hing daher von den einzelnen Menschen, die nun nicht mehr sind, ab. Doch darum hört die Menschheit an sich nicht auf $\mathrm{zu}$ bestehen, vermöge welcher sie doch erst zu Menschen geworden sind; und sie fällt nicht unter das Wort, also den Artbegriff, da ja die Worte durch einen Akt des Verstandes gesetzt sind, sondern ist vielmehr die Wahrheit jenes Artbegriffs, der unter das Wort fällt. Daher bleibt denn auch, wenn das Bild zerstört ist, die Wahrheit an sich bestehen. Und die alle, die das meinen, bestreiten insgesamt, da $B$ das Wesen eines Dinges in nichts anderem bestehe, als da $\beta$ es unter einen Wortbegriff falle. Insofern nämlich die Dinge unter einen Wortbegriff fallen, sind sie Gegenstand der Logik und der Verstandesbetrachtung. Daher untersuchen sie die Dinge im logischen Sinne, vertiefen sich in diese Beschäftigung und loben sie, bleiben aber bei dieser Art der Betrachtung nicht stehen, weil der Verstand und die Logik sich nur mit den Bildern der Form beschäftigen, sondern sie versuchen, dieDinge über die bloße Wortbedeutung hinaus auf theologische Weise zu erschauen und wenden sich zu den Urbildern und Ideen. Ich glaube, daß es nicht mehr Arten der Betrachtung geben könne; wenn Du als Philosoph das auch anderswo gelesen hast, kannst $\mathrm{Du}$ es ja bestimmt wissen. Ich vermute es, so wie ich es sagte.

Philosoph. In ganz vortrefflicher Weise hast Du die Lehren aller Philosophenschulen, seien es Peripatetiker oder Akademiker, gestreift.

Laie. Diese verschiedenen Richtungen und so große Verschiedenheiten der Lehrmeinungen nur denkbar sind, werden ohne Mühe aufgelöst und in eins gebracht, wenn der Geist sich zur Unendlichkeit erhebt. Denn wie Dir der hier anwesende Redner in größerer Ausführlichkeit, gemäß dem, was er von mir gehört hat, auseinandersetzen wird, gibt es dann nur eine unendliche und einzige Form von größter Einfachheit, die in allen Dingen ihren Widerschein findet, gleichsam das vollkommenste 
imposita ineffabilis non comprehenditur. Unde res, ut sub vocabulo cadit, ymago est ineffabilis exempli sui proprii et adequati. Unum est igitur verbum ineffabile, quod est precisum nomen omnium rerum, ut motu racionis sub vocabulo cadunt, quod quidem ineffabile nomen in omnibus nominibus 5 suo modo relucet quia infinita nominabilitas omnium nominum et infinita vocalitas omnium voce expressibilium, ut sic omne nomen sit ymago precisi nominis, et nichil aliud omnes ${ }^{a}$ ) conati sunt dicere, licet forte id, quod dixerunt, melius et clarius dici posset. Omnes enim necessario con${ }_{117} \mathrm{v}$. cordarunt, unam esse infinitam virtutem, quam Deum / dicimus, in qua 10 necessario omnia complicantur, neque ille aliud dicere voluit, qui aiebat humanitatem, ut non cadit sub vocabulo, esse precisionem veritatis, quam ineffabilem illam infinitam formam, quam, dum ad humanam formam respicimus, eius precisum exemplar nominamus, ut sic ineffabilis, dum ad eius ymagines intuemur, omnium nominibus nominetur et unum sim15 plicissimum exemplar secundum exemplatorum specificas differencias per racionem nostram ${ }^{b}$ ) formatas plura esse exemplaria videatur.

Capitulum tercium.

Quomodo intelligantur et concordentur philosophi; et de nomine Dei et precisione; ac quomodo uno preciso ${ }^{c}$ ) no${ }_{20}$ mine cognito omnia cognoscuntur; et de sufficiencia scibilium; et quomodo differunt conceptus Dei et noster. ${ }^{d}$ )

Philosophus. Mirabiliter Trismegisti dictum dilucidasti, qui aiebat Deum omnium rerum nominibus ac omnes res Dei nomine nominari. ${ }^{1}$ )

${ }_{25}$ Y diota. Complica nominari et nominare in coincidenciam altissimo intellectu et omnia patebunt, nam Deus est cuiuscunque rei precisio. Unde si de una re precisa sciencia haberetur, omnium rerum sciencia necessario haberetur. Sic si precisum nomen unius rei sciretur, tunc et omnium rerum nomina scirentur, quia precisio citra Deum non est. Hinc qui pre30 cisionem unam attingeret, Deum attingeret, qui est veritas omnium scibilium.

Orator. Declara queso de precisione nominis.
a) omnes am Rand ergänzt Hs.
b) nostram am Rand ergänzt Hs.
c) preciso korr. Hs.
d) Capitulum tercium - noster. am Rand hinzugefügt Hs.
I) cf. Herm. Trismeg. Poemander Parthey c. 5, p. 47. 
Vorbild aller einzelnen möglichen Formungen. Daher wird es wohl auch sicherlich wahr sein, da $\beta$ es weder viele getrennte Urbilder noch viele Ideen der Dinge gibt. Diese unendliche Form kann freilich kein Verstand erreichen. Und daher kann sie durch alle Worte, die ja nur durch einen Akt des Verstandes gesetzt sind, nicht begriffen werden. So ist das Ding, wie es unter den Wortbegriff fällt, nur ein Bild seines unsagbaren Urbilds, welches nur sich selbst gehört und genau entspricht. Es gibt also ein unsagbares Wort, das der genaue Name aller Dinge ist, insoweit sie durch einen Akt des Verstandes unter einen Wortbegriff fallen. Dieser unsagbare Name scheint in allen Namen auf seine Weise wieder; denn er ist die unendliche Benennbarkeit in allen Namen und die Verlautbarkeit von allem, was durch den Laut ausgedrückt werden kann, so daß jeder einzelne Name nur ein Bild des wirklich genauen Namens ist. Und nichts anderes haben alle anderen insgesamt sagen wollen, selbst wenn das, was sie gesagt haben, vielleicht besser und klarer ausgedrückt werden könnte. Alle sind nämlich notwendigerweise darin einig gewesen, daß es eine unendliche Kraft gäbe, die wir Gott nennen, und in der alles andere beschlossen liegt. Und der Mann, der sagte, daß die Menschheit, insoweit sie nicht unter den Wortbegriff fällt, die Wahrheit in ihrer vollen Genauigkeit sei, wollte nichts anderes sagen, als daß sie die unsagbare und unendliche Form sei, die wir in Hinsicht auf die menschliche Form als deren präzises Urbild bezeichnen. Daraus ergibt sich, daß diese Form, als solche unaussprechlich, mit dem Namen aller Dinge benannt wird, insofern wir auf ihre Abbilder hinsehen, und daß jenes eine und einfachste Urbild zufolge des spezifischen Unterschiedes seiner Abbilder, die durch unseren Verstand gebildet sind, sich uns so darstellt, als ob es nicht ein Urbild, sondern mehrere Urbilder gäbe.

\section{Kapitel.}

Inwiefern die Philosophen sich verstehen und miteinander in Einklang sind. - Über den Namen Gottes und seine genaue Bestimmung; ferner wird gezeigt, daß, wenn ein Name in völliger Bestimmung bekannt ist, alles erkannt werden kann. - Es wird gezeigt, wie alles Wißbare sich selbst genügt und wie unser und Gottes Begriff unterschieden sind.

Philos oph. Mit bewundernswertem Scharfsinn hast Du einen Ausspruch des Trismegistus erhellt, welcher sagte, daß Gott mit dem Namen aller Dinge, und alle Dinge mit dem Namen Gottes genannt würden.

Laie. Fasse Benanntwerden und Benennen in der Weise in Eines, $\mathrm{da} ß$ sie in der höchsten Vernunft koinzidieren, dann wird alles klar sein; denn Gott ist die genaue Bestimmtheit eines jeden Dinges. Hätte man also von einem einzgen Dinge ein genau bestimmtes Wissen, so würde man damit notwendigerweise Wissen von allen Dingen überhaupt besitzen. So würde man die Namen aller Dinge überhaupt wissen, wenn man nur den genau bestimmten und exakten Namen eines einzigen Dinges kennte, da es genaue Bestimmtheit außer in Gott nicht gibt. So würde denn der, welcher nur eine einzige genaue Bestimmung erreichte, Gott selbst erreichen, welcher die Wahrheit alles Wißbaren überhaupt ist.

Redner. Erkläre doch genauer, was Du unter der genauen Bestimmtheit des Namens verstehst. 
Ydiota. Tu nosti, orator, quomodo nos exerimus ex vi mentis mathematicales figuras. Unde, dum triangularitatem visibilem facere voluero, figuram facio ${ }^{a}$ ), in qua tres angulos constituo, ut tunc in figura sic habituata et proporcionata triangularitas reluceat, cum qua unitum $\checkmark$ est vocabulum, quod ponatur esse trigonus. Dico igitur, si trigonus est precisum vocabulum figure triangularis, tunc scio precisa vocabula omnium poligoniarum, scio enim tunc, quod $^{\mathrm{b}}$ ) figure quadrangularis vocabulum esse debet tetragonus et quinquangularis pentagonus et ita deinceps; et ex noticia nominis unius agnosco figuram nominatam et omnes 10 nominabiles poligonias et differencias et concordancias earundem et quidquid circa hoc sciri potest. Pariformiter aio, quod, si scirem precisum nomen unius operis Dei, omnia nomina omnium Dei operum et quidquid sciri posset non ignorarem et, cum verbum Dei sit precisio omnis nominis nominabilis, solum in verbo omnia et quodlibet sciri posse constat.

Orator. Palpabiliter more tuo explanasti.

Philosophus. Miram doctrinam tradidisti, ydiota, omnes philosophos concordandi, nam, dum adverto, non possum nisi tecum consentire non voluisse omnes philosophos aliud dicere quam idipsum, quod dixisti per hoc, quod nemo omnium negare potuit Deum infinitum, in quo solo 20 dicto $^{c}$ ) omnia, que dixisti, complicantur. Mirabilis est hec sufficiencia omnium scibilium et quomodocunque tradi possibilium. Amplius ad mentis tractatum descende et dicito. Esto, quod mens a mensura dicatur, ut racio mensuracionis sit causa nominis, quid mentem esse velis.

Ydiota. Scis, quomodo simplicitas divina omnium rerum est com${ }_{25}$ plicativa. Mens est huius complicantis simplicitatis ymago. Unde si hanc divinam simplicitatem infinitam mentem vocitaveris, erit ipsa nostre mentis exemplar. Si mentem divinam universitatem veritatis rerum | II 8 r. dixeris, nostram dices universitatem assimilacionis rerum, ut sit nocionum universitas. Concepcio divine mentis est rerum produccio, concepcio ${ }_{30}$ nostre mentis est rerum nocio. Si mens divina est absoluta entitas, tunc eius concepcio est encium creacio, et nostre mentis concepcio est encium assimilacio, que enim divine menti ut infinite conveniunt veritati, nostre conveniunt menti ut propinque eius ymagini. Si omnia sunt in mente divina ut in sua precisa et propria veritate, omnia sunt in mente nostra

\footnotetext{
a) figuram facere voluero korr. figuram facio $H s$.

b) quod über der Zeile evgänzt Hs.

c) dicto am Rand ergänzt Hs.
} 
Laie. Du weißt doch, Redner, auf welche Weie wir vermöge des Geistes mathematische Figuren zustande bringen. Wenn ich das Wesen des Dreiecks sichtbar machen will, mache ich eine Figur, in welcher ich drei Winkel konstruiere, in der Weise, daß dann in der Figur, die sich in dieser Weise verhält und diesen Maßen gemäß geformt ist, das reine Wesen des Dreiecks hervorleuchtet. Mit diesem Wesen des Dreiecks fällt dasjenige Wort zusammen, welches als Name für das Dreieck gesetzt wird. Wenn ich also das „Dreieck“, das das exakte Wort für eine dreiwinklige Figur ist, kenne, dann kenne ich, so sage ich, die genaue und exakte Wortbezeichnung aller Vielecke; dann weiß ich nämlich, $\mathrm{da} ß$ das Wort für eine vierwinklige Figur Viereck, für eine fünfwinklige Figur Fünfeck sein muß usf. Aus der Kenntnis des einen Namens erkenne ich sowohl die benennbare Figur, wie überhaupt alle benennbaren Vielecke, ihre Verschiedenheiten und Gleichheiten, und was darüber überhaupt wißbar ist. In gleicher Weise würde ich, wie ich behaupte, alle Namen von allen Schöpfungen Gottes und, was über sie überhaupt gewußt werden kann, genau kennen, wenn ich nur den Namen einer einzigen von ihnen wüßte; und, da das Wort Gottes die genaue Bestimmung jedes überhaupt nennbaren Namens ist, kann allein in diesem Worte alles und jedes gewußt werden.

Redner. Das hast Du nach deiner Art deutlich auseinandergesetzt.

Philosoph. Eine wunderbare Belehrung von der Übereinstimmung aller Philosophen hast Du uns da vermittelt. Denn, wenn ich es mir recht überlege, muß ich mit Dir darin übereinstimmen, daß alle Philosophen gerade das haben sagen wollen, was Du sagtest; denn wie du ja sagtest, hat keiner von ihnen bestreiten können, daß Gott unendlich sei; und in dieser einen Aussage, ist ja alles, was du sagtest, beschlossen; wunderbar ist es doch, wie auf diese Weise alles Wißbare und irgendwie Mitteilbare sich selbst genügt. Gehe aber weiter in der Betrachtung des Geistes und sprich! Denn gesetzt, daß das Wort Geist (mens) sich vom Worte Messen (mensurare) herleitet, so daß das Verfahren der Messung der Grund des Namens ist, was soll dann eigentlich der Geist sein?

Laie. Du weißt, auf welche Weise die göttliche Einfaltung alle Dinge in sich befaßt. Der Geist ist nun das Bild jener alles umfassenden Einfachheit. Wenn Du daher diese göttliche Einfachheit den unendlichen Geist nennst, dann ist dieser nichts anderee als das Urbild unseres Geistes. Wenn Du den göttlichen Geist den allgemeinen Inbegriff der Wahrheit der Dinge nennst, dann wirst Du den unseren den allgemeinen Inbegriff der Angleichung an die Dinge nennen, so, daß er ein Inbegriff der Begriffe ist. Das Begreifen des göttlichen Geistes ist Schöpfung von Dingen, das Begreifen unseres Geistes ist der Begriff der Dinge. Wenn der göttliche Geist absolutes Sein ist, dann ist sein Begreifen Schöpfung von Seiendem, und das Begreifen unseres Geistes Angleichung an das Seiende; was nämlich dem göttlichen Geiste zukommt, als einer unendlichen Wahrheit, kommt unserem Geiste zu als einem Dinge, das mit ihm verwandt ist. Wenn alles im göttlichen Geiste ist, als in seiner genauen und eigentümlichen Wahrheit, dann ist alles in unserem Geiste als in einer 
ut in ymagine seu similitudine proprie veritatis, hoc est nocionaliter; similitudine enim fit cognicio. Omnia in Deo sunt, sed ibi rerum exemplaria, omnia in nostra mente, sed ibi rerum similitudines ${ }^{a}$ ). Sicut Deus est entitas absoluta, que est omnium encium complicacio, sic mens nostra 5 est illius entitatis infinite ymago, que est omnium ymaginum complicacio, quasi ignoti regis prima ymago est omnium aliarum secundum ipsam depingibilium exemplar. Nam Dei noticia seu facies non nisi in natura mentali, cuius veritas est obiectum, descendit et non ulterius nisi per mentem, ut mens sit ymago Dei et omnium Dei ymaginum post ipsum 10 exemplar. Unde quantum omnes res post simplicem mentem de mente participant, tantum et de Dei ymagine, ut mens sit per se Dei ymago et omnia post mentem non nisi per mentem.

\section{Tractatus quartus. ${ }^{\mathrm{b}}$ ) Capitulum quartum.}

Quomodo mens nostra non est explicacio, sed ymago 15 complicacionis eterne, sed que post mentem sunt, non sunt ymago; et quomodo est sine nocionibus habens tamen iudicium concreatum; et cur est corpus sibi necessarium..$^{\circ}$ )

Philosophus. Videris ex multa mentis tue plenitudine dicere velle mentem infinitam esse vim formativam absolutam, sic mentem finitam 20 vim conformativam seu configurativam.

Ydiota. Volo quidem hoc modo, nam quod dicendum est convenienter exprimi nequit, hinc multiplicacio sermonum perutilis est. Attende aliam esse ymaginem, aliam explicacionem, nam equalitas est unitatis ymago. Ex unitate enim semel oritur equalitas. Unde unitatis 25 ymago est equalitas, et non est equalitas unitatis explicacio, sed pluralitas. Complicacionis igitur unitatis equalitas est ymago, non explicacio, sic volo mentem esse ymaginem divine mentis simplicissimam inter omnes ymagines divine complicacionis. Et ita mens est ymago complicacionis divine prima omnes ymagines complicacionis sua simplicitate et virtute 30. complicantis. Sicut enim Deus est complicacionum complicacio, sic mens, que est Dei ymago, est ymago complicacionis complicacionum. Post ymagines sunt pluralitates rerum divinam complicacionem explicantes, sicut numerus est explicativus unitatis et motus quietis et tempus eterni-

\footnotetext{
a) similitudines rerum korr. rerum similitudines $H s$.

b) am Rand hinzugefügt Hs.

c) Capitulum - necessarium, am Rand hinzugefügt Hs.
} 
bildlichen, bzw. ähnlichen Darstellung der eigentümlichen Wahrheit, d.h. in der Form des Begriffes; denn Ähnlichkeit bringt Erkenntnis hervor. Alles ist in Gott, aber dort sind die Urbilder der Dinge; alles ist in unserem Geiste, aber in ihm sind nur die Ähnlichkeiten der Dinge. Wie Gott absolutes Sein ist, welches die Zusammenfassung von allem Seienden ist, so ist unser Geist das Bild jenes unendlichen Seins und ist so die $\mathrm{Zu}$ sammenfassung aller Bilder; in gleicher Weise wie das ursprüngliche Bild eines Königs, der nicht bekannt ist, als Urbild dient, für alle anderen, die nach ihm gemalt werden. Denn der Begriff von Gott und sein Bild ist nur in der geistigen Natur, deren Gegenstand die Wahrheit ist, und steigt nur durch den Geist hinab, damit der Geist ein Bild Gottes sei und das Urbild aller Bilder von Gott. In dem Maße also, wie alles nach dem einfachen Geiste am Geiste teilhat, hat er am Bilde Gottes teil, so daß der Geist durch sich selbst Bild Gottes und das Musterbild aller nach ihm kommenden Bilder Gottes ist. Soweit also alle Dinge, die später sind als der einfache Geist, an diesem teilhaben, haben sie auch am Bilde Gottes teil, so daß der Geist Bild Gottes und Urbild aller Bilder nach ihm ist.

\section{Kapitel.}

Unser Geist ist nicht Entfaltung, sondern Bild der ewigen Einfaltung; was jedoch nach dem Geist ist, ist kein Bild mehr; der Geist ist ohne (angeborene) Begriffe, hat aber eine mit ihm zusammengeschaffene Urteilskraft. Ferner wird erörtert, warum er des Körpers notwendigerweise bedürfe.

Philosoph. Du scheinst vermöge der reichen Fülle Deines Geistes sagen zu wollen, daß der unendliche Geist die formgebende und absolute Kraft sei, der endliche und begrenzte die Kraft der Nachformung und Nachbildung.

Laie. In dieser Richtung bewegt sich jedenfalls meine Meinung; denn was wirklich gesagt werden müßte, kann adäquat nicht ausgedrückt werden. Es ist daher von großem Nutzen, wenn man die Sache auf vielfältige Weise sagt. Erwäge also, daß Bild und Entfaltung verschieden sind; denn Gleichheit ist Bild der Einheit, da aus der Einheit die Gleichheit entsteht. Daher ist die Gleichheit Bild, nicht Entfaltung der Einheit, sondern ihre Entfaltung ist die Vielheit; also ist Gleichheit ein Bild, keine Entfaltung der zusammenfaltenden Einheit. So will ich sagen, daß der Geist ein Bild des göttlichen Geistes sei, und zwar das einfachste unter allen Bildern der göttlichen Einfaltung. So ist denn der Geist das erste Bild der göttlichen Einfaltung, die in ihrer eigentümlichen Kraft alle Bilder der Einfaltung umfaßt. Wie nämlich Gott die Einfaltung der Einfaltungen ist, so ist der Geist, der ein Bild Gottes ist, Bild der Einfaltung der Einfaltungen; nächst den Bildern kommt dann die Vielheit der Dinge, die die göttliche Einfaltung gleichsam auseinanderfalten; so ist die Zahl die Entfaltung der Einheit, Bewegung Entfaltung der Ruhe, Zeit Entfaltung der Ewigkeit, Zusammensetzung Entfaltung des Einfachen, Zeit Entfaltung der Gegenwart, Größe Entfaltung des Punktes, Bewegung 
tatis et composicio simplicitatis et tempus presencie et magnitudo puncti et motus quietis et ${ }^{a}$ ) inequalitas ${ }^{b}$ ) equalitatis et diversitas ydemptitatis ${ }^{c}$ ) et ita de singulis. Ex hoc elice admirandam mentis nostre virtutem, nam in vi eius complicatur vis assimilativa complicacionis puncti, per quam in 5 se reperit, potenciam, qua se omni magnitudini assimilat. Sic eciam ob vim assimilativam complicacionis unitatis habet potenciam, qua se poI 8 v. test omni multitudini assimilare, | et ita per vim assimilativam complicacionis nunc seu presencie omni tempori et quietis omni motui et simplicitatis omni composicioni et idemptitatis omni diversitati et equali10 tatis omni inequalitati et nexus omni disiunccioni. Et per ymaginem absolute complicacionis, que est mens infinita, vim habet, qua se potest assimilare omni explicacioni, et talia multa per te vides dici posse, que mens nostra habet, quia est ymago infinite simplicitatis omnia complicantis.

Philosophus. Videtur, quod sola mens sit Dei ymago.

15 Ydiota. Proprie ita est, quoniam omnia, que post mentem sunt, non sunt Dei ymago, nisi in quantum in ipsis mens ipsa relucet, sicut plus relucet in perfectis animalibus quam ${ }^{\mathrm{d}}$ ) in ${ }^{\mathrm{e}}$ ) imperfectis et plus in sensibilibus quam in ${ }^{f}$ ) vegetabilibus et plus in vegetabilibus ${ }^{g}$ ) quam in ${ }^{\mathrm{e}}$ ) mineralibus. Unde creature mente carentes sunt pocius divine simplicitatis ex${ }_{20}$ plicaciones quam ymagines, licet secundum relucenciam mentalis ymaginis in explicando de ymagine varie participent.

Philosophus. Aiebat Aristotiles menti seu anime nostre nullam nocionem fore concreatam, quia eam tabule rase assimilavit. Plato vero aiebat nociones sibi concreatas, sed ob corporis molem animam oblitam. 25 Quid tu in hoc verum censes.

Ydiota. Indubie mens nostra in hoc corpus a Deo posita est ad sui profectum; oportet igitur ipsam a Deo habere omne id, sine quo profectum acquirere nequit. Non est igitur credendum anime fuisse nociones concreatas, quas in corpore perdidit, sed quia opus habet corpore, ut vis so concreata ad actum pergat. Sicuti vis visiva anime non potest in operacionem suam, ut actu videat, nisi excitetur ab obiecto, et non potest excitari nisi per obstaculum specierum multiplicatarum per medium organi et sic opus habet oculo, sic vis mentis, que est vis comprehensiva rerum et nocionalis, non potest in suas operaciones, nisi excitetur a sensibilibus,
a) et am Rand ergänzt Hs.
c) diversitas ydemptitas $H$ s.
e) in über der Zeile ergänzt Hs.
g) davor vegetabilibus getilgt $H s$.

b) danach et getilgt Hs.

d) quam über quam ergänzt $H s$.

f) in fehlt Hs. 
Entfaltung der Ruhe, Ungleichheit Entfaltung der Gleichheit, Verschiedenheit der Identität, usf. Daran möge man die bewunderungswürdige Kraft unseres Geistes ermessen; denn in seiner Kraft liegt das Angleichungsvermögen an den Punkt, der Einfaltung ist, beschlossen; und durch dieses Vermögen entdeckt er in sich die Fähigkeit, sich jeder Größe zu assimilieren. So hat er auch wegen seines Vermögens der Angleichung an die Einfaltung der Einheit die Fähigkeit in sich, kraft derer er sich jeder Vielheit angleichen kann, und so gleicht er sich kraft seines Vermögens der Angleichung an die Einfaltung des Jetzt und der Gegenwart aller Zeit an. Durch die Angleichung an die Ruhe aller Bewegung, an die Einfachheit aller Zusammensetzung, an die Identität aller Verschiedenheit, an die Gleichheit aller Ungleichheit, an die Verknüpfung aller Trennung. Dadurch, daß er ein Bild der absoluten Einfaltung ist, welche der absolute Geist selbst ist, besitzt er ein Vermögen in sich, durch das er sich jeder Entfaltung anähneln kann, und du siehst ja wohl unmittelbar ein, da $\beta$ viele derartige Formen der Assimilation angeführt werden können, die unser Geist besitzt, weil er Bild der unendlichen Einfachheit ist, die alles umfaßt und einfaltet.

Philosoph. Es zeigt sich also, daß allein der Geist ein Bild Gottes ist.

Laie. So ist es auch in Wahrheit, da alles was nach dem Geist ist, kein Bild Gottes ist, außer, insofern in ihm der Geist selbst sich widerspiegelt. Denn er spiegelt sich doch mehr in den vollkommenen Lebewesen wider als in den unvollkommenen, mehr in dem mit Empfindung Begabten, als in den Pflanzen, mehr in den Pflanzen als in den Mineralien. Daher sind die Geschöpfe, die des Geistes entbehren, eher bloße Auseinanderfaltungen der göttlichen Einfaltung zu nennen, als Bilder von ihr, selbst wenn sie, infolge der Widerspiegelung des Geistes, welcher Bild ist, in der Entfaltung in verschiedener Weise am Bilde teil haben.

Philosoph. Aristoteles sagte, daß dem Geiste, d. h. unserer Seele, kein Begriff anerschaffen sei, da er sie der tabula rasa verglich. Platon dagegen sagte, der Seele seien die Begriffe anerschaffen, doch infolge der trägen Masse des Körpers habe sie die Seele vergessen. Was meinst Du darüber?

Laie. Ohne Zweifel ist unser Geist von Gott in diesen Körper zu seinem Besten gepflanzt worden. Er muß also von Gott selbst alles besitzen, ohne das er sein Bestes nicht erreichen kann. Man kann daher nicht glauben, daß mit der Seele zugleich Begriffe geschaffen worden seien, die sie im Körper verloren hat, da die Seele vielmehr eines Körpers bedarf, auf daß das ihr anerschaffene Vermögen zum Vollzug gelange. Ebenso wie die Sehkraft nicht zu der ihr eigentümlichen Tätigkeit kommen kann, daß sie wirklich sehe, wenn sie nicht von einem Objekt affiziert wird, und wie sie von den Objekten nicht affiziert werden kann, außer dadurch, daß ihr durch Vermittlung eines Organs die vielfältigen Arten der Dinge entgegenstehen, und wie sie also des Auges bedarf, so kommt die Kraft des Geistes, welche eine begriffliche Kraft zur Erfassung der Gegenstände ist, nicht $\mathrm{zu}$ der ihr eigentümlichen Tätigkeit, wenn sie nicht von etwas Sinnlichem affiziert wird; und sie kann nicht affiziert werden außer durch Vermittlung sinnlicher Vorstellungen. Sie bedarf also eines organischen Körpers, dessen Eigentümlichkeit darin besteht, daß ohne 
et non potest excitari, nisi mediantibus fantasmatibus sensibilibus. Opus ergo habet corpore organico, tali scilicet, sine quo excitacio fieri non posset. In hoc igitur Aristotiles videtur bene opinari anime non esse nociones ab inicio concreatas, quas incorporando perdiderit. Verum quo5 niam non potest proficere, si omni careret iudicio, sicut surdus nunquam proficeret, ut fieret citharedus, postquam nullum de armonia apud se iudicium haberet, per quod iudicare posset, an profecerit, quare mens nostra habet sibi concreatum iudicium, sine quo proficere nequiret. $\mathrm{Hec}$ vis iudiciaria est menti naturaliter concreata, per quam iudicat per se de 10 racionibus, an sint debiles, fortes aut concludentes, quam vim si Plato nocionem nominavit concreatam, non penitus erravit.

Philosophus. O quam clara est tua tradicio, cui quisque audiens cogitur assentire. Indubie hec sunt diligenter attendenda, nam clare experimur spiritum in mente nostra loquentem et iudicantem hoc bonum, I19 r. hoc iustum, | hoc verum et nos reprehendentem, si declinamus a iusto,

${ }_{16}$ quam loquelam et quod iudicium nequaquam didicit, sed sibi connatum est.

Ydiota. Experimur ex hoc mentem esse vim illam, que licet careat omni nocionali forma, potest tamen excitata seipsam omni forme assimi20 lare et omnium rerum nociones facere, similis quodammodo sano visui in tenebris, qui nunquam fuit in luce; hic caret omni nocione actuali visibilium, sed dum in lucem venit et excitatur, se assimilat visibili, ut nocionem faciat.

Orator. Ayebat Plato tunc ab intellectu iudicium requiri, quando \&5 sensus contraria simul ministrat. ${ }^{1}$ )

Ydiota. Subtiliter dixit, nam cum tactus ${ }^{a}$ ) simul durum et molle seu grave et leve confuse offerat, contrarium in contrario recurritur ad intellectum, ut de quidditate utriusque, si confuse sentitum plura discreta sint, iudicet $\left.{ }^{b}\right)$. Sic, cum visus magnum et parvum confuse putet, nonne 30 opus est iudicio discretivo intellectus, quid magnum, quid ve parvum. Ubi vero sensus per se sufficeret, ad iudicium intellectus minime recurreretur ut in visione digici contrarium non habentis, quod simul accedat ${ }^{c}$ ).

\footnotetext{
a) tactus über der Zeile korr. Hs.

b) ut de quidditate utriusque sic confuse sentitum plura discreta sint iudicet $H s$.

c) Orator - accedat unter dem Text ergänzt. In der Hs folgt: sequitur Capitulum quintum.
}

I) Rep. VII, $523 \mathrm{~A}$. 
ihn eine Affektion nicht zustande kommen könnte. Insofern scheint also die Meinung des Aristoteles zutreffend zu sein, daß der Seele nicht Begriffe anerschaffen seien, welche sie bei ihrem Eingehen in die Körperlichkeit verloren habe. Wie die Seele jedoch nichts erreichen kann, wenn sie jegliche Urteilskraft entbehrt, so wie ja auch ein Tauber niemals Zitherspieler werden könnte, da er ja in sich kein Urteil über die Harmonien besäße, vermöge dessen er beurteilen könnte, ob er vorwärts gekommen sei, so besitzt auch unser Geist eine anerschaffene Fähigkeit zu urteilen, ohne welche er nichts erreichen könnte. Diese Urteilskraft ist dem Geist von Natur anerschaffen, und vermöge ihrer urteilt er von sich aus, ob seine Schlüsse unsicher oder gewiß und folgerichtig seien; wenn Platon diese Kraft einen Begriff genannt hat, der uns anerschaffen sei, hat er nichts Falsches behauptet.

Philosoph. Wie einleuchtend ist doch das, was Du behauptest, so sehr, daß kein Zuhörer Deinen Behauptungen widersprechen kann. Ohne Zweifel ist das sorgfältig zu beachten. Denn wir erfahren in voller Klarheit, daß ein lebendiger Geist in uns spricht: Das ist gut, das gerecht, das wahr, und uns tadelt, wenn wir vom Rechten abweichen, eine $\mathrm{Zu}$ sprache und ein Urteil, welches er nie gelernt hat, sondern welches ihm angeboren ist.

Laie. Wir erkennen also daraus, daß der Geist jene Kraft sei, die zwar in sich keine bestimmte begriffliche Form hat, die aber, sobald sie von außen affiziert und angeregt wird, sich jeder Form angleichen und Begriffe von allem bilden kann. In gleicher Weise, wie der Mensch, der gesunde Sehkraft besitzt, und im Dunkeln lebt, ohne jemals im Lichte gewesen zu sein, jedes wirklichen Begriffes vom Sichtbaren entbehrt, sobald er aber ans Licht kommt und affiziert wird, sich dem Sichtbaren assimiliert, um einen Begriff von ihm zu bilden.

Redner. Platon sagte, da $\beta$ von der Vernunft dann das Urteil erheischt werde, wenn die Sinne sich in ihren Anzeigen widerstreiten.

Laie. Sehr scharfsinnig hat er das bemerkt; denn, wenn der Tastsinn etwas zugleich als hart und weich, schwer und leicht dem Geiste anzeigt, ein Gegenteiliges in einem Gegenteiligen, so wendet er sich zur Vernunft zurück, damit er über das Wesen von beiden dahin urteile, daß das verworren Empfundene in Wahrheit Mehreres voneinander Geschiedenes sei. Wenn so die Sehkraft in verworrener Weise etwas für groß und zugleich für klein hält, bedarf es da nicht eines unterscheidenden Urteils der Vernunft, was groß, und was klein sei? Wenn aber der Sinn für sich selbst ausreichte, so würde man in keiner Weise auf das Urteil der Vernunft zurückgehen, wie $z$. B. bei der Wahrnehmung eines Fingers, der keine entgegengesetzten sinnlichen Qualitäten an sich hat. ${ }^{1}$ )

I) Zum Verständnis muß hier der Platonische Text (Republ.523 Aff.) herangezogen werden; vgl, oben S. I8o. 
Capitulum quintum.

Quomodo mens est viva substancia et in corpore creata; et de modo quomodo; et an racio sit in brutis; et quomodo mens viva descripcio eterne sapiencie. ${ }^{a}$ ).

$5 \quad$ Philosophus. Omnes pene Peripatetici aiunt intellectum, quem tu mentem dicere videris, fore potenciam quandam anime et intelligere accidens, tu vero aliter.

Y diota. Mens est viva substancia, quam in nobis interne loqui et iudicare experimur, et que omni vi alia ex omnibus viribus spiritualibus, 10 quas $^{\mathrm{b}}$ ) in nobis experimur, infinite substancie et absolute forme plus assimilatur, cuius officium in hoc corpore est corpus vivificare, et ex hoc anima dicitur. Unde mens est forma substancialis sive vis in se omnia suo modo complicans ${ }^{c}$ ) vim animativam, per quam ${ }^{d}$ ) corpus animat vivificando, vitam vegetativam et sensitivam et vim raciocinativam et in15 tellectualem et intellectibilem complicans.

Philosophus. Vis ne mentem, quam et animam fateris, intellectivam ante corpus fuisse, prout Pitagoras et Platonici, et postea incorporatam.

Ydiota. Natura, non tempore. Nam, ut audisti, eam visui in teneso bris comparavi. Visus autem nequaquam actu fuit ante oculum nisi natura tantum. Unde quia mens est quoddam divinum semen sua vi complicans omnium rerum exemplaria nocionaliter, tunc a Deo, a quo hanc vim habet eo ipso, quod esse recepit, est simul et in convenienti terra locatum, ubi fructum facere possit et ex se rerum universitatem 25 nocionaliter explicare, alioquin hec vis seminalis frustra data sibi foret, si non fuisset sibi addita oportunitas in actum prorumpendi.

Philosophus. Ponderose loqueris, sed quomodo hoc in nobis factum sit, audire summopere cupio.

Ydiota. Divini modi sunt precisione inattingibiles; coniecturas so tamen de ipsis facimus alius obscuriores, alius clariores, ego autem arbitror hanc similitudinem, quam dicam, tibi sufficere. Nosti enim visum de sua propria natura non discernere, sed in globo quodam et confuse sentire obstaculum, quod sibi obviat intra speram motus sui scilicet oculum, quod quidem obstaculum generatur ex multiplicacione ${ }^{e}$ ) spe35 cierum obiecti in oculum. Unde si adest visio in oculo sine discrecione

a) Capitulum - sapiencie am Rand ergänzt Hs. b) que $H s$.

c) danach et getilgt Hs. $\quad$ d) quam am Rand wiederholt Hs. e) auf Rasur Hs. 
5. Kapitel.

Geist ist lebendige Substanz und in einem Körper geschaffen; es wird gezeigt, wie dieses zu verstehen sei. - Haben die Tiere Vernunft? - Geist ist lebendige Beschreibung der ewigen Weisheit.

Philosoph. Fast alle Anhänger der peripatetischen Schule behaupten, daß die Vernunft, die du offenbar Geist nennst, eine gewisse Potenz der Seele sei, und daß das Erkennen accidentell sei; Du aber stellst Dir das offenbar anders vor.

Laie. Geist ist lebendige Substanz, die, wie wir erfahren, immer in uns spricht und urteilt, und die mit all ihrem anderen Vermögen vermöge der lebendigen geistigen Kräfte, welche wir in uns spüren, sich der unendlichen Substanz und der absoluten Form ähnlich zu machen sucht; seine Aufgabe aber in diesem Körper ist es, den Körper lebendig zu machen. Daher wird er Seele genannt; und so ist der Geist die substantielle Form oder Kraft, die alles auf ihre Weise in sich beschlossen hält und einfaltet, sowohl das animalische Leben, durch das sie den Körper belebt, als auch das pflanzliche Leben, wie auch das der Empfindung fähige Leben, sowie das Vermögen zu urteilen und auch das anzuschauen und $\mathrm{zu}$ begreifen.

Philosoph. Willst Du damit sagen, daß der Geist, den Du auch Seele nennst, als ein Intelligibles schon vor dem Körper bestanden habe, und dann erst in den Körper eingegangen sei, wie es Pythagoras und die Platoniker behaupten?

Laie. Der Natur, nicht aber der Zeit nach; denn du hast ja gehört, wie ich ihn einer Sehkraft im Dunklen verglich. Sehkraft aber gab es niemals im aktuellen Sinne, bevor es Auge gab, es sei denn der Naturnach. $\mathrm{Da}$ nun der Geist ein göttlicher Samen ist, der in seiner Kraft die Urbilder aller Dinge begrifflich beschlossen hält, ist er von Gott, von dem er diese Kraft hat, dadurch, daß er das Sein empfing, auch zugleich auf den ihm gemäßen Platz gestellt worden, wo er Frucht tragen und aus sich heraus das All der Dinge auf begriffliche Weise entfalten konnte. Sonst nämlich wäre ihm diese Kraft des Samens vergeblich verliehen worden, wenn ihm nicht zugleich die Gelegenheit verliehen worden wäre, zur Wirklichkeit zu gelangen.

Philosoph. Gewichtig ist das, was Du sprichst; aber inwiefern die Sache bei uns Menschen so liegt, wie Du sagst, wünsche ich höchlich $\mathrm{zu}$ wissen.

Laie. Die Beschaffenheiten des Göttlichen sind in völliger Genauigkeit nicht $\mathrm{zu}$ fassen; wir gelangen jedoch zu Vermutungen über sie, die bald undeutlicher, bald wieder genauer sind. Ich aber bin der Ansicht, daß folgendes Gleichnis ausreicht. Du weißt doch, daß das Sehen, seiner ihm eigentümlichen Natur nach, nicht unterscheidet, sondern nur in einer Zusammenballung und verworren das ihm Entgegenstehende empfindet, was ihm in dem Kreise seiner Bewegung, das ist im Auge, begegnet und dieser Gegenstand wird erzeugt aus der Vielheit der Bilder von dem, was dem Auge entgegengetreten ist; findet daher im Auge ein Sehen statt, ohne die Fähigkeit des Unterscheidens (wie z. B. bei den Kindern, wo diese Fähigkeit fehlt), dann kommt der Geist der wahrnehmenden Seele zu Hilfe, wie die Kraft der Unterscheidung der Seh- 
ut in infantibus, ubi deest usus discrecionis, tunc ita advenit mens anime sensibili sicut discrecio visui, per quam discernit inter colores. Et sicut hec discrecio visiva in brutis perfectis animalibus ut canibus suum dominum visu discernentibus reperitur et a Deo data est visui tamquam per5 feccio et forma visus, sic nature humane ultra discrecionem illam, que in brutis reperitur, data est alcior vis se habens ad discrecionem animar19 v. lem sicut illa ad vim sensibilem, | ut mens sit forma discrecionis animalis et eius perfeccio.

Philosophus. Optime et pulchre, sed videris ad opinionem sa10 pientis Filonis accedere, qui animalibus racionem inesse dicebat. ${ }^{1}$ )

Ydiota. Experimur discretivum discursum in brutis, sine quo eorum natura bene subsistere non posset. Unde discursus ${ }^{a}$ ) eorum, quia caret forma scilicet intellectu seu mente, est confusus. Caret enim iudicio et sciencia et, quia omnis discrecio ex racione est, hinc Filo non absurde 15 sic dixisse videtur.

Philosophus. Declara queso, quomodo mens est forma racionis discurrentis.

Ydiota. Iam dixi, quod, sicut visus videt ${ }^{b}$ ) et nescit, quid videat, sine discrecione, que ipsum informat et dilucidat et perficit, sic racio 20 silogisat et nescit, quid silogiset, sine mente, sed mens informat et dilucidat et perficit raciocinacionem, ut sciat, quid silogiset. Ac si ydiota vim vocabulorum ignorans librum aliquem legat, leccio ex vi racionis procedit, legit enim discurrendo per differencias literarum, quas componit et dividit, et hoc est opus racionis, sed ignorat, quid legat, et sit alius, qui legat 25 et sciat et intelligat id, quod legit. Hec est quedam similitudo racionis confuse et racionis formate per mentem, mens enim de racionibus iudicium habet discretivum, que racio bona, que sophistica; ita mens est forma discretiva racionum sicut racio forma discretiva sensuum et ymaginacionum.

so Philosophus. Unde habet mens iudicium illud, quoniam de omnibus iudicium facere videtur.

Ydiota. Habet ex eo, quia est ymago exemplaris omnium, Deus enim est omnium exemplar. Unde, cum omnium exemplar ${ }^{c}$ ) in mente ut veritas in ymagine reluceat, in se habet, ad quod respicit, secundum 35 quod iudicium de exterioribus facit, ac si lex scripta foret viva, illa, quia

a) Danach ille getilgt $H s . \quad$ b) videt visus umgestellt $H s$.

c) Unde, cum omnium exemplar am Rand ergänzt Hs.

I) De Mundi Opif. $\S 52$ Richter 49 . 
kraft, so daß diese alsdann die Farben unterscheidet. Und wie diese Kraft der Unterscheidung des Gesehenen bei den vollkommenen Tieren, wie bei den Hunden, welche ihren Herrn von andern Menschen vermöge des Sehens unterscheiden, sich findet und wie ihnen dies, gleichsam als Vollendung und Form des Sehens von Gott verliehen ist, so ist der menschlichen Natur über jene Kraft der Unterscheidung, die wir bei den Tieren vorfinden, hinaus, ein höheres Vermögen verliehen worden, das sich zur tierischen Unterscheidungskraft verhält, wie jene zur bloß sinnlichen Empfindung, so, daß der Geist die zur Vollendung gelangte Form der tierischen Weise des Unterscheidens ist.

Philosoph. All dies ist trefflich und gut gesagt; es scheint aber, als stimmtest Du der Meinung des weisen Philon bei, der sagte, daß die Tiere Verstand besäßen.

Laie. Wir finden in den Tieren das Vermögen trennender Unterscheidung der Dinge, ohne das ihre Natur nicht wohl bestehen könnte. Daher ist ihr Unterscheidungsvermögen, da es der vollendeten Form, d. h. der Vernunft und des Geistes entbehrt, nur verworren; es entbehrt nämlich des Urteilens und des Wissens; und, da nun alle Unterscheidung eine Leistung des Verstandes ist, hat Philon nicht ohne Grund seine Behauptung aufgestellt.

Philosoph. Erkläre bitte, inwiefern der Geist die zur Vollendung gebrachte Form des unterscheidenden Verstandes ist.

Laie. Ich habe schon gesagt, daß, wie das Gesicht sieht und nicht weiß, was es sieht, ohne ein Vermögen der Unterscheidung, welches es zur Form und ins Klare bringt und es zur Vollendung führt, so der Verstand schließt und nicht weiß, was er schließt, ohne den Geist. Der Geist aber ist es, der die Form und Erhellung gibt und das Vermögen zu schließen zur Vollendung bringt, damit es weiß, was es schließt. So, wie ein Ungelehrter, der die Bedeutung der Worte nicht kennt, und irgendein Buch liest, das Lesen nur vermöge des Verstandes vollbringt: er liest nämlich so, daß er wohl die verschiedenen Formen der Buchstaben unterscheiden kann, welche er zusammensetzt und trennt, und das ist eineAufgabe des Verstandes, aber er kennt nicht den Sinn dessen, was er liest. Daneben möge man sich einen anderen vorstellen, welcher weiß, versteht und einsieht, was er liest; das stellt im Gleichnis das Verhältnis des verworrenen Verstandes zu dem Verstande, welcher kraft des Geistes zur vollendeten Form gelangt ist, dar. Dieser letztere besitzt nämlich ein Unterscheidungsvermögen, welches über die Schlüsse des Verstandes urteilt, ob sie richtig oder sophistisch seien; so ist der Geist die Form, die die Schlüsse des Verstandes sondert, wie der Verstand die Form ist, die Empfindungen und Vorstellungen sondert.

Philosoph. Woher hat der Geist denn jene ihm eigentümliche Urteilskraft, da er doch über alles zu utreilen scheint?

Laie. Er hat sie darum, weil er ein Bild desjenigen ist, was das Urbild von allem ist. Gott nämlich ist das Urbild von allem. Da sich nun das Urbild von allem im Geiste, wie die Wahrheit in einem Bilde, widerspiegelt, besitzt der Geist in sich etwas, worauf er hinblickt und gemäß dem er seine Urteile über die äußeren Gegenstände fällen kann. So würde, wenn es ein lebendiges geschriebenes Gesetz gäbe, dieses Gesetz, als lebendiges, die Entscheidungen, die es zu treffen hätte, 
viva, in se iudicanda legeret. Unde mens est viva descripcio eterne et infinite sapiencie, sed in nostris mentibus ab inicio vita illa similis est dormienti, quousque admiracione, que ex sensibilibus oritur, excitetur, ut moveatur, tunc motu vite sue intellective in se descriptum reperit, ${ }_{5}^{5}$ quod querit. Intelligas autem descripcionem hanc resplendenciam esse exemplaris omnium modo, quo in sua ymagine veritas resplendet, ac si acucies simplicissima et indivisibilis anguli lapidis Diamantis politissimi, in qua omnium rerum forme resplenderent, viva foret, illa se intuendo omnium rerum similitudines reperiret, per quas de omnibus nociones 10 facere posset.

Philosophus. Mirabiliter loqueris et delectabilissima profers; multum exemplum acuciei Diamantis placet, nam quanto angulus ille fuerit acucior et simplicior, tanto clarius omnia in eo resplendent.

Ydiota. Qui vim specularem in se considerat, videt, quomodo est ${ }_{15}$ ante omnem quantitatem, quod, si illam vivam concipit vita intellectuali, in qua reluceat omnium exemplar, de mente admissibilem facit coniecturam.

Philosophus. Vellem audire, an hanc artem tuam in mentis creacione paradigmatice posses applicare.

120 r. Ydiota. Possem etenim. Et pulchro quodam cocleari $\mid$ ad manum ${ }_{21}$ recepto aiebat: Volui facere coclear speculare, quesivi lignum valde unitum et nobile super omnia, applicui instrumenta, quorum motu elicui convenientem proporcionem, in qua forma coclearis perfecte resplenderet. Post hec perpolivi coclearis superficiem adeo, quod induxi in ${ }_{25}$ resplendenciam forme coclearis formam specularem, ut vides; nam, cum sit perpulchrum coclear, est tamen cum hoc coclear speculare. Habes enim in eo omnia genera speculorum, scilicet concavum, convexum, rectum et columpnare, in base manubrii rectum, in manubrio columpnare, in concavitate coclearis concavum, in convexitate convexum. Unde forma ${ }_{30}$ specularis non habuit temporale esse ante coclear, sed ad perfeccionem coclearis addita est per me forme prime coclearis, ut eam perficeret, ut nunc forma specularis in se contineat formam coclearis. Et forma specularis est independens a cocleari, non est enim de essencia speculi, quod sit coclear. Quare si rumperentur proporciones, sine quibus forma ${ }_{35}$ coclearis esse nequit, puta si manubrium separaretur, desineret esse coclear, sed ob hoc forma specularis non desineret esse. Ita quidem Deus 
in sich selbst lesen können. Daher ist der Geist die lebendige Beschreibung der ewigen und unendlichen Weisheit. Doch in unserem Geiste gleicht anfänglich dieses Leben dem eines Schlafenden, bis der Geist durch das Staunen, welches in ihm durch die sinnliche Welt entsteht, entflammt wird, in Tätigkeit zu treten. Und dann findet er, durch die Bewegung seines vernünftigen Lebens, in sich etwas geschrieben, was er zu deuten sucht. Du mußt aber begreifen, daß diese Beschreibung ein Widerschein ist vom Urbild aller Dinge auf die gleiche Art wie die Wahrheit in ihrem Bilde sich widerspiegelt. So könnte die völlig einfache und völlig unteilbare Winkelspitze eines geschliffenen Diamanten, in der die Formen aller Dinge widerschienen, wenn sie lebendig wäre, in sich dadurch, daß sie sich anschaute, Ähnlichkeiten aller Dinge finden, vermöge deren sie Begriffe von allem bilden könnte.

Philosoph. Wundervoll ist das, was Du sprichst, und reizend $\mathrm{zu}$ hören sind Deine Worte. Doch am meisten gefällt mir das Bild von der Spitze des Diamanten; denn je spitzer und einfacher sein Winkel ist, desto heller und deutlicher spiegelt sich alles in ihm wider.

Laie. Wer die spiegelnde Kraft in sich betrachtet, wird gewahr, wie sie vor aller Quantität ist. Und wenn er sie als eine lebendige mit Vernunft begabte denkt, so stellt er über das Wesen des Geistes eine ausreichende Vermutung auf.

Philosoph. Ich würde gern wissen, ob du diese deine Kunst des Löffelschnitzens als Beispiel verwenden kannst, um die Schöpfung des Geistes klar zu machen.

Laie. Das könnte ich schon. Und indem er einen schönen Löffel zur Hand nahm, sprach er: Ich wollte einen Löffel machen, in dem sich die reine Form des Löffels widerspiegelt, und dazu wählte ich mir besonders edles Holz aus einem Stücke, und brachte meine Werkzeug in Anwendung; durch ihre Bewegung brachte ich in ihm das geziemende Verhältnis der Masse zustande, damit in diesem Verhältnis die reine Form des Löffels sich widerspiegele. Dann glättete ich die Oberfläche des Löffels so lange, bis ich den Widerschein der reinen Form des Löffels zu derjenigen Form gebracht hatte, in der sich die reine Form des Löffels widerspiegelt, wie Du es ja siehst. Denn obwohl er ein sehr schöner Löffel ist, ist er doch nur ein solcher, der die reine Form widerspiegelt. Denn Du findest in ihm alle Arten von Widerspiegelung der Form, das Konkave, das Konvexe, das Gerade, das Säulenförmige, nämlich am unteren Teil des Griffes das Gerade, am Stiel des Löffels das Säulenförmige, am hohlen Teil des Löffels das Konkave, und am gewölbten das Konvexe. Und so hat die widerspiegelnde Form kein zeitliches Sein vor dem Löffel, sondern ist nur der ersten Form des Löffels von mir mit hinzugefügt worden, um sie zur Vollendung zu bringen, so daß jetzt die widerspiegelnde Form in sich die Form des Löffels enthält. Vom Löffel ist die widerspiegelnde Form unabhängig, denn zum Wesen dieser Form gehört es nicht, daß ein Löffel da ist. Daher würde, wenn die Maßverhältnisse zerstört würden, ohne welche die Form des Löffels nicht bestehen kann, z. B. wenn der Griff abgelöst würde, er wohl aufhören, ein Löffel zu sein, aber deswegen würde die widerspiegelnde Form nicht aufhören, zu sein. So hat auch Gott durch eine Bewegung des Himmels aus ge- 
per motum celi de apta materia proporcionem eduxit, in qua resplenderet animalitas perfecciori modo, cui deinde addidit mentem quasi vivum speculum modo, quo dixi.

\section{Capitulum sextum.}

5 Quomodo simbolice loquendo sapientes numerum rerum exemplar dixerunt; et de mirabili natura eius; et quomodo est a mente et essenciarum incorruptibilitate; et quomodo mens est armonia, numerus se movens, composicio ex eodem et diverso. ${ }^{a}$ )

10 Philosophus. Apte applicasti et, quando unum dicis intellectum, aperis, quomodo fit rerum produccio ac quomodo proporcio est locus, orbis seu regio forme et locus proporcionis materia, et videris multum Pitagoricus, qui ex numero omnia esse asseruit. ${ }^{\text {b) }}$

Ydiota. Nescio, an Pitagoricus vel alius sim. Hoc scio, quod nul15 lius auctoritas me ducit, eciam si me movere temptet, arbitror autem viros Pitagoricos, qui, ut ais, per numerum de omnibus philosophantur, graves et acutos, non quod credam eos voluisse de numero loqui, prout est mathematicus et ex nostra mente procedit, nam illum non esse alicuius ${ }^{\mathrm{c}}$ ) rei principium de se constat, sed simbolice ac racionabiliter locuti sunt so de numero, qui ex divina mente procedit, cuius mathematicus est ymago. Sicut enim mens nostra se habet ad infinitam eternam mentem, ita numerus nostre mentis ad numerum illum, et damus illi numero nomen nostrum sicut menti illi nomen mentis nostre, et delectabiliter multum versamur in numero quasi in nostro proprio opere.

${ }_{25}$ Philosophus. Explana queso motiva, que quem movere possunt ad dicendum rerum principia numeros.

Ydiota. Non potest esse nisi unum infinitum principium et hoc solum est infinite simplex, primum autem principiatum non potest esse infinite simplex, ut de se patet, neque potest esse compositum ex aliis 30 ipsum componentibus, tunc enim non foret primum principiatum, sed componencia ipsum natura precederent. Oportet igitur admittere, quod primum principiatum sic sit compositum, quod tamen non sit ex aliis,

\footnotetext{
a) Capitulum - diverso am Rand hinzugefügt Hs.

b) asserunt korr. asseruit $H s$.

c) alicus $H s$.
} 
eignetem Stoffe ein Verhältnis der Maße geschaffen, in welchem sich die reine Form des Lebendigen in vollkommener Weise widerspiegelt. Und diesem Maßverhältnis hat er dann noch den Geist gleichsam als lebendigen Spiegel auf die Art hinzugefügt, wie ich es sagte.

\section{Kapitel.}

Es wird erläutert, daß die Weisen, die behaupteten, daß die $Z$ ahl das Urbild der Dinge sei, dies in symbolischer Weise gemeint haben. - Über die wunderbare Natur der Zahl. - Sie stammt vom Geiste und der unverdorbenen Reinheit des Seienden. - Der Geist ist Harmonie, sich selbst bewegende Zahl und Zusammensetzung aus Identischem und Verschiedenem.

Philosoph. Da hast Du ein treffendes Beispiel gewählt. Und wenn Du eine Vernunft sagst, so machst Du damit klar, auf welche Art die Entstehung der Dinge vor sich geht, und es wird deutlich, daß das $\mathrm{Ma} \beta$ verhältnis das ist, worin die Welt und die Form wurzelt, und daß die Materie das ist, worin das Maßverhältnis ist. Und Du scheinst in vielen Stücken Deiner Lehre ein Anhänger des Pythagoras zu sein, welcher behauptete, daß alles aus der Zahl stamme.

Laie. Ich weiß nicht, ob ich Anhänger des Pythagoras oder eines anderen bin. Das aber weiß ich, daß ich mich durch die Autorität keines Menschen, auch wenn sie mich $\mathrm{zu}$ beeinflussen sucht, bestimmen lasse. Gleichwohl glaube ich, daß die Pythagoreer, welche, wie Du sagst, über alle Dinge vermöge der $Z$ ahl philosophieren, ernsthafte und scharfsinnige Männer gewesen sind, nicht etwa, als ob ich der Meinung wäre, als hätten sie von der Zahl sprechen wollen, die Gegenstand der Mathematik ist und unserem menschlichen Geiste entspringt (denn es ist aus sich selbst klar, daß die Zahl, in diesem Sinne genommen, kein Prinzip von irgend etwas überhaupt sein kann); sie haben vielmehr in symbolischer Weise von der Zahl gesprochen, welche dem göttlichen Geiste entstammt, und von der die mathematische Zahl nur ein Abbild ist. Wie sich nämlich unser Geist zum unendlichen und ewigen Geist verhält, so verhält sich die $Z$ ahl in unserem Geiste zu jener göttlichen Zahl, und wir geben jener Zahl den Namen unserer Zahl, wie wir ja auch jenem göttlichem Geist den Namen uuseres Geistes geben; so verweilen wir mit Wohlgefallen bei der Betrachtung der Zahl, als sei sie unser eigenes Werk.

Philosoph. Setze mir doch die Gründe auseinander, welche jemanden zu dem Ausspruch bewegen können, die Zahlen seien die Prinzipien der Dinge.

Laie. Es kann doch nur ein einziges unendliches Prinzip geben, und nur dieses ist unendlich einfach. Dasjenige aber, was als erstes unter dies Prinzip fällt, kann nicht mehr unendlich einfach sein, wie von selbst klar ist; es kann aber auch nicht zusammengesetzt sein aus Teilen. Denn dann wäre es ja nicht mehr das erste, welches unter das Prinzip fällt, sondern die es zusammensetzenden Teile würden ihm von Natur vorausgehen. Man muß also annehmen, daß das erste, das unter das Prinzip fällt, in der Weise zusammengesetzt 
sed ex seipso compositum, et non capit mens nostra aliquid tale esse posse, 120 v. nisi sit numerus vel ut numerus nostre mentis. I Nam numerus est compositus et ex se ipso compositus, ex numero enim pari et impari est omnis numerus compositus, sic numerus est ex numero compositus. Si 5 dixeris ternarium ex tribus unitatibus compositum, loqueris, quasi si quis diceret parietes et tectum separate facere domum, si enim parietes sunt separate et similiter et tectum, non componitur ex ipsis domus, sic nec tres unitates separate constituunt ternarium. Quare si unitates consideras, prout constituunt ternarium, eas unitas consideras, et quid tunc to aliud est tres unitates unite quam ternarius ita ex se ipso ${ }^{a}$ ) compositus. Sic de omnibus numeris, ymo, dum in numero non nisi unitatem conspicio, video numerib) incompositam composicionem et simplicitatis et composicionis sive unitatis et multitudinis coincidenciam. Ymo si adhuc acucius intueor, video numeri ${ }^{\mathrm{b}}$ ) compositam unitatem ut in unitati15 bus armonicis dyapason, diapente $\mathrm{ac}^{c}$ ) diatesseron. Armonica enim habitudo unitas est, que sine numero intelligi nequit. Adhuc ex habitudine semitonii et medietatis duple, que est coste quadrati ad diametrum, numerum simpliciorem intueor, quam nostre mentis racio attingere queat, nam habitudo sine numero non intelligitur, et tamen numerum illum 20 oporteret esse pariter parem et imparem, de quo longus sermo et delectabilis valde haberi posset, si ad alia non festinaremus. Habemus igitur, quomodo primum principiatum est, cuius tipum gerit numerus, neque ad quidditatem eius aliter ac propius accedere possumus, cum precisio quidditatis cuiuscunque rei sit per nos inattingibilis aliter quam in enig25 mate vel figura. Primum enim principiatum vocamus simbolice numerum, quia numerus est subiectum proporcionis. Non enim potest esse proporcio sine numero, et proporcio est locus forme, sine enim proporcione apta et congrua forme forma resplendere nequit, uti dixi proporcione apta cocleari rupta non posse formam manere, quia non habet lo30 cum. Est enim proporcio quasi aptitudo superficiei specularis ad resplendenciam ymaginis, qua non stante desinit representacio. Ecce, quomodo unitas exemplaris infinita non potest resplendere nisi in proporcione apta, que proporcio est in numero. Agit enim mens eterna quasi ut musicus, qui suum conceptum vult sensibilem facere, recipit enim pluralitatem vocum et illas redigit in proporcionem congruentem armonie,

a) danach est Hs. $\quad$ b) numeri durch Ras. korr. Hs.

c) et korr. über der Zeile ac. Hs. 
sei, daß es dennoch nicht aus anderem zusammengesetzt ist, sondern aus sich selbst. Unser Geist begreift nun nicht, daß es etwas derartiges geben könne, außer insofern er die Zahl, und zwar als Zahl unseres Geistes, begreift. Denn die Zahl ist zusammengesetzt und gleichwohl aus sich selbst zusammengesetzt (denn eine jede $\mathrm{Z}$ ahl ist aus einer geraden und aus einer ungeraden zusammengesetzt); so ist die Zahl aus der Zahl zusammengesetzt. Wenn Du sagst, die Dreiheit sei aus drei Einheiten zusammengesetzt, so sprichst Du so, als wenn Du sagtest, Mauern und Dach machten, getrennt voneinander, ein Haus aus; wenn die Wände nämlich für sich sind und in gleicher Weise das Dach, so wird aus ihnen kein Haus zusammengesetzt; so machen auch drei Einheiten getrennt voneinander keine Dreiheit aus. Wenn du daher die Einheiten betrachtest, insofern als sie die Dreiheit setzen, betrachtest du sie in ihrer Vereinigung. Und was ist dann die Vereinigung dieser drei Einheiten anderes, als die Dreizahl, die so aus sich selbst zusammengesetzt ist? Und so verhält es sich mit allen Zahlen. Wenn man aber auf der anderen Seite bei der Zahl nur die Einheit in Betracht zieht, dann kommt man dabei zu einer unzusammengesetzten Zusammensetzung der Zahl, und zu einem Zusammenfallen von Einfachheit und Zusammensetzung, von Einheit und Vielheit. Wenn man hingegen schärfer hinsieht, so bemerkt man die zusammengesetzte Einheit der Zahl, wie in harmonischen Einheiten z. B. Oktave, Quinte, Quarte; denn harmonisches Verhältnis ist Einheit, welche ohne Zahl nicht begriffen werden kann. Daher werde ich in dem Verhältnis vom Halbton zur doppelten harmonischen mittleren Proportionale, welches das Verhältnis von Quadratseite zur Diagonale ist, eine Zahl gewahr, die zu einfach ist, als daß die Berechnung unseres Geistes sie erreichen könnte. Denn ein Maßverhältnis kann nicht erkannt werden ohne eine Zahl; es wäre aber notwendig, daß jene $Z$ ahl zugleich gerade und ungerade sei; hierüber könnte man lange Zeit in höchst kurzweiliger Form reden, wenn wir uns nicht anderen Problemen zuwenden müßten. Wir haben also gefunden, auf welche Weise es ein Erstes gibt, das unter ein Prinzip fällt, dessen Typus die Zahl darstellt. Wir können nun seinem Sein auf keine andere Weise näher kommen (da die genaue Bestimmung der Wesenheit eines jeden Dinges für uns auf keine andere Weise erreichbar ist) als in einem Gleichnis oder einem Bilde. Denn das erste unter dem Prinzip Stehende nennen wir symbolisch Zahl, da die Zahl die Grundlage eines jeden Maßverhältnisses ist; es gibt nämlich kein Maßverhältnis ohne die Zahl. Maßverhältnis aber ist das, was der Form erst ihren Ort gibt; denn ohne ein Maßverhältnis, das mit der Form zusammenpaßt und mit ihr übereinstimmt, kann die Form nicht in sichtbare Erscheinung treten, und wie ich schon sagte: wenn das Maßverhältnis, welches dem Löffel angemessen ist, zerstört ist, kann die Form nicht bestehen bleiben, da sie dann keinen ihren eigentümlichen Ort besitzt. Das Maßverhältnis nämlich ist es, das eine Fläche, welche die reine Form widerspiegelt, fähig macht, als ein Bild zur Erscheinung zu kommen, und wenn das Verhältnis nicht länger besteht, so hört auch die Darstellung auf. Sieh' also, wie die unendliche Einheit des Urbildes nur in dem passenden Maßverhältnis sichtbar werden kann, welches Verhältnis auf der Zahl beruht. Denn 
ut in illa proporcione armonia dulciter et perfecte resplendeat, quando ibi est ut in loco suo et variatur armonie resplendencia ex varietate proporcionis armonie congruentis, et desinit armonia aptitudine proporcionis desinente. Ex mente igitur numerus et omnia.

$5 \quad$ Philosophus. Nonne sine nostre mentis consideracione est rerum ${ }^{\mathrm{a}}$ ) pluralitas.

Y diota. Est, sed a mente eterna. Unde sicut quo ad Deum rerum pluralitas est a mente divina, ita quo ad nos rerum pluralitas est a nostra mente, nam sola mens numerat, sublata mente numerus discretus | non

121 r. est. Mens enim ex eo, quia unum et idem singulariter ${ }^{b}$ ) intelligit et sigilla-

1 tim, et hoc ipsum consideramus, dicimus esse unum; ex hoc, quod unum singulariter et $\mathrm{hoc}^{\mathrm{c}}$ ) semel intelligit, veraciter est unitatis equalitas, sed quando unum singulariter ${ }^{\mathrm{b}}$ ) et multiplicando intelligit, res plures esse diiudicamus binarium dicendo, quia mens unum et idem singulariter bis 15 sive geminando intelligit. Ita de reliquis.

Philosophus. Nonne ternarius ex binario et unitate constituitur, et numerum dicimus colleccionem singularium, quomodo tunc ex mente tu dicis eum esse.

Ydiota. Illi modid ${ }^{d}$ dicendi debent ad intelligendi modum referri, so quia non est aliud colligere quam ${ }^{e}$ ) unum et idem commune circa eadem multiplicare. Unde cum videas sine mentis multitudine binarium vel ternarium nichil esse, satis attendis numerum ex mente esse.

Philosophus. Quomodo pluralitas rerum est numerus divine mentis.

Y diota. Ex eo enim, quod mens divina unum sic intelligit et aliud s5 aliter, orta est rerum pluralitas. Unde si acute respicis, reperis $\left.{ }^{f}\right)$ pluralitatem rerum non esse nisi modum intelligendi divine mentis. Sic irre-

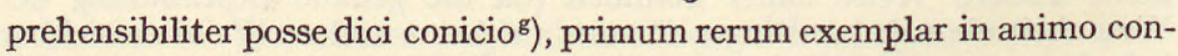
ditoris numerum esse. Hoc ostendit delectacio et pulchritudo, que omnibus rebus inest, que in proporcione consistit, proporcio ${ }^{\mathrm{h}}$ ) vero in se numero, hinc numerus precipuum vestigium ducens in sapienciam.

Philosophus. Illud primo Pitagorici, deinde Platonici dixerunt, quos et Severinus Boecius imitatur. ${ }^{1}$ )

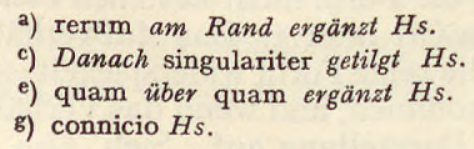

I) cf.: Euclid. Megar. Geometriae 1. II ab An. Manl. Severino Boetio translati I Mi P. L. 63 p. 1333 . b) singulaiter $H s$.

d) modi über der Zeile korr. Hs.

f) respicies korr. respicis $H s$.

h) danach vere getilgt $\mathrm{Hs}$. 
es handelt der ewige Geist gleichsam wie ein Musiker, der seine innere Vorstellung sinnlich machen will; denn er nimmt die Mannigfaltigkeit der Töne auf, und unterwirft sie einem Maßverhältnis, das mit der Harmonie übereinstimmt, so, daß in jenem Maßverhältnis die Harmonie lieblich und vollendet ihren Widerhall findet. Denn dort ist sie als in dem ihr eigentümlichen Orte; und die sinnliche Erscheinung der Harmonie wird verändert, je nach der Veränderung des Maßverhältnisses, welches mit der Harmonie übereinstimmt, und die Harmonie kommt zum Aufhören wenn die angemessene Beschaffenheit des Maßverhältnisses zum Aufhören kommt. Kraft des Geistes ist also die Zahl und alles andere.

Philosoph. Gibt es denn also keine Vielheit der Dinge außerhalb der Betrachtung unseres Geistes?

Laie. Es gibt eine solche Vielheit; sie ist aber ein Werk des ewigen Geistes. Wie daher in Betracht Gottes die Vielheit der Dinge ein Werk des göttlichen Geistes ist, so ist in Betracht unser die Vielheit der Dinge ein Werk unseres Geistes; denn allein der Geist zählt, und es gibt keine für sich bestehende Zahl, wenn der Geist fort gedacht wird. Denn sein Sein besteht ja gerade darin, das er das Eine und das Selbige einzeln und für sich betrachtet, und dies haben wir im Auge und sprechen dann von einer Eins; und sofern er das Eine einzeln ansieht, ist er in Wahrheit die Gleichheit der Einheit. Wenn er aber die Eins einzeln und für sich begreift und sie zugleich vervielfältigt, dann urteilen wir, es gäbe mehrere Dinge und sprechen von Zweiheit, da dann der Geist das Eine und Selbige einzeln zweimal betrachtet.

Philosoph. Setzt sich nicht die Dreiheit aus der Zweiheit und der Einheit zusammen, und nennen wir nicht Zahl die Zusammenzählung der Einzelnen? Wie kannst Du sie dann ein Geschöpf des Geistes nennen?

Laie. Jene Weisen der Aussagen müssen auf die Art der Erkenntnis zurückgeführt werden, da ja Zusammenzählen nichts anderes ist, als das Eine und das Selbe als ein Gemeinsames vielfältig zu setzen. Da daraus nun ersichtlich wird, daß ohne die Vielheit, die im Geiste ist, die Zweiheit oder Dreiheit nichts sei, ist genügend deutlich, daß die Zahl vom Geist gesetzt ist.

Philosoph. Inwiefern ist die Vielheit der Dinge Zahl des göttlichen Geistes?

Laie. Darum weil der göttliche Geist ein Eines auf eine bestimmte Weise erfaßt, und ein Anderes auf eine andere Weise, ist die Vielheit der Dinge entstanden. Bei schärferer Betrachtung wird man daher finden, daß die Vielheit der Dinge nichts anderes sei, als eine Art der Erkenntnis des göttlichen Geistes. Man kann daher meiner Meinung nach mit Recht sagen, daß das erste Urbild der Dinge im Geiste des Schöpfers die Zahl sei. Das beweist der Umstand, daß das Vergnügen und die Schönheit, die allen Dingen innewohnt, in dem Verhältnis ihrer Maße besteht; das Maßverhältnis aber seinerseits ruht wieder auf der Zahl. Daher ist denn die Zahl der trefflichste Pfad, welcher zur Weisheit emporführt.

Philosoph. Eben dieses haben zuerst die Pythagoreer, darauf die Platoniker gesagt, welchen letzteren auch Severinus Boetius folgt. 
Y diota. Pariformiter dico exemplar concepcionum nostre mentis numerum esse, sine numero enim nichil facere potest, neque assimilacio neque nocio neque discrecio neque mensuracio fieret numero non existente. Res enim non possunt alie et alie et discrete sine numero intelligi, nam 5 quod alia res est substancia et alia quantitas et ita de aliis, sine numero non intelligitur. Unde cum numerus sit modus intelligendi, nichil sine eo intelligi potest, numerus enim nostre mentis ${ }^{2}$ ) (cum sit ymago numeri divini, qui est rerum exemplar) est exemplar nocionum. Et sicut ante omnem pluralitatem est unitas, et hec ${ }^{b}$ ) unitas uniens ${ }^{c}$ ) est ${ }^{d}$ ) mens increata, 10 in qua omnia unum, post unum pluralitas explicacio virtutis illius unitatis, que virtus est rerum entitas, essendi equalitas et entitatis equalitatisque connexio. Et hec trinitas benedicta sic in nostra mente est illius trinitatis divine ymago, nam mens nostra similiter est unitas uniens ante omnem pluralitatem per mentem conceptibilem. Et post illam unitatem unientem 15 omnem pluralitatem est pluralitas, que est pluralitatis rerum ymago sicut mens nostra divine mentis ymago, et explicat pluralitas virtutem unitatis mentis, que virtus est ymago entitatis, equalitatis et connexionis.

Philosophus. Video te ex numero mira attingere, age igitur, quoniam divinus Dionisius ait ${ }^{\mathrm{e}}$ ), essencias rerum incorruptibiles ${ }^{1}$ ), an hoc 30 numero ostendere possis.

Ydiota. Quando | attendis ex multitudine unitatis numerum con2I v. stitui, ac quod alteritas sequitur multiplicacionem contingenter, et advertis composicionem numerif ${ }^{f}$ ) ex unitate et alteritate, ex eodem et diverso, ex pari et impari, ex dividuo et individuo, ac quod quidditas rerum ${ }_{25}$ omnium exorta est, ut sit numerus divine mentis, tunc aliqualiter attingis, quomodo essencie rerum sunt incorruptibiles uti unitas, ex qua numerus, que est ${ }^{g}$ ) entitas, et quomodo res sunt sic et sic ex alteritate, que non est de essencia numeri, sed contingenter unitatis multiplicacionem sequens; ita quidem alteritas de nullius rei essencia est, pertinet enim ad interitum 30 alteritas, quia divisio est, ex qua corrupcio, hinc de essencia rei non est. Conspicis eciam, quomodo non est aliud numerus quam res numerate, ex quo ${ }^{h}$ ) habes inter mentem divinam et res non mediare numerum, qui habeat actuale esse, sed numerus rerum res sunt.
a) danach est getilgt $\mathrm{Hs}$.
b) danach est getilgt $H s$.
c) hier numero uniens am Rand hinzugefügt Hs. d) est über der Zeile ergänzt Hs.
e) über der Zeile Ras Hs. f) numeri am Rand hinzugefügt Hs.
g) danach et getilgt $H$ s.
h) hoc korr. quo Hs.
I) cf.: De dio hominibus c. $5 \S 8$, cf. c. $13 \S 3$. 
Laie. So sage ich denn gleich ihnen, daß das Urbild der Begriffe unseres Geistes die Zahl sei. Denn ohne die $Z$ ahl vermag der Geist nichts $\mathrm{zu}$ leisten: keine Angleichung, keinen Begriff, keine Unterscheidung und kein Messen würde es geben, wenn es nicht Zahl gäbe; denn die Dinge können als verschiedenartige und getrennte nicht begriffen werden ohne die $Z$ ahl, denn, daß Substanz und Quantität verschieden sind usf., wird nicht erkannt ohne Zahl. Da die Zahl also die Art und Weise des Erkennens selbst ausmacht, kann nichts ohne sie erkannt werden; denn da die Zahl unseres Geistes ein Abbild der göttlichen $Z$ ahl ist, welche das Urbild der Dinge ist, ist sie Urbild der Begriffe. Und wie vor aller Vielheit gibt es auch hier eine Einheit, und diese einigende Einheit ist der ungeschaffene Geist, in welchem alles Eines ist. Und diesem Einen folgt die Vielheit als Entfaltung der Kraft jener Einheit, die das Sein der Dinge, die Gleichheit des Seins, und die Verknüpfung des Seins und der Gleichheit, ist. Diese gebenedeite Dreieinigkeit ist in unserem Geist? als dem Bilde jener göttlichen Dreieinigkeit. Denn unser Geist ist auf ähnliche Weise eine einigende Einheit, die aller Vielheit, die er $\mathrm{zu}$ begreifen vermag, vorausgeht. Erst nach jener Einheit, welche jede Vielheit in sich vereinigt, ist die Vielheit, welche ein Abbild der Vielheit der Dinge ist, wie unser Geist ein Abbild ist vom göttlichen Geiste. Es entfaltet die Vielheit die Kraft der Einheit des Geistes, welche Kraft ein Abbild ist des Seins der Gleichheit, und ihrer Verknüpfung.

Philosoph. Ich sehe, daß Du mit Hilfe der Zahl Wunderbares begreifst. Da nun der göttliche Dionysius sagt, da $\beta$ die Wesenheiten der Dinge unvergänglich seien, so versuche du, ob Du das an der Zahl nachweisen kannst.

Laie. Wenn Du darauf achtest, daß die Zahl sich aus der Vielheit der Einheit konstituiert, und die Andersheit der Vielheit nur zufällig folgt, und wenn Du die Zusammensetzung der Zahl aus Einheit und Verschiedenheit, aus Geradem und Ungeradem, aus Teilbarem und Unteilbarem bemerkst, und wenn Du siehst, daß die Beschaffenheit aller Dinge entstanden ist, damit die Zahl des göttlichen Geistes wirklich werde, dann begreifst Du irgendwie, inwiefern die Wesenheiten der Dinge unvergänglich sind, ebenso wie es die Einheit ist, aus der die Zahl entsteht, die ja auch reines Sein ist. Und Du siehst nun auch wie die Dinge so oder auf eine andere Weise sind infolge der Andersheit, welche zum Sein der Zahl nicht gehört, sondern nur zufällig aus der Vielheit der Einheit folgt, und so gehört auch die Andersheit zum Wesen keines Dinges. Denn die Andersheit ist das, was die Vergänglichkeit ausmacht, da sie Teilung ist und durch diese entsteht der Verderb und daher gehört sie nicht zum Wesen der Dinge. Du erkennst auch, daß Zahl und gezählte Dinge nichts verschiedenes seien; daraus ergibt sich denn, daß zwischen dem göttlichen Geiste und den Dingen nicht die Zahl als ein Mittleres, das eine eigene Wirklichkeit hat, steht; sondern die Zahl der Dinge besteht nur in den Dingen selbst. 
Capitulum septimum,

Quomodo mens a se exerit rerum formas via assimilacionis et possibilitatem absolutam seu materiam attingit. ${ }^{2}$ )

Philosophus. Dic oro, putas ne mentem nostram esse armoniam 5 aut numerum se moventem aut composicionem ex eodem et diverso vel ex dividua et individua essencia vel endelechiam, nam talibus dicendi modis Platonici et Peripatetici ${ }^{\mathrm{b}}$ ) utuntur.

Y diota. Credo omnes, qui de mente locuti sunt, talia vel alia dixisse potuisse $\operatorname{motos}^{\mathrm{c}}$ ) ex hiis, que in vi mentis experiebantur. De omni ${ }_{10}$ enim armonia iudicium in mente reperiebant mentemque ex se nociones fabricare et sic se movere, quasi vivus numerus discretivus per se ad faciendum discreciones procederet, et iterum in hoc collective ac distributive procedere aut secundum modum simplicitatis ac necessitatis absolute vel possibilitatis absolute vel necessitatis compleccionis vel determinate ${ }_{15}$ vel possibilitatis determinate ${ }^{\mathrm{d}}$ ) aut ob aptitudinem perhenni motus, ob has aut similes varias experiencias talia ac alia de mente aut anima dixisse racionabiliter credendum. Nam mentem esse ex eodem et diverso est eam esse ex unitate et alteritate eo modo, quo numerus compositus est ex eodem quantum ad commune et diverso quantum ad sin20 gularia, qui sunt modi intelligendi mentis.

Philosophus. Continua exponendo animam numerum se moventem.

Ydiota. Faciam ut potero. Arbitror omnes non posse dissentire mentem esse vivum quendam divinum numerum optime ad aptitudinem ${ }_{25}$ resplendencie divine armonie proporcionatum ac omnem sensibilem, racionalem et intellectualem armoniam complicantem, et quitquid circa hoc pulchrius dici potest adeo, quod omnis numerus et omnis proporcio et omnis armonia, que a nostra mente procedunt, ita parum ad mentem nostram $^{\mathrm{e}}$ ) accedunt, sicut mens nostra ad mentem infinitam. Nam mens, so et si sit numerus divinus, est tamen ita numerus, quod est unitas simplex I22 r. ex sua vi numerum suum exerens, unde, que est proporcio / operum Dei ad Deum, illa operum mentis nostre ad mentem ipsam.

Philosophus. Voluerunt plerique mentem nostram esse nature divine et menti divine propinquissime coniunctam.

a) Capitulum - attingit am Rand ergänzt Hs. $\quad$ b) Paripatetici $H s . \quad$ c) moti $H s$. d) deteriate $H s$ e) nostram mentem umgestellt Hs. 
7. Kapitel.

Der Geist schafft aus sich die Formen der Dinge kraft der Angleichung und kommt so in Berührung mit der absoluten Potentialität.

Philosoph. Sage doch bitte, ob du meinst, daß unser Geist Harmonie sei, oder etwa eine sich selbst bewegende Zahl oder eine Zusammenfügung, sei es aus Gleichem und Ungleichem, sei es aus Teilbarem oder Unteilbarem, oder ob Du meinst, er sei Entelechie; denn solcher Art des Ausdrucks bedienen sich die Platoniker und Peripatetiker.

Laie. Ich glaube, daß alle, welche über das Wesen des Geistes gesprochen haben, so etwas oder ähnliches haben sagen können, da sie durch das bestimmt wurden, was sie vermöge der Erfahrung in der Kraft des Geistes vorfanden. Denn sie fanden das Urteil über jede Art von Harmonie im Geiste, sie fanden, daß der Geist aus sich Begriffe erschafft und sich so bewegt, wie eine lebendige und unterscheidende $Z$ ahl durch sich allein zur Feststellung von Unterscheidungen fortschreiten würde; und sie fanden, daß er hierin wiederum verknüpfend und trennend vorgehe, und zwar entweder gemäß dem Modus der Einfachheit und der absoluten Notwendigkeit, oder gemäß dem Modus der absoluten Potentialität oder dem der Notwendigkeit der Verknüpfung, sei es nun dem der determinierten Verknüpfung oder dem der determinierten Potentialität; oder aber sie fanden, er schreite kraft der Fähigkeit zur ewigen Bewegung, die ihm innewohnt, fort. Wegen dieser und ähnlicher Erfahrungen von mannigfacher Art haben sie, wie man mit guten Gründen glauben muß, Solches oder Ähnliches über den Geist und die Seele gesagt. Denn wenn man behauptet, der Geist bestehe aus Gleichem und Verschiedenem, so heißt das, er bestehe aus Einheit und Andersheit, in der Weise, wie auch die $Z$ ahl insofern aus dem Gleichen zusammengestzt ist, insofern sie auf ein allgemeines geht und aus verschiedenem, insofern, sie sich auf ein Einzelnes bezieht; dieses sind nun Erkenntnisarten des Geistes.

Philosoph. Fahre in Deiner Auseinandersetzung darüber fort, daß die Seele eine sich selbst bewegende $Z$ ahl sei.

Laie. Das werde ich nach Kräften tun. Ich glaube, daß niemand bestreiten kann, daß der Geist eine lebendige göttliche Zahl und im höchsten Maße geeignet ist, die göttliche Harmonie in sich widerzuspiegeln und $\mathrm{da} \mathrm{B}$ er in sich jede Harmonie der Sinne, des Verstandes und der Vernunft befaßt, und was darüber hinaus noch Schöneres gesagt werden kann. Das ist er so sehr, daß jede Zahl, jedes Maßverhältnis und jede Harmonie, welche aus unserem Geiste hervorgeht, in gleicher Weise hinter unserem Geiste zurückbleibt, wie unser Geist hinter dem unendlichen Geiste. Denn obwohl der Geist eine göttliche Zahl ist, ist er doch insofern Zahl, als er eine einfache Einheit ist, die aus eigener Kraft ihre Zahl erschafft, Wie sich daher Gottes Werke zu Gott selbst verhalten, so verhalten sich die Werke unseres Geistes zum Geiste selbst.

Philosoph. Die meisten Denker haben unserem Geiste eine göttliche Natur zuschreiben wollen, und haben behauptet, er sei mit dem göttlichen Geiste aufs engste verbunden. 
Ydiota. Non puto aliud illos voluisse, quam dixi, licet alium dicendi modum haberent. Inter enim divinam mentem et nostram interest, quod inter facere et videre. Divina mens concipiendo creat, nostra concipiendo assimilat nociones seu intellectuales faciendo visiones. Di5 vina mens est vis entificativa, nostra mens est vis assimilativa.

Orator. Video philosopho tempus non sufficere, ideo longo silencio me repressi; audivi plura et semper gratissima, sed audire vellem, quomodo mens ex se exerit rerum formas via assimilacionis.

$\mathrm{Y}$ diota. Mens est adeo assimilativa, quod in visu se assimilat visi10 bilibus, in auditu audibilibus, in gustu gustabilibus, in odoratu odorabilibus, in tactu tangibilibus et in sensu sensibilibus, in ymaginacione ymaginabilibus et in racione racionabilibus. Habet enim se ymago $^{2}$ ) in absencia sensibilium ut sensus aliquis absque discrecione sensibilium, nam conformat se absentibus sensibilibus confuse absque hoc, quod sta15 tum a statu discernat, sed in racione cum discrecione status a statu se rebus conformat. In illis omnibus locis vehitur in spiritu arteriarum mens nostra, que excitata per obstaculum specierum ab obiectis ${ }^{b}$ ) ad spiritum multiplicatarum se assimilat rebus per species, ut per assimilacionem iudicium faciat de obiecto. Unde spiritus ille subtilis arteriarum, qui 20 est mente animatus, per mentem ad similitudinem speciei, que obstaculum prestitit motui, spiritui sic conformatur, sicut cera flexibilis per hominem mentis usum ac artem habentem configuratur rei presencialiter $^{c}$ ) artifici presentate. Nam omnes configuraciones sive in arte statuaria aut pictoria aut fabrili absque mente fieri nequeunt, sed mens est, 25 que omnia terminat. Unde si conciperetur cera mente informata, tunc mens intus existens configuraret ceram omni figure sibi presentate, sicut nunc mens artificis ab extrinseco applicata facere nititur; sic de luto et omnibus flexibilibus. Sic in nostro corpore mens facit secundum variam flexibilitatem spirituum arteriarum in organis varias configura30 ciones subtiles et grossas, et unus spiritus non est configurabilis ad id, ad quod alius, quia spiritus in nervo optico non est offendibilis per species sonorum, sed solum per species colorum, ideo configurabilis est speciebus colorum et non sonorum. Ita de aliis. Et est alius spiritus ad omnes sensibiles species configurabilis ${ }^{\mathrm{d}}$ ), qui est in organo ymaginative, sed grosso

\footnotetext{
a) ymago se umgestellt $H$ s.

b) am linken Rand eine Lücke im Papier Hs.

c) principaliter am Rand korr. presencialiter $\mathrm{Hs}$.

d) configurabiles korr. configurabilis $H s$.
} 
Laie. Ich glaube, daß sie nicht anderes haben sagen wollen, als ich, obwohl sie sich auf andere Weise ausdrückten. Zwischen dem göttlichen Geiste und dem unseren ist nämlich derselbe Unterschied, wie zwischen „Tun“ und „Sehen"; der göttliche Geist schafft, wenn er begreift, der unsrige ähnelt sich an, wenn er begreift, indem er Begriffe oder Gesichte der Vernunft hervorbringt; der göttliche Geist ist eine Kraft, welche Sein erschafft, der unsrige eine Kraft, welche sich anähnelt.

Redner. Ich sehe ein, daß den Philosophen die Kürze der Zeit drängt; daher habe ich mich lange Zeit zurückgehalten, und habe viele Dinge von höchster Bedeutsamkeit gehört. Ich möchte jedoch noch hören auf welche Weise der Geist die Formen der Dinge aus sich hervorbringt, kraft seines Vermögens der Anähnelung.

Laie. Der Geist ist in so hohem Maße ein sich angleichendes Vermögen, daß er sich beim Sehen dem Sichtbaren angleicht, beim Hören dem Hörbaren, beim Schmecken dem Schmeckbaren, beim Riechen dem Riechbaren, beim Tasten dem Tastbaren, beim Wahrnehmen dem Wahrnehmbaren, beim Vorstellen dem Vorstellbaren, beim Verstehen dem Verstehbaren. Denn es verhält sich ein Vorstellungsbild ohne Gegenwart der sinnlichen Gegenstände wie sich ein Sinn verhält ohne Unterscheidung der sinnlichen Gegenstände; denn es formt sich wohl in unbestimmter Weise den sinnlichen Gegenständen an, aber ohne streng einen Zustand von einem anderen zu unterscheiden. Im Verstande jedoch formt es sich den Dingen wirklich an mit strenger Unterscheidung eines Zustandes von einem anderen. Und überallhin eilt unser Geist, getragen vom arteriellen Geist. Angeregt nun wird er durch die Begegnung mit den Bildern, die von den Gegenständen aus in den arteriellen Geist auf vielfältige Weise eingehen, und er assimiliert sich den Dingen vermittels dieser Bilder, um so kraft dieser Assimilation ein Urteil über den Gegenstand fällen zu können. Und so gelangt jener feine arterielle Geist, der vom Geiste belebt wird, vermöge des Geistes zur Ähnlichkeit mit der Form, welche seiner Bewegung ein Hindernis entgegensetzt; auf gleiche Weise, wie ein biegsames Wachs vom Menschen, der die gestaltende Kraft seines Geistes gebraucht, dem Dinge nachgebildet wird, welches der Künstler gerade vor Augen hat; denn keine Nachbildung einer Gestalt in der Bildhauerei, der Malerei oder im Handwerk kann ohne den Geist stattfinden; der Geist vielmehr ist es, welcher alles bestimmt. Wenn man sich daher vorstellte, dem Geiste sei Wachs einverleibt, dann würde der Geist, der innen wohnt, das Wachs jeder ihm dargebotenen Gestalt nachformen, wie es sich jetzt der Geist des Künstlers, der von außen angeregt wird, zu tun bemüht, und in gleicher Weise wäre es mit Lehm und mit anderen biegsamen Gegenständen. So erschafft in unserem Körper der Geist je nach der verschiedenartigen Geschmeidigkeit der arteriellen Geister in den Organen verschiedenartige Bildungen von Formen, feine und grobe, und ein arterieller Geist ist nicht auf gleiche Weise formbar, wie ein anderer; denn der arterielle Geist im Sehnerv kann nicht von Tonbildern getroffen werden, sondern nur von Farbbildern; daher kann er nur Farbbildern und nicht Tönen angeformt werden usf. Ein anderer Geist, welcher sich im Organ der Vorstellungskraft befindet, ist zu allen sinnlichen Bildern überhaupt formbar, ist jedoch von grober und schlecht unterscheidender Art. 
et indiscreto modo, et alius in organo raciocinative est ad omnia sensibilia discrete et lucide configurabilis, et hee omnes configuraciones sunt I22 v. assimilaciones | sensibilium, cum fiant medio corporalium spirituum licet subtilium. Unde cum mens has faciat assimilaciones, ut nociones 5 habeat sensibilium, et sic est immersa spiritui corporali, tunc agit ut anima animans corpus, per quam animacionem constituitur animal. Hinc anima brutorum consimiles, licet confusiores, suo modo facit assimilaciones, ut suo modo nociones assequatur, sed nostra vis mentis ex illis talibus nocionibus sic per assimilacionem elicitis facit mechanicas artes 10 et phisicas ac logicas coniecturas et res attingit modo, quo in possibilitate essendi seu materia concipiuntur, et modo, quo possibilitas essendi est per formam determinata. Unde cum per has assimilaciones non attingat nisi sensibilium nociones, ubi forme rerum non sunt vere, sed obumbrate variebilitate materie, tunc omnes nociones tales sunt pocius 15 coniecture $^{a}$ ) quam veritates. Sic itaque dico, quod nociones, que per racionales assimilaciones attinguntur, sunt incerte, quia sunt secundum ymagines pocius formarum quam veritates. Post hec mens nostra, non ut immersa corpori, quod animat, sed ut est mens per se, unibilis tamen corpori, dum respicit ad suam immutabilitatem, facit assimilaciones for20 marum, non ut sunt immerse materie, sed ut sunt in se et per se et immutabiles. Concipit rerum quidditates, utens se ipsa pro instrumento $\sin ^{\mathrm{b}}$ ) spiritu aliquo organico, sicut, dum concipit circulum esse figuram, a cuius centro omnes linee ${ }^{c}$ ) ad circumferenciam ducte sunt equales, quo $^{d}$ ) modo essendi circulus extra mentem in materia esse nequit. Im${ }_{95}$ possibile est $^{\mathrm{e}}$ ) enim duas dari lineas in materia equales, minus est possibile talem circulum posse figurari. Unde circulus in mente est exemplar et mensura veritatis circuli in pavimento. Sic dicimus veritatem rerum in mente esse in necessitate complectionis, scilicet modo, quo exigit veritas rei, ut de circulo dictum est; et, quia mens ut in se et a materia 30 abstracta has facit assimilaciones, tunc se assimilat formis abstractis. Et secundum hanc vim exerit sciencias certas mathematicales et comperit virtutem suam esse se rebus, prout in necessitate ${ }^{f}$ ) compleccionis sunt, assimilandi et nociones faciendi. Et incitatur ad has assimilaciones abstractivas per fantasmata seu ymagines formarum, quas per assimila-

a) conjecture pocius umgestellt Hs. $\quad$ b) sive $H s$.

c) danach ducte getilgt Hs. d) am rechten Rand Lücke im Papier Hs.

e) danach Rasur Hs. f) danach sunt getilgt $\mathrm{Hs}$. 
Wieder ein anderer befindet sich im Organ der Urteilskraft und ist $\mathrm{zu}$ allem Sinnlichem formbar, und zwar in klarer Unterscheidung. Alle diese Formbildungen sind Assimilationen an das Sinnliche, da sie vermittels der arteriellen Geister zustande kommen, welche körperlich sind, mögen sie auch noch so fein sein. Wenn nun der Geist diese Assimilationen vollbringt, damit er Begriffe vom Sinnlichen gewinnt, und so in den körperlichen Geist eintaucht, verfährt er in gleicher Weise, wie die den Körper belebende Seele, durch deren Belebung ja das Lebewesen belebt wird. Daher ruft die Seele der Tiere ähnliche, wenn auch verworrene, Assimilationen auf ihre Weise hervor, so daß sie sogar auf ihre Weise zu Begriffen gelangen können. Die Kraft unseres Geistes aber erschafft aus solchen Begriffen, die vermöge der Assimilation gewonnen sind, mechanische Künste, physikalische und logische Schlüsse und Theorien, und geht an die Dinge sowohl so heran, wie sie in der Potentialität ihres Seins, also in der Materie, erfaßt werden, als auch so, wie diese Potentialität durch die Form determiniert ist. Sofern er nun vermöge dieser Assimilation nur zu Begriffen vom Sinnlichen kommt, wo die Formen der Dinge nicht die wahren sind, sondern vielmehr verdunkelt durch die Veränderlichkeit der Materie, sind alle solche Begriffe vielmehr Vermutungen als feste Wahrheiten. Daher sage ich denn auch, daß die Begriffe, welche vermöge der Assimilationen des Verstandes zustande gebracht werden, ungewiß sind, weil sie eher den Bildern der Formen gemäß sind, als den wirklichen Wahrheiten. Darauf aber schreitet unser Geist - nicht mehr, so fern er in den Körper eingetaucht ist und ihn beseelt, sondern als Geist an sich, wenn auch mit dem Körper vereinbar - dadurch, daß er auf seine Unveränderlichkeit blickt, zur Assimilation an die Formen, die nicht mehr mit der Materie vermischt, sondern für sich und an sich und unveränderlich sind, und erfaßt die Beschaffenheiten der Dinge, seiner selbst sich als Werkzeug bedienend, ohne die Vermittlung irgendeines organischen Geistes. So ist es zum Beispiel, wenn der Geist begreift, daß der Kreis eine Figur sei, von deren Mittelpunkt aus alle Linien, welche zur Peripherie gezogen werden, gleich lang sind, von welcher Seinsbeschaffenheit ja der materielle Kreis außerhalb des Geistes niemals wirklich sein kann. Denn es ist ja unmöglich, daß in der Materie auch nur zwei völlig gleiche Linien gegeben wären; noch weniger also ist es möglich, daß in ihr ein solcher Kreis gebildet werden könnte. Daher ist der Kreis im Geiste das Urbild und das Maß der Wahrheit des Kreises, der beispielsweise auf den Boden gezeichnet wird. So sagen wir denn, daß die Wahrheit der Dinge im Geiste sei, und zwar in notwendiger Verknüpfung, d. h. so, daß die Wahrheit der Sache sich in der Weise zeigt, wie es eben am Kreise gezeigt worden ist. Und da der Geist dann ja, als für sich seiend und losgelöst von der Materie bestehend, diese Assimilation vollzieht, assimiliert er sich hierin den abstrakten Formen. Und kraft dieses Vermögens erschafft er die sicheren mathematischen Wissenschaften, und wird sich der ihm eigentümlichen Kraft bewußt, welche darin besteht, daß er sich den Dingen, insofern sie einer notwendigen Verknüpfung unterworfen sind, assimiliert und Begriffe von ihnen bildet. Und er wird $\mathrm{zu}$ abstrahierender Assimilation bewogen durch die Vorstellungen und Abbilder der Formen, welche er in den Sinnesorganen vorfindet, und welche vermöge der Assi- 
ciones factas in organis deprehendit, sicut excitatur quis ex pulchritudine ymaginis, ut inquirat pulchritudinem exemplaris, et in hac assimilacione se habet mens, ac si flexibilitas absoluta a cera, luto, metallo et omnibus flexibilibus foret viva vita mentali, ut ipsa per seipsam se omnibus 5 figuris, ut in se et non in materia subsistunt, assimilare possit. Talis enim in vi sue flexibilitatis vive, hoc est in se, nociones omnium (quoniam omnibus se conformare posset) esse conspiceret, et, quia adhuc hoc modo mens non saciatur, quia non intuetur precisam omnium veritatem, sed intuetur veritatem ${ }^{a}$ ) in necessitate quadam determinata cuilibet, prout I23 r. una est sic alia sic, et / quelibet ex suis partibus composita, et videt, quod 11 hic modus essendi non est ipsa veritas, sed participacio veritatis, ut unum sic sit vere et aliud aliter sit vere, que quidem alteritas nequaquam convenire potest veritati in se in sua infinita et absoluta precisione considerate $^{\mathrm{b}}$ ). Unde mens respiciendo ad suam simplicitatem, ut scilicet est 15 non solum abstracta a materia, sed ut est materie incommunicabilis seu modo forme inunibilis, tunc hac simplicitate utitur ut ${ }^{\mathrm{c}}$ ) instrumento, ut non solum abstracte extra materiam, sed in simplicitate materie incommunicabili se omnibus assimilet. Et hoc modo in simplicitate sua omnia intuetur, sicut si in puncto omnem magnitudinem et in centro cir2o culum et ibi omnia intuetur absque omni composicione parcium et non, ut unum est hoc et aliud illud, sed ut omnia unum et unum omnia. Et hec est intuicio veritatis absolute, quasi si quis in proxime dicto modo videret, quomodo in omnibus entibus est entitas varie participata. Et post hoc modo, de quo nunc agitur, supra participacionem et varietatem 25 omnem ipsam entitatem absolutam simpliciter intueretur. Talis ${ }^{\mathrm{d}}$ ) profecto supra determinatam compleccionis necessitatem videret omnia, que vidit in varietate, absque illa in absoluta necessitate simplicissime sine numero et magnitudine et omni alteritate. Utitur autem hoc altissimo modo mens se ipsa, ut ipsa est Dei ymago et Deus, qui est omnia, in so ea relucet, scilicet quando ut viva ymago Dei ad exemplar suum se omni conatu assimilando convertit. Et hoc modo intuetur omnia unum et se illius unius ${ }^{\mathrm{e}}$ ) assimilacionem, per quam ${ }^{\mathrm{f}}$ ) nociones facit de uno, quod omnia, et sic facit theologicas speculaciones, ubi tamquam in fine omnium nocionum quam suaviter ut in delectabilissima veritate vite sue quiescit, 35 de quo modo nunquam satis dici posset. Hec autem nunc sic dixerim
a) danach in getilgt Hs.
c) ut über der Zeile ergänzt Hs.
b) considerata Hs.
e) unius illius umgestellt Hs.
d) unleserl. Randbemerkung $H$ s.
f) danach assimilacionem getilgt $H s$. 
milationen entstanden sind, ganz wie jemand durch die Schönheit eines Bildes dazu bewogen wird, daß er nach der Schönheit des Urbildes forscht. Und bei diesen Assimilationen verhält sich der Geist, gleich als ob die absolute Geschmeidigkeit des Wachses, des Lehmes, des Metalles, und aller biegsamen Körper überhaupt, in einem geistigen Leben in ihm lebendig wäre, so daß er sich durch sich selbst allen Figuren assimilieren kann, und zwar so, wie die Figuren an sich selbst sind, nicht so, wie sie in der Materie existieren. Denn ein solcher Geist würde gewahr werden, daß in der Kraft seiner lebendigen Geschmeidigkeit, das ist in ihm selbst, die Begriffe von allem seien, da er sich ja ihnen allen anformen könnte. Und weil auf diese Weise der Geist nicht gesättigt wird, da er nicht die genaue Wahrheit von allem erschauen kann, sondern nur eine Wahrheit, welche innerhalb eines gewissen $Z$ wanges für jedes einzelne determiniert ist (insofern sie auf eine Weise eine Wahrheit ist, auf eine andere eine andere); und da so jede Wahrheit aus ihren Teilen zusammengesetzt ist, so sieht er, daß diese Art des Seins nicht die Wahrheit selbst ist, sondern nur eine Teilhabe an der Wahrheit, so, daß das eine auf solche Weise wahr ist, und ein anderes auf eine andere, eine Verschiedenheit, die auf keine Weise mit der Wahrheit übereinstimmt, wie sie in sich ist, wenn sie in ihrer unendlichen und absoluten Genauigkeit betrachtet wird. Darum blickt der Geist auf seine eigene Einfachheit, wie sie nicht nur von der Materie losgelöst ist, sondern überhaupt mit der Materie nicht in Verbindung treten und sich mit ihr nicht als Form verknüpfen kann, und er gebraucht diese Einfachheit gleichsam als Werkzeug, auf daß er nicht nur abstrakt außer der Materie, sondern in seiner Einfachheit, welche mit der Materie nicht in Verbindung treten kann, sich allem assimiliere. Auf diese Weise, in seiner Einfachheit, vermag er alles zu erschauen, gleich als ob er in einem Punkte jede Größe erschaute, und im Mittelpunkte den Kreis, und hier schaut er alles, ohne jede Zusammensetzung der Teile, und nicht mehr ist das Eine dieses, das Andere Jenes, sondern wie alles Eines ist, ist auch Eines alles. Und dies ist die Schau der absoluten Wahrheit, wenn nämlich jemand in der eben gesagten Art sähe, inwiefern in allem Seienden das Sein, nur in jedem auf verschiedene Weise ist. Und wenn er danach, über jede Teilung und jede einzelne Wahrheit hinaus, auf die eben besprochene Art und Weise die absolute Seinsheit auf einfache Weise erschaute, so würde ein solcher sicherlich, über die determinierte Notwendigkeit der Verknüpfung hinaus, alles erblicken, was er sonst nur in seiner Mannigfaltigkeit sieht, und er würde es sehen ohne Mannigfaltigkeit, in höchster Einfachheit und absoluter Notwendigkeit, ohne Zahl und Größe und ohne jede Andersheit überhaupt. Auf diese erhabene Weise bedient sich der Geist seiner selbst, wie er ist, ein Bild Gottes; und Gott, der alles ist, scheint dann in ihm wieder, wenn er sich mit allen Kräften müht, sich seinem Urbild ähnlich zu machen. Und auf diese Weise vermag er alles als Eines zu erblicken, und erblickt sich selbst als das, was sich jenem Einen ähnlich macht, das Begriffe schafft, über das Eine, welches Alles ist, und so gelangt er $\mathrm{zu}$ theologischen Spekulationen. Und dort ruht er gleichsam am Ende aller seiner Begriffe sich in höchster Lust aus, in der glückseligen Wahrheit seines Lebens. Und hierüber kann niemals genug gesagt werden. Dieses aber 
cursorie et rustice, tu vero decora limacione pulchrius ea poteris adaptare, ut reddantur legentibus graciora.

Orator. Non nisi hoc audire quam avide expectavi, quod sic luculentissime explanasti et veritatem querentibus quam ornatum videbitur. ${ }^{a}$ )

5 Philosophus. Expone queso, quomodo mens possibilitatem indeterminatam, quam materiam vocamus, attingit.

Ydiota. Per adulterinam quandam racionem contrario quodam modo, quo de necessitate compleccionis ad necessitatem transilit absolutam. Nam, dum videt, quomodo omnia corpora per corporeitatem ha10 bent formatum esse, sublata corporeitate in quadam indeterminata possibilitate omnia, que prius vidit, videt. Et que prius vidit in corporeitate distincta et determinata actu existencia, nunc videt confusa indeterminata possibiliter, et hic est modus universitatis, quo modo in possibilitate omnia videntur; non tamen est modus essendi, quia posse esse 15 non est.

Octavus tractatus. ${ }^{b}$ ) Capitulum octavum.

Quomodo an idem sit menti concipere, intelligere, nociones et assimilaciones facere; et quomodo fiant sensaciones secundum phisicos. $\left.{ }^{\circ}\right)$

20 Philosophus. Satis de hoc; ne propositum egrediamur, expone, si concipere mentis est intelligere.

I23 v. Ydiota. Dixi mentem concipiendi virtutem. | Unde excitata se movet concipiendo, quousque intelligat, quare intellectus est mentis motus perfectus.

Philosophus. Quando dicitur concipere.

Ydiota. Quando rerum facit similitudines sive mavis dicere nociones seu genera, differencias, species, proprium et accidens. Unde Deus vim concipiendi creavit in anima, mens autem ea iam dicta facit. Unum tamen et idem est vis mentis et concepcio et similitudo et nocio et genus $s 0$ et species; et, quamvis non dicamus idem intelligere et concipere, tamen quidquid intelligitur et concipitur et econverso, sed actuale intelligitur et non concipitur.

Philosophus. Quomodo ais.

Ydiota. Concipere non est nisi modo materie vel forme vel alio 35 modo comprehendere, actuale vero dicitur intelligi, id est proprietas eius

\footnotetext{
a) ornata videbuntur $H s . \quad$ b) tractatus fehlt $H s$.

c) Octavus - phisicos am Rand evgänzt Hs.
} 
möchte ich jetzt gesagt haben, obenhin und ungeschliffen, wie es meine Art ist. Du aber wirst meine Worte durch geziemende Feilung schöner machen können, auf daß sie dem Leser angenehmer klängen.

Redner. Mit aller Begier habe ich gehofft, das zu hören, was Du so lichtvoll auseinandergesetzt hast, und was denen, die nach Wahrheit suchen, schön und herrlich erscheinen wird.

Philosoph. Setze doch bitte auseinander, auf welche Weise der Geist an die ,,indeterminierte Potentialität“, welche wir Materie nennen, herantritt.

Laie. Gewissermaßen vermöge eines Bastardschlusses, in umgekehrter Art, wie bei seinem Aufstieg von der Notwendigkeit der Verknüpfung zur absoluten Notwendigkeit. Denn, wenn er sieht, inwiefern alle Körper vermöge ihrer Körperlichkeit die Eigenschaft besitzen, gestaltet und geformt zu sein, hebt er alle Körperlichkeit auf und sieht in einer gewissen indeterminierten Potentialität alles, was er vorher gesehen hat. Und was er vorher in der Körperlichkeit als Unterschiedenes und Determiniertes und aktuell Seiendes gesehen hat, das sieht er nun als Zusammenfließendes, Indeterminiertes in bloßer Potentialität. Und das ist die Art der Allgemeinheit, in welcher alles nur in der Potentialität erscheint; Potentialität aber, das ist Möglichkeit zu sein, ist keine Art des Seins, denn das, was nur sein kann, ist eben nicht.

\section{Kapitel.}

Es wird gezeigt, daß für den Geist Begreifen, Einsehen und Bildung von Begriffen und Assimilation das Gleiche ist. - Das Zustandekommen der Empfindungen gemäß den Lehren der Physik.

Philosoph. Davon genug. Damit wir nicht von dem abkommen, was wir uns vorgenommen haben, setze auseinander, ob das Begreifen des Geistes ein vernünftiges Erkennen ist.

Laie. Ich habe gesagt, daß der Geist das Vermögen des Begreifens sei. Wenn er daher affiziert wird, bewegt er sich durch das Begreifen bis zur vernünftigen Erkenntnis. Daher ist diese letztere die vollendete Bewegung des Geistes.

Philosoph. Wann sagt man denn vom Geiste, daß er begreife?

Laie. Wenn er Ähnlichkeiten der Dinge erfaßt oder, wenn dir der Ausdruck lieber ist, dann, wenn er Gattungen, Unterscheidungen, Arten, Eigenschaften oder Akzidenzen feststellt. So hat denn Gott die Kraft des Begreifens in der Seele geschaffen, der Geist aber tut das, was wir eben gesagt haben. All dieses ist jedoch ein- und dasselbe, ob man nun von der Kraft des Geistes, dem Begreifen der Ähnlichkeit, dem Begriffe, der Gattung oder der Art spricht. Und obwohl wir nicht sagen, daß Begreifen und vernünftiges Erkennen dasselbe sei, so muß doch, was vernünftig erkannt werden soll, auch begriffen werden, und umgekehrt: das höchste aktuale Sein aber wird vernünftig erkannt und nicht begriffen.

Philosoph. Wie meinst Du das?

Laie. Begreifen ist nur ein Erfassen unter dem Modus der Materie oder der Form, oder unter irgend einem sonstigen Modus: das aktuale Sein aber wird vernünftig erkannt d. h. seine Eigentümlichkeit 
mente comprehenditur. Dicitur eciam mens intelligere, ex quo movetur, et inicium motus pocius passio dicitur, perfeccio motus intellectus, sed, ut idem est disposicio et habitus, disposicio, dum tendit ad perfeccionem, et post perfeccionem habitus, ita unum et idem passio mentis et intel5 lectus.

Philosophus. Tamen intellectus non videtur dicere perfeccionem.

Ydiota. Bene ais. Proprie mens dicitur intelligere, quando movetur, licet non dicatur intellectus nisi post perfeccionem.

Philosophus. Sunt igitur illa omnia unum et idem vis concipiendi, 10 concepcio, similitudo, nocio, passio et intellectus.

Ydiota. Sunt sic idem, quod vis concipiendi non est aliquid eorum, quia dicitur vis ab aptitudine, quam habet a creacione, concepcio ab imitacione, quia imitatur materiam vel ${ }^{\mathrm{a}}$ ) formam, scilicet eo, quod modo materie vel forme vel compositi comprehendit, ex eo autem, quod con15 cepcio dicitur, ex eo eciam similitudo seu nocio rei; et hec vocabula veraciter de se predicantur, et quodlibet dicitur intellectus.

Philosophus. Miror, quomodo concepcio possit dici intellectus.

Ydiota. Quamvis concepcio dicatur ab imitacione et intellectus a perfeccione, tamen hoc facit perfeccio, quod intellectus dicatur conso cepcio. Tunc enim mens concipit, cum ad perfeccionem ducitur intellectus.

Philosophus. Vis forte eciam admittere passionem mentis vocari intellectum.

Y diota. Volo, nam motus mentis est intellectus, cuius inicium est ${ }_{25}$ passio.

Philosophus. Igitur et concepcio passio.

Ydiota. Non sequitur, ut per te vides; similiter, quamvis genera et species sint intellectus, tamen non propterea sunt passiones anime, transit enim passio anime manentibus generibus et speciebus.

30

Philosophus. Satis de hoc, cum varii varie loquantur. De istis sufficiat michi te audivisse, sed dicito, quomodo nominas vim illam mentis, qua omnia in necessitate compleccionis intuetur, et aliam, qua in necessitate absoluta.

Ydiota. Ego, qui sum idiota, non multum ad verba attendo, puto 35 tamen, quod convenienter vis illa disciplina dici possit, qua mens ad

a) et am Rand korr. vel Hs. 
wird im Geiste erfaßt. Man sagt auch, daß der Geist erkenne, weil er in Bewegung gesetzt werde, und der Anfang der Bewegung kann eher ein Erleiden genannt werden, die Vollendung der Bewegung ein Erkennen. Wie aber Anlage (dispositio) und Zustand (habitus, हैं $\iota_{\zeta}$ ) dasselbe sind, denn von Anlage spricht man, solange etwas noch nach seiner Vollendung strebt, von Zustand, nachdem es diese Vollendung erreicht hat so ist das Erleiden des Geistes und seine Erkenntnis ein und dasselbe.

Philosoph. Dennoch scheint doch das Wort Erkenntnis keinen Zustand der Vollendung auszudrücken.

Laie. Richtig. Die Tätigkeit des Erkennens sprechen wir dem Geist zu, sofern er sich in Bewegung befindet: von Erkenntnis aber sprechen wir erst dort, wo er zu seiner Vollendung gelangt ist.

Philosoph. Jene Ausdrücke besagen also insgesamt ein und dasselbe: Vermögen zu begreifen, Begreifen, Ähnlichkeit, Begriff, Erleiden und Erkenntnis.

Laie. Sie sind in dem Sinne eins, daß das Vermögen des Begreifens durch keinen dieser Ausdrücke allein bezeichnet werden kann. Denn Vermögen nennen wir dasselbe kraft der Tätigkeit, die es mit seiner Erschaffung mitbekommen hat - vom Begreifen sprechen wir, weil es die Materie oder die Form nachahmt, da es bald im Modus der Materie, bald der Form, bald des aus beiden Zusammengesetzten erfaßt. Aus dem nämlichen Grunde aber, aus dem es Begreifen genannt wird, wird es auch Ähnlichkeit oder Begriff einer Sache genannt. Diese Worte sind also in Wahrheit voneinander prädizierbar, und jedes von ihnen wird Erkenntnis genannt.

Philosoph. Ich bin erstaunt, wie Begreifen Erkenntnis genannt werden könne.

Laie. Obwohl es sich im Begreifen um Nachbildung, im vernünftigen Erkennen dagegen um Vollendung handelt, so bewirkt doch gerade die Vollendung, daß das vernünftige Erkennen ein Begreifen genannt wird. Denn gerade dann begreift der Geist, wenn man von der Erkenntnis sagt, sie sei zu ihrer Vollendung gekommen.

Philosoph. Willst Du vielleicht auch behaupten, daß das Erleiden des Geistes vernünftige Erkenntnis genannt werde?

Laie. Ja, gerade das will ich. Denn diese ist eine Bewegung des Geistes, deren Anfang ein Erleiden ist.

Philosoph. Dann ist also auch Begreifen ein Erleiden?

Laie. Das folgt nicht, wie Dir unmittelbar klar sein wird; denn wie sehr auch Gattungen und Arten Erkenntnis sind, sind sie dennoch deshalb kein Erleiden der Seele. Denn das Erleiden der Seele geht vorüber, Arten und Gattungen bleiben bestehen.

Philosoph. Darüber mag ich nun genug von Dir gehört haben, da ja diese Bezeichnungen von verschiedenen im verschiedenen Sinne gebraucht werden. Doch sage, wie Du jenes Vermögen des Geistes bezeichnest, durch welches er alles in der Notwendigkeit seiner Verknüpfung erschaut, und jenes andere Vermögen, kraft dessen er es in seiner absoluten Notwendigkeit erschaut.

Laie. Da ich ja ein Laie bin, gebe ich im allgemeinen nicht viel auf Worte; in diesem Falle jedoch, glaube ich, daß mit einem geziemenden 
suam immutabilitatem respiciendo rerum formas extra materiam considerat eo, quia per disciplinam doctrinamque ad hanc forme devenitur $124 \mathrm{r}$. consideracionem, sed | vis illa, qua mens intuendo ad suam simplicitatem omnia absque composicione in simplicitate ${ }^{a}$ ) intuetur, intelligencia dici s potest.

Philosophus. Legitur per aliquos vim, quam tu doctrinam, intelligenciam et illam, quam tu intelligenciam, per illos ${ }^{b}$ ) intellectibilitatem nominari.

Y diota. Non displicet, quia et sic convenienter vocari possunt.

Orator. Optarem te, philosophe, audire, quomodo Phisici opinentur sensaciones fieri. In hoc te ydiota periciorem puto, qui et gaudebit, si feceris.

Philosophus. Gauderem aliquid accepti posse recitare. Unde id, quod petis, sic se habet: dicunt phisici, quod anima est immixta spiritui 15 tenuissimo per arterias diffuso ita, quod spiritus ille vehiculum sit anime, illius vero spiritus vehiculum sanguis. Est ergo arteria quedam illo spiritu plena, que ad oculos dirigitur ita, ut arteria illa prope oculos bifida fiat et illo spiritu plena ${ }^{c}$ ) ad oculorum orbes, in qua parte pupilla est, proveniat. Est itaque ${ }^{\mathrm{d}}$ ) spiritus ille eatenus per arteriam illam diffusus 20 instrumentum anime, per quod videndi sensum exerceat. Due arterie ${ }^{e}$ ) ad aures diriguntur illo spiritu plene, similiter ad nares, eodem modo ad palatum arterie ${ }^{\mathrm{e}}$ ) quedam diriguntur; diffunditur eciam spiritus ille per medullas usque ad extremitatem articulorum. Spiritus ergo ille, qui ad oculos dirigitur, est agilimus. Cum ergo aliquod exterius ${ }^{f}$ ) obstaculum in25 venit, repercutitur spiritus ille et excitatur anima ad perpendendum illud, quod obstat. Sic in auribus voce repercutitur spiritus, et excitatur anima ad comprehendendum ${ }^{\mathrm{g}}$ ), et, sicut auditus fit in aere tenuissimo, ita quoque odoratus in aere spisso vel pocius fumoso, qui, cum nares subintrat, ex sua fumositate spiritum retardat, ut anima excitetur ad illius fumositatis so odorem comprehendendum. Pariformiter cum humidum spongiosum palatum subintrat, tardatur spiritus et excitatur anima ad gustandum. Utitur eciam spiritu per medullas diffuso anima pro instrumento tactus, cum enim aliquod solidum obstat corpori, offenditur et quodammodo retardatur spiritus et inde tactus. Circa oculos utitur ignea vi, circa 30 aures utitur vi etherea vel pocius aerea pura, circa nares vi spissa aerea

a) in simplicitate am Rand ergänzt $H s$.

b) illi $H s$. hinzugefügt $H$ s.

d) auf Rasur Hs.

e) arteree korr. arterie $H s$.

c) plena am Rand aliquod umgestellt $H$ s.

g) comprehendundum korr. comprehendendum $\mathrm{Hs}$,

f) exterius 
Ausdruck das erste Vermögen eine Disziplin genannt werde, vermöge derer der Geist, indem er auf seine Unveränderlichkeit hinblickt, die Formen der Dinge außerhalb der Materie betrachtet, deshalb, weil er eben vermöge der Disziplin und Doktrin zu dieser Betrachtung der Form gelenkt wird; das Vermögen jedoch, kraft dessen der Geist, indem er auf seine eigene Einfachheit schaut, alles ohne Zusammensetzung in seiner Einfachheit zu erschauen vermag, kann Intelligenz genannt werden.

Philosoph. Wir lesen, daß von einigen das Vermögen, welches du Doktrin nennst, Intelligenz, und das, welches du Intelligenz nennst, „Intellektibilität" genannt werde.

Laie. Ich habe nichts dawider, da auch diese Namen die Sache treffen.

Redner. Ich wünschte von Dir, Philosoph, zu hören, wie sich die Physiker das Entstehen der Empfindungen vorstellen; ich glaube, daß Du in diesem Punkte besser Bescheid weißt, als der Laie, und auch er wird sich freuen, wenn du meine Bitte erfüllst.

Philosoph. Ich freue mich, etwas, was ich gehört habe, wiedergeben zu können. Was Du zu wissen wünschst, verhält sich aber in folgender Weise. Die Physiker sagen, daß die Seele mit einem ganz feinen Lebensgeist gemischt sei, welcher durch die Adern zerstreut sei, und zwar so, daß jener Lebensgeist das Vehikel der Seele ist; das Vehikel des Lebensgeistes selbst aber ist das Blut. Es gibt also z. B. eine Ader, welche mit jenem Lebensgeist angefüllt ist, die zu den Augen hinführt, und zwar so, daß jene Ader nahe an den Augen sich in zwei Teile spaltet, und mit jenem Lebensgeist angefüllt, zu den Augäpfeln gelangt, dorthin, wo die Pupille ist. Es ist also der Lebensgeist, der in dieser Weise in jener Ader verteilt ist, ein Werkzeug der Seele, vermöge dessen sie den Gesichtssinn zur Ausübung bringt. Zwei Adern, die mit jenem Lebensgeist erfüllt sind, werden zu den Ohren geleitet, und in ähnlicher Weise zwei zu der Nase; in gleicher Weise sind gewisse Adern zum Gaumen gerichtet. Jener Lebensgeist ist aber auch verstreut in den Muskeln bis in die äußersten Spitzen der Glieder. Der Lebensgeist aber, der zum Auge gelenkt wird, ist von höchster Beweglichkeit. Wenn er also ein störendes Hindernis von außen vorfindet, wird er zurückgetrieben, und die Seele wird dazu bewogen, dasjenige, was hinderlich ist zu betrachten. So wird er in den Ohren durch den Laut der Stimme zurückgetrieben, und die Seele wird bewogen, den Laut zu erfassen. Und wie das Hören in ganz dünner Luft stattfindet, so das Riechen in dicker, oder besser, rauchiger Luft, welche, wenn sie in die Nasenlöcher tritt, vermöge ihrer Rauchigkeit den Lebensgeist hemmt, so da $\beta$ die Seele dazu angeregt wird, daß sie den Geruch des Rauchigen bemerkt. Analog wird der Lebensgeist gehemmt, wenn etwas Feuchtes und Schwammiges auf den Gaumen kommt, und die Seele wird zum Schmecken angeregt. Den Lebensgeist aber, der in den Muskeln verstreut ist, gebraucht die Seele als Werkzeug zum Tasten; denn dieser Lebensgeist wird, wenn etwas Festes dem Körper widersteht, gestört und gewissermaßen gehemmt und hieraus entsteht das Tasten. In den Augen bedient er sich der Gewalt des Feuérs, in den Ohren der des Äthers, 
et fumosa, circa palatum vi aquea, circa medullas vi terrea, et hoc secundum quatuor elementorum ordinem, ut, sicut oculi alciores sunt auribus, sic spiritus, qui ad oculos dirigitur, alcior est et superior, ut quodammodo igneus dicatur, ut sit in homine sensuum disposicio facta ad simili5 tudinem ordinis sive disposicionis quatuor elementorum. Hinc velocior est $^{\text {a) }}$ visus quam auditus. Unde fit, ut prius coruscacionem videamus quam tonitrua audiamus, licet simul fiant. Facit eciam oculorum adeo fortis radiorum direccio subtilis et acuta, ut aer ei cedat nec aliquid ei obsistere possit, nisi grossum sit terreum vel aqueum. Cum ergo spiritus 10 ille instrumentum sit sensuum, oculi, nares etc. quasi fenestre sunt et vie, per quas spiritus ille ad senciendum exitum ${ }^{b}$ ) habet. Patet, quod

I24 v. nichil sentitur nisi per obstaculum. Unde fit, | ut aliqua re obstante spiritus ille, qui senciendi instrumentum est, tardetur, et anima quasi tarda rem illam, que obstat, confuse per sensus ipsos comprehendat.

15 Sensus enim, quantum in se est, nichil terminat. Quod enim, cum aliquid videmus, terminum in ipso ponimus, illud quidem ymaginacionis est, que adiuncta est sensui, non sensus. Est autem in prima parte capitis in cellula fantastica spiritus quidam multo tenuior et agilior spirituc) per arterias diffuso, quo cum anima utitur pro instrumento, subtilior fit, ut so eciam re absentata formam comprehendat in materia. Que vis anime ymaginacio dicitur, quoniam per eam anima rei absentate ymaginem sibi conformat, et per hoc a sensu differt, qui solum re presente formam comprehendit in materia, ymaginacio vero re absentata, confuse tamen, ut statum non discernat, sed multos status simul confuse comprehendit. ${ }^{\mathrm{d}}$ )

${ }^{25}$ Est vero in media parte capitis, in illa scilicet cellula, que racionalis dicitur, spiritus tenuissimus magisque tenuis quam in fantastica et, cum anima illo spiritu pro instrumento utitur, adhuc ${ }^{\mathrm{e}}$ ) fit subtilior, ut eciam statum a statu discernat vel statum vel formatum, nec tamen rerum comprehendit veritatem, quoniam formas comprehendit materie admixtas.

30 Materia vero confundit formatum, ut veritas circa eam comprehendi non possit. Hec autem vis anime racio appellatur. Cum hiis tribus modis anima corporeo utitur instrumento. Per se ipsam anima comprehendit, quando seipsam recipit, ita ut se ipsa utatur pro instrumento, ut a te audivimus.
a) est fehlt Hs.
c) spiritui $H s$.
b) auf Rasur Hs.
d) comprehendat korr. comprehendit $\mathrm{Hs}$.
e) adhoc korr. adhuc $H s$. 
oder genauer, der reinen Luft, in der Nase der dicken und rauchigen Luft, im Gaumen der Kraft des Wassers, in den Muskeln der der Erde, und zwar gemäß der Ordnung der vier Elemente. Wie die Augen von höherem Wert sind, als die Ohren, so ist auch der Lebensgeist, der zu den Augen führt, von höherem Wert und besser, so daß er in gewisser Weise feurig genannt werden kann. Und so ist im Menschen die Rangordnung der Sinne gemäß der Ordnung oder dem Range der vier Elemente beschaffen. Darum ist auch das Gesicht schneller als das Gehör, und daher kommt es, daß wir früher den Blitz sehen, als den Donner hören, obwohl sie zu gleicher Zeit stattfinden. Der Umstand aber, daß sich die Augenstrahlen so kräftig, so fein und scharf auf sie richten, bewirkt, daß die Luft dem Auge weichen muß, und daß nichts ihm widersteht außer dem Groben der Erde und des Wassers. Da also jener Lebensgeist ein Werkzeug der Sinne ist, so sind Augen, Nase und die anderen Sinneswerkzeuge gleichsam Fenster und Wege, auf denen jener Lebensgeist den Ausgang zum Wahrnehmen findet. Auch ist klar, daß nichts wahrgenommen wird, außer vermöge eines Hindernisses, durch welches jener Lebensgeist, welcher ein Werkzeug der Wahrnehmung ist, wie durch ein Entgegenstehendes gehemmt wird. Und die Seele erfaßt jenes Ding, welches ihr entgegensteht, gleichsam gehemmt, verworren durch die Sinne. Denn die Sinne als solche begrenzen nicht; daß wir, wenn wir etwas sehen, in ihm selbst eine Grenze setzen, das ist vielmehr ein Werk der Vorstellungskraft, welche dem Sinn beigesellt ist, nicht des Sinnes selbst. Denn in der ersten Kammer des Kopfes, in dem für die Vorstellungskraft bestimmten Raume, ist der Lebensgeist viel feiner und beweglicher, als der Geist, der in den Adern verstreut wohnt; wenn sich seiner die Seele als Werkzeug bedient, wird sie um so viel feinfühliger, daß sie auch in der Abwesenheit eines Dinges seine Form in der Materie erfaßt, und dieses Vermögen der Seele heißt Vorstellungskraft, weil durch diese Kraft sich die Seele das Bild eines abwesenden Gegenstandes gestaltet. Dadurch unterscheidet sie sich vom bloßen Sinn, welcher nur in Gegenwart des Gegenstandes die Form in der Materie erfaßt. Die Vorstellungskraft begreift auch in Abwesenheit des Gegenstandes, jedoch verworren, d. h. so, daß sie den $\mathrm{Zu}$ stand des Dinges nicht streng bestimmt, sondern viele Zustände zugleich verworren erfaßt. Es gibt jedoch im mittleren Teile des Kopfes, d. h. in jener Kammer, welche die des Verstandes genannt wird, einen Lebensgeist von höchster Feinheit, welcher dünner ist, als der, welcher in der Kammer der Vorstellung wohnt, und wenn die Seele sich dieses Geistes als Werkzeug bedient, dann wird sie so verfeinert, daß sie auch einen Zustand von einem anderen unterscheiden kann, sei es in bezug auf das Zuständliche, sei es in bezug auf die Form. Und dennoch erfaßt sie auch dann nicht die Wahrheit der Dinge, da sie nur Formen umfaßt, welche mit der Materie vermischt sind; Materie aber bringt das Geformte durcheinander, so da $\beta$ in ihr die Wahrheit nicht erfaßt werden kann. Diese Kraft der Seele aber wird Verstand genannt. Auf diese drei Weisen also bedient sich die Seele eines körperlichen Werkzeuges. Durch sich selbst aber begreift die Seele erst dann, wenn sie sich in sich selbst zurückzieht, und nur sich selbst als Werkzeug gebraucht, wie wir es ja auch von Dir gehört haben.

Studien der Bibliothek Warburg ro: Cassirer. 
Orator. Phisici, qui hec post experienciam nobis manifesta fecerunt, laudandi sunt certe, quia pulchra et placida.

Ydiota. Et hic sapiencie amator laudes et gracias meretur maximas.

$5 \quad$ Nonus tractatus. ${ }^{a}$ ) Capitulum nonum.

Quomodo mens omnia mensurat faciendo punctum, lineam et superficiem; et quomodo est punctus unus et complicacio ac perfeccio linee; et de natura complicacionis; et quomodo facit adequatas mensuras variarum rerum; et unde 10 stimuletur $^{b}$ ) ad faciendum. ${ }^{c}$ )

Philosophus. Video noctem accedere; velis igitur, ydiota, ad multa, que restant, properare et exponere, quomodo mens omnia mensurat, ut a principio asseruisti.

$\mathrm{Ydiota}$. Mens facit punctum terminum esse linee et lineam ter15 minum superficiei et superficiem corporis; facit numerum, unde multitudo et magnitudo a mente sunt. Et hinc omnia mensurat.

Philosophus. Explana, quomodo mens facit punctum.

Ydiota. Nam punctus est iunctura linee ad lineam vel linee terminus. Cum ergo lineam cogitaveris, poterit mens iuncturam ${ }^{d}$ ) duarum 20 medietatum eius secum considerare. Quod si fecerit, erit linea tripunctualis propter duos eius terminos et iuncturam duarum medietatum, quam sibi mens proposuit, nec sunt diversa punctorum genera terminus linee atque iunctura, nam duarum medietatum iunctura terminus est ideo linearum; et si unicuique medietati mens proprium terminum tri25 buat, quadripunctualis linea erit. Ita per quotcunque partes preexcogitata linea dividatur a mente, quot illarum partium termini fuerint, tot punctorum precogitata linea esse iudicabitur.

Philosophus. Quomodo facit lineam.

I25 r. Ydiota. Considerando / longitudinem sine latitudine et superso ficiem considerando latitudinem sine soliditate $\left.{ }^{\mathrm{e}}\right)$, licet sic actu nec punctus nec linea nec superficies esse possint, cum sola soliditas extra mentem actu existat. Sic omnis rei mensura vel terminus ex mente est, et ligna et lapides certam mensuram et terminos habent preter mentem nostram, sed ex mente increata, a qua rerum omnis terminus descendit.
a) tractatus fehlt Hs.
b) simuletur $H s$.
c) Capitulum - faciendum am Rand ergänzt Hs.
d) iuncturarum korr. iuncturam Hs. e) auf Rasur Hs. 
Redner. Die Naturforscher, welche uns dieses alles gemäß der Erfahrung klar gelegt haben, sind gewiß allen Lobes wert. Denn all dieses ist schön und angenehm.

Laie. Der Mann, der dieser Wissenschaft beflissen ist, verdient im höchsten Maße Dank und Lob.

\section{Kapitel.}

Der Geist mißt alles dadurch, daß er Punkt, Linie, und Fläche setzt. - Der Punkt ist Einheit, Einfaltung und Vollkommenheit der Linie. Die Natur der Einfaltung. - Der Geist schafft Maße, die den mannigfaltigen Dingen angemessen sind. - Wodurch wird der Geist zum Schaffen gebracht?

Philosoph. Ich bemerke, daß die Nacht herannaht; daher bitte ich Dich, Laie, daß Du auf viele Dinge eingehst, welche noch für die Betrachtung übrig sind, und auseinandersetzst, inwiefern der Geist alles mißt, wie Du im Anfang behauptet hast.

Laie. Der Geist bewirkt, daß der Punkt die Grenze der Linie sei, die Linie Grenze der Fläche, die Fläche Grenze des Körpers. Er schafft die Zahl, und daher sind Menge und Größe Geschöpfe des Geistes, und mit ihr mißt er alles und jedes. bringt.

Philosoph. Setze auseinander, wie der Geist den Punkt zustande

Laie. Punkt ist das, was eine Linie mit einer anderen verknüpft, oder er ist die Grenze der Linie. Wenn man sich daher eine Linie denkt, kann der Geist die Verknüpfung ihrer beiden Hälften miteinander betrachten. Wenn er das tut, dann entsteht eine Linie mit drei Punkten, wegen ihrer beiden Grenzen, und der Verbindung der beiden Hälften, welche sich der Geist vorgestellt hat. Die Arten der Punkte (Grenzpunkte und Verbindungspunkte) sind nicht artverschieden; denn der Verbindungspunkt der beiden Hälften ist auch die Grenze der Linien. Wenn aber nun der Geist jeder Hälfte einen eigenen Grenzpunkt zuerteilt, entsteht eine Linie mit vier Punkten. In wieviel Teile daher auch die gedachte Linie vom Geist geteilt werden mag, so wird man sie als eine Linie von so viel Punkten bestimmen, als es Grenzen ihrer Teile gibt.

\section{Philosoph. In welcher Weise erschafft der Geist eine Linie?}

Laie. Indem er sich Länge ohne Breite vorstellt, und indem er eine Fläche als bloße Breite ohne Körperlichkeit ansieht, obwohl doch als wirklich weder Punkt noch Linie, noch Fläche sein können, da außerhalb des Geistes allein das Körperliche wirklich existiert. Daher stammt das Maß und die Grenze eines jeden Dinges allein aus dem Geiste, und Hölzer und Steine haben zwar außerhalb unseres Geistes Maß und Grenze, die aber aus dem ungeschaffenen Geist stammen, von dem jede Grenzbestimmung sich herleitet. 
Philosophus. Arbitraris punctum esse indivisibilem.

Ydiota. Arbitror punctum terminalem indivisibilem, quia terminus non est terminus, si divisibilis foret, non foret terminus, quia haberet terminum. Sic non est quantus, et ex punctis non potest quantitas con${ }_{5}$ stitui, quia ex non quantis composita ${ }^{2}$ ) esse nequit.

Philosophus. Concordas cum Boecio dicente, si punctum puncto addas, nichil magis facis, quam si nichil nichilo iungas. ${ }^{1}$ )

Ydiota. Quare si duarum linearum terminos iungas, lineam quidem maiorem efficies, sed nullam constituet quantitatem terminorum 10 coniunctio.

Philosophus. Dicis ne plura puncta.

Ydiota. Neque plura puncta neque plures unitates, sed cum punctus sit linee terminus, ubique in linea reperiri potest, nec tamen in ea est nisi unus punctus, qui extensus linea est.

15 Philosophus. Nichil ergo in veritate reperitur in linea nisi punctus.

Ydiota. Verum est, sed propter variabilitatem materie, que subest, quedam ibi est extensio, sicut, cum non sit nisi una unitas, ex pluribus tamen unitatibus dicitur numerus constare propter alteritatem subiectorum unitati. Linea itaque est puncti evolucio et superficies linee $z_{0}$ et soliditas superficiei. Unde si tollis punctum, deficit omnis magnitudo, si tollis unitatem, deficit omnis multitudo.

Philosophus. Quomodo intelligis lineam puncti evolucionem.

Ydiota. Evolucionem, id est explicacionem, quod non est aliud quam punctum in athomis pluribus ita quod in singulis coniunctis et 25 continuatis esse. Est enim unus et idem punctus in omnibus athomis sicut una et eadem albedo in omnibus albis.

Philosophus. Quomodo intelligis athomum.

$\mathrm{Y}$ diota. Secundum mentis consideracionem continuum dividitur in semper divisibile, et multitudo crescit in infinitum, sed actu dividendo 30 ad partem actu indivisibilem devenitur, quam athomum appello, est enim athomus quantitas ob sui parvitatem actu indivisibilis. Sic eciam mentis consideracione multitudo non habet finem, que tamen actu terminata est, rerum namque omnium multitudo sub determinato quodam numero cadit licet nobis incognito.

35 Philosophus. Est ne punctus linee perfeccio, cum sit eius terminus.

a) auf Rasur Hs.

I) De Arithmetica 1. II c. 4 Migne P. L. 63 p. II 20. 
Philosoph. Glaubst Du, daß ein Punkt unteilbar ist?

Laie. Ich glaube, daß ein Punkt etwas begrenzendes Unteilbares ist; da Grenze keine Grenze wäre, wenn sie teilbar wäre (denn dann wär e sie nicht Grenze, weil sie Grenze hätte). So ist der Punkt keine Größe und aus Punkten kann keine Quantität zusammengesetzt werden, weil eine solche aus nicht-Größen nicht zusammengesetzt sein kann.

Philosoph. Du stimmst darin mit Boethius überein, welcher sagt: wenn man einen Punkt an einen anderen fügt, tut man um nichts mehr, als wenn man ein Nichts an ein Nichts fügt.

Laie. Wenn man daher zwei Linien an ihren Grenzpunkten zusammenfügt, so wird man dadurch zwar eine größere Linie herstellen, die Verbindung der Grenzpunkte selbst wird jedoch keine Quantität ausmachen. gibt?

Philosoph. Willst du sagen, daß es keine Mehrheit von Punkten

Laie. Weder eine solche von Punkten noch von Einheiten; da vielmehr der Punkt Grenze der Linie ist, kann man ihn überall auf der Linie finden, und doch gibt es andererseits auf der Linie nicht mehr als ein en Punkt, welcher in seiner Ausdehnung Linie ist. Punkt?

Philosoph. In Wahrheit findet sich also in der Linie nur der

Laie. Das ist richtig; aber wegen der Veränderlichkeit der Materie, welche zugrunde liegt, gibt es in ihm eine gewisse Ausdehnung. In gleicher Weise sagt man, daß die $Z$ ahl aus mehreren Einheiten bestehe, wegen der Verschiedenheit desjenigen, was der Einheit unterworfen wird, obwohl es doch in Wahrheit nur eine Einheit gibt. Daher ist Linie die Entwicklung des Punktes, Fläche die Entwicklung der Linie, und fester Körper die Entwicklung der Fläche. Wenn man daher den Punkt aufhebt, geht jedwede Größe verloren. Wenn man die Einheit aufhebt, geht jede Vielheit verloren.

Philosoph. Wie meinst Du das, daß die Linie die Entwicklung des Punktes sei?

Laie. Sie ist seine Entwicklung, d. h. seine Entfaltung, denn ob man nun mehrere Unteilbare nimmt oder ob man sie einzeln, als verbundene und verknüpfte, erfaßt, so findet sich in ihnen nie etwas anderes als der Punkt. Denn ein und derselbe Punkt ist in allem Unteilbaren, so wie die gleiche Weiße in allem Weißen ist.

Philosoph. Was verstehst Du unter einem Unteilbaren?

Laie. Zufolge der Betrachtung des Geistes wird ein Kontinuum in ein immer wieder Teilbares geteilt, und die Menge der Teile wächst ins Unendliche. Aber beim wirklichen Akt des Teilens, gelangt man zu einem unteilbaren Teil, welchen ich als Atom bezeichne. Atom ist nämlich eine Quantität, welche wegen ihrer Kleinheit im aktuellen Sinne nicht mehr teilbar ist. So hat auch für die Betrachtung des Geistes die Vielheit keine Grenze, während sie doch aktuell begrenzt ist. Denn die Vielheit von allen Dingen ist einer genau bestimmten Zahl unterworfen, mag diese uns auch unbekannt sein.

Philosoph. Ist denn der Punkt Vollendung der Linie, da er doch ihre Begrenzung ist? 
Ydiota. Est eius perfeccio et totalitas, que lineam in se complicat. Punctare enim est rem ipsam terminare, ubi autem terminatur, ibidem perficitur. Perfeccio vero eius est ipsius totalitas. Unde punctus est terminus linee et eius totalitas $\mathrm{ac}^{\mathrm{a}}$ ) perfeccio, que ipsam lineam in se com5 plicat, sicut linea ${ }^{b}$ ) punctum explicat. Cum enim perfeccionem totalem linee in geometricis dico esse ex hoc a puncto in b, tunc ante protrac$125 \mathrm{v}$. cionem linee de $\mathrm{a} a \mathrm{~d} \mathrm{~b} \mid$ per puncta $\mathrm{a}, \mathrm{b}$ totalitatem linee designavi ${ }^{\mathrm{c}}$ ), scilicet quod linea non debet ultra protrahi. Unde quod est actu vel intellectu rei totalitatem $a b$ hoc in hoc includere, hoc est lineam in puncto 10 complicare, explicare autem est de a in b particulatim lineam trahere, sic linea explicat complicacionem puncti.

Philosophus. Putabam punctum complicacionem linee sicut unitatem numeri, quia nichil in linea reperitur nisi punctus ubique, sicut in numero nichil nisi unitas.

15 Ydiota. Non male considerasti; idem est in diversitate modi dicendi et modo, quo dixisti, in omnibus complicantibus uti ${ }^{\mathrm{d}}$ ). Nam motus est explicacio quietis, quia nichil reperitur in motu nisi quies. Sic nunc explicatur per tempus, quia nichil reperitur in tempore nisi nunc; ita de aliis.

20 Philosophus. Quomodo ais in motu non ${ }^{\mathrm{e}}$ ) nisi quietem reperiri.

Ydiota. Cum movere sit de uno statu in alium cadere, quia, quamdiu res $s^{f}$ ) habet in uno statu, non movetur, sic nichil reperitur in motu nisi quies, motus enim est discessio ab uno. Unde moveri est ab uno, et hoc est ad aliud unum, sic de quiete in quietem transire est movere, ut 25 non sit aliud movere nisi ordinata quies sive quietes seriatim ordinate. Multum proficit, qui ad complicaciones et earum explicaciones attente advertit maxime, quomodo omnes complicaciones sunt ymagines complicacionis simplicitatis infinite et non explicaciones eius, sed ymagines et sunt in necessitate compleccionis. Et mens prima ymago complica30 cionis simplicitatis infinite vim harum complicacionum sua vi complectens est locus seu regio necessitatis compleccionis, quia, que vere sunt, abstracta sunt a variebilitate $\left.{ }^{g}\right)$ materie et non sunt materialiter, sed mentaliter; de quo superflue dictum estimo.

Orator. Nequaquam superflue, eciam si repetite, nam utile est 35 sepe dici, quod nunquam potest satis dici.
a) atque durch Rasur korr. ac Hs.
c) Rasur Hs. $\quad$ d) utere Hs.
b) linea am Rand Hs.
f) se res umgestellt $H s$.
g) variobilitate korr. variebilitate $H s$. 
Laie. Er ist ihre Vollendung und ihre Ganzheit, welche die Linie in sich befaßt und zusammenfaltet. Eine Sache in Punkte einschließen, heißt, sie begrenzen; wo aber begrenzt wird, dort wird zur Vollendung gebracht. Die Vollendung der Linie aber ist ihre Ganzheit. Daher ist der Punkt die Grenze der Linie, und ihre Ganzheit und Vollendung, welche die Linie selbst in sich zusammenfaltet, wie die Linie den Punkt auseinanderfaltet. Wenn ich nämlich in der Geometrie sage, daß eine Linie in ihrer Vollendung und Ganzheit durch die Punkte a und $\mathrm{b}$ bestimmt sei, dann habe ich, bevor ich die Linie von a nach b gezogen hatte, durch die Punkte $a$ und $b$ die Ganzheit der Linie bestimmt, da die Linie über sie hinaus nicht verlängert werden darf. Sofern aber der Wirklichkeit nach oder in unserer vernünftigen Erkenntnis das Ganze der Linie, von ihrem Anfangs- bis zu ihrem Endpunkt, in dieser Weise in sich beschlossen wird, so heißt dies die Linie im Punkte zusammenfalten, entfalten aber heißt, von a bis b die Linie Teil für Teil ziehen, und so entfaltet die Linie die Zusammenfaltung des Punktes.

Philosoph. Ich hielt den Punkt für die Einfaltung der Linie, ebenso wie die Einheit Einfaltung der Zahl ist, deshalb, weil auf der Linie nichts gefunden wird, als überall ein Punkt, wie ja auch in der Zahl nichts gefunden wird, als die Einheit.

Laie. Eine sehr zutreffende Erwägung, und das Gleiche läßt sich in anderer Ausdrucksweise auf alle Einfaltungen anwenden. Bewegung ist Entfaltung der Ruhe, weil in der Bewegung nichts gefunden wird als Ruhe. So wird das Jetzt durch die Zeit entfaltet, weil in ihr nichts gefunden wird als das Jetzt, und so auch in allem anderen.

Philosoph. Wie meinst Du das, daß in der Bewegung nichts als Ruhe gefunden werde?

Laie. Da Bewegung nichts anderes ist, als won einem Zustand in einen anderen übergehen, - denn ein Ding wird, so lange es sich in ei n e $\mathrm{Zu}$ stand befindet, nicht bewegt - so wird in der Bewegung nichts anderes als Ruhe gefunden. Bewegung ist nämlich das Verlassen des einen Zustandes. Daher bewegt sich das Ding von einem Zustand in einen andern. So ist also Bewegung nichts anderes, als von einem Zustand der Ruhe in einen anderen übergehen, dergestalt, daß Bewegung nichts anderes ist, als geordnete Ruhe, oder besser gesagt, nichts anderes als reihenweis geordnete Zustände der Ruhe. Einen großen geistigen Gewinn aber trägt der davon, welcher auf die Einfaltungen und ihre Entfaltungen aufmerksam acht hat, hauptsächlich darauf, daß alle Einfaltungen Bilder von der Einfaltung der unendlichen Einfachheit sind, und nicht ihre Entfaltung, sondern ihre Bilder, und, daß sie der notwendigen Verknüpfung unterworfen sind. Der Geist, welcher das oberste Bild der Einfaltung der unendlichen Einfachheit ist, befaßt das Vermögen dieser Einfaltung in seiner Kraft in sich, und ist so der Ort und der eigentliche Platz für die Notwendigkeit der Verknüpfung; denn was wahrhaft ist, ist losgelöst von der Veränderlichkeit der Materie, und ist nicht stofflich, sondern geistig; doch darüber noch weiter zu sprechen halte ich für überflüssig.

Redner. Es ist in keiner Weise überflüssig, darüber, selbst zu wiederholten Malen, zu sprechen, denn es ist von Nutzen, wenn das oft gesagt wird, was niemals voll und ganz ausgedrückt werden kann. 
Philosophus. Admiror, cum mens, ut ais, ydiota, a mensura dicatur, cur ad rerum mensuram tam avide feratur.

$\mathrm{Y}$ diota. Ut suiipsius mensuram attingat. Nam mens est viva mensura, que mensurando alia sui capacitatem attingit. Omnia enim agit, 5 ut se cognoscat, sed sui mensuram in omnibus querens non invenit, nisi ubi sunt omnia unum. Ibi est veritas precisionis eius, quia ibi exemplar suum adequatum.

Philosophus. Qomodo mens tam variarum rerum se mensuram facere potest adequatam.

10 Ydiota. Modo, quo absoluta facies omnium facierum se faceret mensuram. Quando enim attendis mentem esse absolutam quandam mensuram, que non potest esse maior nec minor, cum sit incontracta ad quantum, et, cum hoc attendis illam mensuram esse vivam, ut per seipsam mensuret, quasi si circinus $^{a}$ ) vivus per se mensuraret, tunc ${ }^{b}$ ) attingis, 15 quomodo se facit nocionem, mensuram seu exemplar, ut se in omnibus attingat.

Philosophus. Intelligo simile in circino nullius determinate quantitatis in eo, quod circinus, et tamen extenditur et contrahitur, ut assimiletur determinatis; sed an se assimilet modis essendi, dicito.

$20 \quad Y$ diota. Ymmo omnibus. Conformat enim se possibilitati, ut omnia I26 r. possibiliter mensuret, | sic necessitati ${ }^{\mathrm{c}}$ ) absolute, ut omnia unice et simpliciter ut Deus mensuret, sic necessitati compleccionis, ut omnia in proprio esse mensuret, atque possibilitati determinate, ut omnia, quemadmodum existunt, mensuret. Mensurat eciam symbolice comparacionis modo, $25 \mathrm{ut}$, quando utitur numero et figuris geometricis, et ad similitudinem talium se transfert. Unde subtiliter intuenti mens est viva et incontracta infinite equalitatis similitudo.

\section{Capitulum decimum.}

Quomodo comprehensio veritatis est in multitudine et 30 magnitudine. ${ }^{d}$ )

Philosophus. Non te tedeat ${ }^{\mathrm{e}}$ ) sermonem in noctem protrahere, mi amicissime, ut adhuc tua presencia frui valeam, necessitor enim cras abire; et exponas dictum Boecii utique doctissimi viri, quid velit dicere,

a) circulus am Rand korr. circinus $H s . \quad$ b) nunc korr. tunc $H s$.

c) necessitate korr. necessitati Hs.

d) Capitulum - magnitudine am Rande ergänzt Hs. e) tediat $H s$. 
Philosoph. Ich wundere mich darüber, daß der Geist (mens), welcher, wie Du sagst, seinen Namen vom Messen (mensurare) her hat, so eifrig bestrebt ist, die Dinge zu messen.

Laie. Dies geschieht, damit er sein eigenes Maß erreiche; denn der Geist ist lebendiges Maß, welches die Fülle seiner selbst dadurch erreicht, da $\beta$ es das andere mißt. Denn dies alles tut er, um sich selbst zu erkennen; wenn er jedoch das $\mathrm{Ma} \beta$ von sich in allem sucht, findet er es nirgends als nur dort, wo alles Eines ist; dort ist auch die Wahrheit seiner genauen Bestimmtheit, da dort sein ihm adäquates Urbild ist.

Philosoph. Wie ist es denn möglich, daß der Geist sich zum adäquaten $\mathrm{Maß}$ so verschiedener Dinge machen kann?

Laie. In gleicher Weise, als wenn das ,,absolute Gesicht" sich zum $\mathrm{Ma} ß$ von allen einzelnen Gesichtern machte. Wenn Du nämlich bedenkst, daß der Geist ein bestimmtes absolutes $M a ß$ ist, welches weder größer noch kleiner werden kann, da es nicht zu einer quantitativen Größe zusammenziehbar ist, und wenn Du bedenkst, daß er lebendiges Maß ist, damit er sich durch sich selbst messe (gleich als wenn ein lebendiger Zirkel durch sich selbst messen würde), dann begreifst Du, warum er sich zum Begriff und Maß und zum Urbild von allem macht, damit er sich in allem auffinde.

Philosoph. Ich sehe die Ähnlichkeit mit dem Zirkel darin, daß dieser, insofern er ein Zirkel ist, von keiner bestimmten Größe ist und doch ausgedehnt und zusammengezogen wird, um sich so dem, was bestimmt wird, anzugleichen. Aber gleicht sich denn der Geist den Arten des Seins an?

Laie. Ja, ihnen allen. Denn er formt sich der Potentialität an, um alles in der Weise der Potentialität $\mathrm{zu}$ messen, und der absoluten Notwendigkeit, damit er alles in der Weise der Einheit und Einfachheit messe, (wie es Gott tut,) und der Notwendigkeit der Verknüpfung, um so alles in Hinsicht auf seine Eigentümlichkeit zu messen; er formt sich endlich der determinierten Potentialität an, um alles hinsichtlich seiner Existenz zu messen. Er mißt aber auch symbolisch, durch Vergleich, wie, wenn er sich der Zahl und der geometrischen Figuren bedient und sich auf sie als Gleichnisse bezieht. Daher stellt sich dem scharfsichtigen Betrachter der Geist als lebendige und unzusammengezogene Ähnlichkeit der unendlichen Gleichheit dar.

\section{Io. Kapitel.}

Die Wahrheit wird in Vielheit und Größe erfaßt.

Philosoph. Mögen wir es uns nicht verdrießen lassen, das Gespräch bis in die Nacht auszudehnen, mein bester Freund, damit ich bis dahin aus meiner Anwesenheit bei Dir Gewinn ziehen kann, denn ich bin gezwungen, morgen fortzureisen. Erkläre mir also einen Ausspruch des Boethius, jenes hochgelehrten Mannes, was er denn meint, wenn er 
quando ait, comprehensionem veritatis omnium rerum esse in multitudine et magnitudine. ${ }^{1}$ )

Y diota. Opinor, quod multitudinem ad discrecionem retulit, magnitudinem ad integritatem. Nam rei veritatem recte comprehendit, qui 5 eam ab omnibus aliis rebus discernit et ipsius eciam rei integritatem attingit, ultra quam vel infra integrum esse rei non progreditur. Disciplina namque in geometria trianguli integritatem determinat, ita quod nec ultra sit nec infra. In astronomia determinat motuum integritatem et quid per singula. Per disciplinam magnitudinis habetur terminus in10 tegritatis rerum et mensura sicut per numeri disciplinam rerum discrecio. Numerus quidem ad confusionem communium discernendam valet, similiter ad colligendam rerum communionem. Magnitudo vero ad comprehendendum integritatis esse rerum terminum et mensuram.

Philosophus. Si magnitudo ${ }^{a}$ ) integritatem ab omnibus discernit, 15 nichil ergo scitur, nisi omnia sciantur.

Ydiota. Verum dicis, nam non scitur ${ }^{a}$ ) pars nisi toto scito, totum enim mensurat partem. Quando enim coclear per partes ex ligno excindo, partem adaptando ad totum respicio, ut coclear bene proporcionatum eliciam. Sic totum coclear, quod mente concepi, est exemplar, 20 ad quod respicio, dum partem fingo. Et tunc possum perfectum coclear efficere, quando quelibet pars proporcionem suam in ordine ad totum reservat. Similiter pars ad partem comparata suam integritatem debet observare. Unde necesse erit, ut ad scienciam unius precedat sciencia tocius et parcium eius. Quare Deus, qui est exemplar universitatis, si 25 ignoratur, nichil de universitate scitur ${ }^{\mathrm{b}}$ ), et, si universitas ignoratur, nichil de eius partibus sciri posse manifestum; ita scienciam cuiuslibet precedit sciencia Dei et omnium.

Philosophus. Adde queso, cur dicat sine quadruvio nulli recte philosophandum.

so Ydiota. Ob ea iam dicta. Nam, quia in arithmetica ${ }^{\mathrm{c}}$ ) et musica continetur virtus numerorum, unde rerum habetur discrecio, in geometria vero et astronomia magnitudinis continetur disciplina, unde tota comprehensio integritatis rerum $^{\mathrm{d}}$ ) emanat, ideo nulli sine quadruvio philosophandum.
a) Rasur Hs.
b) scitur am Rande ergänzt $H$ s.
c) arismetica $H s$
d) rerum über der Zeile ergänst $H$ s.

I) De Arithmetica I c. I; de Musica II c. 2 
sagt, daß die Erfassung aller Dinge auf der Vielheit und der Größe beruhe.

Laie. Ich glaube, daß er das meinte, weil er die Vielheit auf die Unterscheidung, und die Größe auf die Ganzheit zurückführte. Denn die Wahrheit eines Dinges erfaßt der in richtiger Weise, der es von allen anderen Dingen unterscheidet, und der auch die Ganzheit des Dinges erfaßt, jenseits oder diesseits von welcher das Ding nicht weiterhin als ein Ganzes sein kann. Denn die Untersuchung bestimmt in der Geometrie die Ganzheit des Dreiecks in der Weise, daß es über diese Bestimmung weder hinausgeht, noch hinter ihr zurückbleibt. In der Astronomie bestimmt sie die Ganzheit der Bewegungen, und was sie in den einzelnen ist. Durch den Begriff der Größe gewinnt man Grenze und Maß der Ganzheit der Dinge, wie durch den Begriff der Zahl die Unterscheidung der Dinge. Die Kraft der Zahl also besteht darin, daß sie das regellose Beisammen des Gemeinsamen scheidet. In ähnlicher Weise geht sie darauf aus, das Gemeinsame an den Dingen zusammenzufassen. Die Größe aber dient dazu, daß sie die Ganzheit der Dinge als ihre Grenze und ihr Maß begreift.

Philosoph. Wenn die Größe die Ganzheit von allem erfaßt und unterscheidet, so wird also nichts gewußt, wenn nicht alles gewußt wird?

Laie. Du sprichst wahr. Denn kein Teil wird gewußt, wenn nicht das Ganze gewußt wird; denn das Ganze mißt den Teil. Wenn ich nämlich einen Löffel Teil für Teil aus dem Holz sorgfältig schnitze, blicke ich auf das Ganze und passe ihm den Teil an, damit ich einen wohl proportionierten Löffel hervorbringe; so ist der ganze Löffel, den ich im Geist mir vorgestellt habe, das Urbild, auf das ich hinblicke, wenn ich einen Teil verfertige, und nur dann kann ich einen vollkommenen Löffel zustande bringen, wenn jeder Teil sein rechtes Maßverhältnis in der Zuordnung zum Ganzen bewahrt. In gleicher Weise muß ein Teil, wenn er dem anderen verglichen wird, seine Ganzheit bewahren. Daher ist es notwendig, daß der Wissenschaft vom Einen die vom Ganzen und seinen Teilen vorangehe. Wenn man daher von Gott, welcher das Urbild der Allheit ist, nichts weiß, weiß man auch nichts vom All, und es ist ja klar, daß man, wenn man nichts vom All weiß, auch nichts von seinen Teilen wissen könne. So geht jeder Wissenschaft die Wissenschaft von "Gott und allem" voraus.

Philosoph. Sage doch bitte noch, warum man sagt, daß niemand ohne die vier Grundwissenschaften philosophieren könne?

Laie. Aus dem schon genannten Grunde. Denn da in der Arithmetik und der Musik die Bedeutung der Zahlen abgehandelt wird, vermöge deren die Unterscheidung der Dinge stattfindet, in der Geometrie aber und in der Astronomie die Lehre von den Größen gegeben wird, aus der alles Begreifen der Ganzheit der Dinge fließt, so kann niemand ohne die vier Grundwissenschaften philosophieren. 
Philosophus. Miror, si voluit omne id, quod est, esse magnitudinem vel multitudinem.

I26 v. Ydiota. Nequaquam puto, sed quod omne, quod est, | cadit sub magnitudine vel multitudine, quoniam demonstracio omnium rerum fit 5 vel secundum vim unius vel alterius. Magnitudo terminat, multitudo discernit. Unde diffinicio, que totum esse terminat et includit, vim habet magnitudinis et ad eam pertinet, et diffinicionum demonstracio fit necessario $^{a}$ ) secundum vim magnitudinis, divisio vero et divisionum demonstracio secundum vim ${ }^{b}$ ) multitudinis, fiunt eciam silogismorum demon10 straciones secundum vim magnitudinis et multitudinis. Quod enim ex duabus tercia concluditur, multitudinis est, quod autem ex universalibus et particularibus magnitudinis est. Posset eciam ociosior nobis applicare, quomodo ex vi multitudinis quantitates ${ }^{c}$ ), qualitates et cetera predicamenta descendunt, que rerum noticiam faciunt, nam quemadmodum hoc 15 fiat, difficulter cognoscitur.

Capitulum undecimum.

Quomodo omnia in Deo sunt in trinitate similiter et in mente nostra; et quomodo mens nostra est ex comprehendendid ${ }^{\mathrm{d}}$ ) modis composita. ${ }^{\mathrm{e}}$ )

20 Philosophus. Tetigisti superius de trinitate Dei et trinitate mentis. Oro declares, quomodo omnia in Deo sunt in trinitate similiter et in mente nostra.

Ydiota. Vos philosophi asseritis decem genera generalissima omnia complecti.

25 Philosophus. Ita est profecto.

Ydiota. Nonne dum ea, ut actu sunt, consideras $^{f}$ ), divisa esse conspicis.

Philosophus. Ymmo.

Ydiota. Sed dum ea ante inchoacionem essendi consideras sine 30 divisione, quid tunc aliud esse possunt quam eternitas. Nam ante omnem divisionem connexio, illa igitur ante omnem divisionem ${ }^{\mathrm{g}}$ ) unita $^{\mathrm{h}}$ ) et connexa esse necesse est. Connexio autem ante omnem divisionem eternitas

\footnotetext{
a) necessacio $H s$.

b) danach magnitudinis getilgt Hs. $\quad$ c) danach et getilgt Hs.

d) comprehendi Hs. e) Capitulum - composita am Rand evgänzt Hs.

f) danach consideras getilgt Hs. g) connexio - divisionem am Rand ergänzt Hs.

h) unita am Rand wiederholt Hs.
} 
Philosoph. Ich würde mich wundern, wenn er hätte sagen wollen, alles was sei, sei Größe oder Vielheit.

Laie. Das wollte er, wie ich glaube, auch in keiner Weise. Wohl aber, $\mathrm{da} ß$ alles, was ist, irgendwie der Größe und Vielheit unterworfen ist, da die Demonstration von allen Dingen überhaupt auf dieser oder jener beruht. Die Größe begrenzt, die Vielheit trennt. Daher hat eine Bestimmung, welche das ganze Sein begrenzt und einschließt, ihre Bedeutung von der Größe und gehört zu ihr, und die Demonstration solcher Bestimmungen geschieht notwendigerweise gemäß der Größe, Teilung aber und ihre Demonstration beruht auf der Vielheit. Auch die syllogistischen Beweise beruhen auf Größe und Vielheit. Insofern nämlich aus zwei Aussagen sich eine andere ergibt, kommt die Vielheit in Anwendung, insofern aber aus Allgemeinem und Besonderem geschlossen wird, die Größe. Bei größerer Muße ließe sich klar machen, wie aus der Vielheit die Quantität und Qualität und die übrigen Kategorien entstammen, die die Erkenntnis aller Dinge zustande bringen. Denn $\mathrm{zu}$ erkennen wie dieses vor sich gehe, ist sehr schwierig.

\section{Kapitel.}

Alles in Gott ist in der Dreieinheit und in ähnlicher Weise alles in unserem Geiste. Unser Geist ist aus den verschiedenen Arten des Begreifens zusammengesetzt.

Philosoph. Du hast oben andeutungsweise von der Dreieinheit Gottes gesprochen und von der Dreieinheit des Geistes. Erläutre doch bitte, inwiefern alles in Gott in der Dreieinheit ist und in ähnlicher Weise in unserem Geiste.

Laie. Ihr Philosophen behauptet doch, daß zehn Hauptkategorien alle Dinge umfassen.

Philosoph. So ist es ohne allen Zweifel.

Laie. Wenn du sie als aktuell seiend betrachtest, dann sind sie doch voneinander getrennt?

Philosoph. Ja.

Laie. Wenn Du sie aber vor ihrem Eingehen in das Sein ohne Trennung betrachtest, was können sie dann anderes sein, als die Ewigkeit? Denn jeder Trennung geht doch eine Verbindung voraus. Daß jene vor aller Trennung vereint und verknüpft seien, ist also notwendig, Verknüpfung aber vor aller Teilung ist die Ewigkeit in ihrer höchsten Einfachheit, welche Gott ist. Da man also Gott notwendigerweise die Vollkommenheit zuschreiben muß, und da vollkommen das ist, dem nichts fehlt, so sage ich, daß die Allheit der Dinge auf der Voll- 
est simplicissima, que Deus est. Ad hec dico, cum Deus non possit negari perfectus, et perfectum sit, cui nichil deest, hinc rerum universitas in perfeccione, que Deus est, sed perfeccio summa exigit, quod sit simplex et una absque alteritate et diversitate, hinc omnia in Deo unum.

5 Philosophus. Aperta et delectabilis ostensio est, quam facis, sed adice, quomodo in trinitate.

Ydiota. Alibi de hoc agendum foret, ut clarius dici posset; nunc tamen, quia statui omnia, que exigis, pro posse adimplere, sic recipito. Habes omnia ab eterno in Deo Deus esse, considera igitur rerum univer10 sitatem in tempore et, cum impossibile non fiat, nonne vides eam ab eterno fieri potuisse.

Philosophus. Mens assentit.

$\mathrm{Ydiota.} \mathrm{Igitur} \mathrm{omnia} \mathrm{in} \mathrm{posse} \mathrm{fieri} \mathrm{mentaliter} \mathrm{vides.}$

Philosophus. Recte ais.

15 Ydiota. Et si fieri potuerunt, erat necessario posse facere, antequam essent.

Philosophus. Ita erat.

$\mathrm{Y}$ diota. Sic ante rerum universitatem temporalem vides omnia in posse facere.

20 Philosophus. Video.

Ydiota. Nonne ut in esse prodiret rerum universitas, quam vides oculo mentis in absoluto posse fieri et in absoluto posse facere, necesse erat nexus ipsius utriusque scilicet posse fieri et posse facere, alias quod potuit fieri per potentem facere, nunquam fuisset factum.

25

\section{Philosophus. Optime ais.}

Ydiota. Vides igitur ante omnem rerum temporalem existenciam omnia in nexu procedente de posse fieri absoluto et posse facere absoI27 r. luto, sed illa | tria absoluta sunt ante omne tempus simplex eternitas. Hinc omnia conspicis in simplici eternitate triniter.

Philosophus. Sufficientissime.

Y diota. Attende igitur, quomodo absolutum posse fieri et absolutum posse facere et absolutus nexus non sunt nisi unum infinite absolutum et una Deitas. Et ordine prius est posse fieri quam posse facere, nam omne facere presupponit fieri posse, et posse facere id, quod habet scili${ }_{35}$ cet posse facere, habet de posse fieri, et de utroque nexus. Unde, cum ordo dicat posse fieri precedere, sibi attribuitur unitas, cui inest precedere, 
endung beruht, welche Gott ist. Die höchste Vollkommenheit fordert jedoch, daß sie einfach und eins sei, ohne Andersheit und Verschiedenheit; daher ist alles in Gott Eines.

Philosoph. Ein klarer und schöner Beweis! Doch erkläre noch, inwiefern es in Dreieinheit ist.

Laie. Am andern Orte wäre darüber zu handeln, damit es klarer gesagt werden könnte; da ich aber beschlossen habe, alles nach Kräften $\mathrm{zu}$ erfüllen, worum Du mich bittest, so bedenke Folgendes. Wir sagen doch, da $B$ alles von Ewigkeit her in Gott sei. Betrachte also die Allheit der Dinge in der Zeit. Siehst Du nicht, daß, da nur das wird, was möglich ist, diese Allheit von Ewigkeit her möglich war?

Philosoph. Ich stimme Dir bei.

Laie. Du begreifst also im Geiste alles in seinem Werden-Können?

Philosoph. Du hast recht.

Laie. Und wenn es werden konnte, so war doch notwendigerweise, bevor es war, auch ein Bewirken-Können?

Philosoph. So ist es.

Laie. So wird denn klar, daß vor der Allheit der Dinge in der Zeit alles in diesem Bewirken-Können war?

Philosoph. Das sehe ich ein.

Laie. Mußte nicht, damit die Allheit der Dinge zum Sein gelangte, welche Du nunmehr vor Deinem geistigen Auge in ihrem absoluten WerdenKönnen und in ihrem absoluten Tun-Können erblickst, eine Verknüpfung beider stattfinden, d.h. des Werden-Könnens und des Bewirken-Könnens ? Denn sonst wäre das, was werden konnte, durch den, der es bewirken konnte, niemals zustande gebracht worden.

Philosoph. Du hast ganz recht.

Laie. Du siehst also, daß vor jeder zeitlichen Existenz der Dinge alles in vorgängiger Verknüpfung war, die sich ergibt aus dem absoluten Werden-Können und dem absoluten Tun-Können. Jene drei Absolutheiten aber sind vor aller Zeit, einfache Ewigkeit. Daher siehst Du alles als dreifaltig in der einfachen Ewigkeit.

\section{Philosoph. Vollkommen.}

Laie. Beachte also, in welcher Weise das absolute Werden-Können, das absolute Bewirken-Können und die absolute Verknüpfung nur ein unendlich Absolutes sind und eine Gottheit. Und der Ordnung nach ist das Werden-Können früher als das Bewirken-Können, denn alles Bewirken setzt das Werden-Können voraus, und das Bewirken-Können besitzt das, was es hat, nämlich eben die Möglichkeit des Wirkens, vom WerdenKönnen. Und aus diesen beiden ergibt sich dann die Verknüpfung. Da aber der Ordnung nach das Werden-Können voraufgeht, so wird diesem die Einheit zugeschrieben, dem Bewirken-Können wird die Gleichheit zugeschrieben, welche die Einheit voraussetzt, und aus ihnen entsteht, 
et posse facere attribuitur equalitas unitatem presupponens, a quibus nexus et hec nunc ${ }^{a}$ ), si placet, de hoc sufficiant.

Philosophus. Solum unum adice, si Deus intelligit ut trinus et unus.

5 Ydiota. Mens eterna omnia in unitate, unitatis equalitate et utriusque nexu intelligit, quomodo Deus intelligeret eciam in eternitate sine omni successione absque entitate et entitatis equalitate atque nexu utriusque, que sunt trinitas in unitate, non quod Deus aliquid premittat modo materie et cum successione intelligat sicut nos, sed intelligere eius, ${ }_{10}$ cum sit eius essencia, est necessario in trinitate.

Philosophus. Si sic est, suo modo in nostra mente subiungito.

Ydiota. Omnia principiata in se similitudinem principii habere atque ideo in omnibus trinitatem in unitate substancie in similitudine vere trinitatis et unitatis substancie principii eterni reperiri certum teneo.

${ }_{15}$ In omnibus igitur, que principiata sunt, posse fieri, quod descendit a virtute infinita unitatis seu entitatis absolute, posse facere, quod descendit a virtute absolute equalitatis, et composicionem utriusque, que descendit a nexu absoluto, reperiri necesse est. Unde mens nostra, ymago mentis eterne, in mente ipsa eterna ut similitudo in veritate suiipsius men20 suram $^{b}$ ) venari contendit. Est enim ipsa mens nostra, ut est similitudo divine, uti vis alta consideranda, in qua posse assimilari ${ }^{c}$ ) et posse assimilare et nexus utriusque in essencia unum sunt et idem. Unde non potest mens nostra, nisi sit una in trinitate, quidquam intelligere, quemadmodum nec mens divina. Primo enim, dum se movet, ut intelligat, 25 aliquid in similitudine posse fieri seu materie premittit, cui aliud in similitudine posse facere seu forme adiungit, et tunc in similitudine compositi ab utroque intelligit. Dum autem modo materie comprehendit, genera facit, dum modo forme ${ }^{\mathrm{d}}$ ) comprehendit, facit differencias, dum modo compositi, species facit vel individua; sic eciam, dum modo proprie pas${ }^{30}$ sionis intelligit, facit propria, dum modo advenientis intelligit, facit accidencia. Nichil autem intelligit nisi premisso aliquo modo materie et alio modo advenientis forme; modo compositi illa nectat. In hac autem successione, qua dixi aliqua premitti modo materie et forme, vides mentem nostram in similitudine eterne mentis intelligere; eterna enim mens sine I27 v. Successione simul omnia et omni modo | intelligendi intelligit, sed suc${ }_{36}$ cessio est descensus ab eternitate, cuius est ymago vel similitudo. In-

a) nunc am Rand wiederholt Hs.

c) assimilare korr. assimilari $H s$.

b) mensuram am Rand evgänzt Hs.

d) danach Verschreibung getilgt $H$ s. 
die Verknüpfung. Das mag nun über diese Frage genügen, wenn es dir recht ist.

Philosoph. Füge nur noch eines hinzu, ob Gott als dreifaltiger und einer erkennt.

Laie. Der ewige Geist erkennt alles in der Einheit, der Gleichheit der Einheit und beider Verknüpfung. Wie sollte Gott auch in der Ewigkeit ohne jede Succession erkennen, ohne Seinsheit, und ohne Gleichheit der Seinsheit und deren Verknüpfung? Und dieses ist die Dreieinheit in der Einheit, nicht als ob Gott irgendetwas nach Art der Materie voraussetzte und successiv wie wir erkennte. Vielmehr ist sein Erkennen, da es seine Seinsheit ist, notwendigerweise in der Dreieinheit.

Philosoph. Wenn dem so ist, dann verstehe ich das auch in unserem Geiste auf dessen Art.

Laie. Es ist gewiß, daß alles, was unter einem Prinzip steht, in sich eine Ähnlichkeit mit dem Prinzip besitzt, und ich halte es daher für gewi $\beta$, da $\beta$ in allem die Dreieinheit in der Einheit der Substanz gefunden werde, und zwar in Ähnlichkeit zur (wahren) Dreieinheit und Einheit des ewigen Prinzips. In allem also, was unter dem Prinzip steht, wird notwendigerweise ein Werden-Können gefunden, welches sich ableitet von der unendlichen Kraft der Einheit oder der absoluten Seinsheit, ein Bewirken-Können, welches sich ableitet von der unendlichen Kraft der Gleichheit und eine Verknüpfung beider, die sich herleitet von der Kraft der absoluten Verknüpfung. Daher sucht unser Geist, als ein Bild des ewigen Geistes, im ewigen Geiste das Maß seiner selbst zu erjagen, wie die Ähnlichkeit nach der Wahrheit strebt. Es ist unser Geist selbst, insofern er ein Gleichnis des göttlichen Geistes ist, als eine hohe Macht zu betrachten, in welcher potentielles Assimiliert-Werden, potentielles Assimilieren und beider Verknüpfung in ihrer Seinsheit ein und dasselbe sind. Daher kann unser Geist nur, wenn er als einer in der Dreieinheit ist, erkennen, wie es ja auch der göttliche Geist tut. Zunächst nämlich, wenn er sich bewegt, um zur Erkenntnis zu gelangen, setzt er etwas voraus in Ähnlichkeit zum Werden-Können, oder zur Materie, welchem er etwas in Ähnlichkeit zum Bewirken-Können, d. h. zur Form, hinzufügt, und dann erkennt er in Ähnlichkeit zur Verknüpfung beider. Wenn er aber nach Art der Materie begreift, so bildet er Gattungen, wenn nach Art der Form, so bildet er spezifische Unterscheidungen, wenn nach Art des Zusammengesetzten, so bildet er Arten und Individuen. So bildet er auch, wenn er gemäß der eigentümlichen Beschaffenheit erkennt, Eigenschaften; wenn er aber gemäß den zufälligen Eigenschaften erkennt, schafft er Accidentien. Alles aber erkennt er nur unter der Voraussetzung einer bestimmten Art und Weise der Materie und einer anderen Art und Weise der Form, oder aber er verknüpft beide nach Art des Zusammengesetzten. In dieser Reihenfolge aber, in der, wie ich sagte, etwas nach Art der Materie und Form vorausgesetzt wird, siehst $\mathrm{Du}$, wie unser Geist in Ähnlichkeit zum ewigen Geiste erkennt. Denn der ewige Geist erkennt alles zugleich ohne Succession und gebraucht in einem jedem jede Art der Erkenntnis. Succession jedoch ist Abstieg von der Ewigkeit, deren Bild und Ähnlichkeit sie ist. Der Geist erkennt also erst dann successiv, wenn er mit dem Körper ver- 
telligit igitur in successione, dum est unita corpori, quod successioni subicitur. Hoc eciam attente considerandum, quod omnia, ut in mente nostra sunt, sunt similiter in materia, sunt et in forma, sunt et in composito.

Philosophus. Delectabilissima sunt, que dicis. Id autem, quod 5 ultimo attendendum monuisti, clarius oro exprimito.

Ydiota. Libenter; hanc naturam, que est animal, inspicito. Nam eam mens comprehendit aliquando, ut genus est, tunc enim quasi confuse et informiter animalis naturam considerat materie modo, aliquando ut significatur per nomen animalitas et tunc modo forme, aliquando 10 modo compositi ex illo genere et differenciis ei advenientibus et tunc, ut in mente est, dicitur esse in connexione ita, ut illa materia et illa forma vel pocius illa similitudo materie et illa similitudo forme et illud modo compositi consideratum sit una et eadem nocio, unaque et eadem substancia. Sicut dum animal ut materiam considero, humanitatem vero ${ }^{\text {a) }}$ 15 ut formam ei advenientem et connexionem utriusque, dico illam materiam, illam formam et connexionem unam esse substanciam. Aut dum colorem quasi materiam considero, albedinem quasi formam ei advenientem et connexionem utriusque, dico illam materiam, illam ${ }^{\mathrm{b}}$ ) formam et connexionem illius materie et illius forme unum et idem accidens esse. Pariso formiter in omnibus, neque te moveat, quod, cum mens faciat decem genera generalissima prima principia, quod tunc illa generalissima nullum genus commune habent, quod ut materia eis premitti possit, quoniam mens potest aliquid modo materie et idem modo advenientis forme, que tali materie adveniat, atque idem modo compositi considerare, ut dum 25 considerat possibilitatem essendi substanciam vel aliquod aliud de decem, nam racionabiliter dici posset materiam esse possibilitatem essendi, substanciam aut accidens. Et considerat mens idem ut formam advenientem ei, ut est materia, ut sit compositum, quod est substancia vel aliud ex decem, ita quod illa tria unum et idem sint generalissimum. so In illa igitur rerum universitate, que in mente est, omnia sunt in trinitate et in unitate trinitatis ad similitudinem, ut sunt in mente eterna.

Philosophus. Non habent ergo decem generalissima hos essendi modos extra mentis $^{c}$ ) consideracionem.

Ydiota. Decem illa generalissima non in se, sed ut in mente sunt, 35 modo forme vel compositi intelliguntur. In suis tamen inferioribus habere

\footnotetext{
a) vero am Rand evgänzt Hs. $\quad$ b) illam korr. Hs.

c) entis über der Zeile korr. mentis Hs.
} 
eint ist, (welcher selbst der Succession unterworfen ist). Dieser Umstand ist sorgfältig zu beachten, weil alles, sofern es in unserem Geiste ist, in gleicher Weise in der Materie, der Form und in dem Zusammengesetzten ist.

Philosoph. Sehr reizvoll ist das, was Du sagst; was Du aber zuletzt als beachtenswert empfohlen hast, erkläre mir doch bitte noch deutlicher.

Laie. Gern. Betrachte z. B. jene Natur, die wir als Lebewesen bezeichnen. Sie betrachtet der Geist manchmal als Gattung, als Tierheit und dann betrachtet er die Natur des Lebewesens gleichsam verworren und formlos, nach Art der Materie; ein anderes Mal betrachtet er sie gemäß der Form; ein anderes Mal, gemäß dem aus jenem Gattungsbegriff und den $\mathrm{zu}$ ihm hinzutretenden spezifischen Differenzen Zusammengesetzten, und dann schreiben wir dem. Gegenstande, so wie er im Geiste ist, eine Verknüpfung zu, derart, daß jene Materie und jene Form oder besser, jene Ähnlichkeit der Materie und Form und jenes, was nach Art des Zusammengesetzten betrachtet wurde, ein und derselbe Begriff und ein und dieselbe Substanz ist. So sage ich denn, (wenn ich die Tierheit als Materie betrachte, die Menschheit aber als an sie herantretende Form, ferner die Verknüpfung von beiden in Betracht ziehe,) von jener Materie, jener Form und der Verknüpfung, daß sie eine Substanz ausmachen. Oder, (wenn ich die Farbe als Materie betrachte, die Weiße aber als Form, die an sie herantritt und die Verknüpfung von beiden,) so sage ich, daß jene Materie, jene Form und die Verknüpfung jener Form mit jener Materie ein und dasselbe Accidens seien; und so ist es auch bei allen (anderen Kategorien). Es möge Dich auch nicht in Erstaunen versetzen, daß, wenn der Geist seine zehn allgemeinsten Kategorien als erste Prinzipien setzt, jene zehn Kategorien keine ihnen gemeinsame Kategorie haben, welche ihnen gleichsam als Materie zugrunde gelegt werden könnte. Denn der Geist kann ein Ding nach Art der Materie betrachten; er kann dasselbe Ding nach Art der hinzugefügten Form, welche an diese Materie herantritt, betrachten, und ebenso nach Art des Zusammengesetzten, wie z. B. wenn er die Möglichkeit als Substanz oder als irgendeine andere der zehn Kategorien betrachtet, denn man kann doch mit gutem Grunde sagen, daß die Materie, die Möglichkeit des Seins, Substanz oder Accidens sei. So betrachtet der Geist ein und dasselbe als Form, wie sie zur Materie, so wie sie ist, hinzutritt, und wie es ein Zusammengesetztes ist, das entweder Substanz oder irgendeine andere von den zehn Kategorien ist, so daß alle diese drei Betrachtungsweisen ein und dasselbe höchste Allgemeine sind. In der Allheit der Dinge, die im Geiste ist, ist also alles in Dreiheit und in Dreieinigkeit auf die gleiche Weise, wie es auch im ewigen Geiste ist.

Philosoph. So haben also die zehn Kategorien diese Arten des Seins nur in der Betrachtung des Geistes?

Laie. Ja; denn wenn wir von ihnen sagen, daß sie nach Art der Form oder nach Art des Zusammengesetzten gedacht werden, so gilt dies nicht von ihnen, so wie sie an sich sind, sondern von ihnen, wie sie im Geiste sind. Das, was unter sie fällt, das wird gemäß jenen Arten des Seins betrachtet; an sich selbst aber können sie, genau erwogen, 
istos essendi modos considerantur neque, si recte attendis, in se extra mentem modo forme et compositi esse possunt. Presertim idipsum experieris, quando attendis, quomodo qualitas, quantum in se est, accidens dici nequit, sed in suis inferioribus. Sic quoque specialis status, ut in 5 mente est, modo materie forsitan non considerari posse dicetur, cum sit idem status specialis et individualis alio et alio modo consideratus. Dice-

r28 r. mus ergo, quod forsan in se materie / modo non intelligitur, sed in suis superioribus.

Philosophus. Contentor, sed vellem, ut michi ostenderes, quo10 modo ea, que actu sunt, triniter sunt iuxta antedicta.

Ydiota. Facile erit tibi videre, si attendis omnia, ut actu sunt, in ${ }^{a}$ ) materia, forma et connexione esse; hoc ipsum enim ${ }^{b}$ ), id est humanitas, illa scilicet natura, ut est possibilitas essendi hominem, materia est, sicut enim humanitas est, forma est, ut autem homo est, ex utroque 15 compositum, connexum est, ita videlicet, ut unum et idem sit possibilitas essendi hominem, forma et compositum ex utroque rei, ut una sit substancia. Similiter et hec natura, que albedinis vocabulo designatur, ut est possibilitas essendi albedinem, materia est. Illa eadem aliter forma est, eadem quoque compositum est ex utroque, ita tamen quod ut illa so materia, illa forma et illud compositum ex utroque eadem sit qualitatis natura $\left.{ }^{c}\right)$.

Philosophus. Si in materia esse est esse possibiliter, et cum possibile esse non sit, quomodo ergo omnia, que, ut actu sunt, in materia sunt.

${ }_{25}$ Y diota. Non te turbet istud, quod sine repugnancia intelligendum concipias. Nam non recipio esse actu, ut repugnet ei, quod est esse in materia, sed sic intelligendum est, quod omnia, ut actu sunt, id est hic et in hiis rebus sunt, in materia quidem sunt. Verbi gracia in cera hec possibilitas est essendi candelam, in cupro peluim.

so Philosophus. Adde verbum unum queso; Unde dicitur trinitas individua $^{\mathrm{d}}$ ) una.

Y diota. In Deo ab unitate uniente, que est vera substancia, in aliis ab unitate nature, que est quasi quedam ymago unitatis unientis, que proprie est substancia.

35 Philosophus. Cum dicitur, unitas est una, equalitas est una, unde hoc.
a) in über der Zeile ergänzt Hs.
c) natura am Rand ergänzt Hs.
b) danach est getilgt Hs.
d) induvidua korr. individua $H s$. 
nicht außerhalb des Geistes in der Weise der Form oder in der Weise des Zusammengesetzten bestehen. Das wird Dir klar werden, wenn Du darauf achtest, daß z. B. die Qualität, so wie sie in sich selbst ist, nicht als Accidens bezeichnet werden darf, sondern dieser Name gilt nur für das, was unter sie fällt. So wird man auch von einer die Species betreffenden Bestimmung, wie sie sich im Geiste befindet, vielleicht nicht sagen können, daß sie nach Weise der Materie betrachtet wird; denn eben diese Bestimmung ist ja, unter einem andern Gesichtspunkt genommen, auch eine individuelle Bestimmung. Wir werden also sagen, daß sie vielleicht an sich nicht nach der Weise der Materie erkannt wird, sondern nur in dem, was ihr übergeordnet ist.

Philosoph. Ich bin zufrieden; doch zeige mir noch bitte, inwiefern das, was wirklich ist, gemäß dem, was Du vorher sagtest, in der Dreiheit ist.

Laie. Das wird Dir leicht deutlich werden, wenn Du beachtest, daß alles, sofern es wirklich ist, sowohl in der Materie, wie in der Form, als auch in der Verknüpfung sei. Sprechen wir z. B. von jener Natur, die wir „Menschheit" nennen, so ist sie, insofern darunter die Möglichkeit des Mensch-Seins verstanden wird, Materie; wird darunter das (aktuale) Mensch-Sein verstanden, so ist sie Form; insofern sie aber Mensch ist, ist sie etwas aus beidem Verbundenes und Verknüpftes, in der Weise, daß die Möglichkeit des Menschseins, die Form und das aus beiden Zusammengesetzte ein und dasselbe ist, so daß sie nur eine einzige Substanz ausmachen. In gleicher Weise ist auch jene Naturbeschaffenheit, welche wir mit dem Wort ,,weiß" bezeichnen, insofern sie die Möglichkeit des Weißseins ist, Materie; eben dieselbe ist aber, auf andere Weise betrachtet, Form; zugleich aber ist sie das Zusammengesetzte aus beiden, deshalb, weil jene Materie jene Form und jenes aus beiden Zusammengesetzte ein und derselben natürlichen Qualität zugehören.

Philosoph. Wenn Sein in der Materie mögliches Sein und mögliches Sein nicht wirklich ist, wie kann dann das wirklich-Seiende in der Materie sein?

Laie. Das braucht Dich nicht zu beirren, da Du es ohne Widerspruch begreifen kannst. Denn ich verstehe das wirkliche Sein nicht so, daß es dem Sein wie es in der Materie ist, widerspräche; es ist vielmehr so zu verstehen, daß alles insofern es wirklich ist (d. h. hier an diesem Orte und in diesen Dingen) in der Materie ist. Im Wachs z. B. ist diese Möglichkeit, Kerze zu sein, im Kupfer, daß es Becken sei.

Philosoph. Füge doch bitte noch ein Wort hinzu! Warum sagt man von der unteilbaren Dreieinheit, sie sei eine?

Laie. Man sagt das von Gott, als der einigenden Einheit, die eine wahre Substanz ist, bei den anderen Dingen wegen der Einheit derjenigen Natur, welche gleichsam ein Bild von der einigenden Einheit ist, die selbst im eigentlichen Sinne Substanz ist.

Philosoph. Wenn man von der Einheit und von der Gleichheit das Prädikat ,eins" aussagt, von welchem Gesichtspunkt aus tut man das? 
Ydiota. Ab unitate substancie.

Philosophus. Quando autem nostri dicunt theologi unitatem pro $^{2}$ ) Patre et equalitatem pro Filio et nexum pro Spiritu Sancto capientes, quomodo Pater est unus, Filius est unus, unde hoc.

5 Ydiota. A singularitate persone. Sunt enim tres singulares persone in una divina substancia, ut alio tempore, quantum concedebatur, diligenter tractavimus.

Philosophus. Ad finem, ut, que supra dixisti, intelligam, dicito, an velis mentem nostram ex illis comprehendendi ${ }^{b}$ ) modis compositam 10 esse. Tunc, cum mens nostra substancia sit, erunt modi illi partes eius substanciales, hoc, si sic censes, dicito.

Ydiota. Voluit Plato mentem ex individua et dividua substancia componi ${ }^{1}$ ), ut supra dixisti hoc ex comprehendendic ${ }^{c}$ ) modo sumens. Nam, dum modo forme intelligit, tunc individue comprehendit, res enim for15 maliter intellecta individue comprehenditur. Unde eciam humanitates dicere veraciter non possumus, sed bene homines dicimus, quia res modo materie aut modo compositi intellecta dividue intelligitur. Est autem mens nostra vis comprehendendi et totum virtuale ex omnibus comprehendendi virtutibus compositum. Quilibet igitur modus, cum pars so eius sit substancialis, de tota mente verificatur; quemadmodum autem modi comprehendendi sint substanciales partes virtutis, que mens dicitur, difficulter dici posse arbitror. Nam cum mens sic vel sic intelligat, I28 v. tunc virtutes eius intelligendi, | que sunt partes eius, accidencia esse nequeunt; quomodo autem sint partes substanciales atque mens ipsa, 25 difficilimum est dictu et cognitu.

Philosophus. Adiuva me parum in hoc difficili, optime ydiota.

Ydiota. Mens virtualiter constat ex virtute intelligendi, raciocinandi, ymaginandi et senciendi ita, quod ipsa tota dicatur vis intelligendi, vis raciocinandi, vis ymaginandi et vis senciendi. Unde ex hiis tamquam 30 suis constat elementis, et mens omnia in omnibus attingit suo modo. Et quia, ut omnia sunt actu, sunt in sensu quasi in globo et indiscrete, et illa in racione discrete, hinc est expressissima similitudo inter modum essendi omnium, ut sunt actu et ut sunt in mente. Nam vis senciendi in nobis est vis mentis et hinc mens sicut quelibet pars linee linea. Magni35 tudo enim in se extra materiam considerata congruum exemplum est
b) pro über der Zeile ergänzt Hs.
b) comprehendi Hs.
c) comprehendi korr. comprehendendi $H s$.
I) $\mathrm{Tim} .34 \mathrm{C}$. 
Laie. Wegen der Einheit der Substanz.

Philosoph. Wenn das aber unsere Theologen sagen, indem sie die Einheit für den Vater, die Gleichheit für den Sohn, und die Verknüpfung für den Heiligen Geist setzen, inwiefern ist dann der Vater einer und der Sohn einer, und wie erklärt sich das?

Laie. Durch die Einzelheit der Person, es sind nämlich drei einzelne Personen in einer göttlichen Substanz, wie wir es zu anderer Zeit so sorgfältig es nur gehen mochte, gesagt haben.

Philosoph. Damit ich das, was Du vorhin sagtest, verstehe, sage doch, ob $\mathrm{Du}$ so verstanden werden willst, daß unser Geist aus jenen (Erkenntnis-) Arten zusammengesetzt sei? Wenn unser Geist Substanz ist, werden jene Arten doch deren substantielle Teile sein. Sage, ob Du das so meinst.

Laie. Platon hat behauptet, daß der Geist sich aus teilbarer und unteilbarer Substanz zusammensetze, indem er dieses, wie Du oben sagtest, aus der Art seines Begreifens schloß. Denn wenn der Geist nach Art der Form begreift, dann erkennt er ein Ding als unteilbares; denn ein Ding, das formal erkannt wird, wird unteilbar begriffen. Daher können wir in Wahrheit nicht von Menschheiten sprechen, sondern nur von Menschen. Denn ein solcher Gegenstand, welcher nach Art der Materie oder des Zusammengesetzten erkannt wird, wird als teilbar erkannt. Es ist aber unser Geist eine Kraft des Begreifens, und ein virtuelles Ganze, welches aus allen Vermögen des Begreifens zusammengesetzt ist. Da aber jede seiner (Erkenntnis-) Arten ein substantieller Teil von ihm ist, so gilt sie auch vom Ganzen des Geistes. In welcher Weise aber die Arten des Begreifens substantielle Teile des Vermögens sind, welches Geist genannt wird, ist, meiner Meinung nach, schwer begreiflich $\mathrm{zu}$ machen. Denn da der Geist auf die eine oder die andere Weise erkennt, können seine Erkenntnisvermögen, welche seine Teile sind, keine Accidenzen von ihm sein; wie sie aber substantielle Teile und der Geist selbst sein können, ist sehr schwer zu sagen und zu erkennen.

Philosoph. Hilf mir ein wenig, mein bester Laie in dieser schwierigen Frage!

Laie. Der Geist besteht, insoweit er Vermögen ist, aus dem Vermögen, zu erkennen, zu schließen, vorzustellen und zu empfinden, in der Weise, daß er selbst, als Ganzes, Erkenntnisvermögen, Schlußvermögen, Vorstellungsvermögen, Empfindungsvermögen heißt; daher besteht er aus diesen gleichsam als aus seinen Elementen, und der Geist erkennt alles in allem auf seine Weise. Und wie alles, insofern es wirklich ist, in den Sinnen gleichsam zusammengeballt und ungeschieden, in dem Verstande aber geschieden ist, so besteht auch eine ganz ausgesprochene Ähnlichkeit zwischen der Art des Seins von allem, wie es wirklich und wie es im Geiste ist. Denn das Empfindungsvermögen in uns ist ein Vermögen des Geistes, und so Geist, wie auch der Teil einer Linie wieder Linie ist. Denn Größe an sich, außerhalb der Materie betrachtet, ist ein rentsprechendes und zureichendes Beispiel für das, wonach Du gefragt 
eius, quod petisti; quelibet enim pars eius de toto verificatur, hinc eiusdem entitatis est, cuius totum. virtutes.

Philosophus. Cum mens sit una, unde habet has comprehendendi

Ydiota. Ab unitate habet. Nam quod communiter modo materie aut compositi intelligit, habet quia unitas uniens, quod singulariter, similiter ab unitate, que est singularitas, quod formaliter, ab unitate, que est immutabilitas; unde, quod dividue intelligit, ab unitate habet, divisio enim ab unitate descendit.

Capitulum duodecimum.

Quomodo non sit unus intellectus in omnibus hominibus; et quomodo numerus separatarum mencium, per nos. innumerabilis, est Deo cognitus. ${ }^{a}$ )

Philosophus. Adhuc de paucis opto, quid sencias, audire. Aiunt 15 quidam Peripatetici ${ }^{b}$ ) unum esse intellectum in omnibus hominibus, alii ut quidam Platonici non esse unam intellectivam animam, sed quod anime nostre sint eiusdem substancie cum anima mundi, quam dicunt esse omnium animarum nostrarum complexivam, sed differe dicunt ${ }^{c}$ ) animas nostras numero, quia habent diversum operandi modum, dicunt 20 tamen eas in animam mundi post mortem resolvi. Quid tibi in hoc occurrit, dicito.

Ydiota. Ego mentem intellectum esse affirmo, ut supra audisti. Mentem autem unam esse in omnibus hominibus non capio, nam, cum mens habeat officium, ob quod anima dicitur, tunc exigit convenientem 25 habitudinem corporis adequate sibi proporcionati, que, sicut in uno corpore reperitur, nequaquam in alio est reperibilis. Sicut igitur idemptitas proporcionis est immultiplicabilis, ita nec idemptitas mentis, que sine adequata proporcione corpus animare nequit. Sicut enim visus oculi tui non posset esse visus cuiuscunque alterius, eciam si a tuo oculo separare30 tur et alterius oculo iungeretur, quia proporcionem suam, quam in oculo tuo reperit, in alterius oculo reperire nequiret, sic nec discrecio, que est in visu tuo, posset esse discrecio in visu alterius, ita nec intellectus discrecionis illius posset esse intellectus discrecionis alterius. Unde hoc nequaquam possibile arbitror, unum esse intellectum in omnibus homini-

a) capitulum - cognitus am Rand evgänzt Hs.

b) Paripatetici $H s$.

c) dicunt am Rand ergänzt Hs. 
hast. Denn was ich von einem Teil der Größe aussagen kann, das gilt auch für das Ganze (wie ja der Teil einer Linie selbst wieder Linie ist), so daß Teil und Ganzes von gleicher Wesenheit sind.

Philosophus. Da der Geist doch einer ist, woher hat er dann diese verschiedenen Vermögen des Begreifens?

Laie. Er hat sie von der Einheit. Denn was er als Allgemeines nach. Art der Materie oder des Zusammengesetzten erkennt, erfaßt er als vereinigende Einheit; was er als einzelnes erkennt, hat er in gleicher Weise von der Einheit, welche Einzigkeit ist; was er der Form nach erkennt, von der Einheit, welche Unveränderlichkeit ist; daher hat er das, was er geteilt erkennt, von der Einheit; denn Teilung stammt aus Einheit.

I2. Kapitel.

Es gibt nicht eine Vernunft in allen Menschen. - Die Zahl der gesonderten Geister, die von uns nicht gezählt werden kann, ist Gott bekannt.

Philosoph. Ich möchte noch Deine Meinung in einigen Fragen hören. Es sagen einige Peripatetiker, daß es eine einzige Vernunft in allen Menschen gebe. Andere, z. B. einige Platoniker sagen, es gebe nicht ein e vernünftige Seele, sondern unsere Seelen seien zwar von der gleichen Substanz, da es eine Weltseele gäbe, welche, wie sie sagen, alle unsere Seelen umfasse; aber unsere Seelen unterschieden sich durch die Zahl, da sie eine verschiedene Art des Wirkens bätten; sie sagen jedoch, daß sie sich in die Weltseele nach dem Tode auflösten. Was Du zu diesem Punkte zu bemerken hast, sage mir bitte!

Laie. Ich behaupte, daß der Geist Vernunft sei, wie es aber ein en Geist in allen Menschen geben solle, begreife ich nicht. Denn wenn der Geist seine Aufgabe erfüllen soll, um deretwillen man von ihm als Seele spricht, dann braucht er hierfür eine Beschaffenheit, die dem Körper entspricht, der ihm in adäquater Weise zugeordnet ist, und diese Beschaffenheit läßt sich, so wie sie in einem Körper gefunden wird, niemals in irgendeinem anderen finden. Wie also die Identität eines Maßverhältnisses niemals vielfach gesetzt werden kann, so auch nicht die Identität des Geistes, welcher ohne entsprechendes Maßverhältnis den Körper niemals beleben kann. Wie die Sehkraft $D$ eines Auges niemals das Sehen irgendeines anderen werden könnte, auch wenn sie von Deinem Auge getrennt und einem anderen Auge einverleibt würde, weil sie ihr Maßverhältnis, das sie in Deinem Auge findet, in einem anderen Auge nicht finden kann, und so auch nicht die Kraft der Unterscheidung, welche Deinem Sehen innewohnt, Kraft der Unterscheidung im Auge eines anderen sein könnte, so kann auch nicht die Vernunft, so wie sie als Unterscheidungsvermögen in dem einen Subjekt wirkt, nicht mit der Vernunft im Unterscheidungsvermögen eines anderen zusammenfallen. Daher glaube ich auch, daß es auf keine Weise möglich sei, daß es eine Vernunft in allen Menschen gebe. Da aber die Zahl offenbar aufgehoben wird, wenn die Mannigfaltigkeit der Materie aufgehoben wird, wie aus dem früher Gesagten klar ist, und die Natur des Geistes außerhalb des Körpers von aller Materie losgelöst ist, deshalb haben vielleicht die Platoniker gesagt, daß unsere Seelen in eine gemeinsame 
bus, verum, quia numerus sublatus videtur, quando tollitur variebilitas materie, ut ex superioribus patet, et mentis natura extra corpus sit ab r29 r. omni varietate materie / absoluta, ideo forte Platonici dixerunt animas nostras in unam animam communem nostrarum complexivam resolvi, 5 sed hanc resolucionem non puto veram, nam quamvis nos sublata varietate non capiamus multiplicacionem numeri, propter hoc tamen non desinit rerum pluralitas, que est divine mentis numerus ${ }^{\mathrm{a}}$ ). Unde numerus substanciarum separatarum non plus est nobis numerus quam non numerus, quia adeo a nobis est innumerabilis, quod neque est par neque 10 impar, neque magnus neque parvus, neque in aliquo convenit cum numero per nos numerabili, quasi si quis audiret vocem maximam, quam emisit maximus hominum exercitus, quem exercitum emisisse ignorat. Manifestum est in voce, quam audit, cuiuslibet hominis vocem esse differentem et distinctam, tamen audiens non habet iudicium de numero, 15 quare iudicat vocem unam esse, quia modum attingendi numerum non habet. Vel si in una camera multe ardeant candele et camera de omnibus illuminetur, manet lumen cuiuslibet candele distinctum a lumine alterius; et hoc experimur, quando successive eportantur, quia minuitur illuminacio, quando quelibet eportata secum suam illuminacionem educit. ${ }_{20}$ Esto igitur, quod candele ardentes in camera illuminacione remanente extinguantur, et quod quis intret illuminatam cameram, hic, et si videat claritatem camere, tamen distinccionem et discrecionem luminum nequaquam attingere potest, ymmo non posset ille attingere luminum pluralitatem ibi esse, nisi scienciam haberet ibi esse lumina candelarum ex${ }_{25}$ tinctarum, et si hoc assecutus esset scilicet ibi esse pluralitatem, tamen numero discernere unum lumen ab alio nunquam posset. Talia exempla in aliis sensibus adducere poteris, ex quibus te iuvare poteris, quomodo cum sciencia pluralitatis stat quo ad nos impossibilitas discrecionis numeri. Qui autem attendit, quomodo nature abstracte ab omni varietate 30 materie per nos qualitercunque intelligibiles ${ }^{b}$ ) quo ad Deum, qui solum est infinite absolutus et simpliciter, non sunt abstracte ab omni mutacione, quin ab eo mutari et interimi possint ipsi soli Deo secundum naturam immortalitate $^{c}$ ) inhabitante ${ }^{d}$ ), ille videt omnem creaturam numerum divine mentis auffugere non posse.

a) que est divine mentis numerus am Rand ergänzt Hs.

c) immortalitatem $H s . \quad$ d) inhabitantem korr. inhabitante $H s$.

b) intelligibilis $H s$. 
Seele, die alle unsrigen umfasse, aufgelöst würden. Jedoch halte ich diesen Schluß nicht für richtig. Denn obwohl wir, wenn die Verschiedenheit aufgehoben wird, keine Vervielfältigung in der Zahl mehr begreifen, so hört doch darum diejenige Vielheit der Dinge nicht auf, welche auf der Zahl des göttlichen Geistes beruht. Was die gesonderten Substanzen betrifft, so läßt sich daher von ihnen weder sagen, daß sie für uns eine Zahl haben, noch daß sie keine haben: denn ihre Zahl ist für uns unzählbar. Denn sie ist weder gerade noch ungerade, weder groß noch klein, und stimmt in keinem Punkte mit der von uns zählbaren Zahl überein. Es verhält sich damit so, wie wenn jemand einen gewaltigen Schrei hörte, den ein großes Heer von Menschen ausgestoßen hat, ohne doch zu wissen, daß dieser Schrei von einem Heere herrührt. Alsdann ist es klar, da $\beta$ im Rufe, welchen er hört, jedes einzelnen Menschen Stimme besonders und geschieden war, und dennoch hat er beim Hören kein Urteil über die Anzahl. Deswegen urteilt er, daß es nur ein Ruf sei, da er kein Mittel für das Erfassen der Zahl besitzt. Oder, wenn in einem Zimmer viele Kerzen brennen, und das Zimmer von ihnen beleuchtet wird, so bleibt doch das Licht einer jeden Kerze von dem der anderen geschieden. Das bemerken wir dann, wenn sie hintereinander herausgetragen werden, da die Beleuchtung vermindert wird, wenn jede, indem sie herausgetragen wird, ihre Kraft, zu leuchten, mit sich fortführt. Stellt man sich also vor, daß im Zimmer die brennenden Kerzen ausgelöscht würden, und die Leuchtkraft gleichwohl zurückbliebe, und daß jemand das beleuchtete Zimmer beträte, so würde dieser, wenngleich er die Helligkeit des Zimmers sähe, dennoch die Sonderung und Scheidung der Lichter auf keine Weise erreichen können, ja er könnte nicht einmal erkennen, da $\beta$ es dort eine Vielheit von Lichtern gibt, wenn er nicht etwa eine Kenntnis davon hätte, daß das Licht von ausgelöschten Kerzen herrührt. Und auch wenn er zu diesem Wissen gelangt wäre, d. h. wenn er wüßte, daß es dort eine Vielheit von Kerzen gibt, so könnte er doch der Zahl nach ein Licht vom anderen niemals unterscheiden. Solche Beispiele könntest Du auch für die anderen Sinne anführen und aus ihnen Dir begreiflich machen, auf welche Weise es möglich sei, daß für uns mit dem Wissen, daß Vielheit sei, doch zugleich das Unvermögen einer numerischen Unterscheidung gegeben sein könne. Wer aber beachtet, wie die Naturen, die von jeder Mannigfaltigkeit einer für uns noch irgendwie erkennbaren Materie abgelöst sind, dennoch in Bezug auf Gott, der allein auf unendliche und einfache Weise absolut ist, nicht von jeder Veränderlichkeit frei sind, da sie ja von ihm noch verändert und vernichtet werden könnten, weil Gott allein dem Wesen nach Unsterblichkeit innewohnt, der sieht ein, daß keine Kreatur der Zahl des göttlichen Geistes entgehen kann. 
Capitulum tercium decimum.

Quomodo id, quod Plato dicebat animam mundi et Aristoteles naturam, sit Deus, qui operatur omnia in omnibus; et quomodo mentem creet in nobis. ${ }^{2}$ )

Philosophus. Satis de hoc; quid ais de anima mundi.

Y diota. ${ }^{b}$ ) Tempus non patitur omnia discuti; puto, quod animam ${ }^{c}$ ) mundi vocavit Plato id, quod Aristotiles naturam. Ego autem nec animam illam nec naturam aliud esse conicio ${ }^{\mathrm{d}}$ ) quam Deum omnia in omnibus operantem, quem dicimus spiritum universorum.

10 Philosophus. Plato dixit animam illam exemplaria rerum indelibiliter continere et omnia movere, Aristotiles naturam aiebat sagacem omnia moventem.

Ydiota. Forte Plato voluit animam mundi esse ut animam servi scientis mentem domini sui et exequentem voluntatem eius, et hanc 15 scienciam vocavit nociones seu exemplaria, que nulla oblivione obmittun$\operatorname{tur}^{\mathrm{e}}$ ), ut divine providencie non deficeret execucio, et id, quod Plato I29 v. scienciam anime mundi appellavit, | Aristotiles sagacitatem nature esse voluit, que habet sagacitatem exequendi imperium Dei. Ob hoc tribuerunt necessitatem compleccionis illi anime seu nature, quia necessita20 tur determinate sic agere, ut absoluta necessitas imperat, sed non est nisi modus intelligendi, quando scilicet mens nostra concipit Deum quasi artem architectonicam, cui $\operatorname{ars}^{f}$ ) alia executorialis subsit, ut conceptus divinus in esse prodeat, sed, cum voluntati omnipotenti omnia necessario obediant, tunc voluntas Dei alio executore opus non habet, nam velle ${ }_{25}$ cum exequi in omnipotencia coincidit, quasi ut dum vitrificator vitrum facit, nam insufflat spiritum, qui exequitur voluntatem eius, in quo spiritu est verbum seu conceptus et potencia, nisi enim potencia et conceptus vitrificatoris forent in spiritu, quem emittit, non oriretur vitrum tale. Concipe igitur absolutam artem creativam per se subsistentem, ut 30 ars sit artifex et magisterium magister. Hec ars habet in sua essencia necessario omnipotenciam, ut nichil resistere possit, sapienciam, ut sciat, quid agat, et nexum omnipotencie cum sapiencia, ut, quid velit, fiat. Nexus ille ${ }^{g}$ ) in se habens sapienciam et omnipotenciam spiritus est quasi voluntas seu desiderium. ${ }^{b}$ ) Impossibilium enim et penitus ignotorum non
a) Capitulum - nobis am Rand ergänzt Hs.
c) danach puto getilgt $H s$ d) connicio $H s$.
e) amitterentur am Rand korr. obmittuntur $H s$.
g) danach qui getilgt Hs.
b) Ydiota am Rand ergänzt Hs.
f) danach ars getilgt $H$ s.
h) seu desiderium am Rand evgänzt Hs. 
I3. Kapitel.

Was Platon Weltseele nannte und Aristoteles Natur, ist Gott, der alles in allem wirkt und den Geist in uns schafft. sagen?

Philosoph. Davon genug. Was hast Du über die Weltseele zu

Laie. Die Zeit erlaubt nicht, alles zu besprechen. Meiner Meinung nach hat Platon das als Weltseele bezeichnet, was Aristoteles Natur nannte. Ich aber vermute, daß jene Seele und jene Natur nichts anderes sei als Gott, der alles in allem wirkt, und den wir den Geist des Alls nennen.

Philosoph. Platon sagte, daß jene Seele in sich die Urbilder der Dinge unzerstörbar enthalte, und alles bewege. Aristoteles nannte die Natur vernünftig und alles bewegend.

Laie. Vielleicht hat Platon sagen wollen, die Weltseele sei gleich der Seele eines Sklaven, welcher den Sinn seines Herrn kennt und seinen Willen erfüllt. Dieses Wissen nannte er Ideen oder Urbilder, die niemals ganz durch Vergessen verdunkelt werden, auf daß die göttliche Vorsehung zur Ausführung gelange. Und das, was Platon als Wissen der Weltseele bezeichnete, nannte Aristoteles Weisheit der Natur, welche die Weisheit besitzt, den Befehl Gottes auszuführen. Deswegen schrieben sie Notwendigkeit der Verknüpfung jener Seele oder jener Natur $\mathrm{zu}$, weil sie notwendig dazu bestimmt wird, so zu handeln, wie es die absolute Notwendigkeit befiehlt. Es ist jedoch nur eine Art des Sichverständlichmachens, wenn unser Geist Gott so auffaßt, wie die Baumeisterkunst, welcher eine andere ausführende Kunst untergeordnet ist, auf daß der göttliche Gedanke zum Sein gelange. Denn da dem Willen des Allmächtigen alles notwendig gehorcht, bedarf dieser Wille nicht eines anderen, das ausführt; denn Wollen und Wirken fällt in der Allmacht zusammen. Wie wenn ein Glasbläser Glas macht, denn er bläst den Hauch, welcher seinen Willen zur Ausführung bringt, ein, und in diesem Hauch (spiritus) ist sein Wort, sein Begriff und seine Macht. Wäre nämlich Macht und Begriff des Glasbläsers nicht im Hauch, den er entsendet, so würde kein solches Glas entstehen. Denke dir also die absolute Schöpferkunst, die für sich besteht, so, daß hier die Kunst der Künstler und die Lehre der Lehrer ist. Diese Kunst schließt in ihrem Sein notwendigerweise Allmacht in sich, so daß ihr nichts widerstehen kann; sie ist Weisheit, auf daß sie wisse, was sie wirkt, und die Verbindung der Allmacht mit der Weisheit, damit werde, was sie will. Denn jene Verknüpfung, die die Weisheit und Allmacht des belebenden Geistes in sich faßt, ist gleichsam Wille und Begehren. Denn Unmögliches und ganz Unbekanntes wird nicht begehrt: dem vollkommensten Willen wohnt also Wissen und Allmacht inne und er wird gleichnisweise Hauch (spiritus) genannt, 
est voluntas seu desiderium, sic in perfectissima voluntate inest sapiencia et omnipotencia et a similitudine quadam spiritus dicitur eo, quod motus sine spiritu non est, adeo quod et id, quod in vento mocionem facit et in omnibus aliis, spiritum appellemus. Per motum autem omnes artifices 5 efficiunt, quod volunt. Quapropter vis ${ }^{a}$ ) artis creative, que est ars absoluta et infinita seu Deus benedictus, omnia efficit in spiritu seu voluntate, in qua est sapiencia Filii et omnipotencia Patris, ut opus eius sit unius indivise trinitatis. Hunc nexum, spiritum seu voluntatem ignorarunt Platonici, qui hunc spiritum non viderunt Deum, sed a Deo prin10 cipiatum et animam mundum, ut anima nostra intellectiva nostrum corpus, animantem putarunt $\left.{ }^{b}\right)$. Neque eum spiritum viderunt Peripathetici, qui hanc vim naturam rebus immersam, a qua est motus et quies, posuerunt, cum tamen sit Deus absolutus in secula benedictus.

Orator. $O$ quantum exhilaratus ${ }^{c}$ ) sum tam lucidam audiens ex15 planacionem; sed queso, ut iterum aliquo exemplo nos iuves ad concipiendum mentis nostre creacionem in hoc nostro corpore.

Ydiota. Audivisti iam ante de hoc; sed quia varietas exemplorum inexpressibile clarius facit, tibi morem geram $^{d}$ ). Ecce nosti mentem nostram vim quandam esse habens ymaginem artis divine iam dicte. 20 Unde omnia, que absolute arti verissime insunt, menti nostre vere ut ymagini insunt. Unde mens est creata ab arte creatrice, quasi ars illa seipsam creare vellet, et quia immultiplicabilis est infinita ars, quod tunc eius surgat ymago, sicut si pictor seipsum depingere vellet. Et quia ipse non est multiplicabilis, tunc se depingendo oriretur eius ymago. Et quia 130 r. ymago nunquam | quantumcunque perfecta, si perfectior et conformior ${ }_{26}$ esse nequit exemplari, adeo perfecta ${ }^{e}$ ) est sicut quecunque imperfecta ymago $\left.^{f}\right)$, que potenciam habet se semper plus et plus sine limitacione inaccessibili exemplari conformandi. In hoc enim infinitatem ymaginis modo, quo potest, imitatur, quasi si pictor duas ymagines faceret, quarum 30 una mortua videretur actu sibi similior, alia autem minus similis viva, scilicet talis, que seipsam ex obiecto eius ad motum incitata conformiorem semper facere posset, nemo hesitat secundam perfecciorem quasi artem pictoris magis imitantem. Sic omnis mens eciam et nostra, quamvis infra omnes sit creata, a Deo habet, ut modo, quo potest, sit artis in35 finite perfecta et viva ymago. Quare est trina et una habens potenciam,

a) vis über der Zeile ergänzt Hs.
c) exhiratus korr. exhilaratus $H s$.
e) pefecta korr. perfecta Hs. b) putarunt am Rand evgänzt Hs.

d) tibi morem geram. B. fehlt in der Hs.

f) ymago imperfecta umgestellt $H s$. 
darum, weil ohne belebenden Hauch es keine Bewegung gibt, so sehr, $\mathrm{da} ß$ man auch das, was im Winde die Bewegung hervorruft, und überall sonst Hauch benennt. Durch Bewegung aber bewirken alle Künstler das, was sie wollen. Deswegen wirkt die Kraft der Schöpfungskunst, welche die absolute und unendliche Kunst ist, oder der gebenedeite Gott, alles im Geiste und im Willen, in welchem die Weisheit des Sohnes und die Allmacht des Vaters ist, so daß sein Werk das der ungeteilten Dreieinheit ist. Diese Verknüpfung, diesen Geist oder Willen kannten die Platoniker nicht, die diesen Geist nicht als Gott begriffen haben, sondern als etwas, was von Gott gesetzt ist, und deshalb glaubten sie, daß die Weltseele die Welt belebe, gleichwie unsere erkennende Seele den Körper belebt. Jenen Geist haben auch die Peripatetiker nicht erkannt, die diese Kraft als Natur verstanden, die den Dingen innewohne, und das Prinzip der Ruhe und Bewegung sei, während er doch der absolute Geist ist, welcher gebenedeit ist in Ewigkeit.

Redner. Wie bin ich erfreut, durch das Hören einer so lichtvollen Auseinandersetzung! Unterstütze uns jedoch wiederum durch ein Beispiel, damit wir die Schöpfung unseres Geistes in diesem unseren Körper verstehen!

Laie. Schon vorhin hast Du mich über diesen Punkt reden hören; da aber mannigfache Beispiele das Unausdrückbare deutlicher machen, will ich Dir zu Willen sein. Du weißt doch, daß unser Geist eine Kraft ist, indem Du als ein Bild der göttlichen Kunst ansiehst, von der wir gesprochen haben. Daher wohnt denn alles, was der absoluten Kunst in höchster Wahrheit innewohnt, unserem Geiste, wie einem Bilde, inne. So ist denn der Geist von der schöpfenden Kunst geschaffen worden, gleich als ob jene Kunst sich selber hätte schaffen wollen. Da nun die unendliche Kunst keine Vervielfältigung duldet, mußte notwendigerweise ein Bild von ihr entstehen, gleich als wenn ein Maler sich selbst malen wollte. Denn da er selbst nicht vervielfältigt werden kann, entsteht, wenn er sich malt, sein Bild. Und da ein Bild, so vollkommen es sein mag, doch niemals absolut vollkommen ist (denn vollkommener und ähnlicher als das Original selbst kann es ja nicht sein), so besteht es als ein unvollkommenes Bild, das jedoch die Möglichkeit hat, sich immer mehr und mehr, ohne jede Grenze dem unerreichbaren Urbild anzugleichen. Denn gerade in dieser Weise ahmt das Bild die Unendlichkeit nach, so sehr es immer kann. Wenn z. B. ein Maler zwei Bilder malte, von denen das eine leblos, aber ähnlich erschiene, das andere weniger ähnlich aber lebendig, d. h. als ein solches, welches sich selbst, von seinem Gegenstande in Bewegung gebracht, diesem immer mehr und mehr angleichen könnte, so wird doch jeder das zweite für vollkommener erklären, weil es die Kunst des Malers mehr nachahmt. So hat jeder Geist, auch der unsere, wenngleich er geringer beschaffen ist als die anderen Geister, das von Gott, daß er, so sehr er immer kann, ein vollkommenes und lebendiges Bild der unendlichen Kunst ist. Darum ist er dreieinig und einer, da er Macht, Weisheit und beider Verknüpfung besitzt, und erscheint so als ein vollkommenes Bild der Kunst, weil er, in Bewegung gebracht, sich immer mehr und mehr dem Urbild anzupassen vermag. So hat unser Geist, wenn er auch beim 
sapienciam et utriusque nexum modo tali ut perfecta artis ymago, scilicet quod excitata possit se semper plus et plus exemplari conformare. Sic mens nostra, et si in principio creacionis non habeat actualem resplendenciam artis creatricis in trinitate et unitate, habet tamen vim illam concre5 atam, per quam excitata se actualitati ${ }^{a}$ ) divine artis conformiorem facere potest. Unde in unitate essencie eius est potencia, sapiencia et voluntas, et coincidunt in essencia magister et magisterium ut in ymagine viva artis infinite, que excitata se actualitati divine semper sine termino conformiorem facere potest precisione infinite artis inaccessibili semper remanente.

10

Orator. Mirabiliter et planissime; sed oro, quomodo mens creando infunditur.

Ydiota. Alias de hoc audisti; nunc iterum recipe alio exemplo idipsum. Et accepto vitro et pendulob) inter pollicem et digitum ipsum suspendente tetigit vitrum et sonum recepit; sonoque aliqualiter conti15 muato fissum est vitrum, et cessavit sonus. Et aiebat: In vitro pendulo vis aliqua orta fuit per meam potenciam, que vitrum movit. Unde sonus ortus est et rupta proporcione vitri, in qua sonus et per consequens motus residebat, cessavit ibi motus similiter motu cessante sonus. Quod si virtus illa, quia non dependebat a vitro, ob hoc non cessaret, sed sine vitro ${ }^{20}$ subsisteret, exemplum haberes, quomodo vis illa creatur in nobis, que motum et armoniam facit et cessat illam facere per rupturam proporcionis, licet ob hoc non cesset esse. Sicut si ego tibi artem citharisandi in data cithara trado, cum ars a cithara data non dependeat, licet in cithara sit tibi tradita, tunc cithara rupta ob hoc ars citharizandi non 25 est rupta, eciam si nulla cithara tibi apta sit in mundo reperibilis.

Capitulum quartum decimum.

Quomodo mens de Galaxia dicitur descendere per Planetas ad corpus et reverti; et de nocionibus spirituum separatorum indelibilibus et nostris delibilibus. ${ }^{c}$ )

so Philosophus. Ad res raras et a sensu remotas aptissima atque pulcherrima adducis exempla; et quia solis occasus accedit, qui nos non sinet amplius commorari, dic oro, quid sibi velint philosophi, qui aiunt animas descendere de Galaxia per Planetas ad corpora et sic reverti ad Galaxiam $^{1}$ ), et cur Aristotiles ( volens exprimere vim anime nostre a rar 3 v. cione incipit dicens animam de racione ad doctrinam, de doctrina ad

a) actualitate. $\left.H s . \quad{ }^{b}\right)$ pendule $H s$. c) Capitulum - delebilibus am Rand ergänzt Hs. I) cf.: Macrobius Somnium Scipionis I, 4, 4; I, I2, 4 . 
Anfang seiner Schöpfung keinen wirklichen Widerschein der schöpfenden Kunst in der Dreiheit und der Einheit in sich zeigt, dennoch in sich jene mit ihm geschaffene Kraft, von der angetrieben er sich der Wirklichkeit der göttlichen Kunst immer mehr angleicht. Daher ist in der Einheit seines Seins Macht, Weisheit und Wille und in seiner Seinsheit fallen Lehre und Lehrer zusammen als in einem lebendigen Bilde der unendlichen Kunst, welches, wenn es in Bewegung gebracht wird, sich ohne Grenze immer mehr der göttlichen Wirklichkeit angleichen kann, obwohl ihm die genaue Bestimmtheit der unendlichen Kunst immer unerreichbar fern bleibt.

Redner. Das ist wundervoll und mit höchster Klarheit gesagt. Doch erkläre noch, wie der Geist bei der Schöpfung in den Körper gesenkt wird!

Laie. Schon einmal hast Du mich über dieselbe Sache reden hören; nun vernimm zum zweiten Male das Gleiche in einem anderen Beispiele.

Und indem er ein Glas nahm und ein Pendel zwischen Daumen und Zeigefinger herabhängen lie $\beta$, berührte er das Glas mit dem Pendel und brachte einen Ton hervor; nachdem nun der Ton eine Zeitlang gedauert hatte, zerbrach er das Glas, und der Ton hörte auf. Darauf sagte der

Laie. In dem Glase ist vermittels des Pendels durch mich eine Kraft entstanden, welche das Glas bewegte; dadurch entstand ein Ton. Nachdem nun das Maßverhältnis des Glases zerstört wurde, auf dem der Ton, und zwar zufolge der Bewegung beruhte, hörte dort die Bewegung auf und in gleicher Weise mit dem Aufhören der Bewegung auch der Ton. Wenn nun aber jene Kraft, die ja nicht vom Glase abhing, nicht aufhörte, sondern auch ohne das Glas Bestand hätte, so würdest Du darin ein Beispiel dafür haben, auf welche Weise jene Kraft in uns geschaffen wird, welche Bewegung und Harmonie bewirkt und welche infolge einer Auflösung des Maßverhältnisses aufhört, sie zu bewirken, aber darum nicht aufhört zu sein. Wenn ich Dich z. B. an einer bestimmten Zither die Kunst des Zitherspielens lehre, so hängt diese Kunst, obwohl sie an einer bestimmten Zither übermittelt wurde, doch von dieser nicht $a b$ - und zerbricht die Zither, so geht doch darum Deine Kunst des Zitherspieles nicht zu Grunde, auch dann nicht, wenn keine für Dich geeignete Zither in der ganzen Welt gefunden werden könnte.

\section{I4. Kapitel.}

Man sagt, daß der Geist von der Milchstraße über die Planeten in den Körper gekommen sei, und dorthin zurückkehre. - Es wird gehandelt von der Unzerstörbarkeit der Begriffe der seligen Geister und von der Hinfälligkeit der unseren.

Philosoph. Für seltene und von der Sinneswahrnehmung abgelegene Dinge bringst Du Beispiele von höchster Prägnanz und höchster Schönheit. Und da der Sonnenuntergang herannaht, was uns nicht erlaubt, länger zu verweilen, erkläre mir doch bitte, was die Philosophen sagen wollen, welche behaupten: unsere Seelen stiegen von der Milchstraße durch die Planeten in die Körper und kehrten auf demselben Wege wieder in die Milchstraße zurück. Ferner möchte ich wissen, warum 
intellectibilitatem ascendere. Plato vero contrario modo ait ponens intellectibilitatem elementum, et quod degenerando ${ }^{a}$ ) intellectibilitas fiat doctrina seu intelligencia, et intelligencia degenerando fiat racio.

Ydiota. Ignoro scripturas; sed forte primi, qui de descensu et 5 ascensu animarum dixerunt, idem dicere voluerunt, quod Plato et Aristotiles. Nam Plato ad creatoris ymaginem ${ }^{\mathrm{b}}$ ) respiciens, que maxime est in intellectibilitate, ubi se mens simplicitati divine conformat, ibi elementum posuit et substanciam mentis posuit, quam post mortem remanere voluit. Illa ordine nature precedit intelligenciam, sed degenerat $10 \mathrm{in}^{\mathrm{c}}$ ) intelligenciam, quando recedit de divina simplicitate, in qua omnia unum, et vult in se intueri ${ }^{\mathrm{d}}$ ) omnia, ut quodlibet habet esse ab alio distinctum et proprium. Deinde adhuc plus degenerat mens, quando motu racionis comprehendit res non in se, sed ut forma est in variabili materia, ubi non potest tenere veritatem, sed vergit in ymaginem. Aristotiles 15 autem, qui omnia consideravit, ut sub vocabulo cadunt, que motu racionis sunt imposita, facit elementum racionem et racionem forte dicit per disciplinam, que fit per vocabula, ad intelligenciam ascendere, postea altissime ad intellectibilitatem. Unde ponit elementum racionem ad ascensum intellectus, Plato vero intellectibilitatem ad descensum 20 eius. Ita inter eos non videtur differencia nisi in modo consideracionis.

Philosophus. Hoc sic sit. Dic, cum omnes philosophi dicant omnem intellectum fore de substancia et accidente, quomodo hoc est verum de Deo et materia prima.

Ydiota. Intellectus de Deo est inflexus de intellectu huius nominis 25 ens, quia ens non entis, hoc est imparticipabiliter ${ }^{\mathrm{e}}$ ) intellectum, est Deus, et ille est idem ei, qui de eo habetur, quod est substancia et accidens, sed alio modo hoc est inflexe consideratus. Unde intellectus de Deo est complexivus omnium intellectuum de substancia et accidente, sed est simplex et unus. Intellectus vero de materia prima est flexio quedam ab 30 intellectu, qui habetur de corpore. Si enim corpus incorporee, hoc est absque omnibus formis corporeis, intelligis, illud idem, quod corpus significat, intelligis, sed alio modo, quia incorporee, qui proculdubio est intellectus materie.

Philosophus. Putas ne mentes celestes secundum gradus intellec35 tuales creatas et nociones habere indelibiles.

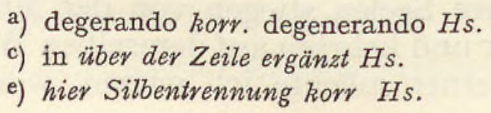

b) am Rand der Zeile quod Hs.

d) intueri in se umgestellt Hs. 
Aristoteles, wenn er die Kraft unserer Seele beschreiben will, mit dem Verstande anhebt, indem er sagt, daß die Seele vom Verstande zur Wissenschaft, von der Wissenschaft zur intelligiblen Schau aufsteige. Platon aber lehrt in entgegengesetzter Weise, indem er die intelligible Schau als Urelement setzt, daß die intelligible Schau durch Entartung Wissenschaft oder Vernunft werde, Vernunft aber durch Entartung bloßer Verstand.

Laie. Ich kenne ihre Schriften nicht. Doch haben vielleicht die ersten, welche über Abstieg und Aufstieg der Seelen gesprochen haben, dasselbe sagen wollen, wie Platon und Aristoteles. Platon nämlich sah, indem er auf das Bild des Schöpfers blickte, welches am meisten im Reich des intelligiblen Schauens liegt, dort, wo der Geist sich der göttlichen Einfachheit anpaßt, das Urelement und die Substanz des Geistes, von der er behauptete, daß sie nach dem Tode zurückbliebe. Jene Substanz geht in der Ordnung der Natur der Vernunft voraus; sie entartet jedoch zur Vernunft, wenn sie abweicht von der göttlichen Einfachheit, in der alles eines ist, und dann in sich alles anschauen will, wie jedes einzelne eine von dem anderen verschiedene und nur ihm eigentümliche Seinsheit besitzt. Darauf entartet der Geist noch mehr, wenn er vermöge einer Bewegung des Verstandes die Dinge nicht an sich betrachtet, sondern so, wie die Form in der veränderlichen Materie ist; denn dort kann sie nicht mehr die Wahrheit besitzen, sondern wandelt sich in ein Bild. Aristoteles aber, der alles so betrachtete, wie es unter die Wortbedeutung gehört, die durch eine Bewegung des Verstandes gesetzt ist, machte den Verstand zum Element, und er will vielleicht sagen, $\mathrm{da} ß$ der Verstand, vermöge einer Wissenschaft über die Lehre von der Wortbedeutung, zur Vernunft aufsteige, und dann zum höchsten Punkte, bis zur intelligiblen Schau. Daher setzte er als Element den Verstand für den Aufstieg zur Vernunft, Platon aber die intelligible Schau als Element für den Abstieg zu ihr. So scheint die Verschiedenheit ihrer Lehren nur in der Betrachtung zu bestehen.

Philosoph. Das mag denn so sein. Erkläre mir doch bitte, inwiefern der Satz aller Philosophen, daß die Erkenntnis aus Substanz und Accidenzen bestehe zutrifft für die Erkenntnis von Gott und der ersten Materie.

Laie. Die Erkenntnis von Gott ist eine Umbiegung der Erkenntnis, die auf das Sein gerichtet ist: denn Gott ist das Sein des Nichtseienden, d. h. das, was ohne alle Teilhabe erkannt wird. Jene umgebogene Erkenntnis ist der gleich, die man von dem hat, was Substanz und Accidens ist, aber freilich wird sie auf eine andere Art, d. h. umgebogen angesehen. Daher ist die Erkenntnis von Gott die Zusammenfassung aller Arten der Erkenntnis von Substanz und Accidens, doch sie ist einfach und einzig. Die Erkenntnis aber von der ersten Materie ist eine Abbiegung von der Erkenntnis, welche man vom Körper hat. Wenn man nämlich den Körper unkörperlich, d. h. außer aller körperlichen Form, erkennt, so erkennt man eben das, was der Körper bedeutet, aber auf eine andere Weise, da es unkörperlich betrachtet wird, was ohne Zweifel eine Erkenntnis von der Materie ist.

Philosoph. Glaubst $\mathrm{Du}$, daß die himmlischen Geister gemäß den Stufen der Vernunft geschaffen seien, und unzerstörbare Begriffe haben? 
Ydiota. Puto alios angelos intellectibiles, ut sunt de supremo ordine, alios intelligenciales ut de secundo ordine, alios racionales ut de tertio, ac quot in quolibet ordine sint, tot gradus similiter, ut sic sint novem gradus seu chori, et quod mentes nostre sint sic infra primum gra5 dum talium spirituum et supra omnem gradum corporalis nature quasi nexus universitatis encium, ut sit terminus perfeccionis inferiorum na-

I3 r r. ture et inicium superiorum. Arbitror eciam nociones ${ }^{2}$ ) / spirituum beatorum extra corpus existencium in quiete habere nociones invariabiles et indelibiles oblivione ob presenciam veritatis obiectaliter se indesinenter 10 offerentis. Et hoc est meritum spirituum, qui fruicionem exemplaris rerum meruerunt, nostre autem mentes ob sui informitatem obliviscuntur sepe eorum, que sciverunt aptitudine concreata permanente ad denuo sciendum. Nam et si sine corpore excitari ad progressum intellectualem non possint, tamen ob incuriam, aversiones ab obiecto, setracciones ad varia 15 et diversa et corporeas molestias nociones perdunt. Nociones enim, quas hic in hoc mundo variabili et instabili acquirimus secundum condiciones variabilis mundi, non sunt confirmate. Sunt enim ut nociones scolarium et discipulorum proficere incipiencium et nondum ${ }^{\mathrm{b}}$ ) ad magisterium perductorum, sed nociones iste hic acquisite, quando mens pergit de mundo varia20 bili ad invariabilem, similiter ad invariabile magisterium transferuntur, quando enim particulares nociones transeunt in perfectum magisterium, desinunt esse variabiles in magisterio universali, que erant particulariter fluide et instabiles. Sic sumus in hoc mundo docibiles, in alio magistri.

\section{Capitulum quintum decimum.}

Quomodo mens ${ }^{c}$ ) nostra sit immortalis et incorruptibilis. ${ }^{\text {d }}$ )

Philosophus. Restat nunc, ut de immortalitate mentis nostre, que sentis, dicas, ut, quantum fieri potuit pro hac die, de mente instruccior factus me in multis gaudeam profecisse.

Ydiota. Qui elementum descensus intellectus intellectibilitatem 30 mentem ponunt nequaquam dependere a corpore, qui elementum ascensus intellectus racionem ponunt et finem intellectibilitatem, mentem nequaquam cum corpore interire admittunt. Ego autem nequaquam hesito, gustum sapiencie habentes immortalitatem mentis negare non posse, uti de hoc alias oratori, que tunc occurrerunt, patefeci. Sic qui 35 attendit intuicionem mentis attingere invariabile et per mentem formas

a) unten auf der Seite spirituum $H s . \quad$ b) nundum $H s$.

c) auf Rasur Hs. $\quad$ d) Capitulum - incorruptibilis am Rand ergänzt Hs. 
Laie. Ich glaube, daß es eine Art von Engeln gibt, die intelligiblen, die der ersten Ordnung angehören, andere, die der Vernunft angehören von zweiter Ordnung, andere von dritter Ordnung, die dem Verstande zugeordnet sind. Und da es in jeder der drei Ordnungen ebenso viele Stufen gibt, gibt es im ganzen neun Stufen oder Chöre. Und weil unsere Geister noch unter dem letzten Grad solcher Geister sind, aber über jedem Grade der körperlichen Natur, so ist unser Geist gleichsam das Band in der Allheit des Seienden, so daß er das Ziel der Vollendung der unteren Naturen ist und der Beginn der höheren. Ich glaube auch, daß die Begriffe der seligen Geister, die außerhalb des Körpers in ewiger Ruhe sind, in sich unveränderlich und unvergeßbar seien, wegen der Gegenwart der Wahrheit, die ihnen immerwährend gegenständlich gegenübersteht, und das ist der Lohn der Geister, die verdient haben, das Urbild der Dinge zu genießen. Unsere Geister aber vergessen wegen ihrer Ungeformtheit oft das, was sie gewußt haben, obwohl ihnen die mit ihnen geschaffene Fähigkeit verbleibt, es von neuem $\mathrm{zu}$ wissen. Denn obwohl sie ohne Körper zum Fortschreiten der Vernunft nicht gebracht werden können, so verlieren sie doch, wegen ihrer Sorglosigkeit und ihrer Abwendung vom Gegenstand und ihrer Hinwendung zum Mannigfaltigen und Verschiedenen und zu den Leiden des Körpers, ihre Begriffe. Denn die Begriffe, die wir in dieser veränderlichen und unsteten Welt erreichen, stehen unter den Bedingungen der veränderlichen Welt, und sind nicht gefestigt. Sie sind nämlich wie die Begriffe der Scholasten und Schüler, die erst anfangen, Fortschritte zu machen, und noch nicht zum Ende der Lehre geführt worden sind. Aber diese hier erworbenen Begriffe gelangen doch, wenn der Geist aus der veränderlichen Welt in die unveränderliche steigt, auf gleiche Weise zur unwandelbaren Lehre. Wenn nämlich die gesonderten Begriffe in die vollendete Lehre eingehen, hören sie in der allumfassenden Lehre auf, veränderlich zu sein, sie, die doch in der Sonderung fließend und unbeständig waren. So sind wir in dieser Welt Lehrlinge, in jener aber Meister.

\section{I5. Kapitel.}

Unser Geist ist unsterblich und unvergänglich.

Philosoph. Es bleibt noch übrig, daß Du Deine Meinung über die Unsterblichkeit des Geistes sagst, damit ich an diesem Tage nach Möglichkeit über die Natur des Geistes belehrt, voller Freude sei, daß ich in so vielem an Kenntnis fortgeschritten bin.

Laie. Wer als Element des Abstiegs der Vernunft das Intelligible setzt, behauptet damit, daß der Geist in keiner Weise vom Körper abhänge; wer als Element des Aufstieges der Vernunft den Verstand setzt, und als sein Ende das Intelligible, gibt zu, daß der Geist keineswegs mit dem Körper zugrunde gehe. Ich behaupte aber ohne Zögern, daß niemand, der einen Funken Weisheit besitzt, bestreiten könne, daß der Geist unsterblich sei, wie ich an anderem Orte dem Redner darüber das auseinander gesetzt habe, was mir damals in den Sinn kam. Denn wenn jemand erwägt, daß das Schauen des Geistes das Unveränderliche erreichen könne, und daß durch die Kraft des Geistes die Formen der Veränderlich- 
$\mathrm{a}^{\mathrm{a})}$ variabilitate abstrahi et in invariabilem regionem necessitatis complexionis reponi, ille non potest hesitare mentis naturam ab omni variabilitate absolutam esse. Ad se enim attrahit, quod a variabilitate ${ }^{\text {b }}$ abstrahit, nam veritas invariabilis figurarum geometricarum non in pavi5 mentis, sed mente reperitur. Et dum anima per organa inquirit, id, quod invenit, variabile est, dum per se inquirit, id, quod invenit, stabile, clarum, limpidum et fixum existit. Non igitur est de natura variabilium ${ }^{c}$ ), que sensu attingit, sed invariabilium, que in se invenit. Sic ex numero potest immortalitatis eius ostensio convenienter venari. Nam cum sit 10 numerus vivus scilicet numerus numerans et omnis numerus in se incorruptibilis, licet in variabili materia consideratus variabilis videatur, mentis nostre numerus non potest concipi corruptibilis; quomodo tunc auctor numeri corruptibilis videri possit. Neque aliquis numerus potest mentis numerandi virtutem evacuare. Unde, cum motus celi per mentem 15 numeretur et tempus sit mensura motus, tempus mentis virtutem non I3 r v. evacuabit, | sed manebit ut omnium mensurabilium terminus, mensura et determinacio. Ostendunt instrumenta motuum celestium, que a mente humana procedunt, motum non plus mensurare mentem quam mens motum. Unde mens motu suo intellectivo omnem successivum ${ }_{20}$ motum videtur complicare, mens ex se exerit motum raciocinativum, sic est forma movendi. Unde si quid ${ }^{d}$ ) dissolvitur, per motum hoc fit, quomodo ergo forma movendi per motum dissolveretur. Mens, cum sit vita intellectualis seipsam movens, hoc est vitam, quod est eius intelligere, exerens, quomodo non semper vivit motus seipsum movens, quomodo ${ }_{25}$ deficit. Habet enim vitam sibi compaginatam, per quam est semper vivens sicut sphera $^{\mathrm{e}}$ ) semper rotunda per sibi compaginatum circulum; si illa est mentis composicio, que numeri ex seipso compositi, quomodo in non-mentem resolubilis. Sic si mens est coincidencia unitatis et alteritatis ut numerus, quomodo divisibilis, cum divisibilitas in ea sit cum in30 divisibili unitate coincidens. Si mens complicat idem et diversum, cum intelligat divisive et unitive, quomodo destruetur. Si numerus est modus intelligendi mentis et in eius numerare coincidat explicacio cum complicacione, quomodo deficiet. Virtus enim, que explicando complicat, minor fieri nequit; mentem autem hoc agere patet, nam qui numerat, 35 explicat vim unitatis et complicat numerum in unitatem. Denarius enim

a) a über der Zeile ergänzt Hs. $\quad$ b) variabilite korr. variabilitate $H s$.

c) invariabilium durch Rasur korr. variabilium $H s . \quad$ d) danach sibi getilgt $H s$. Am Rand Korr. vermerkt Hs. e) spera Hs. 
keit entzogen und in die Region der Unveränderlichkeit und der notwendigen Verknüpfung zurückgeführt werden, so kann er mit der Behauptung nicht zögern, daß die Natur des Geistes losgelöst sei von aller Veränderlichkeit. Denn an sich selbst zieht er all das heran, was er von der Veränderlichkeit abzieht. So findet die unveränderliche Wahrheit der geometrischen Figuren sich nicht auf dem Boden, (auf dem sie gezeichnet werden), sondern im Geist. Forscht die Seele vermittels der Sinne, dann ist das, was sie findet, veränderlich; wenn sie dagegen durch sich selbst forscht, ist das, was sie findet, stetig, klar, durchsichtig und fest; denn dann beschäftigt sie sich nicht mit der Natur des Veränderlichen, an welche sie durch die Sinne herantritt, sondern mit der des Unveränderlichen, das sie in sich selbst vorfindet. So kann an der Natur der Zahl der Beweis der Unsterblichkeit geziemend klar gemacht werden. Denn da die lebendige Zahl, d. h. die zählende $Z$ ahl und jede einzelne $Z$ ahl, an sich unvergänglich sind, und nur, insofern sie in der veränderlichen Materie betrachtet werden, veränderlich erscheinen, so kann die Zahl in unserem Geiste unmöglich als vergänglich verstanden werden. Wie aber sollte dann das Urbild dieser Zahl vergänglich erscheinen können? Auch kann keine $Z$ ahl das Zahlenvermögen des Geistes jemals erschöpfen. Da nun die Bewegung des Himmels durch den Geist gezählt wird, und die Zeit das Maß der Bewegung ist, wird die Zeit die Kraft des Geistes nicht zu nichte machen, sondern er wird bleiben als die Grenze alles Meßbaren, als sein Maß und seine Bestimmung. Es zeigen die Meßinstrumente für die Himmelsbewegungen, welche vom Geist des Menschen geschaffen sind, daß die Bewegung nicht so sehr den Geist mißt, als vielmehr der Geist die Bewegung. Daher scheint der Geist in seiner vernünftigen Bewegung jede successive Bewegung einzufalten. Der Geist erschafft aus sich eine urteilende Bewegung und ist so die reine Form der Bewegung. Wenn nun etwas aufgelöst wird, so geschieht das durch die Bewegung: auf welche Weise könnte aber die reine Form der Bewegung durch die Bewegung zur Auflösung gebracht werden? Und wie sollte der Geist, da er vernünftiges Leben ist und sich selbst bewegt, d. h. da er sein eigenes Leben, das in der Erkenntnis besteht, selbst aus sich entfaltet, nicht ewig leben? Wie soll eine Bewegung nachlassen, die sich selbst bewegt? Denn der Geist besitzt ein ihm verbundenes Leben, durch das er immerwährend lebt, wieeine Kugel immer rund ist durch den ihr zugehörigen Kreis. Wenn der Geist nur in dem Sinne zusammengesetzt ist, wie die Zahl, die nur aus sich selbst besteht, wie kann er dann jemals in etwas, das nicht Geist ist, aufgelöst werden? Wenn der Geist gleich der Zahl Koinzidenz von Einheit und Andersheit ist, wie kann er dann teilbar sein, da er doch eine Teilbarkeit besitzt, welche mit der unteilbaren Einheit koinzidiert? Wenn der Geist in sich das Identische und das Verschiedene befaßt, und durch Teilung und Vereinigung erkennt, wie kann er dann zerstört werden? Wenn Zahl Erkenntnisform des Geistes ist und in seinem Zählen Auseinanderfaltung und Einfaltung koinzidieren, wie kann er dann jemals aufhören? Denn das Vermögen, welches indem es entfaltet, zugleich einfaltet, kann niemals geringer werden; daß aber der Geist das tut, ist klar; denn wer zählt, entfaltet das Vermögen der Einheit und faltet zugleich die $Z$ ahl in die Einheit zusammen. Denn die ,Zehn" ist Einheit, die aus zehn Einheiten zusammengefaltet ist, und daher 
est unitas ex decem complicata, sic qui numerat, explicat et complicat. Mens est ymago eternitatis, tempus vero explicacio, explicacio autem semper minor ymagine complicacionis eternitatis. Qui attendit ad iudicium mentis sibi concreatum, per quod de omnibus racionibus iudicat, 5 ac quod raciones ex mente sunt, videt nullam racionem ad mentis mensuram attingere. Manet igitur mens nostra omni racione immensurabilis, infinibilis et interminabilis, quam sola mens increata mensurat, terminat atque finit sicut veritas suam et ex se, in se et per se creatam vivam ymaginem. Quomodo periret ymago, que est relucencia in10 corruptibilis veritatis nisi veritate communicatam relucenciam abolente. Sicut igitur impossibile est, quod infinita veritas communicatam ${ }^{2}$ ) relucenciam subtrahat, cum sit absoluta bonitas, ita est impossibile, quod eius ymago, que non est nisi communicata ${ }^{a}$ ) relucencia eius, unquam deficiat, sicut, postquam per solis relucenciam cepit esse dies, nunquam sole 15 lucente dies deficiet. Connata religio, que hunc innumerabilem populum in hoc anno Romam et te philosophum in vehementem admiracionem adduxit, que semper in mundo in modorum diversitate apparuit, nobis esse naturaliter inditam nostre mentis immortalitatem ostendit, ut ita nobis nota sit nostre mentis immortalitas ex communi omnium indubi20 tata assercione sicut nostre nature ${ }^{\mathrm{b}}$ ) humanitas. Non enim habemus cer${ }_{132}$ r. ciorem scienciam nos esse homines | quam mentes habere immortales, cum utriusque sciencia sit communis omnium hominum assercio. Hec sic cursim dicta ab ydiota grate recipito, quod si non sint talia, que sponsione oratoris audire expectasti, aliqua tamen sunt, que tibi fortassis ${ }_{25}$ ad alciora qualecunque adminiculum afferre poterunt.

Orator. Interfui hoc sancto et michi dulcissimo colloquio multum mentem tuam de mente profunde disserentem admirans, indubio nunc experimento certissimum habens mentem vim omnia mensurantem existere, gracias tibi agens, optime ydiota, tum mei parte, tum istius adso vene philosophi, quem adduxi, qui, spero, consolatus abibit.

Philosophus. Non me puto feliciorem diem hactenus hac ista vixisse; nescio, quid eveniet; tibi oratori atque tibi ydiote, viro ad modum theoretico, immortales ago gracias, orans nostras mentes ad eterne mentis fruicionem hoc diuturno colloquio miro desiderio incitatas feliciter 35 perduci. Amen. ${ }^{c}$ )

Finivi in monasterio vallis Castri prope Fabrianum die XXIII Augusti. Nicolaus Cardinalis Sancti Petri.

a) über der Zeile Korr. Hs. b) auf Rasur Hs. c) amen von anderer Hand hinzugefügt Hs. 
entfaltet der, der zählt und faltet zugleich ein. Der Geist ist das Bild der Ewigkeit, die Zeit aber ihre Entfaltung; eine Entfaltung aber ist immer kleiner als das Bild der Einfaltung der Ewigkeit. Wer aber auf das Urteil des Geistes, das zugleich mit ihm geschaffen ist, (vermöge dessen er über alle Verstandesbegriffe urteilt), acht hat und bemerkt, daß alle Verstandesbegriffe dem Geiste entstammen, sieht, daß kein Verstandesbegriff an das Maß des Geistes heranreicht. Es bleibt also unser Geist für jeden Verstand unmeßbar, unbestimmbar und unbegrenzbar, und es mißt ihn allein der ungeschaffene Geist, begrenzt ihn und bestimmt ihn, wie die Wahrheit das aus sich und in sich und durch sich geschaffene lebendige Bild mißt. Auf welche Weise aber sollte ein Bild zugrunde gehen, welches der Widerschein der unvergänglichen Wahrheit ist, wenn nicht die Wahrheit selbst den dem Bilde vermittelten Widerschein aufhöbe? Wie es nun aber unmöglich ist, daß die unendliche Wahrheit den dem Bilde vermittelten Widerschein herabminderte, da sie absolute Güte ist, so ist es unmöglich, daß ihr Bild, welches ja nichts ist als der Widerschein, der ihr von ihm mitgeteilt ist, jemals aufhörte; so wie ja auch, wenn einmal durch das Leuchten der Sonne der Tag begonnen hat, niemals, so lange sie leuchtet, der Tag aufhören kann. Die angestammte Religion, welche in diesem Jahre diese unzählbare Menge nach Rom geführt hat, was Dich, Philosoph, in so lebhaftes Erstaunen versetzte, sie, die immer in der Welt in verschiedensten Formen erschienen ist, zeigt, daß uns von Natur die Unsterblichkeit unseres Geistes mitgegeben sei, so daß uns die Unsterblichkeit unseres Geistes durch die allgemeine Beistimmung aller Menschen gewiß ist, ebenso gewiß, wie unsere menschliche Natur. Denn unser Wissen darum, daß wir Menschen sind, ist nicht größer als unser Wissen darum, daß wir unsterbliche Geister besitzen, da in beiden Punkten alle Menschen übereinstimmen. Nimm das also freundlich auf, wie es von einem Laien gesagt wurde. Wenn es auch nicht Dinge sind, welche Du von einem Redner hättest erwarten dürfen, so ist es doch vielleicht etwas, was Dich, gleichsam als Stütze, zu höherer Einsicht führen kann.

Redner. Ich durfte dieser erhabenen und höchst reizvollen Unterredung beiwohnen, und habe Deinen Geist, der über das Wesen des Geistes tiefe Untersuchungen anstellte, immer wieder bewundert. Und nun weiß ich durch ein untrügliches Beispiel ganz gewiß, daß der Geist das $\mathrm{Ma} \beta$ von allem ist. Ich sage Dir Dank dafür, mein bester Laie, sowohl für meine Person, wie für die dieses auswärtigen Philosophen, den ich hierher gebracht habe, und der, wie ich hoffe, getröstet fortgehen wird.

Philosoph. Ich glaube, daß ich bisher keinen glücklicheren Tag erlebt habe, als den heutigen; ich weiß nicht, was folgen wird. Dir, Redner, und Dir, Laie, der Du ein Mann von höchster theoretischer Begabung bist, schulde ich nie verlöschenden Dank, und bete, daß unsere Geister, die durch dieses lange Gespräch mit wunderbarem Sehnen erfüllt worden sind, glücklich zum Genuß des ewigen Geistes geleitet werden.

Amen.

Beendet am 23. August in Val-di-Castro bei Fabriano. Nicolaus Kardinal von St. Peter. 


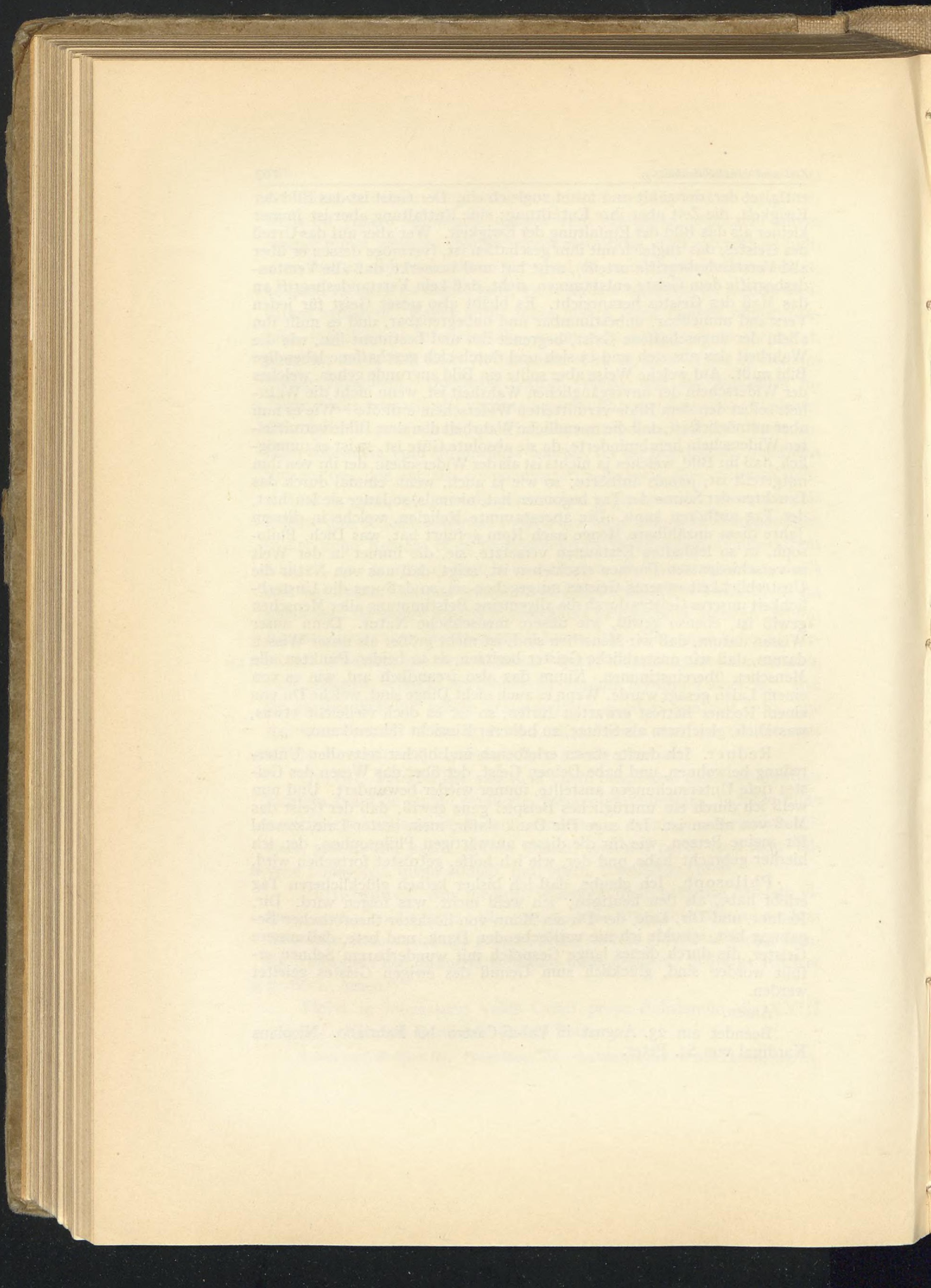




\section{CAROLUS BOVILLUS}

\section{LIBER DE SAPIENTE}

Herausgegeben von Raymond Klibansky.

Der Bovillus-Edition wurde, da kein Manuskript vorhanden ist, der einzige vorhandene Druck des Buches de Sapiente zugrunde gelegt, der zusammen mit anderen Werken des gleichen Verfassers im Jahre I5Io/II in Paris-Amiens bei Stephanus erschien. (De Intellectu, de Sensu, de Nichilo, Ars Oppositorum, de Generatione, de Sapiente, de duodecim Numeris, Epistole complures; insuper mathematicum opus quadripartitum: de Numeris perfectis, de mathematicis Rosis, de geometricis Corporibus, de geometricis Supplementis.) Da sich unter den einzelnen Drucken dieser Ausgabe infolge der mangelhaften Drucktechnik einige Unstimmigkeiten im Text und größere Unterschiede in der Beschaffenheit der Bilder ergaben, wurden die Exemplare der Preußischen Staats-Bibliothek in Berlin, der Bayrischen Staats-Bibliothek in München, der Frankfurter Stadt-Bibliothek, der Heidelberger und der Göttinger Universitäts-Bibliotheken verglichen und bald diesem, bald jenem von ihnen der Vorzug gegeben.

Die Orthographie hält sich im ganzen an die Druckvorlage, um einen möglichst getreuen Eindruck der stilistischen und formalen Eigenarten des Textes zu vermitteln. Auch die Schreibung der griechischen Namen und Fremdworte ist genau wiedergegeben. Selbst wo ein und dasselbe Wort in zwei verschiedenen orthographischen Formen auftritt, wurde diese Schwankung nicht getilgt. Änderungen schienen nur dort geboten, wo durch die Schreibweise der alten Ausgabe für den heutigen Leser eine Zweideutigkeit des Sinnes gegeben wurde. So wurde das Verb consumare des Drucktextes in allen Formen und Ableitungen in consummare geändert.

Die Beibehaltung der Interpunktion der Vorlage hätte das sachliche Verständnis des Textes erheblich erschwert. Es wurde daher in allen den Fällen von der Interpunktion der Vorlage abgewichen, in denen dies zum besseren Verständnis des Textes notwendig erschien.

In dem Gebrauch von Majuskeln und Minuskeln finden sich im Text der Vorlage sehr starke Schwankungen. Offensichtlich ist das Bestreben, 
Termini, die eine bestimmte systematische Bedeutung haben, durch Schreibung von großen Anfangsbuchstaben herauszuheben. So sind z. B. Begriffe wie Sensus, Ratio, Intellectus, wenn auf ihren Zusammenhang mit einer bestimmten Reihe aufmerksam gemacht werden soll, im allgemeinen durch große Schreibung hervorgehoben, doch ist auch dieses so wenig streng durchgeführt, daß hier ein Eingriff berechtigt erschien. Dieser erfolgte in dem Sinne, daß alle systematisch wichtigen Begriffe einheitlich mit großen Anfangsbuchstaben geschrieben wurden, sobald sie in einer prägnanten. Bedeutung verwendet erschienen. So wurde z. B. Homo gesetzt, wenn es sich darum handelte, die Stufe des Menschseins in ihrer Eigenart abzuheben, etwa von der des Engels und der des Tieres, oder wenn es darauf ankam, innerhalb dieser Stufe bestimmte fest umrissene Entwicklungsphasen herauszustellen: Homo natura, Homo virtute. Des weiteren wurden einige Begriffe mit Majuskel geschrieben, wenn sie vom Geiste des Autors aus als Personifikationen erschienen; das eigentümliche Schillern der Worte zwischen Begriff im engeren Sinne und Bild bedingte, daß hier im einzelnen Falle entschieden werden mußte, welches Moment der Bedeutung das stärkere sei.

Die sehr zahlreichen Druckfehler offenkundiger Art, die sich in der Vorlage fanden, wurden stillschweigend verbessert. Abweichungen, bei denen ein Zweifel obwalten konnte, wurden unter dem Text ausdrücklich angeführt, wobei das Sigel ed. auf die Vorlage, die Ausgabe von I5Io, verweist. Da sich im Buch de Sapiente nicht selten Lehrstücke ausgesprochen finden, die in anderen Schriften des Bovillus in ausführlicher Weise entwickelt sind, schienen einige Hinweise angebracht. Zitate, die sich in den Anmerkungen finden, beziehen sich, wo nicht ausdrücklich etwas anderes bemerkt ist, auf die Ausgabe von I5Io. 


\section{^ CAROLUS BOVILLUS SAMAROBRINUS p. $116 r$ AMPLISSIMO PATRI GUILLELMO BRICO- NETO $^{1}$ ), PRESULI LODOVENSI \\ S.}

Rogatus Pythius Apollo, dignissime presul, quenam vera ac precipua esset Sapientia, hoc illico promulgasse fertur oraculum. "O», inquit, "Homo, nosce teipsum.» Hoc ergo oraculum omnium Grecorum sapientum sententia summis votis exceptum mox pro ipsius templi foribus litteris aureis merito consecravit. Sed ethnico fortassis ac gentili deo dices ingens esse piaculum, si credulas aures Christianus admoneat fidemque inani simulachro adhibeat. Ego vero ad hec subiungo deum haudquaquam fuisse Apollinem neque Apollinis simulachrum - quippe mutum - ulla unquam edidisse oracula: spiritum tamen illum, quisquis erat, ficto delitentem ydolo, qui tum et vice simulachri et subrepticio Apollinis nomine locutus est, verissimum humano generi hoc unum intulisse responsum inficias ibit futabitque nemo. Si enim diviniloqui psalmi summam Ho- Diviniloquus psalminis stultitiam attestantur sui esse ignorationem, licet profecto contramus riam illi Sapientiam arbitrari sui esse gnaritatem. "Homo enim», inquiunt ${ }^{2}$ ), "cum in honore esset, non intellexit: comparatus est brutis et iumentis insipientibus et similis factus est illis."

Cuius sacri eloquii interpretatio in hunc a nobis sensum convertetur. Cum Homo natura Homo esset: Hominem tamen se esse non cognovit, rationalem se esse aut immortalem aut Dei imaginem sui decoris immemor non intellexit. Humano quippe fastigio lapsus insipienter obrutuit ${ }^{3}$ ); et qui duntaxat naturalis Hominis specie ab initio prodierat insignis, tetra deinceps obductus ignorantie caligine, velut mentis incompos inconsciusque sui, perdito vivendi modo fera potius quam Homo atque ex toto Homini dissentaneus apparuit. Humana igitur Insipientia, si est

1) Guillelmus Briconnetus (Guillaume Briçonnet): v. J. Viénot, Hist. de la Réforme Française (Paris I926) p. 45 sq. 56 sq. 65 sq.; A. Renaudet, Préréforme et Humanisme à Paris (Paris I9I6), passim.

2) Psal. 48, I3; 21

3) lege: ob-brutuit. 
hec Hominis a propriis naturalibusque bonis prolapsio, qua ${ }^{a}$ ) naturalis Homo Homine vivit indignus: erit, que huic adversatur, Sapientia ea virtus, que Hominem sistit, continet figitque in Homine queve illum vetat ex inferiorum consortio liminibus excedere humanis.

Erit item Sapientia immobilis quedam in humanitate mansio propriorumque bonorum ac naturalium suorum munerum sincera lux, ex qua et phylautia, hoc est sui amor, internusve quidam numerus Homini indiDivi Dionysii verba tur. Nam et ut divi Dionysii Areopagite verbis utamur: «Si», ut ait ${ }^{1}$ ), "scientia cognoscentium et cognitorum coniunctrix est, ignorantia vero ignoranti sue divisionis est author», profecto, qui se novit homo, hic solus Homo est, hic sibimetipsi unus, hic Homo-Homo. ${ }^{2}$ ) Qui vero proprii luminis sueve cognitionis est exors: hic eadem lege ignorantie pessulo a semetipso abercetur, ne sibi congrediatur, ne secum unus evadat neve fiat virtute Homo, qui tamen natura factus est Homo. Unus itaque Sapiens, quali est ortus principio quave emersit scatebra, tali se insignit ac numerat periodo: Homo prius, Homo posterius; corporea specie Homo, mente intus Homo, ut qui preclara Rationis suffultus bilance continetur in Homine.

De hac igitur humana Sapientia, que suorum est bonorum cauta inspectio diligensque sui animadversio, quecunque pro nostri ingenioli modulo dicere sumus aggressi, tibi dicavimus: que - te oro - haud minus dispansa fronte admittito, quam letis votis tibi nuncupata offerimus. Vale.

đHexastichon ad lectorem. ${ }^{3}$ )

Scire volet quisquis, Sapiens quot vivet in annos.

Quod sibi pellucet, quod sibi solus adest,

Quodque simul cunctos expendat inaniter orbes

In nichilumque dies transigat Insipiens:

Hec dabit iste liber. Tu, qui probitatis amator

Diceris, hunc animo fac age conde tuo.

a) quo ed.

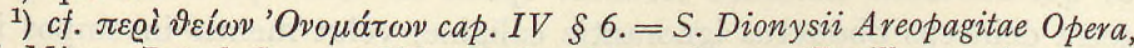
ed. Migne, Patrol. Graec. t. III., Paris. I857, col. 701 . (Bovillus versione Ambrosii Traversarii Camaldulensis usus est a Fabro Stapulensi illustrata et correcta, ed. Venet. I48I, Paris. I498, Argent. I503 et saepius.)

$\left.{ }^{2}\right)$ de notione: Homo-Homo cf. imprimis cap. XXXI; XXII.

$\left.{ }^{3}\right)$ cf. versus in fine operis, $p$. 4I2. 


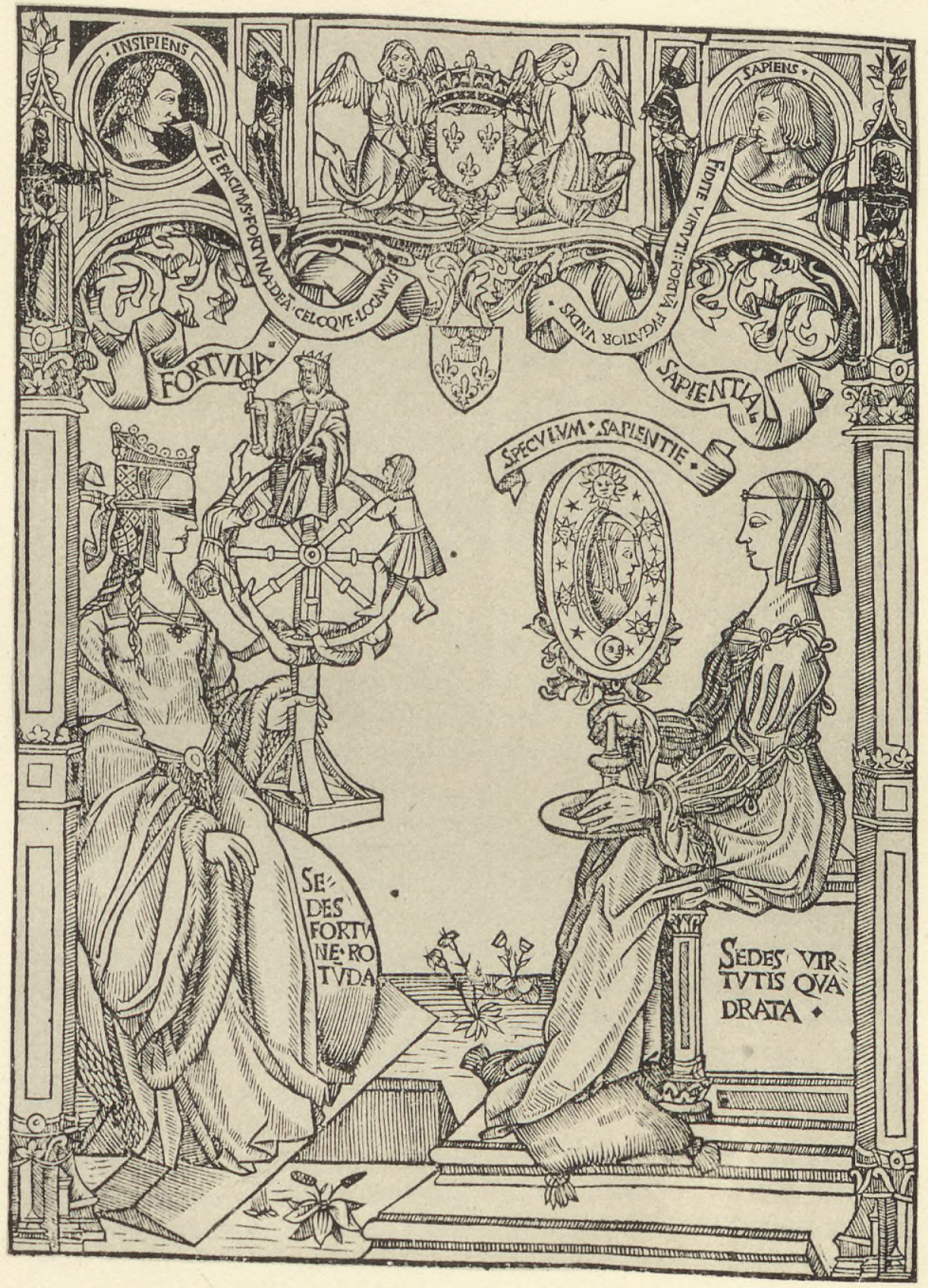

Fortuna und Sapientia. Holzschnltt aus Car. Bovillus,

Liber de Sapiente (Paris-Amiens 1510/11) 


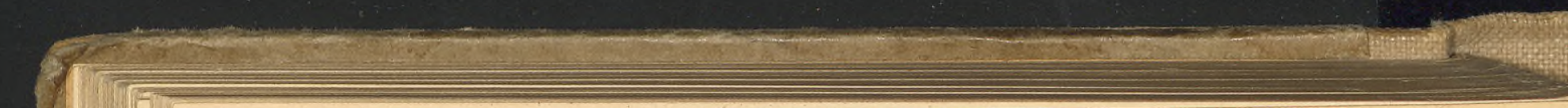




\section{CAROLI BOVILLI SAMAROBRINI LIBER DE SAPIENTE AD REVERENDUM IN CHRI- STO PATREM GUILLELMUM BRICONETUM, PRE- SULEM LODOVENSEM.}

q Quod sint totidem hominum gradus, quotquot et sensibilium rerum.

Cap. I.

Homini omni insunt a natura Substantia, Vita, Sensus et Ratio. Est Differentie homietenim, vivit, sentit et intelligit omnis homo. ${ }^{1}$ ) Ast alii hominum duntaxat ut simplicis Substantie, alii ut Substantie et Vite, alii ut Subp. $\operatorname{II} 7^{\mathrm{r}}\left[\operatorname{II} 9^{\mathrm{r}}\right]$ stantie, Vite et Sensus, alii denique Substantie, Vite, Sensus et Rationis actu atque operatione funguntur.

q Unde fit, ut cuncti homines natura et substantia sint similes et speci- Cunctihomines speei equalitate tantum unus Homo: vivendi autem modo, functione et arte varii ac dissimillimi. Alii siquidem mineralibus aut simplicibus elementis num secundum functiones comparantur, vegetantibus alii, alii brutis animantibus; supremi soli merito Hominum similes, Rationis et habitu et functione rationales, veri perfectique Homines dictitentur.

ণ Cum enim naturalium rerum quattuor sint gradus: subsistentium, viventium, sensibilium et rationalium, cunctos tamen gradus humana species in semet involvit seque distinguit atque dispescit in ordines quattuor. Nam velut complectens omnem naturam, velut ambiens universa gestansque in sese quodlibet, humillima et abiectissima sui parte subsistentibus similis efficitur, secunda viventibus, tertia irrationabilibus animantibus: quarta duntaxat sibi restituitur, in sua fastigia attollitur, se collabellat atque exosculatur. Quo demum in gradu ipsa utrobique, tam inquam arte, virtute et operatione quam naturali Substantie participatione, humana perfectaque censetur.

q Etenim cum gemine sint passiones animi, quibus in varia hinc inde in- Gemine passiones tranquilla mens divellitur, honoris scilicet appetitio et carnis delectacie tantum unus Homo tio: utraque huiusmodi passio trinas sagittas lethali arcu in Animam excutit, trinis veneno madentibus spiculis improvide sauciatam interimit.

1) cf. de Generatione: cap. XVII [XVI] 2-6; XVIII [XVII] 3. 
Nempe ex honoris appetitione Homo, cum supra seipsum extolli, cum medio et sui equalitate fieri superior cupit, in tres immanes scopulos infaustis ventis propulsatur: in Superbiam, Iram, Invidiam, quas spiritales animi labes vocant. Ex carnis vero corporisve illecebris fit item Homo triniter Homine inferior ab humanoque fastigio prolapsus in trinam abyssum mergitur infelix: in Luxuriam, Gulam, Acediam, quas Hominis corporeas esse maculas dicunt. Illinc trinis alis Hominem Homo nefarie transilire conatur divinos expostulans honores, qui nondum humanis dignus habetur honoribus; hinc vero voluptatibus blande mulcentibus illectus, trino itidem gravatus pondere infra Hominem ruit fitque longe ipso Homine inferior.

đ Que autem superaddi solet septima Hominis labes, habendi inquam amor, quam Avariciam dicunt: hec neque ex toto spiritalis neque ex toto corporea esse declaratur, sed velut utriusque extremi particeps se in partem flectit utramque, quandoquidem et utraque de causa ipsa exoritur. Nempe et divitias ipsi partim comparandis honoribus devovemus, partim vero illas expetimus, ne illecebroso genio defraudemur. In utramqueigitur partem digressus a medio Homo evadit infelix. Sive etenim supra Hominem fieri improbe

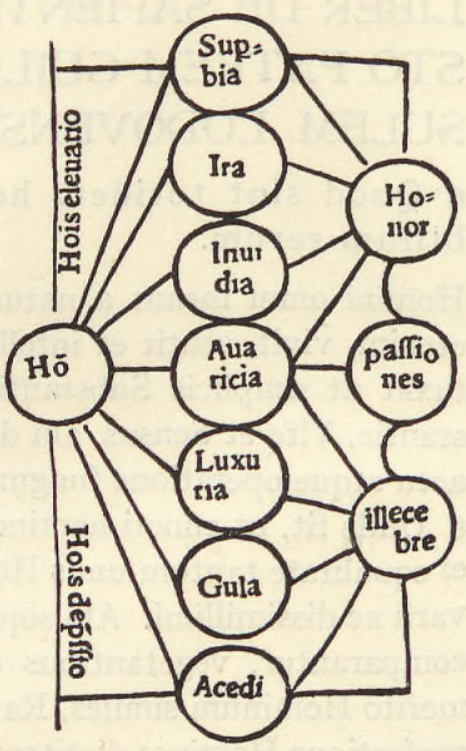
contenderit, sive Homine vixerit inferior: mors illum insidiosa in tenebris prestolatur tristissimique manes illius umbram prosequuntur.

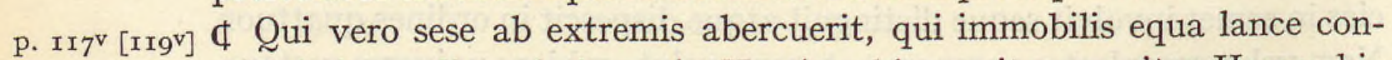
stiterit in medio sederitque in Homine, hic merito veraciter Homo, hic studiosus, probus, Sapiens, felix beatusque censeatur. Circunstant itaque unicum Hominem precipua mala sex, que velut truculentissime fere ex abditis pestifera in eum arma movent illiusque felicitati insidiantur. Avaricia viciorum His vero eadem instrumentaria Avaricie labes famulatur; universas ceca ancilla atque mi- habendi rabies velut impiissima ancilla fovet, alit, nutrit. Largitur siquidem hec divitias, propter quas aut nosipsos honoribus dignos arbitramur - superbe inquam elevamur, inhonorantibus succensemus, paribus invidemus - aut misera carnis blandimenta fluxasque voluptates insipienter prosequimur. ${ }^{1}$ )

1) cf. Bovilli librum de septem Vitiis (Lugd. Batav. I53I), imprimis cap. VII. usque ad XI. et figuram. 
$₫$ Efficit quippe Luxuries et immoderatus fede libidinis amor Hominem Luxuriosus Homo haud bestiis absimilem illumque ab humana sede in brutorum animantium ut bestia gradum infeliciter exturbat, quandoquidem nil prestantius brutis animantibus adsit quam seminis profusio sueque speciei propagatio. Gula sive Gulosus ut planta corporee alimonie irrepressa aviditas hunc a primo propriove loco dejicit in tertium plantisque persimilem efficit, que licet totius sensationis et voluptatis probentur expertes, officia tamen alimentationis exercent. Porro extrema Acedia Hominem in imum ultimumque gradum extrudit Piger ut lapis facitque mineralibus persimilem.

ণ Sicut enim mineralia, que in extremo sedent gradu, haud aliud aliquid habent quam ipsum Esse nullaque naturali operatione exerceri aut per seipsa dimoveri illis indultum est: ita et quoscunque portentosum Acedie monstrum obsederit, assiduo ferme somno consopescunt, ab actu omni et operatione remittuntur, immoti ut lapides perstant, tanquam si simplex Esse sine ulla preclara vi atque laudabilium operationum facultate Natura mater illis esset elargita. Perseverant quippe isti plus quam omnes in Nature muneribus ingrati nullam naturalium suarum virium exercentes: in ipsa Ratione penitus irrationabiles, in Sensu insensibiles, in Vita exanimes, emortui, infecundi; in ipsa denique Substantia ociosi, desides, torpentes. Et hec clarius ex subiecta figura ${ }^{1}$ ) dinoscuntur, | in p. rr $8^{r}$ [r20r] qua in unam partem quaterni rerum ordines exarantur: subsistentium, Quis Homo studioviventium, sensibilium et rationalium; ex alia vero parte humana species sus proportionabiliter in quattuor gradus cernitur distributa. Qui enim supremo in loco residet, verus ac studiosus Homo est, par naturali Homini, utrobique - tam inquam virtute quam natura - Homo. Qui vero homines inferis in gradibus collocantur: hi sunt natura quidem et substantia Homines, Virtutis autem privatione non Homines. Utpote quos ab humane dignitatis apice carnales illecebre deorsum precipites agunt faciuntque illos bestiis, medios plantis, extremos immotis lapidibus pares, similes, equales.

1) cf.p. 306 . 


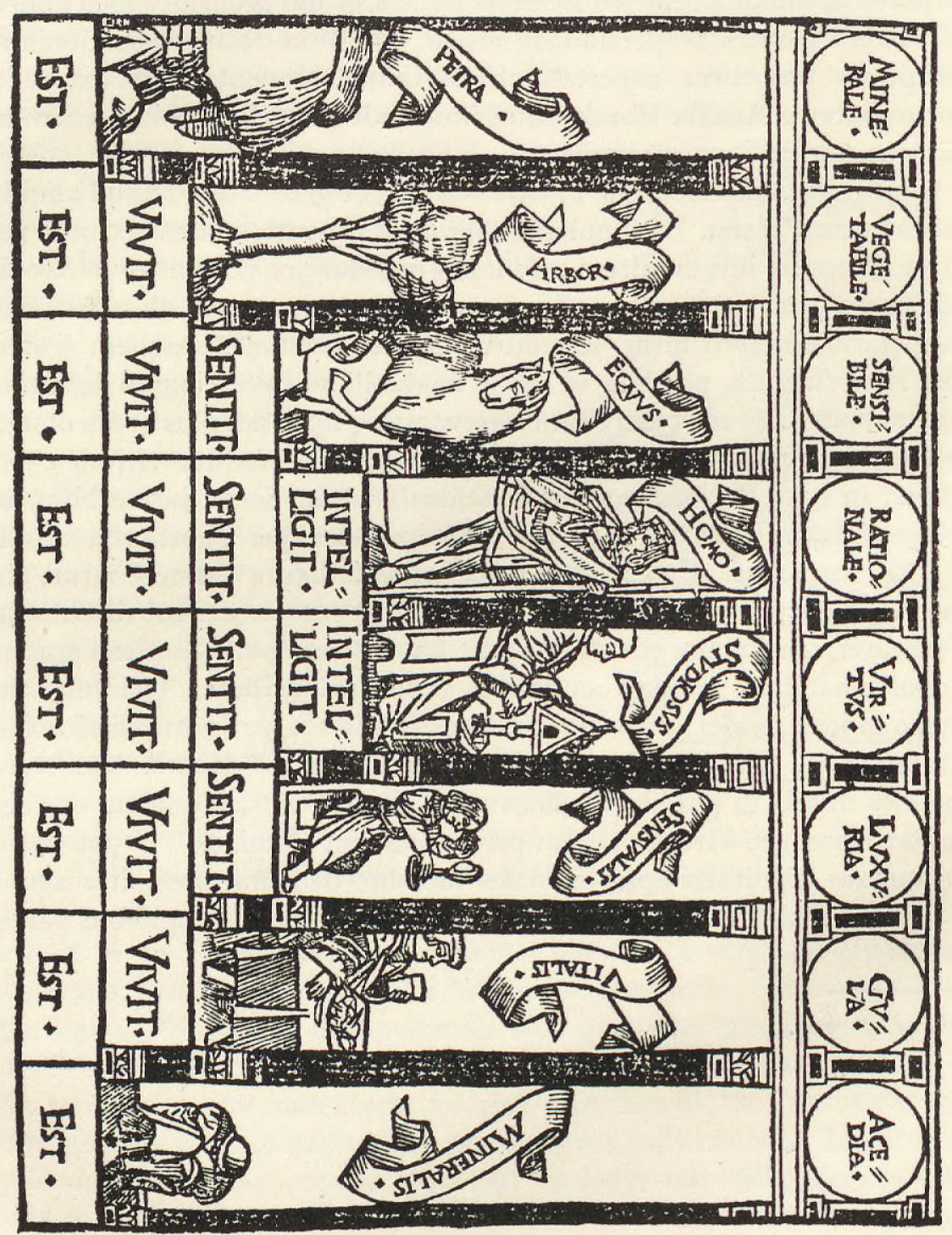


$₫$ De quattuor hominum gradibus per mundana elementa. Cap. II.

Finge rursum naturalem Hominis sedem esse in igne, qui undecunque lunari celo attiguus concavam eius superficiem iugiter exosculatur. Hic verus, probus ac studiosus Homo est: qui aut naturali aut acquisita Virtute igneo in orbe seipsum collibrat nusquamve ab eo prolabitur. Quem autem immundus Luxuriei vermiculus erodit: hic e propria, casta ac sincera ignis mansione in vicinum aeris exturbatus elementum fede maculatur. Quem Lemargie ${ }^{1}$ ) tyrannus crudeliter laniarit: hic secundo loco excidens ab Homine in aquas precipitatur ac mergitur. Quem vero cunctorum fex et retrimentum viciorum, Acedia, mollibus in plumis sepultum $\mathrm{ab}$ omni humana operatione supersedere cogit: hic in retrimentum pariter ac fecem prestantiorum elementorum, hoc est in imam terram, ab summo igne miser extruditur evaditque et immotis mineralibus et immobili itidem terre absque iniuria simillimus.

đ Quod enim solum et simpliciter est, ut terra est. Quod vivit, ut aqua. Subsistentia a) Quod sentit, ut aer. Quod intelligit, ut ignis. Nempe ea, que solum sunt, ut mineralia: suapte natura immota sunt, informia, incomposita, sine differentia, iugiter in terra - ut in comunis omnium matris utero occulta, abdita, sepulta.

đ Que vivunt: vitali aquarum motu participant primaque se movent, Viventia aluntur, augentur, propagantur. Parte sui alia a terra in altum exerta et exporrecta sunt; alia vero sui parte a terra, tanquam a matris uberibus, haudquaquam avelluntur.

đ Bestiis porro et iis, que sentiunt: libera et precipua adest se de loco in Sensibilia b) locum transferendi facultas; qua et quod contrarium est, vitant et quod utile, commodum ac necessarium, sive sedem sive alimoniam perquirunt. Aut enim serptione aut natatione aut progressione aut volatu a terre amota uberibus, a matre penitus exerta atque separata, libero insuper et spontaneo motu predita conspiciuntur. Cunctis tamen ipsis capita in terram vergentia, demissa ac prona sunt.

đ Solis Hominibus erigi, sublimi esse statura et celestia spectare a Natura Rationalia est datum et concessum.

đ Unde fit, ut primi gradus entia acephala sint, quippe homogenea, nonmodo capite, sed et omni partium differitudine ac membrorum ornatu carentia; nam toto, ut dictum est, corpore ipsis terre visceribus in-

a) Substantia. ed. b) Rationalia $e d$.

1) i. e. Laemargia, $\lambda \alpha \iota \mu \alpha p \gamma i \alpha$. 
sepulta. Cetera vero entia capitibus, partium differentia, actu, motu et anima predita cernuntur. Viventium tamen caput, ut radix et qua alimoniam ipsam prehensant quave a matre terra lacteo succo pascuntur, abditum in terra est et a matris uberibus inamotum atque inseparatum. Porro irrationalium ${ }^{a}$ ) caput animantium et siquidem amotum abiunctumque sit a terra, ut que libero motu potiantur: in illam tamen pronum convertitur minimeque celestes ethereosve orbes intueri natum perhibetur. Hominis autem caput natura sublime summam corporis obtinet arcem, versum est in celum: ipsa mundi extrema, sydera inquam celestiave corpora, suspicere atque intueri natum.

Quattuor rerum gradus quattuor elementis similes sunt.

Esse ut terra, Vivere ut aqua, Sentire ut aer, Intelligere ut ignis.

Mineralia homogenea sunt, nullam partium differentiam habentia.

Ceteri tres gradus etherogenei ${ }^{1}$ ) sunt partibusque differentes.

Mineralia acephala sunt: cetera vero caput habentia.

Capita sunt in triplici differentia, scilicet deorsum, ad latus et sursum.

Nam cum caput sit perfectum, ipsum quoque est trinum.

Plantarum caput deorsum est, animalium adlatus, Hominum sursum ${ }^{\mathrm{b}}$ ).

Liquet igitur Hominem esse ut aversam et preposteram plantam.

p. II8v [120v] đ Quod rerum naturalium capita in triplici differentia reperiantur.

Cap. III.

Sunt igitur naturalium capita rerum in triplici differentia: viventium equidem deorsum et abditum in terra; animalium in medio et ad latus; Hominum sursum et in summo, ad sui ipsorum corporis mundique fastigium. Et haud profecto absque ratione in ore ferme omnium id vite paroemii celebratur: Hominem esse ut preposteram et aversam plantam. ${ }^{2}$ ) Est enim in cunctis animantibus id aut caput aut capitis vicarium, quod alimentationis commeatum ab exteris emendicat; id autem in plantis quidem radix, in cunctis vero animalibus caput nuncupatur.

Plante similes in- $₫$ Sunt enim plante persimiles imperfectissimis hominibus, veluti infantibus fantibus, qui assiduo egentes alimento hyanti semper ore matris inherere uberibus lactisque copiam inde promanantem excipere coguntur. Ita et plante, cum sint primi a terra editi in lucem partus primaque sensibilis mundi pignora: ab sue matris, id est terre, uberibus nusquam avelluntur. Eius lac assidue manans admoto semper ore, hoc est radice, excipiunt
a)rationalium $e d$.
b) ad latus hoim. ed. sursum supplevi.
1) lege: heterogenei.
$\left.{ }^{2}\right)$ cf. Bovilli Proverbiorum vulgarium libr. tres, Paris 1531, p. $83^{\mathrm{r}}$. 
sueque substantie fluxum inintermissa alimonie susceptione velut infantes reparant.

q Bruta autem animantia persimilia sunt puerulis, qui post bimatum a Bruta animantia matris quidem uberibus divelluntur neque amplius a matre gestantur, sed puerulis similia nondum id corporis robur consecuti sunt, quo per sese suffulciri, in plantas erigi ac stare sublimes queant, quosque propterea, si per se super terram moveantur, curvos pronosque in terram et pedibus et manibus stabiliri atque incedere velut beluas oportet.

q Rationalia autem perfecto Homini viroque comparantur. Naturalis quippe Homo, cum iam ad virilem pervenit etatem: neque amplius, ut matris exuggat ubera, neque, ut pedibus manibusque super terram pronus uti belua gradiatur, eget, sed solidiore cibo utitur seque ipse fulcit, per seipsum stat atque inambulat.

đ Unde fit, ut humana tota species geminis de causis in quattuor gradus sit dispartienda qua-

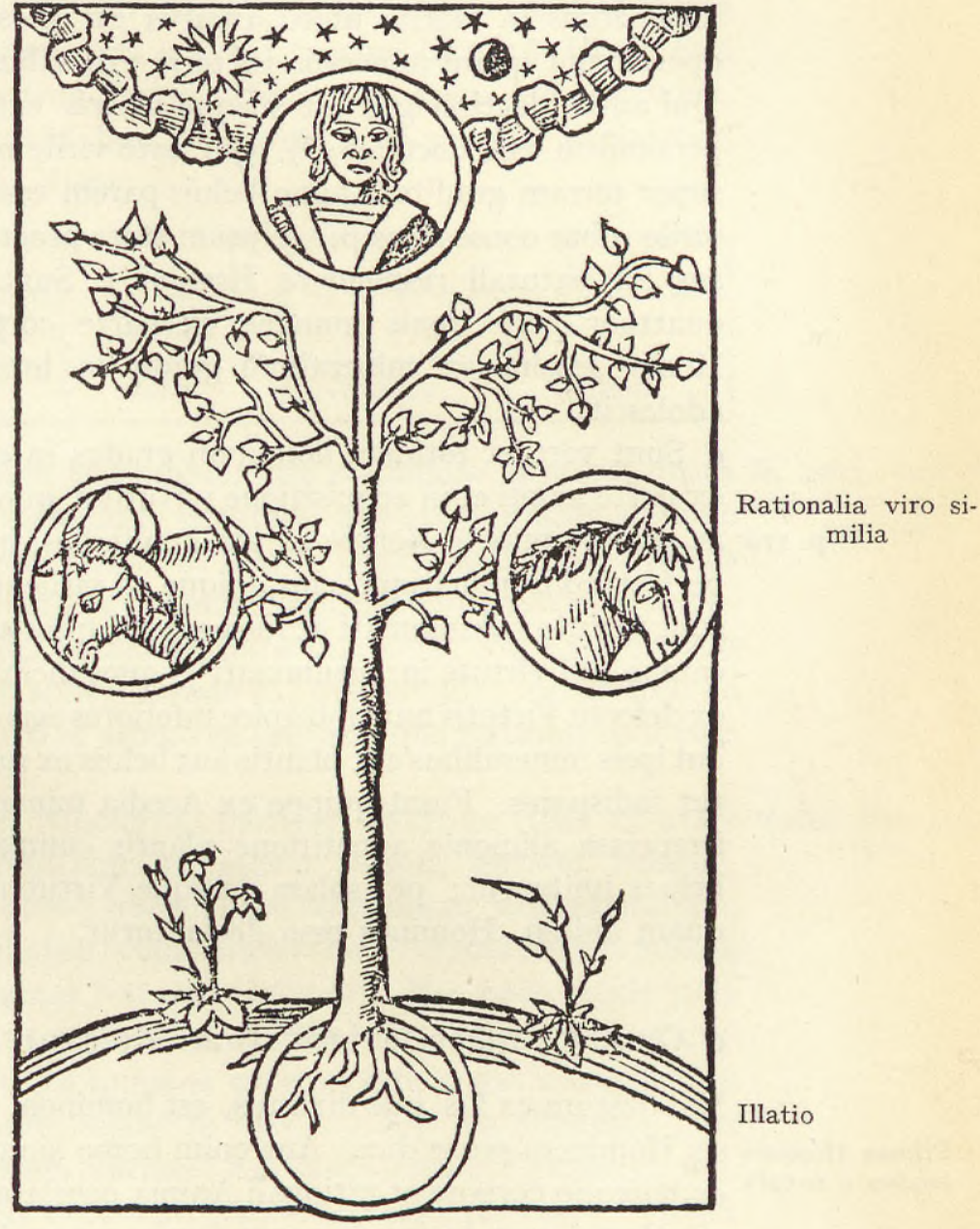
ternisque sensibilium rerum gradibus pervenuste comparanda. Nempe et cum per corpus sive per etatem perficitur Homo et cum animo sive $^{\text {a) }}$ virtute consummatur ${ }^{1}$ ): quattuor hominum utrobique occurrunt gradus, quibus sensim etate et sapientia proficiens ex imo abiectissi-

a) sine $e d$.

1) consumatur $e d$. 
move loco in supremum perfectionis sue gradum scandit, elevatur, attollitur.

Humane etatis $₫$ Etenim in humane perfectione etatis hos gradus numeramus: infans in gradus utero, infans ab uberibus, puer curvus inambulans, vir per seipsum gradiens seque ferre potens. Infans siquidem ante nativitatis sue tempus haud secus in matris utero abditus est perstatque immobilis et sine opere omni quam mineralia in terre visceribus abdita atque suppressa. Qui autem lactiphagus est sueque matris exuggit ubera: hunc plantis persimilem esse docuimus. ${ }^{1}$ ) Qui ante virile robur pedibus manibusque super terram graditur: hunc beluis parem esse probavimus. ${ }^{1}$ ) Qui vero virile robur consecutus per seipsum stare progredique sufficit: hic ostensus est naturali respondere Homini. ${ }^{1}$ ) Sunt igitur hi quidem gradus quattuor perfectionis humane ex parte corporis sive etatis, quibus Homo sensim ex mineralium gradu in humanum scandit, proficit, adolescit.

$₫$ Sunt vero et totidem hominum gradus in consummatione ${ }^{2}$ ) Hominis ex parte animi et in acquisitione virtutum, quos ipsi prius enumeravimus

p. $\mathbf{1} 9^{\mathrm{r}}$ ac recensuimus. ${ }^{3}$ ) Nempe ex his hominibus, qui corpore et substantia | perfecti consummatique sunt quique ad virilem pervenerunt etatem: alii sunt virtute consummati atque perfecti, quos studiosos Sapientesque vocamus, alii virtute inconsummati ${ }^{4}$ ), quos dicimus Insipientes, utpote qui ex defectu Virtutis humano apice inferiores esse cernuntur et, ut diximus ${ }^{5}$ ), aut ipsis mineralibus aut plantis aut beluis ex ipso vivendi modo inveniuntur indispares. Fiunt quippe ex Acedia mineralibus viri persimiles; ex irrepressa alimonie appetitione plantis comparantur; ex feda libidine beluas imitantur; per solam denique Virtutem utrobique, tam corpore quam animo, Homines esse declarantur.

đ Quodhomo trifariam Homo dicatur.

Cap. IV.

Manifestum ex his, que diximus, est hominem trifariam tribusve de cauPrimus Hominis sis Hominem posse dici. Aut enim homo simpliciter est Homo, hoc est modus a natura

ex humano corpore et rationali Anima conflatus; quopacto homo omnis est Homo, tam Insipiens quam Sapiens, tam infantulus quam qui virile robur est consequutus. Hic enim Hominis modus est a natura, quo inter sensibiles substantias humana species quartum efficere gradum comproba-

\footnotetext{
1) p. $308 \mathrm{sq}$.

2) consumatione $e d$.

3) cap. I.

4) inconsumati $e d$.

5) cap.I.
} 
tur. $\left.{ }^{1}\right)$ Aut Hominem quidem vocamus eum, qui perfecta sui corporis ac- Secundus Hominis cepit incrementa quique vir actu evasit; quopacto infans et puer Homi- modus ex etate nes minime dicuntur. Aut denique Homo est, qui animo maturus est Tertius ex virtute virtuteque perfectus; quomodo neque infans neque insipiens vir Homines sunt, sed studiosi soli atque sapientes. Est enim studiosus Homo omnifariam sive triniter Homo: Homo inquam natura, Homo etate et Homo virtute. Qui autem studiosus non est: hic tantum bifariam Homo esse potest; nam et etate et natura Homo. Qui autem etate non Homo est, ut infans: hic unice duntaxat, hoc est a natura, Homo esse declaratur, etate autem et virtute non Homo.

\begin{tabular}{|l|l|l|l|l|}
\hline Infans & natura & & & Homo \\
\cline { 2 - 4 } & etate & natura & & Homo \\
\hline Insipiens & virtute & etate & natura & Homo \\
\hline Studiosus & ete & \\
\hline
\end{tabular}

đ In omni autem hominum acceptione, tam secundum naturam quam In omni humana secundum etatem quam secundum virtutem, quaternis gradibus Homo acceptione gradus perficitur. Naturalis quippe Homo, ut infans, quarto loco a mineralibus dispescitur; etenim mineralia primi sunt Nature partus, viventia secundus, bruta animantia tertius, naturalis Homo supremus. Peperit siquidem imprimis Natura ea, que sunt; deinde ea, que vivunt; tertio loco ea edidit, que sentiunt; quarto et ultimo ea protulit, que Rationis sunt participia.

đ Finge etenim Naturam, cunctorum matrem, quattuor filias ex utero Nature filie quatpeperisse: primam Substantiam, secundam Vitam, tertiam Sensum, tuor quartam Rationem, cunctarum filiarum speciosissimam, sapientissimam, matri Nature parem et equalem, cuius moderamini ceteras filias tanquam imperfectas ac sui incompotes Natura subdiderit. Hoc pacto genitricem Naturam in Hominis usque naturalis sive Rationis ortum quattuor gradibus evectam comperies. In humana autem etate consummanda proportionabiles gradus insunt: infans in utero, infans ab uberibus, puer curvus ambulans, vir seipsum fulciens. Ast in Homine per Virtutem consummando hec distinctio reperitur: Acedia, Gula, Luxuria, Virtus. Quippe ex ipsis viciis, ad que Homo natura pronus est, sensim humana Substantia in ipsam Virtutem scandit, proficit, attollitur. Et hec ex presenti figura peramplius dilucescunt:

1) $\operatorname{cap} . I$. 


\begin{tabular}{|l|l|l|l|}
\hline Mineralia & Viventia & Sensibilia & Rationalia \\
\cline { 1 - 2 } Lapis & Arbor & Bestia & Homo naturalis \\
\hline Esse & Vivere & Sentire & Intelligere \\
\hline Infans in utero & Ablactans & Progrediens & Stans \\
\cline { 1 - 2 } Prima etas & Secunda etas & Tertia etas & Quarta etas \\
\hline Fetus & Infans & Puer & Vir \\
\hline Acedia & Gula & Luxuria & Virtus \\
\hline Piger & Concupiscens & Amans & Studiosus \\
\hline Terra & Aqua & Aer & Ignis \\
\hline Scriptura & Vox & Conceptus & Mens \\
\hline
\end{tabular}

In assecutione intellectualis Virtutis gradus quattuor

q Insuper et ex consideratione intellectualis Virtutis, que post moralem in Homine perficitur, quattuor quoque gradus in Hominis per intellectualem Virtutem consummatione occurrunt. Moralis enim Virtus quoquopacto impropria et extera est animo, utpote que inter animum ${ }^{\mathrm{a}}$ ) et corpus pacis federa sancit, que corpus animo - ut Natura iubet - famulari cogit, queve animi nubes ventosque discutiens enubem illum facit, illi serenitudinem ac tranquillitatem affert. Intellectualis autem Virtus lux p. $1 \mathrm{I}^{\mathrm{v}}$ est et irradiatio animi, que haud secus sine morali | Virtute in animum ${ }^{\mathrm{b}}$ ) introduci in eove splendescere prohibetur, quam Phoebeus radius, ne in caliginoso aere aureo splendore rutilet, vetatur. Hec itaque intellectualis Virtus, qua per moralem enubis ac tranquillus effectus animus demum illustratur, cum sit proprium atque internum animi bonum, habet et gradus quattuor, quibus ipsa maturescit suumque fastigium consectatur. Nam, ut in libro de Sensu predocuimus ${ }^{1}$ ), homo, qui discipulatui subest quique $\mathrm{ab}$ alio homine eruditur, imprimis scribit; ex scriptura vero attollitur in vocem, ex voce elicit conceptum; ex ipsa denique notione, que proxima et intima sue mentis est imago, in sublime mentis Esse, quo nichil prestantius est, elevatur. Hec igitur est vera, potissima et intellectualis Hominis consummatio: ex scriptura in vocem, ex voce in notionem, ex denique notione in mentem.

a) animam ed. b) animam ed.

1) de Sensu: cap. XXX; XXXV cum figuris; cf. de Sapiente: cap. $X X X$ p. $360 \mathrm{sq}$. 
đ Quod sola Ratio sit adulta et perfecta Nature filia.

Cap. V.

Ostensum est prius sensibilem materialemve Naturam quattuor tantum habere filias: Substantiam, Vitam, Sensum, Rationem, que, sicut liber de Generatione recensuit ${ }^{1}$ ), universam materiam inter se dispartiuntur obtinentque totam eius molem, quemadmodum et a quattuor elementis concavus sublunaris celi ambitus universus obtinetur, occupatur, possidetur. Sunt enim ad normam et examen quattuor elementorum substantiales quoque materie actus diducti, cum eadem sit sublunaris concavi et ipsius materiei intercapedo sitque amborum capacitas una.

ণ Nempe tametsi fateamur editos esse a Deo ${ }^{a}$ ) quinque substantiales actus: Angelicus actusmasubstantivum, vitalem, sensitivum, rationalem et intellectualem, id est teriei actus non est angelicum, hunc tamen supremum materialem esse, hoc est in materia subsistere natum, minime assentimur. Hic igitur, cum per se subsistere natus sit, cum sit et ipsa materie et cunctis materiei actibus antiquior, haủdquaquam censetur materie1 actus; perinde atque quintum supremumque mundi corpus, ut celum, quam quintam mundi essentiam vocant, immateriale esse nichilve cum materia habere commune asseveramus $^{2}$ ), ita et angelicus actus, qui ab substantivo et abiectissimo actuum quintus ordine numeratur, antiquitate tamen et origine primus, nichil cum materia commune suscipit, nullo federe eidem alligatur. Abiunctus et per se extra materiam degit, nullam in ea perficit operationem, in qua neque naturale Esse susceperit. Omnem enim actum, qui in materia quippiam profert aut aliquid in ea operatur, materiei inesse oportet, utpote que a separato et abiuncto actu nichil excipere aut pati nata sit; sed duntaxat ab eo patitur, quem intra se claudit quemve suopte in sinu complexa sub lune globo remoratur.

$₫$ Angelicus igitur actus fetus ac pignus non est sensibilis Nature; sed hic ad superiorem intellectualemve Naturam refertur, quandoquidem sensibilem Naturam materiei et sublunari ambitui equare studemus dicentes sensibilem Naturam filias tantum quattuor peperisse, id est formas quattuor materiei indidisse: Essentiam, Vitam, Sensum, Rationem. Harum vero tres imperfectas esse volumus: Substantiam, Vitam et Sensum; quartam vero, Rationem, solam perfectam, integram, consummatam ac matri Nature parem esse predicamus.
a) adeo $e d$.
1) de Generatione: cap. VI 5; XVII 2. [XVI 2].
$\left.{ }^{2}\right)$ ct. de Generatione: cap. VI 2 sq. 
Substantia terre $₫$ Nempe Essentia persimilis est tellureo orbi ${ }^{1}$ ), cuius moles initium quipersimilis dem est plenitudinis sensibilis mundi, non tamen consummata eius plenitudo. Ita et Substantia sive substantivus actus initium est materialis Vita similis aque plenitudinis, haud tamen ab illo materiei consummatur plenitudo. Vita aqueum respicit orbem ${ }^{1}$ ), cuius moles terrene superaddita moli terreumve complicans orbem mundi plenitudinem adauget, non tamen illam consummat. Ita et vitalis actus adiectus essentiali illumve complicans plus quam solus essentialis materiam implet; eius tamen plenitudinem abSensus similis aeri solvit minime. Sensus porro aereo orbi comparatur ${ }^{1}$ ), qui adiectus aqueo terreove orbibus amplius quam inferiorum orbium moles sensibilis mundi spacium, non tamen totum adimplet. Ita et sensitivus actus vitalem essentialemque comitatus actum materiam pleniorem, haud tamen plenissi-

Ratio igni similis mam efficere potest. Que autem superest, Ratio, persimilis igneo est orbi. ${ }^{1}$ ) Hic enim aeream, aqueam ac telluream involvens excipiensque molem sublunaris concavi ex integro plenitudinem absolvit ipsaque celi latera exosculatur. Ita et ceteris actibus: essentiali, vitali et sensitivo superveniens Ratio universum materie hyatum implet, quicquid illi deerat, affert eamque perfecto, potissimo ac lucidissimo decore investit. Celum pater ele- $₫$ Intellige etenim celum patrem esse, principium, naturam, fontem orimentorum ginemque elementorum ipsumque celum terram imprimis in distantissimo a se loco et mundi centro peperisse, deinde aquam, hinc aerem, supremo p. г2 $0^{\text {r }}$ ignem, quamvis in libro de Generatione ${ }^{2}$ ) | simul parta esse elementa docuerimus nullamque in materiei elementatione fluxionem contigisse. Hac ratione ignis prestantissimum se esse elementorum insinuat, quod solus in suam redit originem suumque principium apprehendit, quod solus celo patri vicinus ac proximus evadit illique iugiter oscula prebet. Ita et intellige matrem Naturam quattuor genitricem filiarum: Essentiam imprimis remotissimo a se loco impostergum omnium peperisse tanquam parvulam et omnium minimam; deinde propiore loco grandiusculam edidisse Vitam, que capite toto Essentiam transiliat; tertio vero iterumque propiore gradu partum esse ab ea maturiorem Sensum, qui et quantitate ut capite toto Vitam exuperet; quarto denique attiguo et proximo loco editam esse a Natura Rationem, que et grandior et maturior sit ipso Sensu ac Nature matri equalis. Perspicuum inde fiet e cunctis Nature filiabus solam Rationem esse perfectam; utpote que sola matri Nature coniungitur queve illi par et equalis oscula eidem prebere potest, que insuper unica matri adest, matrem Naturam comprehendere et amplexari nata. Cetere autem tres filie imperfecte et inconsummate

1) cf. de Generatione: cap. VI 5: Analogia pulchra et rite attendenda; XVII $5-6[X V I]$.

2) de Generatione: cap. XIV I-5. [XIII]. 
sunt, quandoquidem et matri Nature impares et eminus collocate abercentur, ut nec illam complecti nec in eam attolli aut illam exosculari sufficiant.

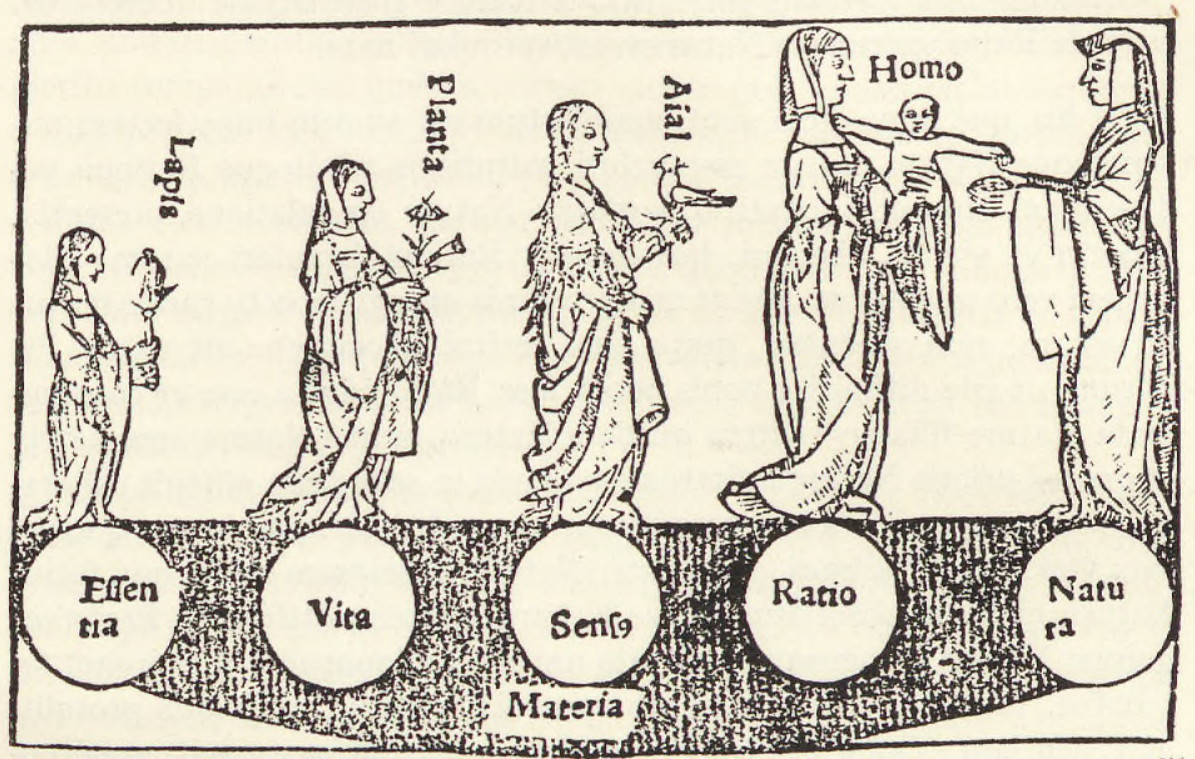

đ Instituit igitur Natura mater Rationem, tanquam adultam perfectissi- Illatio mamque filiarum ac solam sibi parem, ceteris filiabus dominari illique sensibilis totius mundi et eorum, que in eo sunt, permisit moderamen. Eam, que origine ac ordine novissima et ultimogenita est, ampliore quam ceteras amore prosecuta primam progenitamque efficit ac sui heredem instituit, ut ex matris imitatione discat ceteris filiabus sapienter preesse cunctaque per mutuatum a se Sapientie lumen regere, gubernare, moderari.

Sensibilis Natura in quinario perfecta est atque absoluta.

Constant enim, quecunque sub celo sunt, ex materia et actibus quattuor.

Materia unica atque uniformis cunctis actibus subest. ${ }^{1}$ )

Illius actus sunt Essentia, Vita, Sensus, Ratio.

Hos actus quattuor Nature filias appellamus.

Essentia filiarum minima prestantioribus tribus famulatur.

Ratio cunctarum potissima minoribus tribus preest.

Essentia lapidem gerit, Vita plantam, Sensus animal, Ratio Hominem.

1) cf. de Generatione: cap. XII I; 3-4. [XV]. 
In harum procreatione filiarum ab imperfectis ad perfecta Natura processit.

Nam primo edita est Essentia, ultima vero Ratio procreata.

Minores tres Rationis interstitio a Nature speculatione abercentur. Sola Ratio universam Naturam est speculari nata.

đ Ex his, que nunc dicta sunt, manifestum est omnem imperfectam mip. $120^{v}$ noremque Nature | filiam esse veluti maturioris adulteque Rationis pedissequam eiusque interstitio a matris Nature speculatione, presentia, aspectu et vicinia aberceri, ipsi insuper Rationi famulari natam; Rationem vero solam esse, que et matris vicinia et iugi aspectu gaudeat, que illi astare, eam speculari, grata eius perfrui allocutione sit nata. Fit Rationis diffinitio iterum, ut rite diffiniri a nobis possit ipsa Ratio adulta esse et consummata Nature filia sive altera quedam Natura, prime Nature speculatrix et que ad prioris Nature imitationem omnia in semetipsa effingit cuncta-

Alia Rationis diffi- que sapienter - vires supplens matris - moderatur. Rationem quoque nitio eam vim esse diffinimus, qua mater Natura in seipsam redit, qua totius Nature circulus absolvitur quave Natura sibiipsi restituitur. Proferens quippe Natura gignensque $a b$ initio universa aliquopacto in seipsam ferebatur, dum ea, que eminus ab ipsa dissociantur, imprimis protulit, ut Essentiam, Vitam et Sensum, postremo vero id parturivit, quod cominus et in sui vicinia residere seque matrem exosculari natum esse reperitur: cuiusmodi solam Rationem esse docuimus.

đQuod solus Sapiens sit veraciter Homo.

Cap. VI.

Solus Sapiens vera- Etsi cunctis hominibus eadem insit substantia, natura, origo, species citer Homo-Homo sintque cunctorum hominum sublimia capita, nullis insuper desit Substantie, Vite, Sensus Rationisque participatio: solus tamen Sapiens est veraciter Homo; solus Animam ad supremum usque Rationis apicem ex imis gradibus evexit, solus in sua ipsius natura atque Substantia provide feneratur. Est enim et ex ipsius Nature munere sive Substantie participatione Homo et posteriore Virtutis proventu et sacra functione seu vite honestate iterum Homo.

Tres imperfectorum $₫$ Ceteri vero, quos ignava ocia citra Rationis ac preclare Virtutis apihominum gradus cem in abiectiori gradu remorantur, inconsummati et insipientes homines sunt vivuntque naturali munere, hoc est substantiali Homine, indigni, actu ipso, opere vivendique norma irrationabiles; et qui velut naturalis Rationis expertes aut sensitivo aut vitali desiderio aguntur, Homines quidem natura ac substantia, Virtutis autem defectu animo in- 
conditi, sui incompotes, improvidi, incompositi, inhumani. Horum enim trinos esse gradus docuimu $\mathrm{s}^{1}$ ), qui in verum, studiosum ac perfectum Hominem in ipsis viciis desidentes adolescere prohibentur: alios similes mineralibus, qui ab somno blandove corpore velut emortui lapidescunt; alios imitari plantas, ut qui alimentationi seipsos devovere; alios feris merito comparandos, quibus terreno amore prestantius nichil adest.

đ Res perfecta ex materia et forma necessario conflata est, utpote que a materia primum, obscurum, inconditum occultumque Esse receptat, a forma vero secundum, clarum, ordinatum lucidumque Esse capit. Est enim res perfecta id, quod apparet, idque, quod paret, est. Neque quidem est solum neque duntaxat apparet, sed ex utraque, et Essentia et apparitione, conflatur. Quicquid enim foris esse videtur, hoc quoque intus habet; et si quid insuper illa intus habet, hoc ipsum quoque foris sub lucidissimis signis derivat atque propalat.

$₫$ Accipe igitur Sapientis consummatique viri vestigia ex re huiusmodi Sapientis figura ex tota, integra atque perfecta sive ex perfecto, toto et hoc aliquid ente, re perfecta quod utrinque quidem ens est: ens inquam in potentia et ens in actu; ens in principio, ens et in fine; ens in materia, ens et in forma; ens in occulto, ens in aperto; ens inchoatum, ens perfectum. ${ }^{2}$ ) Est enim Sapiens integer, totus ac perfectus Homo. Homo inquam a natura et Homo ab intellectu; Homo in materia, Homo in forma; Homo in potentia, Homo in actu; Homo ex principio, Homo quoque ex fine; Homo existens, Homo et apparens; Homo denique inchoatus, Homo et perfectus.

đ Sapienti quippe primum Substantie munus Natura vice materiei est Natura impartita; Voluntas vero, ars, industria eidem Virtutem, scientiam, lu- Voluntas cem, decorem, ornatum et apparitionem vice forme est elargita. Natura Sapienti simplex Esse condonavit; ipse vero sibiipsi compositum esse, hoc est bene beateque esse, progenuit. Natura illi precipuam Rationis vim indulta est; ipse autem in cunctis Rationis moderamini obtemperans Vite functione rationalis esse contendit. Rationem enim sibi proponit ducem, preter eam nichil agit; illius fulgore illustratur atque ad eius numerum propriam mentem, actus universosque motus componit.

đ Res imperfecta aut est materia simplex, informis, incondita, ignota aut Que res imperfecta forma subiecto destituta, inanis, ociosa, instabilis ac vaga. Hec vero est apparitio sine Substantia, illa autem Substantia sine apparitione. Ex his igitur imperfectis entibus, que verorum totorumque entium sunt partes, imperfecti insipientisque viri disce signa atque vestigia persequi.

1) cap. I.

$\left.{ }^{2}\right)$ cf. Artem Oppositorum: cap. XIII 7 . 
p. I2 $\mathrm{I}^{\mathrm{r}}$ Sicut enim Natura haud simplicem potentiam sine actu neque / extorrem a potentia actum sustinet aliquando - nempe utrumque sine altero ociosum -, ita et haud secus preter Nature seriem accidit Hominem super terram degere Insipientem, qui semper ex parte Homo manet, in integrum totumque Hominem proficiens nunquam. Est enim Insipiens incompositus homo initium quidem habens a Natura: arte tamen et virtute inconsummatum, infinitum, imperfectum. Substantialis et naturalis Homo est immortalis ac rationalis Anime particeps: ea tamen luce privatur, eo animi splendore est exors, quo sua ipse noscere queat munera, quo Rationis participem, immortalem Deique imaginem se esse feliciter apprehendat.

q Quod Sapiens et Insipiens sint natura similes, sola virtute differentes.

Cap. VII.

Sapiens atque Insipiens nullum habent nature aut sue Substantie discrimen; uterque siquidem est et corporis et Anime participatione Homo. Huius tamen vacuus est ac desertus animus; illius vero mens virtute, perfectione, sui gnaritate, spiritali lumine superhabunde ditata sui compos Sapientis et Insipi- evasit. Amborum Hominum idem est initium Deus, finis unus itidem entis idem prin- Deus: sed unicus ille Virtute ac Sapientia Deo similis fit, in suum princicipium Deus pium recurrit naturalemque finem consequitur; hic vero et privatione Virtutis et dissimilitudinis permixtione contrariorumve habituum insitione violatur ac ne in suam recurrat originem neve naturali fine perfruatur, infauste abercetur.

đ Sapienti in promptu adest suiipsius numerus; partes omnes suas apSapiens in terris prehendit: corpus, Animam. Congruum in seipso Nature ordinem serDeus alter vat, ut hec pars dominetur, illa huic famuletur. Cunctas animi vires naturalesve potentias atque facultates iuxta seipsas metitur; illam cunctis prefert ac super omnes excolit, qua ad immortalitatem et beatitudinem via illi reseratur. Vivit denique in terris ut Deus alter: eterni, primi naturalisque Dei - a quo et Substantiam et Virtutem mutuavit vera, precipua et substantialis imago.

đ Contraria vero de Insipiente dicito. Quoniam cum illi ex ignorantia sui Salomonis verba nulla adsit immortalitatis spes, hic merito in hec Salomonis verba ${ }^{1}$ ) prorumpit: "Exiguum et cum tedio est tempus vite mee. Fumus afflatus est in naribus meis, spiritus meus diffundetur tanquam mollis aer. Post hoc ero, tanquam non fuerim; nemo deinceps memoriam habebit operum meorum. Fruar ergo bonis in iuventute, comedam et bibam; cras enim

1) cf. Sap. 2, I-6. 
moriar.» Hac infelici desperatione terrenis fluxisque illecebris addictus Insipiens, dum seve mortis ultricisque pene memoriam abigere contendit, tristem mortem accelerat, penas adauget «itque preceps», ut sacra volunt eloquia ${ }^{1}$ ), (in foveam, quam fecit.»

đ Sapiens finitus Homo est, id est fine compositus atque perfectus. Insipiens vero infinitus est, inconsummatus, imperfectus. Nempe hic principium sine fine, potentiam sine obiecto, vim sine operatione se esse palam ostendit; ille autem principium fini coniunctum, potentiam minime ab obiecto separatam et vim in actu, usu et opere se continentem esse demonstrat. Hic rursum est ut oculus in tenebris aut a re visibili dimotus; ille vero oculorum aciei lumine perfuse ipsique soli, visibilium rerum fonti, iugiter exposite comparatur.

đ Unde fit, ut Insipienti sacrum hoc eloquium ${ }^{2}$ ) merito imputetur: Illatio "Oculos habet apertos, et non videt. Patulas habet aures, et non audit. Cor habet, et non intelligit», nichil salutare meditatur. Sapiens autem est oculus videns, auris audiens ${ }^{3}$ ), cor docile, quod ea intelligit, capessit, meditatur, per que demum in immortalitatem scandit. $₫$ Quo insuper modo Sapiens aliquid et aliquid est, Homo et Homo: ita et Insipiens aliquid et nichil est, Homo est et non Homo. Uterque siquidem per Naturam et Substantiam est aliquid: hoc est naturalis et substantialis Homo. Solus tamen Sapiens studiosorum operum proventu naturalem suum Hominem virtutis Homine duplicavit evasitque et natura et voluntate Homo; Insipiens vero torpore emarcidus naturalem Hominem nulla Virtute illustrare satagit, nullum priori Substantie curat litterarium inducere splendorem. đ Unde fit iterum, ut Sapienti et Insipienti hi haud immerito sacri sermones ${ }^{4}$ ) sint ascribendi: "Habenti dabitur et Sacer sermo abundabit. Ab eo vero, qui non habet, et id, quod habet, auferetur ab eo.» Accepit enim Sapiens a Natura substantialis munus Hominis, ex cuius fecunditate studiosum Hominem parturivit. Insipiens vero parem quoque ac substantialem Hominem mutuavit ${ }^{a}$ ) a Natura, sed nullo Virtutis fenore splendescit. Hic igitur Homo rite habere et non habere, ille vero habere et habere predicatur. Nempe Insipienti simplex habitus inest, qui vocatur naturalis Homo sive mutuatum a Natura talentum, in quo superlucratus est nichil. Sapienti vero gemini insunt habitus: Natureinquam| ta- p. I2 Iv lentum idque, quod superlucratusiure ut suum possidere probatur. Habenti

a) mutauit. ed.

1) cf. Eccle. Io, 8; Psal. 7, I6; (Prov. 26, 27; Eccli. 27, 29).

${ }^{2}$ ) cf. Jerem. 5, 2I; Marc. 8, I7-I8 + Matth. I3, I5; Act. 28, 27.

$\left.{ }^{3}\right) \mathrm{cf}$. Prov. 20, I2.

4) Matth. I3, I2; 25, 29. 
igitur simpliciter, id est utrumque Hominem, naturalem ac studiosum habenti, datur a Domino premiumimmortalitatis fitque uterque Homo: tam is, quem a Natura mutuarat, quam quem demum ex naturali peperit, vera, propria ac peculiaris eius possessio. Ast ab eo, qui studiosum perfectumque Hominem ex seipso non habet: auferetur ab eo et id, quod habet a Domino; naturalis quippe eius Homo in exteras agendus tenebras a sacris scripturis $^{1}$ ) promulgatur.

\section{đ Profectus foenusque Sapientis.}

Cap. VIII.

Fabula Promethei Sapiens in tellureo, quem a Natura possedit, Homine villicatus illum pro viribus excolit. Celestem Hominem inde profert; e tenebris emendicat elicitque splendorem, ex potentia actum, ex principio finem, ex insita vi opus, ex Natura Intellectum, ex inchoatione perfectum, ex parte totum et ex denique semine fructum. Hac enim in parte celebrem illum Prometheum imitatur, qui, ut poetarum fabule canunt, aut divum permissione aut mentis et ingenii acumine admissus nonnunquam in ethereos thalamos, postea quam universa celi palatia attentiore mentis speculatione lustravit, nichil in eis igne sanctius, preciosius ac vegetius reperit. Hunc ergo, quem dii tantopere mortalibus invidebant, illico suffuratus mortalium indidit orbi eoque luteum ac figulinum hominem, quem finxerat ${ }^{\mathrm{a}}$ ) prius, animavit. Ita et Sapiens vi Contemplationis sensibilem mundum linquens penetransque in regiam celi conceptum ibidem lucidissimum Sapientie ignem immortali mentis gremio in inferiora reportat eaque sincera ac vegetissima flamma naturalis ipsius tellureusve Homo viret, fovetur, animatur.

Perpes Nature debitor Insipiens

đ Sapiens Nature munera studioso Homine compensat, seipsum insuper acquisivit seque possidet ac suus manet. Insipiens vero terrenum, carneum ac substantialem Hominem incassum a Natura suscepit, utpote in quo nil profert immortalitate dignum, nichil opere adipiscende beatitudini impendit, ingratus in Naturam matrem perseverat manetque perpes Nature debitor, substantiali Homine oberatus et nunquam suus.

đ Sapiens seipsum mente discrevit geminisque, ut dictum est ${ }^{2}$ ), constat Hominibus: alio Nature atque sensibili, alio vero Virtutis et intellectuali. Sibiipsi nusquam abest, se haudquaquam deserit, sibiipsi congredi solus potest, iuge sibi fit speculum; semet ipse complectitur, in seipsum orbiculariter convertitur; studioso Homine inalterabilis et a seipso immobilis perse-

a) fixerat $e d$.

1) cf. Matth. 25, 30 .

2) cap. I; VI. 
verat; simul denique et in sensibili et in intelligibili mundo conversatur. Nam corpore quidem in terris cum brutis animantibus vivit, animo vero celos exterebrans celestes exedras perlustrat. Intellectualia sola meditatur, immortalia et eodem semper modo habentia sapit:

«Natus» siquidem, ut poeta Bigus ${ }^{1}$ ) canit ${ }^{2}$ ), «ad etherie solatia spiri- Bigus tus aule

Terrena nunquam sede quietus erit.

Ad superas opus est, Sapiens ${ }^{3}$ ) ut transvolet arces,

Gutture se pleno si satiare ${ }^{4}$ ) cupit.»

Hactenus enim sensibilia perfunctorie atque in transitu Sapiens expetit, quatenus corporeo circundatur amictu; nempe ex his solis mens saginatur atque refovetur, que corporis penitus et materiei sunt expertia queve e transmundanis thalamis sacro quopiam afflatu in eam ipsam illabuntur. đ Insipienti autem, cum nichil sit unum, idem, fixum, stabile, cum sit varietatis, divisionis et permutationis amator: contempta illustri, provida et oculata Virtute cecam improvidamque Fortunam ducem expostulat, illam ut deam sublimique locatam celo veneratur ${ }^{5}$ ); instabili eius orbe modo huc, modo illuc agitur, in salebras, in devexa et prerupta viciorum impellitur, incompos sui fit. Omni illectus obiecto, eius fit, quod repente occurrit; in seipso figi aut in seipsum ab exteris remeandi potestatem habet nullam.

đ At Sapienti proprium est iugiter ad individuam et suiipsius et summi Que Sapientis proopificis Dei unitatem feliciter niti, colligi, mente elevari. Carnalium nampria que illecebrarum titillantia spicula magna vi perdomuit, extra seipsum nulla necessitudine elici aut incompos fieri potest mentis. Fortunam calcare eamque nichil expallescere didicit. Interni plenus luminis verorum immortalium bonorum conscius fit; eorum felicissima et immobili spe nititur; sibi assidue gratulatur. Solus aut desolatus esse nequit, cum secum sit plurimus. Inter mundanarum passionum insultus efferatosque fluctus animum preclara Virtutis glarea librans in optimo, quieto et imperturbato mentis statu continetur.

đ Sapiens Homo est, qui veraciter minor mundus, maioris mundi - hoc Alia Sapientis proest Universi - filius, celebratur; solus etenim Sapiens semetipsum ad

1) Lodovicus Bigus Pictorius (Lodovico Bigo Pittorio): cf. Lor. Barotti, Memorie Istor. di Letterati Ferraresi, vol. II., Ferrarae I793, p. 37 sq.; Tiraboschi, Stor. della Lett. Ital., n. ed.t. VI. part. III., Florent. I809, p. 9 I4 sq.

2) Lud. Bigi Pictorii Ferrariensis Christianorum Opusculorum libri tres, Mutinae 1496: lib. II. carm. 37: Dissolvi cupit et esse cum Christo, vers. 37-38, 35-36; Argentor. I509, ed. Beatus Rhenanus, fol. 34 ${ }^{\mathrm{v}}$.

$\left.{ }^{3}\right)$ pro Sapiens ut Bigus dicit: ut libera (sc. mens).

$\left.{ }^{4}\right)$ Bigus: saturare. ${ }^{5}$ ) cf. figuram in initio operis.

Studien der Bibliothek Warburg ro: Cassirer. 
maioris mundi imitationem composuit, discrevit, perfecit; solus Naturam imitari potest, solus omnes sui partes partibus Universi consonas et pro-

p. $122^{\mathrm{r}}$ portionabiles servat. Et profecto Sapiens non modo mi|nor, sed et maior alter mundus iuste est appellandus, quandoquidem, ut liber de Intellectu recensuit ${ }^{1}$ ), tanta est mens Sapientis, quanta totius mundi capacitas, tantis rerum notionibus decoratur impleturque illius Memoria, quantas in mundo cernimus esse substantias. Insipientis autem mens, cum vacua, inanis, ociosa irritaque perseveret: in maiorem mundum haudquaquam aliquando emergit, nunquam maiori mundo par et equalis fit, nunquam, que omnia fieri nata $\left.e^{2}{ }^{2}\right)$, omnium gnaritudine consummatur.

\section{$₫$ Alie Sapientis et Insipientis similitudines ex natura speculi. \\ Cap. IX.}

Que ad perfectam
intuitionem necesintuitionem
saria

Quid oculus animi; quid speculum animi
Perfecti natura speculi est, ut speculum sit unum, integrum, uniforme, solidum, indistractum, altera saltim superficie perlucidum affectumque lumine: ut cunctas species, que illi actu insunt, oculus e regione consistens speculi imbibat, hauriat, speculetur; atque ut perfecta quidem visio et intuitio fiat: oculum speculo, speculantem actum presentatrici potentie addictum intentumque esse oportet nulliusque medii corporis opacitate debet actus a potentia, oculus a speculo intercludi, separari, abiungi; quod maxime continget, si oculus tam speculo propinquabit, ut unius cuiuspiam substantie nexus ac vinculum ex ambobus confletur; si neque oculus a speculo neque speculum ab oculo dissociari poterit unquam, sitque semper oculus in conspectu speculi ea perlustrans, que ipsi ab speculo offeruntur.

q Ex hac igitur analogia disce Sapientis complecti atque internoscere mentem. Sapientis quippe animus licet hoc ipso, quod est, totaque sui substantia unicus, impers et individuus sit: aliam tamen eius partem oculo, aliam speculo persimilem esse alibi demonstravimus. $\left.{ }^{3}\right)$ Pars enim, que similis est oculo, actus est animi impassibilis agensve Intellectus; que vero speculum emulatur, interior est animi pars suapte natura passibilis earumque notionum susceptiva ac fidele promptuarium, que per valvas practici Intellectus in animi aulam irruperunt, quas et postremo ipsa Memoria speculativo Intellectui in eviterne Contemplationis officio offerre presentareque iubetur. $\left.{ }^{4}\right)$ đ Voca igitur agentem Intellectum totius

1) de Intellectu: cap. XII 9.

2) cf. de Intellectu: I 4; 8-9; II 7; VIII 2-3.

$\left.{ }^{3}\right)$ de Intellectu: cap. VI 4.

4) De notionibus: Intellectus, Memoria, Contemplatio cf. de Intellectu, cat. $V I I ; X I V-X V$; de Sapiente, cap. XIII; XXIII. 
animi oculum, possibilem vero dic animi esse speculum..$^{1}$ ) Hoc pacto oculus et speculum animi tam sibi invicem propinquant, ut unius impertis animi substantiam conflent, ut sibi mutuo iugiter adsint, ut nullius intercidentis medii opacitate ab invicem dissocientur aut mutuus eorum ${ }^{a}$ ) prepediatur aspectus. Speculum insuper animi, hoc est Memoria, solidum est, unum, indistractum, uniforme, perlucidum affectumque intellectuali lumine; nempe suapte soliditate, quascunque receptat imagines, haud in profundum mergi neque in abyssum, in oblivionem aut in nichilum abire patitur, sed eas omnes in summa ac perlucida sui superficie retentat cunctasque intellectuali oculo presentat.

đ Quod si ulterius analogie vim prosequi volueris, confestim intelliges, Amplior analogie quid precipue animi oculus in proprio speculo conspicetur, que sit ea potissima imago ac species, quam Memoria in Contemplatione speculativo Intellectui satagat offerre. Nam si materialis oculus et materiale speculum debent e regione et ex opposito sui invicem in ipsa inspectione collocari et si hec est natura speculi eius duntaxat captare, haurire et excipere imaginem, quod illi ipsi ex adverso dyametri collocatur quodve recta distantia ab eodem dispescitur: erit profecto id, cuius imaginem excipi in speculo oportet, haud aliud quam ipse oculus, qui ab speculo per dyametri distat intervallum cuiusve species ductu eiusdem dyametri in speculum ab oculo manat. Precipua igitur, que in speculo recipi nata est, imago est imago ac species oculi. Nec aliud quicquam prestantius intueri in speculo oculus natus est quam seipsum suive speciem. Vera itaque et potissima inspectio est solius oculi inspectio. Idem oculus, qui in speculum suam derivat vibratque speciem, postremo seipsum in eadem imagine a speculo presentata speculari gaudet.

đ Age ergo dic et paria de Contemplatione Sapientis. Haud aliud in- Conclusio analogie quam esse Contemplationem Sapientis quam suiipsius sueve speciei in immateriali speculo iugem intuitum. Nam tametsi oculus animi et speculum animi sint eiusdem et impartibilis substantie vinculum, distant tamen, ut Oppositorum liber ostendit ${ }^{2}$ ), adinvicem spiritali dyametro; rationalis quippe hyatus et intercapedo illa ut opposita seque respicientia contra se sistit et ex adverso dyametri collocat. Precipua igitur species, que in speculo pellucet animi, hoc est in Memoria, species est oculi animi, id est agentis Intellectus, que in ipsam Memoriam ab agente Intellectu per rectum succedit intervallum. | Est itaque agens Intellectus p. $122^{\mathrm{v}}$

a) earum $e d$.

1) De notionibus: Intellectus agens, Intellectus possibilis cf. de Intellectu: cap. X 3; XIII 7; de Sensu: cap. XXIV 3; VI I; de Sapiente: cap. XIII.

$\left.{ }^{2}\right)$ Ars Oppositorum: cap. I 6. 
speculator sui, dum quam prius imaginem in Memoriam effudit, postremo a Memoria relatam contemplari atque intueri letatur. Et hec arcana ac invia sui speculatio beatum efficit Sapientem, spem illi tribuens immortalitatis ac probe erudiens nulla esse veraciter bona aut propter se expetibilia, que extra animum versantur, que semper adesse nequeunt queve possunt a nobis auferri.

đ Comparationes alie Sapientis et Insipientis ex oris, stomachi et cordis proprietatibus.

Cap. X.

Os, stomachus, cor. Sapiens ei rursum similis est, qui hianti ac patulo ore corpoream captans alimoniam eandem obvio stomachi vasculo susceptat continetque intus, ne mox in ima ventris abeat indigesta neve duntaxat per corpus colata seipsam corpori deneget illudque minime saginet, enutriat, alat. Sicut enim alimentaria substantia, priusquam in sanguinem vertatur adaugeatve corpus, trinis corporis partibus imprimis confertur: ori, stomacho, cordi, ita et intellectualis species ${ }^{1}$ ), priusquam mentem pascat saginetque Sapientis, tres in animo recipit status: primum in Intellectu, secundum in Memoria, tertium in Contemplatione, per quam iterum offertur Intellectui.

đ Est enim Intellectus ori, Memoria stomacho, Contemplatio vero corOris et Intellectus di analoga et quam simillima. Os enim et Intellectus anteriores sunt officia partes naturalesque valve, quibus tam corporea quam spiritalis alimonia - hec inquam per hunc in animum, illa vero per illud in corpus - est Stomachi et Me- introducenda. đ Stomachus vero et Memoria interiores partes sunt morie officia corporis et animi, quarum ille procedens manansque ab ore excipit alimentum, hec autem irrumpentibus per Intellectum notionibus it obviam Cordis et Contem- illasque colligit, retentat, conservat. đ Cor autem et Contemplatio hac plationis officia ratione invicem respondere probantur, quod illud quidem introductam $\mathrm{ab}$ ore et $\mathrm{ab}$ stomacho conceptam alimoniam coquit, digerit vertitque in sanguinem: hec vero pariter immissam per Intellectum et a Memoria conceptam atque reservatam notionem digerit, ordinat rursumque Intellectui offert.

Analogia corporee $₫$ Sicut igitur in corporis alimentatione prius est oris quam stomachi alimentationis ad officium, prior alimenti a mundo emendicatio quam eius in corpore ex-
animi pastum ceptio et conservatio, et priora rursus sunt oris et stomachi quam cordis officia, prior inquam cibi in corpus immissio et conservatio quam eiusdem concoctio: ita et in totius animi pastu prior est actio Intellectus Memorie

1) de notione: species intellectualis cf. de Intellectu, cap. VIII 6, 8-Io. 
officio et prius itidem Intellectus et Memoria suis funguntur actibus, quam Contemplationis exerceatur officium.

đ Et quemadmodum nichil nature subire cacabum, hoc est stomachum, Trinis officiis pastus potest, quod sit ab ore inassumptum, nichil est in stomacho, quod neutiquam in ore fuerit, nichil demum cordis calore coquitur, quod non et corporis et animi prius in oris palato et stomachi aula aliquantisper resederit: ita et nichil est in interna Memoria, quod non fuerit in anteriore Intellectu, nichil demum in ipsa versatur Contemplatione, quod non prius fuerit in Intellectu et in Memoria. $₫$ Os ab nulla anteriore corporis parte alimoniam captat, sed per semetipsum mordicus illam prehensat. Stomachus vero, quicquid habet, ab ore derivat. "Cor denique, quicquid torret ac digerit, ab utroque, hoc est ore et stomacho, deduxit. Dic et eodemmodo de partibus animi: Intellectum ab nulla anteriore animi parte speciem captare intellectualem; Memoriam vero eadem specie ab solo Intellectu imbui atque impregnari; Contemplationem demum procedere ab utroque, hoc est ab Intellectu et a Memoria. Sicut enim trinis officiis visibili alimonia corpus enutritur, ita et paribus trinis officiis invisibili esca animus proficit, pascitur, impinguatur. Et he tres corporis animique functiones hac verborum serie exprimuntur: primum a nullo sive per se; secundum ab uno tantum, primo; tertium ab utroque, primo et secundo.

\begin{tabular}{|l|l|l|}
\hline \multicolumn{2}{|c|}{ Trina corporis et animi pascendi officia } \\
\hline Os & Stomachus & Cor \\
\hline Cibi assumptio & Conservatio & Concoctio \\
\hline Intellectus & Memoria & Contemplatio \\
\hline Speciei apprehensio & Reservatio & Representatio \\
\hline Primum & Secundum & Tertium \\
\hline Per se & A primo & Ab utroque \\
\hline A nullo & Ab uno tantum & A duobus \\
\hline
\end{tabular}

đ Unde fit, ut ex opposito Sapientis dinoscatur Insipiens persimilis esse Illatio de Insipiente ori, cui stomachus it obviam nullus, aut pertuso Intellectui, abiuncto et separato a Memoria. Haud enim secus diffluunt perIntellectum invisibiles animi pastus, quam visibilis cibus ab ore prehensus mox $\mid$ in corporis $p$. $123^{\mathrm{r}}\left[125^{\mathrm{r}}\right]$ interna devolvitur. Nempe sicut corporea esca, ut primum oris forcipe ab exteris precisa est et captata, nullas in oris palato moras protrahit, sed sese illico per gutturis clivum in inferiora prorumpit: ita et dapes animi ipseque notiones nulla mora in Intellectu agente perseverant hisque solo 
momento perfruitur Intellectus, cunctas illico in Memoriam traducens. Tolle igitur $\mathrm{ab}$ ore stomachi presidium: poterit quidem ab ore in corpus immitti alimonia, sed colata per corpus nulla eidem tributa exolvet proderitque illi nusquam. Disclude pariter atque abiunge ab Intellectu $\mathrm{Me}-$ moriam: hauriet quidem fortassis Intellectus a mundo aliquid immittetque in animum nonnichil spiritalis alimonie, sed fideli Memorie promptuario minime eidem Intellectui occurrente assumpta ab eodem esca protenus vanescet, nichil animum saginabit aut eundem efficere poterit sapientem.

\section{đ Comparatio Sapientis ad solem et planetas. Cap. XI.}

Sapiens mundanum solem precipue imitatur. Nempe sicut mundanus sol inter errones erraticosve planetas et ordine medius est et motu a medio iugiter indevius fertur nusquamve ab imperti eclyptice orbita ultro citroque evagatur: ita et Sapiens, dum a proprio sole, hoc est a Ratione, dirigitur, dum Rationi in cunctis presidi obtemperat, medio semper calle tutus inambulat, nunquam in scopulorum salebras ab ea vagus abire permittitur.

Septem maioris mundi lampades

q $\mathrm{Si}$ enim minor mundus est Homo, tot utique luminibus ac lichnis Hominem regi atque illustrari oportet, quotquot lampadibus maiorem mundum cernimus esse choruscum atque illustrem. Septem vero lampades accendit Natura in maiore mundo, quarum ductibus eundem mundum gubernari regique voluit: maiores inquam duas, Solem et Lunam, hanc nocti, illam diei presidentem, et minores quinque, Saturnum, Iovem, Martem, Venerem, Mercurium. In medio autem omnium Solem constituit, quem et ceteris prestare lumen et iisdem dominari imperavit iubens, ut medio semper incessu minorum planetarum varios dividuosque errores equa lance metiatur atque dinumeret. Sunt igitur totidem, hoc est septena, luminaria paribus ordinibus atque officiis Homini a Natura indulta nec paucioribus myxis lucernisque Natura filium, hoc est minorem mundum, deinceps insignivit, ornavit, communivit, quam patrem, id est Universum, larga et munifica mater prius dotaverat.

Que sunt minoris $q$ Est autem minoris mundi lampas omnis eius cognitrix spectatrixque mundi lampades facultas, que imprimis in materialem et immaterialem secta divisaque reperitur. Porro materialis cognitio, ut liber de Sensu predocuit ${ }^{1}$ ), senario dispescitur: in Tactum, Gustum, Olfactum, Visum, Auditum et

\footnotetext{
1) de Sensu: praet., p. 21 $\mathrm{I}^{r}$; exodium, p. $5^{8^{r}}\left[59^{r}\right]$; cf. figuram p. $53^{r}$ $\left[56^{r}\right]$.
} 
Imaginationem. Nam Imaginatio quamquam interna sit sensatio, exteris sensibus abditior, iisdem insuper presit, corporeo tamen in organo, ut in cerebro, exercetur et Rationi famulari nata eandem super se presidem iudicemque reveretur. Immaterialis autem Hominis cognitio est ipsius Rationis oculus, qui cunctis abditior penitiorque sensibus nulla sui functione corpori copulatur, nichil eorum spectare aut speculari natus est, que aut in mundo aut in corpore sistuntur; sed omnis eius intuitus in interna sese animi crepidine et invio claustro coercet.

q Corporei igitur ac materiales Hominis oculi suapte natura in latera Tressensussursum, deerrantes ultro citroque per extrema feruntur. Nunc enim supra medium tres deorsum refefiunt sursumque cientur, nunc vero infra medium deorsum raptantur. Que autem cognitio immaterialis et animo propria est, ipsa inquam ignea Ratio, media iugiter incedit, ceteras regit, numerat, metitur. Earum quoque lux et numerus est perinde atque sol minorum planetarum. Sicut enim elevantur quidem supra solem planete tres, illi quoque subesse tres comperiuntur, ita et e famulabus ancillisque Rationis tres, ut alibi docuimus $^{1}$ ), suapte natura sursum aguntur elevanturque supra medium: Imaginatio, Auditus, Visus. Hi etenim sunt discipline sensus ${ }^{2}$ ), cunctorum precipui; qui et inferiorum iudices, arbitri presidesque nuncupantur. Ceteri autem tres: Olfactus, Gustus, Tactus infra medium motitantur; quemadmodum enim precipui tres animi pastum procurant, ita et isti alendo fovendoque corpori suum omne famuletium et obsequium devoverunt. Superi tres liberales dicuntur et honesti; tres vero imi illiberales, abiecti servilesque nuncupantur. ${ }^{3}$ )

đ Hanc ergo geminam sensuum tryadem: alteram summa et alta petentem, alteram vero in ima tendentem, media semperque uniformis Ratio imperti et eodem semper modo se habente monade vincit, scirpat figitque quam potest in medio; utramque temperat, ne hac nimium | effecta sublimi p. $123^{v}\left[{ }^{12} 5^{v}\right]$ divellatur scindaturque Hominis substantia; cuius unitati, integritati et paci insectilis Ratio maximopere consulit ac providet.

q Unde fit, ut e regione solius Rationis contingat et exoriatur omnis Vir- Illatio tus, que in mediocritate sita diffinitur, e directo autem sensuum tam superiorum quam inferiorum omne scateat vicium, quod aut habundat aut deficit, quod in plus aut in minus esse dictitatur. ${ }^{4}$ )

1) cf. de Sensu: cap. XXXI 2-3; 5. figura illustratum.

2) discipline sensus: $c f$. de Sensu cap. XXXI $1 ; 5$

$\left.{ }^{3}\right)$ cf. de Sensu: cap. XXIII; XXXI 2-6; de Sapiente cap. XXX p. 364.

4) cf. Artem Oppositorum: cap. XV 3 . 


\begin{tabular}{|c|l|l|l|l|l|l|}
\hline \multicolumn{3}{|c|}{ Figura similitudinis planetarum et humanarum cognitionum } \\
\hline Saturnus & Iupiter & Mars & Sol & Venus & Mercurius & Luna \\
\hline Imaginatio & Auditus & Visus & Ratio & Olfactus & Gustus & Tactus \\
\hline Tres superiores & Media & & Tres inferiores \\
\hline Liberales, honesti & Neutra & & Illiberales, serviles \\
\hline Animo servientes & Toti & Corpori famulantes \\
\hline Alta petentes & Medium & Inferiora petentes \\
\hline Vicium plus & tenens & Virtus & Vicium minus \\
\hline
\end{tabular}

đ He sunt igitur septem faces, quibus minor mundus splendet maiorique mundo et sibiipsi astat. Omnia a maiore in ipsum iisdem valvis et aditibus traducuntur. His septem ostiis totus maior defluit labiturque in minorem fitque minor omniformis ac maiori mundo equalis. In iis denique sita est Hominis omnis Virtus et Sapientia, si singulorum sui oculorum rectam proportionem servabit indemutato naturali eorum ordine.

đ Nam quandiu principatum obtinuerit Ratio, Homo et serenitate et tranquillitate animi potietur, sensuum illecebras carnisque pelliculationes effugiet, nitidissimo Rationis, ut proprii sui naturalisque solis, micante in tenebris splendore $a b$ extremis dirigetur in medium, plus minusque vitabit eritque suus et sui compos ac seipso iugiter perfruetur. Est enim Ratio velut sagatissima humani totius corpusculi ac domicilii mater familias, senis sensuum fulta ancillulis, quibus sapienter imperitat, nil incassum et sine causa perficiens, cuncta previdens, prosequens, que utilia, pulchra et honesta, que turpia fedaque devitans. Cui quoad permittentur habene, quoad Hominis arbitra et censoria fuerit, cuncta in eo rite disponet tolletque tandem eum e terris ad sidera.

Analogia $₫$ Sicut enim solis in maiore mundo presentia discutit tenebras, nubes dissipat imminentesque tempestates retundit, ita et Ratione in minore mundo cuncta moderante pelluntur ab eo mox errorum tenebre, perturbationum nebule caliginesque recedunt, perditorum desideriorum impetus feruntur $\left.{ }^{\mathrm{a}}\right)$. Absente autem Ratione continuo lux, Sapientia omnisque Virtus Hominem deserunt, atra nox illum nubesque subeunt. Sensuum meretricule illius decorem obliguriunt, Hominem denique totum tenebris offusum lancinant, laniant, interimunt.

a) fernantur ed. 
q Deconstantia verisque bonis Sapientis.

Cap. XII.

Sapiens immotus et imperturbatus vivit. Huius enim propria, vera et Inter que extrema precipua actio, que Contemplatio dicitur, separata est a mundo, a corpore, tempore, loco et a materia. Nempe Contemplatio inter ea extrema contingit, que nullis ab invicem discludi nubibus, ventis aut procellis possunt; in quibus nulla est lucis aut tenebrarum vicissitudo, sed candida et perpetua spiritalis invisibilisque lucis irradiatio.

đ Nam cum trina sit rerum omnium positio seu susceptiva potentia et Trina rerum omlocus: mundus, corpus, Anima, (sunt enim universa Hominis bona aut in mundo aut in corpore aut in Anima, tanquam in potentia, in subiecto et in continente loco) vera et propria Sapientis bona neque in mundo sunt neque in corpore, sed abdita, stata et condita in Anima; quibus assidue, liquidioris et imperturbate Contemplationis actu potitus Sapiens ea semper haurit et videt, que sua sunt. Ex mortali siquidem hac et umbratili terra in lucidiorem, immortalem, spiritalem et invisibilem sue Anime anticthonam, id est in terram terre contrapositam, corporis medio sensuumve obsequiis feliciter transtulit, quicquid suum esse deprehendit.

đ Unde fit, ut haud immerito soli Sapienti ascribi queat Prienei Biantis Biantis Prienei laconismus brevisque oratio, qua suadentibus, ut sua omnia urbe exoratio portaret, respondisse fertur: «Mea omnia mecum fero.» Nam Sapiens omnia habet in Anime potentia, id est in In|tellectu possibili sive in- p. $124^{\mathrm{r}}\left[\mathrm{r} 23^{\mathrm{r}}\right]$ tellectuali Memoria, que est immortale promptuarium et penuarium omnium intellectualium specierum omniumque virtutum et scientiarum arcanum domicilium. In quo locati Sapientum immarcessibiles thesauri iuxta sacrum eloquium ${ }^{1}$ ) tuti a vermibus sunt, a teredine, ab erugine, Sacrum eloquium a corruptione, a tyrannorum rapina. Fortune instabili rote inexpositi sunt, omne tempus exuperant et sine fine in Anima integra, salva et inviolata perdurant.

De Anime immortalitate.

Cap. XIII.

Fit etiam, ut de Sapiente id sacri eloquii iustissimis causis pronuncianSacrum eloquium dum occurrat: "Stabilita sunt illius bona in Domino. ${ }^{2}$ " Et iterum: "Anima illius in manu Dei est et non tanget eum tormentum mortis. ${ }^{3}$ )" Nam si inseparabilis est Intellectus possibilis ab agente Intellectu, utique tota Anime substantia dinoscitur esse impers, individua, immortalis,

1) cf. Matth. 6, 20.

2) Eccli.3I, II.

3) Sap. 3, I. 
iugiter - sive in corpore sive extra corpus - utraque sui parte, actu et potentia, subnixa. Et inter agentem et possibilem Intellectum interhyare, ut diximus ${ }^{1}$ ), medium potest nullum, quo agentis speculatio seu propria Anime actio et Contemplatio interpolletur ${ }^{2}$ ), fatiscat, remittatur. Excolit igitur agens Intellectus passibilem assidue ut propriam et subiectam terram, ut secum eiusdem nature possibilitatem invisibilem, immaterialem, semper presentem, a se inseparabilem, immortalem, sibi denique consubstantialem. Illi ut suapte natura fideli bonorum asservatrici cuncta, que captat a mundo, conmendat in eamque derivat cunctas notiones, quibus perpeti et inconsummabili ${ }^{3}$ ) evo pascendus est.

Ubi spes locatur $\mathbb{q} \mathrm{Hec}$ autem animi functio est Contemplatio, hec vera illa est et laudaSapientis tissima Anime actio immortalis, ad quam hi soli subvehuntur, penetrant, attolluntur, qui hunc beatissimum sue Anime prehenderunt numerum, quo pars partem spectare, quo sibi Anima misceri, ingredi in seipsam, orbiculariter moveri queat. Que enim in orbe et circulo creata est, orbiculari quoque operatione rationabile ${ }^{\mathrm{a}}$ ) est eandem perfici natam. ${ }^{4}$ ) $\mathrm{Hec}$ est Sapientis immobilis spes et penitissima eius inviaque confugella; huic felicissime, imperturbate et inimpedite Anime operationi totus fidit; in hac omnia possidet supra mundum, supra corpus. Nam in semetipso, hoc est in suaipsius Anima, cuncta habens: ea, que aut in corpore aut in mundo sunt, floccipendit.

đ Separabilis etenim est ab Homine mundus, dissociabile pariter ab Anima corpus; Anima autem ab Anima inscissilis atque indivisibilis, id est patiens passibilisve Intellectus inseparabilis ab agente et impassibili. Temporalis est Sensatio, que ab Anima in mundo et circa mundum exercetur; temporanea item et emarcida Imaginatio, que ab Anima in corpore perficitur. Perpes demum et eviterna Contemplatio, que ab Anima exercetur in Anima, ab agente inquam Intellectu in Intellectu passibili.

Cognitionum $q$ Sunt enim, ut in libro Sensuum docuimus ${ }^{5}$ ), materiales animi cognidivisio tiones gemine: Imaginatio et exterior Sensus. Illa simplex, hic quinque partibus disclusus; illa intus in corpore fit, hi vero in mundum discurrunt atque in eo negociantur. Immaterialis autem animi cognitio quandoque unica, quandoque vero trina censetur. Nam plerique omnem immaterialem cognitionem sive immaterialium invisibiliumque rerum noti-
a) rationabili $e d$.
1) cap. IX; cf.p. $323 n . I$.
$\left.{ }^{2}\right)$ lege: interpoletur.
3) inconsumabili $e d$.
4) cf. de Sensu: cap. XXVI; XXVII.
$\left.{ }^{5}\right)$ de Sensu: praefatio, p. $2 I^{r} ;$ cap. I I. 
ciam nomine uno Intellectum vocant. Nos vero, ut diversa ac trina sunt Tria tantum immaimmaterialia, invisibilia, immortalia et sempiterna entia: Deus, Angelus, terialia entia Anima ${ }^{1}$ ), ita et $a b$ ipsis obiectis quodammodo Anime cognitiones et potentias metientes ${ }^{\mathrm{a}}$ ) immaterialem Anime cognitionem trinam esse diffinimus; qua enim sibiipsa it obviam sibique presentatur, vocetur Ratio; Quid Ratio qua angelice scientie fit $^{\mathrm{b}}$ ) particeps, sit Intellectus; qua denique illi Quid Intellectus exigua in tenebris micat et excutitur divinitatis scintillula, Mentis portio Quid Mens dictitetur. $\left.{ }^{2}\right)$

q Omnis itaque immaterialis ${ }^{c}$ ) cognitio cum Contemplatio sit, liquet Contemplationem esse trinam; est enim Contemplatio trium supremorum et precipuorum mundi entium: Dei, Angeli et Anime eviterna et immortalis speculatio. Liquet etiam Sapientis Animam in sui principii, id est trinitatis, numero feliciter consummari.

\begin{tabular}{|c|l|l|l|l|}
\hline Deus & Angelus & Anima & Corpus & Mundus \\
\cline { 3 - 4 } Mens & Intellectus & Ratio & Imaginatio & Sensus \\
\hline Tres immateriales & Due corporee \\
\hline \multicolumn{2}{|l|}{ Tres eviterne } & Due temporales \\
\hline \multicolumn{2}{|l|}{ Trina Sapientis Contemplatio } & Geminum obsequium \\
\hline
\end{tabular}

| Et eandem Animam concinniter miraque venustate ad sensibilium plan- p. 124v [123v] tarum et arborum normam trina extra materiam propagine trinoque pro- Trina Anime extra ventu - foliorum inquam, florum et fructuum - evadere felicem. Anime materiam propago etenim folium sui cognitio est; flos vero angelica gnaritudo; fructus demum divina scientia. His trinipara Anima celos exterebrat, his tricipitem se corpore sensibilique mundo Sapiens exerit ipsoque celo sublimior efficitur. Alio siquidem capite sibi iugiter est presens, alio angelicis choris annumeratur, alio in divinitatis conspectum procedit.

đ De futura corporis instauratione et immortalitate.

$$
\text { Cap. XIV. }
$$

Non modo autem immortalis est tota Anime substantia, non sola Contemplatio nunquam remittetur, sed et ipsius Anime ${ }^{d}$ ) immortalitatis assecla est imprimis totius humane substantie perseverantia, materialium

a) mentientes $e d$.

b) sit ed.

c) materialis $e d$.

d) animi $e d$.

1) cf. de Sensu: cap. VII 3 .

2) de trina immateriali Animae cognitione: Ratio, Intellectus, Mens cf. de Sensu: cap. VII 5 . 
dein cognitionum (Sensationis et Imaginationis) instauratio. Nam si Anime natura est esse in corpore $^{1}$ ), vis insuper omnis et finis Anime est, ut sit eius actus et operatio, necesse est, ut preter naturam Anima migrans e corpore in suam tandem naturam a summo omnium principio revocetur, corpori restituatur corporeasque vires rursum circa mundum corpusque exerceat: in mundo Sensationem, in corpore Imaginationem. ${ }^{2}$ ) Argumentum im- $q \mathrm{Si}$ enim materiam, que prope non ens est, que cunctarum rerum submortalitatis Anime sidentia et eorum, que sunt, ultimum, haud inficiamur esse immortalem,
ex materia sed (tametsi creatam) perpetem, ingenerabilem et incorruptibilem fatemur $^{3}$ ), immutabilem quoque, semper eandem, totam ab initio factam, nunc vero totam subsistentem totamque semper futuram, que neque augeri possit neque minui, que in generatione assumitur, in corruptione relinquitur, esse predicamus ita, ut nichil eius unquam intereat: quanto magis perpes et immortalis asseveranda rationalis est Anima, propter quam unam in sensibili orbe fulciendam universa materie moles a divina omnium opifice Mente ab initio pependit.

Rationalis Anima đ Est enim rationalis Anima supremus potissimusque materie actus, tototius materie finis tius materie et universorum, qui in materia sunt, fluxorum et temporalium actuum naturalis finis; coniunctus, proximus eique vicinus actui, qui primus extra materiam et productus et subsistere natus est, quem divini totius operis initium, conceptum, actum primum primamve creaturam nuncupamus. Hic enim actus Angelus est, hic est, qui bono omnium autori, Deo, semper astans in illius conspectu versatur assidue, hic a quo rationalem Animam paulo imminutam sacra canunt eloquia ${ }^{4}$ ); Divus Dionysius et quem divus Areopagita precipuam Intelligentiam Deo constantissime gratias agentem festivasque laudes illi assidue persolventem appellat. ${ }^{5}$ ) đ Si igitur immortalis est huiusmodi materie actus, propter quem incorruptibilis materia eodem semper habet modo, eadem Substantie immutabilitate subnixa perseverat: erit et supremum, precipuum, speciosissimum prestantissimumque materie opus eidem immortalitatis legi a Natura ascriptum ut actus tam eximii tanteque forme naturalis locus utve proprium verumque eius domicilium. Igitur et immortalis est materia et aliquis in materia immortalis actus ut rationalis Anima; et aliquod ex materia divinum opus instaurandum a Deo futurumque immortale, cuiusmodi humanum volumus esse corpus. Et nonmodo humanum corpus propter Animam, sed et ipsum denique mundum propter humanum

1) cf. de Sensu: cap. VI 5; 7 .

$\left.{ }^{2}\right)$ cf. de Sensu: cap. VI 8.

3) cf. de Generatione: cap. IV 4.

$\left.{ }^{4}\right)$ cf. Psal. 8, 6; Hebr. 2, 7.

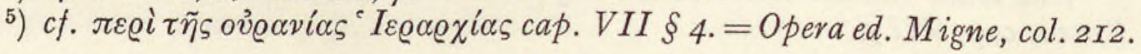


corpus et ut veram humani corporis mansionem a Deo instaurandum perpetemque futurum sacra eloquia compluribus in locis attestantur. ${ }^{1}$ )

đ Unde fit, ut misellus sit et prepostera avi natus Insipiens, qui omnia sua Illatio

habet in mundo et in corpore, nichil in Anima, nichil in Angelis, nichil in Deo. Illius enim bona erugo perdit, latio aufert, obligurit tempus. Mundum princeps mundi huius, sevus Hominum hostis, infestat; elementa corrumpit, maria obturbat, aerem intranquillum reddit, omnia invicem permiscet, corpus levissimis causis morbescit; tyrannus illud diris tormentis excruciatum necare potest; morte tandem pulverascens in atomos evannatur atque resolvitur.

q Hec omnia infelicis hominis irritam faciunt spem; inanem eum, va- Eloquium sacrum cuum et deploratum relinquunt, cui absque iniuria id sacri sermonis ${ }^{2}$ ) ascribitur: «Ecce homo, qui non posuit Deum adiutorem suum, sed in multitudine divitiarum speravit et prevaluit in vanitate sua.»

\section{| $₫$ Sapientis mens quasi iuge convivium. $\quad$ Cap. XV. p. $125^{\mathrm{r}}\left[\mathrm{r} 27^{\mathrm{r}}\right]$}

«Sapientis autem spes», ut a sapientissimo Salomone canitur ${ }^{3}$ ), «immorta- Salomonis verbum litate plena est et illius mens quasi iuge convivium.» Quid enim de Sapiente verius enunciari possit, quid peculiarius illi tribui, quam eius mentem iugiter spiritali alimonia refoveri, divina ac sacra aletudine impregnari $\left.{ }^{a}\right)$, celesti irrorari ambrosia, angelico pasci cibo assidue et exatiari nunquam. Adauget enim celestis alimonia sacrum sui desiderium, suique capacem et se tota ope expetentem facultatem iugi licet voluptate delectet, ampliore tamen semper fame ac siti irritare solet. Hac enim quo magis quispiam cibatur, tanto avidius et maiore cum voluptate eandem concupiscit, quantoque magis ad divini nectaris bibesiam felix Dei sympotes, Angelorum perioecus, Sanctorum conviva et contubernalis admittitur, tanto magis ut semper sitiens, ut nunquam exuberans sacro illius liquore assidue flagrat et exposcit imbui.

đ Hoc enim et ipsa Sapientia in sacris litteris ${ }^{4}$ ) de se ipsa attestatur: Verba Sapientie b) "Qui enim», inquit, "edunt me, adhuc esurient, et qui bibunt me, adhuc sitient. Transite ad me, qui concupiscitis me. Qui enim elucidant me, vitam eternam habebunt.» $\mathrm{Hec}$ Sapientia in plateis clamitat, hec ingenti classico in omnium aures intonat. Pulsitans citansque dormientes, eos, ut se concupiscant, hortatur. Immortalitatem et beatitudinem illis
a) impugnari $e d$.
b) Sapientis ed.
1) cf. e. g. Is. 65, I7; 2. Petr. 3, I3; Apoc. 2I, I; 4. Esdr. 7, 3I sq.
2) Psal. 5I, 9 .
3) ct. Sap. 3, 4 + Prov. I5, I5.
4) Eccli.24, 29; 26; 3I. 
pollicetur, Dei item amicitiam ac celicolarum contubernium. Se nauseosam non esse predicat. Edi semper posse procul fastidio aperit. Melle se dulciorem, expetibiliorem auro, gemmis cunctisque margaritis preferendam, bonorum quoque omnium largitricem, candorem se divine Virtutis enunciat, sinceram claritatis illius emanationem, speculum denique maiestatis eius immaculatum.

đ Infelix igitur Insipiens, qui contempta Sapientie honestate cece, improvide instabilisque Fortune sese indigno famuletio ultro obtulisse videtur, atque ut miseris concupiscentiis inserviat, aureum Sapientie torquem in ferreum Fortune iugum commutasse. Huiusmodi quippe stolidus homo eam tantum depetit ${ }^{\mathrm{a}}$ ) alimoniam, qua haud absque fastidio exaturari potest queve extra Animam est, corporea, materialis, corruptibilis et corporis corruptrix. In qua ${ }^{b}$ ) intemperiem qui sectari voluerit, mox et in Naturam et in seipsum peccat; huius enim exuperantia corpori est iniocunda, Nature contraria, exitialium morborum causa. Nempe et interior stomachus finitus est et exterior ac terrea alimonia finita; hec autem eatenus est prosequenda, qua capax est stomachi amplitudo. Hic enim cum exuberans et nauseosus evaserit, continuo interpolanda sunt numerosa poliphagorum et multibiborum Insipientum communia: silatus, prandium, merenda, vesperna.

Sapientis mensa $\mathbb{q}$ Ast Sapientis, ut diximus, iuge est et perenne convivium; illius dapalis et saliaris est animus; mens denique eius est omnium ${ }^{c}$ ) bonorum presentia, plenitudo et perfruitio. Passibilis eius Intellectus propria ipsius est et verissima mensa cunctis affluens spiritalibus deliciis, que et agenti Intellectui iugiter offertur atque objicitur, cui semper agens Intellectus accumbit, semper in ea veris dapibus convescitur ac splendide epulatur; Bigus poeta hec est enim illa mensa, quam Bigus poeta hoc disticho ${ }^{1}$ ) celebravit:

«O felix nimium et rerum pulcherrima mensa,

O fortunate terque quaterque dapes.»

đ Hic est verus ille et uberrimus animi ager, a quo agricola, hoc est agens Intellectus, emigrare aut exturbari nequit; hec celestis et etherea terra, possibilis inquam Intellectus, genitrix et alumna immarcessibilium bonorum, in quibus impune licet affluere deliciis, transilire et exuperare medium deficiente haudquaquam virenti ac succulento gramine et, que eo pascitur, mente insatiabili permanente. Huic enim ex tam felici symposio ingens fames et sitis ardentior in dies accrescit atque inaugetur.

a) deperit ed. b) quo ed. c) ominium ed.

1) Christianorum Opusculorum lib. II. carm. 28: De divina pace, vers. I9 sq.; ed. Beati Rhenani fol. $27^{\mathrm{r}}$. (cf. p. 32 I n. 2.) 
đ Sapientis moderatio et continentia.

Cap. XVI.

Sapiens sibiipsi indicens modum loris habenisque Rationis artatur, ut Sapiens in trina singula duntaxat eatenus prosequatur, quatenus et bona sunt et ex- sese continet equapetenda. Didicit enim Sapiens ex metro interne potentie exteriora litate obiecta et amabilia queque dimetiri seque hac trina equalitate in pace continere nititur, qua naturalem extremorum (potentie et obiecti) imitatus equalitatem amborum medium, hoc est ipsam appetitionem, qua obiecto copulari nata potentia est, ambobus exequare satagit; hic enim haud plura concupiscit, quam quod suiipsius nature | satis esse credit. p. $125^{\mathrm{v}}\left[127^{\mathrm{v}}\right]$ Tantum intra se admittit exterioris obiecti, quanti interne, ut diximus, potentie amplitudo a Natura capax est effecta.

đ Quod si dixeris ipsa obiecta potentiis esse disparia et inequalia, ut- obiectio pote prope infinita, potentias autem esse longe obiectis minores nec totorum obiectorum capaces - est enim visibilis esca pene immensa, stomachi captu sine modo exuperantior -, in hoc subiungo versari pre- Responsio clarum Sapientis certamen, ut interne potentie potius quam exterioris obiecti naturam sequens ad illius numerum huius substantiam prosequatur; hoc ipsum enim et hec Sapientie verba precipiunt ${ }^{1}$ ): «Ne», inquit, Sapientie verba «intuearis vinum, cum splendescit in vitro.» Hoc et Bigus poeta faciendum Bigus poeta canit $\left.^{2}\right)$ :

«Te», inquit, «vite si tangit amor, si gloria: noli

Maiorem captu ventris habere famem.»

đ Studium ergo Sapientis est hoc imprimis obiectum, quod corporee Insipientum inenecessitudini ascribitur ab interiore metiri potestate nec ampliore flagrare obiecti desiderio, quam hoc illi probetur utile ac necessarium aut quam internarum vascula potestatum sint ${ }^{\mathrm{a}}$ ) natura capacia. Ast Insipientibus contingit horum trium, que diximus, inequalitas ac disproportio; hi siquidem deliniti sola presentia aut certe ipsa dulcedine obiectorum, que duntaxat perfunctorie et in transitu expetenda sunt, ea ut propter se bona toto disquirere et accumulare nituntur affectu. Nulla insuper habita interne sue potestatis ratione, postergato eo, quem intus habent, naturali numero sola ipsa obiecta speculantur, quorum dum irrationabilem concipiunt appetitionis flammam, inequaliter et supra sue nature vires eadem obiecta percipere coguntur.

a) sunt ed.

1) cf. Prov. 23, 3I.

2) Christianorum Opusculorum lib. II. carm. 23: Crapulam detestatur, vers. 32 sq.; ed. Beati Rhenani fol. $24^{v}$. (cf.p. $32 I$ n. 2.) 
Unde omnis privatio $₫$ Unde fit, ut inde oriantur ${ }^{a}$ ) privatio omnis et miseria, que sunt Inet miseria oriuntur sipientie et cecitatis animi comites et assecle. Est enim miseria aut necessariorum privatio bonorum aut eorum desiderium irrationabile; velut cum subiectum aliquod et naturalis potentia aut proprio privatur obiecto propriorumve et naturalium suorum bonorum fit exors aut cum ad obiectum et naturalia sua bona immoderata concupiscentia pertrahitur, allicitur, ardet.

Due miserie cause $₫$ Oritur enim geminis de causis miseria: prima necessariorum et naturalium bonorum defectu, secunda concupiscentie excessu, quando ipsa appetitio utriusque, et subiecti et naturalium eius bonorum seu potentie et obiecti, quantitatem transcendit; ut, si et finita est potentia et finitum eius obiectum, illius tamen ad hoc irrationabilis appetitio; similiter et cum finita sunt subiecta et naturalia bona, illorum tamen ad hec irrepressibilis et inextinguibilis ardor. $₫$ Definiti siquidem sunt imprimis oris, stomachi et ventris captus. Alimentaria itidem substantia, naturale illius et necessarium bonum, a Natura certa est et numero aliquo exequata; amplior tamen cupedivorarum ${ }^{1}$ ) appetitio utriusque quantitatem exuperat. Hinc enim transmarine perdices tot sestertiis empte Philoxenus celebrantur; hinc Philoxenus ille protensiora ad gruis modum guttura Siculus Gnato expostulasse denarratur; hinc Siculum illum Gnatonem, gule facile principem, in pultaria emungi solitum legimus, ut abstinentibus cunctis solus epulis ampliter frueretur. Hinc tot vini calparia et congiaria epotantur, ut plane ad perdenda vina nati plerique hominum prodantur. Hinc capacissimi ventres expetuntur, quibus distendendis terre, maria peragrantur. Adeo ut exiguo inter cuncta animantia Hominum generi alendo vix universa Nature providentia, sufficere posse credatur.

Nature providentia $\mathbb{q}$ Quanta tamen Nature sit providentia, qua humano alendo corpori superabunde prospexerit, docent omnis generis animantia: reptilia, natatilia, gressilia, alata. In quibus cupedivorarum hominum rabies sine modo grassatur. Docent et Pithagoree plante et quicquid sub celis animatum Animave preditum est; id enim fere omne in Hominis vertitur alimentum. Subiecit quippe Deus Homini universa tanquam helvella, hoc est minuta oluscula. Que autem Anime expertia et inanimata sunt, minus in nostrum verti solent edulium; nutritur quippe simile omne a simili, ut vivens a vivente et animatum ab animato.

a) oriatur $e d$.

1) lege: cuppedi-vorarum. 
q Sapiens singulis, quod sat est, tribuit.

Cap. XVII.

Sapiens iuxta dignitatem et prestantiam obiectorum bonorum ea iudicat prosequenda; nulli enim plus equo tribuit. Eterna, spiritalia et vere bona propter seipsa expetens ad ea intentione tota, precipua et prima fertur ut ad animi fines, ut ad pulchrificas virtutes variasque celaturas et perpetua animi ornamenta. Porro sublunaria, materialia et exposita Fortune bona duntaxat ad latus, intentione secunda et ad temporaneum corporis expetit usum.

đ Nam, ut in Sensuum libro docuimus ${ }^{1}$ ), cum Intellectus sit tam extre- Intellectualia bona morum quam mediorum, tam immaterialium quam materialium, | Sensus autem duntaxat materialium et mediorum: ita et immaterialia et ubique bona intelligibilia animi bona simpliciter, tota et ubique sunt bona, tam in extremis quam in medio boni ratione definita. Corporis vero bona, que et sensibilia et materialia sunt, tantum in medio rationem boni sibi vendicant; in extremis vero mala et vitanda reperiuntur. Horum enim id duntaxat, quod neque plus neque minus fuerit, bonum et eligendum est; quod vero exuperat aut deficit, malum est et protenus fugiendum; illorum vero et quod mediocre est, bonum est et, que plus et minus, bona itidem et eligenda sunt. ${ }^{2}$ )

đ Unde fit, ut corporis bona haud tota, sed tantum in parte sint eligenda et in simplici differentia et positione, ut in medio solo, expetibilia et prosequenda. Sunt enim sita inter extrema mala, ut inter exuperantiam atque defectum; ad que interdum aut rationali lumine orbati aut Rationi haudquaquam obtemperantes pellicientibus affectibus nolentes volentesque delapsi peccamus, Naturam offendimus illius legem ac seriem immutantes. Animi autem bona universalia et tota sunt bona, ubique trinisque differentiis et positionibus prosequenda: in medio, in dextro, in sinistro. Nam sive in medium dirigamur, sive in dextrum, sive in sinistrum, nusquam ab eo, quod bonum et eligibile est, dilabimur, peccamus aut Naturam offendimus, sed quocunque pergentibus occurrit nobis bonum, offertur eligibile, succedit prosequendum.

đ Fit etiam, ut corporis bonum simplex, imperfectum et tantum unum sit: animi autem bonum discretum, numerosum, perfectum, unum atque Corporis bonum imperfectum trinum. Est enim illud, ut diximus, tantum in una, hoc vero trina et omni in positione bonum. Et ut illis potiamur fruamurve bonis, addenda est animo moralium virtutum operula ${ }^{a}$ ), quarum presidio fulta et fortior

Corporis bona tantum in medio bona

a) opecula $e d$.

1) de Sensu: cap. XXXVI 2; 3; 5 .

$\left.{ }^{2}\right)$ cf. Artem Oppositorum: cap. XV 3-5; de Sapiente: cap. XI. Studien der Bibliothek Warburg ro: Cassirer. 
effecta Ratio a sensibus haudquaquam superetur, sed iis ut famulantibus imperitans eorum impetus frenet, Hominem ab extremis arceat malis dirigatque in id, quod mediocre est et bonum.

Quod sit moralis q Sine etenim moris Virtute extemplo ab sui principii fastigio dejicitur Virtus utilis regina sensuum, Ratio, obnubilatur Homo, internus eius oculus cecutit ignoransque quod medium et bonum sensuum et ancillarum illecebris in extrema mala, plus minusque, infelici traha devehitur. Ast ut animi perfruamur potiamurque bonis, vel si animo nil preter nativum Rationis candorem et lumen addideris, sine extero et acquisito lumine in id, quod bonum est, per sese animus dirigetur. In his siquidem nulla subsunt precipitia, salebre asperitatesve nulle, sed plana omnia, inaspera, equalia; ubique prata virentia, amenissimis consita floribus, hyatu, abysso et scopulis carentia, per que licet tanquam in nocte et sine extero lumine libere discurrens animus abire in preceps, mergi aut interire nequeat. Temporalium autem bonorum area limosa ${ }^{2}$ ) est, aspera, inequalis, vastis ultro citroque hyans profundis, in que a medio procidens animus illico naufragatur atque perimitur.

đ Unde fit iterum, ut in intellectualibus bonis solutior, liberior et amplior sit animus quam in tellureis et sensibilibus. Nam per illorum aream per se, immediatius et sine extero acquisitove lumine tuto ferri et discurrere undique potest, nunc in extrema, nunc in medium. At horum per prata haud aliter quam sine moralium virtutum et acquisiti rationalis luminis presidio ferri et discurrere iubetur; observandum insuper in eis est medium et ab eo digrediendum nusquam. Et intellectualium verorumque mentis bonorum area est ut linea utraque parte infinita, carens extremis, ubique media, bona et expetenda; in qua qui discurrit animus, timore nullo artatur aut a libero motu prepeditur. Temporalium autem area finita est et dissimilibus, extremis ac precipitiis obsessa, per quam qui graditur, timore et morali Virtute artandus est et ab extremis iisque, que dissimilia, non bona et non entia sunt, continendus in medio.

đ $\mathrm{Hec}$ autem ex pauculis his propositionibus clarius dinoscuntur:

Hominis bona sunt duplicia: alia simpliciter, alia secundum quid.

Simpliciter bona sunt intellectualia et propter se bona.

Secundum quid bona sunt sensibilia et ad aliud bona.

Intellectualia bona sunt triniter et ubique bona.

Sensibilia tantum in medio sunt bona, in extremis vero mala.

In sensibilibus bonis morali opus est Virtute, qua contineamur in medio.

Intellectualia autem bona morali Virtute non egent.

a) lumosa $e d$. 
Cap. XVII.

Nam in intellectualibus bonis, cum ubique sint bona, nulla sunt precipitia.

Intellectualis Virtus Virtus est simplicis et absoluti animi.

Moralis autem Virtus totius est Hominis propria.

Hec etenim inter corpus et animum pacis federa sancit. ${ }^{1}$ )

Animus per le line exteriore lumine difcurrens

p. $126 \mathrm{v}[128 \mathrm{v}]$

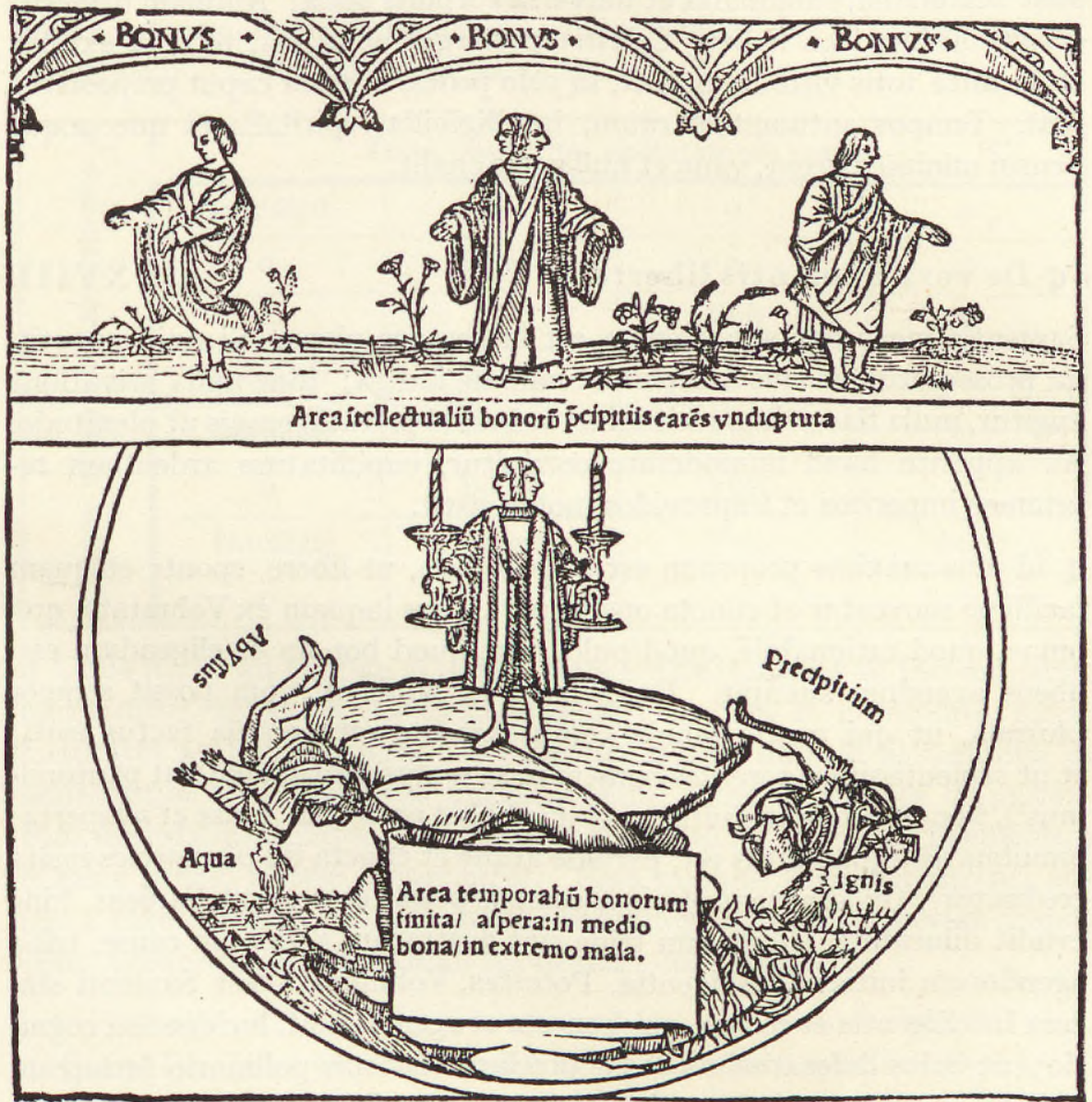

q Sunt enim morales virtutes acquisita in nobis pluri consuetudine lu- Quid morales virmina, interni nostri rationalis oculi presidia, fulture, opitulationes, artutes dentes facule; quas summopere hi in manibus gestare debent, qui Fortune fritillis et instabilibus aleis exponuntur, qui in temporalium bonorum area decertant, qui tuto per voluptaria carnis tempe discurrere et

1) $c f . c a p . I V$. 
peregrinari cupiunt, ut peracto felici peregrinationis sue curriculo emeriti milites, Herculei athlete sagittata in huius mundi palude Lernea ydra in iocundissima semperque virentia intellectualium bonorum prata et topiaria desumantur.

Insipiens preposte- $\mathbb{q}$ Sed cum Insipiens rationali huiusmodi acquisito lumine orbatus in rus Homo tenebris iuxta divinum eloquium ${ }^{1}$ ) ambulet, precipua illi et propter se sunt materialia, sublunaria et universa corporis bona; Animam despicit, corpus Anime loco habet. Celestia postergat et calcat, terrena extollit et in ante totis viribus expetit, in celo pedes, in terra caput preposterus figit. Tempus autumat eternum, intelligibilia, spiritalia et quecunque Sensui minime parent, vana et nulla esse credit.

p. $127^{\mathrm{r}}\left[\mathrm{s} 29^{\mathrm{r}}\right] \mid$ đ De vera Sapientis libertate.

Cap. XVIII.

Sapientis mens exuberantissima est et semper plena. Si quid expetit, ita prosequitur ut eius inexpers et minime indiga; hinc nulla privatione angitur, nulla flacessit amaritudine, sed est ei privatio omnis ut plenitudo. $\mathrm{Ab}$ appetitu haud immoderate corripitur, cupiditatum ardentiam reprimens imperitos et improvidos motus sistit.

Sapiens libere $q$ Id eius maxime proprium est et peculiare, ut libere, sponte et quam cuncta agit facillime moveatur et cuncta operetur. Libere inquam ex Voluntate, qua omne, quod rationabile, quod pulchrum, quod bonum et eligendum est, libens agendum suscipit. Facile vero ex potentia, cum possit semper plurima, ut qui mente omnia comprehendit, actu omnia factus est ${ }^{2}$ ); et ut sapientissimus toreutes omnem in se sculpsit imaginem; ut pantomimus $^{a}$ ), hoc est omnium imitator, omnia habet presentia, nuda et adaperta; omnibus denique insitus est, perinde atque et cuncta illi per species insita creduntur. Quod autem plurima semper possit et peragat Sapiens, hinc evadit dilucidum. Nam cum trine sint nostrarum actionum cause, trina agendorum initia: Intelligentia, Potestas, Voluntas, adest Sapienti sincera Intelligentia et eorum, que honesta et agenda sunt, lucidissima cognitio; ut cuius defecatissima mens preclaro Rationis pollinario furfuream omnem et crassam ignorantie nebulam excussit atque in mundi retrimenta dimisit; suppetit et illi, ut diximus, agendorum Potestas, cum nichil non sit et aliquopacto omnia possit; adest et ipsi postremo eorum Voluntas, que et agenda intelligit et agere potest.

a) pantominus ed.

1) Eccle. 2, I4.

2) cf. de Intellectu: cap. I 4-8; de Sapiente: cap. XXIV. 
đ Ubi igitur hec tria: Intelligere, Posse, Velle una et concordi chorea in- Trium concordia vicem colligantur, libera est, facilis et inimpedita Sapientis actio. Intelli- actionis initium gentia quippe illi, quid agendum sit, imprimis aperit; Potestas deinde subiecti apprehendit metiturque vires; Voluntas demum subiectum permovet, assentitur, prosequitur. $₫$ Quod si harum aliqua causarum defuerit, aut impedita aut nulla subsequetur actio. Nam si intelligit possitque quispiam, quod nolit, aut intelligit velitque, quod non possit, aut possit velitque, quod minime novit, aut si neque noverit neque potuerit neque velit: cassus irritusque movetur.

\begin{tabular}{|c|c|c|c|c|}
\hline \multirow{4}{*}{ 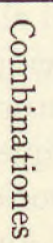 } & \multicolumn{4}{|c|}{ Trine nostrarum operationum cause } \\
\hline & Intelligit & 0 & 0 & 0 \\
\hline & 0 & Potest & 0 & 0 \\
\hline & 0 & 0 & Vult & o \\
\hline ⿷્ఝ & Intelligit & Potest & 0 & 0 \\
\hline 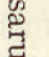 & Intelligit & 0 & Vult & 0 \\
\hline 3 & 0 & Potest & Vult & 0 \\
\hline 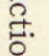 & Intelligit & Potest & Vult & Actio \\
\hline 胥. & 0 & 0 & 0 & 0 \\
\hline
\end{tabular}

đ Unde fit, ut ad omnem actionem deploratus Insipiens sit incommodus, Insipiensa) ad ageninexpeditus, inhabilis; ut cuius Intelligentia ceca et improvida, vires, facultates et habitus nulli. Sunt enim mentis almicie almarumve et honestarum rerum habitus quedam animi vires, facultates et nostrarum operationum cause. He autem $a b$ marcido $^{b}$ ) et ignavo insipiente ${ }^{c}$ ) homine procul abesse dinoscuntur. Eius quoque Voluntas ingenti addicta mycropsycosi, id est animi pusillitati, nil sibi convovere audet, cuius exequendi et adimplendi facultatem non habet.

\section{đ Quod Sapiens omnium finis et ut terrenus quidam Deus.}

Cap. XIX.

Sapiens est rerum omnium materialium et que firmamento ambiuntur verus consummatusque finis et, ut plerique sentiunt, terrenus quidam mortalisque Deus; mortalis tamen, ut docuimus ${ }^{1}$ ), duntaxat toto et id Mors est partium quoque preter naturam et ad tempus: ex temporanea abiunctione et
a) Insipientia $e d$.
b) murcido $e d$.
c) insipiente ignavo $\mathrm{ed}$.
1) cap. XIV. 
separatione ipsius partium. $₫$ Hac enim abiunctione ad tempus id, quod totum Hominem appellamus, subsistere desit, interit, non est; et pars eius altera (ut corpus), que ab reliqua Anima recipit vitam, identidem in suam redit materiem, in cineres abit, in atomos resolvitur. Anima vero natura impers, immaterialis, etheree spiritalisque substantie, haudquap. $127^{\mathrm{v}}\left[129^{\mathrm{v}}\right]$ quam morte labascit, dissolvitur, | interit: sed integra, una, tota et ipsa et que in ea abdita sunt, universa perseverant et in immortalitate perdurant.

Saperde Sapientes $q$ Eam etenim saperdarum et verorum mundi herorum semiquedeorum felicissimam spem esse ostendimus ${ }^{1}$ ), ut duntaxat toto et parte sui altera (ut corpore) norint se esse mortales idque tantum secundum tempus; Anima $^{a}$ ) vero didicerunt sciuntque se immortales et quandoque futurum, ut rursum e tellureo pulvere et priscis atomis evannata dissolutaque sui pars instauretur, Anime rursum perpeti convotione et federe societur redeatque totus Homo in antiquam naturam: corpus scilicet in Anime organum ac naturale domicilium, quo nunquam emigrabit Anima; hec

Spes immortalitatis vero in illius vitam. đ Hec iocundissima immortalitatis sue cogitatio se internis Sapientum oculis dies noctesque ingerit; huic assidue invigilant ac antelucantur, beatissimam et immortalem spem iugi tacitaque mentis pensiculatione versantes.

Sapientum multi- $q$ Unde manifestum est «Sapientum multitudinem», ut sacra canunt elotudo sanitas est quia ${ }^{2}$ ), "Sanitatem esse orbis terrarum», ut qui rerum omnium norunt causas, quid et propter quid sint; singulorum noverunt mensuram, ordinem, numerum, locum; cunctis insuper rebus rite soli utuntur. Suis gradibus et naturalibus sedibus divine instar Mentis continent ac sistunt universa; quodlibet ad proprium finem ducunt; sine his inequalitas in mundo accidit et quedam rerum iniusticia: ut uni plus, alteri minus tribuatur. đ Toti fit iniuria mundo utpote naturali sui speculo carenti. Est enim Homo, presertim Sapiens, naturale speculum Universi, in cuius mente, quecunque in mundo sunt, apparere, dinosci ac splendescere nata comprobantur. ${ }^{3}$ ) Nam quemadmodum rerum substantie in mundo subsistunt: ita et rationabiles earum fulgores, igniculi, species vereque notiones degunt in Homine. Omnia siquidem est mundus: scit tamen novitque nichil. Porro exiguum et fere nichil est Homo: scit attamen novitque universa. Et quantus ille substantia, tantus hic deprehenditur

\footnotetext{
a) Animo ed.

1) cap. XIV.

3) Sap. 6, 26 .

2) cf. cap. IX.
} 
esse scientia. Ille substantiarum omnium, hic rationum est omnium locus. Ille veritas, hic ${ }^{\text {a }}$ similitudo.

đ Mundus omnia presentat: Homo omnia iudicat, intuetur, speculatur. Mundus omnium est obiectum, gestans omnem in se veritatem: Homo vero omnium speculum, omnem continens et sibiipsi objiciens imaginem. Homo denique fulgor est, scientia, lux et Anima mundi: mundus vero ut ipsum Hominis corpus. Uterque maximus est et minimus; mundus maximus substantia, scientia nullus: Homo scientia amplissimus, substantia pusillus. Uterque stat in utroque, uterque utriusque capax; Hominis enim substantia versatur in mundo: mundi vero scientia in Homine.

\begin{tabular}{|l|l|l|l|l|}
\hline Mundus & substantiarum & omnium & locus & est \\
\hline Homo & scientiarum & omnium & domicilium & est \\
\hline In mundo & substantia & omnis & degit \\
\hline In Homine & scientia & omnis & collocatur \\
\hline Mundus & substantiā est & omnia, & scientia nichil \\
\hline Homo & substantiā & pusillus, & scientia omnia est \\
\hline In mundo & rerum substantie & sunt & impermixte \\
\hline In Homine & rerum rationes & sunt & inconfuse \\
\hline
\end{tabular}

Mundus substantialis mundus est: Homo rationalis mundus. Quanta in mundo substantiarum discretio quantaque rerum differitas: tantum

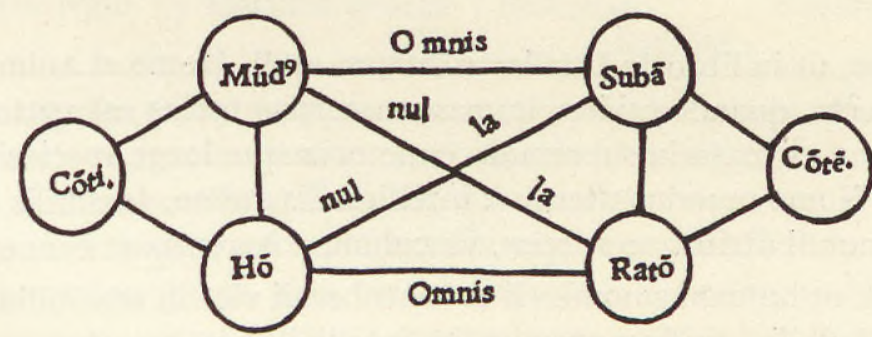

in Homine rationum discrimen. In utroque sunt omnia, in quolibet quodlibet, et in utroque nichil. In Homine Substantia nulla: in mundo Ratio itidem et conceptio nulla. Vacuus uterque est et plenus uterque. Inops rerum Homo rationum dives est: mundus vero rerum plenus inanis rationum.

a) his $e d$.

ad figuram: Cōti., Cōte. $=$ Contemplatio. 
đ Quod duo intellectuales mundi.

Cap. XX.

p. I $28 \mathrm{r}\left[\mathrm{r} 3 \mathrm{Or}^{\mathrm{r}}\right]$ Quis
primus intellectuprimus intellectu
alis mundus

Fit ex his, ut duplex sit intellectualis mundus: unus substantialis, rationalis alter; unus supra firmamentum, alter sub firmamento; unus in rerum natura et Substantia, alter in Ratione et humana mente. $q$ Nam que super celos sunt beatissima entia et prime mundi substantie: ut omnium exemplaria, archetypi et abstractissime forme veraciter intellectuales sunt et penitus insensibiles, eorumque regio primus, naturalis et verus intellectualis mundus nuncupatur.

đ Porro sub celo omnis Substantia cum sensibilis sit, providit aliter sensibili mundo intellectualem regionem Deus in humana mente. In hac siquidem abditus est rerum omnis rationalis fulgor et spiritalis emanatio; in eam, ut in verissimas sensibilis mundi conflages, undecunque mundani procedunt spirantque ventuli; in ea denique ex mundana evaporatione atque suffitu concrescit gigniturque rationalis et lucidissima Sapientis caligo: cuius aspergine, rore et imbre respersa humana mens haud iam mundo inferior cunctarum rerum intellectuali ubertate viret seque hoc pacto (nullis non impregnata speciebus) in alteram intellectualem regionem distendit. Si igitur gemini sunt intellectuales mundi, utique trini erunt mundi: intellectuales duo et sensibilis unus. Nam quicquid est super celum, verus est et primus intellectualis mundus; quicquid autem sub celo (preter Hominem), mundus est sensibilis. Homo vero alter est et secundus intellectualis mundus: rationalis, derivaticius, fecundus. Et nonmodo intellectualis est mundus Homo, sed et quidam sensibilis mundus.

Homo animo et $₫$ Est enim, ut in libro de Intellectu dictum est ${ }^{1}$ ), Homo et animo et corcorpore est universa Nature opus ex materia supremum cunctorumque longe speciosissimum. Est igitur Homo mundus uterque: intelligibilis animo, sensibilis corpore; idem est mundi utriusque scirpus, vinculum, coherentia et connexio.

đ Unde fit, ut humani commercii et contubernii vice in sensibilium regionem intelligibilia traducantur et in intelligibilem mundum sensibilia transportentur emigrentque. Nam nichil sub celis est intelligibilium preter Hominis animum; nullus alius est sublunaris intelligibilium locus. Nil etiam sensibilium supra celum fieri, nil ex materia celos penetrare, nil sublunare in supercelestibus thalamis recipi natum est preter Hominis corpus, quod materiale quidem et sensibile est, ex terra et materia conflatum.

1) de Intellectu: cap. IX 7; 5-6. [VI]. 
q Itaque quandiu Homo sub celis degit, quandiu adeo peregrinus sen- Quando intelligibisibilem incolit mundum: per Hominis mentem intelligibilis mundus in lia in sensibilibus mundo est sensibili; est enim Hominis animus intelligibilis quidam et rationalis mundus, intelligibilium omnium notionum thalamus. Ubi vero post emigrationem e terrenis latomiis tam corpore quam animo, ut in Quando sensibilia futura resurrectione, Angelorum lucidissimis choris annumerabitur Homo, in intelligibilibus ubi Dei sinechus ${ }^{1}$ ) angelico pane convescetur: erunt e diverso per Hominis corpus sensibilia in intelligibilem regionem et sensibilis mundus in intelligibilem traductus; est enim, ut diximus, humanum corpus sensibilis quidam mundus, sensibilium omnium symplegma, concurrentia et finis, totius materie sublimis gloria veraque perfectio. Nam totius materiei pars nulla preter humanam materiam et eam, qua humanum corpus coaluit, in celum nata est attolli.

ণ Igitur sicut e cunctis spiritalibus et incorporeis creaturis tantum una, ut humana Anima, sub celum peregrinatum mittitur in terras: ita et e cunctis corporibus tantum unum, ut humanum corpus, e terris in celum desumetur. Et mirabili profecto concinentia per Hominis medium uterque mundus in utrumque transfertur. In presenti enim seculo per Hominis animum intelligibilis mundus sub celis fit: in futuro vero per Hominis corpusculum contra sensibilis intellectualem regionem subibit, materialis immaterialem, corporeus spiritalem.

\begin{tabular}{|c|c|c|c|}
\hline \multicolumn{4}{|c|}{ Quattuor sunt mundi: duo intellectuales, duo sensibiles. } \\
\hline Intellectualis maior & Intellectualis minor & Sensibilis maior & Sensibilis minor \\
\hline Etherea regio & Hominis animus & $\begin{array}{l}\text { Sublunaris } \\
\text { mundus }\end{array}$ & Hominis corpus \\
\hline
\end{tabular}

Sequuntur propositiones comparationum utriusque mundi adinvicem.

Quattuor sunt mundi: duo sensibiles, duo intelligibiles.

Duo item maiores mundi sunt et duo minores.

Ex maioribus alter est intellectualis, alter vero sensibilis.

Ex minoribus itidem alius est intellectualis, alius vero sensibilis.

Ex maioribus item alter est supercelestis, alter sublunaris.

Ex minoribus vero alter spiritalis, alter corporeus |

Intellectualis maior est supercelestis et etherea regio.

Sensibilis maior est sublunaris sensibilisve mundus.

Intellectualis minor est humana Anima, rationum omnium locus.

Sensibilis minor est humanum corpus, cui omnis sensibilis substantia famulatur.

Universum ex utroque maiore mundo conflatur.

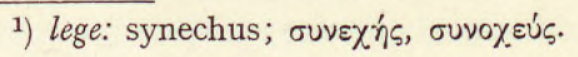


Homo quoque totus ex utroque minore mundo coalescit.

Homo totus equalis est toti Universo constans ex partibus iisdem.

Hominis quoque partes Universi partibus reperiuntur equales.

Hominis animus equalis est etheree supercelestique regioni.

Hominis quoque corpus sublunari mundo probatur equale.

Totum Universum totius est Hominis obiectum, dinosci ab Homine natum.

Universi quoque partes Hominis partium obiecta esse declarantur. Hominis animus capax est etheree regionis et eorum, que in ea versantur.

Hominis item corpus ex omni, que sub celo est, substantia refovetur. Nunc per Hominis animum intelligibilia in sensibili mundo sunt.

Tandem per Hominis corpus sensibilia in intellectualem mundum emigrabunt.

Nullus sub celis est immortalis actus preter Hominis animum.

Nichil ex materia et terra conflatum preter Hominis corpus in celos penetrabit.

Ex omni spirituum genere tantum unus, ut humanus, sub celis degit. Ex omni item corporum genere tantum unum, ut humanum, ibit in celum.

Spirituum immortalium ultimus nunc peregrinatur sub celis.

Corporum omnium supremum in etheream attolli regionem est natum. Naturalis animi regio est intellectualis mundus maior.

Naturalis corporis regio est sensibilis mundus maior.

$\mathrm{E}$ propriis thalamis nunc in corporis regionem peregrinatur animus. E propria quoque regione sua corpus in animi patriam assumetur. Impossible est sine corpore animum sensibili mundo inesse. Impossibile est sine Anima corpus in celum evehi et attolli. Nunc in regione corporis habitat Anima corpori sociata. Tandem in animi regione habitabit corpus animo coniunctum. Nunc per sensibilem mundum corpus Animam defert.

Tandem per mundi intellectualis aulam Anima corpus vectitabit.

Anima nunc in corpore et in sensibili mundo temporalem habet mansionem.

Futurum est, ut corpus cum Anima in intellectuali mundo eternam mansionem recipiat.

Presentes corporis sudores temporanei sunt.

Futura autem eius in regione animi merces immortalis.

Ex presenti animi et corporis temporali federe elicietur eorum indissociabile fedus. 
Si Homo, precipue Sapiens, est Anima mundi: tam utique necessarius est Homo mundo quam corpori Anima. Et eo pacto Universi pars erit Homo, quo et totius Hominis pars est Anima. đ Et si Homo, ut Sapiens, suiipsius capax seque ipsum nosse predicatur: dicendum et Universum sui capax, semetipsum nosse seque posse intueri.

đ Nam nosse seipsum dictitatur Homo, quod in seipsum redeat quodve pars eius altera alteri objiciatur atque presentetur. Et harum partium que alterius arbitra et spectativa est, ut Anima: in seipsam quoque revecta atque reciproca, suiipsius intuitiva et speculativa evadit; reliqua vero ut corpus: neque suipsius neque alterius fert ullum iudicium, sed est omnis Rationis, scientie et intellectionis exors.

đ Homo itaque nosse semetipsum dicitur, haud quia totus totum: sed quoniam pars eius, ut Anima, et seipsam et reliquam partem comprehendit, novit, speculatur. Sed et in hac sui gnaritudine indipiscenda fluxus contingit atque successio, quandoquidem Anima non simul corporis suique notitiam apprehendit, sed prior illi adest corporis, deinde sui cognitio. Ubi vero Anima et sui corporis et suiipsius notitiam est adepta, tum primum consummata censetur; tum etiam primum sapiens Homo totus a seipso cognitus, sibiipsi dilucidus ac pervius pronunciatur. đ | Ita igitur et Universum dicatur sibiipsi dilucidum, a semet cognitum, p. I29r [1 $3^{\left.\mathrm{r}^{\mathrm{r}}\right]}$ consummatum, sapiens atque perfectum, haud quia toti totius: sed quia parti Universi insit totius ipsius ratio, conceptio, scientia. Pars item parti opposita et obiectata a parte prehendatur, spectetur, dinoscatur: ut corpus mundi ab Anima mundi. Est enim Homo mundi Anima; mundus vero et quicquid sub celo visitur, Hominis est ut corpus. Et ex Homine et mundo fit id, quod dicimus Universum, persimile et proportionabile toti Homini. Et huius Universi Anima est totus Homo, corpus vero mundus. Et pars eius una partem alteram deprehendit, ut Homo mundum; pars insuper eadem, que alteram dinoscit, seipsam quoque spectat et suiipsius arbitra et censoria fit. Reliqua vero neque potiorem neque seipsam conspicari et intueri potest; nam neque seipsum neque Hominem mundus ullo pacto apprehendit. Homo autem et mundi et suiipsius arbiter, iudex et speculator efficitur. đ Eadem igitur ratione et causa, qua seipsum sapiens Homo nosse dicitur, dicendum est et Universum nosse seipsum; haud quia a toto totum, sed quia in utroque a parte pars et exinde totum deprehensum et cognitum est: corpus inquam ab Anima, Anima ab Anima, totum denique ab Anima.

† Et sicut Anima non est Homo neque corpus Homo, sed hec duo, Anima et corpus Anima et corpus, sunt ipse Homo: ita et Homo Universum non est neque 
Homo et mundus mundus Universum, sed hec duo, Homo et mundus, ut ex Anima et corsunt Universum pore Universum conflant. Et ut Hominis Anima corpus prius quam seipsam intuetur et ex corporis agnitione claudit infertque sui noticiam: ita et Universi Anima, Homo, mira proportione corpori Universi, idest sublunari mundo, prior quam sibiipsi adesse comperitur et ex mundi scientia in semet ingredi, sibi adesse seque contueri. Et ut ad Hominis subsistentiam $^{\text {a) }}$ necessaria probatur Anima: ita et ad Universi complementum et subsistentiam perquam necessarius et expetendus est Homo et precipue sapiens Homo, qui ${ }^{\mathrm{b}}$ ) est verissima mundi Anima.

\section{đ Peregrinatio humane Anime.}

Cap. XXII.

Specierum ab uno- Sapientis Anima imprimis per extimorum sensuum valvas spiritaliter quoquec) abstractio

extra corpus profecta in mundum peregrinatum abiit et a cunctis rebus, quas in mundo reperit, abstracta sublatave speciei atomo in corpus rediit finxitque ex collectis specierum atomis virtutis Hominem: veram primi sui, naturalis ac tellurei Hominis imaginem, formam, archetypum, lucem, scientiam et apparitionem; cuius habitus Sapientia est et Hominis in omnia sive omnium in Hominem per species transsumptio, traductio et commutatio.

đ Unde manifestum est Sapientiam esse quandam humanitatem et primi nostri, indefecati naturalisve Hominis imaginem veramque speciem seu artis Hominem ex primo, naturali Homine et ipso mundo felici congressu progenitum. Est enim hic secundus Homo velut proprium humane Contemplationis obiectum, velut item mundi exodium exitusve ac palinodia, qua a mundana peregrinatione sapiens Homo recinit canitque receptui. Est et hic Homo quedam progenita primi Hominis Minerva, primi intra se receptio, revocatio, mansio ac sedes. Sapientia Hominis $q$ Manifestum item est Sapientiam esse quendam Hominis numerum,
numerus discrimen, fecunditatem, emanationem eamque consistere in Hominis dyade genita ex priore monade. Primus enim, nativus noster et sensibilis Homo ipsiusque Nature mutuum, monas est et totius humane fecunditatis fons atque initium. Artis vero Homo humanave species Arte progenita dyas est et primi quedam Hominis emanatio, Sapientia, fructus et finis. Cuius habitu, qui a natura Homo tantum erat, Artis fenore et uberrimo proventu reduplicatus Homo vocatur et Homo-Homo.

$₫$ Et non modo ad dyadem, sed et adusque tryadem humane Sapientie vis Hominis numerum extendit humanitatemque propagat. Sine quippe

a) substentiam ed.

b) que $e d$.

c) abunoquo ed. 
medio extrema sunt nulla: sine propinquitate nulla distantia, sine concordia dissociatio nulla et sine concurrentia nulla disparata. Sunt autem monas et dyas, Natura item et Ars quedam extrema; similiter et nature Homo et artis Homo seu substantialis Homo et vera eius imago Virtute progenita, Nature mutuum sive naturale donum et Hominis acquisitum.

đ Horum igitur extremorum symplegma est aliquod, concordia et con- Sapientia in trinicurrentia aliqua; aliquis amor, pax, vinculum et medium aliquod, amtate consistit borum proventus, unio, fructus, emanatio. Iuncta etenim invicem monas et dyas tryadem eliciunt proferuntque suam copulam, unionem et concordiam. Itaque Sapientia quedam est trina Hominis sumptio, Hominis trinitas, humanitas, tryas. Est enim trinitas totius perfectionis $\mid$ emula, p. $129^{\mathrm{v}}\left[\mathrm{I}^{\mathrm{I}} \mathrm{v}\right]$ cum sine trinitate nulla reperiatur perfectio.

\section{đ Omnem cognitionem aliquo pacto esse trinitatem.}

\section{Cap. XXIII.}

Quicunque preclaram cognitionis vim attentiuscule librabit, comperiet profecto haud sine numero, discretione et trinitate cognitionem fieri posse. In omni quippe cognitione aliud est spectativum, aliud presentativum sive obiectum et aliud utriusque medium, quo fit et exercetur ipsa cognitio. Aliud est, quod spectat, aliud, quod spectatur, et alius utriusque actus, amborum emanatio; ut alius est in Anima Intellectus, alia Memoria, alia Contemplatio, amborum (Intellectus et $\mathrm{Me}$ morie) functio.

đ Intellectus primus et spectativus est omnium. Memoria vero specta- Intellectus, Memobilis et omnium Intellectui presentativa. Contemplatio autem est ipsa ria, Contemplatio inspectio et presentatio, per quam Intellectus et Memoria in actu sunt. q Diffinitur enim Contemplatio utriusque actu: speculatione scilicet et presentatione, quorum hic Memorie, ille vero Intellectus est actus. Et Intellectus est ut monas et Homo nature, Memoria ut dyas et virtutis Homo, Contemplatio vero ut tryas et amborum Hominum vinculum. Est enim, ut in libro de Intellectu docuimus, Intellectus Memorie unitas ${ }^{1}$ ) et eius actus prior actu Memorie $^{2}$ ); Memoria vero Intellectus dualitas, numerus et resumptio et eius actus illius actu posterior $^{1}$ ); Contemplatio vero trinitas est et utriusque perfectio. ${ }^{3}$ )

đ Nempe intellectualis species primitus est in Intellectu, secundo in Intellectualis speMemoria, tertio in Contemplatione. Et prima ac simplicissima intelligi- ciei trine in animo bilis speciei sumptio dicitur eius acquisitio et Intellectio; secunda vero
1) de Intellectu: cap. XIII I.
$\left.{ }^{2}\right)$ de Intellectu: cap. VII 3.
3) de Intellectu: cap. VII 7; Io. 
eius sumptio ipsius est conservatio et Memoria; tertia autem eius sumptio Contemplatio et speculatio vocatur. Primus quoque speciei status est in Intellectu, secunda eius sedes in Memoria, tertia vero eius positio in Contemplatione. Et Intellectus primus est et per se: qui gignit, implet fecundatque Memoriam. Ab ambobus vero equa lance Contemplatio et speculatio profertur, derivatur, procedit. ${ }^{1}$ ) Et hec tria unum sunt in Anima: una atque impers Anime substantia, unica eadem et consubstantialis trinitas animi.

Homo ter trinus $₫$ Unde fit, ut, cum tres sint Hominis cognitiones - Ratio, Imaginatio, Sensus -, Homo ter trinus evadat: trinus inquam in Anima, trinus in corpore, trinus in mundo. In Anima trinus est per Rationem et Contemplationem, que fit ab Anima in Anima mediante rationali et intellectuali specie. In corpore sive in toto seipso per Imaginationem, que ab Anima in corpore exercetur presentatione et inspectione spectrorum. In mundo denique per Sensum, qui ab Anima in mundo sub sensibilis speciei medio exercetur.

Omnis cognitio tri- $₫$ Omnis quippe cognitio ut perfectionis emula, ut entis in se conversio nitas quedam est et glomeratio trinitatis numerum sibi asciscit ac vendicat clauditurque geminis extremis et eorum medio: potentia, obiecto et amborum actu.

\begin{tabular}{|l|l|l|l|}
\hline Homo ter trinus & In Ratione & In Imaginatione & In Sensu \\
\cline { 1 - 2 } Homo ter trinus & In Anima & In corpore & In mundo \\
\hline Trinitas Anime & Intellectus & Conceptus & Memoria \\
\hline Trinitas corporis & Imaginatrix & Spectrum & Corpus \\
\hline Trinitas mundi & Sensus & Sensibilis species & Mundus \\
\hline & Principium & Medium & Finis \\
\hline & Spectans & Obiectum & Presentans \\
\hline
\end{tabular}

đ Hominis nichil esse proprium et peculiare preter omnium communitatem.

Cap. XXIV.

Hominis nichil est peculiare aut proprium, sed eius omnia sunt communia, quecunque aliorum propria. Quicquid huius et huius, illius et alterius et Homo universam ita singulorum est proprium: unius est Hominis. $₫$ Omnium enim in se Naturam imitatur naturam transfert, cuncta speculatur, universam Naturam imitatur. Sorbens enim hauriensque, quicquid est in rerum natura: omnia fit. ${ }^{2}$ ) Nam neque peculiare ens Homo est hoc vel hoc neque ipsius est hec aut

1) de Intellectu: cap. VII 7 .

$\left.{ }^{2}\right)$ cf. cap. XVIII. 
hec natura, sed simul omnia est: omnium concurrentia, rationale chasma et congregatio. Et si Hominis finire et complecti volue|ris naturam, sus- p. $13^{\mathrm{r}}\left[\mathrm{r} 32^{\mathrm{r}}\right]$ pice, quicquid in celo est, quicquid in elementis et universo mundo. $\mathrm{Hec}$ enim omnia a cunctis maioris Hominis ratione nomineque finiuntur.

đ Duos igitur Homines Natura procreavit et genuit: maiorem unum, quem Maior et minor vocamus mundum, minorem alterum, qui specialiore nomine Homo nuncupatur. Maior ille actu omnia est, minor vero potestate universa. Huius ergo sedulitate, actu, operatione et motu ex potentia elicitur actus, micat lux e tenebris; et ex confusione numerus, ordo, discretio infertur, quoad minor totum maiorem conceperit, quoad discussa omni native ignorantie caligine nichil non norit minor, nichil non mente teneat, nichil non sit. Hoc enim pacto minor perficitur: dum, quod in eo fuerat turpe, componitur, quod rude, informe et sine specie, «speciei», ut divus Dionysius ait ${ }^{1}$ ), «susceptione evadit illustre.»

đ Intellige rursum Naturam duos Homines peperisse: alterum conflatum Alius de utroque in centro, in mundi medio et in actu subsistentem - hic enim noster est Homo -, alterum vero conflandum, imperfectum, subsistentem in potentia, in circunferentia, in mundo, in materia et in multitudine atomorum, quarum singule singulis insint substantiis. In omni quippe mundana substantia aliquid delitescit humanum; aliqua cuivis substantie indita est Hominis atomus Homini propria: qua componendus est et conflandus studiosus Homo, quam sibi vendicare et ingenii vi abstrahere a materia natus est Homo, qui omnium celebratur esse potentia et cuius aliquid est in quolibet et in quo rursum cuiuslibet aliquid recipi natum est.

đ Qui igitur conflatus est et perfectus a Natura Homo (Homo inquam noster, situs in mundi medio), matris imperio per mundum circunferri iussus: exquirit a singulis, que sua sunt, abstrahit a qualibet mundi substantia proprie speciei atomum. Illam sibi vendicat atque inserit et ex plurium specierum atomis suam elicit profertque speciem, que naturalis et primi nostri Hominis fructus seu acquisitus studiosusve Homo nuncupatur. Hec itaque Hominis est consummatio: cum ad hunc modum ex substantiali scilicet Homine rationalem, ex naturali acquisitum et ex simplici compositum, perfectum, studiosum sufficiat elicere. ${ }^{a}$ )

a) sufficiat elicere deest in ed.

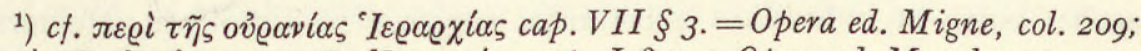

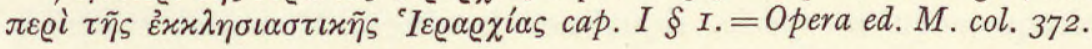


đ Comparatio originis humane substantie ad humanam eruditionem.

Cap. XXV.

Spiritalis trinitas Huic autem spiritali humane trinitati, que in Hominis eruditione, conin
matione studioso et amborum vinculo), proxima et proportionabilis est alia quedam trinitas, que in humane totius substantie ortu sive in prima humani generis a Deo creatione et ad Esse productione successit.

Alia trinitas in Hominis creatione

ণ Nam sicut humanus animus haud simul aut non unico actu eruditur, sed in tempore et actibus trinis - primo Intelligentie, quo profertur et oritur in animo intelligibilis species; secundo Memorie, quo species eadem sistitur, conservatur et collocatur in Memoria; tertio Contemplationis, quo species eadem ab Intellectu spectatur et presentatur a Memoria $\left.{ }^{1}\right)$-: ita et humanum genus humanave substantia haud repentinam habuit originem neque actu unico in Esse nature prodiit, sed in tempore et actibus trinis. $q$ Protulit enim divina Mens imprimis humani generis actum, hoc est virum; deinde ex actu potentiam, id est mulierem, eduxit; tertio ex ambobus extremis, actu et potentia, viro et muliere, eorum medium, statum, consummationem et finem - amborum inquam filium - proferri gignique voluit: per quem humana species integrum, totum, perfectum trinumque Esse naturaliter est adepta.

Adam, Eva, Abel, $₫$ Primus enim vir Adam creatus a Deo est; deinde ex viro genita quibus respondeant et prolata mulier, viri humanique generis potentia; tertius ex viro et muliere prodiit amborum filius. Adam igitur ut Intellectus quidam est, Eva ut Memoria, Abel ut Contemplatio et utriusque actus. Adam rursum ut naturalis noster Homo, Eva ut acquisitus et studiosus Homo naturalisve Hominis species et imago, Abel vero ut Nature et Virtutis copula, ut utriusque, naturalis et studiosi, Hominis connexio. $₫$ Adam homo est per se ex nullo progenitus homine, Eva homo ex homine, Abel homo ex hominibus. Adam rursum monas, Eva dyas, Abel trias. Adam Homo tantum, Eva Homo-Homo, Abel Homo-Homo-Homo. q $\mathrm{Ab}$ Adam in Evam: motus est unius in unum. Ab Adam vero et Eva simul in Abel: duorum in unum motus et in eodem uno status. Adam denique, Eva, Abel et equales inter se sunt et specie unus Homo sive unius speciei et consimilis substantie Homo, qui aliquopacto et unus et trinus est; sicuti et prius humanus animus unus ac trinus esse dictus est $^{2}$ ): unus et individuus substantia, trinus vero Intellectu, Memoria et utriusque acquisita specie. Equalis est Intellectui Memoria; et utrius-

\footnotetext{
1) cf. cap. XXIII.
}

2) cap. XXIII. 
que species - qua fit Contemplatio, que $a b$ hac presentatur, ab illo conspicitur - utrique spiritaliter equalis et consimilis est.

\begin{tabular}{|l|l|l|l|}
\hline Trinitas animi & Intellectus & Memoria & Species \\
\hline Trinitas Hominis & Adam & Eva & Abel \\
\hline Functiones animi & Acquisitio & Conservatio & Contemplatio \\
\hline Processus Hominis & Homo per se & Homo ex Homine & Homo ex Hominibus \\
\hline Numerus Hominis & Homo & Homo-Homo & Homo-Homo-Homo \\
\hline
\end{tabular}

\section{đ Quod Homo Universi speculum.}

Cap. XXVI.

Homo nichil est omnium et a Natura extra omnia factus et creatus est: ut multividus fiat sitque omnium expressio et naturale speculum, abiunctum et separatum ab universorum ordine, eminus et e regione omnium collocatum, ut omnium centrum. Speculi etenim natura est, ut adversum Natura speculi et oppositum sit ei, cuius in sese ferre debet imaginem. $₫$ Finge autem omnia sita esse in mundi circunferentia, velut in firmamento, in quo Homo extra omnia lucidissime rerum omnium exprimuntur visunturque species. Hoc argumento in medio mundi extra omnia factum esse Hominem elicies, ut undecunque in se manantibus mundanarum specierum spiculis atque splendoribus uberius feriatur omnique specie affectus evadat omniformis.

đ Nam si alicui inesset rei Homo, eiusce rei et substantie, cui inditus esset, gnaritatem et scientiam adipisceretur nullam; quandoquidem omnis et cognitio et inspectio seu rerum obiectio specierumque manatio fit seOmnis cognitio in distantia dyametri cundum dyametrum, qua visum, spectatum et obiectum ab se speculante et spectante potentia dirimitur. Est igitur et Homo factus extra omnia, et omnia rursum extra Hominem facta, Homini ex adverso dyametri presentata. Nam si omnia in mundi circunferentia (ut in firmamento) locaveris, in medio et centro locandus est abs te Homo; unde tota mundi circunferentia eidem liquido pelluceat atque reveletur.

đ Si vero omnia in trianguli basi statueris: Hominem in trianguli vertice te locare oportet, quo tota basis per amborum laterum angustias defluit, quove tota triangularis superficies irremigat, et unde tota simul basis est conspicua et facile spectanda. Et in quocunque loco cuncta mundi statueris entia: in eius opposito abs te collocandus et recipiendus est Homo, ut sit universorum speculum.

đ Ea siquidem Hominis est, que et speculi natura. Speculi autem natura est, ut extra omnia locatum sit, cunctis adversum et oppositum, et ut nichil in eo receptum, nulla sit naturali affectum imagine. $₫$ Quod si factus

Eadem Hominis que et speculi natura 
speculum in visibilium rerum parte, ordine et linea constituis: specularem extemplo tollis commoditatem, ut aut nullarum ${ }^{2}$ ) aut non saltim omnium imprimi afficique possit speculum imaginibus. Posito quippe in trianguli basi speculo nulla eorum, que ad basim sunt, ad speculum fiet

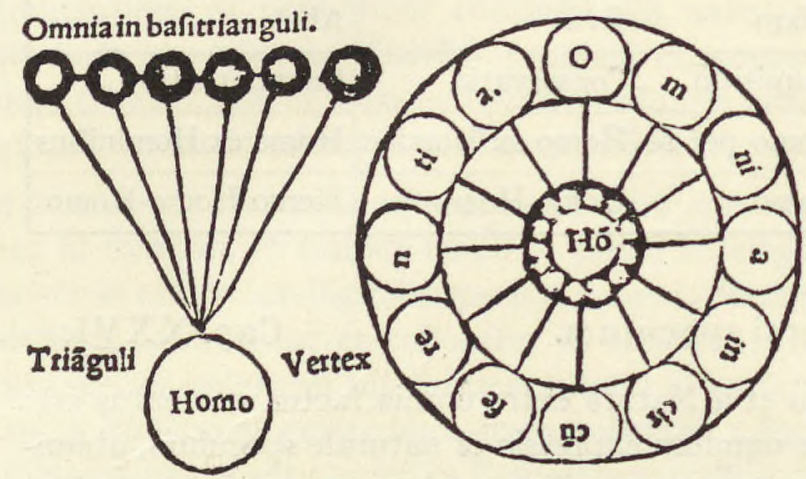
linearum directio, nullum in speculum impluvium specierum fiet. Identidem et si speculum in circunferentia locaveris: indirecte et inequales linee ad ipsum ab universis, que sunt in circunferentia, protenduntur.

Verus speculi et
Hominis locus

t $q$ Verus igitur et speculi et Hominis locus est in oppositione, extremitate, distantia et negatione universorum, ubi inquam omnia non sunt, ubi nichil actu est, extra omnia: in quo tamen fieri omnia nata sunt. đ Sunt enim omnia in circunferentia mundi, et fieri possunt in mundi medio. Ubi omnia sunt, non fiunt. Ubi vero fieri possunt et fiunt, non sunt. Sunt in loco quopiam uno: fieri vero nata sunt fiuntque in eius opposito.

Homo et terra spe- $q$ Unde fit, ut et terra et Homo sint speculum quiddam firmamenti ab cula firmamenti p. $13^{\mathrm{Ir}}\left[133^{\mathrm{r}}\right]$

rude, impolitum, insincerum, | illucidum, imperfectum, inane omni carens imagine. Defluxu vero atomorum et naturalium specierum e stellis firmamenti utraque specula impregnantur atque fecundantur; et utrumque speculum potentia quedam est firmamenti et eorum actuum, qui sublimes in firmamento micare conspiciuntur, naturalis umbra.

Terra umbra stel- $₫$ Discrevit enim Deus ab initio rerum omnium sensibiles actus eosque larum firmamenti in firmamento locavit, quorum cum umbre, radii, acumina, coni, vertices et atomi perpendiculari radio in terram ferantur: terra eorum actuum concurrentia, confusio, umbra et potentia nuncupatur, cuius numerus est et quidam omnium numerus. Nam et firmamentum numerus est et actus omnium; terra vero et ipsa quoque omnium numerus est, sed potentia. Quicquid firmamento inest, fieri in terra potest: sicut et quicquid est in mundo, fieri potest in Homine. Etenim precipua Hominis species, cuius habitum Sapientiam esse docuimus ${ }^{1}$ ): haud huius vel huius est species, sed aliquo pacto species omnium.

a) nullorum $e d$.

1) cap. $X X I I$. 
q Et si eadem est species, que et omnium dicitur species et naturalis no- Hominis numerus

stri Hominis species: necesse est, ut et nativus noster Homo quoquopacto sit ut omnium potentia; utpote cuius actus est omnium actus, cuius omnium est numespecies omnium species, cuius imago omnium imago et cuius denique numerusomnium numerus. Idem est stellarum firmamenti, idem atomorum terre, idem Hominis humaneve speciei et Sapientie numerus: cuius agnitio et deprehensio est et sui et universorum gnaritudo atque scientia. Sicut enim est eadem Hominis et universorum species - nam que Hominis est, omnium est, et que est omnium, est Hominis - : ita et eadem utrorumque scientia, unica ratio, par gnaritudo.

q Est igitur Homo ultima, suprema et precipua sensibilis mundi creatura, sita et collocata extra omnia tanquam omnium potentia et concurrentia; luminum insuper et actuum mundi naturalis umbra et ut quiddam mundi medium. đ Nam consummatis et perfectis omnibus, postquam actus Homo omnium singuli sua loca sortiti sunt: vidit Deus deesse omnium speculatorem et universorum oculum, quem etherei superne micantes igniculi, quem sublimes facule et firmamenti luminaria, quem valvarum intelligibilis supercelestisque mundi pleni infiniti luminis siderea antepagmenta ac tenuissime umbelle irradiarent, cui suffulgerent assidue ut totius mundi filio, ut naturali sue imagini, ut omnium paci et concordie, viditque nullum supremo huic oculo inter cetera superesse locum. Plena quippe actuum erant omnia, quodlibet suo gradu, loco et ordine constiterat; et ex actibus diversis disparatisque speciebus aut rerum differentiis et mundi luminaribus, que per se intermisceri, confundi, concurrere et fas et possibile non est, fieri Homo haudquaquam poterat.

đ Extra igitur cunctorum differentias et proprietates in opposito om- Homo publica nium loco, in conflage mundi, in omnium medio coaluit Homo: tanquam oculus publica creatura, que quod relictum erat in Natura vacuum, potentiis, umbris, speciebus, imaginibus et rationibus supplevit.

đ Cur Phenicum sapientes Hominem in serpentis specie exprimere soliti.

Cap. XXVII.

Et haud immerito Phenicum, ut historie tradunt, sapientes pro suorum templorum antepagmentis Hominem in serpentis ac ydre specie mordicus caudam pertrahentis suam pingi et exprimi voluere.

ฯ Est enim verissima Sapientia suiipsius inspectio atque agnitio, qua in substantia eadem, indivisa, indissecta, una et continua permanente pars partem apprehendit, pars a parte sublabratur, pertrahitur et ad interiora revocatur. đ Nam cum gemina sit omnis cognitio, materialis et imper- Immaterialis cogfecta una, alia vero immaterialis atque perfecta: hec unica in orbe per- nitio in identitate ficitur, in eadem natura, in eadem substantia, indivisa, indiscontinua, substantie perfici- 
attamen numerosa, discreta et fecunda. Fit enim, cum immaterialis substantia flexa et conversa in semet vi speculationis proprie in extrema duo et in amborum medium dispescitur atque propagatur. Materialis autem

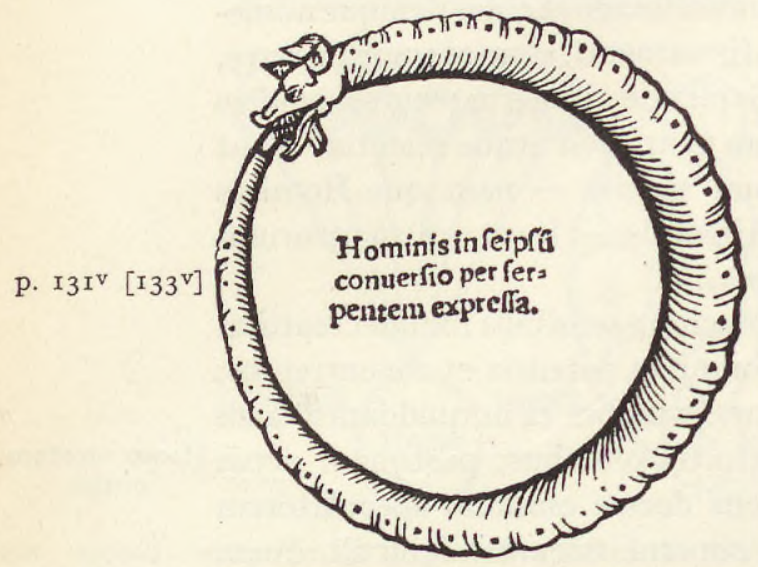
cognitio fit secundum rectum ab uno in aliud, ab eodem in diversum atque dissimile, in diversis item naturis, in abiunctis substantiis; in hac siquidem cognitione aliud est, quod spectat, aliud, quod spectatur et internoscitur. | $₫$ Ut in Imaginatione alia est Anima, aliud corpus, in Sensu quoque alia est Anima, alius mundus. Immaterialis nempe est Anima, corpus vero et mundus ambo ex materia et Anime organa; alia item est Anime et alia corporis mundique substantia. Et in neutra materialium huiusmodi cognitionum Hominis scientiam et Sapientiam locavimus.

Sapientia in cog- $q$ Superest igitur, ut in sola Ratione sit sita Hominis Sapientia sive in nitione Anime ab Anima

immateriali cognitione et in eiusdem a seipso animadversione, ut in notione Anime ab Anima: qua sine sui divisione in se tota Anima flectitur, sibi proponitur, presentatur atque objicitur. Tota enim Anima in

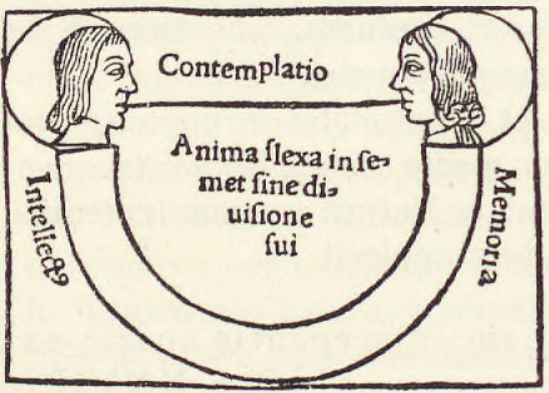
unitate discernitur atque numeratur seque aliquopacto in tria (in extrema inquam duo et medium unicum) distinguit, numerat, multiplicat. In orbem demum semetipsam comprehendens ad instar serpentis in seipsam volvitur, in sua penetralia redit. Pars eius una partem aliam morsicat sublabratque. Ingreditur Anima in semet, se totam absolvit atque pertransit; in seipsa denique sistitur, conditur in se fitque sibi vasculum ac perpes domicilium.

đQuod cognitio haud est entis sese noscitantis divisio. Cap. XXVIII.

Unde fit, ut qui rite cognitionis vim naturamque perpenderint, haud, ut plerique fecere, in teterrimam nefandi erroris Carybdim precipites labentur ob sui cognitionem eorum, que se norunt, substantiam dividentes 
dicentesque plures esse substantias amborum quorumcunque extremorum et eorum medii.

đ Nam si omnis cognitio esset entis divisio et substantie ipsius multiplicatio, utique omnis cognitio esset alterius cognitio. Nil igitur sibiipsi erit agnitum, nil intueri sese seque conspicari et seipso perfrui valebit. Nulla denique erit Sapientia, quandoquidem omnis Sapientia est suimetipsius speculatio, agnitio, scientia. Omnis itaque cognitio erit alterius cognitio; divisa insuper erunt, dissita et separata abinvicem cuiusvis cognitionis extrema; diductum erit et ab extremis id, quod eorum medium appellatur. Atqui, ut diximus ${ }^{1}$ ), cognitio eiusdem a seipso haud est ipsius entis substantialis diductio: sed personalis eius discretio in extrema et medium. Est item eius in seipsum flexura, conversio, orbicularis motus et sine sue substantie divisione in substantie identitate, unitate, continuitate, in personalium suppositorum similitudine, equalitate atque trinitate fecunda propagatio.

đ Fit iterum, ut trina sit Sapientia, quemadmodum est et trina suiipsius Trina Sapientia gnaritudo atque scientia. Nam tria sunt immaterialia entia, que in semet flectuntur, in se convertuntur, que suiipsorum capacia et a seipsis agnita sunt: rationalis Anima, Angelus, Deus. đ Orbis rationalis Anime, id est eius in se gyratio, qua sese intuetur, humana scientia vocitatur; angelicus orbis angelica Sapientia; divinus orbis, quo per Deum Deus in Deum fertur, divina Sapientia, Dei a seipso agnitio divinaque Contemplatio nuncupatur; et huius extrema sunt divinus Intellectus, divina $\mathrm{Me}$ moria ac divina amborum species.

đ Divinus Intellectus monas est prima et per se, primum divinitatis ger- Divus Aveopagita men et, ut divus Areopagita sentit ${ }^{2}$ ), «fontana deitas totiusque divine fecunditatis initium.» Divina vero Memoria dyas est et monadis equalitas eiusque resumptio a monade prolata. Utriusque autem species tryas dicitur: monadis et dyadis status, copula, connexio, manans ab utrisque, finis utriusque, utriusque medium.

q $\mathrm{Hec}$ tria in Deo unus Deus sunt: una atque indivisa divina substantia carens omni inequalitate, alietate, dissimilitudine et permixtione materie aut contrarietatis, sine confusione coniuncta, sine divisione discreta ac trina, in trinitate una, in unitate trina. Inseparabilis est eius Intellectus $\mathrm{ab}$ eius Memoria et ambo ab sua specie inseparabiles. Quantus est divinus Intellectus, tanta est et divina Memoria. Et quanti ambo: tantum amborum sacrum spiramen, spiritus, species et sacra emanatio. Totus

\footnotetext{
1) cap. XXVII.

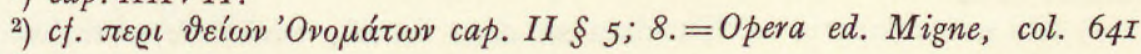
et 645 .
} 
divinus Intellectus in tota divina est Memoria, et hec rursum in illo tota. Ambo quoque in suaipsorum specie sunt toti, ipsaque sacra amborum species degit tota in utrisque.

$₫$ Quod in divine et sacratissime trinitatis agnitione soli merito Christicole gloriari possunt. Cap. XXIX.

p. ${ }^{1} 3^{2^{r}}\left[{ }^{r} 33^{r}\right]$ In huius autem summe ac supersubstantialis omnium cause, beatissime trinitatis cognitione et sacratissima fide merito pre ceteris gloriari possunt Christicole, quod archana illa, suprema et eminentissima veritas, que a condito mundo omnem latuit heresim sive gentilium sive Hebreorum, quam nulli mundi sapientes, philosophi et magi per mundanam sapientiam naturali intelligentie lumine rimari potuerunt, que nullis vel paucissimis prophetarum sub nubis et caliginis tempus innotuit, sibi solis adaperta ac dilucidata sit. ${ }^{a}$ ) Solus inclytus Christianorum dux, novo et insolito sydere e virginis utero ortus in mundum, tante scientie (hoc est divine trinitatis) lumen e sydereis sedibus in orbem terrarum advexit, solus divine substantie numerum et fecunditatem palam edocuit atque publicavit. Primus discretionis divine sermones intulit, qui ipse sub mortali ac tellureo humanitatis amictu unum aliquod erat trium totius divinitatis germinum. Erat enim divinitatis dyas, que ab eterno sese a paterna monade divinitus et postea in terris humanitus ortam, ante tempora et in tempore genitam testata, effata et proloquuta in terris est.

đ Sua item omnia esse paterne monadis et omnia paterne monadis suaipsius esse perdocuit. Speciem quoque ac spiramen utriusque, quicquid habet: hoc et suum et paterne monadis esse promulgavit.

Autoritas $₫$ Itaque ut divinum ipsi numerum, divinam propaginem atque trinitatem fateamur, cient nos imprimis summe et suasibilissime autoritatis loco eterne vite fecundissima verba ac potentissima divine dyadis eloquia.

Coniectura Innumere deinceps et cunctis pervie e rebus naturalibus desumpte coniecture eo assentionis, fidei et firmissime credulitatis impellunt. Intelligentie quoque lumen, quo post vere lucis ortum repurgate et illustrate sunt Hominum mentes, id a seculo inauditum et a priscis inscrutabile

Ratio reserat panditque misterium. Est enim intelligentia fidei consummatio: fides vero intelligentie dispositio sacrumque initium.

\section{đ Noscende divine altissime trinitatis sensibilia signa.}

Cap. XXX.

Non inconveniens autem fuerit, si hoc in loco nonnulla apposuerimus dinoscende beatissime huius divine trinitatis sensibilia presidia, per que

a) sibi solis adaperta ac dilucidata sit deest in ed.; nisi forte anacoluthon servandum est. 
certioribus coniecturis Natura nos tanti misterii cupit effici conscios tanteque scientie nobis reserari iubar. Subiecit enim Natura nostris oculis lucidissima eorum signa, "que oculus non vidit nec auris audivit neque in cor Hominis ascenderunt.»

q Nam si universam Naturam perfectam esse credimus, eandem profecto et trinam esse assentimur dicimusque omni in re naturali quendam splendicare et liquido exprimi divine trinitatis numerum. Omne etenim per-

Omnis Substantia divine trinitatis vestigium fectum est trinum. ${ }^{1}$ ) Et si Deum haud inficias imus omnium esse opificem, authorem, creatorem, fatemur insuper perfectum eundem esse ac trinum: cum sit omnis creatura divinum quiddam (nam divinitatis opus divinusque fulgor et apparitio), erit et omnis creatura, ut divine tudicule forma, relucentia et impressio, clara atque inobscura divine perfectionis atque trinitatis gestans in se vestigia. Itaque ex omni ferme materiei parte, ex cunctis naturalibus rebus tam sublimis et ardua cognitio nostris se mentibus altius infundit, patenter insinuat, sensibiliter explicat. Expetita igitur signa ab Homine enarrare pergamus.

$₫$ Humana species tantum una est, trino tamen actu a Deo substantia- Trinitas in Homine liter condita atque perfecta: primus et per se Homo Adam, ex Adam Eva, ex Adam et Eva Abel. ${ }^{2}$ )

o Rationalis Anima una est et indivisibilis substantia, sine sui divisione Trinitas in rationali trina, numerosa, fecunda: in Intellectum, Memoriam ac Voluntatem sive Anima in Contemplationis actum discreta. Intellectus non est Memoria neque Voluntas, Memoria neque Intellectus est neque Voluntas, Voluntas non Intellectus est neque Memoria: sunt tamen hec invicem relatitia, equata et similia, una insuper eademque Anime substantia. ${ }^{3}$ )

đ Punctum in media linea, cum substantia unicum et insectile sit, ratione tamen trinum reperitur. Est enim idem finis linee prioris, sequentis initium, totius vero medium.

I $₫$ Arbor una est, in stipite coniuncta, in ramis discreta, in quibus tan- p. $13^{\mathrm{v}}\left[\mathrm{r}^{\mathrm{v}} \mathrm{v}\right]$ tum tria profert: folia, flores, fructus.

q Nubes una quedam est et liquida substantia, triniter fecunda. Nam in tantum tria solvitur: pluviam, nivem, grandinem; que hoc carmen complectitur:

Pluvia, nix, grando: hec tria sunt e nubibus orta.

q Animalis nutritio trinis perficitur membris: ore, stomacho, corde. Nam cibus ab ore assumitur, recipitur et continetur ab stomacho, postremo a corde digeritur transitque in animalis substantiam. ${ }^{4}$ )

\footnotetext{
1) cf.cap. XXII.

2) cf. cap. $X X V$.

3) cf. cap. XXIII.

4) ct.cap. X.
} 
Trinitas ignium: solis, ignis, cordis q Hominis quoque, animalium precipui, trino calore atque igne preparatur et concoquitur cibus: primo celesti, secundo elementari, tertio humano; sole, igne, corde. His tribus ignibus preparatur alimentaria Hominis substantia, priusquam ex materia vertatur in sanguinem. Nempe a sole maturantur fructus, herbe, plante et animalia gignuntur; deinde ab elementari igni, quicquid in eis cruditatis et contrarii ac superflui humoris est, exhalatur resolviturque; tertio in Homine cordis calore in sanguinem omnia convertuntur.

Anime trine $q$ Anime numerus est trinus. Omnis enim Anima aut rationalis est aut sensitiva aut vegetativa. Nam que tantum subsistunt, inanimata sunt et Anime expertia.

Intellectus trinus $₫$ Intellectus est trinus: alius divinus, alius angelicus, alius humanus. Et intellectum divinum peculiari nomine Mentem nuncupamus; angelicum proprie Intellectum censemus, humanum vero Rationem. ${ }^{1}$ )

Sapientia trina $₫$ Sapientia est trina: alia divina, alia angelica, alia humana. Omnis enim Sapientia est suiipsius cognitio. Tria autem sunt orbicularia et que se norunt entia: Deus, Angelus, Homo. Unde fit, ut omnis Sapientia sit immaterialis cognitio et omnis immaterialis cognitio Sapientia. $\left.{ }^{2}\right)$ q Fit etiam, ut in materia sit totius divisionis et alteritatis principium, quandoquidem omnis eiusdem a seipso conceptio sit extra materiam et omnis materialis cognitio in divisione et alteritate substantie contingat: in qua aliud est, quod spectat et aliud, quod spectatur, alia extrema, aliud medium.

Sol, luna, terra $₫$ Sol primus est et per se lucidus ipsiusque lucis initium; a sole lux in lunam derivatur; a sole vero et luna in terram. Sol a nullo lumen receptat, luna a sole illustratur, terra ab utrisque. In magnitudinibus $\mid \nsubseteq$ Tantum tria sunt magnitudinum intervalla: longitudo, latitudo, pro-
trinitas. p. $133^{\mathrm{T}}$ funditas; ac tres tantum magnitudines et continue quantitates: linea, superficies, corpus; quarum idem fons atque initium punctum.

Trinitas in numeris $₫$ Tres sunt prime et precipue numerorum unitates: linearis, superficialis, corporea, que ab eadem oriuntur scatentve simplicissima unitate: denaria, centenaria, millenaria. Nam inter numerorum sedes, locos et positiones, que decimo quoque loco denariave distantia notantur: denarius primus est linearis numerus; hecas primus planus, ut quadratus; mille primum corpus, nam cubus.

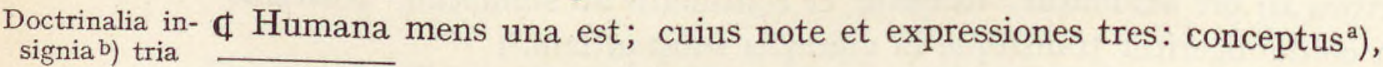

a) conceptio ed. b) isigna $e d$.

1) cf. cap. XIII; de Sensu: cap. VII 5.

2) cf. cap. XXVIII. 


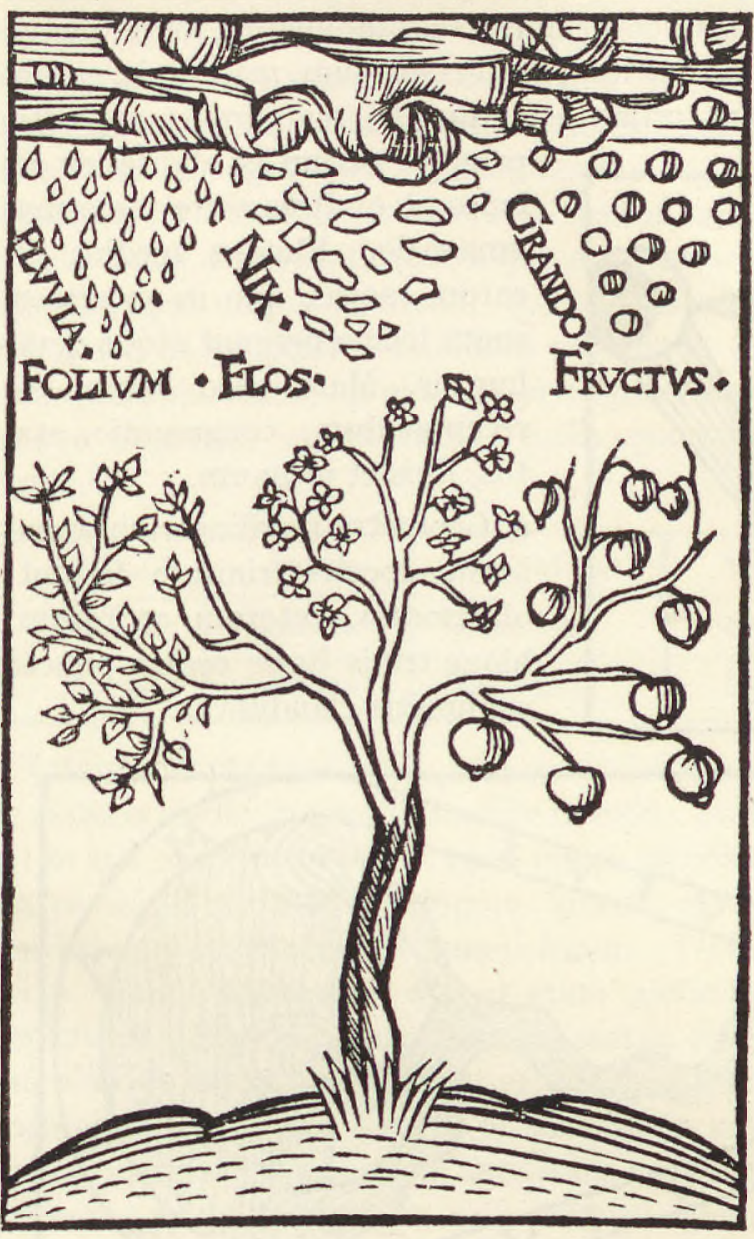

vox, scriptura. In quibus aut omnis est disciplina aut eorum medio disciplina paratur; et ab his signis humane Anime trini oriuntur disciplinares actus: conceptio, loquutio, scriptitatio. $\left.{ }^{1}\right)$ $₫$ Celestia luminis sub- Luminaria mundi iecta et lucifere faces trina sunt trine: sol, ceteri planete,qui errones et erratici dicuntur, et stelle. Nam sol fons est et lucis initium, a quo in ipsos errones et in firmamenti stellas derivatitia lux transfertur. đ Trinus est solis aspec- Trinitas in sole tus: orientalis, meridionalis, occiduus. His enim tribusdifferentiismortalium oculis sol revelatur: primo in ortu, deinde in meridie, tertio in occasu. In septentrione autem et medie noctis puncto nobis est occultus.

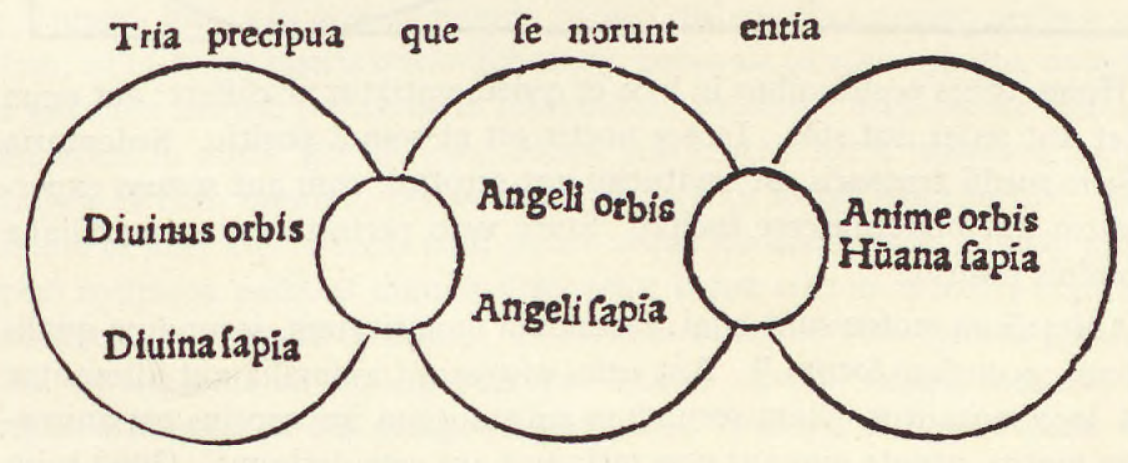

1) cf.cap. IV; de Sensu: cap. XXVII 3-6; XXIX; XXXV. 
Trinitas in delatione $₫$ Aquarum motus trinis differentiis universus adimpletur: fonte, fluvio, aquarum mari. Nam fons aquarum est initium, fluvius medium, mare finis, earum congregatio ac status. Fons prima est aquarum scatebra et apparitio

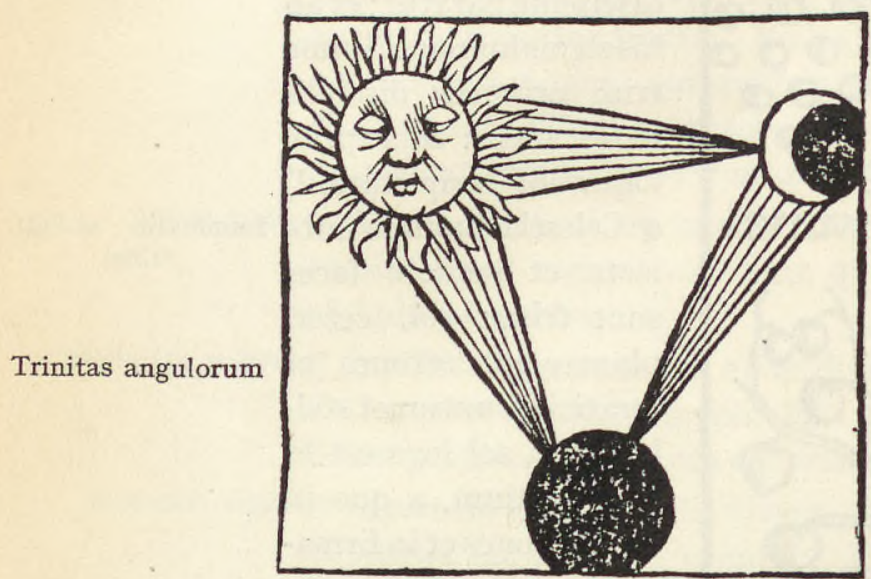
primave earum ex abdito, ex occulto et ex ipsis terre visceribus emanatio. Fluvius medius est earum motus, quo in naturalem suum locum pergunt atque devehuntur. Mare vero earum est receptaculum, congregatio, status, finis et ultimum.

$₫$ Geometre rectilineorum angulorum species trinitate finiunt: obtusorum, rectorum, acutorum; hique trinis lineis eodem puncto coniunctis clauduntur.

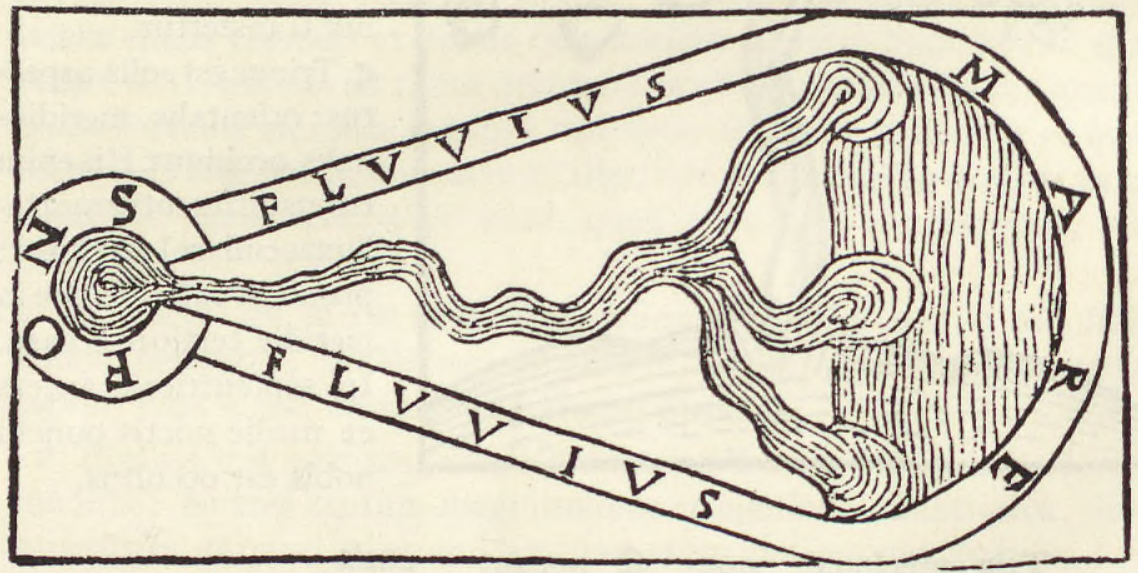

Trinitas in Hominis $₫$ Homo trinis positionibus in loco et quiete variatur ac differt: aut enim positione ac situ iacet aut sedet aut stat. Iacere noctis est et somni positio. Sedentaria positio medii temporis est, matutini aut serotini, cum aut somno expergiscitur aut obdormiscere incipit. Stare vero perfecta est et meridiana Hominis positio.

In motibus anima- $₫$ Animalium motus sunt trini: secundum quantitatem, secundum qualilium trinitas tatem, secundum locum. ${ }^{1}$ ) Aut enim augescunt animalia aut alterantur aut loco mutantur. Nam secundum substantiam improprius est animalium motus, utpote quo aut esse incipiunt aut esse desinunt. Quod enim

1) Sed cf. de Generatione: cap. XVIII 5. [XVIII]. 
fit, nondum est; et quod esse desinit, non subsistit totum. Omnis quippe motus oritur ab Anima. At cum trina sit Anima: alia quidem vegetatrix, alia sensitiva, | alia rationalis, necesse est et trinas tantum esse mo- p. ${ }^{1} 33^{\mathrm{v}}$ tiones: aliam vegetatricis Anime, aliam sensitive, aliam rationalis. Augmentatio est Vite motus, alteratio Sensus mutatio, latio vero Rationis motio. Nam augescunt, quecunque nutriuntur; alterantur dolore atque tristicia, quecunque sentiunt; solus Homo veraciter ex deliberatione, voluntate et proposito secundum rectum in ante mutatur, sui motus, priusquam moveatur, providens precogitansque finem. Que autem sunt Anime expertia, ut mineralia: nullo quoque predita motu conspiciuntur. ${ }^{1}$ )

\begin{tabular}{|l|l|l|l|l|}
\hline Motus & Anime & vegetatricis & Vite & augmentatio \\
\cline { 2 - 4 } Motus & Anime & sensitive & Sensus & alteratio \\
\hline Motus & Anime & rationalis & Rationis & latio \\
\hline
\end{tabular}

đInfantis status sunt trini: primus in minore mundo, secundus in minoris Infantis trinitas et maioris medio, tertius in maiore mundo. Status eius in minore mundo est in sue conceptionis loco, cum adhuc matris utero inest. Medius eius status est in nativitatis tempore, quando ex minoris mundi occulto ac tenebris prodit in maioris mundi lucem. Tertius et ultimus eius status est in mundo maiore, in quo et etate proficit et Sapientia tandem consummatur. Primus autem infantis status similis est mentis conceptui, qui abditus est in mente, sicut et infans in matris utero. Secundus vero status persimilis voci, que est prima interne notionis nativitas atque expressio; edit enim infans in nativitate vocem illico primam fitque tum primum audibilis. Tertius vero infantis status scripture comparatur, que est vocis cumulatio, status et permanentia.

đ Rursum infans in maiore mundo triplici differentia ac statu perficitur. Alia Hominis triNam, ut in huius operis initio diximus ${ }^{2}$ ), prius est in statu plante, deinde nitas in animalis natura, postremo in humanitate stabilitur vivitque ut Homo. Est enim in statu plante, cum adhuc sue matris heret uberibus lactiphagus et cum nundum per seipsum de loco in locum transfertur. Est deinde in animalis natura, cum pubet atque adolescit, cum iamiam progredi incipiens pedibus manibusque velut belua curvus incedit, avulsus abiunctusque a matris uberibus. In Homine autem est vivitque ut Homo, cum ex ephoebis ad virilem pervenit etatem, cum et animo maturescit fitque studiosus et sui compos. Nam cum Hominis Anima eadem sit

1) cf. de Generatione: cap. XVIII. [XVIII].

2) cap. III. 
et vegetativa et sensitiva et rationalis, sicut e tribus distinctis Animabus vegetativa creata est prior, deinde sensitiva, suprema et ultima rationalis: ita et in Homine successio actuum, non virium aut Animarum contingit; prius siquidem in eo exercentur partis vegetatricis actus, deinde sensitive, ultima vero Ratio in eodem consummatur atque perficitur.

q His etenim gradibus sensim rationalis Anima ad sue proprietatis et naturalis perfectionis culmen scandit; his se in proprium vendicat proripitque locum, et que imprimis ab ineunte etate vitali tantum actu agitur, deinde sensitivo: maturior demum composque effecta sui supremo, rationali, proprio et equali actu in sua sistitur natura fitque sibi adequata et una. Nam ut aut vitalem aut sensitivum exercet actum, est seipsa minor atque inferior, ab sua sede exturbatur, in corpore motitatur, corpori congreditur. Ut vero Ratione cietur, corpore sublimior evadit, sibi inseritur, in seipsa residet. In toto enim corpore exercetur ab Anima Vita, in toto quoque corpore Sensatio: ast Rationis functio in nulla corporis parte, sed in mera et sola perficitur Anima.

Trinitas in pastu $₫$ Rursum humana Anima tribus pascitur et eruditur speciebus, sensitiva, imaginativa et rationali: sensitiva a mundo, imaginativa a corpore, rationali a seipsa. Nam mundus sensibilem mittit vibratque speciem; corpus Imaginationis speciem ut spectrum Anime presentat, proponit, offert; porro rationalis species et in Anima subsistit et ab Anima Anime presentatur. Et in hac sola consistit Hominis scientia, eruditio, consummatio, ultimum.

Trinitas in sensibus $₫$ In ipsis quoque sensibus trinitas miro responsu et congruentia relucescit. Nam, ut in Sensuum libro docuimus ${ }^{1}$ ), sensuum alii sunt presentativi, ministrantes et obiectitii: alii passibiles, inferiorum iudices, arbitri, precipui et eorum, que ab illis offeruntur, susceptivi. Manus quippe, que tactus quidam sunt, oculis ministrant scripturas, colores et omnimodarum picturarum varietates. Os Auditui voces, concinentiam omnemque harmoniam offert. Olfactus cerebrum, Imaginationis et spectrorum locum, variis inspirat odoribus grataque fovet suaveolentia. đ Igitur tres sunt, qui offerunt ministrantque sensus: Tactus, Gustus, Olfactus; tres item, quibus ministratur: Visus, Auditus, Imaginatio; tria sunt et que offeruntur quibusve hi ab illis pascuntur, aluntur foventurque: color, vox, odor. Insunt igitur sensibus trine trinitates: prima ministrantium sensuum; secunda eorum, quibus ministratur; tertia obiectorum, que ministrantes prestantioribus offerre iubentur:

1) de Sensu: cap. XXXI; XXIII; cf. de Sapiente: cap. XI. 
Cap. $X X X$.

365

\begin{tabular}{|l|l|l|l|}
\hline \multicolumn{4}{|c|}{ Sensuum trine trinitates } \\
\hline Ministrantes & Manus & Os & Olfactus \\
\hline Obiecta & Scripture & Voces & Odores \\
\hline Precipui & Visus & Auditus & Cerebrum \\
\hline
\end{tabular}

đ Et si generatim omnem cognitionem et cognitivam facultatem numera- In omni cognitione bimus, tres in eis insunt trinitates. Sunt enim immateriales cognitiones tres, divina, angelica, humana: Mens, Intellectus, Ratio. Materiales vero sex: internus Sensus unus et extremi quinque, Auditus, Visus, Olfactus, Gustus, Tactus. Et harum omnium cognitionum aliquopacto inexpertem esse Hominem in Sensuum libro docuimus. ${ }^{1}$ ) Est enim Homo ter trinus novenisque luminaribus, lampadibus, lucernis naturaliumve cognitionum splendoribus natura illustris. Nam extra et supra materiam trimyxus: Mentis, Intelligentie et Rationis particeps; in materia vero bistrimyxus: Imaginatione et quinis sensibus splendicans. Est enim materialis cognitio ad immaterialem numero dupla.

đ Dyalectici trina positione medii tres syllogismorum et ratiocinatio- Trinitas in syllonum figuras modosque eliciunt. Nam medium, ut aiunt, aut medio stagismis tuitur loco aut primo aut ultimo. Finiunt enim primam figuram, cuius medium est medium; secundam, cuius medium est primum; tertiam vero, cuius medium est ultimum. Est autem terminus in ratiocinatione primus, qui superior et cunctis amplior de ceteris rite dicitur atque enunciatur; ultimus vero, qui ceteris subest ac de quo ceteri dicuntur; medius, qui cum uni subsit, alter ei subest.

\begin{tabular}{|c|c|c|c|c|c|c|c|c|}
\hline $\begin{array}{c}\text { Ulti- } \\
\text { mum }\end{array}$ & $\begin{array}{c}\text { Me- } \\
\text { dium }\end{array}$ & $\begin{array}{c}\text { Pri- } \\
\text { mum }\end{array}$ & $\begin{array}{c}\text { Ulti- } \\
\text { mum }\end{array}$ & $\begin{array}{c}\text { Pri- } \\
\text { mum }\end{array}$ & $\begin{array}{c}\text { Me- } \\
\text { dium }\end{array}$ & $\begin{array}{c}\text { Me- } \\
\text { dium }\end{array}$ & $\begin{array}{c}\text { Pri- } \\
\text { mum }\end{array}$ & $\begin{array}{c}\text { Ulti- } \\
\text { mum }\end{array}$ \\
\hline \multicolumn{2}{|c|}{ Prima figura } & \multicolumn{2}{|c|}{ Secunda figura } & \multicolumn{2}{|c|}{ Tertia figura } \\
\hline
\end{tabular}

Tres syllogismorum figure trina positione medii

đ Omnis item dyalectica ratiocinatio trinis et terminis et enunciationi- Alie in syllogismis bus coalescit. Termini sunt: extremitas maior, extremitas minor et metrinitates dium. Propositiones vero: maior propositio, minor propositio et illatio sive conclusio, que duabus premissis et extremitatibus infertur. Maior propositio ut Intellectus est, minor ut Memoria, illatio vero ut utriusque species, status, finis.

đ Et ut propositas divine discretionis atque trinitatis coniecturas ab- Trinitasin Sapientia solvamus, ipsam denique trinitatem trinam suoque dimensam numero

1) de Sensu: Praefatio p. $2 I^{\mathrm{v}}$ cum figura p. $2 I^{\mathrm{r}}$ : Arbor cognitivarum Anime virium et obiectorum earumdem; Exodium. 
fatemur. Nam Sapientiam ipsam docuimus esse trinam ${ }^{1}$ ): aliam divinam, aliam angelicam, humanam aliam. Ast omnis Sapientia est suiipsius agnitio; agnitio vero sui est trina eius, quod nosse seipsum dicitur, discretio. Quanta igitur est Sapientia, tanta est et trinitas: alia divina trinitas, angelica alia, alia humana. Hec enim tria: Intellectus, Memoria, Voluntas trinis duntaxat precipuis entibus: Deo, Angelo et Homini inesse probantur. Trinus igitur est Intellectus, trina Memoria, trina Voluntas.

\begin{tabular}{|l|l|l|l|l|}
\hline Deus & Intellectus & Memoria & Voluntas & I \\
\hline Angelus & Intellectus & Memoria & Voluntas & 2 \\
\hline Homo & Intellectus & Memoria & Voluntas & 3 \\
\hline
\end{tabular}

Omne etenim, quod consummatum est et perfectum, est ex necessitate trinum. Sapientia autem perfecta est, trinitas perfecta est, ideoque et Sapientia trina et trinitas trina reperitur.

\begin{tabular}{|l|l|l|l|}
\hline Trinitas in Deo & Pater & Filius & Spiritus \\
\cline { 1 - 2 } Trinitas in Homine & Adam & Eva & Abel \\
\hline Expressiones & A nullo & Ab uno & Ab utroque \\
\hline Trinitas Anime & Intellectus & Memoria & Voluntas \\
\hline In arbore & Folium & Flos & Fructus \\
\hline In nube & Pluvia & Nix & Grando \\
\hline In animali & Os & Stomachus & Cor \\
\hline Proprietates & Assumens & Recipiens & Digerens \\
\hline In mundo & Intellectualis & Celestis & Sensibilis \\
\hline In corpore & Os & Nervus & Caro \\
\hline In scientiis & Sermocinales & Reales & Naturales \\
\hline In plantis & Arbor & Frutex & Herba \\
\hline In sole & Lux & Lumen & Umbra \\
\hline In luna & Coniunctio & Medium & Oppositio \\
\hline In circulo & Centrum & Dyameter & Circunferentia \\
\hline In ignibus & Sol & Ignis & Cor \\
\hline Proprietates & Maturitas & Decoctio & Digestio \\
\hline
\end{tabular}

1) cap. XXVIII. 
Cap. $X X X$.

\begin{tabular}{|c|c|c|c|}
\hline In Animabus & Vegetativa & Sensitiva & Rationalis \\
\hline In Intellectu & Divinus & Angelicus & Humanus \\
\hline In Sapientia & Divina & Angelica & Humana \\
\hline In mundo & Sol & Luna & Terra \\
\hline In magnitudine & Longitudo & Latitudo & Profunditas \\
\hline Rursum & Linea & Superficies & Corpus \\
\hline In numeris & Linearis & Planus & Solidus \\
\hline In eruditione & Conceptus & Vox & Scriptura \\
\hline In luminosis & Sol & Minor planeta & Stella \\
\hline In aspectu solis & Oriens & Occidens & Meridies \\
\hline In motu aquarum & Fons & Fluvius & Mare \\
\hline In angulis & Obtusus & Acutus & Rectus \\
\hline In Hominis positione & Iacere & Sedere & Stare \\
\hline In motibus & Augmentatio & Alteratio & Latio \\
\hline Proprietates & Quantitas & Qualitas & Locus \\
\hline Infantis status & In utero & In nativitate & Post nativitatem \\
\hline In etate Hominis & Infans & Puer & Vir \\
\hline In pastu animi & Sensibile & Imaginabile & Rationale \\
\hline In sensibus & Imaginatio & Auditus & Visus \\
\hline In abiectioribus & Olfactus & Gustus & Tactus \\
\hline In obiectis & Odor & Lux & Scriptura \\
\hline In intellectualibus & Mens & Intellectus & Ratio \\
\hline In syllogismis & Maior extremitas & Minor & Medium \\
\hline In syllogismis & Prima figura & Secunda & Tertia \\
\hline In syllogismis & Maior propositio & Minor & Conclusio \\
\hline
\end{tabular}

đ His coniecturis sensibilibusque presidiis fulta humana mens divine trinitatis certissimam aut rationem aut fidem aliquopacto eliciet, quandoquidem ab eodem supersubstantiali divinitatis fonte manarunt universa, et materialia et immaterialia, visibilia et invisibilia, que sunt archane illius et eminentissime veritatis vestigia et signa; quorum cum ferme universi ordines ternario discreti sint ac trini, rationabile est omnem crea- 
tam trinitatem ab eterna et increata divina trinitate duxisse originem. Eadem aliter signis, $₫$ Sed aliter signis, aliter causis, archetypis et exemplaribus eadem in-
aliter causis insunt sunt. Nam in his, quas apposuimus, coniecturis plerumque hec accidunt: inequalitas, Substantie divisio, prioritas, posterioritas; sed ex signorum inequalitate conjicienda est summa in Deo equalitas; ex Substantie divisione summa coniunctio et Substantie identitas; et ex posterioritate ac prioritate eternitas. Nam conceptus imprimis, vox et scriptura equales quidem sunt. Conceptus enim omnia est, vox omnia, scriptura omnia: dissiti tamen sunt abinvicem et loco divisi. Nam conceptus in mente, vox in ore, scriptura in charta profertur atque exaratur; et conceptus prior est voce, vox itidem prior scriptura.

$\nsubseteq$ Rursum rectilinei anguli tres: obtusus, rectus, acutus, licet eodem puncto coniuncti sint, a quo linee tres protenduntur, inequales tamen sunt. Obtusus maior, rectus medius, acutus minor. $₫$ Et in Anime trinitate, quam posuimus inter Intellectum, Memoriam et intellectualem utriusque speciem - qua mediante ${ }^{a}$ ) fit ipsa Contemplatio et que ab hac presentatur, ab illo conspicitur - , ipsa quidem species innaturalis est animo et inconsubstantialis Intellectui ${ }^{\text {b }}$ ) atque Memorie; quippe acquisita in Anima et posterior utraque parte animi, Intellectu ac Memoria.

In Deo nil acqui- $q$ In Deo autem nichil est acquisitum, nil temporaneum, inequale, insitum consubstantiale, a Deo disiunctum atque separatum; nil denique prius aut posterius. Omnia quippe in Deo coniuncta sunt, eiusdem Substantie, inseparabilia, naturalia et inacquisita, equalia, infinita, simul, eterna. Sed iam latius evagati longiusve digressi ad Sapientis intentum revertamur.

đ Cur Sapientem Romani bifronte et quadrifronte Iano expressere.

Cap. XXXI.

p. ${ }^{3} 5^{\mathrm{r}}\left[\mathrm{r}_{3} 7^{\mathrm{r}}\right]$ | Sapientem Romani Iano, forculo limentinoque deo, qui foribus liminibusque preesset, haud ineleganter expressere: quem interdum ut bifrontem, interdum ut quadrifrontem pingere soliti traduntur. $₫$ Bifrontem: nam qui liminibus cardinibusque preest, facie una exteriora, alia interiora domus spectare cogitur. Quadrifrontem vero: quia quem finxerunt geminis a Natura spectativis faciebus preditum, adiecerunt et illi ambos vultus: hunc qui extrorsus, alium qui introrsus spectatur. Nam quod deforis et extrorsus conspicitur, vultus quidam est; itidem et quod est introrsus spectabile, facies est altera. Geminis igitur oculis ${ }^{c}$ ) ultro
a) mediate $e d$.
c) osculis $e d$.
b) itellectuali $e d$. 
citroque, qui ab initio bifrons erat, evadit alterna speculatione quadrifrons. Nam potentia spectans hinc obiectum exterius, hinc subcutaneum et internum: utriusque specie quoquopacto afficitur, fit similis utrique, amborum vultum excipit ac refert.

$₫$ Sapiens autem pluribus de causis et bifrons et quadrifrons esse depre- Cur Sapiens bifrons henditur. Nam, ut in eius operis initio dictitavimus ${ }^{1}$ ), Sapiens haud simplex, sed geminus Homo est, id est Homo-Homo: natura inquam Homo et virtute Homo; extimus Homo et subcutaneus sive internus Homo; Homo in mundo et Homo in Homine. Nam Sapiens velut sui calothecnius $^{2}$ ) et optimus artifex ad naturalis Hominis similitudinem virtutis Hominem progenuit, qui studiosus Homo, qui primi Hominis imago, relucentia, apparitio et Sapientia nuncupatur. đ Naturalis quippe noster Homo Homo est tellureus, virtute inconditus ignarusque sui, soli expositus mundo spectansque duntaxat in mundum. Studiosus vero Homo illius ignorantiam resolvit, tenebras discutit, illum a mundo revocat, ad seipsum convertit figitque in seipso. đ Est igitur bifrons Sapiens facie una, naturali scilicet et exteriore, mundanus; alia vero, acquisita et subcutanea, humanus. Qui enim natura spectabat in mundum, didicit arte, virtute et doctrina exterebrare seipsum seque contueri.

đ Est et Sapiens quoquopacto medius inter seipsum et mundum: quandoque quidem in mundo, quandoque vero in seipso residens. Etenim constitutus est Homo a Natura in utriusque limine, in sui mundique carSapiens inter seipsum et mundum est dine ac superficie: nunc Sensu penetrans in profunda et interiora mundi, nunc vero Mente a mundo recinens in sua ipsius viscera revocatur scrutaturque, sub cute, subtacito pectore quicquid habet. $₫$ Adest rursum Sapienti tam sui quam mundi reserandi facultas, clavis, licentia. Nunc mundo, nunc sibiipsi congreditur, adape-

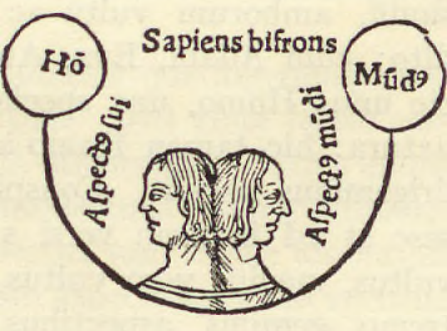
ritur, patet. Clausus est et abditus sibiipsi in initio, cum adhuc negociatur in mundo. Claudit denique mundum, illius pessulum, seras et obices obfirmat, cum seipsum subit, cum sibiipsi post mundanam peregrinationem reseratur, cum post discipulatum mundi sensuumque famuletium rediens ad mentem suiipsius magisterio ac pedotribatui ${ }^{3}$ ) in ipsa Contemplatione preficitur.

đ Porro quadrifrontem esse Sapientem hac ratione ostendere nitimur. Nam Sapientiam non modo in humana dyade, sed et in quadam tryade

1) Praefat. p. 302; cap. I p. 305; cap. VII.

2) lege: calotechnius, $x \alpha \lambda \circ \tau \varepsilon \chi_{*}^{\nu-}$.

3) lege: paedotribatui; $\pi \alpha \iota \delta \circ \tau \rho \iota \beta-$.

Studien der Bibliothek Warburg ro: Cassirer. 
perfectam consummatamque esse docuimus. ${ }^{1}$ ) Est enim Sapiens HomoHomo-Homo; natura inquam Homo, nam Rationis particeps; etate Homo, quippe vir; et virtute Homo, nempe studiosus ac Sapiens. Diximus siquidem prius $^{2}$ ) trifariam Hominem dici: natura, etate, virtute, atque omnifariam Hominem esse Sapientem, cui post naturalem et temporalem Hominem tertius eterno foenore accrevit studiosus Homo. Nam tertius hic Homo Hominis est consummatio, finis, status, contemplatio et Sapientia; utriusque extremorum, nature inquam et etatis Hominum, species, emanatio, proventus, nexus, amor, vinculum, in quo exprimitur utriusque extremorum natura, similitudo, imago. Cum igitur studiosus Homo sit tanquam primi et secundi Hominis emanatio fecundusque ${ }^{\mathrm{a}}$ ) proventus ac fructus - oritur enim Sapientia quodam modo ex naturali et temporali Homine, perinde atque illatio una ex ambabus infertur premissis - : necesse est quadrifrontem esse Sapientem. Nam bifrons est in extremis Hominibus, in singulis quidem unifrons, in tertio vero et medio Homine iterum bifrons, ut in amborum vinculo, ut in utriusque fenore $\mathrm{ab}$ utroque procedente et utrumque spectante. Et tam extremi Homines quam medius Homo: sunt unus Homo, unus Sapiens, perfectus, consummatus et discretus Homo, aspectu quadrifrons et quadrigeminus.

p. $135^{\mathrm{v}}\left[137^{\mathrm{v}}\right]$ of Exempli enim causa sit primus Hominis vultus in Adam, | secundus in Eva, tertius in Abel mixtus ac geminus tanquam in amborum filio, amborum simili, amborum vultu ac specie predito; cum Adam, Eva, Abel sint specie unus Homo, una specialis Hominis natura: hic tamen Homo aspectu quadrigeminus evadit. Conspiciunt enim sese et ad invicem versi sunt extremi vultus, medius vero vultus utrique extremo geminis aspectibus copulatur;

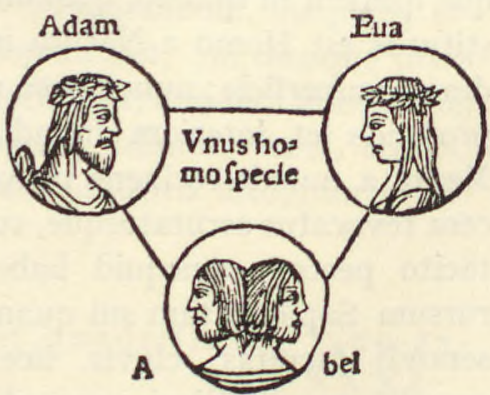
nam utriusque extremi species est et naturalis imago.

Hominis et Esse et $₫ \mathrm{Et}$ sicut Hominis Esse trinis actibus trinisve hominibus Deus ab bene esse trinum initio complevit, ita et Hominis bene beateque esse trinis actibus trinisve Hominibus suo modo perfici voluit. Est autem Hominis Esse humana substantia condita a Deo ab initio et perfecta in tribus: Adam, Eva, Abel. Ast Hominis bene beateque esse: Virtus est et Sapientia, que Hominis sedentaria opera - quiete, ut aiunt, et residentia - mentis animique

a) secundusque $e d$.

1) cap. XXII; XXVIII.

2) cap. IV. 
solerti cultura Homini innascitur. Per hanc enim et tertius Homo, hoc est studiosus Homo, conflatur et Hominis animus evadit aliquopacto trinus: intelligere, memorari et contemplari potens.

\section{đ Alius modus quadrifrontis Sapientis. $\quad$ Cap.XXXII.}

Rursum aliter intellige quadrigeminum esse Sapientem. Universus Hominis animus est quidam Homo: Intellectus quidam Homo, Memoria Homo quidam, et utriusque species - que per Intellectum in animum introducta est et conservatur a Memoria - quidam Homo; licet enim nonnunquam partes totorum nominibus censeri atque appellari. A Natura perfectus est Homo duntaxat habitu extremorum, Intellectus et Memorie, stetitque ab initio imperfectus et inconsummatus utriusque specie, quam minime habet a Natura.

$₫$ Est enim in initio Hominis animus velut syllogismi et ratiocinationis Inconsummatusanipremisse sine illatione, velut extrema sine medio, ut denique monas et mus $\begin{gathered}\text { ut premisse } \\ \text { syllogismi }\end{gathered}$ dyas sine tryade. At cum ratiocinatur et eruditur Homo, ex naturali Intellectus et Memorie habitu mediam utriusque infert speciem, tanquam ex premissis illationem, ex naturalibus extremis medium, ex monade et dyade tryadem: qua qui prius inconsummatus extitit, perficitur; qui Insipiens, Sapiens fit; qui tantum Homo-Homo, fit Homo-Homo-Homo, scilicet Homo intellectu, Homo memoria et acquisita amborum specie Homo.

đ Sapientis igitur et consummati Hominis animus quadrigeminus est, Animi Sapientis id est facierum, vultuum et aspectuum quattuor. Est enim facies eius quattuor aspectus prima intellectualis, qua Intellectus spectat in Memoriam. Facies animi secunda vultus est Memorie, quo versa ad Intellectum respicit Intellectum. Medii vero et acquisiti totius animi aspectus sunt medie amborum speciei, qua fit ipsa Contemplatio; horum enim aspectuum unus vertitur in Memoriam, alius in Intellectum convertitur; nam huiusmodi acquisita species media est inter extremas animi partes, Intellectum et Memoriam, dum in Contemplatione $a b$ hac illi offertur atque presentatur, $a b$ illo vero ${ }^{a}$ ) conspicitur. Et sicut gemini sunt aspectus extremorum animi oculorum, unus ipsius Intellectus, alius Memorie: ita et totius medii oculi sive amborum speciei gemini sunt aspectus, totius vero animi aspectus quattuor. Est enim consummati Hominis animus triophthalmus triumve spiritalium oculorum: duorum quidem naturalium, simplicium et extremorum, et unius acquisiti, medii, mixti, in diversa spectantis, nunc solem - hoc est Intellectum - nunc lunam - hoc est

a) vera $e d$. 
Memoriam - intuentis. Nam Intellectus sol est animi, fons et initium humane totius scientie invisibilisque lucis. Memoria porro est animi luna et invisibilis lucis ab intellectuali sole derivatio. Media autem acquisita species est ut utriusque terra, cui ambo extrema luminaria suffulgent, quam interhyantem atque interpositam librant, ferunt fulciuntque.

Alia quadrifrontis $\mathbb{q}$ Denique et alia est addenda quadrifrontis Sapientis ratio. Si Sapientia, Sapientis ratio ut diximus ${ }^{1}$ ), est suiipsius agnitio perfectaque scientia: erit Insipientia sui inscitia et ignoratio. ${ }^{2}$ )

ฯ Nam finge Hominem geminis a natura vultibus insignem eosdemque vultus pinge tanquam in diversa spectantes seque minime conspicientes: illorum igitur contrarii diversique aspectus Hominis exprimunt ignorantiam et Insipientiam Homini innatam. Eorum autem alternus aspectus mutuave conversio, osculum et collabellatio Hominis scientiam, Sapientiam et suiipsius agnitionem adaperit.

đ Igitur sapiens Homo, cum suiipsius calothecnius, toreutes, cosmeta p. ${ }^{3} 6^{\mathrm{r}}\left[\mathrm{r}^{\mathrm{r}} \mathrm{g}^{\mathrm{r}}\right]$ dictus sit, $\left.{ }^{3}\right)$ id est artifex, $\left(\right.$ celator $\left.^{4}\right)$, ornator: geminis conflactur Hominibus, Homine inquam nature et virtutis Homine. Atqui uterque Homo bifrons ac geminus est. $₫$ Nam nature Homo ignorantia sui est et Insipientia quedam; studiosus vero seu virtutis Homo: sui scientia, lux, aspectus, agnitio et Sapientia nuncupatur. Ignorantia autem sui haud aliud profecto est quam duorum vultuum inaspectus, mutua aversio ac dissociatio. Scientia vero sui est amborum vultuum grata exosculatio.

Principium Sapien- $₫$ Sapiens itaque Homo bisbifrons esse declaratur, naturali inquam Hotenebre, finis mine bifrons et virtutis Homine iterum bifrons; primo quidem bifrons
lux sui inscitia, secundo vero bifrons sui gnaritate. Constat enim sapiens Homo ex tenebris et luce, ex potentia et actu, ex ignorantia et scientia. Nam principium illi sunt tenebre, potentia, ignoratio, aversio, divisio; finis vero et perfectio: lux, actus, scientia, conversio, coniunctio, unitas.

\section{đ Geminis modis quadrifrontem Sapientem posse exprimi.} Cap. XXXIII.

Unde fit, ut bifariam sapientem Hominem quadrifrontem pingi et exprimi contingat. $₫$ Aut enim vultus extremi postergantur extrorsus et in diversa spectantes, medii vero adinvicem convertuntur et in alterutrum spectant. Et hoc pacto simul Sapientis et ignoratio et scientia, Insipientia et Sapientia exprimuntur; nam per extremos vultus Insipientia, per medios vero Sapientia designatur.

\footnotetext{
1) cap. XXX p. 360; p. 366; cap. XXVIII.

$\left.{ }^{2}\right)$ cf. Praefat. $p .302$.

3) cf. cap. $X X X I$.

4) lege: caelator.
} 


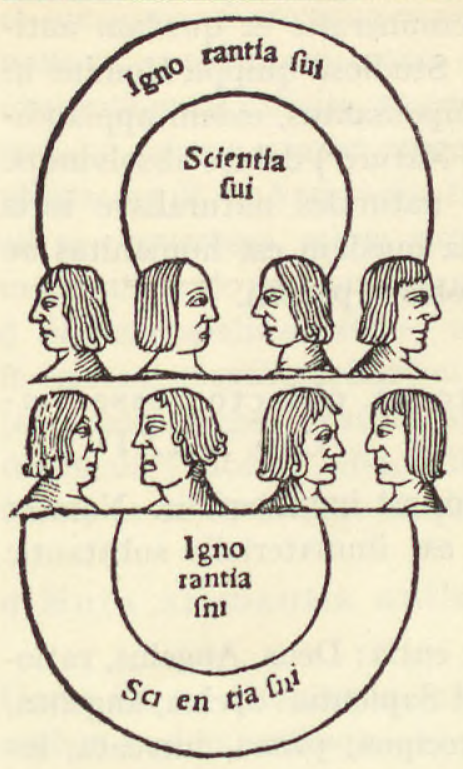

ণ Aut extremi quidem vultus introrsus Secundus modus et in invicem spectant, medii vero ad extremos convertuntur. Et hec Sapientis descriptio priore commodior reperitur. đ Extremi namque Sapientis et consummati animi vultus sunt Intellectus et Memoria, qui suapte natura adinvicem convertuntur seque conspicantur. Medii vero animi aspectus insunt intellectuali speciei, que inter Intellectum et Memoriam velut amborum species, amborum spectativa efficitur.

đ Sapientem igitur merito ad Iani instar nunc ut bifrontem, nunc ut quadrifrontem experimur. Etenim Sapiens in cardine sui mundique locatus nunc sibiipsi, nunc mundo congreditur, patescit, reseratur.

đ Spectat et in omnem simul mundi par- Sapiens in omnem tem: ut orientem, meridiem, occasum et medie noctis punctum. Toti mundi spectat paradest mundo estque cunctis presens, omnia simul eius oculus perlustrat tem atque intuetur.

ণ Hunc a tergo pinsit nemo, huic postica sanna impingitur nulla. Animo defecatus et imperturbatus instar liquidissimi celi vivit; in seipso manet contentus seipso sibique sufficiens. Nam numerosus, discretus et in seipso plurimus est. Indesertus indesolatusque manet: nullius indigus, spiritalis alimonie plenus, qua iugiter et assidue pascitur illius animus.

đ Utramque naturam exprimit, intellectualem atque sensibilem. Collo- In Sapiente uterque catus $^{2}$ ) enim, ut diximus ${ }^{1}$ ), in utriusque mundi speculo: nunc sensuum mundus exprimitur vehiculo in sensibilem mundum devehitur, nunc vero mente celos exterebrans supercelestia et intellectualia scrutatur, rimatur, perquirit. đ Sensibilem insuper mundum, ut diximus ${ }^{2}$ ), in intelligibilem et intelligibilem in sublunarem traducit. Sunt enim ambo mundi coniuncti in Homine, utpote in cuius Anima intellectualis mundus, in eius vero corpore sensibilis mundus exprimitur. Est insuper Sapiens Nature alternatio donorumque vicissitudo, quandoquidem primus noster Homo naturalis Homo est et primum Nature donum ac mutuum: secundus vero,

a) Collocatured.

1) cap. XXVI.

2) cap. XX.

ad figuram: sni pro sui. 
qui virtutis Homo, est ut ipsius Nature remuneratio et quedam antipelargosis, hoc est beneficiorum retributio. Studioso quippe Homine in naturam munifici sumus, munera illius compensamus, eidem applaudimus, gratamur ac denique nosipsos universo Nature ${ }^{a}$ ) debito absolvimus. Sicut enim primi Hominis naturali dono naturales naturalisve iuris sumus: ita et virtutis Homine, que secunda quedam est humanitas ac Sapientia, nostrates efficimur, nostri iuris nobisve proprii.

đ Sapientiam utrobique, et subiecto et obiecto, esse immaterialem.

Cap. $\left.X X X I V^{b}\right)$.

p. ${ }^{136 v}\left[129^{v}\right]$ | Sapientia utrobique, et subiecto et obiecto, est immaterialis. Nam et immateriali substantie Sapientia inest et est immaterialis substantie gnaritudo, scientia, cognitio.

Divina Sapientia $₫$ At cum tria sint precipua et immaterialia entia: Deus, Angelus, ratiomonas, angelica dyas, humana tryas nalis Anima, hinc trina, ut diximus ${ }^{1}$ ), evadit Sapientia: divina, angelica, humana. Divina Sapientia omnium est precipua, prima, increata, infinita, eterna, qua Deus ab eterno ante condita secla sibimet arcane innotuit, sibiipsi suffulsit, resplenduit, apparuit. Angelica vero Sapientia est, qua cognitus est ab Angelo Deus et qua Angelus a seipso. Humana porro est, qua ab Anima Deus, Angelus, Anima internoscitantur. Divina Sapientia monas est et tantum suiipsius noticia, omni alteritate et divisione sublimior. Angelica Sapientia orta et creata a monade dyas est et haud tantum sui, sed alterius, ut Dei, cognitio; et in hac Sapientia prima alteritas primaque divisio contingit. Humana vero Sapientia ultima est Sapientia ac tryas; est enim trium entium cognitio: Anime, Angeli, Dei. $₫$ Colligit enim imprimis rationalis Anima in sublunari mundo sensuum corporisque famuletio sensibilium omnium rerum notiones, species, imagines: e quibus demum ut proprie notionis opifex in semetipsa propriam confingit, elicit profertque speciem, que est humane Sapientie initium et ipsius Anime ab seipsa cognitio. $₫$ Deinde post suiipsius adeptam gnaritatem sensim in angelicam et simpliciorem perfectionem scandens fit angelice scientie consors; postremo vero ad sublimiora enitens divina quoque cognitione et scientia consummatur fitque verissime Sapientie particeps.

đ Nam sicut carneus noster et visibilis oculus summo, speciosissimo et lucidissimo visibili delectatur, ut sole: ita et vis omnis cognitiva supremo et lucidissimo cognoscibili, ut Deo, totius lucis autore, imbui, illustrari

a) natura $e d . \quad$ b) XXXIII $e d$.

1) cap. XXVIII; XXX p. 360; p. 366. 
et consummari precipue expetit. Est enim Deus universe nature sol verumque ac proprium omnis cognitive facultatis obiectum; in quo exuberantissima, infinita, sincera et immixta lux omnem speculativam perstringit aciem: semper patens, fusa super omnia, parata semper et explicita», ut divus Areopagita testatur ${ }^{1}$ ), "cunctis ad participandum», omnia Divus Areopagita ad se convertens, seipsa expetibilis et ab omni sive materiali sive immateriali oculo semper amanda, prosequenda, haurienda.

ণ Sed materialis oculus - ut Imaginatio et extimus Sensus, ut curvus in terram, ut gravastellus ${ }^{a}$ ) et pressus senio, ut longiore a suo fonte distantia consenescens: beatam hanc suspicere et exhaurire nequit splendidissimam $^{b}$ ) lucem; abditi illius solis iubar intueri et spectare nequit, cuius, ut sacra canunt eloquia ${ }^{2}$ ), "sicut tenebre eius, ita et lumen eius.»

\section{đ Muta animantia nullam Dei consequi noticiam.}

Cap. XXXV.

Unde fit, ut quecunque infra Hominem stata sunt, muta animantia, nullam veri naturalisque sui solis noticiam consequantur.

$\nsubseteq$ Ad illius enim immensum iubar ex toto caligant atque cecutiunt. In perpetuis totius invisibilis fontalisque lucis tenebris degunt. Ignorant eum, qui altissimas et eminentissimas lucis tenebras posuit latibulum suum. ${ }^{3}$ ) Sapientie sunt expertia neque seipsa quidem norunt neque suum autorem et opificem Deum. Nam neque corpore neque spiritu ipsos exterebrare celos aut in sydereos attolli thalamos nata sunt. Tota equidem in terris orta nataque sunt: tota quoque in terris emori, occumbere et occidere nata.

đ Fit etiam, ut omnis immaterialis cognitio et Sapientia ad senarii, primi perfecti numeri ${ }^{4}$ ), mensuram rite compleatur. Sunt enim immateriales cognitiones numero quidem sex, specie tamen haud tribus plures: Mens, Intellectus, Ratio. Tres quippe sunt Mentes, duo Intellectus, Ratio unica. đ Nam Mentem diffinimus eiusdem ab eodem conspectum, scientiam, noticiam; Intellectum vero noticiam esse proximi et attigui a proximo et immediato; Rationem denique cognitionem mediatam esse fatemur, qua principium finem per medium exquirit, vestigat scrutaturque.

a) granastellus $e d$. b) spendissimam $e d$.

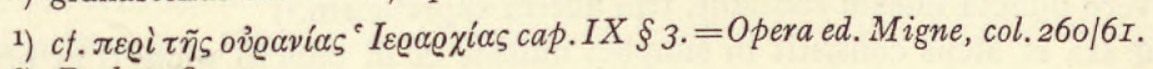

2) Psal. 138,12 .

3) cf. Psal. I7, I2.

4) cf. Epistolam ad Germanum Ganaiensem (Germain de Ganay), 6. Sept. I5IO, p. $I 63^{\mathrm{v}}\left[I 73^{\mathrm{v}}\right]$, sq.; de duodecim Numeris: de hexade cap. I, p. I5 $I^{\mathrm{v}}$ $\left[I 53^{\mathrm{v}}\right]$; de perfectis Numeris, praefatio, $p \cdot I 69^{\mathrm{v}}\left[I 7 I^{\mathrm{v}}\right]$ sq. 
Trine Mentes $q$ Trine igitur sunt Mentes: prima, qua cognitus est a Deo Deus; seDuo Intellectus cunda, qua ab Angelo Angelus; tertia, qua ab Anima Anima. đq Duo pariter sunt Intellectus: primus, quo Deus cognitus est ab Angelo; secundus, quo Angelus ab Anima. Nempe inter Deum et Angelum et

Unica Ratio inter Angelum et Animam medium interhyat nullum. đ Unica vero Ratio est, qua Deus per angelicum ${ }^{a}$ ) medium nostris Animabus innotescit. Obtinet enim Angelus medium inter Deum et Animam locum eoque traduce divine lucis iubar divinusque fulgor in Animam usque nostram pertingit atque derivatur.

\begin{tabular}{|c|c|c|c|c|}
\hline \multirow[t]{6}{*}{ p. $137^{r}\left[139^{r}\right]$} & Deus & Deus & Mens & prima \\
\hline & Angelus & Angelus & Mens & secunda \\
\hline & Anima & Anima & Mens & tertia \\
\hline & Deus & Angelus & Intellectus & primus \\
\hline & Angelus & Anima & Intellectus & secundus \\
\hline & Deus & Anima $^{b}$ ) & Ratio & unica \\
\hline
\end{tabular}

ণ Ad hunc itaque modum immateriales cognitiones, que Contemplationes et Sapientie dicuntur, specie quidem solam tryadem secundumve trigonum implere probantur, numero vero ipsam exadem, trigonum tertium primumque perfectum, restituunt:

\begin{tabular}{|c|c|c|}
\hline Deus & Angelus & Anima \\
\hline Mens & Mens & Mens \\
\hline & Intellectus & Intellectus \\
\hline
\end{tabular}

đ Est autem Mens ut punctum, monas, unitas; Intellectus ut linea, duo puncta et dyas; Ratio vero ut superficies, tria puncta, tryas. $₫$ Nam Mens sola unitate perficitur, Intellectus duobus extremis clauditur, Ratio vero in tribus: principio, medio et fine consistit. Punctum enim unitas quedam est, linea dualitas et puncta duo, superficies vero trinitas et puncta tria. Unum quippe punctum haud aliud est quam punctum, duo vero puncta lineam conflant, tria autem superficiem. ${ }^{1}$ )

q Ita et Mens consistit in simplici unitate et in puncto subiecti et obiecti; Intellectus in eorum dualitate et linea; Ratio in eorum trinitate
a) angelum $e d$.
b) Anima | Deus ed.
$\left.{ }^{1}\right)$ cf. de duodecim Numeris: de decade cap. IV. 
et superficie. $₫$ Nam seorsum hec tria puncta: Deus, Angelus, Anima tres Mentes sunt. He vero due linee: Deus Angelus, Angelus Anima, duo sunt Intellectus. At hec tria simul: Deus, Angelus, Anima, que sunt una superficies, unam Rationem unamve mediatam Dei cognitionem conflant, cuius principium idque, quod discurrit, Anima est; medium, per quod fertur et motus ipsius lux, Angelus; finis vero idque, quod perquiritur, Deus.

đ Trina igitur est Mens, trinus Intellectus, trina et Ratio: diversis tamen modis et causis. Nam Mens est trina numero, cum sint tres Mentes, termini tres et puncta tria: Deus, Angelus, Anima. Intellectus sunt numero quidem tantum gemini; quia tamen in tribus terminis: Deo, Angelo et Anima ambo Intellectus clauduntur, trinus Intellectus censetur. Ratio pariter numero unica et sola est, substantia tamen et coalitione trina; conflatur enim Ratio his tribus: Deo, Angelo et Anima. Dicitur quippe Ratio Anime ratiocinatio, qua per Angelum in Deum evadit, qua angelico medio inseritur Deo suoque fine et naturali sole potitur.

\begin{tabular}{|c|c|c|c|c|}
\hline I & Mens & Deus & & \\
\hline 2 & Mens & Angelus & & \\
\hline 3 & Mens & Anima & & \\
\hline 4 & Intellectus & Deus & Angelus & \\
\hline 5 & Intellectus & Angelus & Anima & \\
\hline 6 & Ratio & Deus & Angelus & Anima \\
\hline
\end{tabular}

đ Accidit enim in Anima quod in dyalecticis sillogismis; hi namque et Analogia Anime ad terminis et enunciationibus sunt trini. Enunciationum vero et pro- dyalecticum sillopositionum due sunt prime, immediate, precipue, simplices et intellectuales, quarum una maior, alia minor vocari solet. Reliqua vero propositio mediata, media, rationalis et extremis illata, quam illationem et conclusionem vocant. $₫$ Simplicior autem est in sillogismis terminorum et vocum notitia cognitione propositionum et simplicior iterum premissarum cognitio illationis scientia. $₫$ Sit itaque trium terminorum noticia velut trina Mens; premissarum cognitio sit geminus Intellectus; illationis vero scientia Ratio vocitetur. Liquet quanta concinnitate ex tribus Mentibus duo Intellectus et ex geminis Intellectibus una pendeat Ratio atque illatio.

đ Ita igitur et in Anime discursu perge. Dic imprimis Deum sibiipsi Anime discursus notum, Angelum sibi, Animam iterum sibiipsi; he sunt tres Mentes, he simplicissime omnium cognitiones. Deinde enuncia Deum de Angelo et 
Angelum de Anima, cognitum inquam esse ab Angelo Deum et ab Anima Angelum; geminos hoc pacto componis Intellectus: illum maiorem, hunc vero minorem. Deinde inferendus abs te est cognitus ab Anima Deus; que est immaterialium ${ }^{\text {a) }}$ ) cognitionum ultima, priorum gnaritatum illatio, Anime consummatio, ratiocinatio et Sapientia.

\begin{tabular}{|c|c|c|}
\hline Mens & Mens & Mens \\
\hline Deus & Angelus & Anima \\
\hline Maior & & ellectus \\
\hline
\end{tabular}

đ Hoc rationali sillogismo, hac ratiocinatione atque discursu rationalis Anima perficitur, sapiens fit, evadit in Deum. Angelus siquidem prius et per se evadit in Deum; Anima autem sine medio evadit quidem in Angelum, per Angelum autem assumitur in Deum.

q Irrationalis autem anima in Deum transit nunquam. Eius etenim cognitio, quam sensitivam vocitamus, versatur in abdito et in profundo et est ut puncta quattuor ${ }^{1}$ ) sive ut corpus undecunque dimensum, con|p. $137^{\mathrm{v}}\left[\mathrm{r}_{39^{\mathrm{v}}}\right]$ flatum, compositum, sectile et nulla ex parte unum, simplex, immortale. Cetere autem cognitiones tres immateriales sunt, impertes, immortales, simplices et ut trini magnitudinum termini: punctum, linea, superficies.

đ Denarium numerum cognitionibus restitui.

Cap. XXXVI.

Insuper fit, ut ad decadis et quarti trigoni numerum excrescat omnis cognitio. ${ }^{2}$ ) Nam cognitio omnis aut Mens est aut Intellectus aut Ratio aut Sensus. Atqui Mens unitate, ut diximus ${ }^{3}$ ), conflatur, Intellectus dualitate, Ratio trinitate, Sensus quaternitate; que simul decadem implent. $₫$ Mens est ut punctum, Intellectus ut linea, Ratio ut superficies, Sensus ut corpus. Mens Dei propria est, Intellectus Angelorum, Ratio Hominum, Sensus irrationalium animalium.

a) materialium $e d$.

1) cf. p. 376 n.I.

$\left.{ }^{2}\right)$ cf. de duodecim Numeris: de decade cap. II-IV; V.

3) p. 376 . 


\begin{tabular}{|l|l|l|l|}
\hline Deus & Angelus & Homo & Animal irrationale \\
\cline { 2 - 3 } Mens & Intellectus & Ratio & Sensus \\
\cline { 2 - 3 } & Linea & Superficies & Corpus \\
\hline I & 2 & 3 & 4 \\
\hline
\end{tabular}

$₫$ Et harum quattuor cognitionum sicut potissime tres immateriales ${ }^{a}$ ) sunt, cetera vero materialis: ita et abiectissime tres create sunt, sola vero precipua et suprema increata et eterna. Create sunt he: Intellectus, Ratio, Sensus; Mens vero sola increata. Immateriales autem sunt he: Mens, Intellectus, Ratio; materialis vero sola sensitiva.

ণ Angelus prior Deo inseritur fitque cum Deo unus. Deinde Anima una fit cum Angelo; postremo Anima una cum Deo.

q Huiusce quippe ratiocinationis et substantialis sillogismi, quo Dei et Substantialis sylloAnime inferenda unitas est, Deus et Anima ${ }^{b}$ ) extremi termini sunt, megismus dius autem terminus Angelus est.

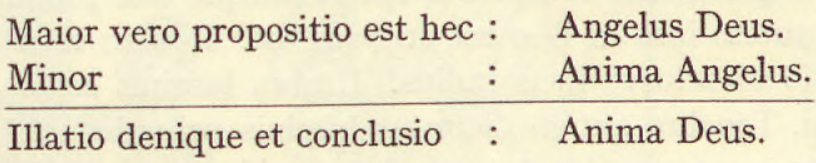

đ Hoc enim pacto perge, discurre, conclude:

Angelus est Deus.

Anima Angelus est.

\section{Igitur Anima Deus est.}

Ubi namque Angelus vi cognitionis in Deum evasit et coniunctus Deo est, aliquo pacto Deus est. Identidem et Anima in Angelum prior quam in Deum velivolat atque irremigat tandemque per Angelum in Deum evadit. $₫$ Nam et superiora et priora, ut logici volunt, ad inferiora et posteriora enunciantur. Deus autem superior est Angelo; Angelus vero prior et superior Anima. Quatenus igitur inferiora et minus precipua in prestantiora et potiora evadere nituntur: dicitur imprimis Deus de Angelo, deinde Angelus de Anima, postremo Deus de Anima. Hec enim substantialis ratiocinatio in prime syllogismorum figure dispositione, modo et ordine contingit: qua per extremas unitates Angeli et Dei, Anime et Angeli rationalis Anima Deo copulatur atque inseritur.

\footnotetext{
a) materiales $e d$.

b) angelus ed.
} 
đ Quod omnis cognitio pro viribus in Deum intenta.

Cap. XXXVII.

Deus cum sit precipuus et verissimus totius nature sol et supremum omnis cognitive facultatis obiectum, omnis vis cognitiva, quantum ipsi indultum est, in Deum ut potentia in actum convertitur; et est ut quidam ipsius Dei aspectus, fulgoris ipsius receptaculum naturalisve emanatio. Unaqueque enim vis cognitiva, quoad permittitur, nititur in Deum, ut in proprium obiectum, ut in verum solem, ut in finem suique consummationem.

Non eodemmodo đ Ceterum non modo eodem omni cognitive facultati pellucet, revelatur omni cognitive fa- reseraturque Deus: non facie eadem eodemve aspectu Intellectui, RaDeus tioni et Sensui nudatur discooperiturque. Nam Intellectui revelatur in lumine, Rationi in umbra, Sensui in tenebris. Ab Angelo siquidem conspicitur clarus et nudus, ab Homine umbratilis; ab irrationali animanti cum nullo pacto spectetur Deus, ab eodem in tenebris, in nocte, in totius lucis privatione conspicuus spectabilisque esse pronunciatur.

Lux. Lumen. $q$ Lux autem ipsa in Deo est et Deus est. Lumen vero prima est lucis

Umbra. Tenebre emanatio directusve lucis radius. Umbra luminis est aut refractio aut reflectio. Tenebre autem dicuntur luminis privatio. $₫$ Lux in sole est et nativa quedam solis claritas. Lumen id est, quod directo et infracto radio a sole derivatur, ut quicquid est a sole usque ad nubes. Umbra est lumen refractum, quale sub nubibus visitur usque ad terre superficiem. Tenebre sunt defectus luminis, qualis a terre superficie ad usque eius meditullium et centrum contingit. $₫$ Lux est precipua et prima; lumen lucis est species; umbra luminis vestigium; tenebre privatio et non ens. $₫$ Quandiu lucis radius per simile medium fertur, unus, continuus, p. $\mathrm{r}_{3} \mathrm{gr}^{\mathrm{r}}\left[{ }_{4} \mathrm{Or}^{\mathrm{r}}\right]$ directus et / infractus: lumen est. Ubi vero dissimili quidem ac densiore medio, sed transparente atque inopaco frangitur, spargitur, multiplicatur, ut ab occursu nubium: umbra censetur. Ast ubi medium occurrit intransparens, solidum, opacum, ut terra, illic tenebrarum est initium, ibi totius lucis occidit interitque species; est enim opacum corpus ab luce impenetrabile.

đ Omnem igitur a sole et celo ad terre usque centrum mundi regionem in quattuor partimur: in regionem lucis, luminis, umbre, tenebrarum; atque in his ipsis volumus omnem Dei aspectum, cognitionem et scientiam contineri easque esse ut naturales rerum omnium mansiones ac sedes. $₫$ Deus enim est in regione lucis, Angelus in regione luminis, Homo in regione umbre, irrationale animal in regione tenebrarum.

đ Lucis regio est ipsum celum et universa celorum spissitudo. Locus vero et regio luminis est igneum elementum et superior aeris regio seu 
quicquid est a lune concavo ad nubium convexum. Universa enim hec regio orbicularem celi motum imitata: serena, tranquilla et pacata mitissimas ac saluberrimas auras volvit; nulla in ea gignitur nubecula nullave caligo, qua aut luminis radius frangatur aut umbella causetur. Umbre regio est, quicquid a nubibus usque ad terre faciem patet; huius enim regionis aer umbratilis et caliginosus, superiore insalubrior et impacatior reperitur. Tenebrarum regio est tellurea moles universa, que nullum lucis excipit admittitque iubar.

q Fons et ortus lucis est in celo. Lumen vero a celo ad nubes usque infractum, unum continuumque pertransit. Fractus autem a nubibus lucis radius ad terram usque umbre nomen sortitur. Quicquid denique sub terra, tenebre dicuntur. $₫$ Aliter igitur patet Deus Angelo, aliter Homini, aliter irrationali animanti. Divina enim species, que in Intellectu recipitur angelico, lumen est; que vero in humana Ratione, umbra; que autem in animalis Sensu, tenebre totiusque divine lucis privatio.

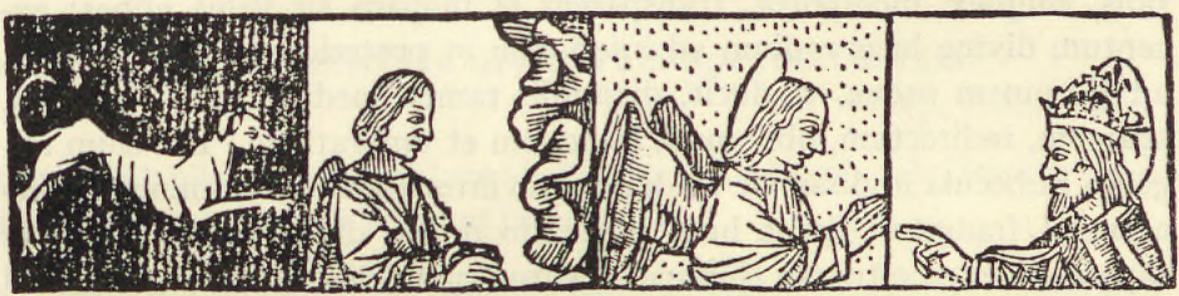

đ Unde fit, ut tantum due sint creature divine scientie participes, tan- Tantum due creaUnm due lucis ture divine scientie species: lumen et umbra. Lumen autem est angelica scientia, umbra vero participes scientia humana; tenebre autem solo nomine dicuntur tertia lucis species; re enim vera tenebre nichil sunt preter quam sola lucis privatio. $₫$ Angelicus igitur Intellectus Deum novit in prima lucis specie, ut in lumine; humana Ratio in secunda specie, id est in umbra; animalis Sensus in tertia lucis specie, id est in tenebris, in obscuro, in negatione et in mera lucis privatione, que est vera et sincera Dei ignoratio animali innata. đ Nam cognoscere in tenebris Deum haud aliud est quam ignorare Deum, speculari in tenebris Deum est non videre Deum, affici tertia divine lucis specie, id est divinis tenebris, est nullo pacto divina luce feriri $\left.{ }^{a}\right)$, nullam Dei suscipere speciem, nullam divini solis consequi gnaritatem.

a) feriari $e d$. 
đ Deum fontem esse lucis, Angelum vero primum esse lucis speculum. ${ }^{1}$ )

Cap. XXXVIII.

Angelicus Intellec- Rursum Deus fons est totius lucis et ut immensus eius sol. Angelus vero tus ut transparensa) est ut clara, candida et transparens nubecula Deo iugiter obiecta illique vicina, proxima, attigua. Manans quippe a Deo lucis radius nullo dissimili medio abercetur, qui.in angelicum usque Intellectum unus continuusque derivetur. Inter enim Deum et Angelum nichil interhyat, cuius obice ipsum lucis spiculum obliquum et indirectum ad latus incedat. Nichil est, quod divinum ab Angelo liquidum, sincerum ac nudum auferat aspectum; nil quod ipsi Angelo causet divini estus, ardoris et claritatis umbram.

q Prima itaque divine lucis extra Deum profectio, prima divine claritatis positio et emanatio primusve eius status, receptio et continentia angelicus est Intellectus sive angelica tota substantia. Hec autem cum spiritalis, simplex, incorporea, transparens et inopaca sit velut nubes: exceptum divine lucis radium ad inferiorem et posteriorem creaturam, ut ad Hominem usque, traducit, dissimilis tamen medii occursu fractum, sparsum, indirectum, obliquum, lateralem et umbratilem. Est enim angelica nubecula id dissimile medium, quo inter Deum et Hominem intercurrente frangitur divine lucis irradiatio quove divini solis ardores et supereminentes estus ab Homine arcentur, quo denique causatur Homini divine claritatis umbra. Cernit quippe Deum Homo haud, uti est, purum, simplicem, nudum, aspectu primo: sed in quadam umbra, sub caligine et nube angelica, sub mitiore et temperantiore aura et aspectu secundo.

p. $1^{38^{v}}\left[\mathrm{r}_{4} \mathrm{O}^{\mathrm{v}}\right] \mid$ | Est enim Homo secunda divine lucis positio, secundus eius attactus, status, susceptio, continentia et sedes. Hactenus itaque Homo divinus speculator et contemplator evadit, qua illi divina species, haud nuda sed sub transparenti angelici Intellectus caligine in umbra revelatur atque demonstratur.

Homo corpore in- $q$ At cum intransparens sit et impervius Homo totusque ab luce impertransparens transibilis, ut qui duntaxat candido et perlucido spiritu, terreo vero et opaco corpore conflatur: sistitur in Homine divina lux et ad ulteriora transmittitur nusquam. Opacitate siquidem et soliditate humani corporis continetur, arcetur et colligitur in Homine. $₫$ Humani igitur corporis opacitas divino obiecta intentaque soli ad postergatam et inferiorem creaturam, ut ad irrationale animal, tenebras emanat funditque omnem divine lucis inaspectum et Sapientie privationem.

a) Intransparens $e d$.

1) cf. de Intellectu: cap. IV 3-6. 
đ Est enim cominus sub Deo collocatus Angelus, sub Angelis Homo, sub Homine vero irrationale animal. Angelus rursum sub nullo medio Deum speculatur atque intuetur. Homo vero sub nube et angelico spiritu Deum videt. Irrationale autem animal, cum nullo pacto divine sit scientie aut speculationis consors, persimile est ei oculo, qui mersus in terre profundo tellureaque mole obrutus solem intueri contendit; obruta etenim est irrationalium animantium acies mole humani corporis, per quam, ut diximus, divina luce irradiari ${ }^{a}$ ) prepeditur.

đ Rursum humane umbre causa est angelicus spiritus; tenebrarum vero irrationali animali causa corpus humanum. Et sicut divina prima et immediata species lumen est, quo pascitur, afficitur et illustratur angelicus Intellectus: ita et angelica species est umbra, qua Homo humanusve Intellectus satiatur. Humana vero species humanive corporis irradiatio tenebre sunt, que ab humano corpore in animal irrationale manant, illud operiunt faciuntque divine cognitionis expers.

\section{đ Iterum de diversitate divinarum speculationum.}

Cap. XXXIX.

Contemplabilis autem est Deus ab Angelo velut in celo, ab Homine velut in nubibus, $\mathrm{ab}$ animali bruto ut in terra.

đ Statue quippe angelicam aciem in celo, humanam in nubibus, animalium oculum in terra: ac dilucide perpendes uniuscuiusque speculatoris oculi naturam. Nam si prestantius est celum nubibus ipsique Deo vicinius, utique et hic oculus, quem in celo collocabis, propiore brevioreque radio illustrabitur a Deo eo oculo, cui in ipsis nubibus deputaveris sedem. Et sicut celum et nubes corpora sunt suapte natura transparentia lucisque capacia, terra autem corpus opacum, luci impervium: ita et hi profecto oculi, qui in celo et nubibus collocantur, ambo divini luminis participes ${ }^{b}$ ) fiunt; que vero acies in terre profundo residere probatur, ad illam usque divina lux pertingit minime.

đ E tribus igitur creatis oculis: angelico, humano, animali, sive intellectuali, rationali, sensibili potissimi duo - quanquam differenter - ad naturalis sui solis, hoc est Dei conspectum, admittuntur. Angelica nempe acies Deum in lumine, humana vero eundem in umbra speculatur. Reliquus autem oculus, qui mutis animantibus inest: hic et nullo pacto suum solem intueri posse et in tenebris illum speculari pronunciatur.

đ Et ut hec evadant clariora, intellige omnem vim cognitricem, ut alibi Quadrigemini oculi

a) irradiri $e d$.

b) particeps $e d$. 
diximus $^{1}$ ), quaternario claudi finirique numero sive omnem speculatorem oculum esse quadrigeminum: divinum increatum, ceteros vero tres, angelicum, humanum, animalem e divino oculo vi creationis quandoque emersisse. Voca insuper divinum oculum lucem, angelicum albedinem, humanum ruborem, animalem nigritatem. Sicut enim lux fons est et initium et actus colorum omnium, cunctis coloribus longe prestantior: ita et divinus oculus fons est et initium omnium oculorum. Et sicut omOmnis color lucis nis color trinis tantum coloribus exprimitur, duobus inquam extremis et species colore medio: ita et omnis creatus oculus est trinus. Omnis enim color species quedam est et emanatio lucis; omnis quoque creatus oculus divine increate aciei species est et substantialis emanatio.

đ Sint igitur nunc pro coloribus extremis albedo, nigredo; pro medio vero colore rubor. Dicemus divinum oculum sibiipsi ab eterno in luce et fonte colorum perspectum suique speculatorem ante omne principium extitisse. Angelicum vero oculum fatebimur in prima lucis specie, hoc est in albore sive in lumine, ad divini oculi admitti conspectum. Humanum porro oculum divine aciei in secunda lucis specie, hoc est in rubore et umbra, evadere speculatorem. Oculo vero animali haud aliter quam p. ${ }^{3} 39^{r}\left[{ }^{1} 4^{r}\right]$ in extrema lucis specie, id est in nigritate atque | in tenebris, divinam aciem revelari dicimus. $₫$ Perspectus est itaque sibiipsi Deus ut sincera et immaculata lux; Angelo vero revelatur ut infigurata albedo et lumen, Homini velut rubor et umbra, muto animanti ut nigritas et tenebre.

\begin{tabular}{|l|l|l|l|}
\hline Deus & Angelus & Homo & Animal \\
\hline Mens & Intellectus & Ratio & Sensus \\
\cline { 1 - 2 } Lux & Lumen & Umbra & Tenebre \\
\cline { 2 - 4 } Lux & Albedo & Rubor & Nigredo \\
\cline { 2 - 3 } Supercelestia & Celum & Nubes & Terra \\
\hline
\end{tabular}

đ Divina rursum in Angelo apparitio persimilis est aspectui meridiani solis, qui sine nubibus nostris oculis imperturbatus, liquidus, sincerus, purus albusque nudatur. Divina vero in Homine apparitio medio solis aspectui, hoc est in ortu et in occasu, pari proportione respondet; oriens quippe aut occidens Phebus longiore infirmioreque radio nostris oculis imprimis pellucet et nequaquam purus aut albicans, sed per medios vapores, rubens umbratilisque demonstratur. Divina denique in sensibili

1) de Sensu, exodium; cf. de duodecim Numeris: de tetrade, cap. II; de Sapiente: cap. XXXVI. 
oculo emicatio tam nulla est, quam sol in medie noctis puncto conspici nequit.

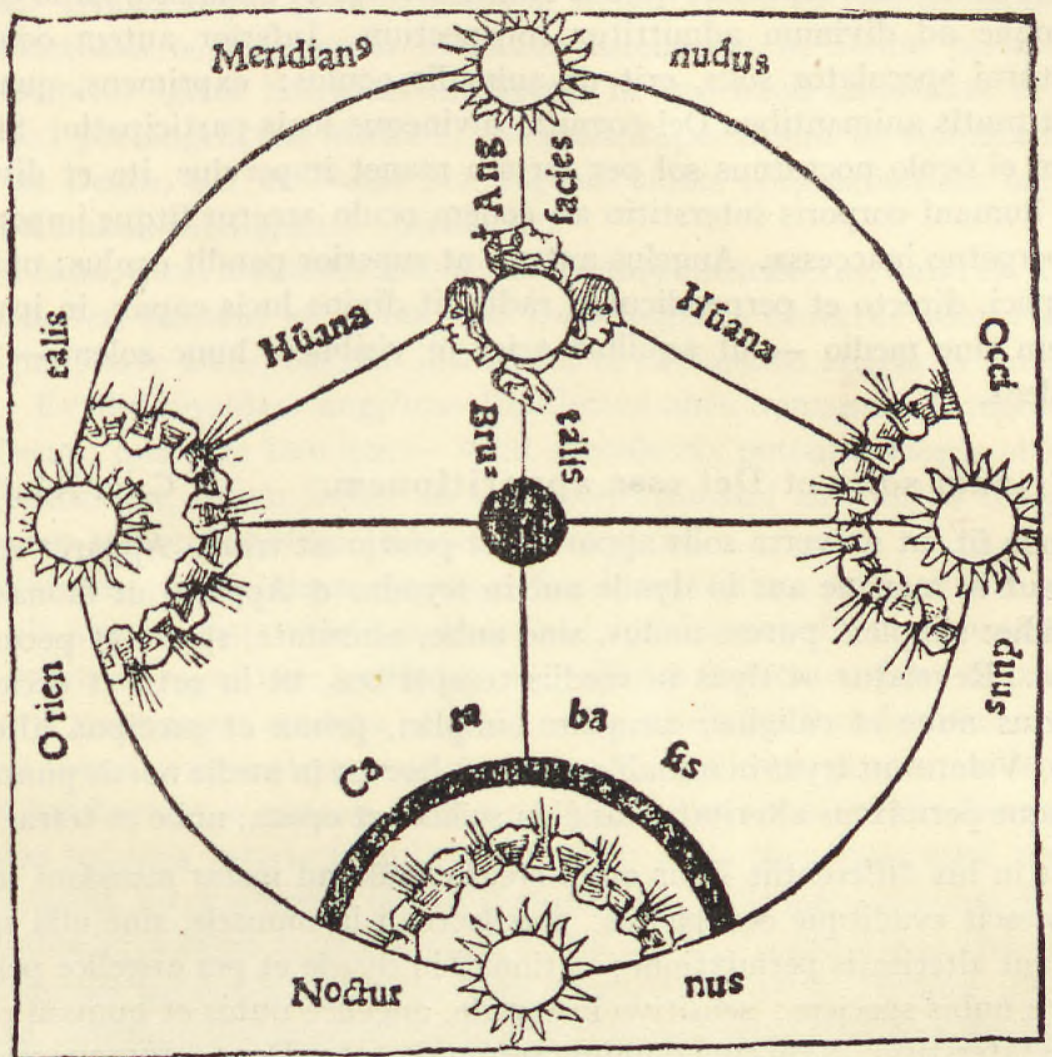

$₫$ Angelica facies sursum in Deum intendit, ut ad meridiei punctum aut ad zenith orizontis et hemisperii conversa. Humana in utramque partem et ad latera - nam bifrons est Homo - Deum ut solem nunc orientem, nunc occiduum videt. Ast irrationalium animantium capita in terram sunt prona et ad medie noctis punctum vergentia. $₫$ Nam finge in celo soles quattuor: meridianum, orientem, occiduum et nocturnum; meridianum sincerum et nudum; orientem vero et occiduum velut per nubes apparentem, nebula circundatum; nocturnum denique ut sub terra delitentem, opertum terra. Intellige et orbem aliquem inter terram et celum in nostro hemisperio omnem vim intuitivam aspectumque librantem atque deferentem; circa quem pinge quattuor aspectus oculosve aut facies quattuor. 
Differentie specula- $q$ Superior igitur oculus versus in meridianum solem erit ut angelicus tionum per solis Intellectus. Medii oculi, qui orientem et occiduum intuebuntur solem, erunt ut humani aspectus, quibus Homo dividue et obliquato radio ultro citroque ad divinum admittitur conspectum. Inferior autem oculus, nocturni speculator solis, erit ut animalis oculus: exprimens, quanta insit mutis animantibus Dei cognitio divineque lucis participatio. Sicut enim ei oculo nocturnus sol per terram manet impervius, ita et divina lux humani corporis interstitio ab eodem oculo arcetur fitque impervia et perpetuo inaccessa. Angelus autem, ut superior pandit oculus: unico, simplici, directo et perpendiculari radio fit divine lucis capax, in ipsum Deum sine medio - ut aquilina acies in visibilem hunc solem - intendens.

\section{đ Trinam solis et Dei esse apparitionem. $\quad$ Cap. XL. ${ }^{a}$ )}

p. $139^{v}\left[\mathrm{I}^{\mathrm{r}} \mathrm{I}^{\mathrm{v}}\right]$ | Unde fit, ut universa solis apparitio et positio sit trina. Apparet enim sol aut in monade aut in dyade aut in tryade. $₫$ Apparet ut monas in meridie: simplex, purus, nudus, sine nube, alteritate, specie et permixtione. Revelatur ut dyas in mediis temporibus, ut in ortu et occasu: opertus nube et caligine, tanquam simplici, prima et precipua alteritate. Videtur ut tryas in mundi cathabasi, hoc est in medie noctis puncto: utraque permixtus alteritate, candida scilicet et opaca, nube et terra.

q Et in his differentiis Deus omni creato oculo ad instar mundani solis innotescit evaditque conspicuus: intellectuali in monade, sine ulla speciei aut alteritatis permixtione; rationali in dyade et per angelice pellucentis nubis speciem; sensitivo in tryade, angelice nubis et humani corporis interstitio. Nam cum omnium rerum sit autor Deus earumque verissima essentia, solus omnia fert, solus continet gestatque universa; omnia in eo fulciuntur et in eundem evadere singula iuxta suum queque gradum nata sunt. $₫$ Et precipue ea, quibus cognitiva adest facultas, quecunque vi naturalium cognitionum predita et illustrata sunt: ut Angelus, Homo, animal, cetera cuncta anteeunt entia suisque gradibus in sui prospectu autoris versantur.

Angelus in Deum $q$ Angelus autem coram Deo primus, in Dei locatus vicinia et propinquitate: divine lucis splendidissimum iubar liquida et imperturbata acie haurit primusque sine medio in Deum evadit, recipitur in Deo, Deus fit, inseritur Deo, unitur Deo fitque divini solis prima ad sequentium oculorum aciem obumbratio.

Homo post Angelum $₫$ Post autem Angelum Homo per angelicam transparentiam et divina in Deum evadit imprimis luce feritur et demum subvectante eadem claritate in Deum

a) XLI ed. 
evadit. Eodem quippe medio, quo divina claritas a Deo in Hominem manat, descendit derivaturque, Homo in Deum scandit, evadit fitque Deus. Evasit autem prior Angelus in Deum; prior in Deo receptus est intellectualis oculus, quam humanus Intellectus in Deum perveniat. $₫$ Recipitur igitur humanus Intellectus in Deo haud immediate et per se, sed per angelicum medium. Neque insuper Deum ut simplicem et per se Deum, sed ut Deum per angelice nubis transparentiam micantem humana intelligentia speculatur.

đ Id enim, quod humanus speculatur videtque Intellectus, haud est Deus Angelica mens prior simpliciter, sincerus et nudus: sed Deus angelica obtectus adopertusve quam humana in caligine; sive Deus, cui iam insitus est et coniunctus angelicus Intellectus. Evadit siquidem angelicus Intellectus ante humanum Intellectum in Deum, qui cum Deo ipsi - velut speculatrix potentia suopte obiecto - insitus est, ipsum Deum ad sequentem humani Intellectus conspectum sua nubecula obtegit, adoperit, obumbrat.

đ Post denique Hominem quarto a Deo loco, tertio a prima creatura, id est ab Angelo, distat irrationale animal, quod unica duntaxat materiali et sensitiva cognitione preditum est. Huius autem oculum si pariter dixeris suo quoque numero et gradu: tam ut divina luce feriatur, quam ut in Deum evadat atque pertranseat eniti, - dicam quoniam et eius a Deo irradiationi et proprio nisui seu delationi ac transitioni in Deum -, obstat humana interiecta substantia. Hec enim cum materialis, corporea, opaca, intransparens et luci impervia sit: per eam neque lux divina in animalis oculum traduci neque in Deum ferri copularique Deo idem irrationalis oculus potest. Ubi enim receptus est in Deo Homo, ubi humana substantia coniuncta et inserta Deo est: incassum expers Rationis animal aut divinam exhaurire lucem aut in ipsum Deum evadere contendit.

đ Procedens quippe a Deo divina lux pertransit quidem angelicam men- Processus divine lutem sinceram, incorpoream, immaterialem velut nubem transparentem atque inde in humane usque mentis oculum lux eadem pergit facitque Hominem divine scientie consortem. At humana mens cum inferiore ex parte materiei et corpori addicta sit, mox ipsius corporis opacitate lux eadem in Homine colligitur, sistitur et in inferiorem irrationalemve oculum derivari inhibetur.

đ Est enim humanum corpus terminus divine lucis, in quod usque per- Humanum corpus lata divina lux mox illius attactu, opacitate ac soliditate resilit recurrit- divine lucis reflexio que in eum fontem, quo prius emersit. Est et humanum corpus eorum, que in Deum assumuntur queve Deo inseruntur, ultimum; a Deo ut rite diffiniri humanum corpus possit divine totius lucis meta eiusque reflexio et in suum fontem recursus. 
$₫$ Sunt enim tria duntaxat, que in Deum evadere illique copulari queant: angelica mens, humanus animus et humanum corpus. Sed cum ex humano animo et humano corpore confletur a natura humana tota substantia, cuius verus et precipuus oculus rationalis appellatur, tantum duo entia in Deum assumi nata esse profitemur: Angelum et Hominem, tantumque geminos esse oculos: intellectualem et rationalem, qui divinum increatum oculum iugiter spectare et intueri sint nati, intellectualem in lumine, rationalem in umbra. $₫ \mathrm{Ex}$ his itaque, que dicta sunt, hec elicimus. Sicut Deus suapte natura et substantia ab eterno Deus est, ita p. 140 $^{[}\left[{ }^{1} 4^{2}\right]$ et Angelus | et Homo vi immaterialium cognitionum et illustrantur a Deo et divine lucis participatione in Deum assumuntur.

Eadem via descensus lucis ab obiecto et ascensus potentie in obiectum

$q$ Vis etenim obiecti, ut lux manans ab obiecto in speculatricem potentiam, eandem potentiam ipsi obiecto inserere probatur, quemadmodum linea est eadem, qua divina lux in angelicam humanamque mentem descendens spargitur superneque illabitur et qua demum utraque mens in ipsum Deum scandit illique copulatur.

ণ Irrationale autem animal, ut dictum est ${ }^{1}$ ), neque divinum excipere lumen neque in Deum scandere potest. Obest enim illi utrinque humani corporis moles, per quam geminis de causis Deo inseri Deusque fieri prohibetur: prima causa est ex parte ipsius lucis, secunda ex parte aciei et spectantis oculi. Nam divina ipsa lux, ut diximus ${ }^{2}$ ), trans humanum corpus in animalem oculum traduci nequit, utpote que in humano corpore sistitur. Acies item irrationalis oculi invalida ac hebes humani corporis soliditate abercetur, ne quicquam, quod supra humanum fuerit corpus aut quod in illius claustris deliteat, conspicetur.

q Et hec universa clarius perpendes, si in quattuor orbibus omnem oculum collocabis. Divinum in orbe medio et omnium centro. Intellectualem sive angelicum in orbe secundo, qui undecunque in divinum nitatur evoletque oculum. Rationalem in orbe tertio, qui pariter, sed post angelicum oculum divinam aciem undecunque speculetur. Animalem denique oculum in orbe quarto et ultimo. Divinus autem oculus, cum sit immultiplex et natura unicus, fiat in medio circulo tantum unus; creati vero oculi, cum in multitudine et varietate pene innumera increati divini oculi explicent unitatem, plurimi sunt circa oculum divinum describendi.

q Sed et cum divina Mens dicta sit $^{3}$ ) esse lux, angelica velut lumen et albedo, humana ut rubor et umbra, animalis oculus ut nigredo et tenebre:

\footnotetext{
1) cap. XXXVIII, XXXIX.

2) cap. XXXVIII.

3) cap. $X X X I X$.
} 
hic orbis, in quo Deum aut divinum collocabis oculum, pingendus est abs te aureus, quandoquidem aureum imitari colorem fontana et intentissima lux (qualis in sole) videatur; orbis autem secundus, quem complent Angeli, albus est relinquendus; orbis tertius, que mansio Hominum est, rubro colore inficiendus erit; quartus denique orbis, qui animalium mansioni deputatur, atro pullove colore nigrescat. Irrationalium siquidem animalium oculi ad divinum conspectum ex toto cecutiunt deguntque in regione tenebrarum et in omni divine lucis ac Sapientie occasu.

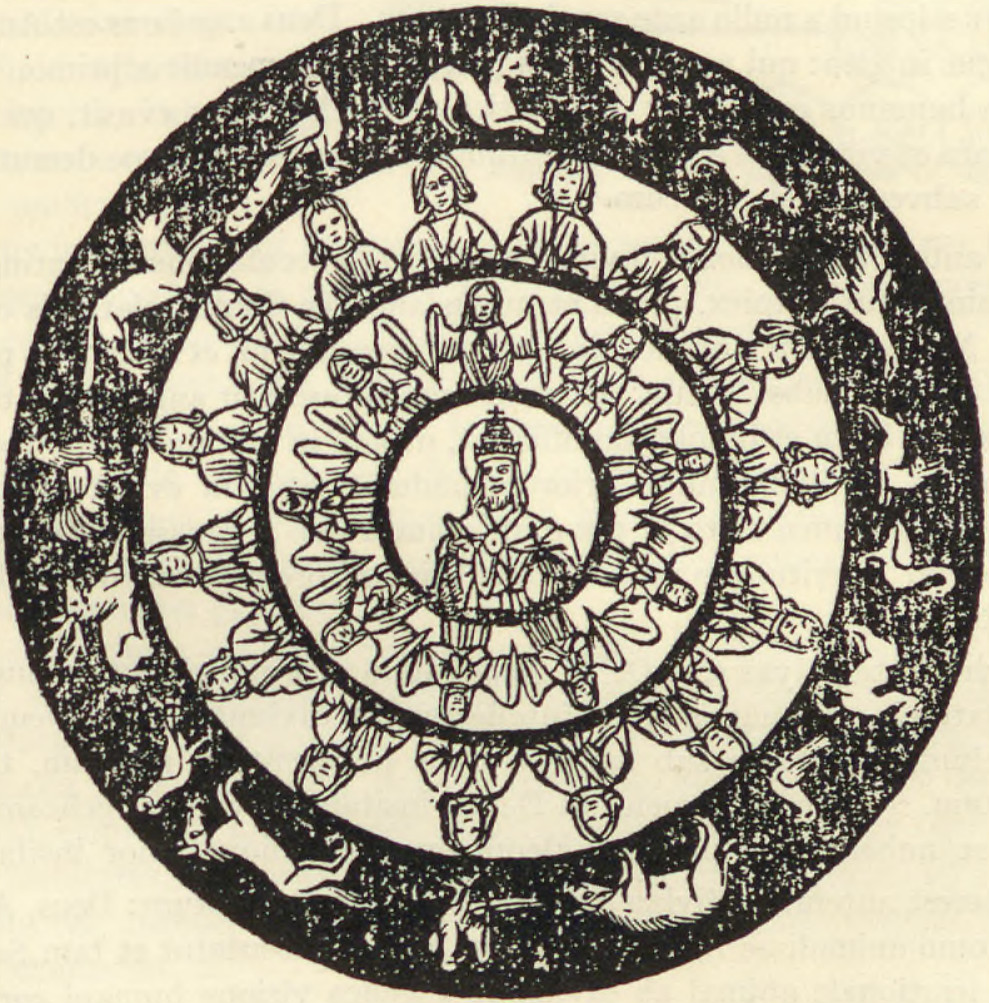

đ Hi itaque quattuor orbes adaperiunt palam, quo pacto Deus simpliciter, hoc est nudus, sincerus purusque, Angelis demonstratur; Hominibus vero haud simpliciter ac nudus, sed angelicis Intelligentiis undecunque adopertus; irrationalibus autem oculis cum et angelicis Intelligentiis et humanis Animis atque corporibus obtectus circundatusque suffulgeat, nullo pacto ab iisdem spectabilis esse predicatur. 
p. ${ }^{14^{v}}\left[{ }^{1} 4^{v}\right] \mid q$ Deum extrorsus perinde atque introrsus esse trinum.

Cap. XLI. ${ }^{a}$ )

Si Angelus et Homo et divine lucis influentia et sacro quodam nisu in Deum assumuntur, fiunt utique participatione dii, pro viribus illum imitantes, qui ut naturalis, verus, eternus precipuusque Deus celebratur. Evadit itaque angelica et humana insitione naturalis Deus tam extra seipsum quam intra semetipsum trinus: Deus inquam divinus, Deus angelicus et Deus humanus. Deus enim divinus est verus naturalisque Deus: qui per seipsum a nullo ante secula Deus est. Deus angelicus est Angelus exceptus in Deo: qui a seipso Deus non est, sed pependit a primo. Deus autem humanus est Homo: qui participatione Dei Deus evasit, qui Substantiam et vires cum a primo naturalique Deo acceperit, ope demum angelica subvectus est in Deum.

Angelice specula- $₫ \mathrm{He}$ autem subvectiones divinarum virtute speculationum contingunt. Est enim Deus simplex, purus et nudus angelice Contemplationis obiectum. Nil siquidem angelico Intellectui presentatur et objicitur preter solam divinam substantiam; in quam cum subvehitur angelicus Intellectus, puram illam et immixtam offendit, utpote in qua nulla ante recepta est species, in quam nulla prior secundum naturam evasit creatura; prima igitur immaculato et per omnia sincero ac serenissimo Deo angelica inditur inseriturque mens, prima illius nitorem humano Intellectui obumbrat.

Humane specula- $₫$ Divina autem dyas sive Dei et Angeli unio exprimit obiectum humane speculationis. Humanus enim Intellectus, ut diximus ${ }^{1}$ ), non Deum videt solum, sed Deum sub angelica nube pellucentem, pervium, transparentem. Nam cum pervenit in Deum, insitam illi videt angelicam speciem et nubem, que prior in Deum evaserat illique prior insita est. đ Superest autem, ut divina quedam tryas sive hoc totum: Deus, Angelus, Homo animali ac Sensui objiciatur atque presentetur et tam Sensus quam irrationale animal ab divina et angelica visione humani corporis obice et opacitate arceantur.

Illatio $q$ Unde fit, ut videatur Deus ab Angelo ut sol: purus, nitidus, immixtus, sine ulla specie et maculosa facie, sine caligine et nube. Ab Homine vero ut luna: velut sub insitione angelice speciei, sub maculosa facie, sub nube et caligine. $\mathrm{Ab}$ animali autem ut terra: per humani corporis speciem, per materiam et humanas tenebras. đ Apparet item Angelo per se, ut sol

a) $\mathrm{XL} e d$.

1) cap. XXXVIII, XXXIX. 
candidus et albus; Homini per angelicam nubem, rubens ut luna; animali per materialem Hominis substantiam, nigricans ut terra, id est in privatione, negatione et ignorantia. Sunt enim albedo et nigredo extremi colores, rubor vero medius et derivaticius color. Albedo omnium colorum est simplicissimus et primus, nigritudo vero eorum finis. Albor lux quedam est, rubor lux in nube et quedam umbra, nigri-

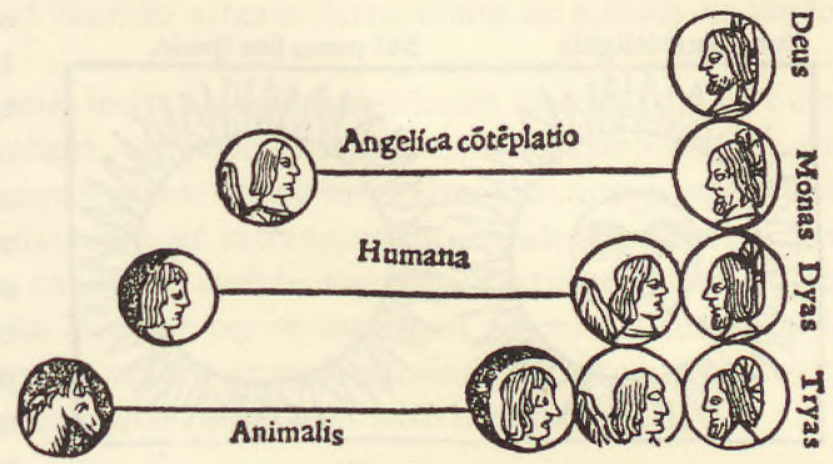
tas lux in corpore aut tenebre et lucis privatio. Albor omnem recipit colorem et speciem, in omnia vertitur, omnia fit. Nigritudo vero nullum recipit, nullo inficitur, nichil continere aut fieri potest.

đ Ita et Deus omnia est, initium est omnium, omnia gestat, recipit, con- Analogia tinet, in seipso fulcit, ut albedo. Irrationale autem animal nichil fieri potest, impingibile est, omnium denique cognitionum et apparitionum est ultima et ut ipsa universorum nigritas, ignorantia, tenebre. Angelus et Homo sunt ut medii colores, qui divine lucis aut in nubem aut in solidum corpus incidentia gignuntur.

đ Deus ut ignis est, Angelus ut aer, Homo ut aqua, animal ut terra. Deus ut mens, Angelus ut mentis conceptus, Homo ut vox, animal ut scriptura. Hec sunt quattuor precipua Universi entia, hec vera et substantialia mundi elementa, hec illa "quattuor animalia plena", ut sacra canunt eloquia ${ }^{1}$ ), "oculis ante et retro.» Oculi enim eorum sunt cogni- Sacrum eloquium tive facultates, que solis his quattuor insunt. Mens divinus est oculus; Intellectus angelica acies est, Ratio humana; Sensus uterque animalium oculus est.

I \& Cur sol appareat sine specie, luna vero maculosa facie p. ${ }^{4} 4^{r}\left[{ }^{1} 43^{r}\right]$ insignis conspiciatur. Cap. XLII.a)

Fit iterum ex his, cur corporeus et visibilis sensibilis huius mundi sol purus sit, simplex, candidus, immixtus, sine specie, nube et caligine: luna vero insincera sit, speciei admixta, alteritate, nube et caligine suffusa ac maculosa quadam facie et pullo aspectu insignis.

a) XLI ed.

1) Apoc. 4,6. 
đ Nam talis a nobis visitur sensibilis iste sol, fons totius visibilis lucis, qualis angelice aciei archanus ille, eminentissimus et exemplaris sol, invisibilis fons lucis, revelatur. Et qualis rursum humano Intellectui

Luna[pecie infignis

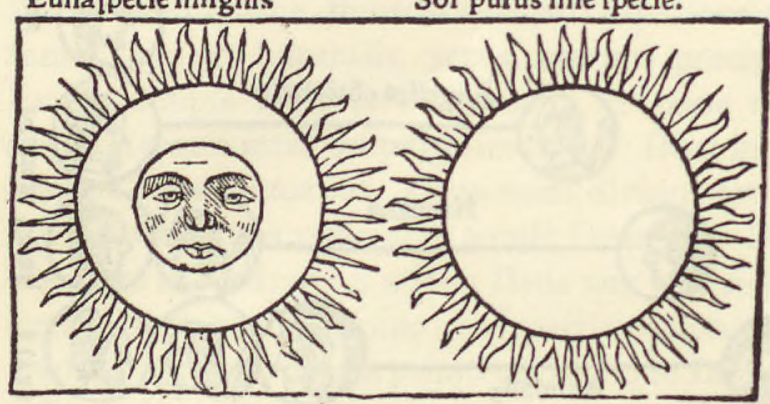

sub angelice speciei interstitio nudatur Deus, talis luna nostrorum oculorum mortalem aciem ferit corporeisve nostris luminibus sub cuiusdam umbelle et caliginis admixtione presentatur. Est enim, ut diximus ${ }^{1}$ ), Deus simplex et ut sol ange-

lice Contemplationis obiectum, idem vero ut opertus angelica nube, ut facies in eo visitur angelica, humane Contemplationis obiectum vocatur. Accessus utriusque $₫$ Angelus Deum solum et inopertum videt, nullam in eo deprehendens divine imaginis ad imaginem nullamve nubilam aut maculosam faciem. Est enim Angelus primus a Deo procreatus vultus, quo nullus prior aut anterior in Deum evadit in Deoque recipitur. Huius autem accessu ad Deum seu receptione ac statu in Deo ei demum creature, que post Angelum in Deum succedit, ut Homini, reseratur et expatatur Deus ut luna, qui priori creature ac prime sue imagini ut sol sincerus purusque suffulsit. $₫$ Accedens enim

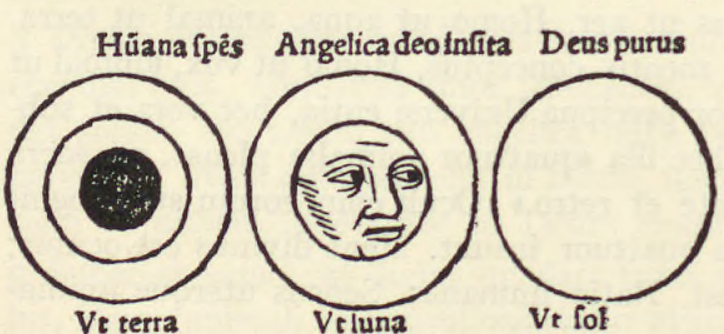
secunda Dei imago et species, id est Homo, ad Deum cernit prius in eo receptam primam speciem atque imaginem, id est angelicum Intellectum, Deum operientem atque obumbrantem, persimilem ei maculose faciei, que est in luna. Deus enim per se et ut Angelo demonstratur, est ut sol; qui angelica insitione transit evaditque in speciem lune.

Deus ut speculum $q$ Visitur enim spectaturque Deus ab Angelo ut speculum mundum, sinmundum cerum et purum, sine imagine; ab Homine vero ut speculum in imagine et in quo recepta visitur imago. Nam Deus speculum quiddam est natura et per se sincerum, sine imagine ac specie, cuius naturales ac vere imagines sunt angelice et humane species in divino speculo vi Contem-

1) cap. $X L I$. 
plationis recipiende Deoque inserende. đ Sicut nempe in albore recipi natus est omnis color sive medius, ut rubor, sive extremus, ut nigritas: ita et in Deo, qui lux, albor et veritas quedam est, et medius et extremus color ipsiusve lucis et fontalis alboris derivationes ac species in analogia recipiuntur.

đ Angelica igitur species insita Deo illius candorem Homini in colore medio, ut in rubro, explicat, tanquam si lux in nube et claro corpore excepta per illius transparentiam spectetur. Humana autem species et substantia cum ob materiam sit intransparens, accedens ad Deum ipsique Deo insita illius candorem suapte nigritate irrationali animanti inviam ponit. Est enim Deus ut per se sumptus: albor; ut cum Angelo et angelica obtectus nube: rubor et medius color; ut vero cum Homine et insitione humane substantie: nigritas et extremus color.

đ Hominem secundam et ultimam esse Dei imaginem in Deo recipi natam. (Cap. XLIII. $\left.{ }^{a}\right)$

| Unde fit, ut haud immerito Homo ultima sit Dei imago extremusque p. I $^{\mathrm{I}^{\mathrm{V}}}{ }^{\left[\mathrm{I}_{4} 3^{\mathrm{v}}\right]}$ vultus in Deo recipi natus et irrationalis creatura Homine inferior Deo inseri et in Deo recipi non possit. $₫$ Nam sicut in nigritate pingi nulla Analogia nigritatis potest visibilis species, nichil in ea scribi, nulla exprimi imago et in nullum colorem verti nigritas potest, nulla affici ac tingi versicoloritate: ita et ubi recepta est humana species in Deo, in divino speculo posterior nulla nata est recipi imago. đ Ubi vero intelligis solam angelicam speciem in Deum evasisse et in Deo receptam, superest adhuc locus humane speciei, quo in Deo recipiatur et collocetur Homo. Nempe angelica in Deo receptio haud extremo colori, sed medio, ut rubori, comparatur, qui adhuc nigritate tingi, infici et inscribi potest.

đ Sicut igitur in albedine, colorum fonte et primo, recipi nati sunt medius color, ut rubor, et extremus, ut nigritas, et rursum in medio colore, ut in rubore, recipi potest extrema nigritas, in nigritate vero nichil: ita et intellige Deum suapte natura et substantia candicantem et album, hoc est sincerum purumque, uti est, Angelo apparere; eundem vero angelico accessu velut solem nubibus opertum Homini rubrum sive umbratilem demonstrari; humana vero insitione eundem omni postergate creature claudi, denegari, pullum evadere, impervium, incognitum, inaccessum. q Est enim Homo, ut diximus ${ }^{1}$ ), verus mundi Ianus, Clusius et Patul- Homo mundi Ianus cius, hoc est aperiens et claudens. Omni namque inferiori creature divi-

a) XLII ed.

1) cap. $X X X I$. 
num claudit aspectum occulitque Deum, illum in sese continens et ad inferiora nulla traducens. Idem vero in altum et sursum pergentibus primus est divini iubaris ortus, primus, cui reseratur et adaperitur Deus, prime intellectualis mundi valve, primum divine lucis speculum et immortalitatis initium. Idem ultimus et primus divinitatis particeps est, ultimus et tertius a Deo, primus a mundo totiusque sensibilis mundi Deus.

Hominis et Intellec- $₫$ Ipse preest nocti, id est sensibili mundo, sicut et Angelus diei, id est intus et obiectum ut tellectuali mundo. Eius Intellectus ut luna est et eius obiectum ut luna.
luna Angelicus vero Intellectus ut sol, eius quoque obiectum ut sol. đ Sol soli obiectus est et luna lune a natura obiectata et presentata. Sol a sole et luna a luna deprehenditur, spectatur, visitur.

Simile simili obiec- $\mathbb{q}$ Nam simile ab solo simili deprehendi et spectari natum est: simplex a simplici, immixtum ab immixto, mixtum et varium a mixto et vario. đ Deus natura simplex est et angelicus Intellectus, cui patet Deus, identidem simplex. Humanus vero Intellectus mixtus est et specie affectus; id quoque, quod humano objicitur Intellectui, haud simplex est Deus, sed adumbratus opertusque Deus.

đ Que sint propria angelice et humane Contemplationis obiecta.

Cap. XLIV. $\left.{ }^{a}\right)$

Quod sit angelice et quod humane Contemplationis obiectum, quid natura spectet Angelus quidve speculetur Homo, hec ratio prosequetur.

ণ Deus et Angelus nullo abinvicem medio discluduntur. Deus autem obiectum est et ut speculum, Angelus vero ut eius oculus et speculatrix potentia. Vi autem cognitionis et potentia obiecto inseritur in eoque recipitur, et obiecti species in potentiam manans in ea sistitur, colligitur, continetur. Deus igitur ut Deus, ut simplex, purus et immixtus ante angelicum in se accessum angelici Intellectus dicitur obiectum. Pari pacto et angelicus Intellectus ut Intellectus, ut simplex, purus, immixtus, priusquam divina specie misceatur, ut nondum suscepta est in eo divina species, cognitiva Dei facultas et potentia vocatur.

$₫$ Divino autem et angelico congressu et mutua eorum accessione finge coalescere hinc simile humano Intellectui, illinc humano persimile obiecto, et utrinque lunam ac dyadem. Nam ut receptus est Angelus in Deo, ut obumbratur et operitur angelica nube Deus: in hunc modum ab Homine contemplabilis et spectabilis est evaditque humane mentis obiectum. Sicut enim angelicum obiectum est simplex nudusque Deus, ita et huma-

a) XLIII $e d$. 
num obiectum velatus umbratilisque Deus. Sicut Angelus intuetur Deum solem, id est purum, immixtum et sine specie: ita et Homo intuetur Deum lunam, hoc est Deum sub nube et specie angelica et in quo angelicus vultus insitus est prior. Ut vero divina species in angelico recepta est Intellectu, ut mixtus est et insignis divina specie Intellectus angelicus: conflat id, quod simile est humano Intellectui.

q Est enim humanus Intellectus Intellectus mixtus, id est Intellectus specie, vultu ac divina imagine insignis. Nam sicut aliud est speculum et speculum mixtum, in quo actu recepta est et visibilis imago, (ut enim speculum simplex est et carens imagine) : ita et alius est Intellectus et mixtus Intellectus. $₫$ Intellectus quippe, ut huiusmodi est, Intellectus purus est et specie immixtus, qualem angelicum natura censemus. Ut vero Intellectus est divina mixtus et affectus specie, humanus est et secundus Intellectus et dyas.

| $₫$ Igitur et purus est Deus et angelicus Intellectus itidem purus. Uter- p. I $^{2^{\mathrm{r}}}\left[\mathrm{I}_{4} 4^{\mathrm{r}}\right]$ que est sol, uterque et monas: ille tamen obiectum, hic vero potentia eius cognitiva; ille rursum ut speculum, hic vero ut speculator eius oculus. Purum est speculum et obiectum, purus et est eius oculus et cognitiva facultas. Deus speculum est liberum et immateriale; angelicus quoque Intellectus oculus est immaterialis et liber. \ Accessu autem et congressione amborum et angelica substantia inseritur Deo et divina species in angelico Intellectu suffulget. Congrediuntur enim copulanturve ambo: Deus Angelo, Angelus Deo; in Deo fulcitur Angelus, in Angelo Deus divinaque species.

ণ Hoc itaque congressu e gemino sole intellige geminam exoriri proferrique lunam, e duplici monade duplicem prosilire dyadem, e geminis simplicibus bina composita: hinc, quod humanum Intellectum, illinc vero, quod humani Intellectus exprimit obiectum. Est enim humanus Intellectus tanquam angelicus Intellectus cum divina specie; humanum vero obiectum tanquam Deus cum Angelo sumptus. đ Nam Intellectus ut per se, sine divina specie, angelicus est. Et Deus ut per se, sine angelica insitione, angelicum obiectum. Accessu autem divine speciei in angelicum Intellectum prodit Intellectus mixtus affectusque specie, qui similis est humano. Positione vero ac statu angelice substantie in Deo, ut in proprio naturalique fine, coalescit, quod humano simile est obiecto, id est umbratilis Deus.

đ Igitur a sole visitur sol, a luna luna, a monade monas, a dyade dyas; a puro oculo purum cernitur speculum, ab immixto immixtum, a simplici simplex, a nudo nudum, a libero liberum atque absolutum. Similiter et ab oculo mixto et corporeo amictu investito mixtum pariter cer- 
nitur speculum, vultu aliquo atque effigie figuratum. Ambo insuper soles utramque lunam gignunt; ambe monades geminam pariunt dyadem. Simplicium et primorum accessu secunda et mixta procreantur, in parte obiecti obiecta et in parte potentie ipse facultates et cognitive vires.

ฯ Quod si sistere volueris Hominem in Deo et in Homine Deum, complebis utrinque tertio distantium loco congressu tryadem. Est enim Homo ultimus, qui evadit scanditque in Deum,

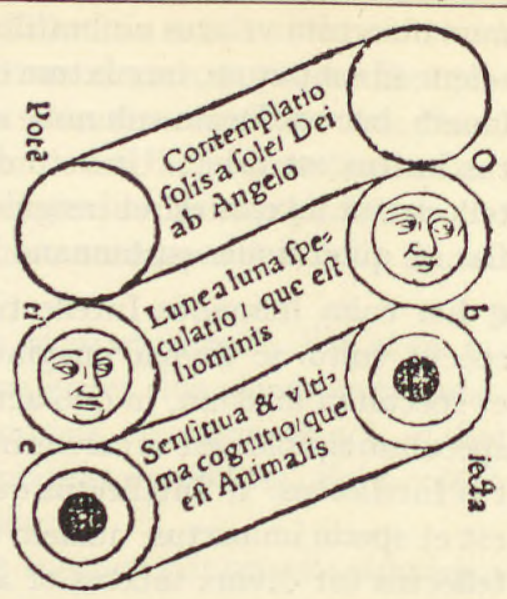
et iterum ultimus, in quem demittitur descenditque Deus.

đ Trina esse spectata et obiecta, trina quoque spectativa et speculativa.

Cap. XLV.a)

Et sicut monadi monas obiecta est et dyas dyadi, ita et tryadi tryas presentata. Sicut a sole visitur sol, a luna luna, ita et terre terra opposita et contraposita et a terra spectabilis terra. Est enim Deus sol, Angelus luna, Homo terra; et rursum Angelus sol, Homo luna, irrationale animal terra. Deus sol cognitus, Angelus sol cognitivus. Angelus spectata luna, Homo spectativa et intuitiva luna. Homo denique obiecta et cognita terra, irrationale vero animal spectativus eius oculus.

Que sint obiecta et $\mathbb{q}$ Alius enim obiectorum et alius potentiarum ordo. Obiecta sunt hec: que potentie Deus, Angelus, Homo; eorum vero potentie: Angelus, Homo, irrationale animal. Deus summum est et omnium obiectum, sol et monas, nullius ${ }^{b}$ ) preterquam sui cognitiva potentia. Angelus secundum obiectum est et prima Dei speculatrix acies: que ut obiectum dyas est et luna, ut vero potentia sol est et monas, pura, simplex, immixta, simplicis et immixti Dei contemplatrix. Homo vero est cognoscibilium quidem et obiectorum ultimum: non tamen ultima, sed secunda vis cognitiva. Homo igitur, ut spectabilis est, tryadi et terre comparatur: ut vero speculativus, dyas est et luna. Spectat enim et intuetur angelicam dyadem, spectatur vero ab irrationabili tryade.

Irrationale animal $₫$ Demum irrationale animal ab ordine et serie spectabilium atque obspectabile non est iectorum eximitur, quandoquidem nulla est inferior creatura particeps cognitive facultatis, cui Rationis expers creatura presideat, quam regat
a) XLIV.ed.
b) nullus $e d$. 
et moderetur et a qua merito reverenda spectabilisque censeatur. Itaque muta animantia spectant quidem, cernunt et intuentur Hominem ut presidem, ut suum obiectum et finem, illi obtemperant, illum sequuntur. Sed cum ab inferioris generis ente minime in honore habeantur minimeque spectentur, $\mathrm{ab}$ obiectorum et spectabilium serie ac ratione facessunt solisque potentiis ac speculativis facultatibus annumerantur. Est enim irrationale animal incognoscibile quidem, sed tamen cognoscentium ultimum.

$₫$ Nam cum cognitio omnis, intuitio et speculatio, sit perpetuus quidam posteriorum et inferiorum in anteriora et potiora successus sive in Deum, summum omnium obiectum, naturalis cona|tus ac nisus, e quattuor p. ${ }_{44^{2}}\left[{ }_{144} \mathrm{v}\right]$ primis ac precipuis entibus: Deo, Angelo, Homine, animali muto anteriora et superiora tria ab inferioribus tribus singillatim spectata et cognita dicuntur et he potentie, illa vero earum obiecta censentur. Trina enim sunt obiecta et potentie trine.

$₫$ Deus igitur sicut solum spectabilis est nulliusque potioris spectativus, Deus solum spectaita et irrationale animal duntaxat spectativum est et a nullo inferiore bilis, animal solum evadit circunspectum. Supra Deum nichil est, quod spectetur a Deo sitque spectativum divine Contemplationis obiectum. Infra itidem animal nulla est cognitio, nichil degit cognitive facultatis particeps, a quo spectari debeat animal.

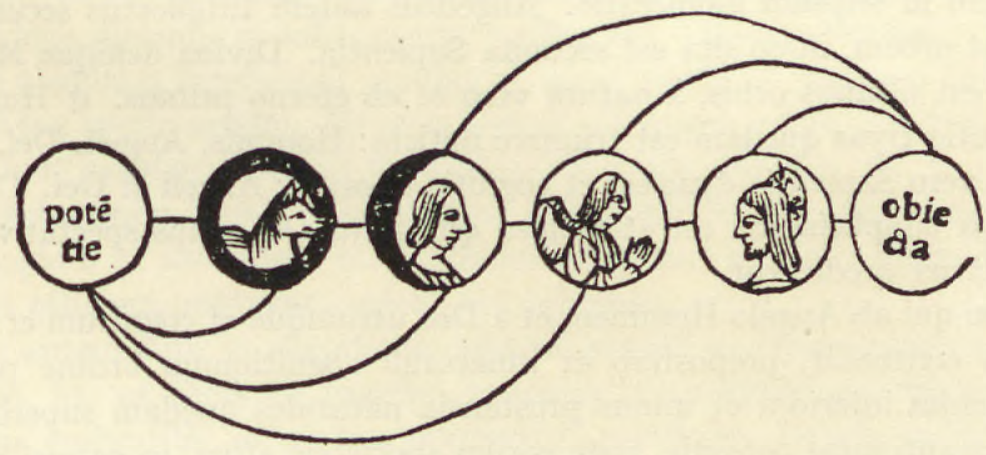

đ Animalem Sensum in altiora nitentem finiri in Homine.
Cap. XLVI. ${ }^{a}$ )

$\mathrm{Ab}$ animali itaque irrationali spectatur, conspicitur et dinoscitur solus Homo; nam sensitive virtutis acumen exterebrare Hominem et ad Angeli aut Dei usque conspectum pertingere nequit. Humani siquidem corporis opacitate artatur atque in humano corpore ut in proprio obiecto et naturali fine sistitur.

a) XLV ed. 
Ratio adusque Deum fertur

Infra Rationem nulla Sapientia đ Humane autem cognitionis et Rationis acies recta in Angelum pertendit, qui cum pelluceat et transpareat ut nubes, haud in illo sistitur colligiturque, sed exterebrato eo in anteriora et altiora pergens adusque Deum pertingit, in quo demum ut precipuo, summo et ultimo obiecto ac propter se spectabili finitur. $₫$ Angelice porro cognitioni primus et ultimus, qui in rectum occurrit, qui illi objicitur et presentatur, Deus est. Deo autem nichil est obiectum, nil ab eo spectabile.

$₫$ Itaque in rectum, in anteriora, in natura priora et potiora vero et naturali cognitionum ordine atque aspectu succedendo animali Sensui obiectus est solus Homo; Homo unus ab animali spectandus. Humano vero aspectui obiecti et pervii sunt Angelus et Deus. Angelo denique solus Deus. $₫$ In orbe autem et circulari in seipsum flexione Sensui obiectum est nichil, quandoquidem Sensus minime suiipsius arbiter aut capax efficitur neque potest irrationale animal ulla vi nosse seipsum. Humana autem Ratio suipsius in orbe compos evadit. Angelica Intelligentia itidem seipsam in circulo capescit. Mens quoque divina in orbem volvitur, seipsam prehensat suique capax et compos efficitur.

$₫$ Rursum in Sensu, in muto animali, infra Rationem nulla Sapientia locata est, nullus sui aspectus, nulla sui cognitio. In humana Ratione prima sursum pergentibus occurrit Sapientia, prima sui inspectio, prima eiusdem in seipsum glomeratio. Angelicus autem Intellectus secundum conflat orbem, in eo sita est secunda Sapientia. Divina denique Mens a nobis est ultimus orbis, a natura vero et ab eterno primus. $q$ Humana Sapientia tryas quedam est triumve noticia: Hominis, Angeli, Dei. Angelica vero Sapientia dyas est et cognitio duorum: Angeli et Dei. Divina demum simplicissima est et monas, qua Deus Dei solius spectativus et cognitivus predicatur.

đ Nam qui ab Angelo Hominem et a Deo utrumque et cognitum et spectatum contendit, prepostero et innaturali cognitionum ordine pergit. Sunt enim inferiora et minus prestantia naturales quedam superiorum et prestantiorum potentie, nate eorum speciebus affici, in ea niti atque in eis recipi. Superiora vero sunt ut inferiorum et spectativorum oculorum actus, lumina, scopuli, fulgores et obiecta, ad quorum culmina et eminentissima fastigia inferiora perfectionis sue causa pro viribus scandunt.

đ Et cum omnis cognitio trinitatis numerum involvat sitque trinitate perfecta - continetur enim hec tribus: potentia, obiecto et amborum actu -, erit humana Sapientia ter trina, angelica bistrina, divina unitrina. Nam trina cognitio trina trinitas est, gemine cognitiones gemine sunt trinitates, unica cognitio trinitas una.

đ Ex his manifestum est opacam humani corporis molem causam esse, 
ne superiore ex parte divina lux irrationali creature Homine inferiori suffulgeat et ne ex parte inferiore animalis Sensus quicquam infraa) aut supra Hominis corpus intueatur. Arcetur enim ab humano corpore divina lux, ne ultra Hominem traducatur; arcetur et ab eodem animalis Sensus, ne supra Hominem vis illius pertingat. Humanum quoque corpus illinc meta est divine imaginis totiusque invisibilis lucis in summa reflectio et in suum fontem recursus; hinc vero terminus est ac finis irrationalis Sensus eiusque reflectio et recursus in ima.

I đ Quod Angelus intelligat sine specie et imagine, Homo p. r $43^{\mathrm{r}}\left[\mathrm{I}_{4} 5^{\mathrm{r}}\right]$ vero cum specie et imagine.

Cap. XLVII. ${ }^{\text {b }}$

Ex his item, que nuper dicta et pertractata sunt, manifesta est angelice et humane Intelligentie sive Intellectionis differitas; quodve simplicior sit angelica quam humana Intellectio, quemadmodum et simplicius angelicum quam humanum obiectum, et intelligat Angelus sine specie, Homo vero cum specie et imagine.

q $\mathrm{Nam}$ utrinque ${ }^{c}$ ) et angelica Intelligentia et eius obiectum pura, sincera, simplicia et immixta sunt veluti monades et soles. Humanus vero Intellectus et eius pariter obiectum utrinque mixta et operta sunt velut quedam dyades et lune, que, ut docuimus ${ }^{1}$ ), naturali quodam utriusque prioris monadis et solis accessu conflantur. Ut enim miscetur divina specie angelicus Intellectus, conflat id, quod simile est humano Intellectui divina specie insigni. Ut vero insitus est Angelus Deo, ut Deum sua obumbrat caligine: humani Intellectus obiectum complet.

đ Angelus enim Deum videt purum, simplicem, immixtum, sine specie Angelus Deum videt et imagine, ut monadem et lucidissimum solem, in quo nullam depre- ut speculum sine hendit effigiem, umbram, nubem aut caliginem.

đ Hic autem cum vi cognitionis primus evadat in Deum recipiaturque in Deo, fit, ut Deus ab angelica insitione et coniunctione aliquopacto dicatur umbratilis, effigiatus, adopertus, persimilis speculo indita specie atque effigie adumbrato; hec enim effigies est Angeli in divino speculo, tanquam potentie in obiecto receptio atque insitio. Sub hac itaque angelica effigie, imagine et umbra divinum speculum humano Intellectui qui post angelicum Intellectum secundo loco in Deum succedit, nititur, evadit - revelatur. $₫$ Humanus enim Intellectus, quem in Deum angelicus precessit, Deum speculatur cum specie, id est cum angelica effigie; Deum cernit per speciem, id est per angelice faciei et imaginis um-

a) intra ed.

b) XLVI ed.

c) utriusque $e d$.

1) cap. XLIV. 
bram, per quam haud ferme secus nostro Deus Intellectui pellucet, quam lunare speculum sub umbra et insitione maculosi vultus nostris oculis demonstratur.

$₫$ Intelligit igitur angelicus Intellectus cernitque Deum sine specie et imagine: ut monas monadem, ut sol solem, ut immixtus oculus immixtum speculum. Humanus vero cum specie Deum videt, hoc est per angelicum vultum: tanquam dyas dyadem, luna lunam, mixtus oculus mixtum speculum, operta potentia opertum obiectum, hoc est Deum nube tectum et sub angelica umbra delitentem. Est enim angelicus Intellectus simplex, prima et immediata Dei species et ut vere Intellectus; humanus vero secunda et geminata Dei species divineque imaginis resumptio et ut Memoria.

Cur sol innocue a $₫ \mathrm{Ex}$ his quoque dilucet, cur visibilis iste mundanus et corporeus sol nobis videri nequeat mortalium nostrorum oculorum infirmam et inbecillam aciem caligantesque et invalidos obtutus exuperare, perstringere et obtundere videatur, luna vero temperatis ignibus remissioribusque lucis spiculis sese nobis innocue visendam prebeat. Est enim solis lampas ut sublimioris oculi velut angelici Intellectus - obiecti vestigium; luna autem id, quod nostris Intellectibus a natura obiectum atque presentatum est, congrue exprimere videtur. Sol visibile signum est angelice totius scientie et contemplationis; luna vero visibile itidem signum humane speculationis atque scientie. $₫$ Nam angelico Intellectui patet Deus ut sol et ut speculum sine imagine; humano vero innotescit ut luna utve speculum vultu aliquo, specie atque imagine insigne. Est enim sol speculum sine imagine, luna speculum figuratum, insitam gestans effigiem.

đ Et si angelicus Intellectus est prima, proxima et immediata Dei imago,

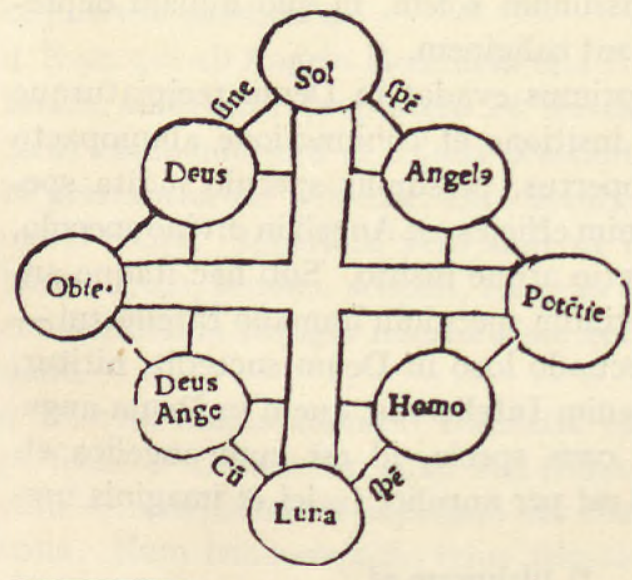
effigies ac species, inter quam et Deum nulla interhyat media species aut creatura: qui fiet, ut angelicus Intellectus non per se et sine intercurrente specie Deum intelligat? Humanus autem Intellectus, cum sit secunda mediataque Dei imago, vultus ac species: qualis utique est, taliter profecto et ipse Deum intelligit; cum enim mediata et secunda sit, immediate, per se et primo

ad figuram: $\mathrm{spe}=$ specie; Obie. $=$ obiecta. 
intelligere Deum nequit, sed mediante ${ }^{a}$ ) angelica specie et imagine Deum intelligit, per quam et ipsa ab obiecto proprio, hoc est a Deo, distare comperitur.

\section{Iđ Quod sol et luna omnis create Sapientie sunt signa.}

$$
\text { Cap. XLVIII. }{ }^{\text {) }}
$$

Sol duorum est visibile signum: angelici inquam Intellectus et angelici obiecti; luna vero identidem duorum: humani Intellectus et humani obiecti est visibilis expressio.

đ In sole lux est sincera, sine macula, sine nube, umbra aut caligine; in luna vero adumbrata et permixta visitur lux. Sol speculum est sine imagine et specie; luna speculum mixtum, visibili specie et imagine insigne. Sol igitur et luna, ingentia mundi luminaria ac lucidissime terreni orbis faces, omnem nobis creatam Sapientiam insinuant, omnem divinam apparitionem reserant, modum omnem, quo creatura cum intellectualis tum sensibilis, angelica et humana, evadit in Deum fitque divinitatis, immortalitatis et vere beatitudinis particeps, adaperiunt. $₫$ Angelus primus, Homo ultimus evadit in Deum; irrationale vero animal in Deum transit nunquam. $₫$ In Deo prima est substantialis et increata Sapientia. Post autem Deum Angelus, post Angelum vero Homo Sapientie consortes: ambo et divine et proprie cognitionis ac scientie thesauro locupletantur. Irrationale animal, inops et expers Sapientie, neque divine neque proprie cognitionis aut immortalitatis munere dotatur.

đ Divina Sapientia immutabilis est, perseverans in Sapientia, identi- Divina Sapientia tate, bonitate, virtute, pulchritudine, luce et claritate, eliminans ab sese fugansque procul omnem Insipientiam, alteritatem, maliciam, dissimilitudinem, inequalitatem, permixtionem, tenebrarum obscuritatem, infirmitatem et lapsum; omni insuper oblivione reperitur superior, omni sui ignoratione candidior, vastis errorum syrtibus et precipiti falsitatis abysso perpetuo inaccessa.

đ Angelica autem et humana creature vascula quidem sunt Sapientie Angelica ethumana capacia divineque imaginis ac lucis naturalia specula, ad flexanimam mens labi potuere Sapientiam precipue nata et archana quedam divini fulgoris promptuaria; quia tamen haud eterna sunt, sed ex non-Esse in Esse prodierunt, labi potuere in deterius et lapsa tandem a Deo atque ab eius pace dissociata passibilia sunt effecta. Evaserunt enim Insipientie, alteritati, inequalitati, dissimilitudini, permixtioni, varietati, divisioni, ignorantie, tenebris, errorum precipitiis et mortis obliterationi obnoxia.

a) mediate $e d$ b) XLVII ed. 
Irrationale animal $q$ Irrationale vero animal liberi exors arbitrii, utpote cuius in Hominis nequesapiens neque
insipiens manu versantur habene, ab suo ordine haudquaquam decidisse vimque sue nature intulisse dictitatur; quod enim docile et ad Sapientiam Deus non fecit, in Insipientiam mutari non potuit. Sicut nempe a Natura iubetur, illius instructu motitatur; Homini paret, illi subditur, ab eo regitur. Nil sibi conscium est; nullius immortalis divinique fulgoris particeps neque sapiens neque insipiens, peccans aut impeccans censetur.

$₫$ De divina constantia et angelico atque humano lapsu.

Cap. XLIX. $\left.{ }^{a}\right)$

Deus a Deo cadere non potest, Deus negare seipsum, dividi a seipso, dissidere sibimet aut non esse Deus nequit; semper enim Deus est, secum iugiter unus est, unius voluntatis, unius et individue substantie, in trinitate persistens. Angelus autem imprimis a Deo, Homo vero deinceps et a divina et $\mathrm{ab}$ angelica pace deciderunt fuitque illis divina secessio primave a Deo prolapsio et proprie ipsorum a seipsis et mutue abinvicem discordie causa.

Analogia $₫$ Nam sicut omnis numerus haud aliter quam coniunctus adiugatusve unitati, numerorum fonti, et quam participatione unitatis unus est, sine qua et tota numerorum series et quisque numerus sibipsi et alteri dissidet divisusque est et plurimus: ita et nullo pacto quam divine unitatis patula fusione et super omnem creaturam unifice ipsius virtutis derivatione universa creaturarum series est una. ${ }^{1}$ )

đ Tolle autem divinam fontanamque unitatem: in mundo, in creaturis pax superest nulla, unitas et concordia nulla. Que enim cum Deo una non est, neque cum alia ulla neque ipsa secum poterit esse una; que scissa et separata est a Deo, et omni alii et sibiipsi adversetur oportet. đ Divina unitas omnis unitatis, pax pacis et concordie concordia est causa; divina quoque lis, dissidentia et discordia omnis et proprie et mutue litis, dividii, dissidentie et discordie est causa. "Per divinam ineffabilem pacem», ut divus Areopagita testatur ${ }^{2}$ ), «neque amplius adversum Angelos aut Deum belligerare discimus, sed cum ipsis», ut ait, «divina potius pro viribus peragemus.» Sine divina autem pace neque ipsi nobiscum neque in invicem neque cum Angelis neque cum Deo congruimus, inserimur, unimur.

đ Sicut divina illa, supersubstantialis, intima et eterna trium divinarum et beatissimarum personarum trinitas geminis sibi connexa est vinculis

a) XLVIII $e d$.

1) cf. de duodecim Numeris: de monade, cap. I-II.

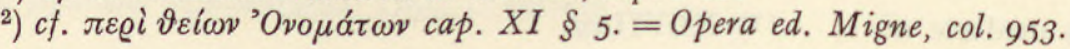


binisque nodulis secum coheret, substantia et voluntate (sunt enim divine tres persone et eiusdem substantie et concordis atque indissidentis voluntatis): ita et oportet extimam trium immaterialium, precipuorum et immortalium entium, Dei, Angeli et Anime trinitatem - nam et Angelus et Anima dii quidam sunt et divinifere creature - , cum substantia dissideat sitque divisa, reliquo saltem ut voluntatis vinculo, sibi fieri consonam atque unam. Eterne et interiores Dei persone uniuntur et substantia et assensu voluntatis. Exte|rioris autem trinitatis persone: Deus, p. ${ }^{144^{\mathrm{r}}}{ }^{\left[{ }^{1} 4^{6} \mathrm{r}\right]}$ Angelus, Homo, cum substantia quidem dissite sint et trine, nulla earum superest quam volitionis ${ }^{a}$ ) mutueque pacis et concordie unitas. đ Intra se Deus personis trinus est; substantia tamen et voluntate uniformis ac sibiipsi concors. Extra se vero Deus personis et substantia trinus est: Deus, Angelus, Homo, que si et ${ }^{b}$ ) voluntatis assensu pares et sibi consentanee erunt, in optimo statuerunt universa.

đ Omnium enim principium sicuti monas est: ita et debet omnium finis, status et consummatio esse monas. Nempe et ipsius dyadis numerum velut primum, qui a monade deficit, ut dividii totius et divisionis authorem, ut defectionis et prolapsionis initium, ut denique materiei numerum et non entis viciniam plerique theologorum adeo collutilant, repudiunt, despiciunt, ut infamem appellitent. ${ }^{1}$ )

đ Nil quippe est in universis non unum, nil duale, nil adversum se aut Nichil est non unum aliud quodvis dissidens preter delapsam a Deo angelicam et humanam preter angelicam et Voluntatem. He etenim Voluntates divini amoris defectu materiei affixe tatem c) ac sui decoris oblite in pernitiosissimum sui exitium, in mortem immortales ruerunt. «Non enim - iuxta diviniloquos psalmos ${ }^{2}$ ) - cum in honore essent et Dei similes, intellexerunt: comparate sunt brutis et iumentis insipientibus et similes facte sunt illis.»

đ Venatio Sapientis ex similitudine visibilium oculorum, solis item et lune. Cap. L. $\left.{ }^{\mathrm{d}}\right)$

Volumus demum ex similitudine visibilium nostrorum oculorum Sapientis venari perscrutarique naturam. Nostri quippe visibiles oculi perpulchre inconsummati imperfectique hominis exprimere Intellectum videntur.
a) volitonis ed. b ) et si $e d$.
c) preter angelicam et humanam Voluntatem deest in ed.
d) XLIX ed.
1) cf. de duodecim Numeris: de dyade, cap. II.
2) Psal. 48, I3; 21 . 
Carnales oculi media tantum parte videntes, media vero parte ceci

ণ Ambo etenim oculi integri equidem perfectique sunt orbes: haud tamen integre et toto orbe vident, sed duntaxat ad mediam sphere partem mundum versus luce coloribusque cientur. Reliqua vero sphere medietate, qua gestantur a capite quave intra Hominem spectant natura ceci sunt et neque lucis excipere spicula neque colorum feriri speciebus nati. Carnales igitur nostri oculi haud minus sunt natura ceci quam illustres lucisve capaces. In tantum in tenebris degunt, quantum in luce. Sunt denique tantum non videntes, quantum videntes. Nempe extimis duntaxat suorum orbium medietatibus vident excipiuntque lucem et visibilium species rerum; internis vero medietatibus, quibus Homini capitique insunt, visionis haudquaquam exercent officium, sed et ceci sunt et in tenebris degunt.

q Quid, obsecro, hec tam lucida promunt signa, quam Naturam inchoasse quidem Hominem, illum tamen inconsummatum imperfectumque reliquisse, utpote cui Substantiam cum indulta sit, Sapientiam tamen ei minime indiderit; sive cui cum mundum et exteriora queque entia extima sensuum cognitione spectare et exhaurire posse donaverit, seipsum tamen et quecunque intra pectora gerit, interna cognitionelustrare rimarique posse haudquaquam $a b$ initio condonavit. Aperuit enim Natura ab initio mundanum duntaxat et extimum Hominis oculum; humanum vero atque internum eius oculum clausit, operuit cecumque reliquit.

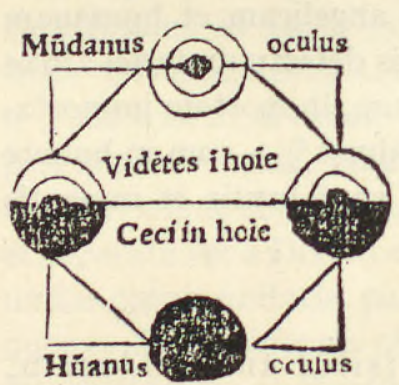

đ Nam finge amborum oculorum liquidas, visivas perspicacesque medietates suo concursu gignere unum quempiam oculum totum videntem; hunc oculum appellamus mundanum. Internas quoque cecasque medietates intellige pari congressu efficere unius oculi ex toto ceci orbem; hic oculus priori ex adverso dyametri collocatus atque oppositus a nobis dicitur humanus.

Quantum Natura Homini ab initio affuerit

$₫$ Adest igitur hactenus Natura Homini, qua anteriorem, extimum mundanumve eius oculum ab initio efficit illustrem illique mundum universum presentat atque offert. Qua vero eius internam, posteriorem et humanam aciem cecam reliquit, eatenus Hominem pauxillum deseruit voluitque, ut propriis officiis ac sedulis actibus Homo emendicatum a priore oculo lumen in secundum oculum importaret evaderetque demum et ipse oculo utroque illustris. $₫$ Circa id quippe humane omnes virtutes atque negocia versantur, ut a priore oculo natura illustri derivetur lux in secundum; sive ut Homo, cui imprimis objicitur illucescitque mundus, demum ex mundo redeat in seipsum; ut item ex priore mundi luce atque scientia propriam lucem atque scientiam elicere discat. 
đ Haud enim mundana lux est Sapientia, sed est Sapientie initium. Eius vero scientia, quod est precipuum, prestantius et propter se, ut Hominis, propter quem factus est mundus ${ }^{1}$ ): hec Sapientia vocitatur. đ Neque enim Sapiens est, qui priorem tantum aciem gerit illustrem quique duntaxat in mundum spectare sufficit, sed cui uterque oculus actu perspicuus inest, qui et in mundum et in seipsum spectare potest; cui item ut bifronti Iano tam extima quam intima agnita, pervia et manifesta sunt.

đ Mundano siquidem oculo mundum Sapiens perlustrat; humano vero, Claves gerit Sapiens quicquid habet sub | cute, rimatur. Claves gerit Sapiens et mundi et sui et mundi suiipsius: hac adaperiens mundum, illa seipsum reserans. Stat ex equo in sui mundique medio: Sensu quidem, ut nonnunquam diximus $^{2}$ ), mundo congrediens, Intellectu vero recinens a mundo sequeipsum complectens. $₫$ Est enim Sensus mundano persimilis oculo, Intellectus vero humanum oculum imitatur. Nam prior in Homine sensitiva quam intellectiva perficitur cognitio, prior mundo per Sensum adest Homo, quam per Intellectum in seipsum

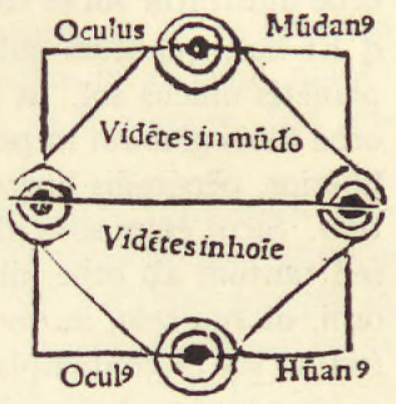
recurrat adsitque sibiipsi. đ Intellectus insuper prior ut practicus circa mundum sensibus evectus negociatur, quam abiunctus a sensibus et opis eorum minime indigus circa Hominem contemplativus esse queat.

$₫$ Sicut enim visibilis noster oculus, quandiu capiti erit infixus, medio duntaxat orbe videbit, reliqua vero medietate erit non videns ac cecus: ita et humanus Intellectus, quandiu evehitur sensibus, quandiu opis eorum indigus practicus est et negociosus circa mundum, tandiu medio duntaxat orbe erit illustris et alio medio orbe cecus videbitque ea tantum, que in mundo sunt, non autem ea, que insunt Homini. $₫$ Intellige igitur carnalem oculum a naturali capitis insitione fieri immunem, eximi a subiecto, fieri denique liberum sese tanquam in aere fulcientem. Hic utique oculus pre-

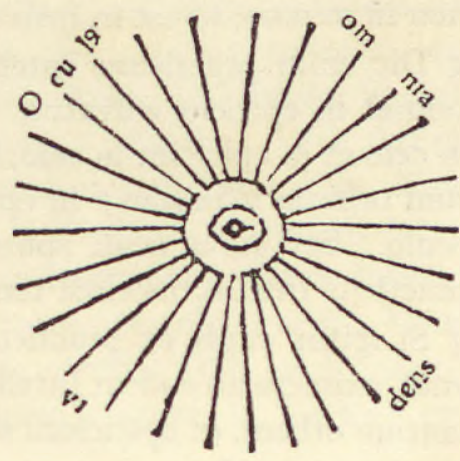
clarum est contemplativi consummatique Intellectus vestigium. Est enim contemplativus Intellectus omnia videns, ut qui non tantum medio, sed toto orbe et que extra et que intus sunt, speculari sufficit

1) cf. de Sensu: cap. I 3 .
2) e.g. cap. XXXI. 
et cui iam superfluit sensuum famuletium quique libere et per se omnia intelligit deferens fulciensque semetipsum.

Alia analogia ex $q$ Possunt et ea, que diximus, Sapientis et Insipientis vestigia liquido in sole et luna sole et luna reperiri. Nam luna similis est oculo capiti infixo, qui media tantum sui orbis parte videt, media vero obscurus est et cecus; similis item est practico et inconsummato Intellectui, qui soli mundo, non Homini adest. Lunaris siquidem globus haud unquam plus medio orbe Phoebeum excipit lumen; impossibile est, ut totus aliquando illustretur, quanquam toto interdum orbe lumine privari queat. Sol autem et liberum oculum et contemplativum exprimit Intellectum; nempe toto iugiter orbe illustratur sol et nativo nunquam lumine spoliatur.

Sol cur careat epi- $q \mathrm{Et}$ hec, quantum subsipio, vera et precipua causa est, cur e cunctis ciclo $^{1}$ planetis unicus sol, ut astrologi volunt, careat epiciclo, hoc est minore orbe illius globum in proprio celo deferente. Est enim sol omni planeta liberior, persimilis libero atque absoluto oculo et Intellectui contemplativo. Sicut enim solis globus haud ex toto quidem absolutus est ab orbe, sed tantum $\mathrm{ab}$ orbe minore, ut ab epiciclo, inest autem maiori iugiter orbi, ut suo celo, in quo circa terram velut precipuus mundi oculus defertur: ita et contemplativus noster Intellectus haud ex toto absolutus et liber esse probatur.

đ Hoc enim solis angelicis competit Intellectibus, qui planetis et stellis ex toto liberis seque sine quovis orbe maiore atque minore, sine epiciclo ac celo ferentibus merito comparantur. Sed hactenus noster Intellectus, postquam contemplativus evasit, liber et absolutus esse dicitur, ut careat epiciclo, non careat celo, ut in maiore semper orbe, hoc est in corpore, non in minore, id est in ipsis sensuum organis, evehatur.

Practicus Intellec- $₫$ Dic enim practicum Intellectum similem esse lune, cum luna et in tus similis lune

celo et in epiciclo volvatur. Volvitur cieturque practicus Intellectus et in celo et in epiciclo: in celo, hoc est in humano corpore, qui est humanorum orbium maximus; in epiciclo vero, id est in organo sensuum, ut in oculo. Est enim oculi sphera minor orbis, in quo cum maiore orbe practicus Intellectus circa terram per mundum defertur.

Quo pacto ex prac- đ Si igitur cupis ex practico Intellectu elicere inferreque contemplatitico Intellectu eli- vum, eximere ab eodem Intellectu te oportet non utrumque, sed minorem ciatur contemplatantum orbem, ut epiciclum sive oculi spheram: a qua abiunctus Intellectus fertur quidem manetque semper in corpore, sed tanquam sol in maiore huiusmodi orbe sine minoris presidio liberior incedit atque defertur. $q$ Nam sicut tam sol quam luna ambo in maiore feruntur orbe

1) cf. Bovilli Proverbiorum vulgarium libr. tres, Paris 1531, p. $124^{\mathrm{v}} \mathrm{sq.}$ 
et proprio celo, luna tamen insuper minoris orbis sive epicicli expetit opem: ita et uterque Intellectus humanus, tam speculativus quam practicus, in maiore Hominis orbe, hoc est in corpore motitatur, practicus tamen solus minoris insuper orbis, ut carnalis oculi, indiget presidio.

I q Qui autem Intellectus neque maiore neque minore indiget orbe, ut p. ${ }^{4} 5^{\mathrm{r}}\left[{ }^{\mathrm{r}} 47^{\mathrm{r}}\right]$ qui ex toto absolutus per seipsum degit, hic humano reperitur sublimior; et hunc angelicum esse prediximus ${ }^{1}$ ), persimilem soli, planetis stellisque omni orbe liberis. đ Et huius qui analogie seriem ulterius prosequetur, De mysterio resurfuture resurrectionis mysterium perfacile intelliget. Nam sicut ea natura rectionis est solaris globi haudquaquam ab omni, sed duntaxat a minore absolvi orbe, ut ab epiciclo, semperque in maiore orbe, ut in proprio celo, volvi atque circunferri: ita et ea nostri Intellectus natura est, ut ex practico in contemplativum proficiens a minoris tantum orbis, ut ab oculi, abiungatur opitulamine, non autem ab orbe maiore, ut a corpore, fiat immunis.

đ Haud enim usquequaque in angelicam perfectionem conscendit speculativus Intellectus, ut penitus suam naturam immutet fiatque corporis immunitate par angelico Intellectui; sed qui Substantiam accepit in corpore, qui cepit in materia esse, licet preter naturam nonnunquam extra corpus agatur subsistatque per se: nubere rursum corpori et in corpore fieri peroptat, perinde atque Phoebus suo iugiter celo natus est et expetit inesse.

\section{đ Exhortatorius ${ }^{a}$ ) sermo ad Sapientiam capescendam.}

Igitur, o Homo, qui natura Homo non Homo es, qui Substantiam a natura humana Virtutis et Sapientie indigam expertemque mutuasti, qui tibimetipsi ab initio ignotus es, incompos tui, divisus abs teipso: Sapientiam libens capesce, enitere pro viribus nosse teipsum. Tuas discute tenebras:sui ignoratio viaticum mortis est, perpes vita sui agnitio. Hanc etenim beatam suiipsius lucem famosissimum illud in ore omnium decantatum Delphici Apollinis oraculum summam Sapientiam esse vulgavit. ${ }^{2}$ ) $₫ \mathrm{Ne}$, Homo, lapidesce, ne in plantam degenera neve obrutesce. ${ }^{3}$ ) Homo Quattuor rerum es: sistere in Homine. Fulciat te Substantia, nutriat Vita, eruditioni tue gradus Sensus ancilletur: Ratio imperitet. Rationem sequere, in Ratione per-
a) exortatorius ed.
b) L. ed.
1) p. $399 \mathrm{sq}$.
2) cf. Praefat.
3) lege: ob-brutesce. 
siste. $q$ Sta, sede ac stabilire in his, que sunt. Ede ea, que vivunt. Animalia tibi famulentur, dominator tui. ${ }^{1}$ )

đ Sensu in mundum veheris peregrinus, Ratione in teipsum colligitor. Hac demum celos exterebrato, meditator celestia, in celestibus mente resideto. In spiritalem Synam ${ }^{2}$ ) ad sacratissimi nomothete Dei admissus conspectum ne retro aspicito; ne carnis illecebre tibi mox in Egypti latomias, in prisce vallem servitutis, in obscurissimam mortis umbram, in eterne noctis catabasim Stygiasque paludes repedandum sugillent.

Salomonis verba $₫$ Here, iungere, assentire Deo, cui te amabilem alexicaca ${ }^{a}$ ) malorumve cunctorum expultrix Sapientia prestabit. "Neminem quippe», ut Salomonis verba dictitant ${ }^{3}$ ), «diligit Deus, nisi eum, qui cum Sapientia inhabitat». "Ama», inquit ${ }^{4}$ ), «illam et exquire toto corde. Amicam et sponsam voca illam. Supra pulchritudinem et speciem dilige illam. Injice in compedes eius pedes tuos et in torquem eius collem tuum. Non enim habet amaritudinem conversatio illius nec tedium coniunctus illius. Iugum eius suave est et onus eius leve. Preciosior est auro, argento, lapidibus preciosis et omni desiderabili. Sole et omni dispositione stellarum longe speciosior, luci denique comparata invenitur prior; luci succedit nox, Sapientiam autem non vincit malicia.» đ Hec eius sunt sacra. testimonia, qui Sapientiam ipsam haud ab Hominibus, sed divino munere et spiritu consecutus eam super omnia amabilem, expetibilem, regnis cunctisque divitiis preferendam apseuti ${ }^{5}$ ) et veridico ore promulgavit.

$₫$ Homo natura, ut diximus ${ }^{6}$ ), oculatus es et multividus in mundo, cecus in teipso. Spectas ab initio in mundum: spectare in teipsum nitidissima Sapientie face irradiatus disce. Oculorum tuorum gemine acies extremiter et qua parte mundo copulantur, liquide sunt lucisque capaces; qua vero parte intra te sunt teque prospectant, operte ac cece visionis officio privantur. $₫$ Itaque exquammandi ${ }^{7}$ ) abs te sunt atque defecandi introrsus tui oculi, ut ololampi ${ }^{8}$ ) fiant totique videntes. Cecam ab initio tui pectoris aulam sive Sapientie radius influat, ut, sicut Natura spectas in mundum, discas Virtute et Sapientia spectare in teipsum.

a) alexitaca $e d$; alexicacus, ${ }_{\alpha}^{\lambda} \lambda \varepsilon \xi \xi \varkappa \alpha \varkappa \circ \varsigma$.

1) cf. cap. I-II.

2) lege: Sinam.

3) Sap. $7,28$.

4) cf. Sap. 8, I. + Sap. 7, Io. + Eccli. 6, 25. + Sap.8, I6.+ Matth. II, 30.+ Sap. 7, 29-30.

5) apseutes i.e. $\dot{\alpha} \psi \varepsilon v \delta \eta \dot{\eta}$.

6) cap. L.

7) lege: exsquammandi.

8) lege: hololampi, $\delta \lambda o \lambda \alpha \mu \pi-$. 
đ Circunstat te visibilis huius mundanique solis lux tuique corporis ex- Ex visibili luce trema undecunque illius iubar attingit ac ferit. Admitte illam in profundum, introduc eam in cellaria tua, ut tibi ipsa, que in te abdita sunt, sua conjicienda invisiclaritate adaperiat atque insinuet; aut saltim ex visibili eius aspectu bilis lux meliorem aliam invisibilem conjice lucem, que haud secus a mentalibus thalamis tenebras erroresque depellit, quam sol exoriens a mundo noctis facessere cogit umbram.

I đ Elice ex luna solem, ex parte totum, ex Sensu Intellectum, ex visibili p. $\mathrm{I}_{45^{\mathrm{v}}}\left[\mathrm{I}_{4} 7^{\mathrm{v}}\right]$ invisibile, ex corporeo spiritale, ex eo, quod extra te est, id, quod tibi insitum sit: ex mundo teipsum. Finis ipse es mundi ac tuiipsius noticia mundane cognitionis est finis. Prestantior es mundo: duc pluris scire tejpsum quam nosse mundum. Propter te factus est mundus: flocci mundum feceris, ut tibi insis plurior, ut teipso peramplius frui atque in temetipso sisti queas.

đ Id cave tuum esse dixeris, quod tuo in animo condi et abdi nequeat; Nichil veraciter quod enim aut in mundo aut in corpore locatum est, mox abs te auferri nostrum esse, nisi et aliene effici ditionis potest. Quod vero inest tuo Intellectui, id duntaxat veraciter est tuum situmque est in solius eius potestate, qui spirituum Dominus est, idque cum ipso spiritu ad eum revertetur, qui creavit illum et qui ut fidelis Deus «reddet unicuique mercedem iuxta opera sua. $\left.{ }^{1}\right)$ » Hic est, qui et repromisit, quoniam «capillus de capite nostro haudquaquam peribit» $\left.{ }^{2}\right)$, qui et «vivificabit iterum suscitabitque corpora nostra $\left.»^{3}\right)$, quibus et ipsos animos federe rursum sociabit amico, quod nullo denuo interitu solvetur. Et sicut instaurabit domicilium animi, corpus: ita et totius Hominis mansionem, visibilem inquam mundum, instauraturus creditur.

$\uparrow$ "Huius sanctus ac beatus timor initium est Sapientie» ${ }^{4}$ ); hunc revereri immortalitatem et beatitudinem confert; huic obsequi in eternum regnare est. Hic et ipsam largitur Sapientiam, que ab initio et ante secula creata et usque ad futurum seculum non desitura a sacris eloquiis ${ }^{5}$ ) predicatur, que item in malivolam animam non introitura neque habitatura in corpore subdito peccatis ${ }^{6}$ ), que et dubiis et infidis haudquaquam apparere solet. In illorum siquidem animas superne illabetur, qui - iuxta divi Divus Iacobus Iacobi verba ${ }^{7}$ ) - illam ipsam a Domino simplici corde nichil hesitantes expostulant. Ait $\left.\operatorname{enim}^{8}\right)$ : «Si quis indiget Sapientia, postulet a Domino, qui dat omnibus affluenter et non improperat: et dabitur ei.»
1) $c f$. . Apoc .22, I2.
4) cf. Eccli. $I, I 6$.
6) Sap. I, 4 .
7) cf. Iacob. I, 6.
8) Iacob. I, 5 .

2) Luc. $2 I, I 8 . \quad$ 3) cf. Rom. 8, II.

5) Eccli. 24, I4. 
đ $\mathrm{Ne}$, Homo, assentire priscorum quorundam fabulis, qui preclarum $\mathrm{Sa}-$ pientie munus Deum mortalibus invidisse nefarie asserebant. His enim, qui hoc pacto senserint, ego hec sacra eloquia ${ }^{1}$ ) objiciam: «Qui solem suum facit oriri super bonos et malos, qui novit dare dignis et indignis.» $\mathrm{Si}$ novit terrenus pater dare panem esurientibus filiis: quanto magis celestis ille pater, cum excellenter bonus sit, dabit bona petentibus se. «Petite et accipietis; pulsate et aperietur vobis. Omnes sitientes venite ad aquas; et qui non habetis argentum, properate, emite et comedite; venite, emite absque argento et absque commutatione vinum et lac. $\left.{ }^{2}\right)$ "

đ Et culpans eos Scriptura, qui non a Deo sed ab Hominibus Sapientiam exquirunt, rursum ait $^{3}$ ): "Quare appenditis argentum non in panibus et laborem vestrum non in saturitate? Audite audientes me et comedite bonum, et delectabitur in crassitudine anima vestra.» Humana doctrina
non satiat Humana etenim doctrina nos ut plurimum ieiunos relinquit atque sitibundos. Divina autem Sapientia esca eiusmodi est, "que», ut Bigus ait ${ }^{4}$ ), "satiat vivo pectora nostra cibo.»

Salomonis verba \& Audi iterum Salomonem, qui Deum Sapientiam mortalibus invidisse addubitare audes: "Nunquid», ait ille ${ }^{5}$, «non Sapientia clamitat et Prudentia dat vocem suam in summis excelsisque verticibus, supra viam, in mediis semitis stans, iuxta portam civitatis, in ipsis foribus loquitur dicens: O filii, ad vos clamito et vox mea ad filios hominum. Intelligite parvuli astutiam et Insipientes animadvertite. Audite disciplinam et estote Sapientes et nolite abjicere eam. Beatus homo, qui audit me et qui vigilat ad fores meas quotidie et observat ad postes ostii mei. Qui me invenerit, inveniet vitam et hauriet salutem a Domino: qui autem in me peccaverit, ledet animam suam. Omnes, qui me oderunt, diligunt mortem.»

đ Hi sacri sermones quid aliud attestantur quam Sapientiam haud invitam sed ultroneam e celis in nostrum orbem proficisci, penetrare usque in inferiores partes, pulsare singulos et inspicere omnes dormientes, apparere autem his presertim, qui sperant in Domino?

đ Eos denique, qui hoc pacto Sapientiam Dei livore Hominibus denegari credere non erubent, hoc decasticho nostro, aliter ut sentiant, hortamur:

\footnotetext{
1) Matth. 5, 45.

2) Matth. 7, 7.+ Isaias 55, I.

3) Isaias 55,2 .

4) Christianorum Opusculorum lib. II. carm. 28: 'De divina pace vers. I8; ed. Beati Rhenani fol. 27 r. (cf. p. 321 n. 2.)

5) Proverb. $8, I-5 ; 33-36$.
} 
Solliciti a supero si quicquam numine nobis Expetimus, gratis munera queque dabit.

Non ibi profuerit fulvi spes ulla metalli, Pascit enim sola nos bonitate Deus.

Si bonus est, natura boni nil denegat ullis; Dinosci cupiens omnibus illa patet.

Ergo pii tante lucis iubar ede sinamus

E supera nostras irradiare domos;

| Sponte etenim mentes lux influet illa piatas:

Utile quicquid erit, conferet ipsa viris.

đ Quo enim pacto Deum mortalibus Sapientiam invidere fatebimur, quibus priorem Substantiam minime probatur invidisse? Et si, ut divus Dionysius testatur ${ }^{1}$ ), «nulla magis proprietas quam ipsa bonitas Deum Divus Dionysius ab initio exciverit, ut conderet crearetque universa», ut, qui solus erat ab eterno, aliis quoque esse indulgeret: sentiendum profecto est, ut bonitas eadem, que divinam substantiam Hominibus Esse impartiri imprimis allicefecit, iisdem et Sapientie splendorem benigne elargiri allicefecerit atque evicerit.

q Qua enim bonitate primum naturaleque Hominum Esse Deus ab initio sanxit, eadem postremo bonitate et secundum atque intellectuale eorum Esse statuere voluit. Qui Substantiam Homini dedit, et Sapientiam illi minime denegavit. Qui naturalem Hominem procreavit, illum deinceps voluit studioso Homine splendescere, perfici, consummari.

đ Est enim studiosus Homo naturalis lux et splendor Hominis: per quem mens, que in tenebris degit ab initio, in lucem, claritatem cunctorumque scientiam emergit. đ "Age igitur, o Homo», ut sacer Dionysius suadet ${ }^{2}$ ), Sacer Dionysius «cognoscentia et provida corda gerens sursum erigere. Agnosce patrem luminum, a quo lux omnis procedit suique motus initium sumit.» Ac ne pro iis, que non sunt, ipsum ens verum unquam permutes: cuius sapida et suaveolens agnitio vera est, perfecta et consummata Sapientia.

Valebeare.

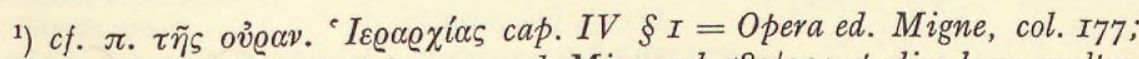

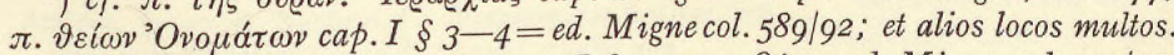

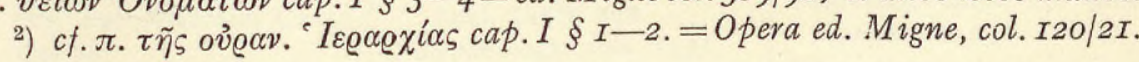


$₫$ Libri de Sapiente finis anno divine

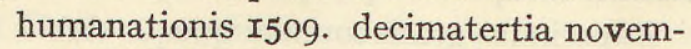
bris. Divine, increate et intemerate Sapientie innumere laudes: angelice et humane Sapientie conditri-

ci

đ Editus est in edibus reverendi in Christo patris Francisci de Hallewin, pontificis Ambianensis.

đ Quantus, qui sapit, est mens quantaque conscia veri, Que contemplari seque Deumque potest, Quodque immortalis nullisque perire diebus Mens ea, que sese noverit, esse queat, In mortem ruat Insipiens quod cecus opacam, Stulta quod obscurum mens petitura chaos:

Hec liber hic confert revocatque in pectora mentem. Munera percurrat, qui sua nosse cupit. ${ }^{1}$ )

1) cf. Hexastichon in initio operis. 


\title{
I N D I C E S.
}

\author{
Von
}

Gertrud Bing.

\section{EIGENNAMEN.}

Abraham bei Cusanus 3 I

Adam:

Prometheus und, bei Bovillus 98

im Mittelalter Ioo

Aggsbach, Vincent von s. Vincent

Aglaophamus bei Ficino 65

Aindorffer, Gaspard, Brief des Nikolaus Cusanus an I4. 4 O. 76

Albert von Sachsen:

Physik des 186

Vertreter der 'moderni' 36

Alberti, Leon Battista:

Fortuna bei $8 \mathrm{I}$

Mathematik bei 54

Natur und Genie bei I70

Stellung zu Cusanus 54

Albertus Magnus, PseudoDionysius bei 8

Aleria, Johannes Andrea von, s. Andrea

Alexander bei Pico I26

Alexander von Aphrodisias, Kommentar des Pomponazzi zu 86

Alfonso von Este, Hochzeit des 77

Ambrogio da Rosate in Mailand 149854

Anaxagoras :

Kritik Platons an ${ }^{7} 76$

Physik des 27

Andrea, Johannes, Nachruf des, auf Nikolaus Cusanus 36

Aphrodisias, Alexander von s. Alexander

Apollo als Verkörperung d. Allwissens bei Valla 85
Araber (s. auch Averroïsmus):

Bildungsgeschichte, in der 4. I08. I35. I 44 f. I 47 Seele bei den I34. I38. I44. 147

Vermittlung der Astrologie durch die 104. 108

Archimedes, Studium des, bei Cusanus 36

Areopagita s. Dionysius

Aretinus, Leonardus s. Bruni, Leonardo

Aristoteles:

Astronomie des 26

Bessarion, bei $\mathrm{I}_{7}$

Cusanus, bei I2. I 5 f. Igf. 56. 186

Frankreich, in 93

Galilei, bei 165.192

Kosmologie des 185

Kritik an I54. I56. I65. I86. 192

Logik des I2. I5. 56

Neuplatonismus und 19

Ort bei I84f. I9If.

Padua, in der Schule von I43f.

Physik des 25 f. I08. I33. I54. I83 ff. I9I. I93f.

Pico, bei 2. 89. I22. I26. I39. 179

Platon und I5. I7 f.

Pomponazzi, bei 85 f. ro 8 . I 43 f. $x_{45}$ ff. $x_{4} 8$ Psychologie des I33f. I 43 f. I 45 ff. I 55 Renaissance, Stellung in der If. I5f. I9f. 63. I3r. I 86

\section{Aristoteles :}

Seele und Selbstbewußtsein bei I33f. I46f. I54 Telesio, bei $\mathrm{r}_{54} \mathrm{ff}$.

Thomismus, im 145 f. Valla, bei 85

Ascoli, Cecco d' s. Cecco

Assisi, Franz von s. Franz

Augustin:

Astrologie bei 105

Campanella, bei $57 \mathrm{f}$.

Ficino, bei 69. 74. 201

Geschichtsphilosophie

des $75 \mathrm{f}$.

Individuum bei 135

Natur bei 152

Petrarca, bei 39. 69. I04. I36. I52

Urmensch-Idee bei 98 . IOo

Verehrung des 104

Vermittlung Platons durch I6. I04

Bacon, Francis, Erfahrung bei 154

Barbaro, Ermolao, Brief Picos an $2 \mathrm{f}$.

Basel, Konzil zu $6_{4}$

Bayle, Pierre, Dogmenkritik bei $82 f$.

Bembo, Pietro, Erfindung und Nachahmung bei 174

Benivieni, Girolamo, Erostheorie bei 138

Bern, Gobelin in 32

Bessarion, Johannes: Beziehung zu Nikolaus Cusanus I6 
Bessarion, .....

Entscheidung zwischen

Platon und Aristoteles

I7. 49

Ficino über 49

Boccaccio, Giovanni, Prometheusmythos bei roof.

Boethius bei Pico 126

Borgia, Lucrezia, Hochzeit der 77

Bouelles, Charles de s. Bovillus, Carolus

Bovillus, Carolus:

Acedia bei 96

Allegorie bei 98

Antike bei 98

Christentum bei 98

Erkenntnistheorie des 93

Ethik des $95 \mathrm{f}$

Grundcharakter seines

Werkes $93 \mathrm{f}$.

Hegel und 94. 96

Kosmologie des 93. 102

Mikrokosmosidee bei 93 .

97f. Ior ff.

Natur und Geist bei 94 ff.

IO2

Prometheus-Motiv bei 99 .

IOIf.

Selbstbewußtsein bei 95 Stoa bei 102

Bracciolini, Poggio s. Poggio

Brahe, Tycho de s. Tycho

Brüssel, Selbstbildnis Rogers van der Weyden in 32

Bruni, Leonardo:

Aristoteles - Übersetzung des I

Forschung, moderne, über 5

Bruno, Giordano:

Abhängigkeit des, von Cusanus 49f. 74

Anschauung bei I98f.

Allegorie bei 79

Astrologie bei I28. I 56

Autonomie bei I03. I74. I99f.

Bewegung bei $197 \mathrm{ff}$.

Copernicus bei 198

Erkenntnistheorie des 78 . I98f.
Bruno, Giordano:

Ethik des 79. I28f. I43. I98. 200

Fortuna bei 77 f. 82

Genie und Regel bei I74

Individuum bei roz $f$.

Kosmologie des 39. 74 . I $28 \mathrm{f}$. 198.200

Magie bei ${ }^{5} 6$

Mythologie des 104. 108

Natur bei I $28 \mathrm{f}$.

Neuplatonismus bei 143 . I98

Phantasie bei 197. I99

Raum bei I97ff. 200

Selbstbewußtsein bei I43. I99f.

Stoa bei 198

Symbol bei 78

Unendlichkeit bei I97. 200

Burckhardt, Jacob, über:

Astrologie 113

Festwesen 78

Geschichte II 3

Individuum 37

Pico 9I

Philosophie der Renaissance $3 f$.

Stellung zur Welt $\mathrm{I}_{53}$

Caesalpin, Botanik des ${ }_{54}$

Campanella, Tommaso:

Erkenntnislehre des 57 . ${ }^{7} 78$

Gott und Natur bei 57

Magie bei I56. 158f. I6I. I 78

Mikrokosmosidee bei ${ }_{5} 5$ Mythos und Wissenschaft bei 108

Thomas v. Aquino bei 57

Cardano, Girolamo:

Einheit des Alls bei 157 f. Stellung des, zur Astrologie 107

Cavalcanti, Guido:

Ficinos Briefe an 106

Sprache des 169

Cecco d' Ascoli, astrologische Geschichtskonstruktion des II 3

Chalcidius als Vermittler Platons 133
Cicero:

Petrarca, bei 39

Vermittlung durch I6

Platons

Clauser, Christoph, Brief des Paracelsus an II 7

Colonna, Giacomo, Brief Petrarcas an 39

Controni, Luca, Brief des Ficino an 139

Copernicus:

Bruno über 198

Einfluß des Cusanus auf 37

\section{Kepler über I27}

Loslösung des, von der Astrologie IO 7

Cortese, Erfindung u. Nachahmung bei ${ }^{7} 74$

Cosimo, Piero di, s. Piero

Cusano, Niccolo, Arzt, in Mailand I 49854

Cusanus, Nikolaus:

Alberti und 54

Antike bei I6. 2 Iff. 28 . 36. 42. 53. 62. 97. 103. I4I. I $80 \mathrm{f}$.

Aristoteles bei I2. I5f. I9f. 56. I $86 \mathrm{f}$.

Astronomie des 29. 43. 6r. 187,189

Ausdehnung bei 43

Autonomie bei 187

Averroïsmus und 137

Bessarion und 16

Bewegung bei 25. 27 f. I4I. I86. I89

Bruno und 49 f. 74

Chorismos bei 23. 38. $4^{\mathrm{I}}$

Christentum bei 40 ff. IO 3

Christus-Idee bei 40 f. 75 . I03

Coincidentia oppositorum bei 8. 4 o. 43 f. 56. 64. 92 . I 89

Copernicus, Einfluß auf 37

Deventer, in 34 f. 54

Devotio moderna bei $34 \mathrm{f}$. 52

Dionysius und 8. 16

Eckhart und 8. 35. 39

Erbsünde bei 45. 100

Erfahrung bei 24. 62. I8I. I 89 
Cusanus, Nikolaus:

Erkenntnisproblem bei Ioff. 24 . 4 o. 43.52 f. 54 . 56. 67.137 .180 .186

Erlösung bei 42. 68

Ficino und 49.63 .67 .138 . I4 I

Frankreich und 93

Freiheit bei 46.69 f. 88 . I03. I4I. I5I. I 87

Florenz, Verbindung mit 67. 88. I4I

Geschichtsauffassung des 45

Gottesbegriff des $13 \mathrm{ff}$ 24. 29. 32 ff. $3^{8} \cdot 4^{2} .46$. 56. 72. 100. 103. 189

Hierarchie bei $x_{3} .64$

Humanismus bei 20. 36 . 53. 88

Humanität bei 40 ff. $7 \mathrm{I}$. 75. 103

Individuum bei $30.32 \mathrm{f}$. 37. I03. I37. I4I. I5

Italien und 36.49 ff. 5 I. 54. 62

Kirche, in der 64

Kosmologie des 27 ff. 39 . 7 I. II6. $187 \mathrm{ff}$.

Kultur bei 46

Kunst bei 73 . 180

Laienwissen bei 53.59

Leonardo und $52 \mathrm{f}$. 54 . I6r

Logik des I2f. I5. 43. 56 . $6 \mathrm{I}$

Mathematik des I5. 23. 36f. 43. 56. $62 \mathrm{f}$.

Maximum, absolutes, bei 2 Iff. I 89

Methexis bei 23. $3^{8} \cdot 4^{\mathrm{I}}$

Methode bei 53 f. I63f.

Mystik, und die I3f. 34 f. 39

Natur bei 4 Iff. 56 . I90

Neuplatonismus bei 16 . I 38

Notwendigkeit bei ${ }_{5}$. 23. $43.58 \mathrm{f}$

Ort bei 187.189

Physik des 25f. 43. 6I. 74. I 4 I. I 86 ff. $188 \mathrm{f}$. I92 Pico und 49f. 63. 88. 92 Platon bei I6. 2Iff. 28 . 36. $62.14 \mathrm{I}, 180$
Cusanus, Nikolaus:

Proportion bei 55

Raum bei 43. 45. 6I. 74 . I86. I88. I92

Scholastik, und die IIf. 2 Iff. 25 f. 27.35 f.

Seele bei 44. I37

Sinnlichkeit bei 180

Sprache des 2of. 36

Symbol bei 32. 56.72

System, einheitliches, des 7. 39.64

Technik bei $6 \mathrm{If}$.

Theodizee des 30

Theologie bei II. ${ }_{3} \mathrm{ff} .24$. 29. 38 ff. 48 . 57. I03

Toleranz des $3 \mathrm{I}$

Trinität bei 95

Unendlichkeit bei II. I3. 2Iff. 4 of. 56. 74. I89

Vernunft bei 187

Welt bei $26 \mathrm{ff} .29 .38 \mathrm{f} .46$. 56f. I 88

Wert bei 46

Wille bei $13 \mathrm{ff}$.

Wirkung, zeitgenössische, des 49 ff. $54.62 \mathrm{f}$.

Wissen bei II. I3. 23. 38 . 4I. 46. 52. 57. 59. 6 I

Zeit bei $43.45 .6 \mathrm{I}$. 74 . 186. I88. 192

Dante:

Formgefühl bei 169

Fortuna bei $8 \mathrm{I}$

Mittelalterliches bei 169

Wissenschaftssystem, astrologisches, bei 105

Descartes:

Bewegung bei 196

Koordinatensystem bei I96

'Mathesis universalis' des I94

Selbstbewußtsein bei 130 . I 35

Deventer (s. auch Brüder vom gemeinsamen Leben und devotio moderna) Cusanus' Erziehung in 34f. 52

Dionysius Areopagita: Cusanus über 8. I6

Erlösung bei 9

Gottwerdung bei I4
Dionysius, Areopagita:

Hierarchie bei 9. I9

Neuplatonismus u. Christentum bei 9 . I9

Theodizee des 10

Thomas v. Aquino über 8 Diotati, Brief Galileis an 59

Duns Scotus, Physik des 26

Eckhart:

Beziehung zu Ruysbroeck 35

Cusanus über 8. 35. 39

Gottwerdung in der Seele bei 35

Enea Silvio Piccolomini, Sprache des 20

Erasmus von Rotterdam: devotio moderna bei 35 Erfindung und Nachahmung bei $\mathrm{I} 74$

Ercole von Este, Vater Alfonsos 77

Eriugena, Johannes, s. Johannes

Este:

Alfonso von s. Alfonso

Ercole von s. Ercole

Faber Stapulensis, Jacob: Stellung zu Cusanus 36 . 93 Wirkung in Frankreich 93

Fermat:

Bewegung bei 197

Koordinatensystem bei I $96 \mathrm{f}$.

Ferrara, Hochzeit der Lucrezia Borgia in 77

Ficino, Marsilio:

Ästhetik des 67 f. 72 . IOI. I50. I70

Askese bei 66

Astrologie bei I05ff. II6. II9f. I5O. I6o

Augustin bei 69. 74. 201

Bessarion bei 49

Bewegung bei I4I

Christentum und Toleranz bei 76

Christus-Idee bei 75

Cusanus und 49 f. 63.67 . I38. I4I 
Ficino, Marsilio:

Erkenntnistheorie des 67 .

201

Erlösung bei 70

Erostheorie bei 138. I40 ff

Fatum bei II9f. I5O

Freiheit bei 69 f. 8I. Ior.

I05f. II9f. I4I. I48

Geschichtsphilosophie des 75 f.

Gott bei 67. 70. 76. 20I

Grundcharakter, philosophischer des 65 f.

Hermetik bei 3. 65.9 I

Hierarchie bei 70 . I 16

Humanität bei 7 r. 75 .

IOI

Individuum bei $\mathrm{r}_{3} 8 . \mathrm{I}_{4} 8$

Kosmologie des 7I. II6. 2OI

Kunst und Natur bei 7.2 . IOI. I5O. I70

Magie bei 160

Medizin des I I9

Natur bei 72 f. IоI. Io6. I20. I49f. I 70

Neuplatonismus bei $3 \cdot 74$. I38. I40. I78

Notwendigkeit bei Io6. I 20

Offenbarung bei 3.76

Orpheus bei 3. 65

Physik des II6. I23

Planeten bei ıо6. Ixgf.

Platon, Stellung $\mathrm{zu} 2 \mathrm{f}$.

65. 74. 9I. I39. I78

Pomponazzi und $\mathrm{I}_{4} 8$

Reformation bei 70 f.

Religionsphilosophie des 67f. 70. 76. I39. I48. 2OI

Seele bei 68. 7x. 75. II9. I38f. I48. I57. 20 I

Theologie bei I20. I39

Unsterblichkeit bei 74 . I45. $x_{48}^{8}$

Wille bei 75 . II9. I38

Zeit bei 74

Filelfo, philologisches Interesse bei

Florenz:

Humanismus in 88

Kunsttheorie in $67 \mathrm{f}$. $7 \mathrm{I}$. I40. 178

Paris und 93
Florenz:

Platonismus in, siehe Platonismus

Scholastik in $65 \mathrm{ff}$.

Frankreich:

Cusanus in 93

Faber Stapulensis in 193

Florenz und 93

Humanismus in 93

Franz von Assisi:

Bahnbrecher der Renais-

sance, als 5

Gott und Natur bei $55 \mathrm{f}$.

Gaguin, Robert, Brief an Ficino 93

Galilei, Galileo:

Aristoteles bei I65. I92

Astrologie bei 107

Autonomie bei $x 78$

Bewegung bei 183 . $192 \mathrm{ff}$.

Campanella über $x_{5} 6$

Erfahrung bei 62. I07. I56. I72. I74f. I77. I8r. $\mathrm{r} 83$

Erkenntnistheorie des I 7 If. I78. I 8 I

Gesetz bei I65f. I73. I77. I82. 193

Gestaltung bei I75

Kosmologie des 39

Kritik des, an Aristoteles 165 . I92

Kunst bei I6I. I66. I74

Leonardo und I 64 f. I77

Mathematik bei $58 \mathrm{f}$. I65.

I7I. I73. I78. I82. I93f.

Methode bei I 56. I8I. I94

Natur bei 58 . I65f. I77.

I82. I93

Offenbarung bei 59

Platon bei 178

Proportion bei I7I. I74

Raum bei r92f. 198

Scholastik, gegen die 165 .

I73

Symbol bei 59

Ursache bei I65. I 81

Vernunft bei I56. I78. I 8 I

Wissen bei I7If. I78. I 82 f. I94

Gaza, Theodorus, Entscheidung zwischen Platon $\mathrm{u}$. Aristoteles bei I7
Georg von Trapezunt, Entscheidung zwischen Platon u. Aristoteles bei I7

Gerson, Johannes, s. Johannes

Giordano Bruno, s. Bruno

Goethe:

Ganymed bei 20I

Gesetzlichkeit der Schönheit bei $I_{72}$

Manier und Stil bei I66 Phantasie, exakte, bei ${ }^{6} 67$ Symbol bei 32

Groote, Gerard, Beziehung zur deutschen Mystik 35

Guinicelli, Guido, Sprache des 169

Hegel:

Begriff der Philosophie bei I. 7 .

Bovillus und 94. $96 \mathrm{f}$.

Erkenntnis bei $4 \mathrm{I}$

Heidelberg, Cusanus' Studium in $35 \mathrm{f}$.

Herkules im Festspiel, Rom I $50 \mathrm{O}-77$

Hohenheim, Theophrast v., s. Paracelsus

Humboldt, Sprache und Gedanke bei 60

Inghen, Marsilius von, s. Marsilius

Innocenz III, Einwirkung des, auf Joh. v. Saaz IoI

Johannes Andrea s. Andrea

Johannes Eriugena:

divisio naturae bei 43

Pseudo-Dionysius bei 8

Johannes Gerson als Vor-

läufer des Nikolaus $\mathrm{Cu}$ sanus 12.36

Johannes von Saaz, Urmensch-Idee bei 98

Johannes Scotus s. Johannes Eriugena

Italien:

Einwirkung des Cusanus auf $49 \mathrm{ff} .54 .62$

von, auf Cusanus $36.5^{\mathrm{I}}$ nach Frankreich 93

Juno im Festspiel, Rom I $50 \mathrm{I}-77$ 
Jupiter als Verkörperung der Allmacht bei Valla 85

Kant, Immanuel, Genie u. Regel bei I 74

Kepler, Johannes:

Astrologie bei 127

Astronomie des 127. 190

Autonomie bei 190

Bewegung bei 190. 195

Copernicus und 127

Exaktheit als methodische Forderung bei 172

Gesetzlichkeit bei I 74

Kausalität bei I23. 127

Methode bei I 72

Naturbetrachtung des 58 .

I74

Optik des 190

Ort bei r9o. 198

Pico weitergebildet bei I23. 127

Planeten bei 127. I74. I90

Platon bei $\mathrm{I} 74$

Porta bei 160

Stereometrie des 195

Ursache bei 123. 127

Vernunft bei 190

Zeitbegriff bei 45

Kopernikus s. Copernicus

Kues, Nikolaus von, s. Cusanus

Lactanz, Prometheusmythos bei 100

Lagrange, virtuelle $\mathrm{Ge}$ schwindigkeit bei 164

Landino, Christoforo, Erosbegriff bei 138

Langland, William, Urmensch-Idee bei 98

Leibniz:

Ähnlichkeit des Bovillus mit 94

Fatum, über das $\mathrm{IO}_{4}$ Monadenlehre, Vorbildung der 97 f. 137

Platonismus bei 65

Selbstbewußtsein bei rзо. I37

Valla, über 84

Zeitbegriff des 45

Leonardo da Vinci:

Autorität, gegen die 52 .

60

Studien der Bibliothek Warburg ro: Cassirer. I 7 I I 82 Lessing: 82. 84 5 $8 \mathrm{r}$ II 4 in 54
Manetti, Giannozzo:

Freiheit bei 88

Humanität bei ror

Stoa bei 88 52f. 54.162

Erfahrung bei 6o. 62 . I56. I6I. I63f. I72. I8I Erkenntnistheorie des I63. I66. I77f. I8I Experiment bei I63. I8I Galilei und 164 f. 177

Gesetzlichkeit bei $164 \mathrm{f}$.

Gestaltung bei 7I. I7I

Kausalität bei 62

Kunst und Natur bei 74 I66f. I7of. I77f. I 79 f. Mathematik, Stellung zur 54. 58. I62 f. I65. I77

Methode bei $53 \mathrm{f}$. I 56 I63f. I8I. I94

Naturbetrachtung des 58 . 62. I63. I82

Phantasie bei I67. I70. I72. I79

Platon bei $177 \mathrm{f}$.

Proportion bei I 7 I

Sinne bei 163 . I 79

Vernunft bei 156.163 . I65. I77. I8I

Wahrheitsbegriff des 163

Dogmenkritik bei 82

Genie und Regel bei I74 Vallas Ähnlichkeit mit

Lorenzo de' Medici:

Forschung, moderne, üb. Lebensstimmung des 66 .

Lukrez, Kommentar des Ficino zum 66

Lucrezia Borgia s. Borgia

Macchiavelli:

Florentiner Akademie einwirkend auf 67 Schicksal bei $8 \mathrm{I}$

Mahomet, zeitliche Bedingtheit des, bei Pomponazzi

Mailand, Versammlung $\mathrm{I} 498$ ster von 67

Marliani in Mailand 149854

Marsilio Ficino s. Ficino

Marsilius von Jnghen: derna durch 35 des 12 renzo

Michelangelo:

Eros bei $x_{43}$

Galilei über I6r. I75

Moses: bei Pomponazzi II 4 cino 3 bei Pico 65

Neapel: I6o

Lorenzo Valla in 82

Newton: als 166

Ursache bei 123 land $\mathrm{r}_{498} 54$

Nürnberg, Bild im Rathaus von 32 Wilhelm

Orpheus: 6r cino 3. 65 I3If. sterblichkeitslehre ${ }^{4} 47$

Pacioli, Luca: Proportion bei 55

Marco, San, Pico im Klo-

Einführung der via mo-

System, scholastisches,

Medici, Lorenzo de' s. Lo-

Bedingtheit, zeitliche, d.,

Offenbarung des, bei Fi-

Schöpfungsgeschichte d.,

Accademia dei Secreti in

moderner Naturforscher,

Novarese, Andrea, in Mai-

Occam, Wilhelm von, s.

Lyra des, bei Cusanus 44 .

Offenbarung des, bei Fi-

Seele in der Lehre des

Ovid, Metamorphose des, als Analogon der Un-

Bericht über eine akademische Versammlung 54 
Padua:

Cusanus in 16.36 .137

Schule von 4.49 .88 . I 35 . I 43

Paracelsus, Theophrastus:

Astronomie bei II $7 \mathrm{f}$.

Medizin des II7. II 8

Physik und Ethik bei I 8

Welt und Mensch bei II 7

Paris, Platonismus in 93

Patrizzi, Francesco:

Erkenntnistheorie d. I42. I $57.178 \mathrm{f}$.

Erostheorie bei $\mathrm{I}_{42}$

Naturphilosophie des ro2. I23

Seele bei 157

Paulus bei Nikolaus Cusanus 31.69

Pavia, Professur des Arztes Cusano in 54

Petrarca:

Acedia bei 39. I53

Antike bei $39 f$.

Astrologie bei 105

Augustin bei 39. 69. I04f. I36. I52

Averroïsmus, gegen den I $35 \mathrm{ff}$.

Christentum bei $39 \mathrm{f}$.

Cicero bei 39

Formgefühl, neues, bei I69

Freiheit bei 8o. 105

Individuum bei 136

Mystik, und die 136

Natur bei ${ }_{5} \mathrm{Iff}$.

Platon, Stellung zu $\mathrm{I}_{5} \mathrm{f}$.

Schicksal bei 80 . I05

Scholastik, Angriff gegen

die $\mathrm{I} .5 \mathrm{If}$. 136

Seele bei 136 . 152

Unendlichkeit bei 199

Peurbach, Georg, Einfluß des Cusanus auf 37.62

Picatrix, Physik des, bei Ficino II 6

Piccolomini, Enea Silvio s. Enea

Pico von Mirandola, Giovanni:

Aristoteles bei 2f. 89. I22. I26. I39. I79

Askese bei 9I
Pico von Mirandola, Giovanni:

Astrologie bei II5. I2I ff. I24

Bibel bei 65

Burckhardt über 9I

Chorismos bei 9I

Cusanus und 49 f. 63.88 . 92

Erfahrung bei r22f.

Erkenntnistheorie des 9I. I23 ff.

Erostheorie des 139

Freiheit bei $82.88 \mathrm{f}$. IO2. I22. I25f. I7of.

Genie bei 125

Gesetz bei 123 f. $15^{8}$

Gnade bei I 7 I

Hierarchie bei 89

Humanität bei 91 . I22

Individuum bei 89

Kepler und I23. 127

Magie bei I2I. I58. I60.

I 79

Mathematik bei I22. I24

Mensch als Schöpfer bei

89. I02. 125

Methexis bei 9I

Mikrokosmos bei $88 \mathrm{f}$. 97

Mystik, und die I2I

Mythos bei 90

Natur bei I23f. I58. I7 I. I 79

Neuplatonismus bei 89 . I2If.

Physik des I23

Platon bei 2f. 91. I22. I39. I79

Raum bei r22f.

Schicksal bei 87

Stoa bei 87

Theologie bei $65 \mathrm{f}$.

Wille bei $88 \mathrm{ff}$. I 25

Pico von Mirandola, Giovanni Francesco:

Brief Giovanni Picos an 66

Nachahmung und Erfindung bei 174

Piero di Cosimo, Prometheusbilder des 100

Pirovano in Mailand ${ }^{4} 49854$ Platon:

Anaxagoras und 176
Platon:

Aristoteles, Verhältnis zu I5. I $7 \mathrm{f}$.

Astronomie bei I8If.

Augustin und I6. 104

Bessarion, bei 17.49

Bewegung bei 139 . 182

Chalcidius-Kommentar

zu I33

Chorismos bei I7. 139

Cicero als Vermittler von I6

Cusanus, bei I6. 2 If. 28 . 36. 62 . I4I. 180

Eros bei 139

Ficino, bei 2f. 27. 65. 74 . 91. I39. I 78

Galilei, bei $177 \mathrm{f}$.

Grundgedanke, methodischer, von $\mathrm{I} 7 \mathrm{f}$.

Grundlage der modernen Philosophie, als 65. 177 Kepler, bei $\mathrm{I}_{74}$

Kunst bei 180

Leonardo, bei $177 \mathrm{f}$.

Mathematik bei I 76 f. I 8 I

Methexis bei I7. I32. I39

Naturerkenntnis bei $176 \mathrm{f}$. I 82

Neuplatonismus im Verhältnis zu I7. I9. I04

Petrarca, bei $15 \mathrm{f}$.

Pico, bei 2f. 9I. I22. I39. I79

Pomponazzi, bei 146

Prometheusmythos bei 98. I3If.

Seelenbegriff des I3If. I 46

Selbstbewußtsein bei 132 . I46

Stellung, wechselnde, zu 2 f. I 5 ff. 49. 63. IO4. I 75 f.

Wissen bei 132

Zeitbegriff des I32

Plethon, Georgios Gemistos:

Beziehung zu Nikolaus Cusanus I6

Entscheidung zw. Platon und Aristoteles bei I7

Plotin (s. auch Neuplatonismus):

Befreiung von I22 
Plotin (s. auch Neuplatonismus):

Bruno, bei 143

Ficino, bei 3. 74

Pico, bei 122

Prometheusmythos bei 98

Ursache bei 140

Vereinigung von Platon und Aristoteles bei I9

Poggio Bracciolini:

Forschung, moderne, über

5

Freiheit und Schicksal

bei 80

Gegensatz zu Cusanus, als 36

Wissenschaften bei I 50

Poliziano, Angelo:

Erfindung und Nachahmung bei I74

philologisches Interesse bei 2

Pomponatius s. Pomponazzi

Pomponazzi, Pietro:

Aristoteles bei 85 f. xo8.

I 43 f. I 45 ff. $I_{4}^{8}$

Astrologie bei 87 . Io8f. IIIf. I6o

Cusanus, Verhältnis zu 49 Dogmenkritik bei $85 \mathrm{f}$. I 45

Erfahrung bei 108

Ethik des $79.85 \mathrm{ff}$, I Io

Ficino und ${ }^{4} 48$

Freiheitsbegriff des $79 \mathrm{f}$. 85 ff. I IO. $1_{4}^{8}$

Gott bei 87 . II 4 f.

Geschichte bei Ir2f.

Individuum bei I44. I48

Kausalität bei 87 . Iogf.

II I

Kirche, katholische und 86

Kosmologie des I Io

Magie bei rog. I60

Mathematik bei IIIf.

Mythologie bei Io8f. I47

Natur bei Iogff. I43. I 48

Notwendigkeit bei 87 .

Iogf. II2f. II4.

Offenbarung bei II3. I45

Platon bei $\mathrm{I}_{4} 6$

Psychologie des I Io. I43f. I 45 f. I 49
Pomponazzi, Pietro:

Religion, zeitliche $\mathrm{Ge}$ bundenheit der, II3ff. Scholastik, über die 86 . I $45 \mathrm{ff}$.

Thomas von Aquino bei I $45 \mathrm{f}$.

Unsterblichkeit bei $79 \mathrm{f}$. I45. I 49

Wunder bei I09. II 4

Zeit bei 87 . I $2 \mathrm{ff}$.

Pontano, Freiheit u. Schicksal bei 80

Porta, Giambattista:

Campanella und ${ }_{5} 5$

Kepler über 160

Magie, natürliche, bei I 58

Mikrokosmosidee bei I 59

Proklus, Kommentar zum Parmenides, bei Cusanus I6

Pseudo-Dionysius s. Dionysius

Ptolemäus, Astrolab des, bei Cusanus 44. 6I

Pulci, Luigi, in der modernen Forschung 5

Pythagoras bei Ficino 3. 65

Raffael bei Galilei x6x. I75

Regiomontan, Einfluß des Cusanus auf 37.62

Roger van der Weyden, Selbstbildnis in Brüssel 32 Rom:

Festspiel I 5 or in 77

Pico in 88

Pico über I79

Rosate, Ambrogio da, in Mailand I 49854

Rucellai, Brief des Ficino an $8 \mathrm{If}$.

Ruysbroeck, Beziehung zu den 'Brüdern vom Gemeinsamen Leben' 35

Saaz, Johannes von s. Johannes

Salutati, Coluccio:

Forschung, moderne, über 5

Freiheit und Schicksal bei 8 o. 105

Wissenschaften bei I 50 . I62
Sassetti, Francesco, Fortuna bei 80

Saturn, Planet:

Dante, bei ro5

Ficino, bei ıo6. Ixgf.

Savonarola und die Florentiner Akademie 66f. 8I. I 2 I

Schedel, Hartmann, Äußerung über Cusanus 36

Schelling über Religion und Wissenschaft 57

Schöffer, Druck von I499 bei 36

Scotus, Johannes s. Johannes

Sforza, Lodovico Maria, Versammlung I 498 bei 54 Sigismund von Österreich, Konflikt des Cusanus mit 40

Silvio Piccolomini, Enea s. Enea

Tauler bei Nikolaus Cusanus 39

Tegernsee, Verhältnis des Cusanus zu den Mönchen von $32.40 .4^{8}$

Telesio, Bernardino:

Analogie bei I 57

Aristoteles bei I 54. I56

Astrologie bei $I_{5} 6$

Erfahrung bei I 54

Erkenntnistheorie d. I55.

I57

Geist bei I 50

Kritik des I54. I56

Magie bei ${ }^{5} 6$

Naturphilosophie d. I23. I54f. I77

Psychologie des I 55

Vernunft bei I 55

Tertullian, Prometheusmythos bei Ioo

Theodorus Gaza s. Gaza

Theophrast v. Hohenheim s. Paracelsus

Thomas v. Aquino:

Aristoteles und $145 \mathrm{f}$.

Averroïsmus, gegen den

I34. I 45

Campanella, bei 57

Dualismus des 194

Pomponazzi gegen $\mathrm{I} 45^{\mathrm{f}}$. $27^{*}$ 
Thomas v. Aquino:

Pseudo-Dionysius bei 8

Psychologie des I34. 145 f.

Wissen bei $\mathrm{I} 34$

Tizian bei Galilei I6r. I75

Toscanelli, Paolo, Freundschaft des Cusanus zu 36f.

Trapezunt, Georg von, s. Georg

Tycho de Brahe bei Kepler I27

Valla, Lorenzo:

Allegorie bei 85

Aristoteles und 85
Valla, Lorenzo:

Christentum bei $83 \mathrm{f}$.

Cusanus, Gegensatz zu 36

Forschung, in der modernen 5

Gottesbegriff des 85

Hierarchie bei $83 \mathrm{f}$.

Individuum bei $8_{3}$

Leibniz, bei 84

Sprache des 20. 169

Vernunft bei $83 \mathrm{f}$.

Willensfreiheit bei $82 \mathrm{ff}$.

Vergil:

Ficino, bei 3

Pico, bei 179
Vincent von Aggsbach, Gegner des Nikolaus Cusanus $\mathrm{I}_{4}$

Vinci, Leonardo da, s. Leonardo

Wenck, Johannes, Gegner des Nikolaus Cusanus I2 Wilhelm v. Occam:

Cusanus und IIf. 36 Marsilius v. Inghen und 35. 36

Physik des 26

Zoroaster bei Ficino 3. 65

\section{ZITIERTE WERKE.}

Alberti, L. B.

Della tranquillità dell' animo $8 \mathrm{I}$

Intercoenales $8 \mathrm{I}$

Trattato della pittura 170

Alexander von Aphrodisias:

De fato 86

Aretino, Leonardo:

Libellus de disputationum usu 2

Ariosto, Lodovico:

Orlando furioso 165

Aristoteles:

De coelo 185. 199

Nikomach. Ethik I

Politik I

Augustin:

Confessiones $\mathrm{I}_{52}$

De civitate Dei 76

De trinitate 135

De vera religione ${ }^{1} 52$

Benivieni:

Canzone dell'amore celeste e divino 138

Boccaccio, Giovanni:

Genealogia deorum roof.

Bovillus, Carolus:

De sapiente $93 \mathrm{ff}$. rorf.

Bruno, Giordano:

Degli eroici furori 82. 103. I74. I99f.

De immenso et innumerabilibus 198

Del'infinito, universo e mondi 199
Bruno, Giordano: De umbris idearum 78 . I43

La cena de la ceneri I98

Spaccio della bestia trionfante 77 . $128 \mathrm{f}$

Caesalpin:

De plantis ${ }_{54}$

Campanella, Tommaso:

Apologia pro Galileo I $_{5} 6$ De sensu rerum et magia

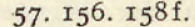
Philosophia rerum iuxta propria dogmata $\mathrm{I}_{59}$

Cardanus:

De subtilitate 158

Chalcidius, Übersetzung des Timäus 133

Cusanus, Nikolaus:

Apologia doctae ignorantiae I2. 35. 49. 56

Brief an Aindorffer I4. 40. 76

Brief an die Mönche v. Tegernsee 32. $4^{\text {O. }} 4^{8}$ De apice theoriae $3^{8}$

De beryllo I4I

De concordantia catholica 20.64 .83

De coniecturis 24 f. 30 . 45. 47. 6I. 92. I8I

De dato patris luminum 45. 100
Cusanus, Nikolaus:

De docta ignorantia 8. Iof. 21. 23.25 ff. 28 f. 39.40 42. $45 \cdot 49 \cdot 54$ ff. $57 \cdot 72$. 75. 103. I 86.189

De filiatione Dei 14 . $4^{8}$

De ludo globi 43f. 46. 6r. 75

De mathematica perfectione $\mathrm{I}_{5}$

De pace fidei $29 \mathrm{ff}$.

De transmutationibus geometricis $36 f$.

De venatione sapientiae 22

De visione Dei 32. 34. 38 . 42. $69 f$.

Dialogus de possest I 5

Excitationes 4I. 46. 6r. 73

Idiota I6. 38. 44. 47. 52f. 57.59 f. 72 f. 75 . 138. 180

Dante:

Convivio 105

Vita nuova 169

Dionysius Areopagita:

Von den göttlichen Namen 9

Von der Hierarchie des Himmels 9

Von der Hierarchie der Kirche 9 


\section{Fermat:}

Ad locos planos et solidos isagoge 197

Ficino, Marsilio:

De christiana religione 3 . 70. 76. 139

De vita triplici Io6. II6. I20. 160

Dialogus inter Deum et animam Theologicus 201 Epistolae 3. 49f. 65. 75 . 8I. I0I. I06. I38f.

Sopra lo amore o ver' Convito di Platone 139 Theologia Platonica 65 . 68. 69. 74 f. IоI. I20. I38. I4I

Übersetzung der hermetischen Schriften 9I

Gaguin, Robert:

Epistolae 93

Galilei, Galileo:

Brief an Diodati 59

Dialogo sopra i due massimi sistemi del mondo I6I. I7If. I73. I75. I78 Discorsi e dimostrazioni matematiche intorno a due nuove scienze 183

Il saggiatore 58. I6 6

Goethe:

Ganymed 20I

Maximen und Reflexionen 172

Homer:

Ilias 165

Innocenz III.:

De contemptu mundi ror

Johannes von Saaz:

Ackermann aus Böhmen $98 \mathrm{f}$. IOI

Johannes Scotus:

De divisione naturae 43

Kepler, Johannes:

Apologia Tychonis 123

De Stella nova 127

Discurs v. d. großen Conjunction $\mathrm{I} 27$

Harmonia mundi $127 \mathrm{f}$. I 74
Kepler, Johannes:

Mysterium Cosmographicum 45

Stereometria doliorum I95

Lactanz:

Divina Institutio roo

Landino, Cristoforo: Disputationes Camaldulenses ${ }_{13} 8$

Langland, William:

Piers the Plowman 98

Leibniz;

Theodizee 104

Leonardo da Vinci:

Codice Atlantico fol. 7552. fol. $86 \mathrm{r}-\mathrm{r} 63$. fol. II $5 \mathrm{r}-60$. fol. II $7 \mathrm{~V}$ 6o. fol. II9r-I64. fol. I4 I I - I 73. fol. $147 \mathrm{~V}-$ 62. I77. fol. $\mathrm{I}_{54} \mathrm{r}-\mathrm{I} 63$ fol. $345 \mathrm{r}-\mathrm{I} 68$.

Mss. ed. Ravaisson Ash. fol. $20 \mathrm{r}-\mathrm{I} 8 \mathrm{o}$. B fol. $\mathrm{I}_{4} \mathrm{~V}-\mathrm{I} 64$. C fol. $23 \mathrm{v}-$ I65. D fol. I3 $\mathrm{r}-\mathrm{I} 67$. $\mathrm{E}$ fol. $8 \mathrm{v}-\mathrm{I} 82$. E fol 55r-I8r. G fol. $47 \mathrm{r}-$ 72. G fol. $96 \mathrm{v}-162$. I fol. $18 \mathrm{r}-62$. fol, $49 \mathrm{r}-$ I7I.

Mss. ed. Richter Nr. 3I78. Nr. II33-I65. Nr. II 5 I-I64. Nr. II 57 58. Nr. II68-I62.

Trattato della pittura 72 . 74. I62. I79f.

Lorenzo de' Medici:

Canti carnascialeschi 66

Hymnen 66

Macchiavelli:

Il Principe 8I

Manetti, Giannozzi:

De dignitate et excellentia hominis 88 . IOI

Michelangelo:

Sonette I43

Pacioli, Luca:

De divina proportione 54 Paracelsus:

Buch Paragranum II7. II 8
Paracelsus:

Brief an Clauser II9

De imaginibus II 8

Patrizzi, Francesco:

Panarchias $\mathrm{I}_{42}$

Pancosmia 102

Panpsychia $\mathrm{I}_{57}$

Petrarca, Francesco:

Append. litt. epist. ${ }^{52}$

De contemptu mundi I 53

De remediis utriusque

fortunae 8o

De secreto conflicto curarum suarum 39. 104

De sui ipsius et multorum ignorantia I. 5If. I99

Epistolae rerum familia-

rum 39. I05. I52

Sonette 169

Trionfi della fama I5

Pico della Mirandola, Giovanni:

Brief an Ermolao Barbaro $2 f$.

Briefe an Giov. Franc. Pico 66

Conclusiones I2I

De hominis dignitate $8 \mathrm{gff}$. 93. I2I. I25. I58. I7I

Epistolae 3

Heptaplus 65

In astrologiam 82. I22f. I24.I26.I28.I58.I60.I 79 Kommentar zur Canzone des Benivieni 139

Platon:

Apologie I6

Kriton 16

Menon I6

Parmenides 16

Phaidon 16 . 176

Phaidros I6

Philebos 21

Politeia I6. 2I. 28, I8of. I82

Protagoras 98

Symposion 139

Theaetet I3If.

Timaios I32f.

Plethon:

Über die Unterschiede des Platon und Aristoteles I7

Plotin:

Enneaden I40. I43 
Poggio:

Epistolae 8of.

Pomponazzi, Pietro:

De causis... effectuum naturalium 87 . $108 \mathrm{ff}$. 160

De fato, libero arbitrio, de praedestinatione 79 85. 87

De immortalitate animae 79. III. I 43 f. $147 f$.

De incantationibus III. II 4 f.

Kommentar zu Alexander v. Aprodisias 86 $\mathrm{zu}$ Aristotelis de anima ${ }^{4} 8$
Porta, Giambattista:

Magia naturalis ${ }_{5} 8$

Salutati, Coluccio:

De fato et fortuna ro5

De nobilitate legum et medicinae 162

Telesio, Bernardino: De rerum natura ${ }_{55}$. I 57

Tertullian:

Adv. Marc. 100

Apologia roo

Thomas v. Aquino:

De unitate intellectus 134
Valla, Lorenzo:

Apologia 83

Confutat. in Benedictum Morandum 83

De .... donatione Constantini 83

De libero arbitrio 82.85 . 87

De professione religiosorum $83 f$.

De voluptate 84.87 . I69 Dialecticae disputationes 85. 169

Elegantia linguae Latinae 169

\section{WISSENSCHAFTSGESCHICHTLICHE BEGRIFFE.}

Acedia :

Bovillus, bei 96

Petrarca, bei 39. I53

Aesthetik s. Kunst, Kunsttheorie, Phantasie, Poetik

Akademie, florentinische (s. auch Platonismus): Aesthetik der 67f. 7r. I 4 off.

Aristoteles in der $2 \mathrm{f}$.

Askese in der 66. 9I

Platon in der $2 \mathrm{f}$. $9 \mathrm{If}$. IO4.

I39. 178

Psychologie der 74. Ir9. I38. I48f. $20 \mathrm{I}$

Savonarola und die $66 \mathrm{f}$. 8I. I2I

Stellung der, zu Cusanus 67. 88. I38. I4I.

zu Pomponazzi $148 f$.

Theodizee in der 67.140

Theologie der 65 ff. Io3

Wirkung der, in Frankreich 93

auf d. Kunst $7 \mathrm{I}$

auf d. Philosophie 88

Alexandristen in d. Schule v. Padua 4

Allegorese:

Bovillus, bei 98

Bruno, bei 79

Festspiel, im 77

Prometheusmythos, im $98 \mathrm{f}$.
Allegorese:

Renaissancelyrik, in der I69

Valla, bei 85

Analogie:

Natur und Mensch, zwischen II 4 . II7

Naturphilosophie, in der I 57 f. I 59

Telesio, bei 157

Ursachensetzung, statt I27

Anschauung (s. auch Erfahrung, Sinnlichkeit):

Bruno, bei $198 \mathrm{f}$.

Gesetzlichkeit der $x 68$

Methode Leonardos, als I67

Methode der Naturbetrachtung, als $\mathrm{I}_{53}$

Sinnlichkeit und 183

Antike (s. auch Aristoteles, Platon):

Bovillus, bei 98

Bruno, bei 104. 108

Christentum und 39. 4 off. rozf.

Cusanus und die $\mathrm{r} 6.2 \mathrm{Iff}$ 28. 36. 4 off. 53.62 .97 I03. I4 I. I8o. I8If.

Festwesen, im 77

Frührenaissance-Philosophie, in der 104
Antike (s. unter Aristoteles, Platon):

Kosmologie in der $\mathrm{I} 3 \mathrm{I}$. I39. I83 f.

Mythologie der 77. 85 . 98. 104. 108f. 147

Petrarca, bei $39 f$.

Philosophie der I04. I22

Pico, bei I22

Pomponazzi, bei I08f. I 47 Stellung, neue, zur ${ }^{7} 75 \mathrm{f}$. I 77 ff.

Stoff, als I68f.

Valla, bei 85

Zauberei der 108

Askese in der Florentiner Akademie 66. 9I

Astrologie (s. auch Planeten) :

Araber, bei den I04. I08 Augustin, bei ro5

Bruno, bei 128. 156

Burckhardt über die II 3

Cardano, bei 107

Christentum und IO4ff.

II 3

Copernikus, bei ro7

Dante, bei 105

Ficino, bei I05ff. II6. Irgf. I50. 160

Galilei, bei I07

Geschichte und II $2 f$.

Gesetzlichkeit in der 87 . I09. III 
Astrologie (s. auch Planeten):

Humanismus, im 105

Kampf gegen die I26ff.

Kepler, bei 127

Kosmologie und 107. Iogff.

Logik und rro

Magie und rogf.

Medizin und II9

Methode, bedeutsame,

der 108. III. I24. I26ff.

Mikrokosmos in der II 5 f. II 7 f.

Natur und ro7. IIof. I 58 f. I6of. I 79

Notwendigkeit in der 87 . I06. Iogf. I20. I22f.

Petrarca, bei ro5

Pico, bei II5. I2Iff. I24 Pomponazzi 87. rogf.III. I6o

Schicksal in der ro4. II8f. I5o

Scholastik, in der 108

Telesio, bei ${ }^{5} 6$

Theologie und 105.108.102

Wunderglaube und rogf. Astronomie:

Aristoteles über 26

Cusanus über 29. 43. 6r. I87. I89

Kepler, bei 127. 190

Mathematik und I8rf.

Medizin und $\mathrm{II}_{7} \mathrm{f}$.

Mittelalter, im 26

Paracelsus über II $7 f$.

Platon über $\mathrm{I} 8 \mathrm{If}$.

Ptolemäus, des 44. 6I

Ausdehnung bei Nikolaus Cusanus 43

Autonomie (s. auch Ethik, Freiheit):

Aesthetik, der 172

Bruno, bei I03. I74. 199

Cusanus, bei 187

Galilei, bei 178

Gesetzlichkeit und 149

Humanität und ro3. 125

Kepler, bei 190

Menschen, des 103. I25.

I74. 199

Pico, bei 125

Schöpfung, der 125

Vernunft, derI78. 187.190
Averroïsmus (s. auch Araber) :

Astrologie im 108. I34f.

I47

Angriffe gegen den $135 \mathrm{ff}$.

I 44 f. 147

Cusanus und der 137

Erkenntnistheorie des I34

Humanismus und ${ }_{3} 6$

Logik des 134

Mystik des I34. I36

Quelle der Renaissance-

Lyrik, als 169

Psychologie des 134 . 138 . I44. I 47

Schule von Padua, in der 4. I35

Seele im I34. I38. I44. 147

Thomas v. Aquino gegen den I34. I 45

Ursache im I44

Bewegung (s. auch Physik, Mechanik):

Aristoteles, bei 26. I33. I 83 ff. 193

Bruno, bei $197 \mathrm{f}$.

Cusanus, bei 25. 28. I4I. I86. I88f.

Descartes, bei 196

Eros als I4I

Fermat, bei 197

Ficino, bei $14 \mathrm{I}$

Galilei, bei 183 . I92ff.

Geometrie und $194 \mathrm{f}$. I96

Gesetzlichkeit der I93. I95f.

Hauptproblem d. exakten Wissenschaften, als I83. $193 \mathrm{ff}$.

Kepler, bei 19o. I95

Leonardo, bei 164 . I 82

Platon, bei I39. I 82

Raum und 195. I97f.

Relativität der $\mathrm{r} 86 \mathrm{f}$. I 89

Seele, der 69

Bewußtsein s. Seele, Selbstbewußtsein

Botanik (s. auch Natur), erste wissenschaftliche I 54
Brüder, die, vom gemeinsamen Leben (s. auch devotio moderna):

Beziehung der, zur deutschen Mystik 35

Cusanus' Erziehung bei den 34 f. 52

\section{Chorismos:}

Cusanus, bei 23. 38. 4I. Pico, bei 9I

Platon, bei 17 . I 39

Christentum (s. auch Theologie):

Antike und 39.40 ff.98.103

Astrologie und $\mathrm{IO}_{4} \mathrm{ff}$. II 3

Bedingtheit des II 4

Bovillus, bei 98

Cusanus, bei 40 ff. I0 3

Erostheorie und 139

Ficino, bei 76

Individuum und $134 \mathrm{f}$.

Mythos und 98

Neuplatonismus und 9. I9

Offenbarung des 59. I45

Petrarca, bei 39

Platonismus und 139

Pomponazzi, bei II4

Pseudo-Dionysius, bei 9 . x9

Toleranz und 76

Vernunft und $83 \mathrm{f}$.

Valla, bei $83 \mathrm{f}$.

Christus:

Idee der Humanität, bei Cusanus $40 \mathrm{ff} .75$. 103

bei Ficino 75

Nativität von II3

Coincidentia oppositorum: Grundprinzip des Cusanus, als 8. 40. 43. 44 . 56. 64. 92 . 189

Pico, bei 92

Dämonenglaube:

Astrologie, in der 124

Magie und 158 f. I6o. I79

Mittelalter, im 105

Platonismus, im Florentiner 9I

Pomponazzi, bei I Io

Demiurg als Schöpfer I $32 \mathrm{f}$. devotio moderna, Rolle der, in Cusanus' Erziehung 34f. 52 
Dogmenkritik (s. auch Theologie):

Methode der 82

Occamismus, im 86

Pomponazzi, bei 85 f. 145 Symbolbegriff in der 76 Valla, bei $83 f$.

Vernunft in der $82.85 \mathrm{f}$. I45. I47

Dynamik s. Physik, Bewegung, Ort

Einfühlung, Denken beruhend auf 157

Elemente (s. auch Physik): Aristoteles, bei $25 \mathrm{f}$. $184 \mathrm{f}$. Begriff, neuer, der 183

Bovillus, bei roz

Cusanus, bei 27

Eloquenz als Bildungsideal der Frührenaissance I. I6 19. 169

Empirie s. Erfahrung

Entelechie:

Seele als, bei Aristoteles I33. I46

Ubersetzung des Wortes 2

Erbsünde bei Cusanus $4^{6}$. IOO

Erfahrung (s. auch Erkenntnistheorie, Natur):

Augustin, bei 135

Bacon, bei 154

Cusanus, bei 24. 62. I8I. I 89

Exaktheit der 172

Galilei, bei 62 . I07. I 56 I 72 ff. 177.181 .183 Leonardo, bei 6o. 62 . ${ }_{5} 6$. I63f. I72. I77. I8I

Magie und I57. I6I. I78f.

Mathematik und I6r. I64 I74. I77. I8If. 193

Methode, als I59f. I8I. I94

Naturbegriff, im neuen I53f. I56. I6of. I73. I82f.

Pico, bei $122 \mathrm{f}$.

Pomponazzi, bei 108

Spontaneität und I $73 \mathrm{f}$.

Telesio, bei ${ }_{54} \mathrm{f}$.

Vernunft und 156.163

Wunder und 160
Erkenntnistheorie (s. auch Erfahrung, Logik, Wahrheit usw.):

Averroïsmus, im ${ }^{3} 34$

Bovillus, des 93

Bruno, des 78. 198f.

Campanella, des 57. I7 8

Cusanus, des Ioff. I3 f. I 5 22f. 24.4 I. 43.52 f. 54 . 56f. 67. I37. 180. I $86 \mathrm{f}$ Erosidee in der $\mathrm{I}_{4} \mathrm{Iff}$.

Freiheit und 128. 197. I98

Ethik und 128. 198

Ficino, des 67. 201

Galilei, des I7If. I78. I8I Gesetzlichkeit in der II2. II5. I5I. I73. I77. I82 Hegel, bei 4I

Kunsttheorie und I68. I72. I78

Leonardo, des 163. I66. I77f. I8I

$\mathrm{MaB}$ in der II. 2I. 54 . I $86 f$.

Mathematik und I62.I7I. I8I

Mystik, der I4I

Naturbeobachtung und I54f. I57. I67. I73. I78. I8I. I94

Neuplatonismus, im $I_{4} \mathrm{I}$ Patrizzi, des I42. I57. I79

Pico, des 9r. I23ff.

Psychologie und 157 . 199

Telesio, des $\mathrm{I}_{55}$. I 57

Theologie und $24.4^{8}$

Erlösung:

Cusanus, bei 42.68

Ficino, bei 70

Mittelalter, im 42

Pseudo-Dionysius, bei 9

Eros (s. auch Kosmologie):

Benivieni, bei 138

Bruno, bei 143

Christentum und I39

Erkenntnistheorie, in der I4 If.

Ethik, in der 143

Ficino, bei $139 \mathrm{ff}$. I40ff.

Grundproblem d. Renaissancepsychologie $138 \mathrm{f}$.

Kunsttheorie, in der ${ }^{4} 42 \mathrm{f}$.

Landino, bei 138
Eros (s. auch Kosmologie): Michelangelo, bei 143

Patrizzi, bei $\mathrm{I}_{43}$

Pico, bei 139

Platon, bei 139

Psychologie, in der $\mathrm{I} 43$

Theodizee, als I4Of. I42

Ethik (s. auch Autonomie,

Freiheit, Notwendigkeit, Wille usw.):

Bovillus, des $95 \mathrm{f}$.

Bruno, des 79. I29. I43. I98f. 200

Cusanus, des 3I. 45. 69 f. 88. 100. 103. I4I.I5I. 187 Erkenntnistheorie und I28. 198

Erostheorie in der $I_{43}$

Ficino, des 69f. 8I. Ior. IO5f. IIgf. I4I

Physik und, bei Paracelsus 118

Pico, des 82. $88 f$. IO2. I2If. I24f. I 7 of.

Pomponazzi, des 79.85 ff. IIO

Experiment (s, auch $\mathrm{Na}$ tur):

Leonardo über das I63. I 8 I

Schöpfung der Renaissance 160

Fatum s. Schicksal, Fortuna

Festwesen:

Burckhardt über 78

Ferrara, in 77

Form:

Lyrik, in der 169

Petrarca, bei 169

Platonismus, im Florentiner 67.7 I

Zentralproblem in der Renaissance, als 54. I68f.

Fortuna (s. auch Schicksal): Alberti, bei 8I

Bruno, bei 77 f. 82

Dante, bei $8 \mathrm{I}$

Darstellungen der 8of.

Festspiel der (I5OI) 77

Macchiavelli, bei $8 \mathrm{I}$

Poggio, bei 80

Sassetti, bei 80

Überwindung des Begriffs der 126 

Erkenntnistheorie, Ethik, Notwendigkeit, Spontaneität, Wille, usw.):

Bovillus, bei 95

Bruno, bei 197. 199

Cusanus, bei 46 f. 69 f. 88 . I03. I4I. I5I. I 87

Denkens, des I97. 199

Erkenntnis und I28

Ficino, bei 69 f. 8 I. IOI. I05. I2O. I4I. 148

Fortuna als Bild der 8 of. Gesetzlichkeit und, als

Korrelate I5I. I6I

Grundproblem der Früh-

renaissance 4 . IO3. II 5

Natur und II5. I25. I43f.

I49. I5I. I70

Petrarca, bei 8o. 105

Phantasie und 197. I99

Pico, bei 82. 88f. I02. I22. I25 f. I7of.

Poggio, bei 80

Pomponazzi, bei $79.85 \mathrm{ff}$. IIo. 148

Pontano, bei 80

Salutati, bei 80 . I0 5

Scholastik, in der 84

Valla, bei $82 \mathrm{ff}$.

Vernunft und 120

Wille und 82 . $84.85 \mathrm{ff}$. 88 ff. I 25 f. I 70

Genie (s. auch Ästhetik):

Bruno über das I74

Natur und I 7 of.

Pico über das I 25

Regel und I74

Geometrie (s. auch Mathematik):

Descartes, des 196

Galilei, des 193

Kepler, des I95

Geschichte:

Astrologie und II 3

Augustin über $75 \mathrm{f}$.

Begriff, neuer, der $175 \mathrm{f}$.

Burckhardt über II 3

Cusanus über 45

Ficino über $75 \mathrm{f}$.

Gesetzmäßigkeit der 87 . I09. II2f. II 5

Pomponazzi über II $2 f$.

Zeit und 45 heit, Kausalität, Notwendigkeit):

Anschauung, der künstlerischen $\mathrm{I} 68$

Astrologie, der 87. Iog. III

Autonomie und 149

Bewegung, der 193. I95f. Erkenntnistheorie, in der II2. II5. I5I. I73. I77. 182

Freiheit und, als Korrelate I5I. I6I

Forderung, als methodische I23. I58, I65. I77. I 87

Galilei, bei 165 f. I73. I77. I82. 193

Genie und 174

Geschehen, im 87. 109. II2f. II 5

Goethe, bei $I 72$

Kepler, bei 174

Kunst, in der I5I. I6I. I66. I68. 172

Leonardo, bei I64ff. I7I Magie, der I09. III. I58. I6I. I78f.

Mathematik und $16 \mathrm{I}$

Methode, als I23. I58. I65. I77. I 87

Natur, der I23f. I5I. I 58 . I61. I65. I72. I77. I79. I 8 If. I 85 ff.

Offenbarung, der II 3

Phantasie, der 172

Pico, bei 123 f. 158

Pomponazzi, bei 87. 109.

II2. II4

Religion, der II2

Schönheit, in der I68. I72. I74

Schöpfung, der 172

Seelenbegriff, im I49. I5I

Selbstbewußtsein, im I 49

Ursachensetzung, gleich I24

Wahrheit, gleich ${ }^{7} 73$

Wissen, des 194

Wunder, der Io9. II4. I 58

Gestaltung:

Cusanus, bei 72

Ficino, bei $7 \mathrm{I}$
Gestaltung:

Galilei, bei 175

Gott, durch 72

Kosmos, des 7r. 72

Kunst, in der I66. I7I.

I75. I79

Leonardo, bei 7I. I7I

Natur, in der I66. I7I.

I79

Prozeß der 7 I

Seele, durch die $7 \mathrm{I}$

theoretische und künstlerische $\mathrm{I} 75$

Gnade (s. auch Freiheit,

Natur, Religion):

Cusanus über $69 \mathrm{f}$.

Gegensatz zur Natur I 7 of

Gott (s. auch Religionsphilosophie):

Ästhetische Begründung von 68

Campanella, bei 57

Cusanus, bei I 3 f. I5. 24 29ff. 3 If. 33 f. 38.42 .46 . 56f. 72 f. 189

Eckhart, bei 35

Erkenntnis von I $_{3}$ f. I5. 24. 29 ff. $38,42.46 .57$ 67. 7 o. 189

Ficino, bei $67 \cdot 70.76$ 201

Franz v. Assisi, bei 55

Grundproblem der Frührenaissance, als $4.3^{8 \mathrm{f}}$. 56

Kosmos und $20 \mathrm{I}$

Mathematik zur Begrün-

dung von 56

Natur und 55. 57 f. I6 65

Pomponazzi, bei 87 .

II4f.

Pseudo-Dionysius, bei $9 \mathrm{f}$ $x_{4}$

Schau von 33 f. $35.56 f$

Schöpfer, als $72 \mathrm{f}$.

Unendlichkeit von II. I3 2 Iff. 4 of. 56.74 . I 89

Valla, bei 85

Vielfältigkeit der Verehrung von 3 If. 76 . II $4 \mathrm{f}$.

Wissen von $85.87 . \mathrm{II}_{4}$

Griechische Sprache, Cusanus und die 36 
Harmonie:

Intellekts, des menschlichen, bei Cusanus 44

Weltall, im, bei Kepler I 74

Heidentum, zeitliche $\mathrm{Be}$ dingtheit des, bei Pomponazzi II 4

Hermetik:

Cusanus, bei 16

Ficino, bei 3. 65. $9 \mathrm{I}$

Urmensch-Idee und 98

Hierarchie:

Aufhebung der 70

Cusanus, bei I3. 64

Ficino, bei 7o. II6

Logik, in der $x_{3}$

Neuplatonismus, im I33

Pico, bei 89

Problem der I I

Pseudo-Dionysius, bei 9 . I9

Valla, bei $83 \mathrm{f}$.

Humanismus:

Aristoteles und der 93

Astrologie im 105

Averroïsmus und 136

Cusanus und der 20. 36 . 53. 88

Einwirkungen des ror

Florenz und der 88

Frankreich, in 93

Philologie und 2. 20

Philosophie und ror

Platonismus und 88

Religion und ror

Scholastik und 20

Sprachgefühl des r6gf.

Wissenschaften, Reihen-

folge der, im I 50

Humanität:

Autonomie und 103. I25

Cusanus, bei 4 off. 7 I. 75 . IO3

Ficino, bei 7I. 75. IOI

Mikrokosmosidee, in der I 5

Pico, bei 9I. I22

Theologie und $39 \mathrm{f}$. 103

Individuum (s. auch Autonomie, Mikrokosmos, Seele):

Augustin, bei I 35

Averroïsmus, im I34. I44

Bruno, bei ro2f.
Individuum (s. auch Autonomie, Mikrokosmos, Seele):

Christentum, Grundvoraussetzung des I34f.

Cusanus, bei 3o. 32. 37 . I03. I37. I4I. I5I

Ficino, bei Ior. I38. ${ }^{4} 8$ Mystik, in der 39

Petrarca, bei 136

Pico, bei 89

Pomponazzi, bei I44. 148 Valla, bei 83

Islam, zeitliche Bedingtheit des, bei Pomponazzi II 4

Judentum, zeitliche Bedingtheit des, bei Pomponazzi II 4

Jurisprudenz bei Salutati I 50

Kausalität (s. auch Astrologie, Gesetzlichkeit, Notwendigkeit) :

Begriff der, neugestaltet I23

Bovillus, bei 94

Geschehen, im II2f.

Kepler, bei I23. I27

Leonardo, bei 62

Mathematik, in der I 65

Newton, bei 123

Pico, bei I 25

Plotin, bei 140

Pomponazzi, bei 87. Iogf. I I I

Teleologie und I $7 \mathrm{f}$.

Kirche, katholische:

Kosmologie der 39. I 86

Logik und I45

Stellung Pomponazzis zur 86

Wirksamkeit des Cusanus in der $64 \mathrm{f}$.

Koordinaten, Einführung der I96f.

Kosmologie (s. auch Eros): Aristoteles, des 185

Astrologie und 107. I09ff.

Bovillus, des 93 f. IO2

Bruno, des 39. 74. I28f. I98ff.

Cardano, des I $57 \mathrm{f}$.

Cusanus, des 27 ff. 39. 72 . II6. I $86 \mathrm{f}$. I $88 \mathrm{f}$.
Kosmologie (s. auch Eros):

Eros in der 139

Ficino, des 7I. II6. 20 I

Galilei, des 39

Gottesbegriff und 20I

griechische I3I. I39. I83f.

Kepler, des I74

Kirche, in der katholischen 39. I 86

Paracelsus, des I 7 f.

Platonismus, im Floren-

tiner 68. 74

Pomponazzi, des I ro

Raum und I92

Scholastik, in der 26. I 86

Seele in der 68. I55. I57.

201

Theologie und $38 \mathrm{f} .57$

Umformung der $\mathrm{I}_{3}$

Unendlichkeit in der II.

I3. 2 Iff. 4 of. 56.74 .189 .

I97f. r99. 200

Kosmosmensch s. Mikrokosmos

Kraft (s. auch Bewegung, Physik), Begriff der, bei Bruno I99

Kultur:

Cusanus über 46

Manetti über 88

Pico über $125 \mathrm{f}$.

Kunst (s. auch Ästhetik,

Kunsttheorie) :

Cusanus, bei 73. I 80

Erostheorie in der $\mathrm{I}_{42}$

Ficino und die 67. $72 \mathrm{f}$ IOI. I5O. I70

Fortunadarstellungen in der 8 of.

Galilei über I6r. I66. I $74 \mathrm{f}$.

Gesetzlichkeit der I5I. I6I. I66. I68. I72. I74

Leonardo, bei 74. I66. I 70 ff. I 77 f. 180

Mathematik und I6rf. I64. I74. I79. I92

Mensch und 97

Metaphysik und I 50

Mittelalter, im I 72

Natur und $72 \mathrm{f}$. 97 f. Ior. I50. I66f. I7If. I79f.

Philosophie, Stellung in

der 67 f. 7 I. I8o

Platon, bei 180 
Kunst (s. auch Ästhetik,

Kunsttheorie) :

Proportion in der 55. I68.

I7I. I74

Raum in der 192

Schöpfung in der $x_{5} \mathrm{x}$. I 70

Seele und I $49 \mathrm{f}$.

Kunsttheorie (s.auch Kunst,

Phantasie, Schöpfer):

Alberti, des I 70

Autonomie in der $\mathrm{I}^{2} 2$

Bedeutung der I50. I6r.

I68. I77. 180

Bembo, des 174

Bruno, des I74. I97. I99

Cortese, des 174

Cusanus, des 55. 73. I 80

Erfindung und Nachah-

mung, in der 174

Eroslehre in der I4Iff.

Erkenntnistheorie und I68. I72. I 78

Ficino, bei 67 f. 72 f. Ior. I50. I70

Form in der 54. 67. 7 I. $\mathrm{r} 68 \mathrm{f}$.

Galilei, bei I6I. I66. I74f.

Genie in der I25. I7of. I 74

Gestaltung als Begriff in der I66. I7 I. I75. I79

Gesetzlichkeit in der $\mathrm{I}_{5} \mathrm{I}$.

I6I. I66. I68. I72. I74

Goethe, bei I66f. I72

Gott in der 68

Leonardo, bei 7I. 74 . I $66 \mathrm{ff}$. I $70 \mathrm{ff}$. I $77 \mathrm{f}$. I 79

Mathematik und 16 If. I64. I7 I. I74 f. I79. I92

Metaphysik und 150

Natur in der $72 \mathrm{f}$. $97 \mathrm{f}$. IOI. I50. I67. I7If. I $79 \mathrm{f}$.

Notwendigkeit, in der I 50 f. I6I. I66. I72

Perspektive und 192

Pico (Gio. Franc.), bei I74

Platon, des I80

Platonismus, des Florentiner 67 f. 7 I. I40. I78

Polizian, des 174

Proportion als Begriff der 55. I68. I7I. I74
Kunsttheorie (s.auch Kunst, Phantasie, Schöpfer):

Raum und I92

Seelenbegriff in der $\mathrm{r} 49 \mathrm{f}$. Spontaneität, in der I7o Theologie und 172

Laienfrömmigkeit als devotio moderna 34.52

Laienwissen als Ideal bei Cusanus 53. 59

Latein als Sprache d. Scholastik u. d. Frührenaissance 20 f. 59 f. 169

Leben, die Brüder vom gemeinsamen, s. Brüder

Liebe s. Eros

Logik:

Aristotelische I2. I5. $5^{6}$

Astrologie, begründet durch r ro

Averroïstische I34

Cusanus, des I2f. I5. 43 . 56. 6r

Gegensatz der kirchlichen Lehre zur I 45

Mathematik, der 56. I94 Naturbetrachtung, der Io $f$.

Scholastische II ff. I5. 23 Theologie und IIf. 24 . I34

Lyrik:

Form in der 169

Naturgefühl in der I 5 If. Quellen, philosophische, der 169

Magie:

antike ro8

Astrologie und rogf.

Bruno, bei I 56

Campanella, bei I56. I59.

I6r. 178

dämonische I58f. I6o. I79

Erfahrung und I57. I6I. I $78 \mathrm{f}$.

Ficino, bei 160

Gesetzlichkeit der rog. III. I58. I6I. I $78 \mathrm{f}$.

Naturgeschehen, als III. I 58 f. I6of. I74. I79

Naturphilosophie, in der 58. I07f. I09. I 57 f. I 78
Magie:

Picatrix, im I 6

Pico, bei I2I. I58. I60.

I79

Pomponazzi, bei ro8ff.

I60

Porta, bei 158

Religionsphilosophie, in der I2I

Telesio, bei ${ }^{5} 6$

Überwindung der I74.

r $78 \mathrm{f}$.

Wille und 179

Wissenschaft, als 179

$\mathrm{MaB}$ :

Cusanus, bei II. 2I. 54 .

I $86 \mathrm{f}$.

Erkenntnis und II. 2 I. 54. I86f.

Logik, als Mittel der I07

Naturwissenschaft, als

Mittel der I23. I64. I93

Proportion und 53 ff. 67

Mathematik:

Alberti, bei 54

Astronomie und 182

Bewegung und I94f. I96

Cusanus, bei $x_{5} \cdot 23.36 \mathrm{f}$. 43. 56. 62

Descartes, bei I94. I96

Einheit der 194

Erfahrung und $x 6 r$. I6 3 f. I73f. I77f. I82. I93

Erkenntnistheorie und I62. I7I. I8I

Galilei, bei 58 f. I65. I7 1 . I73. I78. I82f. I93 Gewißheit, Maximum der I62

Gotteserkenntnis und 56 Grund, zureichender, in der I65. I 8 I

Kepler, bei $195 \mathrm{f}$.

Kunsttheorie und I6If.

I64. I7I. I74. I79. I92

Leonardo, bei $54.5^{8}$.

I62 ff. I65. I77. I82

Logik der 56. 194

Methode, als I59f. I8I.

I94

Notwendigkeit in der 15 .

23. 43. $58 \mathrm{f}$. I $22 \mathrm{f}$

Physik und 194

Pico, bei I22. I24

Platon, des I76f. I8If. 


\section{Mathematik:}

Pomponazzi, bei IIIf.

Proportion, als I $7 \mathrm{I}$

Raum und I92. I94ff.

reine und angewandte I $82 \mathrm{f}$.

Renaissancedenker über die 54. 58. 160

Seelenbegriff, moderner, und I49

Symbole in der 59

Unendlichkeit in der $195^{f}$.

Wissenschaft, exakte und I6o

Maximum, Absolutes als, bei Cusanus 23

Mechanik (s. Bewegung, Dynamik, Physik), bei Leonardo I64. I82

Medizin:

Alchemie und II $f$.

Astrologie und II9

Astronomie und II $7 \mathrm{f}$.

Ficino, bei II9

Mikrokosmosidee in der II 7 f.

Paracelsus, des II 7

Philosophie und II 7 .

Salutati, bei I $_{5}$ O. 162

Methexis:

Chorismos und 9I

Cusanus, bei 2 I. 23. 38. $4 \mathrm{I}$

Eros als 139

Ficino, bei $68 \mathrm{f}$.

Pico, bei 9I

Platon, bei I7. I32. I39

Seele als $68 \mathrm{f}$. 132

Methode:

Anschauung als $I_{53} .167$

Astrologie, der I08. III. I24. I26ff.

Cusanus, des 53 f. 163 f.

Dogmenkritik, der 82

Erfahrung als I59f. I8r. I94

Galilei, bei I56. I8I. I94

Gesetzlichkeit als Forde-

rung der I23. $x_{5} 8,165$.

I 77.187

Kepler, des ${ }^{7} 72$

Leonardo, bei 53 f. 156 . I63f. I8r. I94

Mathematik als I59f.I8r. I94

Seinsproblem und 194
Methode :

System als Forderung der 58

Wissenschaft der $149 \mathrm{ff}$. I62. 183 . I93 ff.

Mikrokosmosidee:

Adammotiv und 98. I0o antike Herkunft der $4 \mathrm{I}$. 97

Astrologie, in der II $5 \mathrm{f}$. II $7 \mathrm{f}$.

Bovillus, bei 93. 97. Ior ff. Campanella, bei 159

Cusanus, bei 4I. 97

Humanitätsideal in der II $5 \mathrm{f}$.

Medizin, in der $I I f f$.

Naturbegriff und $\mathrm{II}_{5} \mathrm{f}$.

Paracelsus, bei $\mathrm{II}_{7} \mathrm{f}$.

Pico, bei $88 \mathrm{f} .97$

Platonismus, im Florentiner $68 \mathrm{f}$.

Porta, bei I 59

Prometheusmythos und $98 \mathrm{f}$. IoIf.

Minnesang, Renaissancelyrik und $\mathrm{r} 69 \mathrm{f}$.

Mittelalter (s. auch Scholastik):

Begriff des, in der modernen Forschung $4 f$.

Gebrauch des Wortes 36 Lebensgefühl des, bei Dante 169

Mythos im Ioof. IO4

Naturbegriff im 55

Platonismus im I33. I45f.

Renaissance und 55

Stellung der Kunst im I 72

Theologie im I2. I05. I08. I34. I94. I99

Monade, Begriff der, vorgebildet in der Renaissance 97. I37

Musik als Wissenschaft bei Cusanus 43. 6I

Mystik:

Averroïsmus, des I34. I36

Brüder vom gemeinsamen Leben und 35

Cusanus und die ${ }_{3} f$. 34f. 39

Erkenntnistheorie der I4I
Mystik:

Ficino, bei $\mathrm{I}_{4} \mathrm{O}$

Individualismus und 39

Naturhingabe in der 55

Petrarca und die 136

Pico und die I2I

Scholastik und 8. 55

Mythologie, antike:

Bovillus, bei 98

Bruno, bei 104. 108

Festwesen, im 77

Philosophie und $\mathrm{IO}_{4}$

Pomponazzi, bei Io8f.

I47

Valla, bei 85

Mythos:

Bovillus, bei 98

Bruno, bei ro4. 108

Campanella, bei 108

Erneuerung des 104. 108

Mittelalter, im Ioof. IO4

Pico, bei 90

Platon, bei 98. I3If

Pomponazzi, bei 147

Unsterblichkeitslehre und I47

Valla, bei 85

Zeit im 132

Natur:

ästhetische Betrachtung der I5O. I67

Aristoteles, bei ${ }_{1} 83 \mathrm{f}$.

Arten in der Betrachtung der $57 f$.

Astrologie, innerhalb der I07. IIof. I58f. I6of. I79

Augustin, bei I 52

Bovillus, bei $94 \mathrm{ff}$. 102

Bruno, bei $28 \mathrm{f}$.

Buch Gottes, als 57 f. 165

Campanella, bei 57

Cusanus, bei $4 \mathrm{Iff}$. $56 \mathrm{f}$. I90

Entwicklung des Begriffs der 57 ff. I07. I53. I77 Erfahrung in der ${ }_{53} \mathrm{f}$. I56. I59f. I6I. I73. I82f. Erkenntnis und I $_{54}$ f. I 57 I67. I73. I78. I 81 . I94 ethische Betrachtung der I $28 \mathrm{f}$.

Ficino, bei $72 \mathrm{f}$. I0I. I06. I20. I49f. I7O 
Natur:

Franz von Assisi 55 f.

Freiheit und II5. I25.

I43f. I49. I5I. I7O

Galilei, bei 58 . I65. I77.

I82. I92f.

Genie und I 70 f.

Gesetzlichkeit der I24. I5I. I58. I6I. I65. I72. I77. I79. I 8 If. I85f.

Gestaltung der I66. I7 I. I79

Gnade und r 70 f.

Johannes Scotus, bei 43

Kepler, bei $5^{8}$. I74

Kunst und 72 ff. 97 f. IOI. I50. I66f. I7of. I77f. I $79 \mathrm{f}$.

Leonardo, bei 57 f. 62 . I62 f. I65. I67. I70. I72. I77. 182

Magie innerhalb der I Io. I 58 f. I6of. I74. I $78 \mathrm{f}$.

Manetti, bei 88

Mensch und 97. II4. II7

Mikrokosmos in der

I $5 \mathrm{f}$.

Mittelalter, im 55

Notwendigkeit in der 87 . I06f. IOgff. III. II5. I20. I43f. I48. I5I. I6I. I6 5 f. I77. I $8 \mathrm{If}$.

Offenbarung der 59

Patrizzi, bei I02. 123

Petrarca, bei I $5 \mathrm{Iff}$.

Phantasie und $I_{72}$

Pico, bei I24. I58. I7I. I79

Platon, bei I76f. I8If

Pomponazzi, bei Iogff. I 43 f. 148

Proportion in der 168 .

I 7 I

Seele und I43f. I $49 \mathrm{f}$.

I 5 If. I 57

Selbstbewußtsein und I 53

Sinnlichkeit und I 54. I77.

I79. 183

Substantialität der I 50

Telesio, bei I23. I54f. I77

Vernunft und I55. I65. I77

Wahrheit der I73

Wunder und 160
Naturphilosophie (s. auch Eros, Kosmologie, Magie, Natur):

Assthetik und 167

Analogie in der II4. II7. I 57 f. I 59

Ethik und I28f.

Erkenntnistheorie u. I $54 \mathrm{f}$. I57. I67. I73. I78. I8I. I94

$\mathrm{Maß}$ in der I23. I64. I93

Naturwissenschaft s. Astrologie, Astronomie, Bewegung, Elemente, Erfahrung, Experiment, Gesetzlichkeit, Kausalität, Kosmologie, Medizin, Notwendigkeit, Physik, Planeten

Neuplatonismus:

Aristoteles im I9

Bruno und der 198

Christentum und 9. I9

Cusanus und der I6. 138

Erkenntnistheorie d.

I4 I

Ficino und der 74. I38. I40. I 78

Hierarchie im 133

Leonardo und der $\mathrm{I}_{77 \mathrm{f}}$. Lichtmetaphysik des 102 Pico und der 89. I2If.

Platon im I7. I9. 104

Platonismus, im Florentiner 91. I77

Prometheusmythos im 98 Pseudo-Dionysius, bei 9 . I9

Seele im I33f. I38. I40

Selbstbewußtsein im I34

Neupythagoräismus bei Pico I 2 I

Notwendigkeit (s. auch Gesetzlichkeit):

Anschauung, in der $167 \mathrm{f}$. $\mathrm{r} 72 \mathrm{f}$.

Astrologie, in der 87. ro6. Iogf. I2O. I22f.

Christentum, im Io6. I20

Cusanus, bei I5. 23. 43 . $58 \mathrm{f}$.

Erkennbarkeit der I73

Ficino, bei Io6. I20

Freiheit als Korrelat der I5I. I6I
Notwendigkeit (s. auch Gesetzlichkeit):

Galilei, bei 165 f. I77. I 82 .

I93

Geschichte, in der II2.

I I 5

Kunst, in der $15 \mathrm{r}$. $16 \mathrm{r}$. I66. I72

Kriterium der Wissenschaft, als 162

Leonardo, bei I64f. I7I

Mathematik, in der $I_{5}$

23. $43.5^{8 f}$. I $22 \mathrm{f}$.

methodische Forderung,

als II 5.162

Natur, der 87. I06f. Iogf.

III. II $5.120 .143 . I_{4} 8$

I5I. I6I. I65. I77. I82

Offenbarung, in der $\mathrm{II}_{3}$

Pico, bei I22ff. I 58

Pomponazzi, bei 87. Iog f.

II2f.

Proportion, als I7I

Seelenbegriff, im modernen I49. I 5 I

Occamismus, Dogmenkritik im 86

Offenbarung:

Ablehnung der 145

biblische 59 . I45

Einheit aller 3. 76

Ficino, bei 3.76

Galilei, bei 59

Gesetzmäßigkeit in der I 3

natürliche 59

Platonismus, im Florentiner $65 \mathrm{f}$.

Pomponazzi, bei II 3 . I45

Sicherung der $65 \mathrm{f}$.

Optik:

Kepler, des I90

Porta, des r6o

Ort:

Aristoteles, bei $\mathrm{I} 84 \mathrm{f}$. I9I $\mathrm{f}$

Cusanus, bei 187 . I89

Kepler, bei I90. 198

Relativität des I86.

Papsttum, Stellung des $\mathrm{Cu}$ sanus zum 64

Pelagianer, Einwirkung der, im 'Ackermann v. Böhmen' 99 
Peripatetiker, Physik der 27. 183.187 . I9I

Perspektive, Schaffung des Raumes in der 192

Phantasie (s. auch Ästhetik): Freiheit der, bei Bruno I97. 199

Goethe, bei 167

Leonardo, bei I67. I70. I72. I79

Wirklichkeit und 172

Philologie s. Humanismus

Physik (s. auch Bewegung, Elemente):

Albert von Sachsen, des I 86

Aristoteles, des 25 f. 108 .

I33. I54. I83ff. I9I. I93

Bruno, des I97ff.

Cusanus, des 25 f. 27.43 . 6I. 74. I4I. I86f. I $88 \mathrm{f}$. I92

Descartes, des 196

Duns Scotus, des 26

Ethik und 118

Ficino, des II6. I23

Galilei, des I65. I83. I $92 \mathrm{ff}$.

Geometrie und $193 \mathrm{ff}$.

Lagrange, des 164

Leonardo, des I64. I8If.

Paracelsus, des 118

Peripatetiker, der 27. 183 .

I87. I9I

Pico, des I23

Scholastik, des 26. I86. 194. 199

Theologie und I94. I99

Planeten (s.auchAstrologie):

Dante über die I05

Ficino, bei I I $9 f$

Grenzen des Einflusses der IIgf.

Kepler, bei I27. I74. 190

Pomponazzi über die II2

Zuordnung der, zu den Religionen II2

zu den Wissenschaften I05

Planetenkinder bei Ficino I2O

Platonismus:

Leibniz, bei 65

Mittelalter, im I33. I45f.

Neuentdeckung des I6f.
Platonismus, Florentiner

(s. auch Ficino):

Ästhetik im 67f. 7I. I 4 o ff. I 78

Askese im 66. 9I

Augustin im 69. 74. 104 $20 I$

Begriffe, platonische, im 9If. I39. I 78

Christentum und 65 f. 76 . I39

Cusanus, Stellung zu ${ }_{13} 8$

Erosbegriff im $138 \mathrm{f}$.

Frankreich, in 93

Humanismus und 88

Individuum im 9I. Ior. I3I. 138.148

Kosmologie im 68. 74

Leonardo und der 178

Mikrokosmosidee im $68 \mathrm{f}$

Neugestaltung d. Renaissancephilosophie durch den 88

Neuplatonismus im 9I. I77

Offenbarung im $65 \mathrm{f}$.

Platon im 2 f. 15 f. $49.9 \mathrm{If}$ I04. I39. I 78

Pomponazzi, Stellung zu I 48 f.

Scholastik und 65 ff. 88 . IO7

Seelenbegriff im 74.138. I 45 f. I $48 \mathrm{f}$.

Stellung des Menschen im 9I. IOI. I3I

Theologie im $65 \mathrm{ff}$. I03

Unsterblichkeit im 74 . $\mathrm{I} 45 \mathrm{f}$.

Poetik:

Erfindung und Nachahmung in der 174

Form in der $168 \mathrm{f}$.

Prometheusmythos:

Adam-Motiv und 98. Ioo

Bedeutung, methodische, des 128

Bilddarstellungen des Ioo Boccaccio, bei roof.

Bovillus, bei $98 \mathrm{f}$. Iorf.

Lactanz, bei roo

Mikrokosmosidee u. $98 \mathrm{f}$. IoIf.

Neuplatonismus, im 98

Platon, bei 98. I3If.
Prometheusmythos: Schöpfersymbol, als I02. I75

Tertullian, bei Ioo

Prophetie (s. auch Astrologie), Abhängigkeit der, von den Himmelskörpern II3

Proportion (s. auch Ästhetik):

ästhetischer Grundbegriff, als 55

Cusanus, bei $54 \mathrm{f}$.

Galilei, bei I7I. I74

Idee, als 174

Leonardo, bei I7 I

$\mathrm{MaB}$ und $53 \mathrm{ff} .67$

Mathematik und I 7 I

Natur und Kunst, in I68. I 7 I

Pacioli über 55

Platonismus, im Florentiner $67 \mathrm{f}$.

Psychologie (s. auch Seele, Eros):

Araber, der I34. I38. I44. I 47

Aristoteles, d. I33f. I43f. I 45 f. I 55

Descartes, des 130. I35

Erkenntnislehre und ${ }_{57}$. I99

Ficino, des 71. 75. II9. I38f. I48. I57. 201

Neugestaltung der I49f.

Platon des I3Iff. I46

Platonismus, im Florentiner 74. I38. I45f. I48f. Pomponazzi, des r Iof. I43f. I 45 ff. I 49

Spätscholastik, der I4. I34. I45f. I 47

Telesio, des 155

Theologie und I39

Raum (s. auch Physik):

Aggregat- I9I

Aristoteles, bei I84f. I9I. I94

Bewegung und I94ff. I97f.

Bruno, bei 197 ff. 200

Cusanus, bei 43.45 . $6 \mathrm{I}$. 74. I $86 \mathrm{ff}$. 192

Galilei, bei I92f. 198 
Raum (s. auch Physik): Homogeneität des $192 \mathrm{f}$. Kepler, bei I9of. 198

Kunst, in der 192

Mathematik u. 192. $194 \mathrm{ff}$. Perspektive, in der 192

Pico, bei $122 \mathrm{f}$.

System- I9I

Unendlichkeit des $195 \mathrm{ff}$. I98

Reformation der Welt und des Menschen bei Ficino 7 of.

Religionsphilosophie (s.auch Erlösung, Gott, Kirche, Theologie, Unsterblichkeit):

Cusanus, des 9 f. II. I 3 ff. 24. 29. 3off. 38. 4 off. 45 f. $48.56 .64 \cdot 72.75$. I00. I03. 189

Erosbegriff in der 139

Ficino, des 3.67. $70.74 \mathrm{ff}$. I39. I45. I48. 201 Gesetzmäßigkeit in der I 2

historisch begründete II $3 \mathrm{ff}$.

Kunsttheorie und 172

Magie und I2I

Planetenglaube und II2. I 20

Pomponazzi, d. 87. II 3 ff. Schelling über 57

Seelenbegriff in der 35 . 68f. 74. 79f. I38. I45ff. Symbol in der 56.72 Valla, des $83 \mathrm{ff}$.

Renaissance:

Begriff der 5

Mittelalter und 55

Schicksal (s. auch Freiheit): Astrologie, in der IO4. II 8 f. 150

Ficino, bei IIgf. I50

Fortuna als Symbol des 77 f. 8 of. 126

Leibniz, bei I04

Macchiavelli, bei 8I

Petrarca, bei 8o. I05

Pico, bei 87

Poggio, bei 80

Pontano, bei 80

Salutati, bei 80 . I05
Schönheit (s. auch Kunst, Kunsttheorie) : Gesetzlichkeit der I68. I 72. I74

Gestalt, als 7If.

Theodizee, als $67 \mathrm{f}$.

Schöpfer:

Autonomie des 125

Begriff des 72. 103

Bovillus, bei 102

Bruno, bei 103

Cusanus, bei $44 \cdot 72 \mathrm{f}$. 103

Demiurg als I $32 \mathrm{f}$.

Erkenntnis im 128

Freiheit im 128

Galilei, bei 175

Gesetzlichkeit im I 72

Gott als $72 \mathrm{f}$.

Kunst, in der 151 . 170

Mensch als 89. IO2f. I25

Pico, bei 89 . IO2. I 25

Platon, bei $132 \mathrm{f}$.

Prometheus, als Typus des 102. I75

Seele, menschliche als 44 . 7x. 73 f.

Wissenschaft, in der $\mathrm{I}_{5} \mathrm{I}$. I 70

Scholastik (s. auch Mittelalter):

Astrologie und 108

Aufklärung und 86 . I45 f.

Averroïsmus und 108 . I 34 f. 147

Cusanus' Stellung zur IIf. 2 Iff. 25 f. 27.35 f.

Erneuerung der, im I4. Jahrhundert 65

Frührenaissance und If. I3. 2 I. 53. 55. 65 f. 107. I35

Galilei gegen die I65. I73

Humanismus und 20

Kosmologie in der 26. I86

Kritik an der I. 5 I f. I36

I45f. I47. I65. I73

Logik der IIf. I5. 23

Lyrik unter dem Einfluß der 169

Marsilius v. Inghen und die 12

Mystik und 8. 55

Petrarca und die I. 5If. I36

Physikder 26.I86.I94.I99
Scholastik (s. auch Mittelalter):

Platonismus, Florentiner, und 65 ff. 88. I07

Pomponazzi, bei 86 . I 45 ff.

Psychologie der I4. I45f. I47

Willensfreiheit in der 84 Seele, menschliche (s. auch Psychologie):

All, im I 55. I 57

Aristoteles, bei 133 . $146 f$. I 54

Averroïsmus, im I34. 138 .

I 44. I47

Bewußtsein und 138

Bruno, bei $\mathrm{I}_{43}$

Cusanus, bei 44. 137

Eckhart, bei 35

Ficino, bei 68. 71. 74. II9. I38. I45. I48. I57. $20 \mathrm{I}$

Gesetzlichkeit im Begriff der I49. I5I

Gottwerdung in der 35 griechische Philosophie über die I3I

Kunst und $149 \mathrm{f}$.

Methexis, als 68f. I32

Mitte der Welt, als 68.

I57. $20 \mathrm{I}$

Natur und I43. I49f. I5If. I 57

Neuplatonismus, im I $33 \mathrm{f}$. I38. I40

Orphik, in der I3If.

Patrizzi, bei ${ }^{5} 57$

Petrarca, bei I36. I 52

Platon, bei I3If. I46

Platonismus, im Floren-

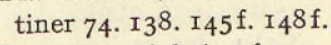

Pomponazzi, bei 79 f. I Io.

I $43 \mathrm{ff}$. I $48 \mathrm{f}$.

Schöpferkraft der 44. 7 I. 74

Selbstbewegung der 69

Telesio, bei 155

Thomas, bei $145 \mathrm{ff}$.

Unsterblichkeit der 74 . 79f. $1_{38} 8$. $145 \mathrm{ff}$.

Wissen und 133

Zeit und $44 \cdot 74$

Selbstbewußtsein:

Aristoteles, bei $133.146 f$.

I 54 
Selbstbewußtsein:

Averroïsmus, im I34. I44

Bovillus, bei $95 \mathrm{f}$.

Bruno, bei I 43. I9.9f.

Descartes, bei I30. I35

Eros, als I 43

Ficino, bei ${ }_{13} 8$

Gesetzlichkeit des I49

griechische Philosophie

über das I3I

Klärung des Begriffs $130 \mathrm{f}$

Leibniz, bei I30. I37

Natur als Gegensatz zum

I53

Neuplatonismus, im I34

Petrarca, bei 136

Platon, bei $\mathrm{I}_{32}$. I 46

Pomponazzi, bei I44f. I 46

Thomas v. Aquino, bei

I34. $I_{4} 6$

Sinne:

Cusanus, bei 180

Leonardo, bei I63. I79

Naturbeobachtung und

I54. I77. I79. I83

Neubewertuug der I8I

Spontaneität (s. auch Autonomie, Erkenntnistheorie, Freiheit):

Denken, im I73f. I99

Formen, im 170

Galilei, bei $x 78$

Sprache (s. auch Philologie):

Cavalcanti, des 169

Cusanus, des 2of. 36

Enea Silvio, des 20

Humboldt, bei 60

neue, in der Frührenais-

sance $59 \mathrm{f}$. I69f.

Valla, des 20. 169

Stoa:

Kosmologie des Bovillus,

in der 102

Kraftbegriff des Bruno, im I98f.

Kulturbegriff des Manetti, im 88

Schicksalsbegriff des $\mathrm{Pi}$ co, im 87

Substanz, Natur als ${ }_{50}$

Symbol:

Bruno, bei 78

Cusanus, bei 32. 56. 72
Symbol:

Dogma als 76

Galilei, bei 59

Goethe, bei 32

Gott, zur Erfassung von 56. 72

Kult als 76

Mathematik, der 59

Mensch als natürliches II 5

Wissenschaft, in der 124

Sympathie (s. auch Eros, Kosmologie), Grundkraft des Weltalls ${ }_{5}{ }^{8}$

System:

Cusanus, bei 7. 39. 64

Forderung, wissenschaftliche, der Frührenaissance 58

Pflanzen, der, bei Caesalpin I $_{54}$

Raum als Igof.

Wissenschaften, der 105. I5o. I62

Technik, Stellung der, in der Frührenaissance 6I

Theodizee (s. auch Gott, Religionsphilosophie):

Akademie, der Florentiner 67.140

Erostheorie als I 4 of. I42 Pseudo-Dionysius, des Io

Theologie (s. auch Dogmenkritik, Kirche, Religionsphilosophie):

Akademie, in der Florentiner $65 \mathrm{ff}$. Io3

Astrologie und 105. 108. I20

Cusanus, des II. I 3 ff. 24 . 29. 38 ff. 48.57 . IO 3

Erkenntnistheorie und24. 48

Ficino, des I20. I39

Frührenaissance, in der 4. 63 f. 67.83

Humanität und $39 \mathrm{f}$. I03 Kosmologie und 38f. 57 Kritik an der 82 f. 85 f. I 45

Kunsttheorie und 172

Logik und II. I2. 24. I34

Mittelalter, im I2. I05. 108. I34. 194. I99
Theologie (s. auch Dogmenkritik, Kirche, Religionsphilosophie):

Philosophie und 4. 9 f. I9. 63f. 65 f. 67.83

Physik und 194. I99

Pico, bei 65 f.

Pomponazzi, des 85 f. I 45 Pseudo-Dionysius, des of. I9

Psychologie und 139

Valla, des $82 \mathrm{f}$.

Vernunft und $82 \mathrm{f}$. $85 \mathrm{f}$. I45. 147

Tierkreiszeichen (s. auch Astrologie), neue Bedeutung der, bei Bruno 128

Trinität bei Cusanus 95

Unendlichkeit (s. auch Kosmologie, Physik):

Bruno, bei I97ff. 200

Cusanus, bei II. I3. 2 Iff. 4of. 56. 74. 189

Ficino, bei 74

Gottes II. I3. 2Iff. $40 \mathrm{Of}$. 56. 74. I 89

Geistes, des 74

Kosmos, des II. I3. 2 Iff. 4of. 56. 74. I89. $197 \mathrm{ff}$. I99f. 200

Kraft, der 198

Leonardo, bei 74

Mathematik, in der $195 \mathrm{f}$.

Petrarca, bei 199

Raumes, des 195. 197f.

Universalreligion bei Nik. Cusanus $30 f$.

Unsterblichkeit:

Ficino, bei 74 f. 145 . $\mathrm{r}_{4} 8$

Grundproblem, als philosophisches 4

Metamorphose und ${ }^{4} 47$

Mythos und 147

Pomponazzi, bei 79f. 145 . I $47 \mathrm{ff}$.

Seele, der 74 f. 79 f. I38. I45. $147 f$.

Urmensch (s. auch Mikrokosmos):

Augustin, bei 98. I00

Mittelalter und Renaissance, in 98 
Ursache (s. auch Gesetzlichkeit, Kausalität, Notwendigkeit) :

Averroïsmus, im 144

Erosbegriff als $\mathrm{I} 39 \mathrm{f}$.

Galilei, bei 165 . I 81

Geschichte, in der II $2 f$.

Gesetzlichkeit gleich 124

Kepler, bei 123. 127

Korrelation statt $127 \mathrm{f}$.

mathematische 165 . I8I

nächste 123

Newton, bei 123

Pico, bei 123

Plotin, bei 140

Pomponazzi, bei $\log _{\mathrm{ff}}$.

transzendente $\mathrm{I} 44$

Vernunft:

Astrologie und 1 ro

Autonomie der 178 . I87. 190

Cusanus, bei 187

Dogmenkritik, in der 82 .

85 f. 145.147

Erfahrung und 156,163

Ficino, bei 120

Freiheit und 120

Galilei, bei I 56. I78. I 8 I

Glaube und $83 \mathrm{f}$.

Kepler, bei 190

Leonardo, bei I56. I63. I65. I77. $18 \mathrm{I}$

Natur und $1_{55} \cdot I_{65} . I_{77}$ Pomponazzi, bei 85 f. x 10 .

I 45 . I47

Telesio, bei 155

Valla, bei $83 \mathrm{f}$.

Via moderna an der Heidelberger Universität ×2. 35

Vision als Mittel der Erkenntnis bei Nikolaus Cusanus $\mathrm{I}_{4}$

Wahrheit (s. auch Erkenntnistheorie) :

Leonardo, bei 163

Natur, der 173

Welt (s. auch Acedia, Kosmologie) :

Begriff der, in der griechischen Philosophie I 3 I
Welt (s. auch Acedia, Kosmologie):

Bovillus, bei $96 \mathrm{f}$.

Burckhardt über Stellung

der Renaissancemenschen zur I53

Cusanus, bei $26 \mathrm{ff}$. 29 . 38f. 46.56 f. 188

Erkenntnis der, durch Empirie und Magie ${ }^{57}$ Ficino, bei 67.69

Gott und $38 \mathrm{ff}$

Homogeneität der 193

Mensch und $89 \mathrm{ff}$. $96 \mathrm{f}$.

Petrarca und die 39. 153

Pico, bei $89 \mathrm{ff}$.

Platonismus, im Florentiner $67 \mathrm{f}$.

Zwiespältigkeit in der Stellung zur 39. I53. $200 f$.

Wert:

Bovillus, bei 102

Cusanus, bei $46 \mathrm{f}$.

Valla, bei 84

Wille (s. auch Ethik, Freiheit, Psychologie):

Cusanus, bei $\mathrm{I}_{3} \mathrm{f}$.

Ficino, bei 75 . 1 $19.1_{3} 8$

Freiheit des 82. 84. $85 \mathrm{ff}$.

88 ff. I25f. I 70

Magie und 179

Natur im I 70

Pico, bei 88 ff. r25f.

Pomponazzi, bei $85 \mathrm{ff}$.

Scholastik, in der 84

Valla, bei 82.84

Wissen (s. auch Erkenntnistheorie, Psychologie):

Aristoteles, bei 133

Averroïsmus, im I34

Bovillus, bei $94 \mathrm{f}$.

Cusanus, bei Ir. I3. 23. 38. 4 I. 46.52 . 57 . 59. 61

Einheit des 194

Galilei, bei I7If. I78. I82f. I94

Gesetzlichkeit des 194

Gottes 85.87 . II 4

Pico, bei 90
Wissen (s. auch Erkenntnistheorie, Psychologie):

Platon, bei $\mathrm{I} 32$

Platonismus, im Florentiner 68. 20I

Pomponazzi, bei $86 \mathrm{f}$. r ro

Seele und 133

Sein und Werden im 132

Thomas v. Aquino, bei I 34

Wissenschaft:

Astrologie als 105. 107f.

Campanella, bei ro 8

Cusanus, bei 43 f. 72

Dante, bei I05

Grundlegung der 43 f. 72

Humanismus, im I 50

Leonardo, bei $\mathrm{r}_{2}$

Magie als 179

Methode der exakten I49ff. I62. I83. $193 \mathrm{ff}$.

Mittelalter, im I05

Pico, bei 179

Poggio, bei 150

Salutati, bei 150.162

Schöpfung in der ${ }_{5} \mathrm{I}$.

I 70

Symbole in der 124

System der 105. I5O. I62

Wunder:

Erfahrung und 160

Gesetzmäßigkeit der, bei Pomponazzi rog. Ir4. ${ }_{15} 8$

Zauberei s. Magie

Zeichen (s. auch Symbol): magisches und intellektuelles bei Pico $x \mathbf{2 4}$

Wissenschaft als Ordnung von, bei Cusanus 72

Zeit:

Cusanus, bei $43 \mathrm{ff}$. $6 \mathrm{If}$. 73. I86. I88. I92

Ficino, bei 74

Kepler, bei 45

Leibniz, bei 45

Mythos, im 132

Platon, bei $\mathrm{r}_{32}$

Pomponazzi, bei 87 . 1 I $2 \mathrm{ff}$

Seele und 44.74 


\section{INDICES}

\section{$\mathrm{ZU}$}

\section{NICOLAUS CUSANUS LIBER DE MENTE.}

\section{BEGRIFFS-REGISTER.}

absencia 244

ymago in absencia sensibilium 244. absolutum 270.

unum infinite a. 270 .

accidens 228. 250. 272. 274. 276. 278. 290. modo advenientis (passionis) facit

(mens) accidencia 272 ; omnem intellectum fore de substancia et accidente 290 . actu 262. 276.278 .

a. vel intellectu 262 ; omnia ut a. sunt in materia forma et connexione esse 276 ; Ea que a. sunt triniter sunt 276 ; similitudo inter modum essendi omnium ut sunt a. et ut sunt in mente $27^{8}$. actualitas 288 .

acucies 232 .

adminiculum 296.

admiracio 204. 232. 296.

a. stimulus 204; a. que ex sensibilibus oritur 232 .

aer 254 .

ae $c f . \mathrm{e}$

albedo 26o. 274. 276 .

una et eadem a. in omnibus albis 260 . alteritas 240. 248. 260. 270. 294 .

a. divisio est 240 ; a. de nullius rei essencia est 240; pertinet ad interitum a. 240; a. sequitur multiplicacionem contingenter 240; a. nequaquam convenire potest veritati in se 248 ; mens est coincidencia unitatis et alteritatis 294 . amator 258 .

sapiencie a. 258 .

angelus 292.

puto alios angelos intellectibiles alios intelligenciales alios racionales 292; novem gradus seu chori (angelorum) 292. angulus 220. 232. anima 204. 208. 224. 226. 228. 230. 242. 246. 250. 252. 254. 256. 280. 282. 284 . 286. 288. 290. 294 .

a. brutorum 246 ; a. animans corpus 246 cf. 208.256 .286 ; de descensu et ascensu animarum 290 cf. animas descendere de Galaxia per Planetas ad corpora et sic reverti ad Galaxiam 288; deus vim concipiendi creavit in anima 250; excitatur a. ad perpendendum illud quod obstat 254 ; a. rei absentate ymaginem sibi conformat 256; dum (a.) per se inquirit id quod invenit stabile limpidum et fixum existit $295 c f .256$; eandem esse mentem et hominis animam mentem per se animam ex officio 208 cf. 228.242.280; advenit mens anime sensibili 230; a. mundi 280.282 .284 .286 cf. ego nec animam illam (mundi) aliud esse conicio quam Deum 284; non est credendum anime fuisse nociones concreatas 224 cf. 226; animam numerum se moventem 242 cf. ex numero potest immortalitatis (anime) ostensio venari 294; dum a. per organa inquirit id quod invenit variabile est 294 ; intellectum fore potenciam anime 228; spiritus per arteriam diffusus instrumentum anime 254; Aristotiles (animam) tabule rase assimilavit 224. (cf. mens). animacio 246.

animal 208. 224. 230. 246. 274.

animalibus racionem inesse 230 ; per animacionem constituitur a. 246. (cf. bru tum).

animalitas 234. 274 .

animare $208.246 .280,286$

animus 238 .

a. conditoris 238 . 
aptitudo 236.238 .242 .252 .292$.

arithmetica 266 .

ars 206. 210. 212. 214. 244. 246. 284. 286 . 288 .

mens nostra concipit Deum quasi artem architectonicam cui a. alia executorialis subsit $284 \mathrm{cf}$. concipe absolutam artem creativam per se subsistentem ut a. sit artifex $284 c f$. vis artis creative que est a. absoluta et infinita seu Deus 286 ; mens est creata ab arte creatrice quasi a. illa seipsam creare vellet 286 cf. 288 ; a. citharizandi 288 ; a. coclearia 206. 2 Io. 2 I4; omnes humanas artes ymagines esse infinite et divine artis 2 10 cf. 2 12. 286 cf. artem omnem humanam finitam 2I2; infinitam artem omnium artium exemplar 212 cf. 288 ; immultiplicabilis est infinita a. 286 cf. precisione infinite artis inaccessibili semper remanente 288; nostra vis mentis facit mechanicas artes et phisicas 246; Platoni de arte pingendi familiaria exempla 206; configuraciones in arte statuaria aut pictoria aut fabrili 244 . arteria 244.254.

spiritus subtilis arteriarum 244.

articulus 254 .

artifex 244.284 .286$.

per motum omnes artifices efficiunt quod volunt 286

ascensus 290. 292.

a. animarum 290; a. intellectus 290 cf. 292.

assercio 296.

communis omnium hominum a. 296. assimilacio 220. 240. 244. 246. 248

(mens) incitatur ad assimilaciones abstractivas 246; anima brutorum facit assimilaciones 246 ; nostra vis mentis per assimilacionem facit artes ac coniecturas 246; (mens) intuetur se unius assimilacionem 248; neque a. fieret numero non existente 240 ; racionales assimilaciones 246 ; assimilaciones sensibilium 246 .

assimilare 224. 228. 244. 272.

mens nostra in qua posse assimilari et posse a. et nexus utriusque in essencia unum sunt et idem 272 .

astronomia 266 .

in astronomia magnitudinis continetur disciplina 266 .

athomus 260.

unus et idem punctus in omnibus athomis 260 ; est a. quantitas actu indivisibilis 260 . auctoritas 234 .

auditus $244 \cdot 254 \cdot 256$.

a. fit in aere tenuissimo 254 ; velocior est visus quam a. 256.

aures 254.256

oculi alciores sunt auribus 256 .

aversio 292 .

\section{basis 232 .}

binarius 238

bonitas 296 .

infinita veritas cum sit absoluta $b$. 296

bruta 230. 246 .

anima brutorum suo modo facit assimilaciones 246; discretivum discursum in brutis 230; discrecio visiva in brutis 230 .

camera 282

candela 276. 282 .

canis 230 .

capacitas 264 .

caput 256 .

causa 204. 2 I0. 220

cellula 256 .

c. fantastica 256 ; c. racionalis 256 .

celum 234. 294 .

motus celi per mentem numeretur 294;

Deus per motum celi proporcionem edu-

xit $232 / 234$.

centrum 246. 248 .

cera $244 \cdot 248.276$.

chorus 292 .

novem gradus seu chori (angelorum)

292.

circinus 264 .

c. vivus 264 .

circulus 246. 248.294 .

circulum esse figuram a cuius centro

omnes linee ad circumferenciam ducte sunt equales 246 ; c. in mente exemplar et mensura veritatis circuli in pavimento 246 cf. c. extra mentem in materia esse nequit 246 .

circumferencia 246 .

c. (circuli) 246 .

cithara 288

citharedus 226 .

civis 206.

clades 206.

claritas 282 .

clyma 204.

coclear 206. 2I2. 2I4. 232. 266. 
coclearitas 214 .

formam coclearitatis in figurali proporcione resplendere 214 .

cognicio 204. 222.

c. ut ipsa se mens cognoscat 204; similitudine fit c. 222 .

coincidencia 218.236 .294$.

mens est c. unitatis et alteritatis ut numerus 294 cf. 236 .

colligere 238 .

est c. unum et idem commune circa eadem multiplicare 238 .

collocucio 208.

color 214.230 .244 .274$.

communio 266 .

numerus ad colligendam rerum communionem 266

comparacio 264.

compleccio (complectio, complexio) 242 . 246. 252. 262. 264. 284. 294.

omnes complicaciones sunt in necessitate compleccionis 262 ; mens est locus seu regio necessitatis compleccionis 262 ; veritatem rerum in necessitate complectionis 246.

complicacio 222. 224. 262. 294. 296.

complicacionum c. 222 ; omnes complicaciones sunt ymagines complicacionis simplicitatis infinite et non explicaciones eius 262 cf. explicacio semper minor ymagine complicacionis 296; in (mentis) numerare coincidat explicacio cum complicacione 294 ; pluralitates rerum divinam complicacionem explicantes 222; c. puncti 262 .

composicio 236. 242. 248. 254. 272. 294

mentis c. que numeri ex se ipso compositi 294; composicionem que descendit a nexu absoluto 272 ; numeri incompositam composicionem 236 .

compositum 274. 278 .

res modo compositi intellecta dividue intelligitur 278 .

comprehensio 266 .

comprehensionem veritatis omnium rerum esse in multitudine et magnitudine 266.

concavitas 232 .

concepcio 220. 240.250 .252$.

c. ab imitacione 252; (divine mentis) c. est encium creacio et nostre mentis c. est encium assimilacio 220; exemplar concepcionum nostre mentis numerum esse 240; unum et idem est vis mentis et c. 250. conceptus 208. 236.284 .

c. divinus 284 ; conceptum sensibilem facere 236 ; verbum seu c. 284 .

concipere 250 .

c. non est nisi modo materie vel forme vel alio modo comprehendere 250 ; c. mentis est intelligere 250 .

concordancia $2 \mathrm{I}_{4} .22 \mathrm{O}$.

concordanciam racio facit $2 \mathrm{I}_{4}$.

condicio 292.

condiciones variabilis mundi 292 .

conditor 238 .

configuracio $244 \cdot 246$.

confusio 266 .

numerus ad confusionem communium discernendam valet 266 .

coniectura 208. 214. 228. 232. 246.

nostra vis mentis facit logicas coniecturas 246 ; racio in coniectura et opinione occumbit $2 \mathrm{r}_{4}$.

conjunccio 260 .

nullam constituet quantitatem terminorum c. 260 .

connexio 240. 268. 274. 276 .

entitatis equalitatisque connexio 240 ;

c. ante omnem divisionem eternitas 268 .

consideracio 254. 260. 274. 290.

consuetudo 206 .

continuum 260.

c. dividitur in semper divisibile sed actu dividendo ad partem actu indivisibilem devenitur 260 .

contrarium 226

c. in contrario recurritur ad intellectum 226; contraria simul 226 .

convexitas 232 .

corporeitas 250 .

corpora per corporeitatem habent formatum esse 250 .

corpus 204. 206. 208. 224. 226. 228. 244 246. 250. 258. 274. 280. 282. 286. 288 . 290. 292.

anima animans corpus 246 cf. 288 ; corpora per corporeitatem habent formatum esse 250 ; mens nostra in hoc corpus posita est ad sui profectum $224 c f .208 .280$; in nostro corpore mens facit configuraciones 244 ; sine corpore excitari ad progressum intellectualem non possint (mentes) 292 cf. 226; mentem nequaquam dependere a corpore 292 cf. mentem nequaquam cum corpore interire 292 ; (c.) successioni subicitur 274; superficiem (terminum) corporis 258 . 
corrupcio 240 .

divisio, ex qua c. 240.

coruscacio 256 .

costa 236 .

creacio 220. 232. 252. 286. 288.

concepcio (divine mentis) est enciun

c. 220; mentis nostre c. in hoc nostro corpore 286 .

creator 290.

creatura 224. 282 .

creature mente carentes sunt pocius divine simplicitatis explicaciones quam ymagines 224; omnem creaturam numerum divine mentis auffugere non posse 282 .

cuprum 276

cura 204.

deitas 270 .

delectacio 238 .

d. omnibus rebus inest 238 .

demonstracio 268 .

denarius 294. 296.

d. est unitas ex decem complicata $294 / 96$.

descensus 272. 290. 292.

d. animarum 290; d. intellectus 290 cf. 292; successio est d. ab eternitate 272 . descripcio 232.

mens viva d. eterne et infinite sapiencie 232.

desiderium 284. 286. 296.

voluntas seu d. 284 cf. 286 .

determinacio 294.

(mens) omnium mensurabilium d. 294. deus 204. 2 10. 218.220 .222 .228 .230 .232$. 234. 242. 248. 250. 264. 266. 268. 270. 272. 282. 284. 286. 290.

(d.) qui solum est infinite absolutus et simpliciter 282; ego nec animam illam (mundi) aliud esse conicio quam deum 284; ars absoluta seu d. 286 cf. mens nostra concipit deum quasi artem architectonicam 284 ; d. est complicacionum complicacio 222; ens non entis est d.290; d. est entitas absoluta 222; eternitas simplicissima que d. est $268 / 70$; in deo sunt rerum exemplaria 222 cf. 230. 266; soli deo secundum naturam immortalitate inhabitante 282; intellectus de deo est complexivus omnium intellectuum de substancia et accidente sed est simplex et unus 290 cf. intellectus de deo est inflexus de intellectu nominis ens 290; intelligere (dei) cum sit eius essencia est necessario in trinitate 272 ; nature abstracte quo ad deum non sunt abstracte $\mathrm{ab}$ omni mutacione 282 ; deum omnium rerum nominibus ac omnes res dei nomine nominari 218 of. 220; omnia ab eterno in deo d. $270 \mathrm{cf}$. omnia in deo unum 270 cf. 248 ; d. est cuiuscunque rei precisio $218 c t .220$; d. per motum celi proporcionem eduxit $232 / 4$ cf. 242 ; scienciam cuiuslibet precedit sciencia dei 266 ; deum quem dicimus spiritum universorum 284 cf. deus si ignoratur nichil de universitate scitur 266 cf. 270 ; trinitas individua una in deo $\mathrm{ab}$ unitate uniente 276 cf. 268 ; (d.) veritas omnium scibilium 2x8; unam esse infinitam virtutem quam deum dicimus 218; voluntas dei alio executore opus non habet 284. (cf. conditor, creator, eternitas, facies absoluta, filius, mens eterna, pater, simplicitas absoluta, unitas absoluta, Spiritus sanctus etc.)

devocio 204 .

Diamas 232.

diameter 236 .

dyapason 236 .

diapente 236 .

diatesseron 236 .

dies 296.

differencia 214. 220. 230. 250. 272. 274. 290 . modo forme facit (mens) differencias

272 cf. differenciam racio facit $2 \mathrm{I}_{4}$.

diffinicio 268 .

diffinicionum demonstracio fit secundum vim magnitudinis 268 .

digitus 226. 288 .

direccio 256 .

discessio 262 .

disciplina 252.254 .266 .290$.

d. in geometria integritatem determinat 266 ; d. magnitudinis 266 ; d. multitudinis 266; per numeri disciplinam (habetur) rerum discrecio 266 ; d. que fit per vocabula 290.

discipulus 292 .

discrecio 2I4. 230. 240. 242. 244. 266. 28 o. 282.

forma discrecionis animalis 230; per numeri disciplinam habetur rerum d. 266 cf. 240,282 ; discrecionem racio facit 214 cf. 230 ; advenit d. visui 230.

discursus 230 .

d. in brutis 230 ; d. confusus 230 .

disiunccio 224 . 
disposicio 252. 256 .

d. ad perfeccionem 252 ; sensuum d. facta ad similitudinem ordinis sive disposicionis quatuor elementorum 256 .

distinccio 282 .

diversitas 204. 224. 262. 270. 296.

d. (explicacio) ydemptitatis 224 .

dividue 278 .

res modo materie aut modo compositi intellecta d. intelligitur 278 .

divisibilitas 294 .

d. in (mente) cum indivisibili unitate coincidens 294 .

divisio 240. 268. 280 .

alteritas d. est 240 ; ante omnem divisionem connexio 268 ; d. ex qua corrupcio 240 ; d. et divisionum demonstracio secundum vim multitudinis 268 ; d. ab unitate descendit $28 \mathrm{o}$.

docibilis 292.

sumus in hoc mundo docibiles in alio magistri 292.

doctrina 220. 254. 288. 290.

d. seu intelligencia 290 .

donum 204.

dei d. 204.

elementum 256. 278. 290. 292.

e. mentis 290; sensuum disposicio facta ad similitudinem ordinis sive disposicionis quatuor elementorum 256 .

endelechia 242.

enigma 236.

ens 2I 4. 216. 220. 222. 248. 290.

encium assimilacio 220 ; encium creacio 220; e. non entis est Deus 290; entitas absoluta omnium encium complicacio 222 cf. 248; encia racionis 214.216.

entitas 220. 222. 240. 248. 272. 28 o.

deus est e. absoluta que est omnium encium complicacio 222 cf. 220 ; in omnibus entibus est e. varie participata 248; pars eiusdem entitatis est cuius totum 280 ; posse fieri quod descendit a virtute infinita unitatis seu entitatis absolute $272 \mathrm{cf}$. unitas que est e. 240 .

equalitas 222. 224. 238. 240. 264. 272. 276 . 278.

entitatis e. 272 cf. essendi e. ${ }^{2} 40$; dicunt theologi equalitatem pro Filio 278 ; inequalitas (explicacio) equalitatis 224: posse facere attribuitur e. 272 ; e. est unitatis ymago 222 cf. 238,272 cf. e. est una 276 .

\begin{abstract}
esse 228. 232. 250. 276. 284. 290.
conceptus divinus in e. prodeat 284 ; in materia e. est e. possibiliter 276 $c f$. posse e. 250 ; quodlibet habet e. proprium et distinctum 290; temporale e. 232. essencia 232. 240. 242. 284. 288.

dividua et individua e. 242 ; in unitate essencie (mentis) est potencia sapiencia et voluntas 288 ; e. numeri 240 ; essencie rerum incorruptibiles 240 .

eternitas 206. 212. 222. 268. 270. 272. 296. connexio ante omnem divisionem e. 268 ; e. simplicissima que Deus est 270 cf. est sola et unica absoluta e. ipsa infinitas que est sine principio $2 \mathrm{I} 2$; mens est ymago eternitatis 296; successio est descensus ab eternitate 272 ; templum eternitatis 206 ; tempus (explicacio) eternitatis 222 cf. 296.
\end{abstract} evolucio 260 .

linea est puncti e. 260 .

excitacio 226 .

corpore organico sine quo e. fieri non posset 226 .

execucio 284 .

executor 284 .

exemplar 210. 212. 216. 218. 222. 228. 230. 238. 240. 248. 264. 266. 284. 286. 288. 292.

deus est omnium e. 30 cf. in deo sunt rerum exemplaria 222 cf. 266 ; ymago que potenciam habet se semper plus et plus inaccessibili exemplari conformandi 286 $c f .288$; mens ymaginum post ipsum e. 222 cf. 264 ; nociones seu exemplaria que nulla oblivione obmittuntur 284 ; primum rerum e. numerum esse 238 cf. e. concepcionum numerum esse 240 ; precisum e. 218 ; pulchritudo exemplaris 248 ; exemplaria natura precedere sensibilia 216 ; unum simplicissimum e. 2 I 8 cf. 222 cf. non esse multa separata exemplaria 216 . exemplum 206. 218. 278. 282. 286. 288.

exequi 284 .

velle cum e. in omnipotencia coincidit 284 .

exercicium 206.

exercitus 282.

existencia 270 .

experiencia 258 .

experimentum 208.

explicacio 222. 224. 240. 260. 262. 294. 296.

omnes complicaciones sunt ymagines complicacionis simplicitatis infinite et non explicaciones eius 262 cf. aliam esse ymaginem aliam explicacionem 222 cf. e. semper minor ymagine complicacionis 296 ; 
in (mentis) numerare coincidat e. cum complicacione 294 ; pluralitas e. 240. extensio 260 .

extremitas 254 .

e. articulorum 254 .

facere 244 .

f. et videre 244

facies 204. 222. 264 .

absoluta facies $264 c f$. dei noticia seu

f. 222 .

fama 206.

fantasma 226. 246 .

fantasmata seu ymagines ${ }^{2} 46$

fenestra 256 .

oculi nares etc. quasi fenestre ${ }^{2} 56$. fides 204 .

omnium fidem unam in tanta corporum

diversitate 204; ydiotas clarius fide attingere quam philosophos racione 204 .

figura 220. 244. 246. 248. 264. 294 .

veritas invariabilis figurarum geometricarum non in pavimentis sed mente reperitur $294 \mathrm{cf} .264$.

filius 278.286 .

dicunt theologi equalitatem pro Filio 278 .

finis 204 . 212.248 .

f. nocionum 248 .

flexibilitas $244 \cdot 24^{8}$.

flexio 290.

forma 2 I0. 2 I2. 2 I 4. 2 I6. 2I8. 226. 228. 230. $232.234 \cdot 236.244 \cdot 246.250 .252 .254 .256$ 272. 274. 276.278 . 290. 292. 294 .

f. coclearis 232 ; $f$. discretiva $230 \mathrm{cf}$. $\mathrm{f}$. discrecionis animalis 230 ; infinita $f$. est solum una et simplicissima omnium et singulorum formabilium adequatissimum exemplar $216.218 \mathrm{cf}$. infinitam formam nulla racio attingere potest 216 ; rerum formas extra materiam 254 ; forme rerum obumbrate variebilitate materie $246 \mathrm{cf}$. 256. 290; (mens) que licet careat omni nocionali forma potest tamen seipsam omni forme assimilare $226 \mathrm{cf}$. 246. 292/294; omnia ut in mente nostra sunt sunt et in forma 274; dum modo forme intelligit tunc individue comprehendit 278 ; posse facere seu f. 272 ; proporcio est locus forme 234 cf. $21_{4} \cdot 232.236$; f. specularis 232 ; $\mathrm{f}$. visus 230 ; formam adducere vocabulum 2 Io.

fruicio 292. 296.

f. exemplaris rerum 292 cf. ad eterne mentis fruicionem perduci 296 .

fumositas 254 .
Galaxia 288 .

animas descendere de Galaxia per Planetas ad corpora et sic reverti ad Galaxiam 288.

genus 2I4. 232. 250. 252. 268. 272. 274 . decem genera generalissima omnia complecti $268 \mathrm{cf}$. (decem genera) generalissima nullum g. commune habent 274 , decem illa generalissima non in se sed ut in mente sunt intelliguntur 274; modo materie facit (mens) genera 272 ; unum et idem est vis mentis et g. 250; genera ut sub vocabulo cadunt sunt encia racionis $2 \mathrm{I}_{4}$.

geometria 266.

globus 278 .

gradus 290. 292.

gradus intellectuales 290 ; novem gra-

dus seu chori (angelorum) 292.

gravitas 204 .

gustus 2 I $_{4} \cdot 244 \cdot 292$.

g. sapiencie 292.

habitudo 236.280 .

armonica h. unitas est 236 ; h. sine

numero non intelligitur 236 .

habitus 252 .

post perfeccionem h. 252 .

armonia 226. 238.242 .288$.

mentem omnem sensibilem racionalem

et intellectualem armoniam complicantem 242 ; in proporcione a. 238 cf. desinit a. aptitudine proporcionis desinente $23^{8}$.

homo 206. $216.244 \cdot 256.276 .278 .280 .282$. 296.

h. per humanitatem 2I6; unum esse intellectum in omnibus hominibus (Peripatetici) 280; non habemus cerciorem scienciam nos esse homines quam mentes habere immortales 296; in homine sensuum disposicio facta ad similitudinem ordinis sive disposicionis quatuor elementorum 256.

humanitas 2I6. 2I8. 274. 276. 278.296. humanitatem ut non cadit sub vocabulo esse precisionem veritatis $218 ; \mathrm{h}$. in se et ex se deinde homo per humanitatem deinde species in racione $216 \mathrm{cf}$. h. ut est possibilitas essendi hominem materia est sicut h. est forma est ut homo est ex utroque compositum est $27^{6} \mathrm{cf} \cdot 27^{8}$.

ydea 212. 216

non esse multas rerum ydeas 216 . 
idemptitas (ydemptitas) 224. 280 .

diversitas (explicacio) ydemptitatis 224 ;

i. mentis 280 ; i. proporcionis est immultiplicabilis 280 .

ydiota 204. 208

ydiotas clarius fide attingere quam philosophos racione 204 cf. 208

ignotum 284 .

penitus ignotorum non est voluntas $284 / 286$.

illuminacio 282 .

ymaginacio 230. 244. 256 .

racio forma discretiva ymaginacionum

230; y. re absentata comprehendit 256 . ymago 208, 210. 214. 216, 218, 220, 222. 224. 234. 236. 240. 244. 246. 248. 256. 262. 276 . 286. 288, 290. 296.

y. in absencia sensibilium 244 cf. 256 ; imperfecta y. que potenciam habet se semper plus et plus inaccessibili exemplari conformandi 286 ; aliam esse ymaginem aliam explicacionem 222 cf. explicacio semper minor ymagine complicacionis 296; fantasmata seu ymagines formarum 246 ; formam simplicem in figurali proporcione quasi in ymagine eius resplendere $2 \mathrm{I}_{4}$; mens prima y. complicacionis simplicitatis infinite $262 \mathrm{cf}$. mens nostra omnium ymaginum complicacio $222 \mathrm{cf}$. omnia post mentem non sunt dei y. nisi in quantum in ipsis mens ipsa relucet 224 cf. mens ut viva y. dei 248 cf. 208 . 286. 296; omne nomen sit y. precisi nominis 218 ; post ymagines sunt pluralitates rerum 222; ymagine destructa manet in se veritas $216 \mathrm{cf}$. quomodo periret y. nisi veritate communicatam relucenciam abolente 296.

imitacio 252.

immortalitas 204. 282. 292. 294. 296

soli deo secundum naturam immortalitate inhabitante 282; nobis nota sit nostre mentis i. ex communi omnium indubitata assercione 296 cf. 292 cf. nobis esse naturaliter inditam nostre mentis im mortalitatem 296; ex numero potest immortalitatis ostensio venari 294; nosti quanta inquisicione opus habet mentis immortalitatem racione pertractans 204 . immutabilitas 246. 254. 280 .

imperium 284.

i. dei 284 .

imposicio 210. 214.

vocabula non ex imposicione sed $a b$ eterno et i. sit libera 210 cf. 214 ; i. vocabuli fit motu racionis $2 \mathrm{I}_{4}$

impossibile 284 .

impossibilium non est voluntas $284 / 286$. impossibilitas 282 .

inchoacio 268 .

i. essendi 268 .

incuria 292 .

individuum 272.278 .

modo compositi species facit (mens) vel individua 272 cf. res formaliter intellecta individue comprehenditur 278 .

inequalitas 224

i. (explicacio) equalitatis 224 .

infans 230 .

infantibus ubi deest usus discrecionis 230.

infinitas 212. 216.286.

infinitum 208. 210. 212 .

mens in se subsistens aut infinita aut infiniti ymago 208 ; impossibile est plura esse infinita realiter distincta 212

informitas 292.

mentes nostre ob sui informitatem obliviscuntur 292

inquisicio 204 .

instrumentum 232. 248. 254. 256. 294.

anima corporeo utiturinstrumento 256

instrumenta motuum celestium 294 .

integritas 266 .

per disciplinam magnitudinis habetur terminus integritatis rerum 266.

intellectibilitas 254. 290. 292.

i. ubi se mens simplicitati divine conformat 290. Plato (ponit elementum) intellectibilitatem ad descensum (intellectus) 290 cf. 292.

intellectus 206. $214.218,226.228,230,234$ 250. 252. 262. 280. 290. 292.

actu vel intellectu 262; intellectum fore potenciam anime (Peripatetici) 228; (Aristotiles) ponit elementum racionem ad ascensum intellectus 290 cf. 292 ; contrarium in contrario recurritur ad intellectum 226; Plato (ponit) intellectibilitatem ad descensum (intellectus) 290 cf. 292 ; i. de deo est complexivus omnium intellectuum de substancia et accidente $290 \mathrm{cf}$. i. de deo est inflexus de intellectu nominis ens 290; nequaquam possibile arbitror unum esse intellectum in omnibus hominibus 280 (cf. unum esse intellectum in omnibus hominibus (Peripatetici) 280); ab intellectu iudicium re- 
quiri 226 ; i. de materia prima est flexio quedam ab intellectu qui habetur de corpore 290 ; i. est mentis motus perfectus $250 \mathrm{cf} .228 .252 \mathrm{cf}$. unum et idem passio (mentis) et i. 252 ; omnem intellectum fore de substancia et accidente 290; unum dicis intellectum 234 .

intelligencia 208. 2 16. 254. 290 .

de mente i. 208 ; doctrina seu i. 290 ; vis qua mens intuendo ad suam simplicitatem omnia in simplicitate intuetur i. 254 .

intelligere 228.250 .252 .272 .

i. accidens (Peripatetici) 228, i. (dei) cum sit eius essencia est in trinitate 272 ; concipere mentis est i. 250 ; mens dicitur i. quando movetur 252 .

interitus 240 . pertinet ad interitum alteritas 240 . intueri 216. ultra vim vocabuli theologice i. ${ }^{2}$ I6. intuicio 248.292 . intuicionem mentis attingere invariabile 292 ; i. veritatis absolute 248 .

invariabile 292. 294 . intuicionem mentis attingere i. 292 cf. 294 .

iubileum 204.

iudicium 226. 230. 242. 244. 282. 296. opus est iudicio discretivo intellectus 226 cf. 230 ; i. mentis sibi concreatum per quod de omnibus racionibus iudicat 296 cf. 226. 242; iudicium requiri quando sensus contraria simul ministrat $226 \mathrm{cf}$. i. de exterioribus 230.

iunctura $25^{8}$.

punctus i. linee ad lineam $25^{8}$.

labor 204 .

lapis 232.258

latitudo 258 .

(mens) facit superficiem considerando latitudinem sine soliditate $25^{8}$

leccio 230 .

lex 230.

lignum 206. 212. 232. 258. 266.

limacio 250 .

limitacio 286 .

linea $246,258,260,262,278$.

(mens) facit lineam considerando longitudinem sine latitudine 258 ; impossibile est duas dari lineas in materia equales 246 ; quelibet pars linee 1.278; punctus est terminus linee et eius totalitas ac perfeccio 262 cf. 258.260 ; reperitur in linea nichil nisi punctus 260 cf. 262 ; lineam in puncto complicare $262 ; 1$. puncti evolucio 260 cf. 262 ; punctus iunctura linee ad lineam 258; quadripunctualis 1. 258; superficies (evolucio) linee 260 ct. lineam terminum superficiei 258 ; 1 . tripunctualis $25^{8}$.

lingua 210 .

locus 234. 236. 238. $244 \cdot 262$.

1. orbis seu regio 234 cf. $262 ; 1$. forme 236.

logica 216

racio seu 1. circa ymagines formarum versatur $2 x 6$.

longitudo 258 .

(mens) facit lineam considerando longitudinem sine latitudine $25^{8}$.

loquela 226 .

lumen 282

lutum $244 \cdot 248$.

lux 226.

magister $284.288,294$.

m. - magisterium 284 cf. 288 ; sumus in hoc mundo docibiles in alio magistri 292.

magisterium 284. 288. 292.

magister - m. 284 cf. 288 ; nociones hic acquisite ad invariabile m. transferuntur 292 cf. particulares nociones desinunt esse variabiles in magisterio universali 292.

magnitudo $224 \cdot 248 \cdot 258 \cdot 260.266 .268 .278$. 280 .

diffinicionum demonstracio fit secundum vim magnitudinis 268; in geometria et astronomia magnitudinis continetur disciplina 266; per disciplinam magnitudinis habetur terminus integritatis rerum et mensura 266 ; $\mathrm{m}$. in se extra materiam considerata 278 ; $\mathrm{m}$. a mente 258 ; omne cadit sub magnitudine et multitudine $268 \mathrm{cf}$. comprehensionem veritatis esse in multitudine et magnitudine 266; quelibet pars (magnitudinis) de toto verificatur $280 ; \mathrm{m}$. (explicacio) puncti $224 \mathrm{ct} .248 \mathrm{cf}$. si tollis punctum deficit $\mathrm{m} .260$; fiunt silogismorum demonstraciones secundum vim magnitudinis et multitudinis $268 \mathrm{cf}$. quod ex universalibus et particularibus (concluditur) magnitudinis est $268 ; \mathrm{m}$. terminat 268 .

manubrium 232.

manus 212. 
materia 210. 214. 216. 234. 246. 248. 250 . 252. 254. 256. 260. 262. 272. 274. 276. 278. 280.282 .290$.

circulus in materia esse nequit 246 ; forme rerum obumbrate variebilitate materie 246 cf. 256 . 290; m. confundit formatum 256; intellectus de materia prima est flexio quedam ab intellectu qui habetur de corpore 290; impossibile est duas dari lineas in materia equales 246 ; omnia ut in mente nostra sunt sunt similiter in materia $274 \mathrm{cf}$. mentis natura extra corpus ab omni varietate materie absoluta 282 ; res modo materie intellecta dividue intelligitur 278; numerus sublatus videtur quando tollitur variebilitas materie 282 ; possibilitatem indeterminatam materiam vocamus $250 \mathrm{cf}$. in materia esse est esse possibiliter 276; in similitudine posse fieri seu materie 272 ; locus proporcionis m. 234 .

mathematicalis 220 .

exerimus ex vi mentis mathematicales figuras 220 .

mediare 240 .

medietas 236. $25^{8}$.

m. dupla 236; duarum medietatum iunctura $25^{8}$.

medium 206. 2 I2.

scripturas in m. conferre 206.

medulla $254 \cdot 256$.

mens passim

eandem esse mentem et hominis animam mentem per se animam ex officio 208 cf. 228. 242. 246. 280; advenit m. anime sensibili 230 ; m. est creata ab arte creatrice $286 \mathrm{cf}$. excitata (m.) se actualitati divine artis conformiorem facere potest 288; mens nostra infra omnes creata 286 ; nostra vis mentis facit mechanicas artes et phisicas 246; mentem esse vim illam que careat omni nocionali forma potest excitata seipsam omni forme assimilare et nociones facere 226 cf. $244.246 ; \mathrm{m}$. se assimilat rebus per species $244 ; \mathrm{m}$. faciat assimilaciones ut nociones habeat sensibilium 246; (m.) incitatur ad assimilaciones abstractivas 246; (m.) intuetur se unius assimilacionem 248 ; $\mathrm{m}$. nostra in qua posse assimilari et posse assimilare et nexus utriusque in essencia unum sunt et idem 272 ; mentes celestes secundum gradus intellectuales creatas et nociones habere indelibiles 290; circulus in mente est exemplar veritatis circuli in pavimento
246 ; cognicio ut ipsa se m. cognoscat coniunctamque cum divina mente se senciat 204 cf. (m.) omnia agit ut se cognoscat 264 cf. (m.) mensurando alia sui capacitatem attingit $264 ; \mathrm{m}$. est coincidencia unitatis et alteritatis $294 ; \mathrm{m}$. complicat idem et diversum 294; mentem nostram esse composicionem 242 cf. illa est mentis composicio que numeri ex seipso compositi 294 ; concepcio divine mentis est rerum produccio 220 ( $c f$. encium creacio 220) cf. 244; nostre mentis concepcio est encium assimilacio 220 (cf. rerum nocio 220) cf. concipere mentis est intelligere 250 $c f$. $m$. concipit cum ad perfeccionem ducitur intellectus 252 ; (m.) se movet concipiendo $250 ; \mathrm{m}$. facit configuraciones 244 ; (m.) omnibus se conformare posset 248 ; nostra vis mentis facit logicas coniecturas 246; alia est $\mathrm{m}$. in se substistens alia in corpore 208 cf. 246.280 ; mentem intellectivam ante corpus fuisse natura non tempore $228 ; \mathrm{m}$. nostra in hoc corpus posita est ad sui profectum $224 c f$. (mentes) sine corpore excitari ad progressum intellectualem non possint 292; (mentis) officium in hoc corpore est corpus vivificare $228 c f .280$; (m.) intelligit in successione dum unita est corpori 274; mentem. nequaquam dependere a corpore $292 \mathrm{cf}$. mentem nequaquam cum corpore interire 292; (m.) manebit ut omnium mensurabilium determinacio 294; $\mathrm{m}$. est viva descripcio eterne et infinite sapiencie 232 $c f$. mentem nostram esse nature divine et menti divine propinquissime coniunctam $242 c f$. inter divinam mentem et nostram interest quod inter facere et videre 244 ; m. divina est absoluta entitas 220 cf. 222 ; mentem esse ex eodem et diverso 242 ; $\mathrm{m}$. est unitatis equalitas $238 \mathrm{cf}$. m. est viva et incontracta infinite equalitatis similitudo 264; (m.) se facit exemplar 264; (m.) per se ipsam se omnibus figuris ut in se subsistunt assimilare possit $248 \mathrm{cf}$. (m.) utitur figuris geometricis $264 ; \mathrm{m}$. in vi sue flexibilitatis vive hoc est in se nociones esse conspiceret $248 ; \mathrm{m}$. est forma substantialis 228 ; $\mathrm{m}$. forma discrecionis animalis et eius perfeccio $230 ; \mathrm{m}$. est forma movendi $294 ; \mathrm{m}$. est forma racionis discurrentis $230 ; m$. ex se exerit rerum for mas 244 ; dum modo forme intelligit tunc individue comprehendit $278 ; \mathrm{m}$. in se et a materia abstracta se assimilat formis 
abstractis 246 ; nostras mentes ad eterne mentis fruicionem desiderio incitatas perduci $296 ; \mathrm{m}$. faciat decem genera generalissima prima principia 274; mentem nostram esse armoniam $42 \mathrm{cf}$. mentem omnem sensibilem racionalem et intellectualem armoniam complicantem 242; idemptitas mentis 280 ; sola $\mathrm{m}$. dei ymago 224 cf. 222 (cf. viva y. 248 ; artis infinite y. 286; prima y. complicacionis simplicitatis 262 cf. 220. 222. 224; entitatis infinite y. 222; eternitatis y. 296; y. exemplaris omnium 230; infiniti y. 208; y. mentis eterne 272 ; y. infinite simplicitatis 224 ) ; m. omnium dei ymaginum post ipsum exemplar 22 cf. omnia post mentem non sunt dei ymago nisi in quantum in ipsis $m$. ipsa relucet 224 ; nobis esse naturaliter inditam nostre mentis immortalitatem 296 cf. 292 cf. quanta inquisicione opus habet mentis immortalitatem racione pertractans $204 ; \mathrm{m}$. dum respicit ad suam immutabilitatem 246; nostre mentes ob sui informitatem obliviscuntur 292; mentem intellectum esse $280 \mathrm{cf}$. motus mentis est intellectus cuius inicium est passio 252 ; m. dicitur intelligere quando movetur.. intellectus nisi post perfeccionem $252 \mathrm{cf}$. 250 ; in intellectibilitate ubi se mens simplicitati divine conformat $290 \mathrm{cf}$. in intellectibilitate elementum posuit et substanciam mentis (Plato) 290; (m.) intuetur omnia unum $248 \mathrm{cf}$. (m.) vult in se intueri omnia 290; intuicionem mentis attingere invariabile 292 ; $m$. intus existens $244 ; \mathrm{m}$. nostra habet sibi concreatum iudicium 226 cf. 296 ; mens de racionibus iudicium habet discretivum 230 ; mentem esse ex qua omnium rerum terminus et mensura 208 cf. 220. 258. 294 (cf. viva mensura 264); m. nostra in mente eterna suiipsius mensuram venari contendit 272 cf. 296; mentem a mensurando dici 208 cf. 220. 258 . 264.296; m. mensurando alia sui capacitatem attingit 264 ; (m.) mensurat symbolice comparacionis modo $264 ; \mathrm{m}$. nostra quam sola $\mathrm{m}$. increata mensurat 296; $\mathrm{m}$. omnia in omnibus attingit suo modo 278 ; modi comprehendendi substanciales partes virtutis que $\mathrm{m}$. dicitur $278 \mathrm{cf}$. quilibet modus de tota mente verificatur 278 ; expressissima similitudo inter modum essendi omnium ut sunt actu et ut sunt in mente 278 ; motum non plus mensurare mentem quam m. motum
294 cf. motus celi per mentem numeretur 294; $\mathrm{m}$. ex se exerit motum raciocinativum 294 ; m. motu suo intellectivo successivum motum videtur complicare 294 ; multitudo et magnitudo a mente sunt $25^{8}$ cf. $238 ; \mathrm{m}$. eterna quasi ut musicus 236 ; (m.) conformat se necessitati absolute 264 ; $\mathrm{m}$. est locus seu regio necessitatis compleccionis 262 cf. 264 ; mentes nostre nexus universitatis encium ut sit terminus perfeccionis inferiorum nature et inicium superiorum 292; mentem ex se nociones fabricare 242 cf. 248 ; (m.) se facit nocionem 264; sola $\mathrm{m}$. numerat $23^{8} \mathrm{cf}$. 294; in (mentis) numerare coincidat explicacio cum complicacione 294; (numerus) ex divina mente procedit 234 cf. omnem creaturam numerum divine mentis auffugere non posse $282 c f$. inter mentem divinam et res non mediare numerum ${ }^{2} 40$; numerus nostre mentis ymago numeri divini 240; mentem sic se movere quasi vivus numerus discretivus 242 ; numerus mentis nostre est exemplar nocionum 240 ; $\mathrm{m}$. facit numerum $25^{8} \mathrm{cf}$. 234. 238.242 . 294 cf. sublata mente numerus discretus non est 238; (m.) utitur numero 264 ; pluralitatem rerum esse modum intelligendi divine mentis $23^{8} \mathrm{cf} .282$; explicat pluralitas virtutem unitatis mentis 240 cf. 238 ; (m.) conformat se possibilitati 264 (cf. possibilitati determinate 264); $\mathrm{m}$. possibilitatem indeterminatam attingit per adulterinam racionem $250 ; \mathrm{m}$. facit punctum 258; (m.) incontracta ad quantum 264 ; (m.) concipit rerum quidditates utens se ipsa $246 ; \mathrm{m}$. in fine omnium nocionum ut in veritate vite sue quiescit $24^{8}$; omnes res post simplicem mentem de mente participant 222 ; m. exercit sciencias certas mathematicales 246 ; de mente scripturas reperiri $206 ; \mathrm{m}$. est quoddam divinum semen $228 ; m$. nostra similitudo divine $272 \mathrm{cf}$. in nostra mente rerum similitudines 222 cf. 254. 290; m. excitata per obstaculum specierum 244; m. facit theologicas speculaciones 248 ; mentem quasi vivum speculum 234; m. immersa spiritui corporali 246 cf. spiritus arteriarum mente animatus 244; spiritum in mente nostra loquentem et iudicantem 226; m. est viva substancia 228 $c f$. mentem ex individua et dividua substancia componi (Plato) 278; eterna m. sine successione simul omnia intelligit 
272 cf. in successione vides mentem nostram intelligere 272; Aristotiles eam (mentem) tabule rase assimilavit 224; templo menti per T.Attilium Crassum in Capitolio dedicato 206; tempus mentis virtutem non evacuabit $294 ; \mathrm{m}$. omnia terminat $244 \mathrm{cf}$. ex mente increata rerum omnis terminus descendit 258 ; (m.) manebit ut omnium mensurabilium terminus 294 cf. 208; non potest m. nostra nisi sit una in trinitate quidquam intelligere 272 cf. 240.274 cf. m. eterna omnia in unitatis equalitate et utriusque nexu intelligit $272 ; \mathrm{m}$. est unitas simplex 242 ; unitas uniens est $\mathrm{m}$. increata $240 \mathrm{cf} . \mathrm{m}$. nostra unitas uniens per mentem conceptibilem 240; quod (m.) communiter modo materie aut compositi intelligit habet quia unitas uniens 280; mentem esse ex unitate et alteritate 242 ; in unitate essencie (mentis) est potencia sapiencia et voluntas 288 ; mentem divinam universitatem veritatis rerum nostram universitatem assimilacionis rerum 220 $c f$. in illa rerum universitate que in mente est omnia sunt in trinitate et in unitate trinitatis ad similitudinem ut sunt in mente eterna 274; utitur m. seipsa 248 ; mentis naturam ab omni variabilitate absolutam esse 294; veritas invariabilis figurarum geometricarum mente reperitur $294 ; \mathrm{m}$. virtualiter constat ex virtute intelligendi raciocinandi ymaginandi et senciendi $278 \mathrm{cf} .250 ; \mathrm{m}$. comprehendendi virtutes ab unitate habet 280 ; vis mentis est vis comprehensiva rerum et nocionalis 224 cf. nostra vis mentis facit mechanicas artes et phisicas ac logicas coniecturas 246 ; divina $\mathrm{m}$. est vis entificativa 244 cf. mentem infinitam esse vim formativam absolutam sic mentem finitam vim conformativam seu configurativam 222; vim illam que in nobis est quam mentem appello nequaquam proprie nominari 2 10 cf. 228; unum et idem est vis mentis et concepcio et similitudo et nocio et genus et species $250 ; \mathrm{m}$. vita intellectualis seipsam movens 294 cf. (m.) est semper vivens 294 .

mensura 208. 212. 220. 264. 266. 272. 294 . mens a mensura $220 \mathrm{cf}$. mens est viva m. $264 \mathrm{cf}$. mentem esse ex qua omnium rerum terminus et m. 208 cf. 294 ; tempus m. motus 294 .

\section{mensuracio 220. 240 .}

racio mensuracionis sit causa nominis 220 ; neque $\mathrm{m}$. fieret numero non existente 240 .

mensurare 208. 2 I0.

mentem a mensurando dici $208 \mathrm{cf}$. 2 I0. metallum 248 .

metrum 212 .

minerale 224 .

mocio 286.

modus $216.218 .228 .234 .238 .240 .242,244$. $246.248 .250 .252 .262 .264 \cdot 272.274 \cdot 276$. 278. 280. 282. 284. 290. 294. 296.

m. compositi 252. 272. 274. 276. 278. $280 \mathrm{cf}$. res modo compositi intellecta dividue intelligitur 278; modi comprehendendi sint substanciales partes virtutis que mens dicitur $278 \mathrm{cf}$. quilibet $\mathrm{m}$. de tota mente verificatur $278 ; \mathrm{m}$. dicendi 238 . 242. 244. 262 cf. modi dicendi debent ad intelligendi modum referri 238 ; divini modi precisione inattingibiles 228 ; $\mathrm{m}$. essendi $248.250 .264 .274 \cdot 276.278$; expressissima similitudo inter modum essendi omnium ut sunt actu et ut sunt in mente $278 ; \mathrm{m}$. forme 252.272 .274 . 276.278 ; modo forme individue comprehendit $278 \mathrm{cf}$. modi intelligendi 240.242 . 284. 294; numerus est modus intelligendi mentis $294 \mathrm{cf} .240 \mathrm{cf}$. pluralitatem rerum esse modum intelligendi divine mentis 238; m. materie 252. 272. 274. 276. 278 . $280 \mathrm{cf}$. res modo materie intellecta dividue intelligitur 278 ; $\mathrm{m}$. universitatis 250 . molestia 292.

mors 204. 280.

animas nostras in animam mundi post mortem resolvi (Platonici) 280.

motus 21 4. 2 I6. 222. 224. 232. 234. 242. 244 . 250. 252. 262. 266. 286. 288. 290. 294.

per motum omnes artifices efficiunt quod volunt 286; deus per motum celi proporcionem eduxit $234 \mathrm{cf}$. $\mathrm{m}$. celi per mentem numeretur 294; m. est discessio ab uno 262; si quid dissolvitur per motum fit 294; mentis m. 250. 252. 294 cf. inicium motus (mentis) passio $252 \mathrm{cf}$. perfeccio motus (mentis) intellectus $252 \mathrm{cf}$. motum non plus mensurare mentem quam mens motum 294; mens ex se exerit motum raciocinativum 294; mens motu suo intellectivo omnem successivum motum videtur complicare $294 ; \mathrm{m}$. est explicacio quietis 262 cf. 222. 224; nihil reperitur in motu nisi quies $262 ; \mathrm{m}$. racionis $2 \mathrm{I}_{4}$. 
216. $290 \mathrm{cf} . \mathrm{m}$. racionis est circa res que sub sensu cadunt $2 \mathrm{r}_{4}$; cessavit motu cessante sonus 288 ; m. sine spiritu non est 286; tempus mensura motus 294 . movere 262 .

$\mathrm{m}$. sit de uno statu in alium cadere 262 ; non sit aliud $\mathrm{m}$. nisi ordinata quies sive quietes seriatim ordinate 262 .

multiplicacio 240.282 .

alteritas sequitur multiplicacionem contingenter 240 ; sublata varietate non capiamus multiplicacionem numeri 282 . multiplicare 238 .

non est aliud colligere quam unum et idem circa eadem m. 238.

multitudo 224. 236. 240. 258. 260.266. 268 .

$\mathrm{m}$. discernit 268 ; divisio et divisionum demonstracio secundum vim multitudinis 268; $\mathrm{m}$. non habet finem que tamen actu terminata est 260 ; omne cadit sub magnitudine et multitudine 268 ; m. a mente 258 ; ex vi multitudinis quantitates qualitates et cetera predicamenta 268 ; fiunt silogismorum demonstraciones secundum vim magnitudinis et multitudinis $268 \mathrm{cf}$. quod ex duabus tercia concluditur multitudinis est 268 ; si tollis unitatem deficit m. 260; ex multitudine unitatis numerum constitui 240; comprehensionem veritatis esse in multitudine et magnitudine 266.

mundus 204. 280. 284. 286. 288. 292. 96. anima mundi 280 cf. 284 . 286; condiciones variabilis mundi 292 ; sumus in hoc mundo docibiles in alio magistri 292 . musica 266.

in musica continetur virtus numerorum 266.

musicus 236 .

mens eterna quasi ut m. 236.

mutacio 282 .

nature abstracte quo ad deum non sunt abstracte ab omni mutacione 282 .

nares $254 \cdot 256$.

n. quasi fenestre et vie 256 .

natura 214. 216. 222. 228, 234. 242. 274 . 276. 282. 284. 286. 292. 294 .

animam mundi vocavit Plato id quod

Aristotiles naturam 284 cf. ego nec animam illam (mundi) nec naturam aliud esse conicio quam deum 284; nature abstracte $282 ; n$. corporalis 292 ; mentis n. extra corpus ab omni varietate materie absoluta 282 cf. 294 cf. mentem nostram nature divine coniunctam 242 ; naturam rebus immersam a qua est motus et quies (Peripatetici) 286.

necessitas 242.246 .248 .250 .252 .262 .264 . 284. 294 .

n. absoluta 242.248 .250 .252 .264 . 284 ; n. compleccionis 242.246 .248 .250 . 252. 262. 264. 284. $294 c f$. omnes complicaciones sunt in necessitate compleccionis 262 cf. mens est locus seu regio necessitatis compleccionis $262 \mathrm{cf}$. supra determinatam compleccionis necessitatem omnia in absoluta necessitate $24^{8} \mathrm{cf} .242$. nervus 244 .

nexus $224 \cdot 270.272 .278 .284 \cdot 286.288 .292$. composicionem que descendit a nexu absoluto $272 \mathrm{cf}$. ante rerum temporalem existenciam omnia in nexu procedente de posse fieri absoluto et posse facere $a b$ soluto $270 \mathrm{cf}$. absolutum posse fieri et absolutum posse facere et absolutus $\mathrm{n}$. non sunt nisi unum infinite absolutum et una deitas 270 ; dicunt theologi nexum pro spiritu sancto 278 ; n. universitatis $292 ; n$. in se habens sapienciam et omnipotenciam spiritus est quasi voluntas seu desiderium 284 .

nichil 260 .

si punctum puncto addas n. nichilo iungas 260 .

nocio 220. 224. 226. 232. 240. 242. 244. 246 . $24^{8} \cdot 250.252 \cdot 264 \cdot 274 \cdot 284 \cdot 290.292$.

non est credendum anime fuisse nociones concreatas 224 (cf. Plato aiebat nociones sibi concreatas 224) cf. 226; nociones seu exemplaria 284 ; nociones incerte 246 cf. nociones quas in hoc mundo acquirimus non sunt confirmate $292 \mathrm{cf}$. nociones hic acquisite ad invariabile magisterium transferuntur 292; unum et idem vis mentis et n. $250 \mathrm{cf}$. (mens) se facit nocionem 264; (mens) in se nociones omnium esse conspiceret 248 ; (mens) in fine omnium nocionum quiescit 248 ; mentes celestes nociones habere indelibiles 290 (nociones spirituum beatorum 292); neque $\mathrm{n}$. fieret numero non existente 240; particulares nociones desinunt esse variabiles in magisterio universali que erant particulariter fluide et instabiles 292; nociones scolarium et discipulorum 292; nociones sensibilium 246 ; similitudo seu n. rei 252 ; nocionum universitas 220; nociones seu intellectuales visiones $\mathbf{2 2 4}$. 
nomen 210. 214. 218, 220. 234. 274. 290. deum omnium rerum nominibus ac omnes res dei nomine nominari 218 ct. 220 ; ineffabile $\mathrm{n}$. in omnibus nominibus relucet $218 ; n$. ens $290 ; n$. ab adventu forme $2 I_{4} \mathrm{cf}$. $\mathrm{n}$. forme unitum $2 \mathrm{I}_{4}$; imposicio nominis fit ad beneplacitum $2 \mathrm{I}_{4}$ cf. congruum nomen imponi licet illud non sit precisum 2IO; n. naturale 214; omne n. ymago precisi nominis 218; racio mensuracionis sit causa nominis 220 . nominabilitas 218 .

nominare 218 .

complica nominari et $\mathrm{n}$. in coincidenciam 218.

noticia 220. 222. 268.

dei n. seu facies 222; n. nominis 220 ; predicamenta que rerum noticiam faciunt 268 .

numerare 238, 294. 296.

sola mens numerat 238; in (mentis) numerare coincidat explicacio cum complicacione $294 \mathrm{cf} .296$.

numerus 222. 234. 236. 240. 242. 258. 260 . 262. 264. 266. 282. 294

neque assimilacio fieret numero non existente 240 ; in arithmetica et musica continetur virtus numerorum $266 ; \mathrm{n}$. ad colligendam rerum communionem $266 \mathrm{ct}$. numerum dicimus colleccionem singularium 238; composicionem numeri ex unitate et alteritate ex eodem et diverso ex pari et impari ex dividuo et individuo 240 cf. n. compositus est ex eodem quantum ad commune et diverso quantum ad singularia 242 cf. 236 ; n. est ex numero compositus 236 ; n. ad confusionem communium discernendam valet 266 cf. per numeri disciplinam rerum discrecio fit $266 c f$. 240; essencia numeri 240 ; primum rerum exemplar in animo conditoris numerum esse $238 \mathrm{ct}$. $240 \mathrm{ct}$. exemplar concepcionum numerum esse 240 ; ex numero potest immortalitatis ostensio venari 294 cf. omnis $\mathrm{n}$. in se incorruptibilis $294 ; \mathrm{n}$. sublatus videtur quando tollitur variebilitas materie 282 ; mentem esse vivum quendam divinum numerum 242 (cf. animam numerum se moventem 242) cf. 294; ex mente n. 238 cf. 258. 294. sublata mente $n$. discretus non est 238 ; neque aliquis $n$. potest mentis numerandi virtutem evacuare 294; (Pythagorici) simbolice locuti sunt de numero qui ex divina mente procedit cuius mathematicus est ymago 234; rerum pluralitas que est divine mentis n. 282 cf. 238 ; omnem creaturam numerum divine mentis auffugere non posse 282 ; inter mentem divinam et res non mediare numerum 240 ; n. nostre mentis ymago numeri divini 240 ; (n.) mathematicus ex nostra mente procedit 234 cf. versamur in numero quasi in nostro proprio opere $234 ; n$. nostre mentis exemplar nocionum 240; neque mensuracio fieret numero non existente 240; ex numero mira attingere 240; n. modus intelligendi 240 cf. 294 ; rerum multitudo sub determinato quodam numero nobis incognito 260 ; n. numerans 294; ex numero omnia esse 234; pluralitas rerum est $\mathrm{n}$. divine mentis $238 \mathrm{cf.} \mathbf{2 8 2}$; cum sciencia pluralitatis stat quo ad nos impossibilitas discrecionis numeri 282 ; rerum principia numeros $234 ; n$. est subiectum proporcionis 236 cf. $238 ; \mathbf{n}$. rerum res sunt 240 ; $n$. precipuum vestigium ducens in sapienciam 238; quod alia res est substancia et alia quantitas sine numero non intelligitur 240 cf. n. substanciarum separatarum non plus est nobis n. quam non n. 282 ; reperitur in numero nichil nisi unitas 262 $c f .236 .240 \mathrm{cf}$. n. est explicativus unitatis 222 cf. ex pluribus unitatibus dicitur n. constare propter alteritatem 260 cf. 236 . 240 ; vivus n. 242 cf. 294.

nunc 224. 262.

nichil reperitur in tempore nisi n. 262 cf. 224 .

obiectum 224. 228. 244. 292 ,

specierum ab obiectis ad spiritum multiplicatarum 244 cf. 228.

oblivio 284.292.

nociones seu exemplaria que nulla oblivione obmittuntur 284 cf. nociones spirituum beatorum indelibiles oblivione ob presenciam veriatis 292 .

obstaculum 224. 228. 244. 254. 256.

o. generatur ex multiplicacione specierum objecti 228; nichil sentitur nisi per o. 256; (vis visiva) non potest excitari nisi per obstaculum specierum 224 cf. 244 . oculus 208. 224. 228. 254. 256. 270.280.

oculi alciores sunt auribus 256; oculi quasi fenestre et vie 256 ; o. mentis 270 . odoratus 244.254 . 
officium 208. 228.280 .

mens habeat officium ob quod anima

dicitur 280 cf. 208.228.

olla 212 .

omnipotencia 284.286.

in perfectissima voluntate inest o. 286

ct. velle cum exequi in omnipotencia coincidit 284 .

opinio 214 .

racio in coniectura et opinione occumbit 214 .

opportunitas 228 .

opus 2 10. $220.234 \cdot 242$.

que est proporcio operum dei ad deum

illa operum mentis nostre ad mentem

ipsam 242.

orbis 234.254 .

locus orbis seu regio 234 .

ordo 208.216 .256 .266 .270 .290$.

o. quatuor elementorum 256 ; o. nature

216 cf. 290.

organum 224 . 244. 246.248 .294$.

anima per organa inquirit 294 .

ostensio 294.

palatum 254. 256 .

pallor 204.

paradigma 212 .

symbolica paradigmata $2 \mathrm{I} 2$.

pars 248.260 .266 .278 .280 .

partem actu indivisibilem athomum appello 260 ; p. ad partem comparata suam integritatem debet observare 266 ; p. substancialis 278 ; quelibet p. de toto verificatur 280 cf. 266 ; p. eiusdem entitatis est cuius totum 280 .

participacio 248 .

parvitas 260.

passio 252.272.

p. anime 252 ; inicium motus (mentis) p. 252 cf. unum et idem p. mentis et intellectus 252; modo advenientis (passionis) facit (mens) accidencia 272; modo proprie passionis facit (mens) propria 272. pater 278.286.

dicunt theologi unitatem pro Patre 278 . pavimentum 246. 294 .

veritas figurarum geometricarum non

in pavimentis 294 cf. 246 .

peccatum 204.

peluis 276 .

pentagonus 220 .

perfeccio 212. 232. 252. 260. 262. 270.292. disposicio ad perfeccionem post per-

feccionem habitus 252; p. motus (mentis) intellectus 252; punctus est (linee) p. 262; p. summa 270 ; p. est totalitas 262 . perfectum 270 .

p. cui nichil deest 270 .

perficere 262 .

ubi terminatur ibidem perficitur 262.

persona 278 .

sunt tres singulares persone in una

divina substancia $27^{8}$.

phantasma v. fantasma

philosophus 204. 208

ydiotas clarius fide attingere quam phi-

losophos racione 204; literati philosophi

208.

pictor 212. 286 .

p. trahat exemplaria a rebus 212 .

Planete 288.

animas descendere de Galaxia per

Planetas ad corpora 288 .

pluralitas 222. 238. 240. 282 .

post ymagines sunt pluralitates rerum

divinam complicacionem explicantes 222 ;

p. rerum est numerus divine mentis 238

cf. 282; quo ad nos rerum p. a nostra mente 238 cf. 240 ; cum sciencia pluralitatis stat quo ad nos impossibilitas discrecionis numeri 282 ; unitatis explicacio p. 222 cf. 240 .

poligonia 220.

si trigonus est precisum vocabulum figure triangularis tunc scio precisa vocabula omnium poligoniarum 220 .

pollex 288 .

pondus 208.

pons 204.

posse esse 250 .

posse facere (p. fieri) 270.272 .

absolutum p. fieri et absolutum p. facere et absolutus nexus non sunt nisi unum infinite absolutum et una deitas 270 ; p. facere attribuitur equalitas 272 ; in similitudine p. facere seu forme 272 ; ante rerum universitatem temporalem omnia in p. facere 270 ; ordine prius est p. fieri quam p. facere 270 ; in similitudine p. fieri seu materie 272 ; omnia in p. fieri mentaliter vides $270 ;$ p. fieri attribuitur unitas $270 \mathrm{cf} .272$; in omnibus que principiata sunt $\mathrm{p}$. fieri p. facere et composicionem utriusque 272 .

possibilitas 242. 246. 250. 264. 274.276 .

p. absoluta 242 ; p. determinata 242 . 264 ; p. essendi $246.274 \cdot 276 \mathrm{cf}$. p. essendi seu materia 246 ; mens possibilitatem in - 
determinatam (materiam) attingit per adulterinam racionem 250 .

potencia 224. 228, 284. 286. 288.

precisio 2I2. 2I4. 218. 220. 228. 236. 248. 264. 288 .

deus est cuiuscunque rei p. $218 \mathrm{cf}$. p. citra deum non est 2 I 8 cf. 220 ; infinita et absoluta p. 248 ; p. quidditatis per nos inattingibilis aliter quam in enigmate vel figura 236; ubi sunt omnia unum ibi est veritas precisionis $264 c f$. veritas et $\mathrm{p}$. que est immultiplicabilis et incommunicabilis nequaquam potest perfecte sensibilis fieri $2 \mathrm{I}_{4}$ cf. 228,288 .

predicamentum 268 .

ex vi multitudinis predicamenta que rerum noticiam faciunt 268 .

presencia 224. 292.

tempus (explicacio) presencie $224 \mathrm{cf}$. nunc seu p. 224; p. veritatis 292 .

principiatum 234. 236. 272.

omnia principiata in se similitudinem principii habere atque ideo in omnibus trinitatem 272 cf. in omnibus que principiata sunt posse fieri posse facere et composicionem utriusque 272 ; primum p. non potest esse infinite simplex 234; primum $\mathrm{p}$. vocamus symbolice numerum 236.

principium 212. 234. 272. 274. 288 .

solum absolutum p. est infinitum 212 cf. 234 ; p. creacionis 288 ; mens faciat decem genera generalissima prima principia 274 ; rerum principia numeros 234 . produccio 220. 234 .

progressus 292.

proporcio 214. 232. 234. 236. 238. 242. 266 280. 288.

in proporcione armonia 238 ; deus per motum celi proporcionem eduxit 234; p. est locus orbis seu regio forme 234 cf. 232. 236; formam (coclearitatis) simplicem et insensibilem in figurali proporcione quasi in ymagine eius resplendere 214 cf. 236; idemptitas proporcionis est immultiplicabilis 280 ; locus proporcionis materia 234; numerus est subiectum proporcionis $236 \mathrm{cf} .238$.

proprietas 250.

proprium 250.272.

p. et accidens 250; modo proprie passionis facit (mens) propria 272

protraccio 262.

p. linee 262 .

providencia 284 . pulchritudo 238.248.

p. exemplaris 248 ; p. ymaginis 248 ; p. omnibus rebus inest 238 .

punctare 262.

p. est rem ipsam terminare 262 .

punctus 224. 248. 258. 260. 262 .

unus et idem p. in omnibus athomis 260; p. est terminus linee et eius totalitas ac perfeccio que ipsam lineam in se complicat 262 cf. 258. 260; unus p. qui extensus linea est 260 ; p. iunctura linee ad lineam 258; si tollis punctum deficit magnitudo 260 cf. 224. 248; ex punctis non potest quantitas constitui 260 cf. si punctum puncto addas nichil nichilo iungas (Boecius) 260; arbitror punctum terminalem indivisibilem 260 .

pupilla 254

quadrangularis 220 .

quadratum 236.

quadruvium 266.

sine quadruvio nulli recte philosophandum 266.

qualitas 268. 276 .

q. quantum in se est accidens dici nequit 276 ; ex vi multitudinis qualitates 268.

quantitas 232. 240. 258, 260. 264.

est athomus q. actu indivisibilis 260 ; quod alia res est substancia et alia q. sine numero non intelligitur 240 ; ex punctis non potest q. constitui 260: nullam constituet quantitatem terminorum coniunctio 260 .

quidditas 210. 226. 236. 240. 246.

(mens) concipit rerum quidditates utens se ipsa 246; q. rerum exorta est ut sit numerus divine mentis 240 ; precisio quidditatis per nos inattingibilis aliter quam in enigmate vel figura $236 \mathrm{cf}$. racio humana quidditatem operum dei non attingit 210 .

quies 222. 224. 262. 286. 292 .

motus est explicacio quietis $262 c f .222$. 224 cf. nichil reperitur in motu nisi q. 262; non sit aliud movere nisi ordinata q. sive quietes seriatim ordinate 262 .

quinquangularis 220 .

racio 2 I4. 216.218 .220 .226 .230 .244 .250 256. 278 . 288, 290. 292. 296.

animalibus racionem inesse $230 ; r$. bona 230; $r$. in coniectura et opinione occumbit 214; discrecionem concordanciam et dif- 
ferenciam r. facit 214 cf. 230.278 ; encia racionis 214.216 ; $r$. forme discretiva sensuum et ymaginacionum 230 ; infinitam formam nulla $\mathrm{r}$. attingere potest $2 \mathrm{I} 6$; elementum ascensus intellectus racionem 292 ; r. seu logica circa ymagines formarum versatur 216 ; mens est forma racionis discurrentis $230 \mathrm{cf}$. manet mens nostra omni racione immensurabilis 296 ; iudicium mentis sibi concreatum per quod de omnibus racionibus iudicat $296 \mathrm{cf}$. raciones ex mente sunt 296; mens possibilitatem indeterminatam attingit per adulterinam racionem 250 ; motu racionis comprehendit (mens) res non in se 290 cf. motus racionis est circa res que sub sensu cadunt $21_{4}$; r. mensuracionis 220 ; nichil sit in racione quod prius non fuit in sensu $2 I_{4} ; r$. silogisat et nescit quid silogisat sine mente 230 ; r. sophistica 230 ; (vocabula) motu racionis sunt imposita 290 cf. 214.218.

raciocinacio 230 .

mens informat et dilucidat et perficit raciocinacionem 230 .

radius 256 .

oculorum r. 256 .

rectum 232.

regio 234.262 .294 .

locus orbis seu r. 234 cf. 262.

religio 296.

connata $r$. que semper in mundo in modorum diversitate apparuit 296.

relucencia 296.

impossibile est quod infinita veritas communicatam relucenciam subtrahat 296. representacio 236 .

res passim

r. ymago est ineffabilis exempli 218 ; omnes res post simplicem mentem de mente participant 222 ; inter mentem divinam et res non mediare numerum 240 cf. numerus rerum res sunt 240 ; delectacio et pulchritudo que omnibus rebus inest 238.

resplendencia 232. 236. 238. 242. 288.

ruptura 288 .

r. proporcionis 288 .

sagacitas 284

sanguis 254 .

spiritus vehiculum s. 254 .

sapiencia 232. 238. 258. 284. 286. 292. gustum sapiencie habentes 292 ; mens est viva descripcio eterne et infinite Studien der Bibliothek Warburg ro: Cassirer sapiencie 232 ; numerus precipuum vestigium ducens in sapienciam 238; in perfectissima voluntate inest s. 286 cf. 284 . sapiens 204.

scabellum 208.

sciencia 218. 230. 246. 266. 282. 284. 296.

s. anime mundi 284 ; scienciam cuiuslibet precedit s. dei et omnium 266; non habemus cerciorem scienciam nos esse homines quam mentes habere immortales 296; mens exerit sciencias certas mathematicales 246; si de una re precisa $\mathrm{s}$. haberetur omnium rerum $s$. haberetur $2 \mathrm{I} 8$; ad scienciam unius precedats. tocius et parcium 266.

scriptura 206.

scutella 212 .

secta 216.

s. philosophorum 216.

seculum 286

sensacio 254 .

sensus $214 \cdot 216.226 .230 .244 \cdot 254 \cdot 256.278$.

s. absque discrecione sensibilium 244 cf. omnia sunt in sensu quasi in globo et indiscrete 278 ; sensuum disposicio facta ad similitudinem ordinis sive disposicionis quatuor elementorum 256 ; (s.) re presente formam comprehendit in materia 256 ; s. per se 226 ; motus racionis est circa res que sub sensu cadunt $2 \mathrm{I}_{4} \mathrm{cf}$. racio forma discretiva sensuum 230 ; spiritus instrumentum sensuum 256; $\mathrm{s}$. nichil terminat 256 .

sermo 264 .

setraccio 292.

silogismus 268 .

fiunt silogismorum demonstraciones secundum vim magnitudinis et multitudinis 268 .

similitudo 222. 232. 244. 250. 252. 264. 272 . 274.

similitudine fit cognicio 222; unum et idem est vis mentis et $\mathrm{s} .250 \mathrm{cf}$. mens est viva et incontracta infinite equalitatis s. 264 ; in nostra mente rerum similitudines 222 cf. s. seu nocio rei 252 cf. 250.

simplicitas 208. 220. 222. 224. 236. 242. 248 . 254. 262. 290.

s. complicans 220; composicio (explicacio) simplicitatis 224 ; s. divina omnium rerum est complicativa 220 ; mens prima ymago complicacionis simplicitatis infinite 262 cf. 290 ; (mens) in simplicitate sua omnia intuetur 248 cf. 254 . 
singularitas 278.280 .

s. persone 278 .

$$
\text { sol 288. } 296 .
$$

soliditas 258 . 260 .

sola s. extra mentem actu 258 ; s. (evo-

lucio) superficiei 260.

sollicitator 208 .

sonus $244 \cdot 288$.

cessavit motu cessante s. 288 .

species 2I4. 224. 228, 244. 250, 252. 272.

s. colorum 44 ; species sint intellectus

252 ; unum et idem est vis mentis et species 250 ; mens se assimilat rebus per speciem 244 cf. modo compositi species (mens) facit vel individua 272; excitari per obstaculum specierum multiplicatarum 224 cf. 228. 244; s. sonorum 244; species ut sub vocabulo cadunt sunt encia racionis $2 \mathrm{I}_{4}$.

speculacio 206. 248 .

(mens) facit theologicas speculaciones 248 .

sphera 294.

s. semper rotunda 294 .

spiritus 226. 244. 246. 254. 256. 278.284 . 286. 292.

s. subtilis arteriarum mente animatus 244 cf. s. per arteriam diffusus instrumentum anime 254; spiritus vehiculum sanguis 254 ; nociones spirituum beatorum 292; mens immersa spiritui corporali 246 ; deum quem dicimus spiritum universorum 284 ; $\mathrm{s}$. igneus 256 ; spiritum in mente nostra loquentem et iudicantem 226 ; motus sine spiritu non est 286 ; retardaturs. 254cf. 256; dicunt theologi nexum pro Spiritu sancto 278 ; s. instrumentum sensuum 256 cf. oculi nares etc. quasi fenestre sunt et vie per quas s. ad senciendum exitum habet 256 ; s. ad omnes sensibiles species configurabilis 244 ; nexus in se habens sapienciam et omnipotenciam spiritus est quasi voluntas seu desiderium 284 cf. 286.

statuarius $2 \mathrm{I} 2$.

status $244 \cdot 256.262 .276$.

movere sit de uno statu in alium cadere 262 ; idem $\mathrm{s}$. specialis et individualis 276 .

substancia 228. 240. 272. 274. 276. 278.282 . 290.

omnem intellectum fore de substancia et accidente 290; sunt tres singulares persone in una divina substancia 278 ; mens est viva s. 228 cf. 278.290 .; mentem ex individua et dividua substancia componi (Plato) 278; numerus substanciarum separatarum non plus est nobis numerus quam non numerus 282 ; (unitas uniens) est vera s. 276 cf. 272 .

successio 272.274 .

s. est descensus ab eternitate 272 ; (corpus) successioni subicitur 274; (mens nostra) intelligit in successione 274 cf. eterna mens sine successione simul omnia intelligit 272 .

sufficiencia 220 .

superficies 232.236 .258 .260 .

superficiem (terminum) corporis 258 ; (mens facit) superficiem considerando latitudinem sine soliditate 258 ; lineam terminum superficiei $25^{8} \mathrm{cf}$. $\mathrm{s}$. (evolucio) linee 260 ; soliditas (evolucio) superficiei 260 .

\section{tabula 224.}

Aristotiles (mentem) tabule rase assimilavit 224 .

tactus 214. 226. 244. 254.

talaris 204 .

templum 206.

t. eternitatis 206; templo menti dedicato 206.

tempus 204. 222. 224. 228. 262. 270. 294. 296.

t. (explicacio) eternitatis 222 cf. 296; t. mentis virtutem non evacuabit 294; t. mensura motus 294; nunc explicatur per t. 262 cf. nichil reperitur in tempore nisi nunc 262 cf. $t$. (explicacio) presencie 224.

tenebre 226 .

terminare 262 .

ubi terminatur ibidem perficitur 262; punctare est rem ipsam t. 262.

terminus 208. 212. 256. 258. 260. 262. 266. 288. 294 .

t. non est t. si divisibilis foret 260 ; omnis rei t. ex mente est 258 cf. 208. 294 cf. ex mente increata omnis t. descendit 258 ; punctus linee t. 260 cf. 258.262 ; nullam constituet quantitatem terminorum coniunctio 260 .

ternarius 236.238 .

quid aliud est tres unitates unite quam t. ex se ipso compositus 236 .

tetragonus 220 .

theologice 216 .

ultra vim vocabuli th. intueri 216. 
theoria 206.

tipus 236 .

toga 204

totalitas 262 .

perfeccio est t. 262 ; punctus est (linee)

t. 262 .

totum 266. 278.280 .

est mens nostra t. virtuale 278 ; t. men-

surat partem 266 cf. 280 .

triangularitas 220 .

triangulus 266 .

trigonus 208. 220.

si t. est precisum vocabulum figure triangularis tunc scio precisa vocabula omnium poligoniarum 220.

trinitas 240. 268. $272.274 \cdot 276.288$.

dicitur $t$. individua una in deo ab unitate uniente $276 \mathrm{cf}$. intelligere (dei) est necessario in trinitate 272 ; in illa rerum universitate que in mente est omnia sunt in trinitate et in unitate trinitatis 274 cf. $\mathrm{t}$. benedicta in nostra mente trinitatis divine ymago 240 cf. 268.272 ; in omnibus (principiatis) trinitatem reperiri 272

unitas 222. $224 \cdot 236.238 .240 .242 .260 .262$ 270. $272.274 \cdot 276.278 .28$ o. 288.294 .296$.

u. complicata 296; divisio ab unitate descendit 280 ; u. que est entitas 240 cf. 272; equalitas est unitatis ymago 222 cf. 272 ; mens est unitatis equalitas 238; u. exemplaris infinita 236 ; u. que est immutabilitas 280; mens est coincidencia unitatis et alteritatis 294; in unitate essencie (mentis) est potencia sapiencia et voluntas 288 ; mens est $u$. simplex 242 cf. u. uniens est mens increata $240 \mathrm{cf}$. $276.280 \mathrm{cf}$. mens nostra u. uniens 240; si tollis unitatem deficit omnis multitudo 260; u. nature que est quasi ymago unitatis unientis 276 ; numerus est explicativus unitatis 222 cf. 236. 240. 262; ex multitudine unitatis numerum constitui $240 \mathrm{cf}$. ex pluribus unitatibus dicitur numerus constare propter alteritatem 260; dicunt theologi unitatem pro Patre 278; unitatis explicacio pluralitas 222 cf. 240; posse fieri attribuitur u. 270 cf. 272 ; u. que est singularitas 280; quid aliud tres unitates unite quam ternarius 236 ; u. trinitatis 274 cf. 272. 276; non sit nisi una unitas 260 cf. 276 ; unitas uniens 240. 276.280 . universale 268 .

universitas 220. 228. 250. 266. 270. 274. 292. deus si ignoratur nichil de universitate scitur 266 cf. 270 ; mentes nostre quasi nexus universitatis $292 \mathrm{cf}$. in illa rerum universitate que in mente est omnia sunt in trinitate 274 ; modus universitatis 250; si u. ignoratur nichil de eius partibus sciri posse manifestum 266; considera rerum universitatem in tempore et vides eam ab eterno fieri potuisse 270 .

universum 284 .

deum quem dicimus spiritum universorum 284 .

usus 208. 230. 244 .

u. discrecionis 230 .

variabilitas $\mathrm{v}$, variebilitas

variebilitas 246.260 .262 .282 .292 .294$.

v. materie 260. $262 \mathrm{cf}$. forme rerum obumbrate variebilitate materie 246 ; numerus sublatus videtur quando tollitur v. materie 282 ; mentis naturam ab omni variabilitate absolutam esse 294 ct. per mentem formas a variabilitate abstrahi $292 / 294$.

varietas 238. 248. 282. 286 .

sublata varietate non capiamus multiplicacionem numeri 282 ; mentis natura extra corpus ab omni varietate materie absoluta 282 .

vehiculum 254 .

velle 284 .

v. cum exequi in omnipotencia coincidit 284 .

ventus 286 .

verbum 2 I8. 220. 284

v. seu conceptus 284 ; v. dei 220 ; unum v. ineffabile quod est precisum nomen omnium rerum $218 \mathrm{cf}$. 220.

veritas 2I2. 2I4. 2I6. 2I8. 220. 222. 230. 232. $246.248 .250 .256 .260,264 \cdot 266.272$. 290. 296 .

infinita v. cum sit absoluta bonitas 296 ; alteritas nequaquam convenire potest veritati in se 248 ; comprehensionem veritatis esse in multitudine et magnitudine (Boecius) 266; (deus) v. omnium scibilium $2 \mathrm{r} 8$; v. invariabilis figurarum geometricarum mente reperitur 294; in ymagine v. resplendet $232 \mathrm{cf}$. $230 \mathrm{cf}$. ymagine destructa manet in se v. 216 ; impossibile est quod infinita $v$. communicatam relucenciam subtrahat 296; veritatem rerum in mente esse in necessitate com- 
plectionis 246; (mens) in veritate vite sue quiescit 248 ; participacio veritatis 248 ; nociones indelibiles ob presenciam veritatis obiectaliter se indesinenter offerentis 292; ubi sunt omnia unum ibi est v. 264 ; v. rei 246 ; v. et precisio nequaquam potest perfecte sensibilis fieri $2 \mathrm{I}_{4}$. videre 244 .

facere et v. 244

virtus $218.222 .224 \cdot 240.250 .266 .278 .288$. 294.

unam esse infinitam virtutem quam deum dicimus 2I8; est mens nostra totum virtuale ex omnibus comprehendendi virtutibus compositum 278 ; v. numerorum 266.

vis 208, 210. $216.222 .224 .226 .228,232$. 244. 246. 248. 250. 252. 254. 256. 268. 278. 286. 288.

v. aerea 254 ; v. animativa 228 ; v. ab aptitudine 252 ; v. aquea 256 ; v. assimilativa 224. 244; v. comprehensiva et nocionalis 224 cf. 278 ; v. concipiendi 252 ; v. entificativa 244 ; v. etherea 254 ; ignea v. 254 ; v. ymaginandi 278 ; v. intellectibilis 228 ; v. intellectualis $228 c f$. 278 ; v. iudiciaria menti naturaliter concreata 226; v. mentis 224. 246. 250. 278 cf. mentem infinitam esse vim formativam absolutam sic mentem finitam vim conformativam seu configurativam 222; $v$. qua mens omnia in simplicitate intuetur intelligencia 254 ; v. raciocinandi 278 of 228 ; v. seminalis 228 ; v. senciendi 278 ; v. terrea 256 ; v. visiva anime excitetur ab obiecto 224 cf. una est v. sensitiva et visiva oculi in animali 208 ; v. vocabuli 210. 216 visio 226.228 .244

intellectuales visiones 44 ; v. in oculo 228.

visus 226. 228, 230. 244. 256. 280 .

velocior est v. quam auditus 256 visum non discernere 228 cf. 226 cf. advenit discrecio visui 230 ; v. nequaquam actu fuit ante oculum nisi natura 228 . vita 204. 228. 232. 248. 294.

mens $\mathrm{v}$. intellectualis seipsam movens 294 cf. 232 v. sensitiva 228 ; v. vegetativa 228 .

vitrificator 284 .

vitrum 284. 288 .

vocabulum 2 I0. 2 I4. 2 I6. 2 I8, 220. 252. 276 . 290.

(disciplina) fit per vocabula 290 ; v. eo ipso unitum quo forma materie advenit 210; vocabula motu racionis imposita 210. 214.216. 218. $290 \mathrm{cf}$. vocabula non ex imposicione sed ab eterno 2 Io; vocabula ad placitum instituta $2 \mathrm{IO}$; $\mathrm{v}$. naturale $2 \mathrm{I}_{4}$; proprietas vocabulorum recipiat magis et minus $2 \mathrm{IO}$; $\mathrm{v}$. precisum ignorari $2 \mathrm{IO}$ cf. si trigonus est precisum v. figure triangularis tunc scio precisa vocabula omnium poligoniarum 220.

vocalitas 218 .

voluntas 284.286 .288

v. dei alio executore opus non habet 284 cf. in perfectissima voluntate inest sapiencia et omnipotencia 286 cf. 288 ; impossibilium et penitus ignotorum non est v. seu desiderium $284 / 86$; in spiritu seu voluntate 286 .

vox 214.238 .282 .

\section{AUTOREN- UND NAMEN-REGISTER.}

Achademicus 2 I6.

Aristoteles 224. 226. 284. 288. 290.

Boecius 238. 260. 264 .

Capitolium 206.

Crassus, T. Attilius 206.

Delphi 204

Dionysius (Areopagita) 240.

Hermes Trismegistus 218 .
Peripateticus (Peripatetici) 204. 216. 228. 242. 280.286.

Philo 230.

Phisici 254. 258

Plato 206. 224. 226. 278. 284. 290.

Platonici 228. 238. 242. 280. 282. 286.

Pythagoras 228.

Pythagoricus (Pythagorici) 234. 238.

Roma 204. 206. 296.

Theologi 278 . 


\section{INDEX}

\section{$\mathrm{ZU}$}

\section{BOVILLUS, LIBER DE SAPIENTE.}

\section{BEGRIFFS-REGISTER.}

Abstrahere: cf. Species; Atomus; Forma Acedia: 304 sq. 307. 310; cf. figuram 306 Actio: -nis cause trine $340 \mathrm{sq}$.

Angelus: actus primus 332 ; prima emanatio 382 ; non materialis 313 ; -ice speculationis obiectum 390; -i Sapientia 374; intelligit sine specie 399 ; -i cognitio Dei 385 sq. 390-95; recipitur in Deo 399; Deus fit 386; ut sol 396 ; ut luna 396 ; ut transparens nubecula 382 ; cf. Immaterialia

Anima: -e natura 382 ; -e trine 360.364 ; peregrinatio humane -e 348 ; de consummatione -e 330. 347. 374; a) irrationalis -a 378 ; b) rationalis -a una est et indivisibilis substantia 359; sine sui divisione trina 359.350 ; in Intellectum, Memoriam ac Voluntatis sive in Contemplationis actum discreta 359; immaterialis -e cognitio trina 33I; supremus materie actus 332; Angelo vicina 332 ; r. -a et Angeli dii quidam 403; de immortalitate r. -e 329-32; analogia -e ad sillogismum $377 \mathrm{sq}$; $c f$ Immaterialia

Animal: neque sapiens neque insipiens 402; -i nulla Dei cognitio $375-78.38 \mathrm{I}-9 \mathrm{I}$; -ia cernunt Hominem ut suum finem 397; cf. Sensus

Animus: triophtalmus $37 \mathrm{I}$; intelligibilis quidam mundus 345 sq.; -i cognitiones 330 ; -i bona 337 ; intelligibilium notionum thalamus 345; Sapientis -us quadrigeminus $37 \mathrm{x}$; inconsummatus -us ut premisse syllogismi 37 I

Archetypus 344

Ars: Natura et -s quedam extrema; similiter et -tis et nature Homo 349; -tis Homo humanave species -te progenita dyas est et primi Hominis emanatio et finis 348 ; cf. Sapiens sui calothecnius et optimus artifex 369.372 ; cf. HomoHomo

Atomus: Anima a cunctis rebus, quas in mundo reperit, abstracta speciei -o rediit in corpus finxitque ex collectis specierum -is virtutis Hominem 348. cf. $35 \mathrm{I}$; Deus rerum omnium sensibiles actus in firmamento locavit, quorum -i perpendiculari radio in terram feruntur 354 ; cf. Species; Substantia

Bonum: -a duplicia 337 sq.; vera $-a$ in Anima 324. 329

Celum: pater elementorum 3 I 4

Cognitio: omnis -o aut Mens aut Intellectus aut Ratio aut Sensus 378 sq. 38r. 39r. 398; omnis -0 in Deum intenta 380.397 ; excrescit ad decadis numerum 378 ; omnis -o trinitas: a) Intellectus - Memoria - Contemplatio 322-25. 329 sq. 349 sq. 352. 371 ; b) Intellectus - Memoria utriusque species 365.37 I. 357 ; $^{\text {c) }}$ potentia - obiectum - amborum actus 398; Hominis -ones tres: Ratio - Imaginatio - Sensus 350 ; in omni humana -one trine trinitates 365.398 ; omnis -o gemina: ${ }^{\alpha}$ ) immaterialis $-\beta$ ) materialis $355 ;{ }^{\alpha}$ ) immaterialis -o a plerisque unica, a nobis trina diffinitur $330 \mathrm{sq}$.; ad senarii numerum completur $375 \mathrm{sq}$.; in identitate substantie perficitur 355 . cf. 357 ; est Sapientia 360 ; $\beta$ ) -o materia lis senario dispescitur 326 ; gemina 330 ; in abiunctis substantiis fit 356 ; instaurabitur 332 ; -o omnis in distantia dya- 
metri fit 353 ; non est entis sese noscitantis divisio neque substantie multiplicatio $356 \mathrm{sq}$.; -nes planetis comparantur $326-28$

Coniectura: -e e rebus naturalibus desumpte 358. $367 s q .409$

Contemplatio: est ipsa inspectio et presentatio, per quam Intellectus et $\mathrm{Me}$ moria in actu sunt 349 ; - o trinitas et perfectio Intellectus et Memorie 349; omnis immaterialis cognito est $-033 I$; -o trina 33I; analogia speculi 323 ; -o Sapientis iugis suiipsius intuitus 323 : laudatissima Anime actio, eviterna 330 que propria angelice et humane -onis obiecta $394-96$; cf. Cognitio a)

Corpus humanum: totius materie finis, gloria, perfectio $344 \mathrm{sq}$.; sensibilis quidam mundus 345 sq.; immortale $33 \mathrm{I}-$ 33; divine lucis reflexio et meta 387. 399; sensibilium solum supra celum fieri natum 344; -oris bona 337

Deus: verum omnis cognitive facultatis obiectum 375 . 380 ; de contemplatione $-\mathrm{i} 38 \mathrm{r}-86$; trinus intra se 403. 357; trinus extra se 390.403 ; videtur ut sol luna - terra $390 \mathrm{sq}$.; simplex - umbratilis $394 s q$. ; sol 396. 374 sq.; Substantiam et Sapientiam Homini dedit 4II; sola bonitate nos pascit $4 \mathrm{Ir}$; cf. Immaterialia.

Dyas: divisionis author, infamis 403; materie numerus 403

Essentia: $c f$. Substantia

Fides: intelligentie dispositio sacrumque initium $35^{8}$

Forma: supercelestia entia ut omnium exemplaria et abstractissime -e 344; res perfecta a -a ordinatum lucidumque Esse capit 317

Fortuna: ceca $32 \mathrm{I}$; -e instabilis orbis $32 \mathrm{I}$, rota 329 ; fritille et alee 339 ; ferreum -e iugum 334; exposita -e bona 337; Sapiens -am calcat $32 \mathrm{I}$; cf. figuram in initio operis

Gradus: rerum 303. 305. 313-I6. 407; hominum in assecutione virtutis moralis 303. 305. 307. $309 \mathrm{sq}$.; hominum in assecutione virtutis intellectualis 312 . 36I. 39I; hominum ex parte corporis 309 sq.; elementorum 307. 3I4. 39I; Anime 363 sq.; colorum 384. 39I; lucis
380 sq.; obiectorum 396; potentiarum 396 ; inter se comparantur

Gula: 304 sq. 307. 310; cf. figuram 306

Homo: omnium potentia $35 \mathrm{x}$. 355 ; omnia fit 350 ; simul omnia est $35 \mathrm{I}$; omnium oculus 355 ; speculum Universi 342.353 sq.; ut quiddam mundi medium 355 ; -inis locus in oppositione et negatione universorum 354; utriusque mundi vinculum 344. 373 ; est mundus uterque $344 s q . ;$ secundus intellectualis mundus 344; Anima mundi 343. 347 sq.; ter trinus 350 ; ultima Dei imago 393. 396; intelligit cum specie et imagine 399; quo modo videat Deum 382. $390 s q .394 s q$; substantia pusillus, scientia omnia 343 ; -inis perfectio ex parte corporis $308 \mathrm{sq}$., ex parte animi $303 s q .309$ sq., secundum naturam $3 \mathrm{II}$; -inis consummatio $35^{\mathrm{I}}$. 305 ; sibi restituitur 303 ; Deus fit $387 \mathrm{sq}$.; comparatur elementis 307 , rerum gradibus 303.309 .363 , mundo 343 , lune et terre 396 ; maior et minor -o $35 \mathrm{I}$; mundus maior -o $35 \mathrm{I}$; primus -o: -o naturalis sive tellureus sive substantialis; secundus - 0 : -o Artis sive Virtutis sive studiosus sive rationalis $c f$. 348. 35 I cf. Homo-Homo; Homo-HomoHomo; Mundus minor; Gradus; passim Homo-Homo: Sapiens geminus Homo est, id est -0 , natura Homo et virtute Homo 369; -o: et Substantie participatione et Virtutis proventu Homo 316 ; qui a natura Homo tantum erat, Artis proventu reduplicatus Homo vocatur et -o $34^{8}$. cf. 302; Eva -o 352 sq.

Homo-Homo-Homo: Sapiens -o: natura Homo, etate Homo, virtute Homo 370; $-o$, scilicet Homo intellectu, Homo memoria et acquisita amborum specie Homo 37I; Abel -o 352; cf. 353. 3ro sq.

Humanitas: Sapientia est quedam -as $34^{8} \mathrm{sq}$., Sap. est immobilis quedam in -ate mansio 302 ; virtutis Homo secunda quedam est -as 374 ; Sapientie vis adusque tryadem -atem propagat $34^{8}$

Imaginatio: interna sensatio 327. 330, corporeo tamen in organo exercetur 327 ; ab Anima in corpore perficitur presentatione spectrorum 330. 350; exteris sensibus preest 327 ; Rationi famulari nata $327 ; c f .356$

Immaterialia entia: sunt trina: Deus, Ange- 
lus, Anima 331. 374 sq. 378 sq.; eorum differentie $402 \mathrm{sq}$.

Insipiens: -tis signa $3 \mathrm{I} 7 \mathrm{sq.;}$ divisionis amator $32 \mathrm{I}$; incompositus homo 318 ; perpes Nature debitor 320; humano apice inferior 3 Io; prepostera avi natus 333; preposterus homo 340; ad agendum incommodus $34 \mathrm{I}$; morte in atomos evannatur 333. of. 4I2. 302; Sapienti comparatur 318-20; aut mineralibus aut plantis aut beluis similis 3 Io

Insipientia: sui inscitia 372 ; Hominis a propriis bonis prolapsio 302

Intellectus: I. obstant Mens, -us, Ratio: diffinitio -ūs: noticia proximi et attigui a proximo et immediato 375 ; plerique omnem immaterialem cognitionem nomine uno -um vocant 331. cf. 360. 377; angelicus -us vere et proprie -us 360 . 378. 400 ; duo sunt -ūs: primus, quo Deus cognitus ab Angelo; secundus, quo Angelus ab Anima 376; -us maior et minor 378; dyas 376 ; ea immaterialis Anime cognitio, qua angelice scientie fit particeps $33 \mathrm{I}$; cf. Cognitio

2. obst. -us angelicus, -us humanus: angel. -us simplex 394 ; purus et specie immixtus 395; eius obiectum simplex nudusque Deus 394. 399; Deum in lumine videt 380 ; immediata Dei species 400; ut sol et eius obiectum ut sol 394 sq.; humanus -us mixtus 394 sq.; eius obiectum velatus Deus 395; Deum videt cum specie $399 \mathrm{sq.;}$; mediata Dei species 400 sq.; ut Memoria 400; ut luna et eius obiectum ut luna $394 s q$.; in corpore fieri peroptat 407 ;

3. obst. -us agens sive impassibilis sive speculativus, -us passibilis sive possibilis; -us proprie dictus, Memoria, Contemplatio sive Voluntas:

-us agens animi oculus 322 sq. ; -us possib. animi speculum 323 ; -us ag. speculator sui, dum quam prius imaginem in $\mathrm{Me}-$ moriam effudit, postremo a Memoria relatam contemplari letatur 324 ; ag. -us excolit pass. ut propriam terram 330, ut agricola 334; -us pass. animi ager 334, mensa cunctis affluens spiritalibus deliciis 334 ; -us pass. ab ag. inseparabilis 329; nichil in interna Memoria, quod non fuerit in anteriore -u 325; analogia - ūs et oris 324 ; - us naturales valve, quibus spiritalis alimonia in animum est introducenda 324 ; -us primus est et per se, qui gignit fecundatque Memoriam 350 ; ut sol 37r; of. Cognitio a); Anima; 4. obst. Sensus: -us tam immaterialium est quam materialium 337. cf. 405; 5. obst. -us practicus, -us contemplativus sive speculativus: -us prior ut practicus circa mundum evectus negociatur, quam abiunctus a sensibus contemplativus esse queat 405. cf. 406; contempl. -us similis soli, pract. -us lune 406 sq.; cf. 322 Intelligentia: fidei consummatio $35^{8}$ Intelligibilia: quando in sensibilibus 345

\section{Laemargia $c f$. Gula}

Luna cf. Intellectus humanus, Homo Luxuries 304 sq. 307; cf. figuram 306

Materia: cunctis actibus subest $3 I_{3}$. 3I5. $3^{\mathrm{I}} 7$; illius actus sunt Essentia, Vita, Sensus, Ratio 315; prope non ens 332 ; totius divisionis et alteritatis principium 360 ; -e numerus dyas 403; propter Animam in sensibili orbe fulciendam a divina Mente pependit 332; immortalis 332 Memoria: speculum animi 323 ; ab solo Intellectu specie impregnatur 325; -e actus est presentatio 349 ; species speculativo Intellectui presentat 322 . cf. 324 ; immortale promptuarium omnium intellectualium specierum 329. 352 ; omnium scientiarum arcanum domicilium 329; ut luna 372 ; cf. Cognitio ${ }^{a}$ ); Intellectus ${ }^{3}$ )

Mens: -tem diffinimus eiusdem ab eodem noticiam 375 ; a) intellectum divinum peculiari nomine -em nuncupamus 360 ; Dei propria 378 ; ut punctum, monas, unitas 376.378 ; b) -es trine: prima, qua cognitus est a Deo Deus; secunda, qua ab Angelo Angelus; tertia, qua ab Anima Anima 376 sq.; -s humana et "angelica labi potuere 40I; -s humana una est, eius note tres $360 \mathrm{sq}$. ; in hac abditus est rerum omnis rationalis fulgor 344 ; c) ea est immaterialis Anime cognitio, qua illi exigua in tenebris micat divinitatis scintillula $33 \mathrm{I}$; cf. Cognitio

Miseria: quid sit, unde oriatur 336

Monas: omnium principium -as, omnium finis -as 403

Mundus: perpes creditur 333. 409; comparationes -i et Hominis 343; Homo est minor -us 326; -us maior Homo 35I; analogie maioris et minoris $-\mathrm{i} 326 \mathrm{sq}$. $345 \mathrm{sq}$.; Sapiens veraciter minor -us est, 
maioris -i filius celebratur $32 \mathrm{I}$; maior -us est Universum 32I; Hominis locus est in oppositione -i $354 \mathrm{sq}$.; quicquid est in -0 , fieri potest in Homine 354 ; $-\mathrm{i}$ trini 344 ; - $-\mathrm{i}$ quattuor 345 ; -us intellectualis duplex: unus in Substantia, alter in Ratione 344 ; -us propter Hominem factus 409

Natura: cunctorum mater 305. 3II; Hominem inchoavit, inconsummatum reliquit 404 ; Sapienti simplex Esse condonavit 317. 404; quattuor peperit filias 3II. 313-r6; duos Homines procreavit $35 \mathrm{I}$; filium, i. e. minorem mundum, ornavit 326 ; -e providentia 336 ; cf. Ratio

Ordo: ferme universi -ines ternario discreti 367 ; cf. Gradus

Passio: -nes animi gemine 303

Ratio: -nis diffinitiones: a) cognitio mediata, qua principium finem per medium exquirit 375 ; b) Anime ratiocinatio, qua per Angelum evadit in Deum 377; c) adulta et consummata Nature filia sive altera quedam Natura 3I6. cf. 3II. $3^{\text {I3 } 3}$ $s q . ;$ d) ea vis, qua mater Natura in seipsam redit 316; Naturam matrem exosculari nata 316 ; e) ea immaterialis Anime cognitio, qua sibi it obviam sibique presentatur 33r; intellectus humanus -o nuncupatur 360 . 378 ; -nis functione homines veri Homines 303; regina sensuum 338. 327. 407; mater familias humani domicilii 328 ; sol Sapientis 326 ; ignea 327.314 ; Hominem ad sidera tollet 328 ; tryas 376 ; Deum in umbra conspicit 380; adusque Deum fertur 398; preclarum -nis pollinarium 340; latio -nis motio 363 ; cf. Cognitio

Res: -rum gradus quattuor $303.407 \mathrm{sq.;}$ humana species cunctos -rum gradus in semet imvolvit 303 sq. 407 sq.; -rum gradus elementis comparantur $307 \mathrm{sq}$. $3{ }_{4}$; -rum capita in triplici differentia 308 ; -s perfecta et imperfecta $3{ }^{1} 7$; -s perfecta ex materia et forma necessario conflata $3^{I} 7$

Sapiens: solus veraciter Homo 316 sq.; geminis constat Hominibus 320,372 ; progenita primi Hominis Minerva 348 ; Homo-Homo 316. 369; Homo-Homo-Ho- mo 370 ; Prometheum imitatur 320 ; Universi filius $32 \mathrm{I}$; ut pantomimus 340 ; verissima mundi Anima 348; S. et Insipiens nullum habent Substantie discrimen; illius vero Mens sui gnaritate sui compos evadit 318 ; bifrons et quadrifrons ut Ianus 368-74. 405; suiipsius calothecnius et optimus artifex 369.372 ; claves gerit mundi et suiipsius 405 ; libere cuncta agit 340 ; constat ex ignorantia et scientia 372 ; utramque naturam exprimit, intellectualem et sensibilem 373 ; ipso celo sublimior efficitur 33I; immortalis 342 ; Deo similis fit 318 ; Dei substantialis imago 318 ; divine instar Mentis suis gradibus continet universa 342 ; Deus alter, D. terrenus, D. mortalis $3 \mathrm{I} 8$. 34I; felix Dei sympotes 333; semper sitiens 333 ; soli comparatur 326 ; cf. Homo-Homo; Homo-Homo-Homo; passim

Sapientia: verissima -a est suiipsius inspectio atque agnitio 355 . cf. $301 \mathrm{sq}$.; ipsius veri entis suaveolens agnitio perfecta est -a $4 \mathrm{II}$; eius scientia, quod est precipuum et propter se, ut Hominis, hec -a vocitatur 405 ; est quedam humanitas 348 sq.; consistit in eiusdem a seipso animadversione, i. e. in cognitione Anime ab Anima 356; est immaterialis cognitio, et subiecto et obiecto 374.360 ; in trinitate consistit 349 ; trina est -a: humana, angelica, divina $357 \cdot 360$, earum differentie 366. 374. 398. 40I. 4I2; divine claritatis emanatio 334 ; Deus -am mortalibus non invidit 4 ro $s q$.; malorum cunctorum expultrix 408 ; -e ignis 320 ; aureus -e torques 334 ; cf. figuram in initio operis; cf. Humanitas; passim

Sensatio: ab Anima in mundo exercetur 330 ; temporanea 330 ; cf. Sensus; Imaginatio

Sensibilia: quando in intelligibilibus 345 ; cf. Gradus rerum

Sensus: irrationalium animalium proprius 378. 315; duntaxat materialium est 337 ; tertia Nature filia 3 II. 313-r6; ut corpus 378 ; Deum in tenebris conspicit 380 ; materialis oculus 375 ; mundano similis oculo 405; -u in mundum veheris 408 ;

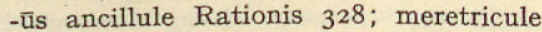
328; eruditioni ancilletur 407; - ūs discipline 327 ; liberales et illiberales 327 ; trine trinitates in -ibus $364 s q$.; quaternitate conflatur 378 ; alteratio -us mutatio 363 ; -us animalis finitur in Homine 397; cf. 
Cognitio; Animal; Gradus rerum; figuram 306

Sol: analogia Dei et -is 374; Deus universe nature s. 375 ; Deus ab Angelo videtur ut s. $390 \mathrm{sq}$.; angelicus Intellectus ut s. 394; Sapiens -em imitatur 326; sine specie 39I sq.; caret epiciclo 406; cf. Deus; Intellectus ${ }^{3}$ )

Species: Homo abstrahit a qualibet mundi substantia proprie -ei atomum; illam sibi inserit et ex plurium -erum atomis suam elicit -em, que naturalis Hominis fructus seu studiosus Homo nuncupatur 34 $\mathrm{I}$. cf. 348; humana Anima tribus pascitur -ebus: sensitiva a mundo, imaginativa a corpore, rationali a seipsa 364 ; 1 . mundus mittit vibratque sensibilem -em $364 ; 2$. corpus Imaginationis -em ut spectrum Anime presentat 364 ; 3. rationalis -es et in Anima subsistit et ab Anima Anime presentatur; in hac sola consistit Hominis consummatio 364 ; 4. intellectualis -es innaturalis est animo et inconsubstantialis Intellectui atque Memorie 368. cf. 37I; precipua -es, que in speculo pellucet animi, h. e. in Memoria, -es est oculi animi, i. e. agentis Intellectus 323 ; int. -es, qua mediante fit ipsa Contemplatio, ab Memoria presentatur, ab Intellectu conspicitur 368 ; int. -es tres in animo recipit status 324.349 sq.; Contemplatione iterum offertur Intellectui 324 ; -es divini Intellectus et divine Memorie 357 sq.; cf. Cognitio b); passim

Speculum: analogia $-i$ et Hominis 353 sq. 342, $-\mathrm{i}$ et Dei 392 , $-\mathrm{i}$ et Memorie 322 sq.

Studiosus: qui substantia et virtute consummati, -os vocamus 3 Io; -us Homo omnifariam sive triniter Homo $3 \mathrm{II}$; fructus naturalis Hominis $35 \mathrm{I}$. cf. 319. 374; lux et splendor nat. Hominis $4 \mathrm{II}$; $c f$. figuram 306

Substantia: prima Nature filia 3II. 3I3I6; initium est materialis plenitudinis, haud tamen consummatio $3^{I} 4$; lapidem gerit $3 I_{5}$; tellureo orbi similis $3 I_{4}$; Deus -am Homini dedit 4II; -am a natura humana Virtutis et Sapientie expertem mutuasti 407 . cf. 404; Sapiens et Insipiens nullum habent sue -e discrimen 3I8; Sapiens solus in sua -a provide feneratur 316 ; hec est consummatio Hominis, cum ex -li Homine rationalem sufficit elicere $35 \mathrm{I}$; mundus intellectualis duplex: unus in $-a$, alter in Ratione 344; que super celos sunt prime mundi -e ut omnium exemplaria veraciter intellectuales 344 ; sub celo omnis -a sensibilis 344 ; mundus -a maximus, Homo -a pusillus 343 ; in omni mundana -a aliquid delitescit humanum 35I. cf. 343; aliqua cuivis -e indita est Hominis atomus Homini propria $35^{\mathrm{I}}$; omnis -a divine trinitatis vestigium 359 ; ex -e divisione conjicienda -e identitas 368 ; immaterialis cognitio in identitate -e perficitur 35557; materialis cognitio in abiunctis -iis 356; omnia in Deo eiusdem -e 368 ; - a sine apparitione; apparitio sine -a 317 ; $c f$. Gradus rerum; figuram 306

Terra: mater 307 sq.; speculum firmamenti 354 ; umbra stellarum 354 ; omnium numerus est, sed potentia 354 ; fex ac retrimentum prestantiorum elementorum 307; Esse ut -a 308; Deus ab animali contemplabilis ut in $-\mathrm{a} 383$; $c f$. Acedia; Substantia; Homo

Trinitas: sine -ate nulla reperitur perfectio 349; omnis cognitio est -as 349 sq.; interior divina -as 402 sq.; exterior divina -as 403; agnitio divine -atis $35^{8}$; signa noscende -atis divine $35^{8-68}$; -as in Hominis consummatione 352 ; -as in Hominis creatione 352 ; cf. Cognitio; Homo; Ratio; Sapientia; Sensus; Voluntas; passim

Unitas: omnis -atis causa divina -as 402; omnis numerus haud aliter quam coniunctus -ati, numerorum fonti, et quam participatione -atis unus est 402; ita divine -atis fusione universa creaturarum series est una 402 ; cf. Mens; Monas Universum: cf. Mundus maior; Homo et mundus -um conflant 348 ; proportionabile toti Homini 347 ; se novit seque potest intueri 347 ; Homo, presertim Sapiens, -i speculum 353 sq. 342; Sapiens -i filius 321 . cf. 326

Vicium: in plus aut in minus esse dictitatur 327; de septem -iis 303. 305; -a spiritalia et corporea 304

Virtus: in mediocritate sita diffinitur 327 ; per solam -tem utrobique, tam corpore quam animo, Homines esse declarantur 3Io; Sapiens et Substantie participatione Homo et -tis proventu iterum Homo 3 I6. 
passim; Ars Sapienti -tem vice forme est elargita 3I7; Hominis consummatio 309 $s q . ;$-us oculata $32 \mathrm{I}$; a) -us moralis totius est Hominis propria 339 ; b) -us intellectualis est simplicis et absoluti animi 338 ; a) -us moralis impropria et extera est animo 3 I2; inter animum et corpus pacis federa sancit 3I2. 339; sine moris -te ab sui principii fastigio dejicitur Ratio 338 . b) -us intellectualis post moral. in Homine perficitur 312 ; sine moral. -te in animum introduci prohibetur 312; lux est et irradiatio animi 3I2; quattuor gradus in assecutione moral. et intell. -tis cf. Gradus; cf. Homo-Homo; Homo-Homo-Homo; figuram 306

Vita: secunda Nature filia 3 II; plantarum propria $307 \mathrm{sq}$. 315 ; te nutriat 407 . cf. 408 ; similis aque $3{ }^{1} 4$; in toto corpore ab Anima exercetur 364; -e motus aug- mentatio 363 ; cf. Gradus rerum; figuram 306

Voluntas: rationalis Anima in Intellectum, Memoriam ac -tem sive in Contemplationis actum discreta 359. cf. 366 ; Intellect., Memor., -s invicem relatitia, equata, similia, una eademque Anime substantia 359; tertia actionis causa 340 sq.; Sapiens libere agit ex -te, qua omne, quod rationabile, pulchrum, bonum est, libens agendum suscipit 340 ; -s Sapienti Virtutem vice forme est elargita $3 \mathrm{I} 7$; Insipientis -s ingenti addicta mycropsycosi $34 \mathrm{I}$; intra se Deus personis trinus, substantia tamen et -te unus 403; extimam trinitatem, cum substantia sit divisa, reliquo saltem ut -tis vinculo sibi fieri unam oportet 403; nil in universis non unum preter delapsam a Deo angelicam et humanam -tem 403

\section{AUTOREN-REGISTER.}

Biblia sacra:

Psalmista 301. 319. 332.

333. 375. 403

Proverb. 3I9. 333. 335 .

4 IO

Ecclesiastes 319. $34^{\circ}$

Sap. Salom. 318. 329.

333. 342. 408. 409

Ecclesiasticus 329. 333. 408. 409

Isaias $333.4^{10}$

Jeremias 3 I 9

Matth. 3I9. 320. 329. 408. 4 IO
Biblia sacra:

Marc. 3 I9

Luc. 409

Paul. ep. ad Rom. 409

Iacob. 409

Apoc. 391. 409

Esdra 333

Bigus, Lodovicus: Christiana Opuscula 321. 334 . 335. 4IO

Bovillus, Carolus:

Ars Oppositorum 323

de Generatione 3 I 3 . 3I4

Bovillus, Carolus:

de Intellectu 322. 344 . 349

de Sensu 312. 326. 327. 33o. $337 \cdot 364 \cdot 365 \cdot 3^{8} 4$

Dionysius Areopagita: de caelesti Hierarchia332. 35I. 375 . 4 II de divinis Nominibus 302 . 357. 402. $4 \mathrm{II}$ de ecclesiast. Hierarchia $35 \mathrm{I}$

\section{PERSONEN-REGISTER.}

Abel 352 sq. 359. 370

Adam 352 sq. 359.370

Apollo Pythius 301. 407

Bias Prieneus 329

Briconetus, Guilelm. 3оr. 303

Christianorum dux $35^{8}$
Christiani 3or. $35^{8}$

Eva 352 sq. 359. 370

Gnato 336

Greci 301

Hebrei $35^{8}$

Ianus 368. 393. 405

Minerva $34^{8}$
Phenices 355

Philoxenus 336

Phoebus 407

Pithagor-eus 336

Prometheus 320

Romani 368

Salomo 318. 333. 410 


\section{Von Ernst Cassirer erschienen:}

im Verlage von B. G. Teubner, Leipzig und Berlin:

DIE BEGRIFFSFORM IM MYTHISCHEN DENKEN. 1922. [V u. $62 \mathrm{~S}$.] (Studien der Bibliothek Warburg. Heft I.)

SPRACHE UND MYTHOS. Ein Beitrag zum Problem der Götternamen. I925. [87 S.] (Studien der Bibliothek Warburg. Heft 6.)

DER BEGRIFF DER SYMBOLISCHEN FORM IM AUFBAU DER GEISTESWISSENSCHAFTEN. (Enthalten in: Vorträge der Bibliothek Warburg. I. Bd. $192 \mathrm{I} / 22$.)

EIDOS UND EIDOLON. DAS PROBLEM DES SCHÖNEN UND DER KUNST IN PLATONS DIALOGEN. (Enthalten in: Vorträge der Bibliothek Warburg. II. Bd. 1922/23.)

im Verlage von Bruno Cassirer, Berlin:

DAS ERKENNTNISPROBLEM IN DER PHILOSOPHIE UND WISSENSCHAFT DER NEUEREN ZEIT. Drei Bände. Band I. 3. Aufl. 1922. [XVIII u. 6or S.] Band II. 3. Aufl. 1922. [XV u. 832 S.] Band III. 2. Aufl, 1920. [XIV u. 483 S.]

SUBSTANZBEGRIFF UND FUNKTIONSBEGRIFF. Untersuchungen über die Grundlagen der Erkenntniskritik. 2. Aufl. 1923. [XV u. 459 S.]

FREIHEIT UND FORM. Studien zur deutschen Geistesgeschichte. 3. Aufl. I922. $[575 \mathrm{~S}$.

IDEE UND GESTALT. Goethẹ. Schiller. Hölderlin. Kleist. Fünf Aufsätze. 2. Aufl. 1924. $[202$ S. $]$

KANTS LEBEN UND LEHRE. Sonderausgabe des II. Bandes von Immanuel Kants Werken. 2. Aufl. I921. [VIII u. 449 S.]

ZUR EINSTEINSCHEN RELATIVITÄTSTHEORIE. Erkenntnistheoretische Betrachtungen. I $92 \mathrm{I}$. [ $\left.\mathrm{I}_{34} \mathrm{~S}.\right]$

PHILOSOPHIE DER SYMBOLISCHEN FORMEN. Teil I: Die Sprache. 1923. [XII u. $293 \mathrm{~S}$.]

PHILOSOPHIE DER SYMBOLISCHEN FORMEN. Teil II: Das mythische Denken. 1925. [XVI u. 320 S.]

PHILOSOPHIE DER SYMBOLISCHEN FORMEN. Teil III: (Abschluß des Werkes.) Die Symbolfunktion im Aufbau der theoretischen Erkenntnis. Dieser Band ist in Vorbereitung und wird voraussichtlich Anfang des Jahres 1928 erscheinen.

IMMANUEL KANTS WERKE. Gesamtausgabe in I I Bänden. In Gemeinschaft mit Hermann Cohen, Artur Buchenau, Otto Buek, Albert Görland, B. Kellermann, Otto Schöndörffer. Herausgegeben von Ernst Cassirer. 


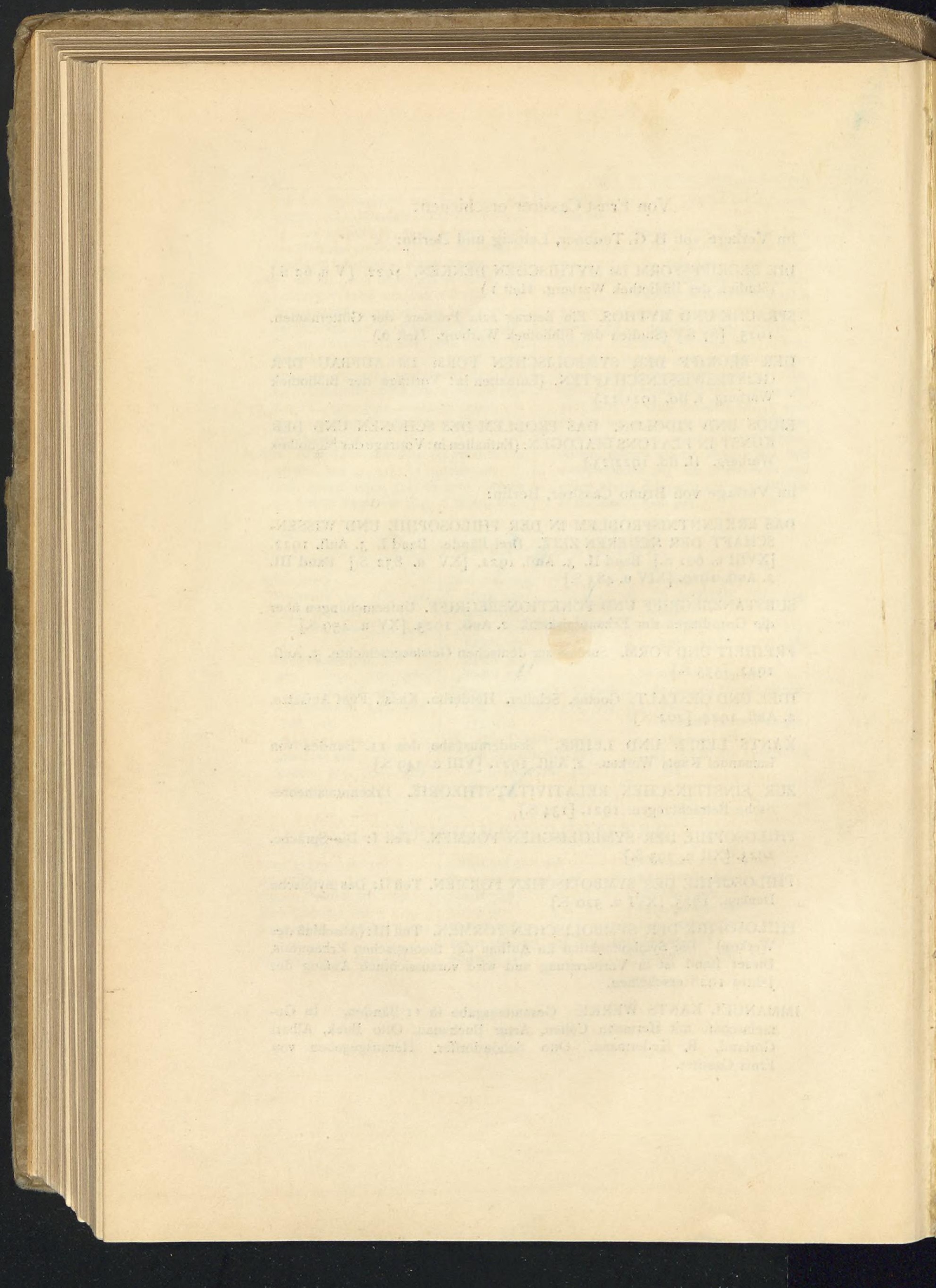




\section{VERÖFFENTLICHUNGEN DER B IBLIOTHEK WARBURG}

I. STUDIEN. Herausgegeben von F. SAXI

DIE BEGRIFFSFORM IM MYTHISCHEN DENKEN. Von E. Cassirex. (Heft I.) Steif geh. R.M 2.-

DÜRERS 'MELENCOLIA. I'. Eine quellen- und typengeschichtliche Untersuchung. Von E, Panofsky und F. Saxl. Mit 45 Tafeln. (Heft 2.) Steif geh. $\Re \mathscr{L}$ 12., , in Ganzleinen geb. $\Re \mathscr{K}$ 15.-

DIE GEBURT DES KINDES. Geschichte einer teligiösen Idee. Von E. Norden. (Heft 3.) Steif geh. R.S 6.40, in Ganzleinen geb. Rֶ/ 8.-

FULGENTIUS METAFORALIS. Ein Beitrag zur Geschichte der antiken Mythologie im Mittelalter. Von H. Liebeschittz. Mit 56 Abb. auf 32 Tafeln. (Heft 4.) Steif geh, R\&C 8.60

IDEA. Ein Beitrag zur Begriffsgeschichte der älteren Kunsttheorie. Von E.Pan ofsky.

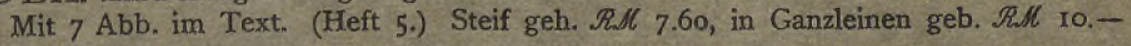

SPRACHE UND MYTHOS. Ein Beitrag zum Problem der Götternamen. Von E. Cassirer. (Heft 6.) Steif geh. MR 4.-

STUDIEN ZUM ANTIKEN SYNKRETISMUS. AUS IRAN UND GRIECHENLAND. Von R. Reitzenstein u. H. H. Schaeder. Mit 8 Fig. auf 4 Tafeln. (Heft 7.) Geh. IS 18.-, in Ganzleinen geb. RM 20.-

ANTIKE GÖTTER IN DER SPÄTRENAISSANCE. Ein Freskenzyklus und ein "Discorso" des Giacopo Zucchi. Von F. S axl. (Heft 8.) [Unter der Presse 1927.]

REMBRANDT UND DER HOLLÄNDISCHE BAROCK. Von R. Schmidt.Degener. Ubersetzt von A,Pauli. (Heft 9.) [Unter der Presse 1927.]

INDIVIDUUM UND KOSMOS IN DER PHILOSOPHIE DER RENAISSANCE. Von E. Cassirer. (Heft Io.)

PICATRIX (ARABISCHER TEXT UND UBBRSETZUNG). Von H. Ritter. (Heft 12.) [Unter der Presse 1927.]

PSEUDO-ANTIKE LITERATUR DES MITTELALTERS. Von P. Lehmann. Mit 6 Tafeln. (Heft 13.) Steif geh. RM 5.-

DIE ITALIENIS CHE ANTIKE IM ZEITALTER REMBRANDTS. Von A. Warburg. (Heft 14.) [Unter der Presse 1927.].

II. VORTRÄGE. Herausgegeben von F.SAXL

Bd. I: VORTRÄGE $1921-1922$. Steif geh. $\mathscr{R} \mu$ 8.-

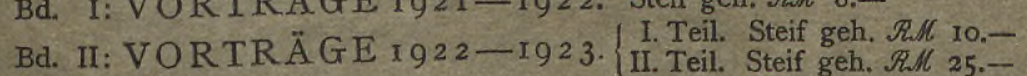

Bd.III: VORTR ÄGE 1923 -I924. Geh. RM 12.-

Bd. IV: VORTRÄGE $1924-1925$.

Bd. V: VORTRÄGE 1925 -1926. [Unter der Presse 1927.]

Bd. VI: VORTRÄGE I927-I928. [In Vorbereitung 1927.]

LEIPZI G • B. G. T E U B N E R B E R L I N 


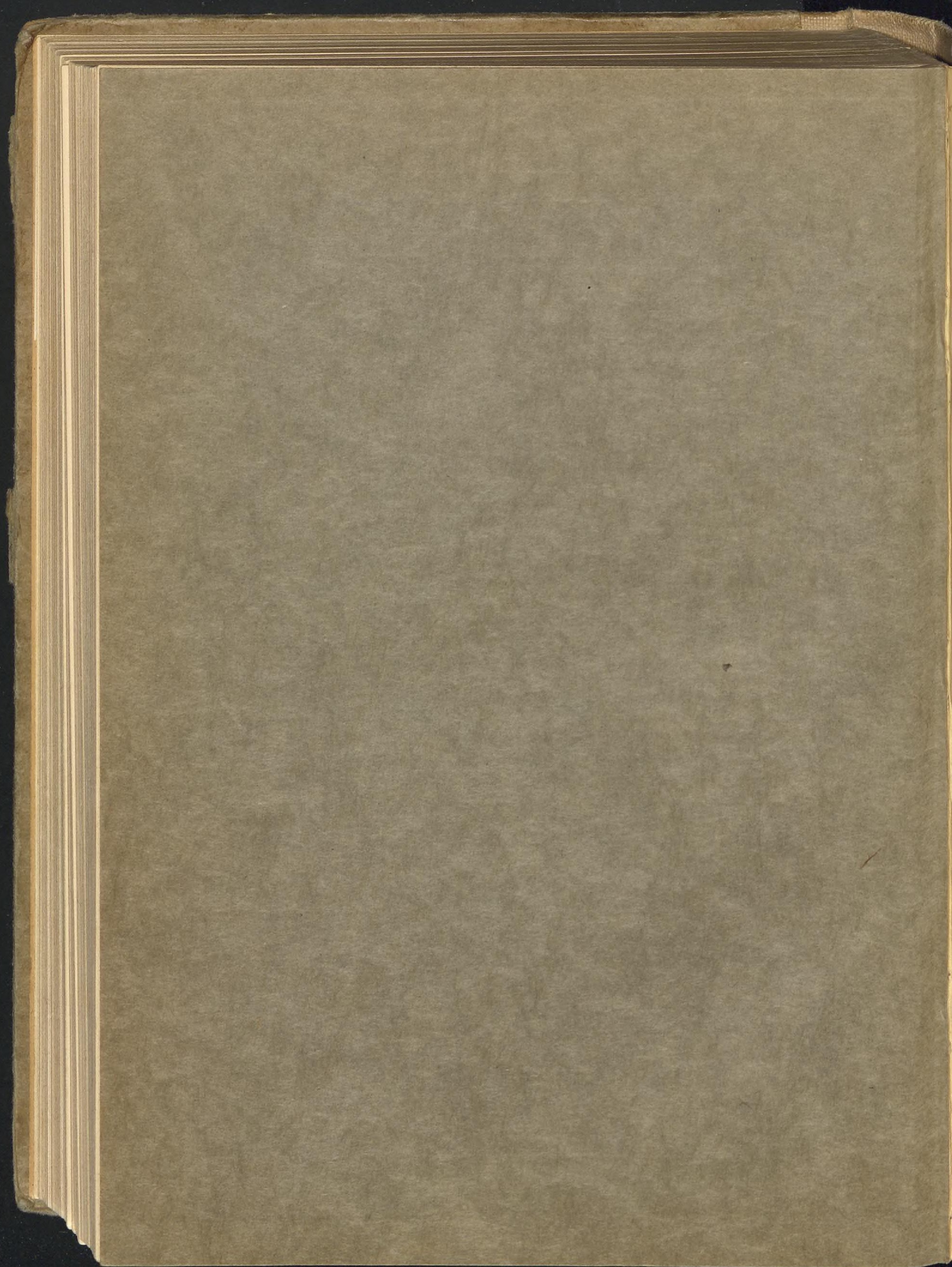




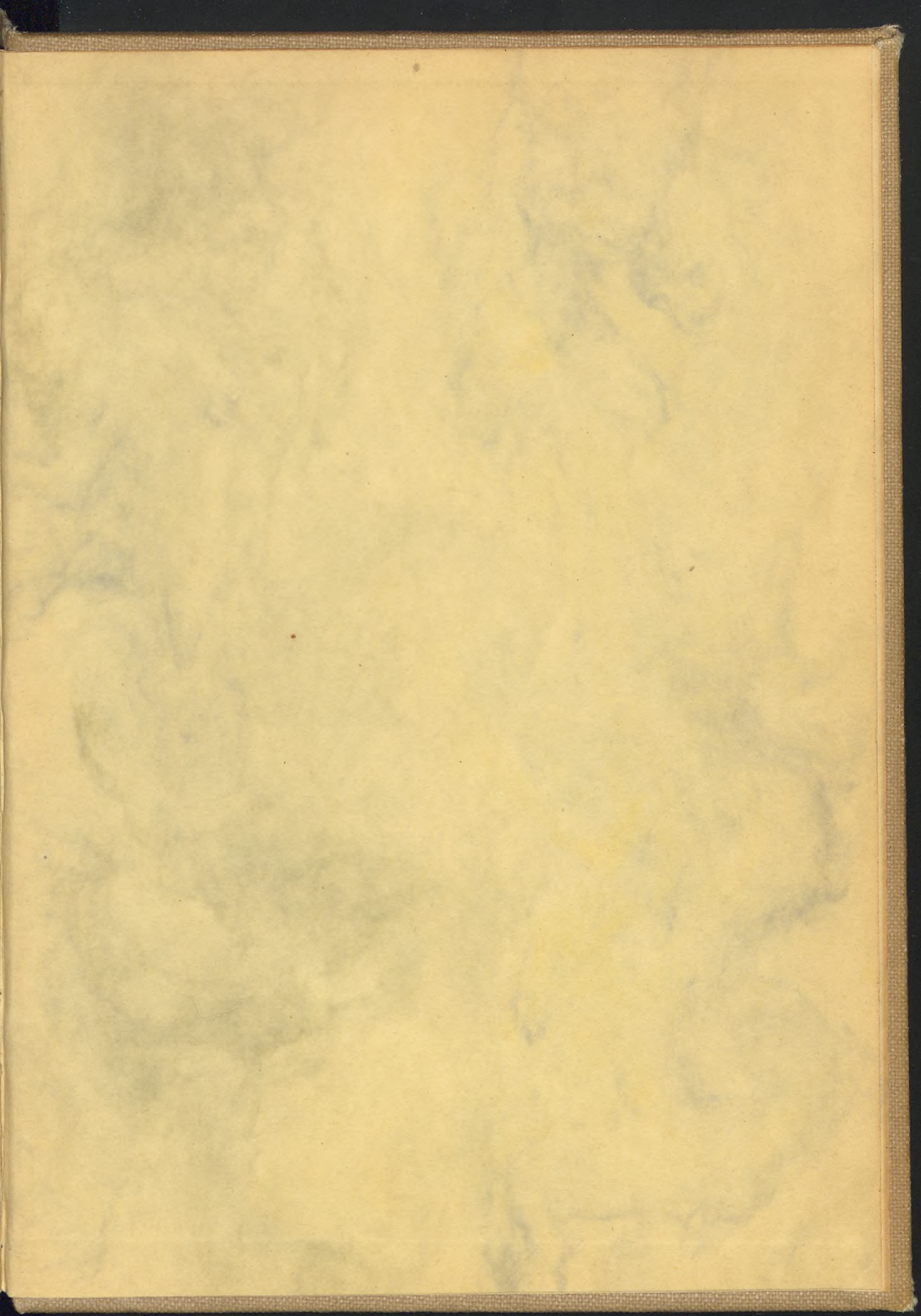




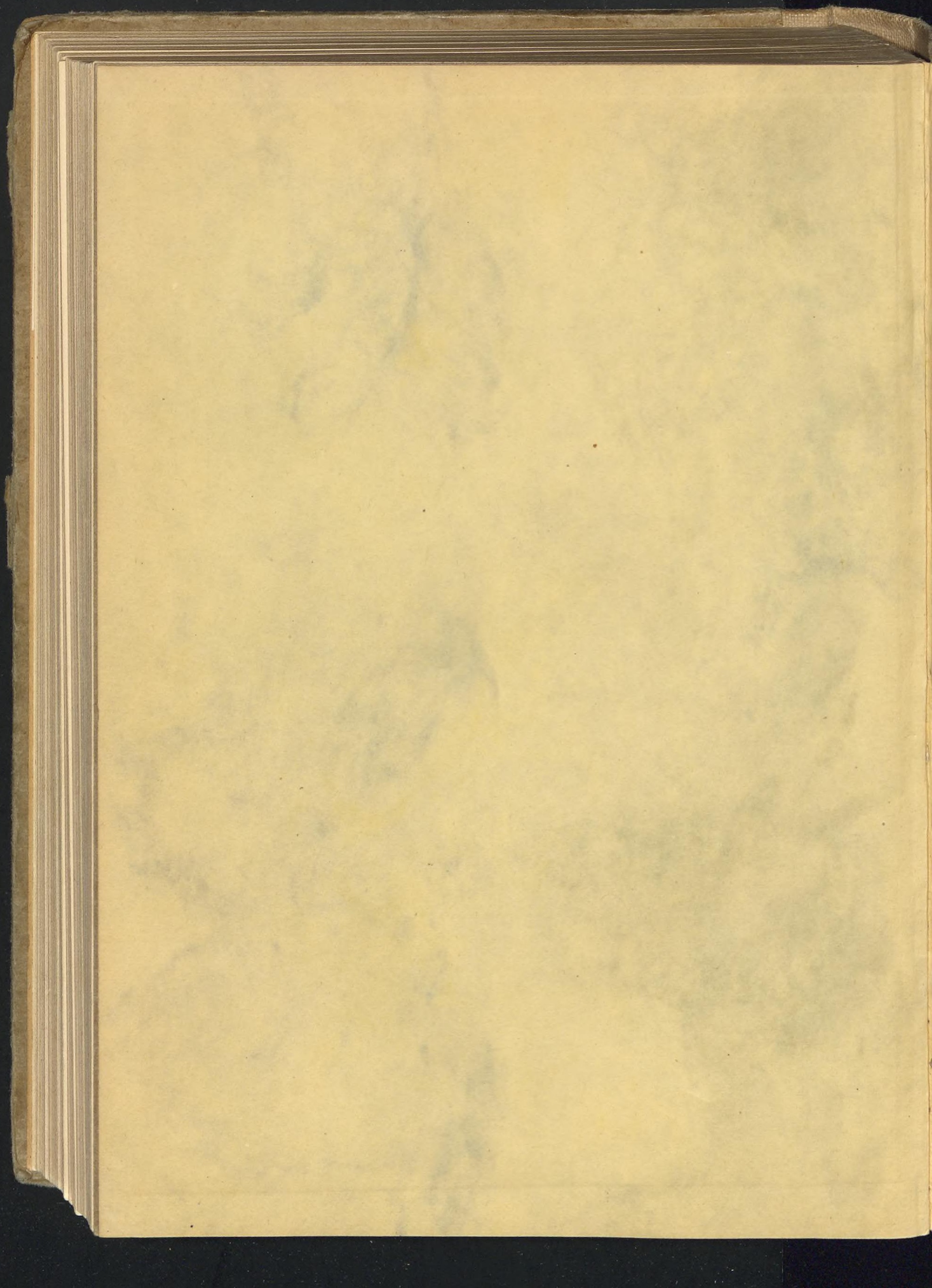




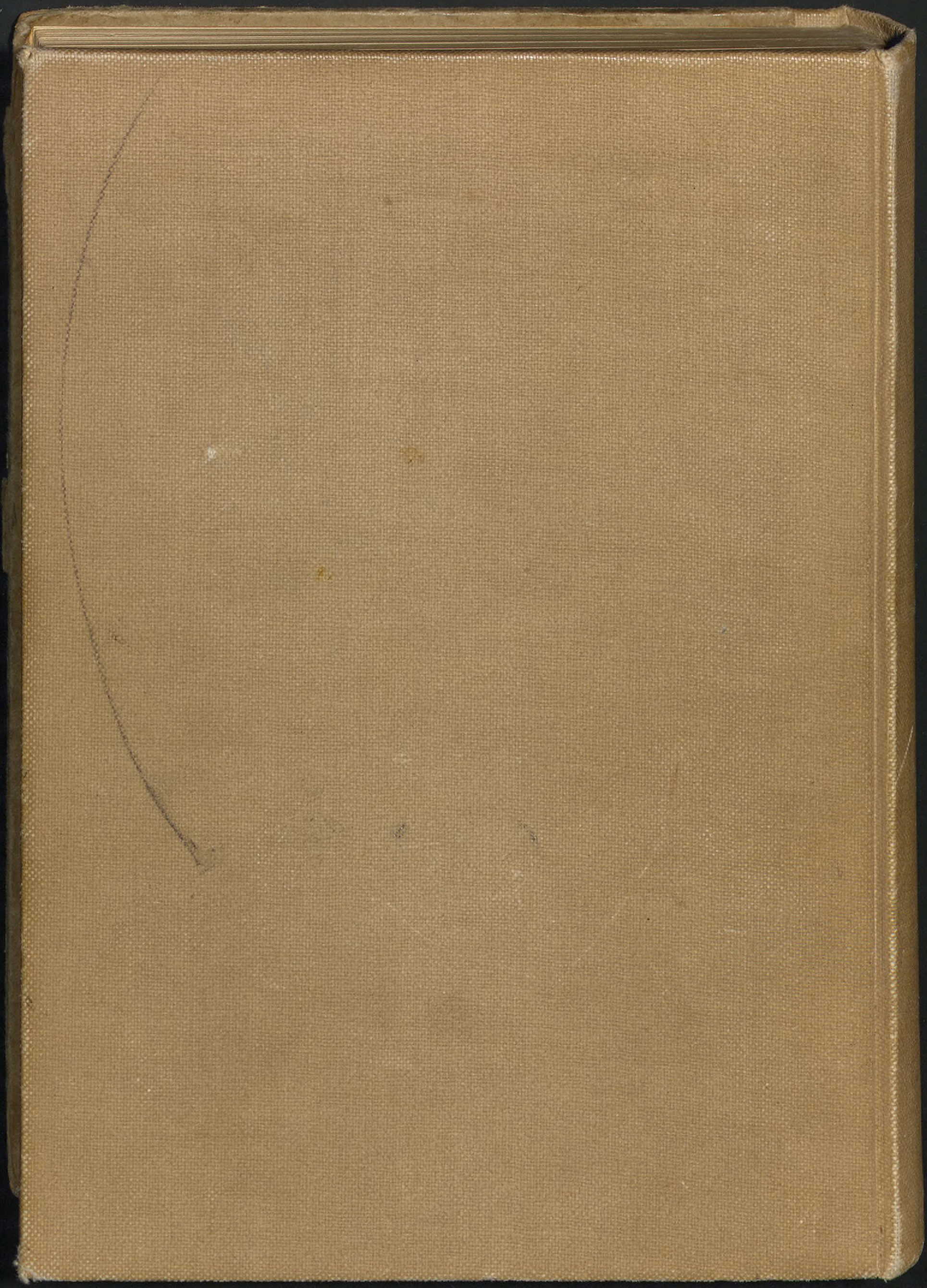

